REPAIR, EVALUATION, MAINTENANCE, AND REHABILITATION RESEARCH PROGRAM

TECHNICAL REPORT REMR-CS-4 $161-185$

\title{
REPAIR OF WATERSTOP FAILURES: CASE HISTORIES
}

RECEIVED

by

James E. McDonald

Structures Laboratory

DEPARTMENT OF THE ARMY

Waterways Experiment Station, Corps of Engineers

PO Box 631, Vicksburg, Mississippi 39180-0631

\section{University of Illinoig \\ Metz Reference Room B106 NCET \\ 208 II. Romine Street Urbana, Illinois 61803 .}

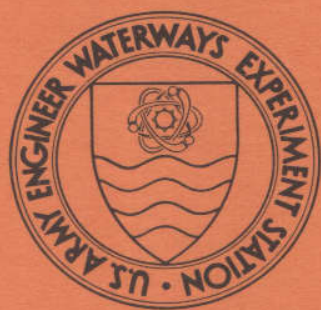

November 1986

Final Report

Approved For Public Release; Distribution Unlimited

Prepared for DEPARTMENT OF THE ARMY

US Army Corps of Engineers Washington, DC 20314-1000

Under Civil Works Research Work Unit 32307 
The following two letters used as part of the number designating technical reports of research published under the Repair, Evaluation, Maintenance, and Rehabilitation (REMR) Research Program identify the problem area under which the report was prepared:

Problem Area

$\begin{array}{ll}\text { CS } & \text { Concrete and Steel Structures } \\ \text { GT } & \text { Geotechnical } \\ \text { HY Hydraulics } \\ \text { CO Coastal }\end{array}$

Problem Area

EM Electrical and Mechanical

El Environmental Impacts

OM Operations Management

For example, Technical Report REMR-CS-4 is the fourth report published under the Concrete and Steel Structures problem area.

Destroy this report when no longer needed. Do not return it to the originator.

The findings in this report are not to be construed as an official

Department of the Army position unless so designated by other authorized documents.

The contents of this report are not to be used for advertising, publication, or promotional purposes. Citation of trade names does not constitute an official endorsement or approval of the use of such commercial products.

\section{COVER PHOTOS:}

TOP - Little Goose Lock monolith joint $11 / 13$ leakage prior to repair.

BOTTOM - Resin-impregnated tube being inserted into a drill hole which straddles a leaking monolith joint at Pine Flat Dam. 
Unclassified

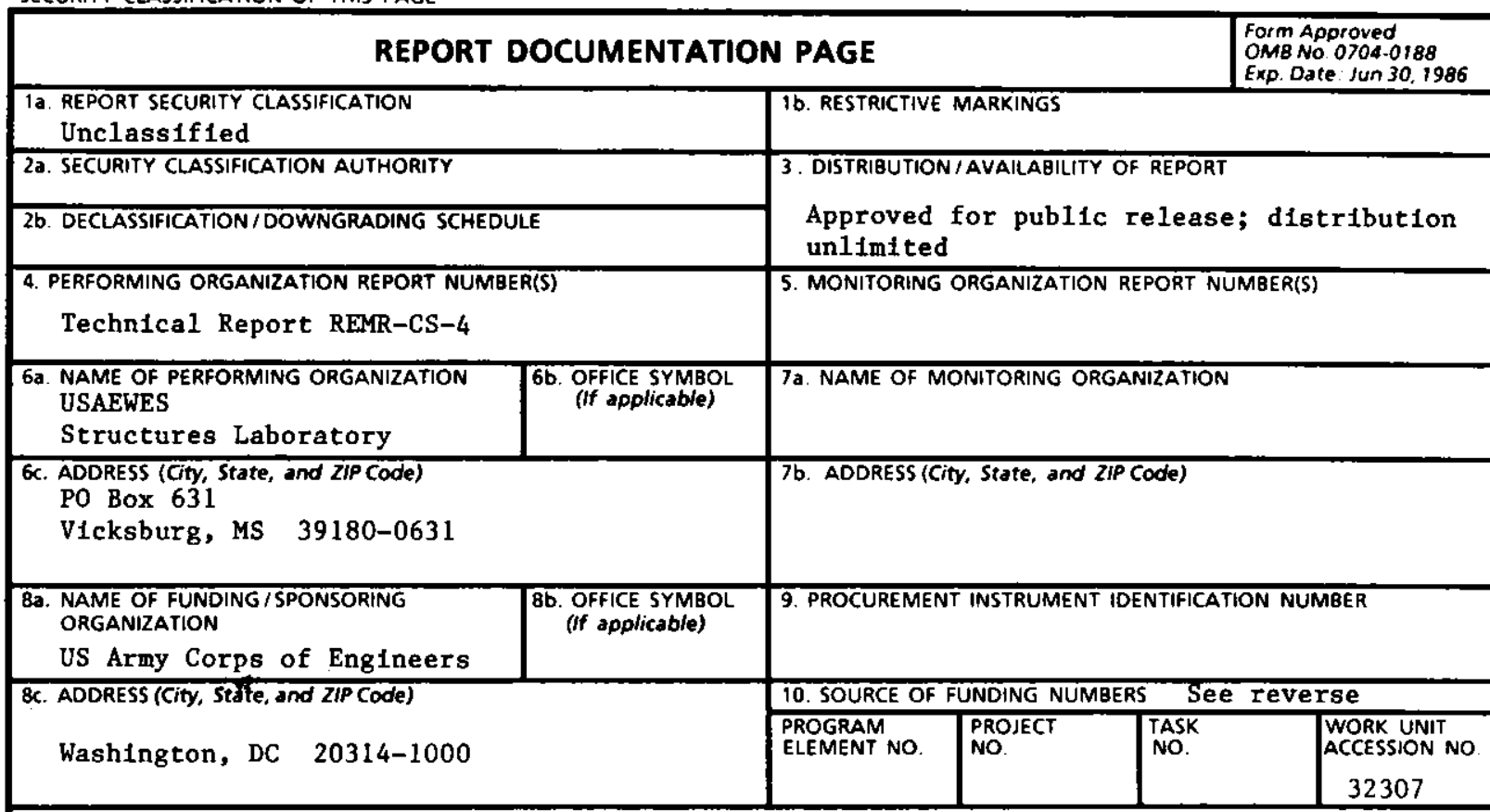

11. TITLE (Include Security Classification)

Repair of Waterstop Failures: Case Histories

12. PERSONAL AUTHOR(S)

McDonald, James E.

\begin{tabular}{|l|l|l|l|}
\hline $\begin{array}{l}\text { 13a. TYPE OF REPORT } \\
\text { Final report }\end{array}$ & $\begin{array}{l}\text { 13b. TIME COVERED } \\
\text { FROM_ DATE OF REPORT (Year, Month, Day) }\end{array}$ & $\begin{array}{c}\text { 15. PAGE COUNT } \\
244\end{array}$ \\
\hline
\end{tabular}

16. SUPPLEMENTARY NOTATION

See reverse

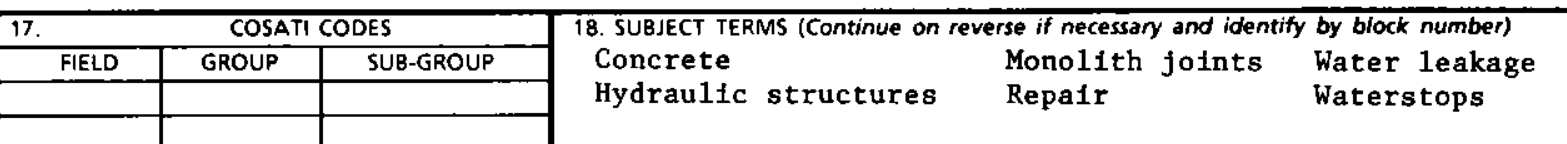

19. ABSTRACT (Continue on reverse if necessany and identify by block number)

Nearly every concrete structure has joints that must be sealed to ensure 1 ts

integrity and serviceability. This is particularly true for monolith joints in hydraulic structures such as concrete dams and navigation locks. Embedded waterstops are generally used to prevent water passage through the monolith joints of such structures. A waterstop failure can result in varlous problems ranging from minor leakage with cosmetic concern to significant hydraulic forces and structural overloading which could threaten the stability of a structure.

The primary objective of this study was to identify materials and techniques which have been used in repair of waterstop failures. Also, based on a review and evaluation of current practices, a secondary objective was to identify those areas where research is needed to supplement existing technology.

(Continued)

\begin{tabular}{|c|c|c|c|}
\hline $\begin{array}{l}\text { 20. DISTRIBUTION/AVAILABILITY OF ABSTRACT } \\
\square \text { UNCLASSIFIEDIUNLIMITED } \square \text { SAME AS RPT. }\end{array}$ & 口DTHC USERS & $\begin{array}{l}\text { 21. ABSTRACT SECURITY CLASSIFICAT } \\
\text { Unclassified }\end{array}$ & TION \\
\hline 22a. NAME OF RESPONSIBLE INDIVIDUAL & & 22b. TELEPHONE (include Area Code) & 22C. OFFICE SYMBOL \\
\hline
\end{tabular}

DD FORM 1473, 84 MAR

83 APR edition may be used until exhausted. All other editions are obsolete.
SECURITY CLASSIFICATION OF THIS PAGE

Unclassified 
10. SOURCE OF FUNDING NUMBERS (Continued).

Civil Works Research Work Unit 32307

16. SUPPLEMENTARY NOTATION (Continued).

This is a report of the Concrete and Steel Structures problem area of the Repair, Evaluation, Maintenance, and Rehabilitation (REMR) Research Program. Available from National Technical Information Service, 5285 Port Roya1 Road, Springfleld, VA 22161.

\section{ABSTRACT (Continued).}

Although the information obtained from the various sources varted widely from project to project, attempts were made to obtain (a) a description of the project, (b) cause and location of the leakage, (c) descriptions of repair matertals and techniques, and (d) results of follow-up evaluations. Sufficient information to prepare a case history was obtained from 20 projects, several of which involved multiple repairs. In addition, limited information on three other repair projects is included.

Leakage through monolith joints reported herein ranged from minor flows to more than $600 \mathrm{gal} / \mathrm{min}$. In general, leakage was the result of waterstop defects Including (a) excessive movement of the joint which ruptures the waterstop, (b) honeycomb areas adjacent to the waterstop resulting from poorly consolidated concrete, (c) contamination of the waterstop surface which prevents bond to the concrete, (d) puncture of the waterstop or complete omission during construction, and (e) breaks in the waterstop due to poor or no splices.

More than 80 different materials and techniques have been used, individually and in varlous combinations, to repair the waterstop fallures reported herein. Some appear to have been successful, while many have falled. Because of a lack of appropriate test methods and equipment, most materials have been used in prototype repairs with limited or no laboratory evaluation of their effectiveness in the particular application. A definfte need exists for development of testing procedures and equipment to allow systematic laboratory evaluation of waterstop repair techniques prior to application in prototype structures. 


\section{PREFACE}

The study reported herein was authorized by Headquarters, US Army Corps of Engineers (HQUSACE), under Civil Works Research Work Unit 32307, "Techniques for Joint Repair and Rehabilitation," for which Mr. James E. McDonald is Principal Investigator. This work unit is part of the Concrete and Steel Structures Problem Area of the Repair, Evaluation, Maintenance, and Rehabilitation (REMR) Research Program sponsored by HQUSACE. The Overview Committee at HQUSACE for the REMR Research Program consists of Mr. John R. Mikel, Mr. Bruce L. McCartney, and Dr. Tony C. Liu. Technical Monitor for this study was Dr. Liu.

The study was performed at the US Army Engineer Waterways Experiment Station (WES) under the general supervision of Mr. Bryant Mather, Chief, Structures Laboratory (SL), and Mr. John M. Scanlon, Chief, Concrete Technology Division (CTD), and under the direct supervision of Mr. James E. McDonald, Research Civil Engineer, CTD, who prepared the report. The report was edited by Mr. Robert A. Baylot, Jr., Information Products Diviston, Information Technology Laboratory, WES. Program Manager for REMR is Mr. William F. McCleese, CTD.

The following individuals provided information for this report: Mr. Johnny Browko, USAED, Little Rock

Mr. Bob Denson, WES, Vicksburg, MS

Mr. David F. Dorsch, Structural Preservation Systems, Inc., Baltimore, MD

Miss. Carolyn Flaherty, USAED, Portland

Mr. Byron Foster, USAED, South Atlantic

Mr. John Gribar, USAED, Pittsburgh

Mr. Bill Heyenbruch, USAED, Sacramento

Mr. Bert Kriekemans, De Neef America, Inc., St. Louis, Mo

Mr. Richard Moix, USAED, Little Rock

$\mathrm{Mr}$. Luther Newton, USAED, Vicksburg

Mr. Jim Parnel1, Barton Southern Corp., Atlanta, GA

Mr. Charlie Rome, USAED, New Orleans

Mr. Lloyd Schell, USAED, Huntington

Mr. Steve Tatro, USAED, Walla Walla

Mr. Stephen T. Waring, GELCO Grouting Service, Kent, WA 
Mr. R. W. Wiinamaki, USAED, Detroit

Mr. Jim Woodruff, 3M Company, St. Paul, MN

Mr. J. Wickham Zimmerman, Structural Preservation Systems, Inc., Baltimore, MD

COL Dwayne G. Lee, CE, was Commander and Director of WES during publication of this report. Dr. Robert W. Whalin was Technical Director. 
PREFACE . . . . . . . . . . . . . . . . . . . . . . . . 1

CONVERSION FACTORS, NON-SI TO SI (METRIC) UNITS OF

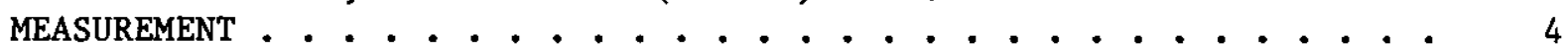

PART I: INTRODUCTION ...................... . . . 5

Background ....................... 5

Purpose . . . . . . . . . . . . ....... 6

Scope . . . . . . . . . . . . . . . . . . 6

PART II: CASE HISTORIES . . . . . . . . . . . . . . . . 7

Algiers Lock . . . . . . . . . . . . . . . . . . 7

MacArthur Lock . . . . . . . . . . . . . . . . . 18

Michael J. Kirwan Dam . . . . . . . . . . . . . . . 20

Clearwater Dam . . . . . . . . . . . . . . . . . . 28

Sardis Dam . . . . . . . . . . . . . . . . . . . 29

Lock and Dam No. 3, Arkansas River . . . . . . . . . . . 40

John Day Lock and Dam . . . . . . . . . . . . . . . . 47

Ice Harbor Lock and Dam . . . . . . . . . . . . . . . . 58

Lower Monumental Lock and Dam . . . . . . . . . . . . . 83

Little Goose Dam . . . . . . . . . . . . . . . . . . . 90

New Cumberland Locks .................. . 107

McNary Lock .. . . . . . . . . . . . . . . . 109

Pine Flat Dam . . . . . . . . . . . . . . . . . 112

Dardanelle Lock and Dam, Arkansas River . . . . . . . . . . 147

R. D. Balley Dam . . . . . . . . . . . . . . . 157

Applegate Dam ........................ 162

Richard B. Russell Dam . . . . . . . . . . . . . 173

Easton Reservoir Dam ................... 206

Bagnell Dam . . . . . . . . . . . . . . . . . 209

Caruthersville Floodwall . . . . . . . . . . . . . 223

Miscellaneous Repairs . . . . . . . . . . . . . 226

PART III: DISCUSSION . . . . . . . . . . . . . . . . 230

Surface Plates . . . . . . . . . . . . . . 230

Caulked Joints .................. . . . 233

Grouted Joints .. . . . . . . . . . . . . . . 234

Drill Hole with Filler . . . . . . . . . . . . . 235

PART IV: CONCLUSIONS AND RECOMMENDATIONS . . . . . . . . . . . . 238

Conclusions . . . . . . . . . . . . . . . . . 238

Recommendations . . . . . . . . . . . . . . . . 238

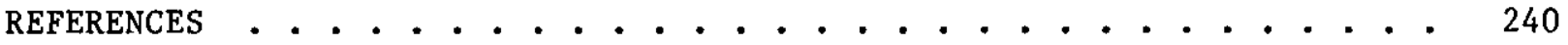




\begin{tabular}{|c|c|c|}
\hline Multip1y & By & To Obtain \\
\hline cubic feet & 0.02831685 & cubic metres \\
\hline cubic yards & 0.7645549 & cubic metres \\
\hline degrees (angle) & 0.01745329 & radians \\
\hline Fahrenheit degrees & $5 / 9$ & Celsius degrees or kelvins* \\
\hline feet & 0.3048 & metres \\
\hline gallons (US 1iquid) & 3.785412 & cubic metres \\
\hline horsepower (electric) & 0.746 & kilowatts \\
\hline inches & 2.54 & centimetres \\
\hline miles (US statute) & 1.609347 & kilometres \\
\hline ounces (avoirdupois) & 0.02834952 & kilograms \\
\hline $\begin{array}{l}\text { pounds (force) per } \\
\text { square inch }\end{array}$ & 6.894757 & kilopascals \\
\hline pounds (mass) & 0.4535924 & kilograms \\
\hline pounds (mass) per foot & 1.488164 & kilograms per metre \\
\hline $\begin{array}{l}\text { pounds (mass) per cubic } \\
\text { foot }\end{array}$ & 16.01846 & kilograms per cubic metre \\
\hline square feet & 0.09290304 & square metres \\
\hline
\end{tabular}

* To obtain Celsius (C) temperature readings from Fahrenheit (F) readings, use the following formula: $C=(5 / 9)(F-32)$. To obtain Kelvin (K) readings, use: $K=(5 / 9)(F-32)+273.15$. 


\section{REPAIR OF WATERSTOP FAILURES: CASE HISTORIES}

\section{PART I: INTRODUCTION}

\section{Background}

1. Nearly every concrete structure has joints that must be sealed to ensure the integrity and serviceability of the structure. This is particularly true for monolith joints in hydraulic structures such as concrete dams and navigation locks. Embedded waterstops are generally used to prevent water passage through the monolith joints of such structures. Traditionally, waterstops have been subdivided into two classes: rigid and flexible. Most rigid waterstops are metallic: steel, copper, and occasionally lead or wood. A variety of materials are suitable for use as flexible waterstops; however, polyvinyl chloride (PVC) is probably the most widely used.

2. The earliest types of embedded waterstops were made of rigid or semiflexible metal, usually copper. A crimp or fold was usually provided in the copper at the center of the joint to accommodate movement between adjacent monoliths. More recently, embedded PVC waterstops have been used on US Army Corps of Engineers projects. In conjunction with waterstops, open drains may be located along the joint between two waterstops to relieve any pressure that could build up between them.

3. A search of the US Army Engineer Waterways Experiment Station (WES) damage and repair data base (McDonald and Campbell 1985) identified over 400 cases where seepage at monolith joints has been reported through the Corps periodic inspection program. The majority (271) of these observations were located in dams. The 166 projects involved account for approximately onethird of the dams owned and operated by the Corps. In addition, 56 navigation locks with seepage problems at monolith joints were identified. The cause of seepage at monolith joints was identified and reported in less than two percent of the observations; however, it is believed that, in many cases, seepage was related to waterstop deficiencies.

4. A waterstop failure can result in various problems ranging from minor leakage with cosmetic concern to significant hydraulic forces and structural overloading which could threaten the stability of a structure. 
Consequently, there is a need for basic repair materials and techniques which can be adapted to a variety of joint repair conditions.

\section{Purpose}

5. The primary objective of this study was to 1dentify materials and techniques which have been used in repair of waterstop failures. Also, based on a review and evaluation of current practices, a secondary objective was to identify those areas where research is needed to supplement existing technology.

\section{Scope}

6. Information on the repatr of waterstop failures was obtained through (a) a search of the WES damage and repair data base, (b) detailed review of periodic inspection reports, (c) discussions with project personnel, (d) visits to project sites, and (e) discussions with contractors and material manufacturers. Although the information obtained from the various sources varied widely from project to project, attempts were made to obtain (a) a description of the project, (b) the cause and location of the leakage, (c) descriptions of repair materials and techniques, and (d) results of follow-up evaluations. 
7. Sufficient information to prepare a case history was obtained for 20 projects, several of which involved multiple repairs. Descriptions of the repairs, which spanned a period of approximately 30 years, are arranged in roughly chronological order in the following. In addition, limited information on three other repair projects is included.

\section{Alglers Lock}

8. Alglers Lock is located in Orleans Parish, Louisiana, on the west side of the Mississippi River about 7 miles* southeast of New Orleans. The lock is of a reinforced-concrete, U-frame-type construction (Figure 1) with sector-type gates in each gate bay. The lock has a usable chamber $75 \mathrm{ft}$ in width and $755 \mathrm{ft}$ in length. Because of unfavorable foundation conditions, the lock was founded on wood pilings which average between 50 and $55 \mathrm{ft}$ in length. The lock was constructed during the period 1947 to 1952 with the lock masonry essentially completed in August 1950.

9. The monoliths in the floor slab of the lock chamber and approaches were separated by construction joints and joined by reinforcing steel at the top and bottom of the slab. No waterstops were used in the construction joints. The floor slabs of the gate bay monoliths (No. 5 and 36 ) were separated from the adjoining monoliths on either side by 1/2-in.-wide expansion joints which contain copper waterstops (Figure 2). The walls of all monoliths are separated from adjacent monoliths by 1/2-in.-wide expansion joints, except for the construction joint between monoliths 1 and 2. All expansion joints in the walls contain copper waterstops (Figure 2). A 2-ft length of copper waterstop was embedded in the base slab at each construction joint during construction of the base slab and later lapped to the waterstop in the wall section.

10. When the first cold weather occurred in late 1950, it was noticed that the expansion joints between the chamber section and the west gate bay section had widened. During an exceptionally cold spell in February 195l, the joint opening on the north side between the chamber section and the west gate

* A table of factors for converting non-SI units of measurement to SI (metric) units is presented on page 4. 

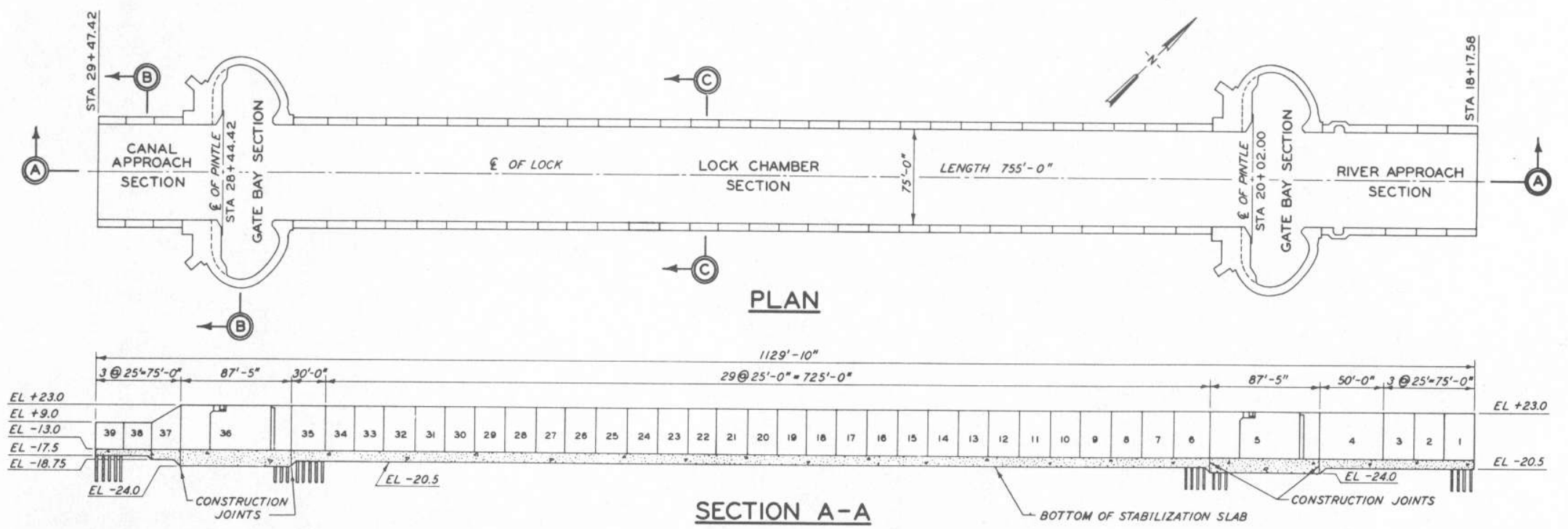

SCALE IN FEET
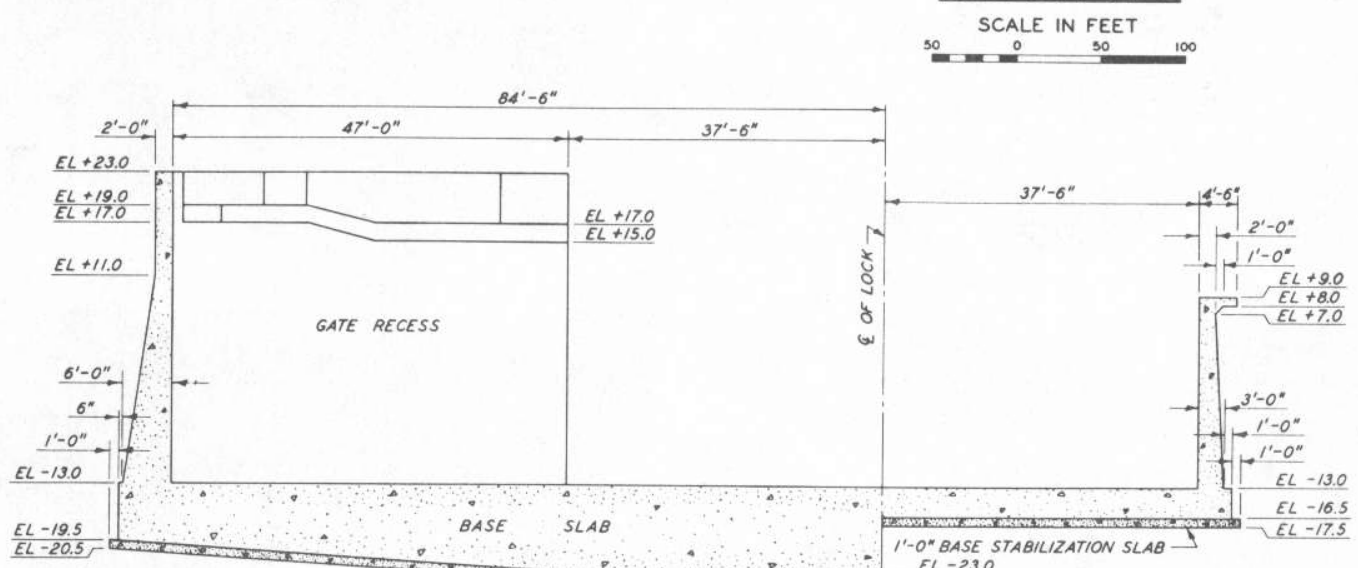

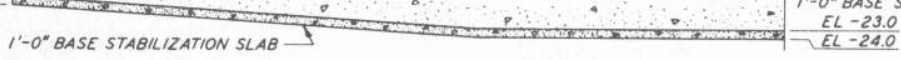

SECTION B-B

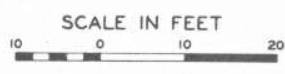

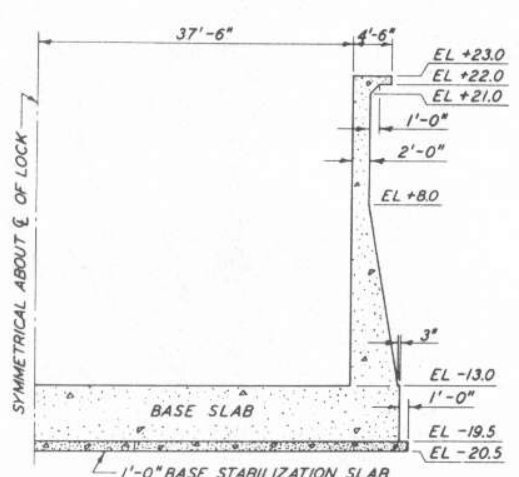

SECTION C-C

Figure 1. Plan and typical sections, Algiers Lock 
University of Illinols

Metz Reforence Room

B106 IICEL

208 in. Pomine Street

Urbana, Illinois 61801

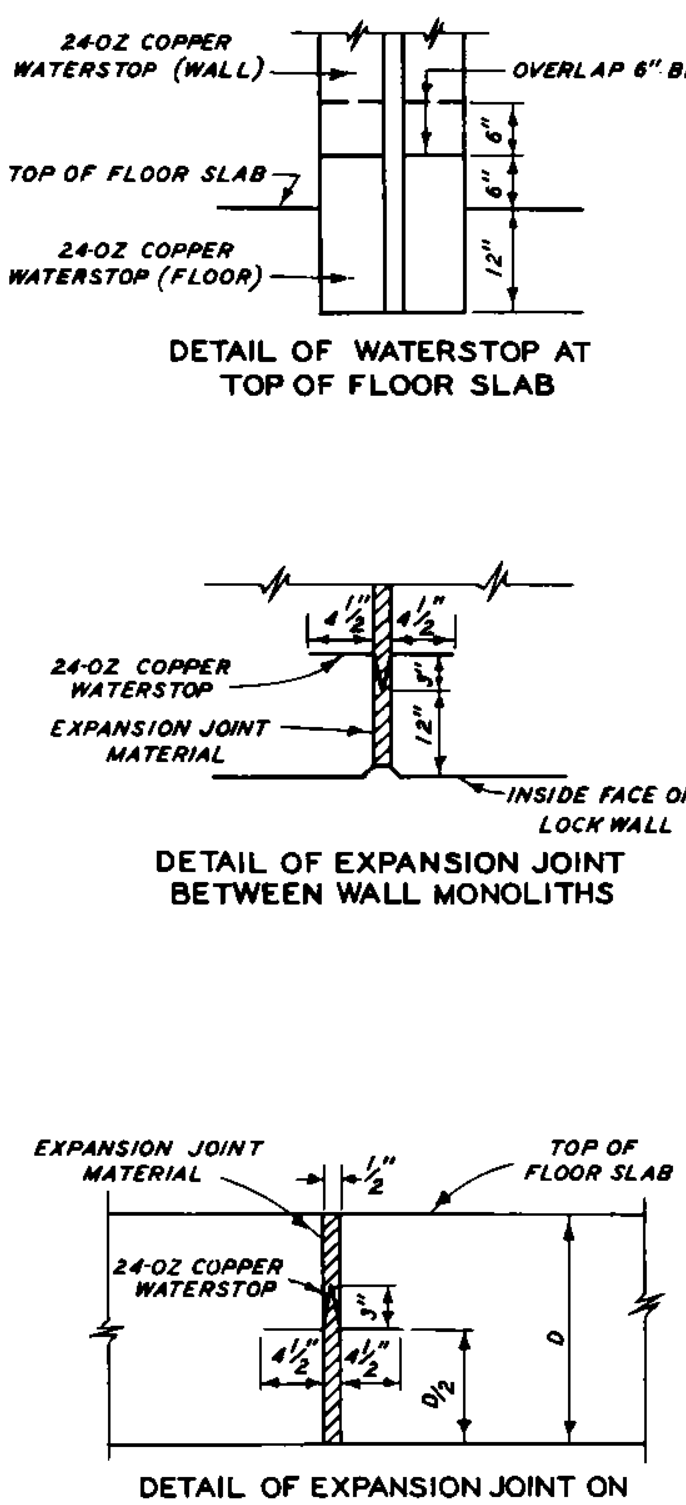

EITHER SIDE OF MONOLITHS 5 AND 36

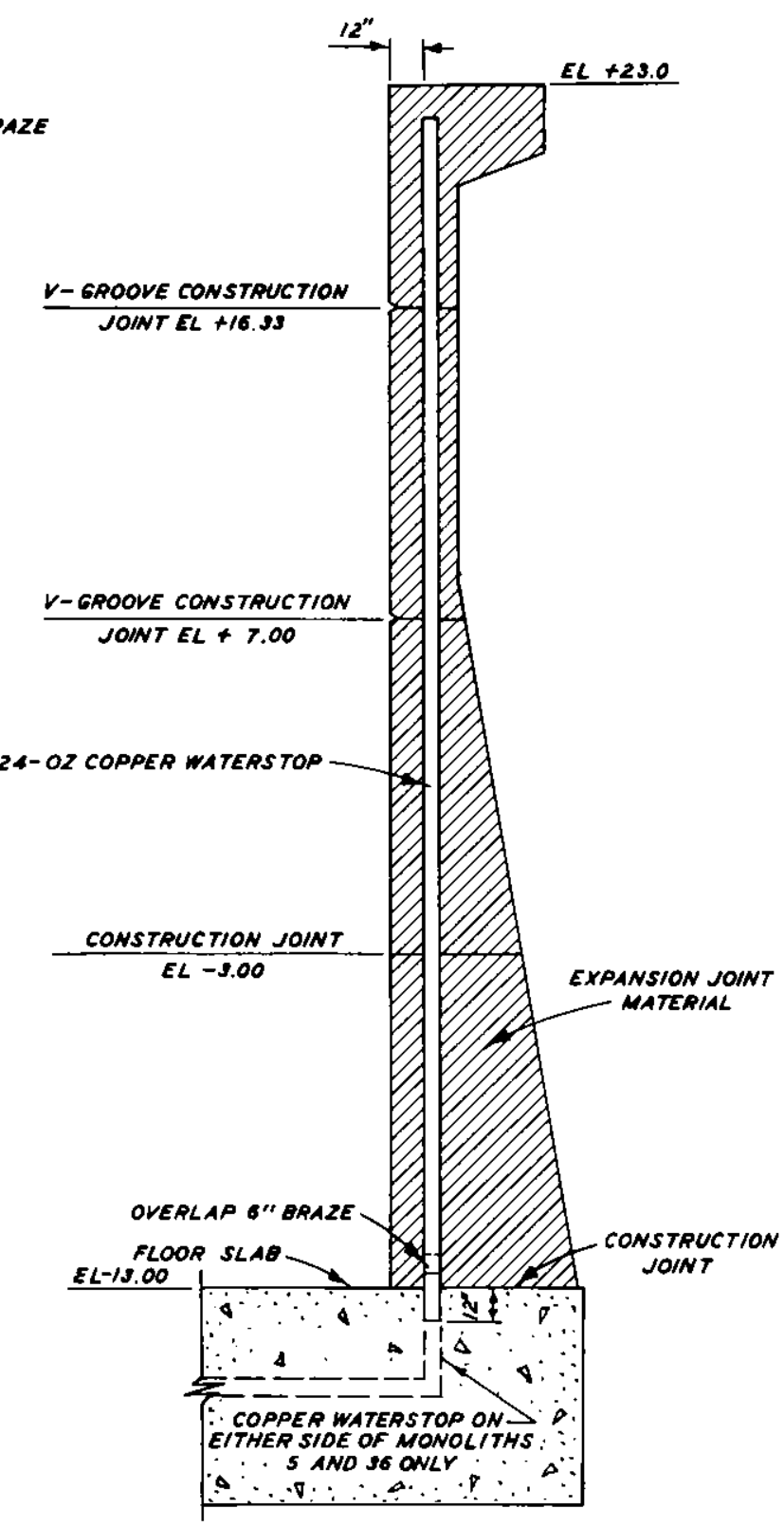

SECTION OF EXPANSION JOINT

BETWEEN WALL MONOLITHS

NOTE: EXPANSION JOINTS IN FLOOR SLAB

AT MONOLITHS 5 AND 36 ONLY.

Figure 2. Joint details, Algiers Lock 
bay was estimated to be about $2 \mathrm{in}$. wide, and the joint opening on the south side was estimated to be about 1-3/4 in. wide. It was observed that the joints closed slightly after the cold weather ended. Apparently, no noticeable change took place during the summer of 1951. However, at the beginning of cooler weather in October, it was observed that not only had the joint opening between the chamber and west gate bay increased, but also the joint opening between the chamber and east gate bay had increased. Systematic measurements of the vertical and lateral displacements of the joints at the top of the walls on either side of the gate bays were initiated in October 1951. Longitudinal displacements at the same joints were measured perlodically starting in 0ctober 1952. The results of these observations were reported by WES (1959). By 1955, joint openings on the east side of the west gate bay had progressed to a maximum of about 4 in.

11. Progressive enlargement of the joint openings on the east side of the west gate bay was attributed to fill material entering the joints, thus preventing free expansion and contraction of the lock with seasonal variations in temperature. Therefore, it was decided to clean out the expansion joints in the walls and base slab down to the waterstop where the gate bays adjoin the lock chamber, to permit expansion joints to function as designed. In addition, it was decided to extend the wall armor across those joints where relatively large lateral displacements had occurred to prevent damage to the lock walls by lock traffic. The repair work was done in June 1955. The lock was unwatered and excavations, shored with sheet piling, were made in the backfill behind each of the four joints where the lock chamber adjoins the gate bays.

12. It was noticed during the repair work that, as a result of the longitudinal displacement of about $4 \mathrm{in}$. at the west gate bay, the uppermost 5 to $10 \mathrm{ft}$ of the waterstop in the wall had separated from the concrete. After cleaning, the joints were packed from both faces of the wall with sponge rubber joint filler and the intervening space was filled with hot-poured asphaltic joint compound. It was felt that the joint filler would be effective in preventing further entrance of backfill soil into the joints and therefore that no plates would be needed on the backfill side of the joints. Subsequent measurements indicating a continued progressive opening of the joints suggest that it might have been advisable to place plates across the backfill side of the wall joint. Steel plates $12-3 / 4 \mathrm{in}$. by $3 / 4 \mathrm{in}$. by 
$23 \mathrm{ft} 4 \mathrm{in}$. were welded to the wall armor across the two inslde joints at both ends of the chamber section on the north side where lateral displacements varied between $2-1 / 4$ and 3 in.

13. It was noted during repair of the joints in the base slab that gas was bubbling up through the joint between the west gate bay and the west edge of the lock chamber; this indicated that the copper waterstop either had ruptured or had separated from the concrete. Both expansion joints in the base slab where the gate bays adjoin the lock chamber were cleaned out above the waterstop, and the recess was filled with hot-poured asphaltic joint compound, except for the upper $18 \mathrm{in}$. which was filled with sponge rubber joint filler. The benefit of the repair work to the joints in the base slab was probably limited by the fact that it was not possible to eliminate the entrance of foundation soll into the joint below the waterstop. As indicated by the gas bubbling up through the joint, piping into the lower part of the joint probably occurs during any contraction of the lock chamber due to temperature effects.

14. Longitudinal displacements at the joints between the gate bays and lock chamber increased with time. An opening of 5 in. on both sides of the lock was reported during cold weather in the early part of 1958. Based on a review of performance data through mid-1956 (WES 1959), it was concluded that the longltudinal movement at the joints between the gate bays and lock chamber was the result of seasonal expansion and contraction of the lock due to temperature changes, permitting fill material to enter the joints during contraction of the lock. Differential water loads and relatively poor foundation soils also contributed to the longitudinal movement. In addition, movement of the west gate bay away from the lock chamber may be expected to continue and eventually may cause complete rupture of the waterstops between the lock chamber and west gate bay unless remedial measures are taken. The following recommendations were made as a result of the review:

Obtain elevations of all reference marks every two years and when the lock is unwatered.

Observe the vertical, lateral, and longltudinal displacements at the joints between the gate bays and lock chambers at monthly intervals during the winter and summer. If the longltudinal displacement at any joint, and in particular the joint on the east side of the west gate bay, should continue to increase with time, and approach 6 in., steps should be taken to prevent further movement, since further 
rupture of the waterstops may cause piping of the foundation soils and would render subsequent repair work very difficult (and expensive). Movement of the gate bays away from the lock probably could be prevented most effectively by structurally uniting the floor slabs of the gate bay to the floor slab of the chamber section.

15. While the lock was dewatered during 1959, monolith joints in the lock walls and floor were repaired using Thiokol, a synthetic rubber compound. This material was selected because it would elongate 150-300 percent of its length without rupturing and would adhere to clean concrete surfaces, thus preventing the passage of water through the joints. In addition, the joints between the west gate bay monolith and adjacent chamber monoliths were excavated on the landside to apply sheet rubber over the joints. The rubber waterstop material was attached to adjacent monoliths with steel plates anchored to the concrete with expansion bolts. Also, a portion of the backfill adjacent to the walls of the west gate bay was excavated to reduce earth pressure on the gate bay. These corrective measures were reported as successful in a 1968 inspection.

16. During the 1968 inspection, seepage through the joint between the approach monolith and the river end gate monolith was reported. Subsequent to the inspection, the leaking joint was ringed with sandbags. The seepage was clear, indicating no piping of foundation material.

17. The joints between lock chamber monoliths and those between approack. monoliths appeared to be in good condition with no unusual openings or offsets when inspected in 1973. However, joints between the gate bay monoliths and adjacent monoliths showed visual evidence of considerable movement (Figures 3 and 4). Also, there were indications that considerable water passed through the joints between the west gate bay monolith and adjacent chamber monoliths during the recent high water (Figure 5). Gate bay joint movements as measured in October 1973 are shown in Figures 6 and 7. No joint repairs were considered necessary at the time; however, repairs during the next scheduled dewatering in 1978 were anticipated.

18. Numerous voids in the embankments along the chamber walls were reported. Possible causes of these voids included (a) animal burrows, (b) piping or seepage of water downstream along the sides of the structure, (c) leakage of water through the chamber monolith joints, and (d) settlement of the fill along the structure walls. 


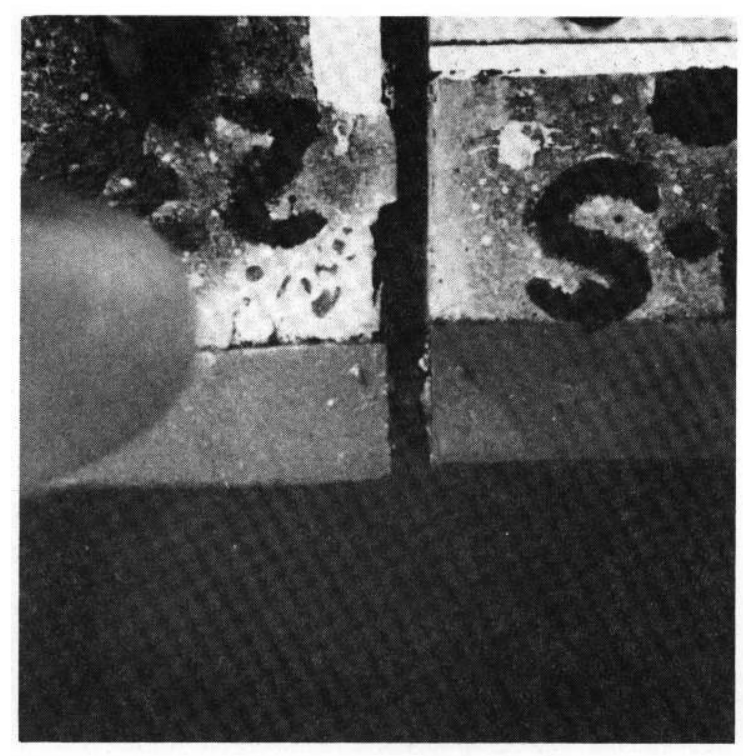

a. Southeast corner

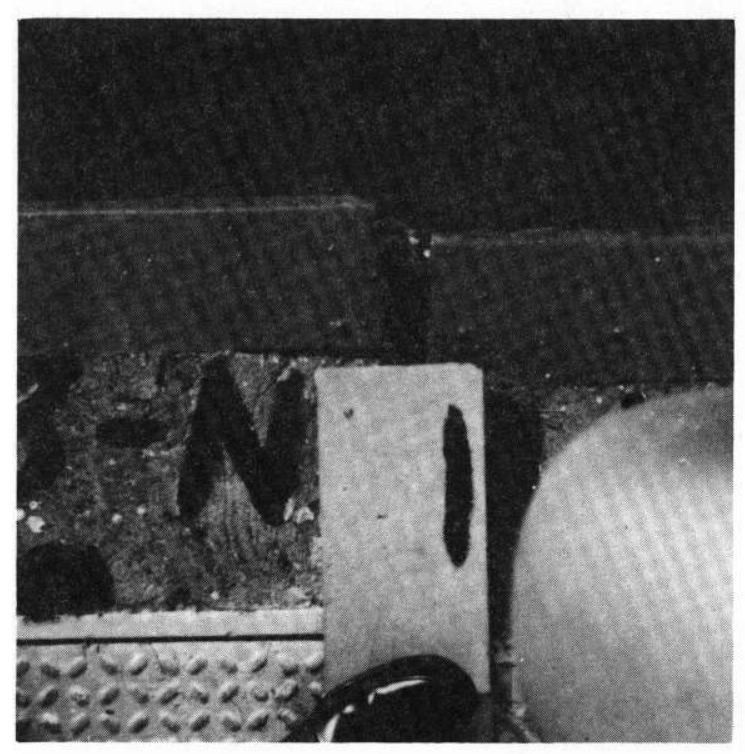

c. Northeast corner

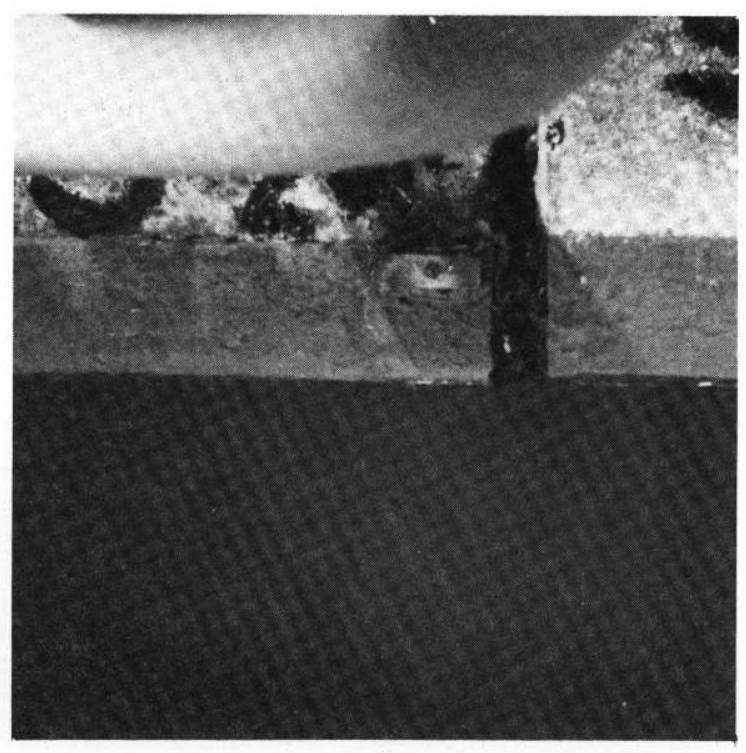

b. Southwest corner

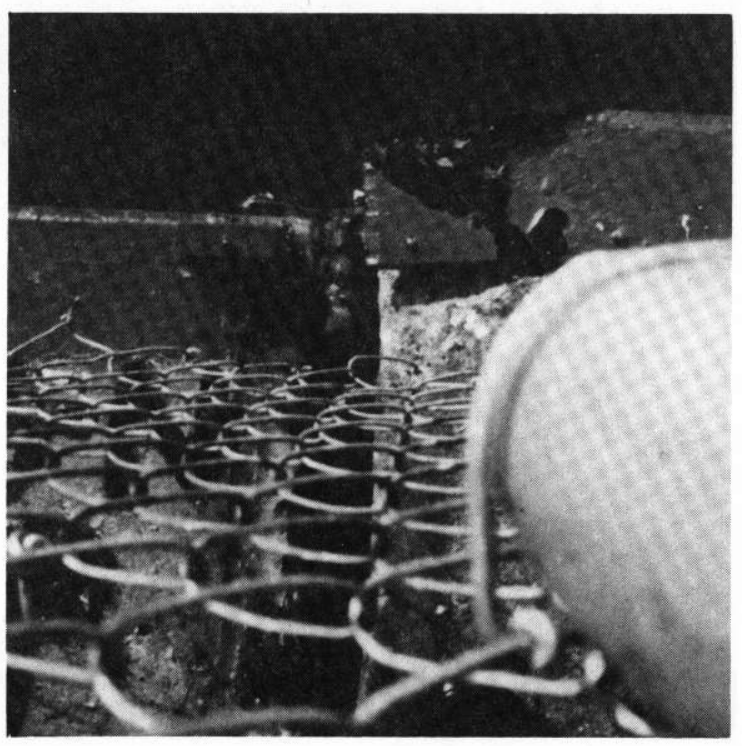

d. Northwest corner

Figure 3. Movement between east gate bay monolith and adjacent monoliths as viewed from top of lock wall, November 1973, Algiers Lock 


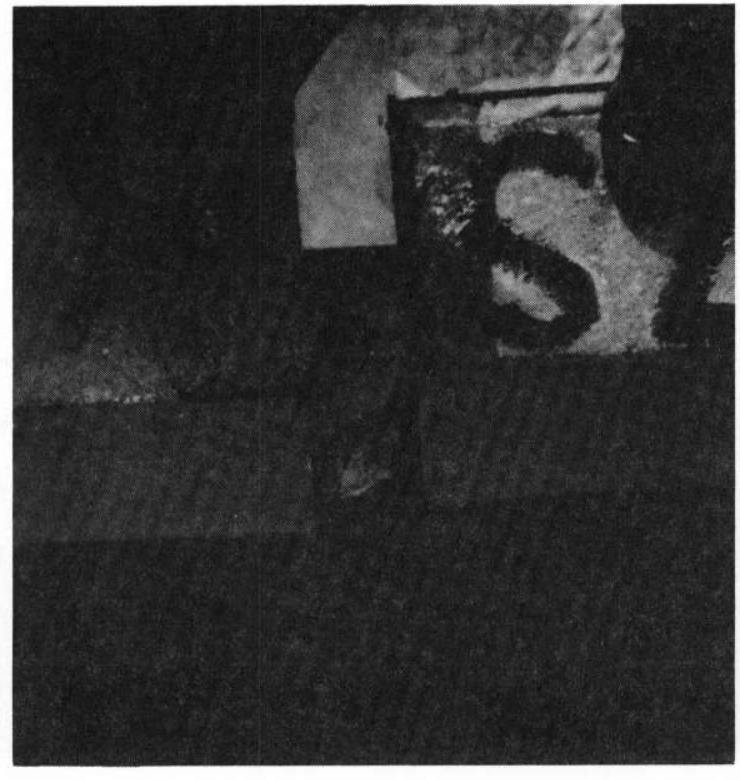

a. Southeast corner

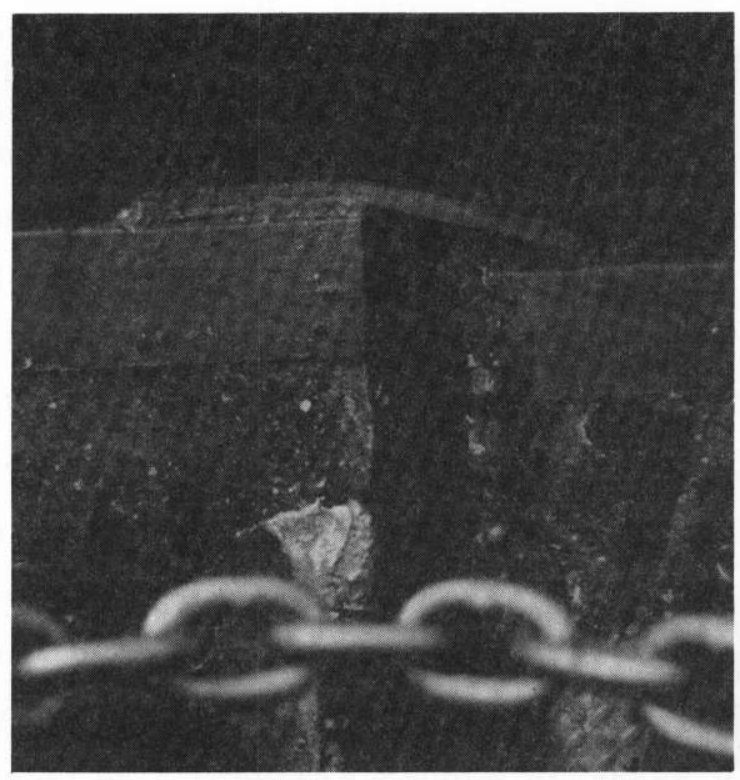

c. Northeast corner

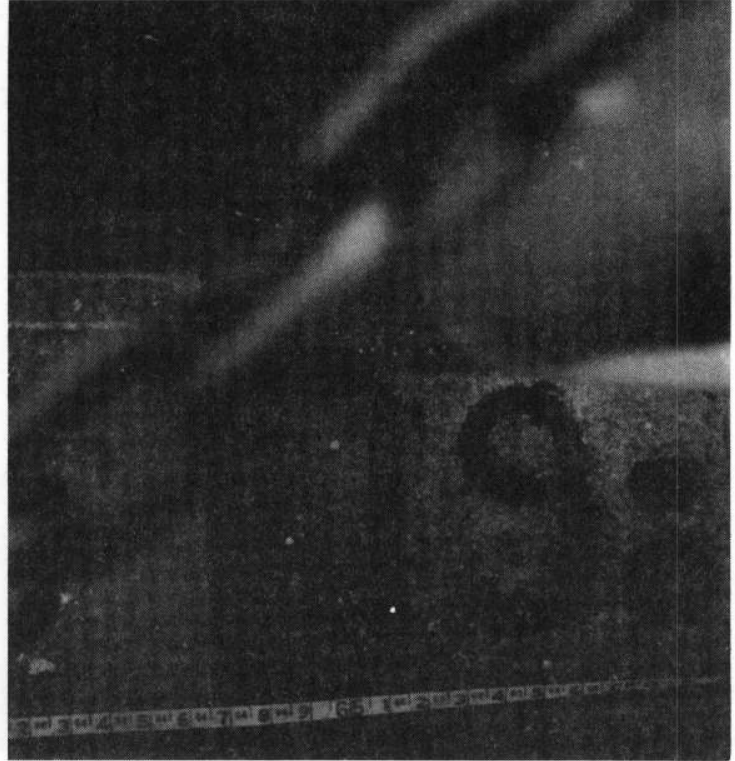

b. Southwest corner

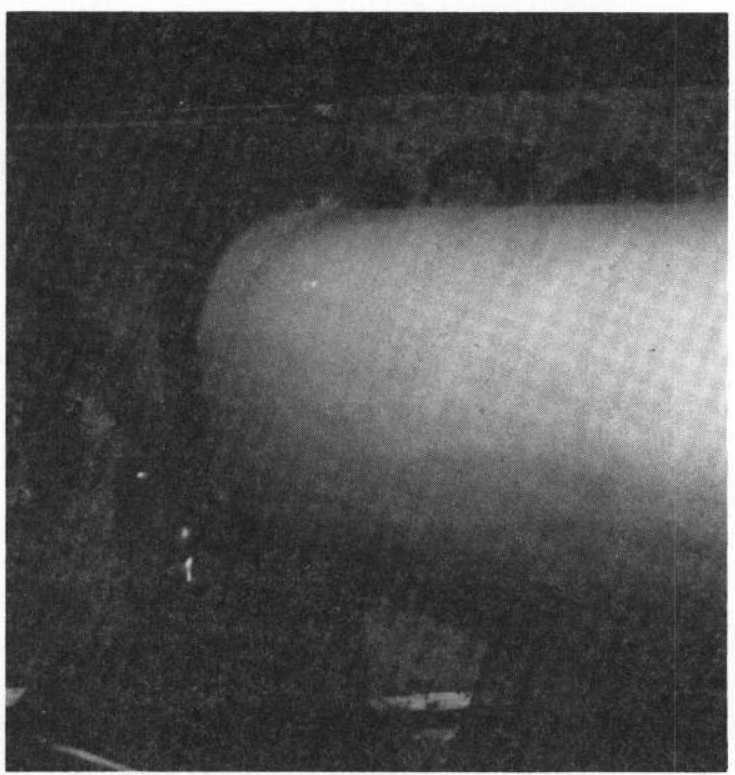

d. Northwest corner

Figure 4. Movement between west gate bay monolith and adjacent monoliths as viewed from top of lock wall, November 1973, Algiers Lock 
a. Southeast corner
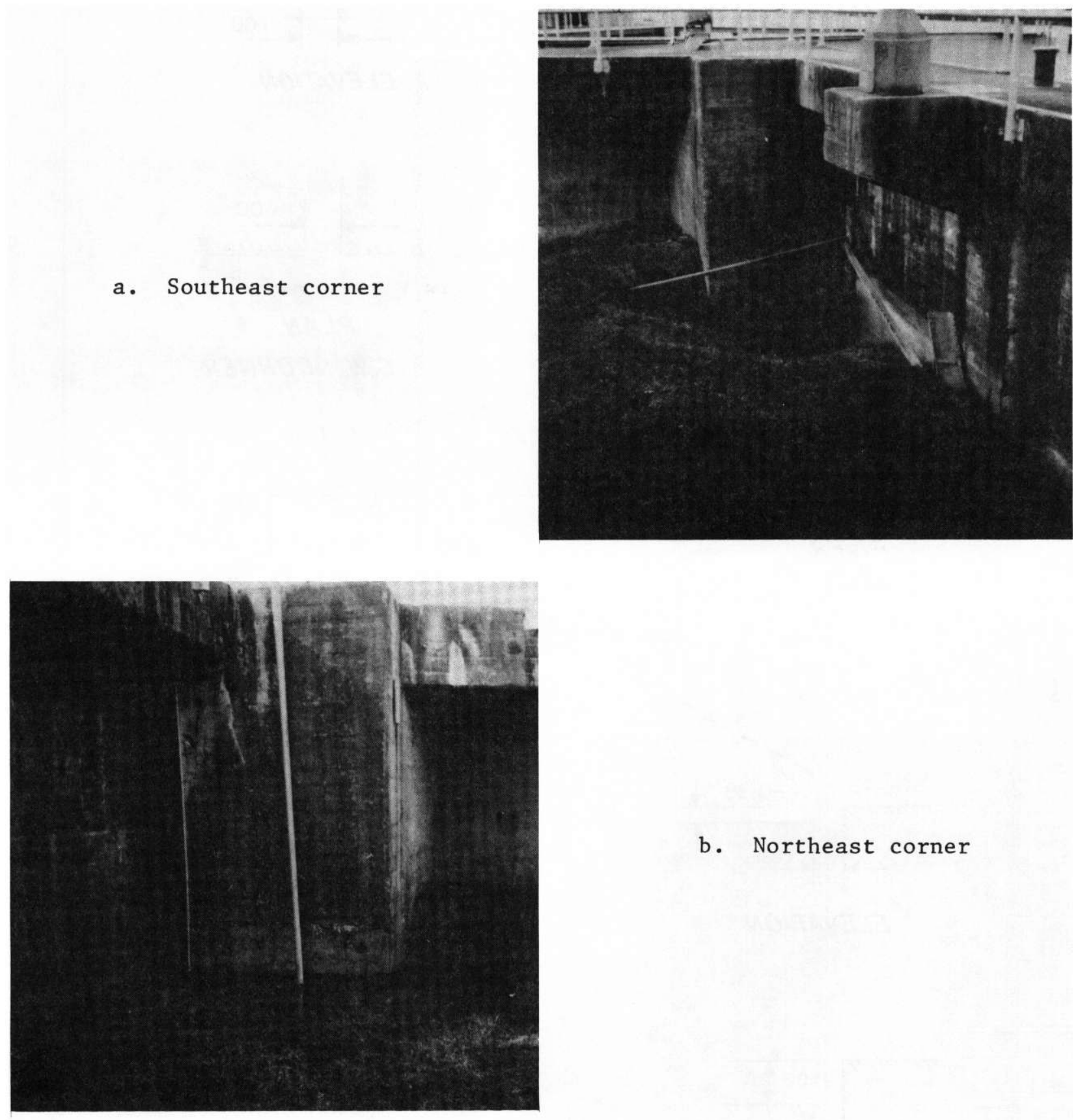

b. Northeast corner

Figure 5. Joints between west gate bay monolith and adjacent chamber monoliths, November 1973, Algiers Lock 


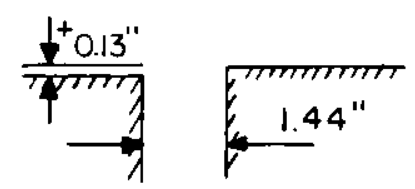

ELEVATION
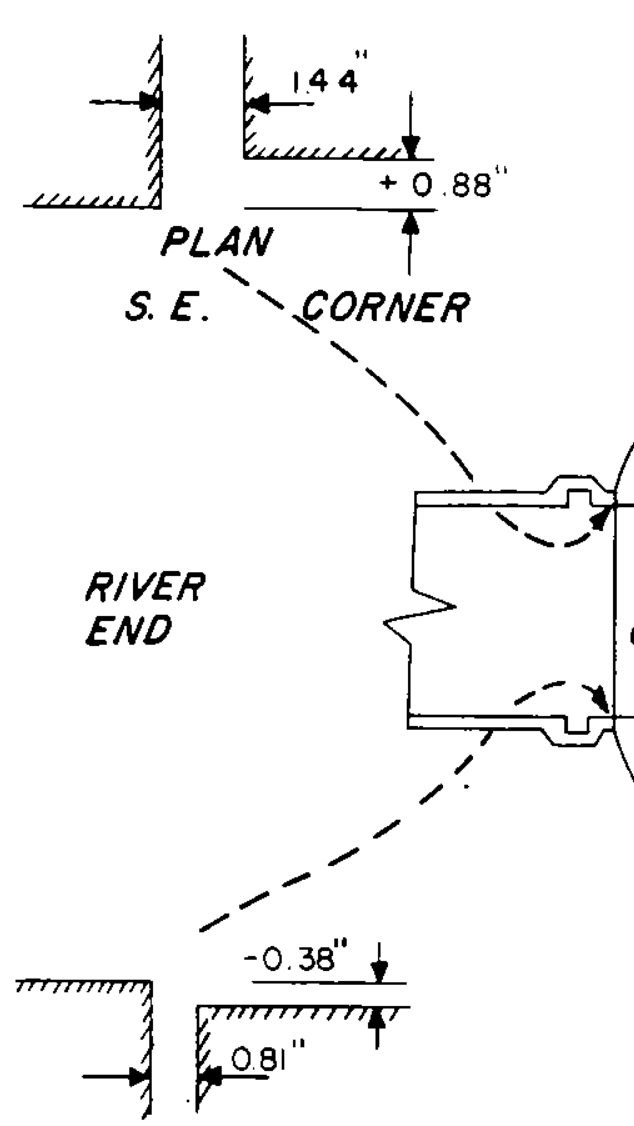

ELEVATION

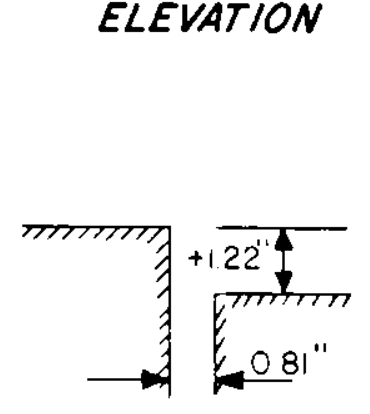

PLAN

E. CORNER

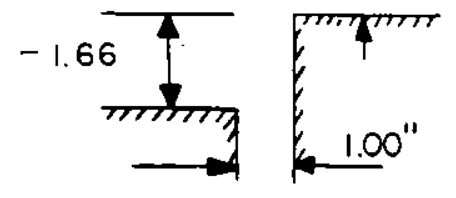

ELEVATION

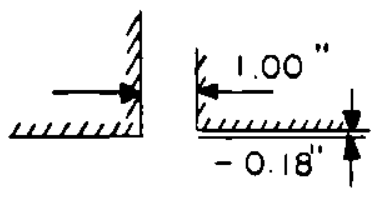

PLAN

S.W. ICORNER
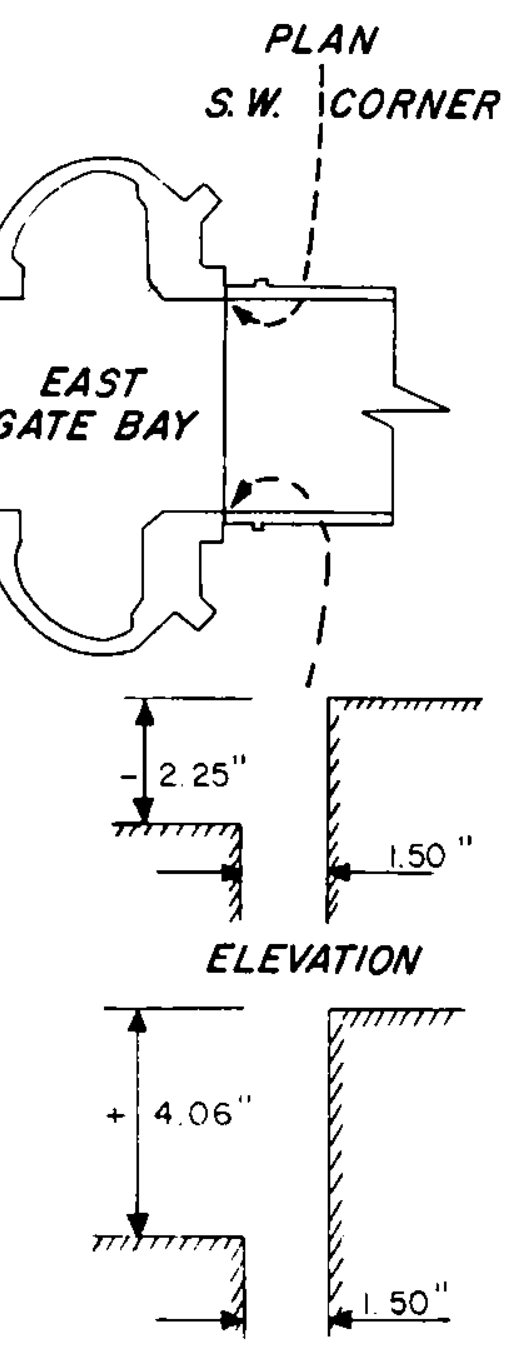

PLAN

N.W. CORNER

Figure 6. East gate bay joint movements, October 1973, Algiers Lock 

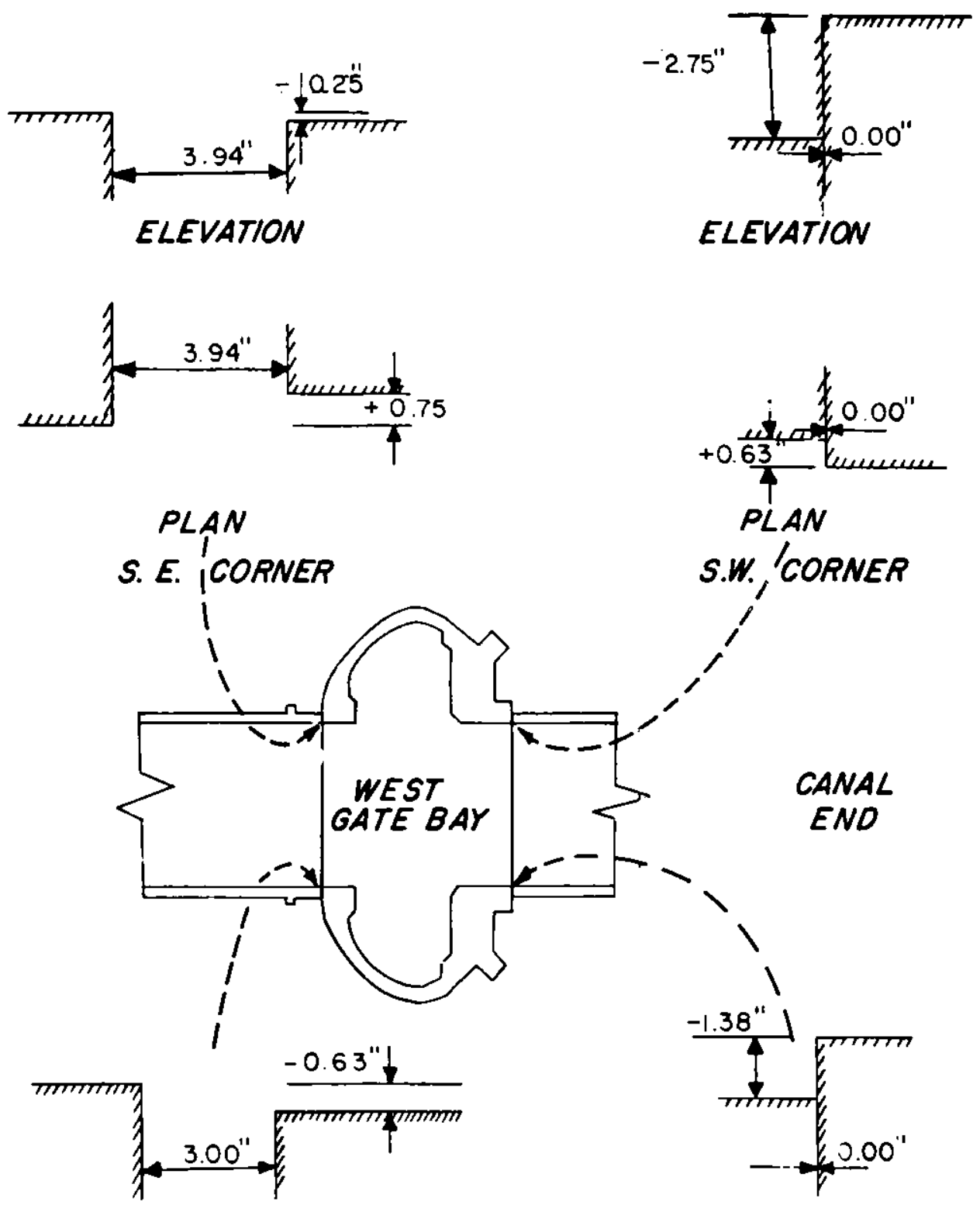

ELEVATION

S.W. 'CORNER

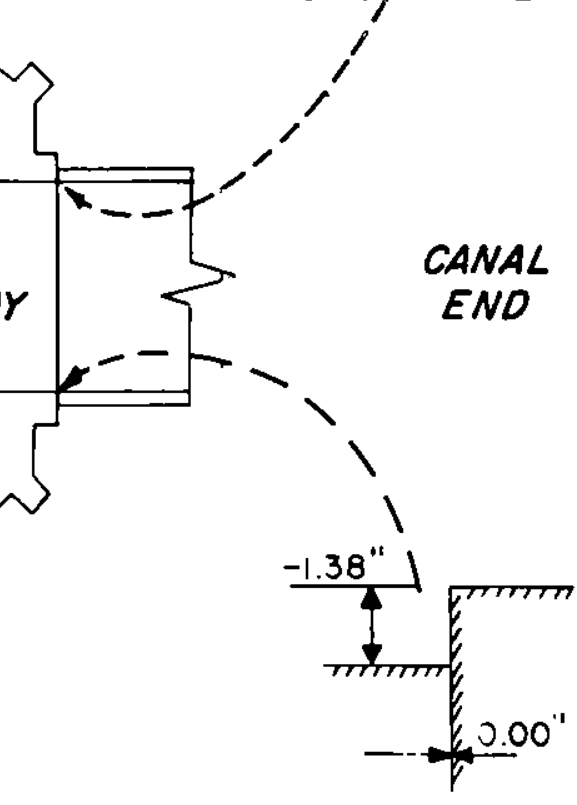

\section{ELEVATION}

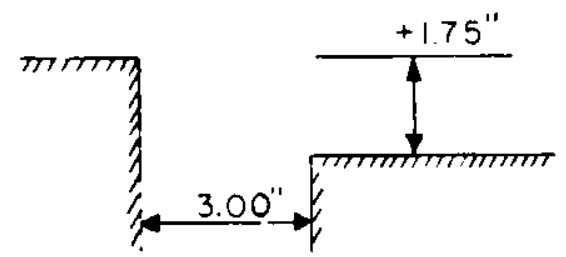

PLAN

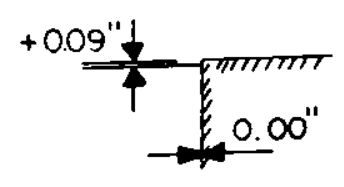

PLAN

N.W. CORNER

N.E. CORNER

Figure 7. West gate bay joint movements, October 1973, Algiers Lock 
19. Joints between the west gate bay and adjacent chamber monoliths were leaking severely when inspected in 1979. Although small dikes had been constructed on the landside of the walls to confine the leakage, the leakage was so severe that the dike on the southeast side of the wall was usually overtopped when the lock chamber was full.

20. Joints between the gate bay monoliths and adjacent chamber mono1iths were repaired in 1980. A portable cofferdam was used to dewater the joints which were then cleaned and sealed with Sikaflex la. Repairs were accomplished by District maintenance forces at a cost of approximately $\$ 42,000$.

21. The exposed upper portion of the external rubber waterstop installed in 1959 apparently deteriorated with time allowing considerable water leakage through the joint during high water stages. During the high river stages in the spring of 1983, temporary steps were taken to prevent leakage through the deteriorated rubber strip on the south wall. This involved construction of a small wooden cofferdam adjacent to the joint which reduced leakage during high river stages. Leakage was effectively controlled eventually by wedging Styrofoam into and against the opening (Figure 8). In February 1985, partia1 repairs were made to the landside of the joints in the north and south lock walls between monoliths 35 and 36 by replacing the deteriorated top part of the rubber pad and metal strips with similar materials.

22. Current plans are to install rubber sheets to the land side of the lock wall at the four wall joints of the east gate bay monolith and two wall joints of the chamber monolith. This work is identical to the work performed in 1959, i.e., one item of work identified in paragraph 15. This repair method has displayed longevity and most directly and effectively eliminates the problem of backfill infiltrating the joint openings during annual cycles of thermal changes and river stage loadings.

\section{MacArthur Lock}

23. MacArthur Lock is one of the four locks located on the South St. Mary's River at Sault Ste. Marie, Michigan. The lock chamber, completed in 1943, is $800 \mathrm{ft}$ long and $80 \mathrm{ft}$ wide with a $11 \mathrm{ft}$ of $22 \mathrm{ft}$. The reinforced concrete floor and monolithic concrete walls were constructed on a sandstone foundation. Each lock chamber wall contains a service gallery and a filling and emptying culvert (Figure 9). Reported rocking of lock monoliths during 

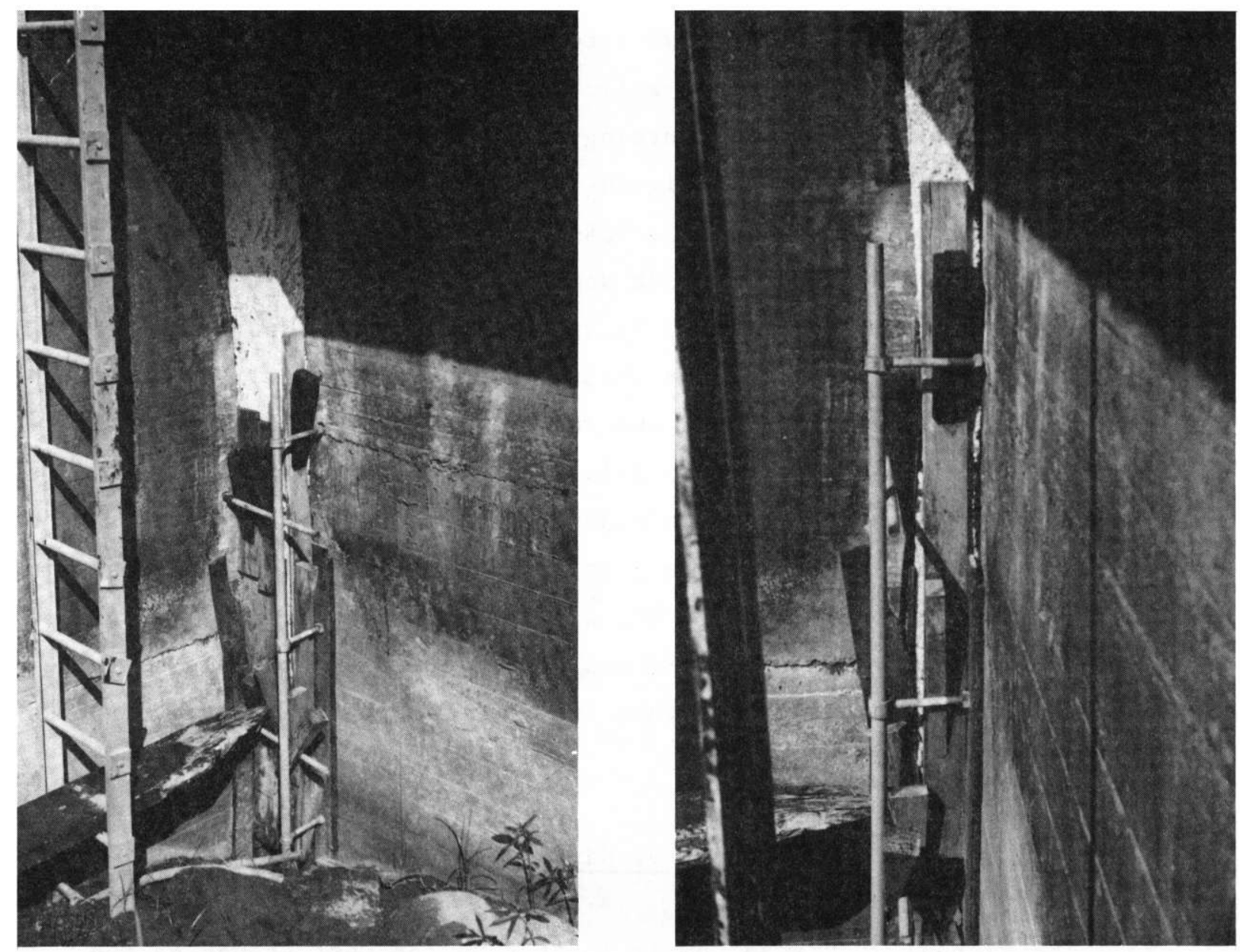

Figure 8. Styrofoam applied over existing rubber waterstop, Algiers Lock

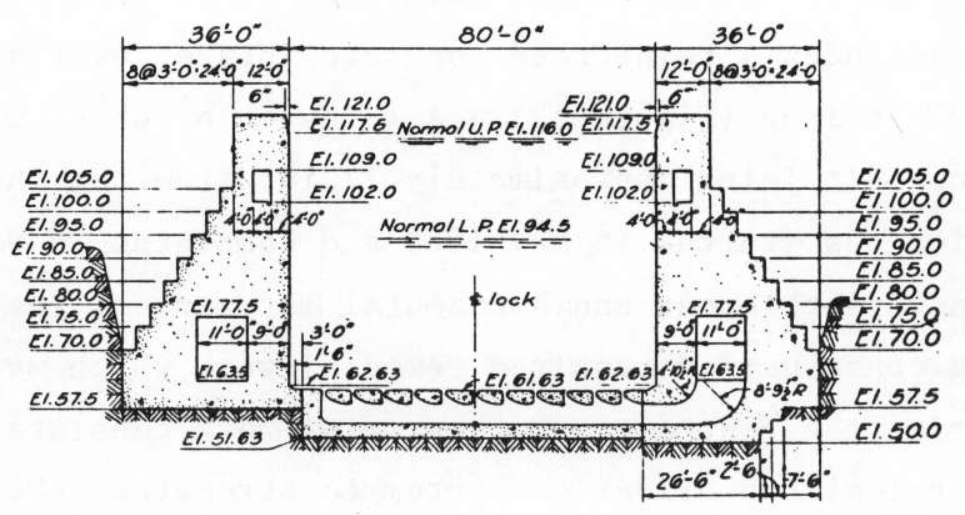

Figure 9. Typical section through lock chamber, MacArthur Lock 
filling and emptying was attributed to a thin zone of softened rock discovered between the monoliths and foundation during investigations for the adjacent Poe Lock.

24. External waterstops were used to repair excessive leakage through 14 monolith joints in the lock cable galleries during the period 1955-60. The joints were prepared for repair by cutting a 3/4-in. chamber around the sides and top of the gallery as shown in Figure 10. Next, 3/8-in. expansion joint filler was inserted in the joint and a 3/4-in.-diameter rubber rod positioned over the joint filler. Clamp bars with set screws were installed on one monolith. The clamp bars were generally spaced 8 to 12 in. apart but were varied to suit physical conditions or obstructions at the monolith joint. A steel angle retainer was placed over the rubber rod and the set screws tightened to hold the rod in place (Figure 11 ). The steel angles were in three individual lengths (top and two sides), but the rubber rod appears to be continuous for the full length of the joint. Apparently, some later adjusting of the set screws was required after the waterstops were initially installed to stop minor leakage. This procedure has worked quite effectively over the years because no maintenance, other than that of priming and painting exposed steel surfaces, has been required.

\section{Michael J. Kirwan Dam}

25. The Michael J. Kirwan Dam is located on the West Branch of the Mahoning River about 10.6 miles above the junction of the branch and the Mahoning River at Newton Falls, Ohio. The rolled earth-fill embankment has a crest length of $9,900 \mathrm{ft}$ and a maximum helght of $83 \mathrm{ft}$ above the steam bed. The outlet works includes a reinforced concrete intake tower and three 5-by 8 -ft conduits, $693 \mathrm{ft}$ long (Figure 12). A three-bulb rubber waterstop was located at each conduit joint approximately $12 \mathrm{in}$. from the interior concrete face. Construction was started in May 1963 and completed in November 1966.

26. Excessive settlement and horizontal movement of the embankment and foundation during construction required remedial work which was accomplished by a change order to the contract. The remedial work consisted of the insta1lation of an electrical consolidation system to strengthen the foundation clays and reduce the excess pore pressures in these clays under the center portion of the dam. As a result of the foundation movement, the conduit 


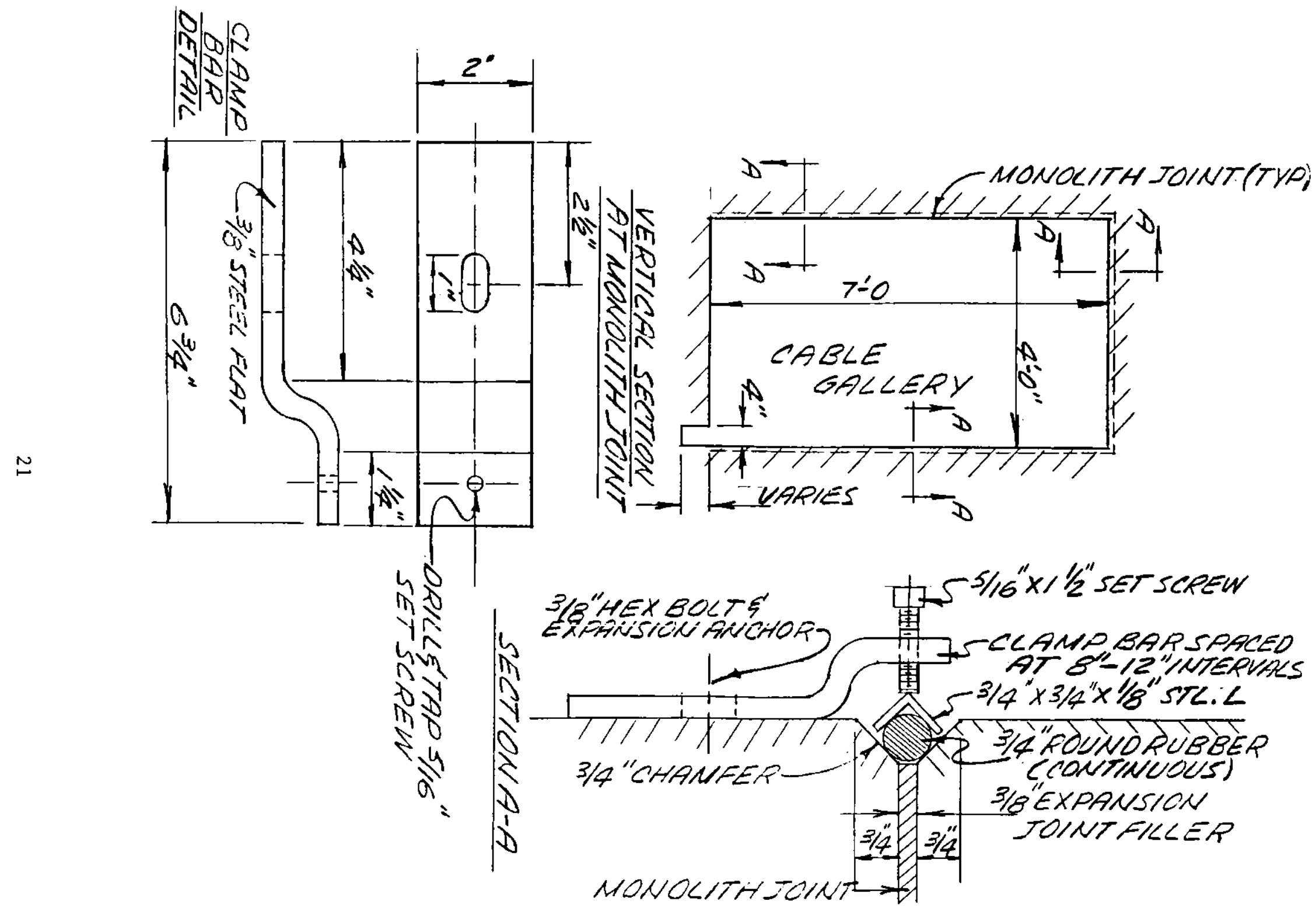

Figure 10. External waterstop design, MacArthur Lock 


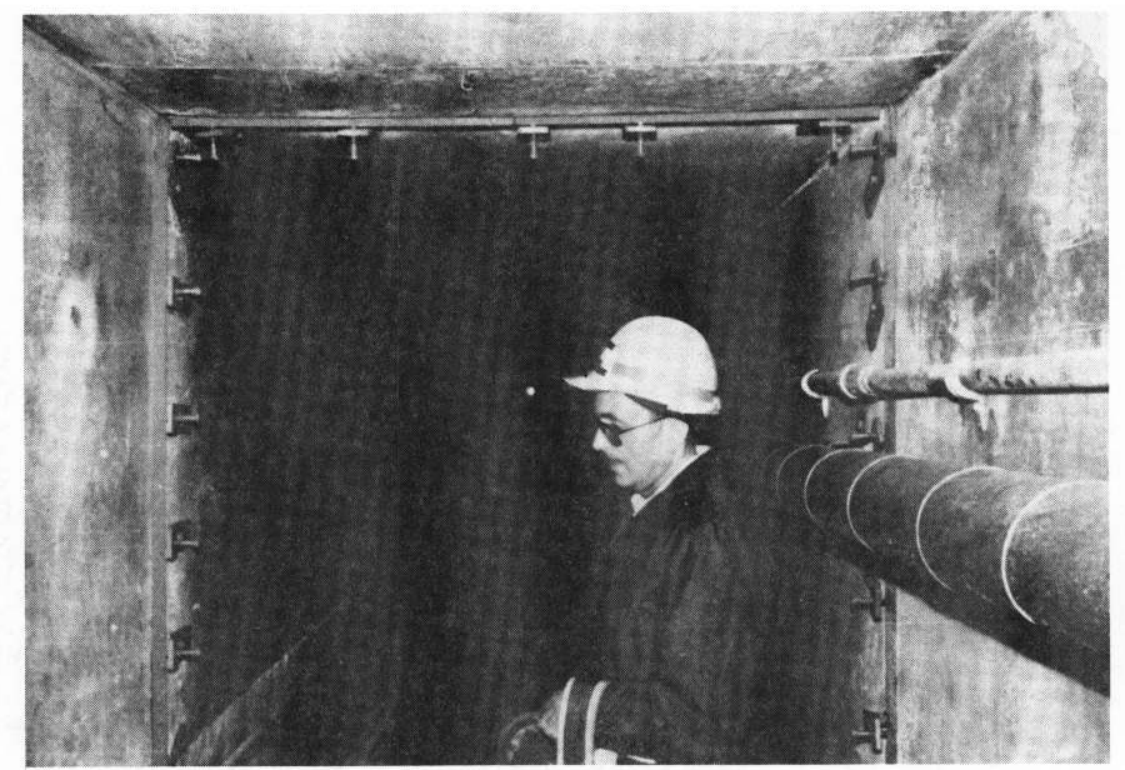

Figure 11. External waterstop installed in cable gallery, MacArthur Lock

settled about $4.1 \mathrm{ft}$ and elongated $1.89 \mathrm{ft}$. This resulted in the opening of a number of joints with a maximum joint opening of 12-3/4 in. Major repairs were required on eight joints and seven joints required minor remedial measures to repair ruptured waterstops and reseal the joints. This work was accomplished by the Operations and Maintenance (O\&M) Branch.

27. Several repair techniques were used depending on the width of the joint opening. Details of the various repair techniques including material specifications are shown in Figure 13. A new 6-in. rubber waterstop was installed in the joint (15/16) with the maximum opening. Where joint openings were in the range of 1 to $7 \mathrm{in.,}$ a $1 / 2-$ by 6 -in. neoprene seal element shaped in a "U" configuration was placed in the joint as a replacement waterstop. Following placement of polyethylene packing at the convex fold of the seal element, the joint was filled with a sanded cement grout. A 3/8- by 12-in. neoprene diaphragm was then anchored across the joints. Those joints with smaller openings were typically repaired with caulking sealant.

28. The left and middle conduits were inspected in June 1970 and joint repairs were reported to be in good condition. Joint $3 / 4$, which was repaired by spreading sealant across the surface of the joint, had opened 1/16 in. but was not leaking. At several of the joints, the sealant had been washed out from the joint in the floor. The neoprene diaphragm across joint $13 / 14$ in the middle barrel had a 1-in. cut about $1 \mathrm{ft}$ off the floor on the right side. 


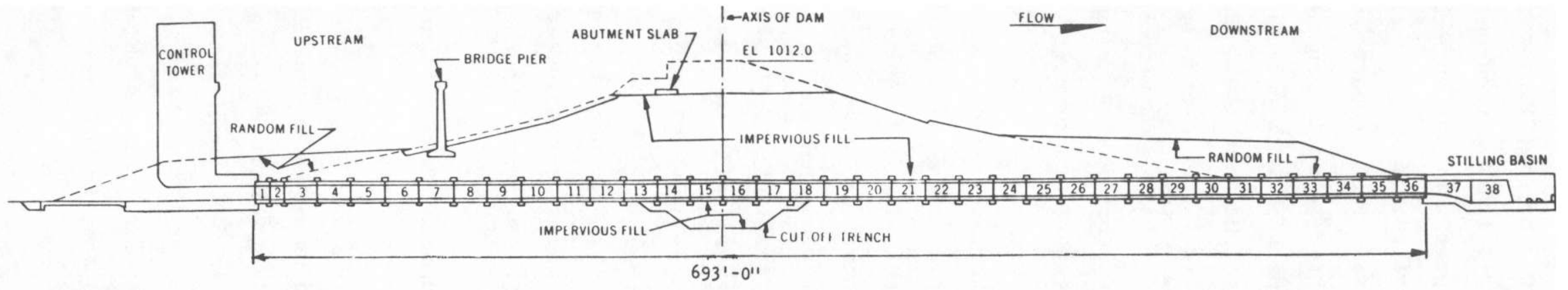

a. Section through outlet works

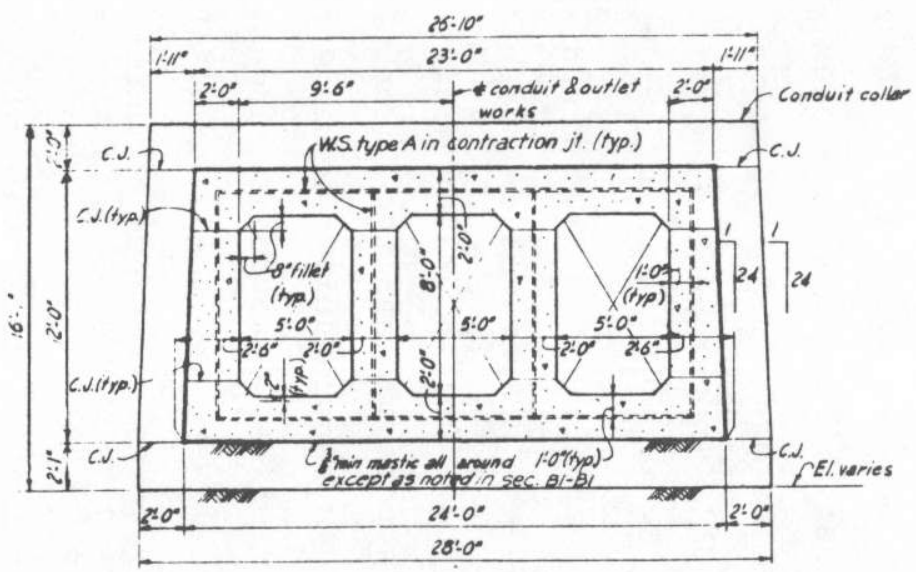

b. Typical conduit section

Figure 12. Outlet works conduits, Kirwan Dam 
Measurements of joint separation taken monthly showed no significant recent movement. The measurements were taken between pencil lines marked on opposite sides of the joint. These pencll lines and other pertinent markings in the barrels had been recently replaced by permanent scribed pins.

29. The center and right barrels of the three-barrel conduit were inspected in June 1972 and jolnt repairs were reported to be in generally good condition. The joints that were repaired by back-packing with polyethylene foam and filling with sealant had the sealant washed out from the joint to the flow line. At several of the joints, $10 / 11$ and $11 / 12$ in the center barrel and $10 / 11$ in the right barrel, some of the foam packing extended out from the joint. This appeared to be the result of excessive foam packing being forced Into the joint and the sealant not being strong enough to contain it. At these joints the waterstop was intact, and the failure of the repair work did not affect the joint. Where the more open joints were repaired by clamping a neoprene diaphragm across the jofnt, two of these diaphragms were noted to be torn. At joint $13 / 14$ in the center barrel, the right side had a slit 12 to $14 \mathrm{in.} \mathrm{long} \mathrm{about} 18 \mathrm{in.}$ from the floor. The diaphragm at joint $14 / 15$ in the right barrel was torn across the floor and about $2 \mathrm{ft}$ up each wall. The repair work behind the diaphragms of these joints was tight and in good condition. No seepage was noted. Measurements taken periodically to determine individual joint separation and total conduit elongation showed very little or no movement although the conduit continues to settle at a slow rate.

30. The perforated diaphragms across joints $13 / 14$ (center barrel) and 14/15 (right barre1) were replaced in May 1973. Damage was attributed to efther localized material weakness or the passage of rough and sharp-edged debris through the conduit.

31. A comparison of conduit joint separation measurements taken from the time joint repairs were completed in March 1967 to February 1976 showed only minor separations. The maximum separation $(0.025 \mathrm{ft})$ was at joint $12 / 13$. The majority of the conduit joints were reported to be contracting.

32. The center and right barrels of the outlet conduit were inspected in July 1976 and joint repairs were reported to be in fair condition. Several of the joints with larger openings (14/15 in the center barrel, and $14 / 15$ and $16 / 17$ in the right barre1) had torn or eroded neoprene diaphragms which needed immediate attention. Also, the steel clamping bars used to hold the neoprene diaphragms were badly rusted and replacement was recommended. 

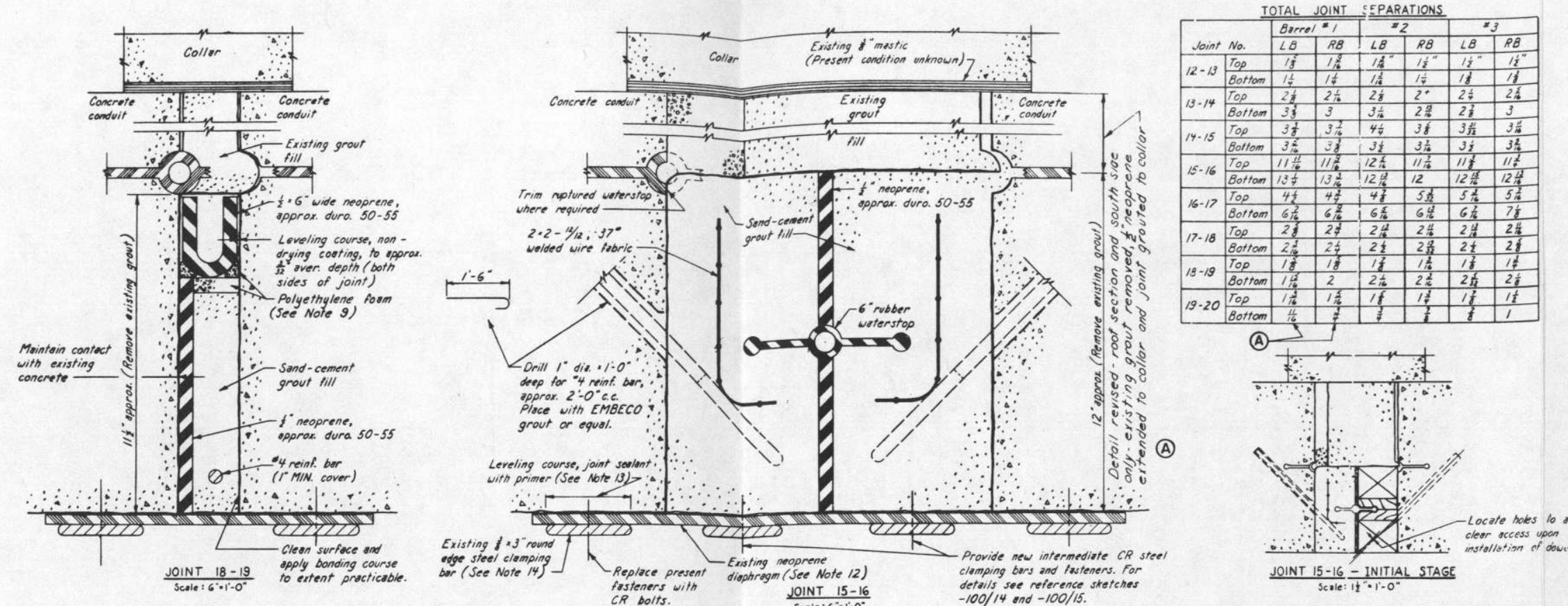

Provide new divatregs.:.

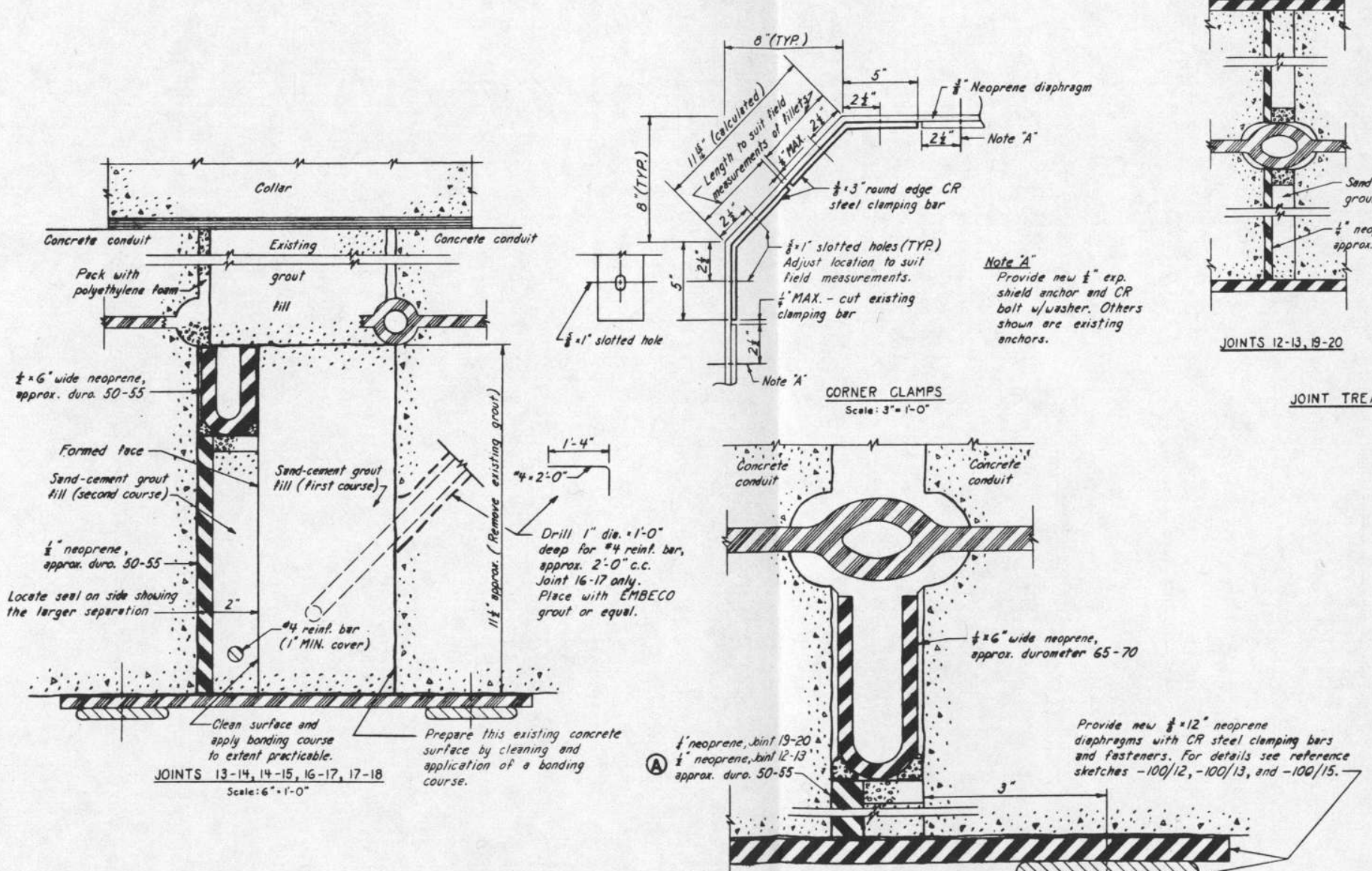

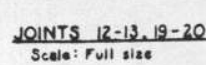

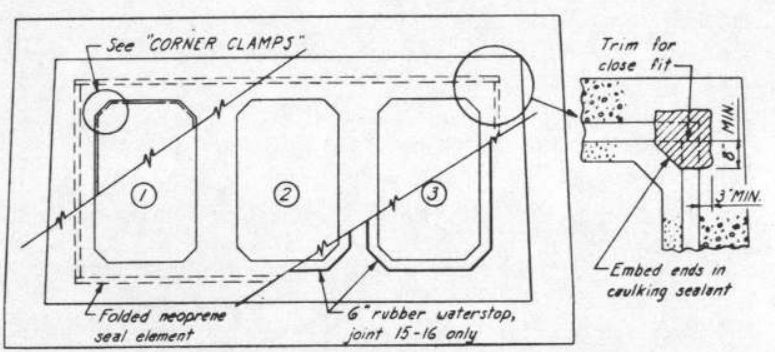

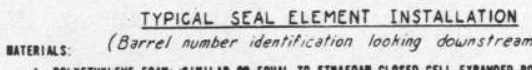

2.

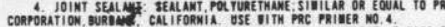
0.010 io so

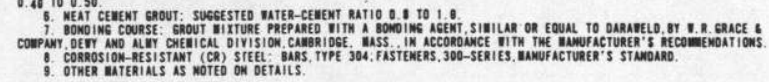

wanum ats.

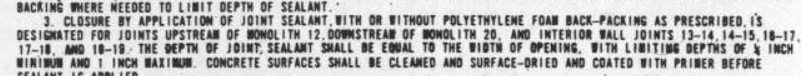

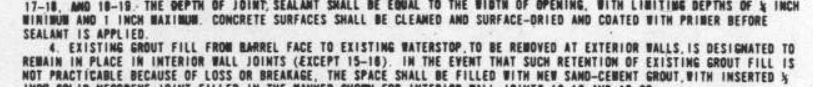

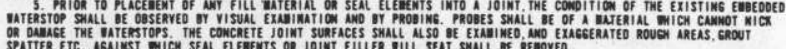

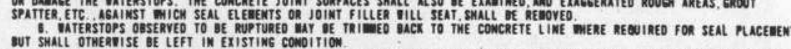

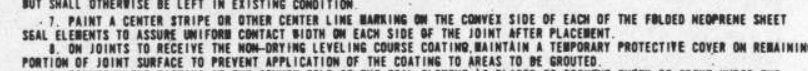

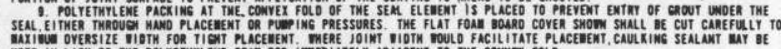

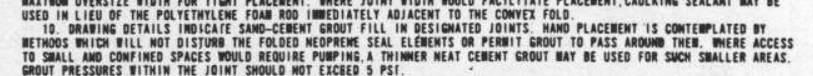

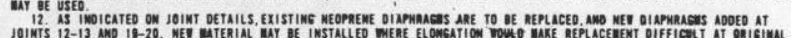

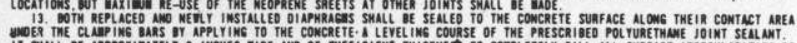

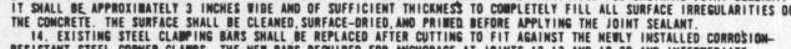

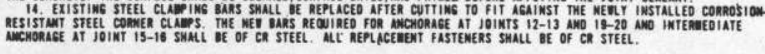

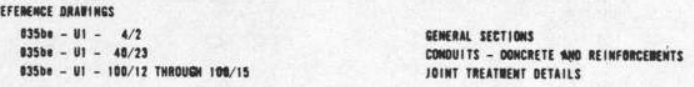



33. District operations personnel repaired 19 of the conduit joint seals during January 1977 . Outside temperatures during the repair period ranged from $10^{\circ}$ to minus $15^{\circ} \mathrm{F}$. Tarpaulins were hung over the conduit entrance during the repair and electric space heaters were used to keep the temperature of the joints above freezing. Details of the repair are summarized as follows:

Center barrel:

Right barre1:
Jo1nt 14/15 : Replaced neoprene membrane (3/8 in. by 14 in. by $25 \mathrm{ft}$ )

Original bars and bolts installed. Polyurethane joint sealant (PRC 210) applied behind and on edges of neoprene.

Joint $11 / 12$ : Repacked joint with polyethylene foam (Ethafoam) and resealed the joint with PRC 210.

Joint 10/11 : Repacked and resealed. Joint $9 / 10$ : Repacked and resealed. Joint $8 / 9$ : Removed old caulk and resealed. Joint $3 / 4$ : Removed old caulk and resealed.

Joint $16 / 17$ : Replaced neoprene membrane (3/8 1n. by $14 \mathrm{in.} \mathrm{by} 25 \mathrm{ft}$ )

Installed original bars and bolts. Caulked behind and on edges of neoprene with Sikaflex la.

Joint 14/15 : Removed loose bolts, pulled neoprene tight, retightened the bars, and caulked the edges.

Joint 10/11 : Repacked with Ethafoam rod and resealed.

Joint $9 / 10$ : Repacked and resealed.

Joint $8 / 9$ : Resealed.

Joint $7 / 8$ : Resealed.

Joint $6 / 7$ : Resealed.

Joint $5 / 6$ : Resealed. 


$$
\begin{array}{ll}
\text { Joint } 4 / 5 & \text { : Resealed. } \\
\text { Joint } 3 / 4 & \text { : Resealed. }
\end{array}
$$

Left barrel: Joint 20/21 : Recaulked with Sikaflex la.

Joint $11 / 12$ : Repacked and resealed.

Joint 10/11 : Repacked and resealed.

34. All three barrels of the outlet conduit were inspected in June 1981. The joint seals in the left and center barrels were in good condition, although some of the steel clamping bars were rusting. In the right barrel, two or three of the neoprene joint seals had either ruptured or torn loose from the clamping bars.

\section{Clearwater Dam}

35. Clearwater Dam is located on the Black River near Pledmont, Missouri. The rolled earth-fill dam has a crest length of 4,225 ft and a maximum height of $154 \mathrm{ft}$. The outlet works, completed in 1942, includes a gate tower and a 23-ft-diameter circular conduit.

36. Lake water migrating between the backfill material and conduit caused differential movement between the first conduit monolith and the transition section to the gate tower. This movement either ruptured the upper copper waterstop or made the waterstop ineffective by producing a path for water to circumvent the waterstop. This resulted in a leaking joint which produced unacceptably high flows.

37. The repair was begun by first bolting a 6-in.-wide steel plate over the interior top half of the monolith joint. This was followed by the drilling of several l-in.-diameter holes on $1.5-\mathrm{ft}$ centers through the conduit wa11 near the joint. Portland-cement grout was then pumped into the holes until the joint behind the plate was sealed. The drill holes were plugged at the completion of grouting. This repair was completed in 1966 for an estimated cost of $\$ 12,000$.

38. In 1972 it was reported that although the repalr was effective in stopping most of the leakage, a considerable amount of water was dripping from the repaired joint. The conduit joint is currently in need of repair according to District personnel. 
39. Sardis Dam is located in northwestern Mississippi on the Little Tallahatchie River, approximately 10 miles southeast of Sardis. The main embankment is hydraulic fill and the abutment dikes are rolled fill. Total length of the dam is approximately 15,300 ft with a maximum height above streambed of $117 \mathrm{ft}$. The outlet works includes a concrete approach, fourgated control structure, transition to a single conduft, conduit, chute and stilling basin (Figure 14). The egg-shaped conduit has a height of $18.25 \mathrm{ft}$ and a width of $16 \mathrm{ft}$ at the spring line and a length of $560 \mathrm{ft}$ including the transition. Copper waterstops are embedded at each monolith joint and in a longitudinal joint located 2 ft 9 in. below the spring line (Figure 15).

40. In 1955, small streams of water carrying small quantities of sand were emerging from near the invert of the joint between the transition monolith and conduit monolith 1. Similar leakage was reported between the Invert and the spring line at joint 2/3. Minor seepage was also reported on seven other conduit joints $(3 / 4,4 / 5,5 / 6,6 / 7,9 / 10,12 / 13$, and 13/14).

41. In 1966, several condult joints were leaking water below the spring line (Figure 16) and at least two joints (2/3 and 4/5) were passing some sand particles with the water. In addition, the original joint filler (concrete key) was in generally bad condition, being loose or lost in many locations. The rate of sand displacement while the conduit was dewatered appeared negligible; however, the effects of additional head, flow through the conduit, and cumulative sand removal during extended perlods of operation were unknown. Accordingly, it was felt that foundation investigations should be made.

42. Drilling holes in the conduit invert was rejected due to the danger of releasing damaging flows and the difficulties of working in the conduit. It was proposed to drill a hole on each side of the conduit at leaking joints and grout by gravity, and observe the conduit for any signs of grout.

43. After the general inspection and while the outlet works were still dewatered, the following work was performed by hired labor:

a. Joints $2 / 3,4 / 5$, and $5 / 6$ were repaired at leaking areas by removing the remaining concrete key, packing the joint below the keyway with oakum, sealing the oakum with lead wool, and replacing the key with Skimkote, which is described by the manufacturer, Hallemite Co., Cleveland, Ohio, as a "thin-ply concrete" that will adhere to set surfaces. 


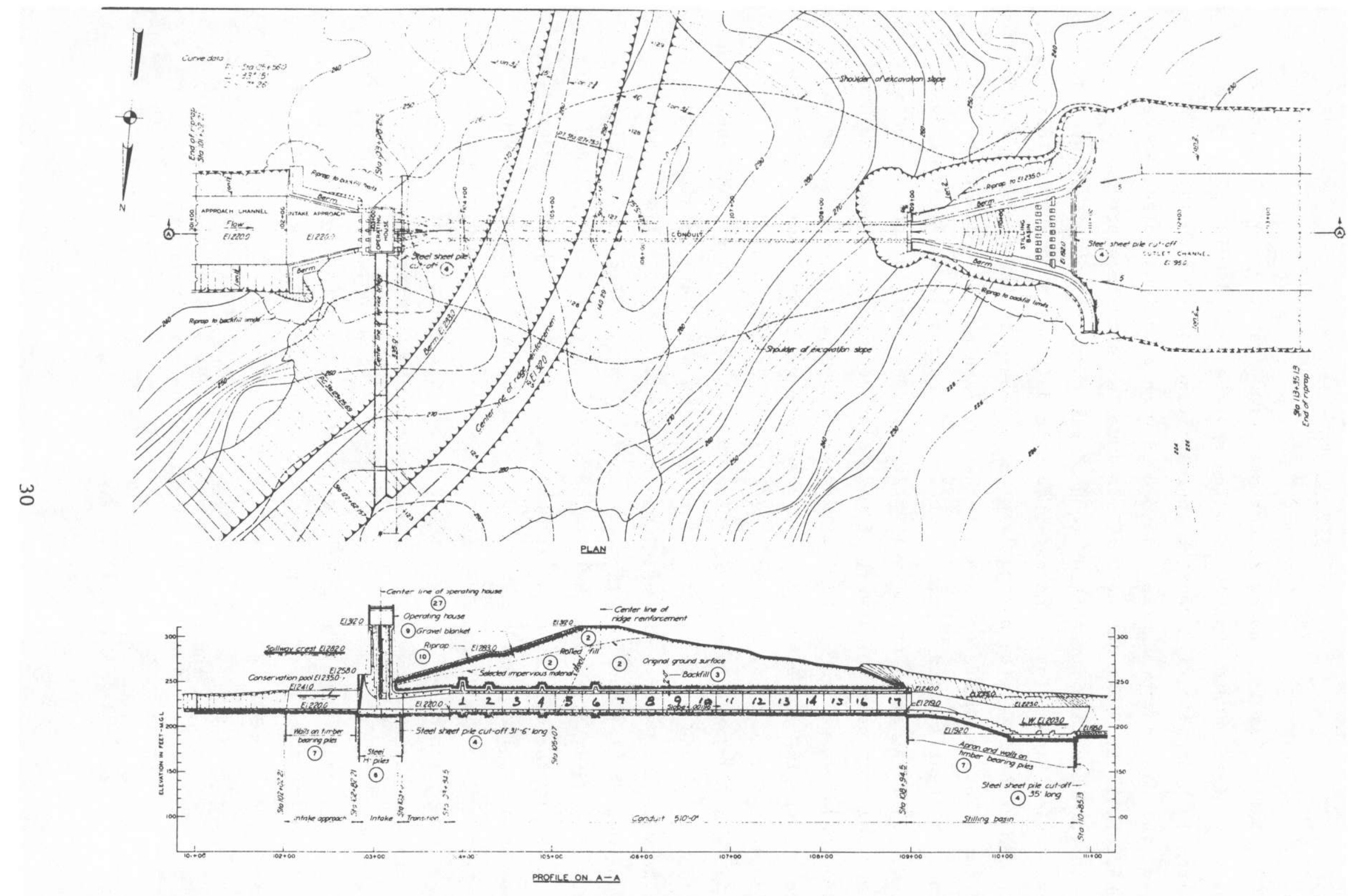

Figure 14. Outlet works, Sardis Dam 


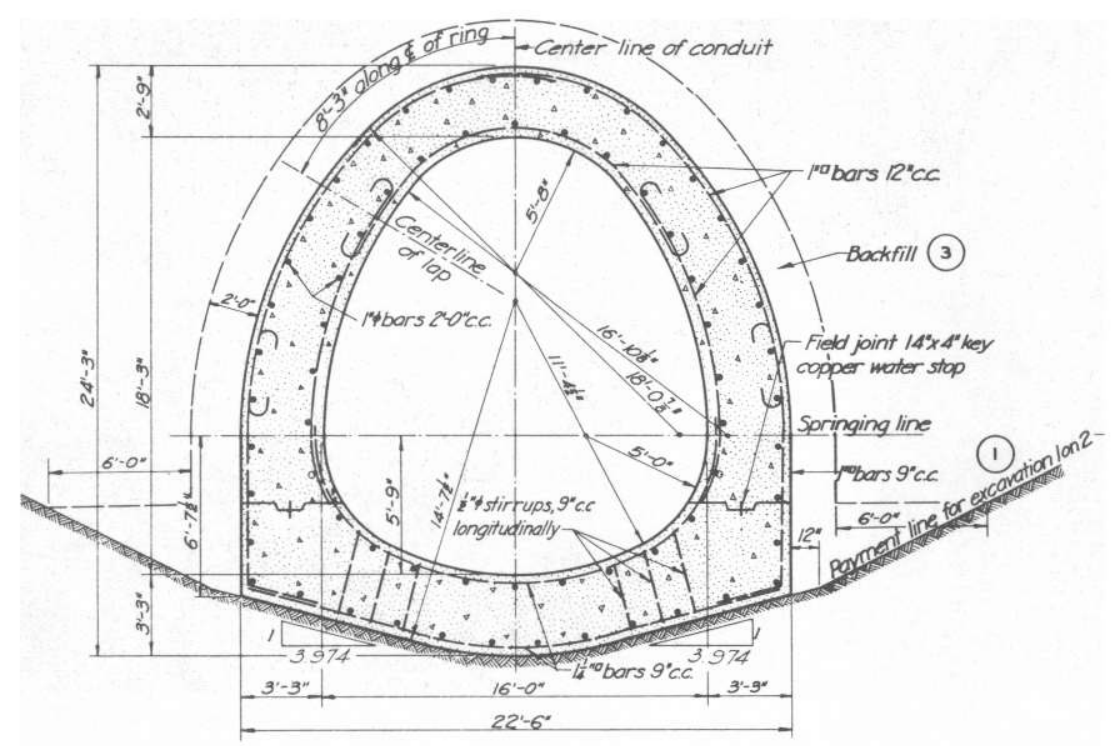

a. Typical section

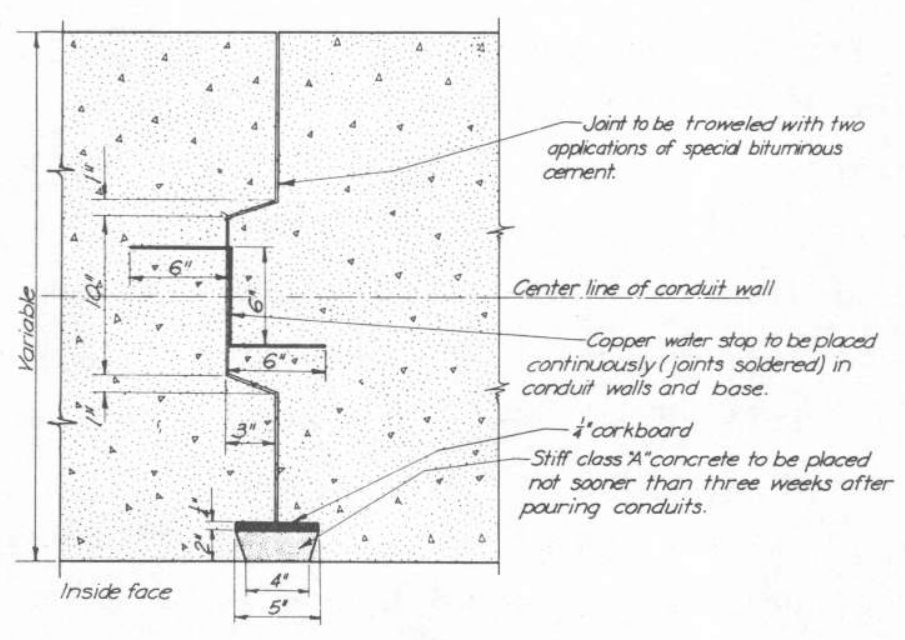

b. Expansion joint detail

Figure 15. Outlet works conduit, Sardis Dam 


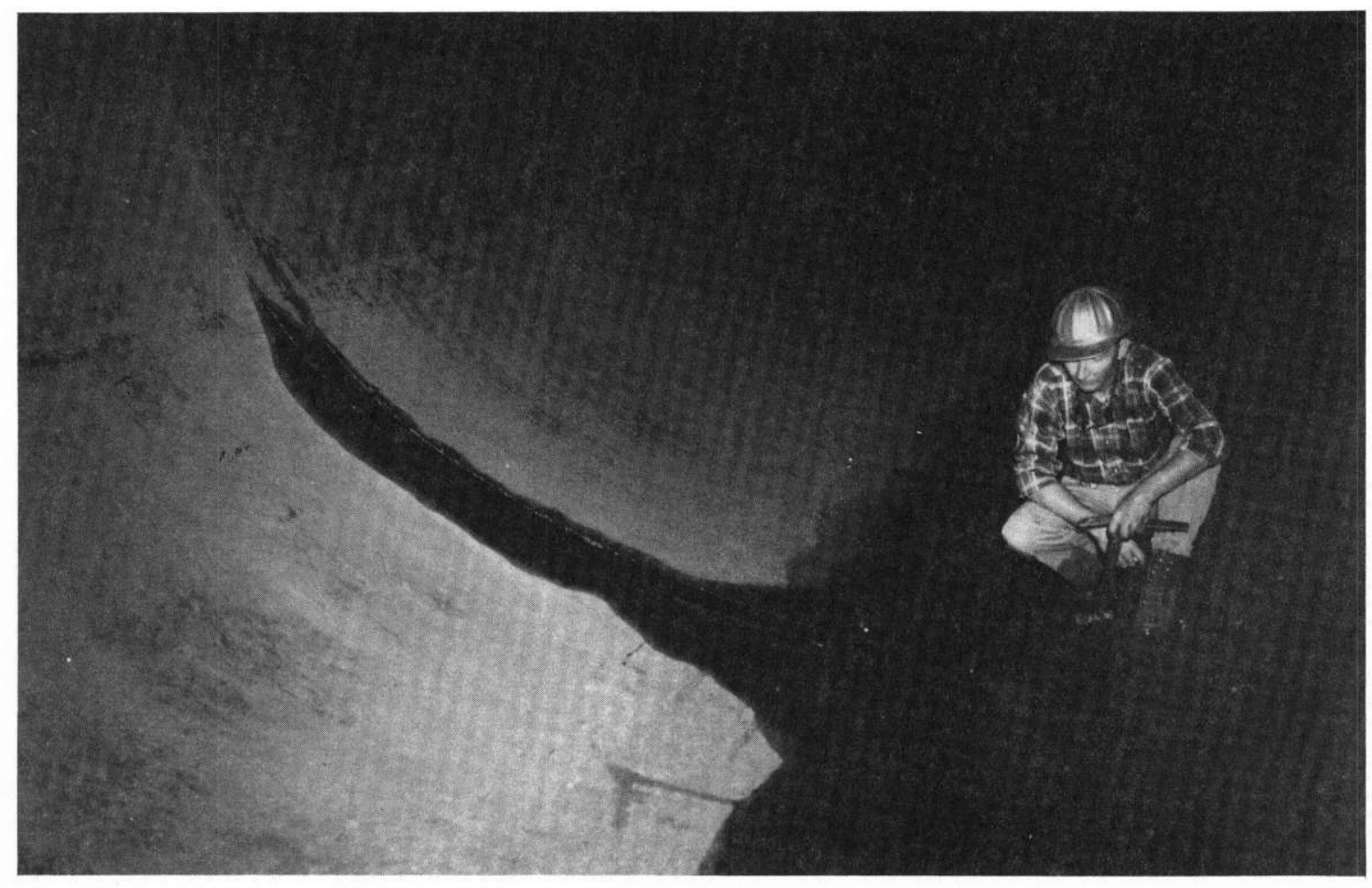

Figure 16. Leakage at conduit joint 4/5, Sardis Dam, 1966

b. The keyway between the transition section and conduit monolith 1 was filled with Skimkote.

Photographs taken during these repairs are shown in Figures 17-19.

44. Grouting of the outlet works conduit proposed in the 1966 inspection report was completed in March 1970. Grout holes were drilled from the embankment surface over the conduit to a depth approximately $1 \mathrm{ft}$ below the conduit. A total of $118.5 \mathrm{cu} f t$ of neat portland cement-fly ash grout was placed in the eight drill holes immediately adjacent to monolith joints $1 / 2$, $2 / 3,4 / 5$, and $5 / 6$. Grout density and compressive strength were approximately $114 \mathrm{lb} / \mathrm{cu} \mathrm{ft}$ and $3,000 \mathrm{psi}$, respectively.

45. Inspection of the conduit after the grouting was completed indicated that the operation was successful in filling the voids and stopping the water and piping leaks. Approximately $113 \mathrm{cu} \mathrm{ft}$ of grout was placed in the formation around the conduit with the remainder in the drill hole casings. Points of major grout-take occurred at monolith joints 5/6, 4/5, and 1/2. Maximum grout travel occurred at joint $4 / 5$ when joint 5/6 was being grouted. It was apparent that the waterstops at these joints have ruptured and voids were created as a result. Grout return on the inside of the tunnel for the most part 


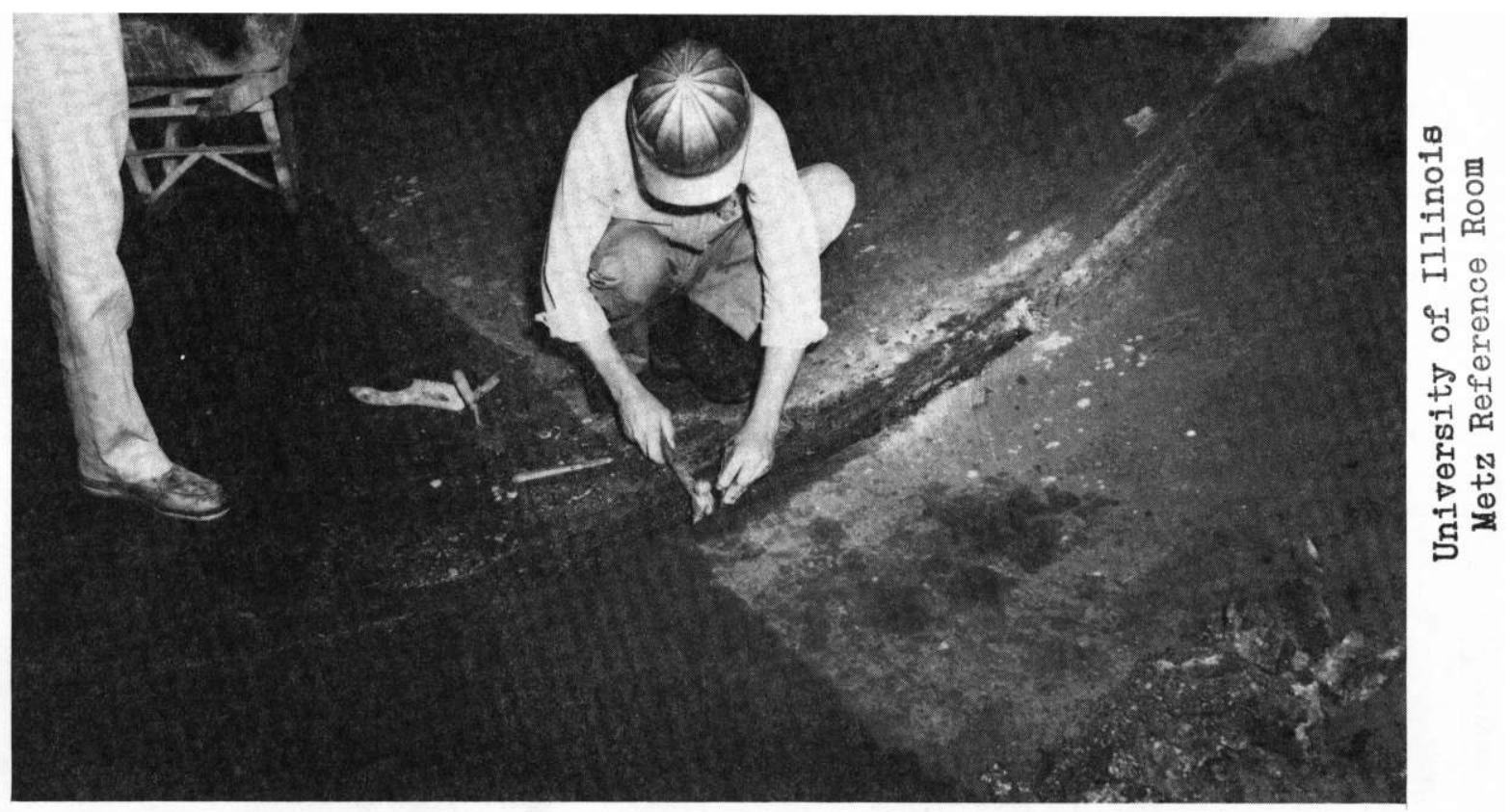

Figure 17. Removal of a portion of the remaining concrete key in preparation for repair, Sardis Dam

Figure 18. Packing a conduit joint, Sardis Dam

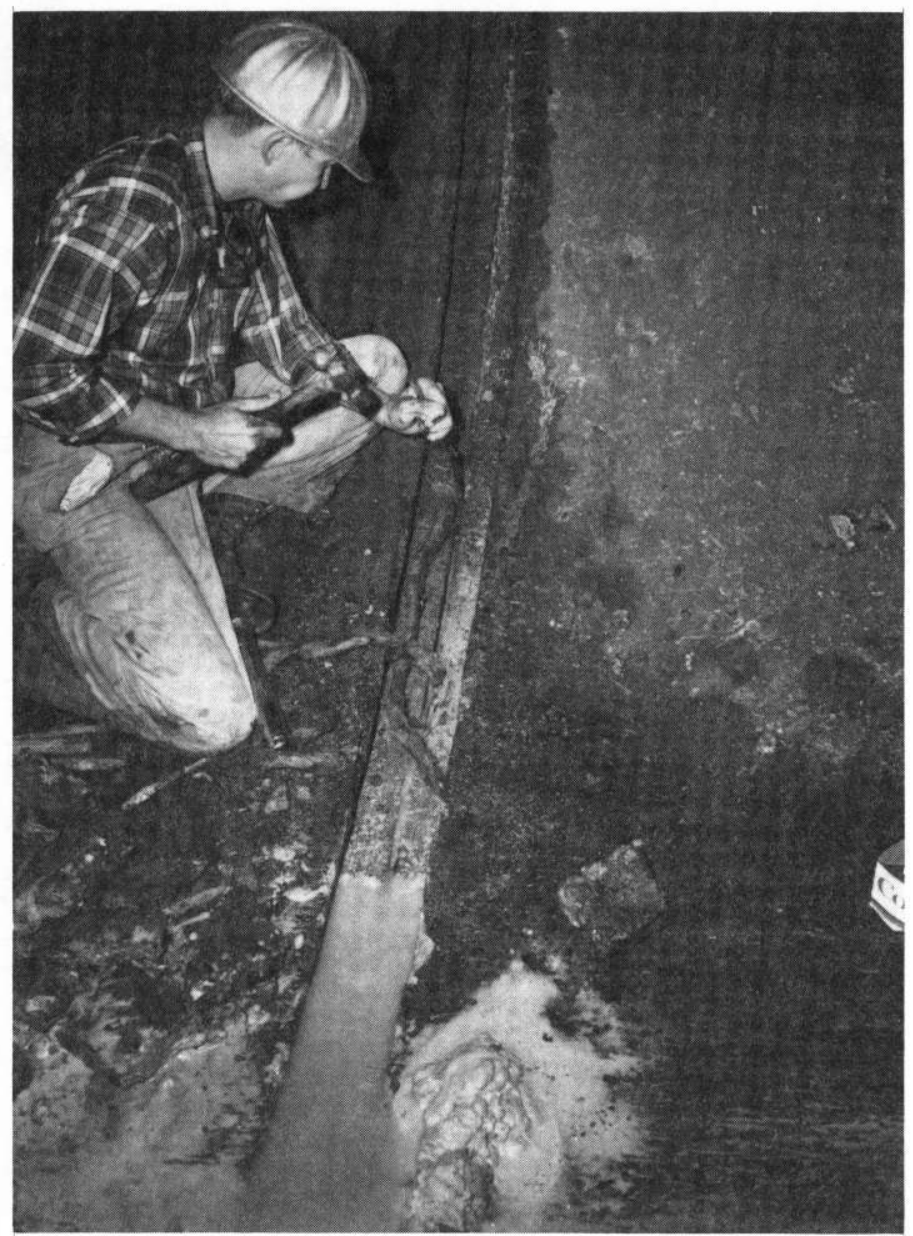




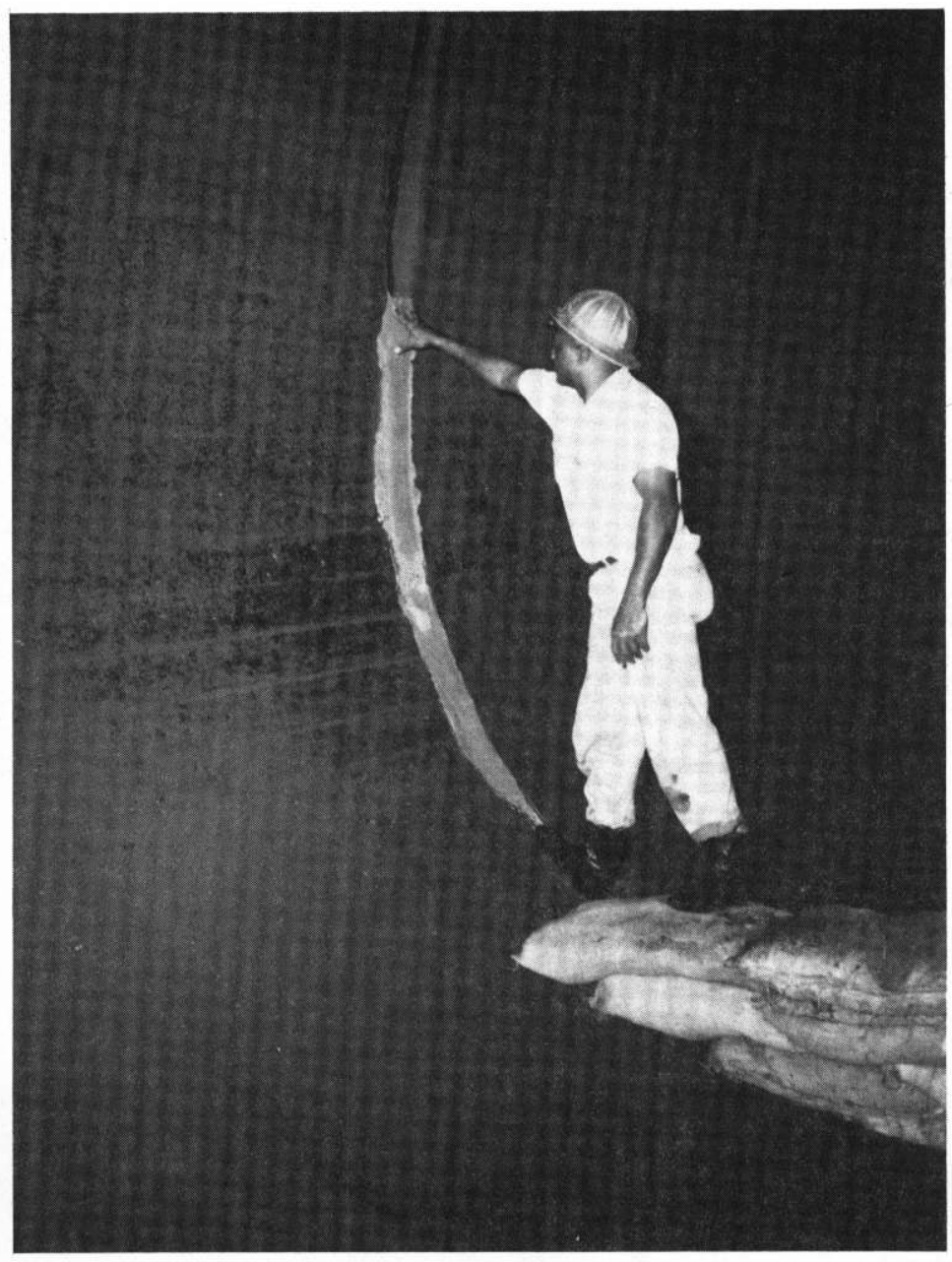

Figure 19. Partially replaced joint keyway, Sardis Dam

occurred at or near the crown. This does not necessarily mean that the voids were all located at the crown. The waterstops may be ruptured at the invert where the joints have separated due to settlement and the grout traveled between the waterstops and joint keys to the crown of the tunnel where the keys and joint material had deteriorated or were absent. Since it is possible that further settlement of the conduit could break the grout seal and cause a recurrence of the piping condition in the future, frequent inspection of the conduit by project personnel was recommended. In view of the considerable grout-take at these four joints, it was proposed that all joints with a history of leakage be grouted from the inside of the conduit.

46. In a September 1971 inspection, wet areas were noted near the invert of each conduit joint from the transition monolith through monolith 5 , 
the general area grouted in 1970. No loss of sand through the joints was noted. Grouting around leaking joints as previously proposed was recommended. 47. Nine joints (transition/monolith $1,1 / 2,2 / 3,3 / 4,4 / 5,5 / 6,6 / 7$, 14/15, and 15/16) were selected for additional grouting in September and October 1972 (US Army Engineer District, Vicksburg 1972). The location of the grout holes infially selected was 5 in. downstream of the centerline of the joints, approximately $2 \mathrm{ft}$ in elevation above the conduit invert (Figure 20). The 2-1/2-in.-diameter holes were drilled 5 in. downstream of the joint on a 10 - to 20-degree angle from the vertical. As reinforcing steel was encountered in most holes after a few inches penetration, minor relocations were necessary. Eight of the 22-1n.-deep grout nipple holes were drilled and the 1-1/2-1n. inside diameter grout nipples grouted in place. After quick shutoff valves were installed, attempts were made to penetrate the remaining conduit thickness with 1-1/2-in.-diameter holes, but only one hole was successfully completed. Reinforcing steel was encountered in the others and they were abandoned. The hole locations were changed to $0.8 \mathrm{ft}$ downstream of the joints with similar results. The abandoned holes were plugged by f1lling with a thick cement grout, allowing the grout to set, screwing a cap onto the grout nipples and filling the remaining depressions with grout flush with the inside surface of the conduit.

48. It was decided that the only possible location that would allow successful completion of the grout holes was along the monolith joints. Accordingly, the 2-1/2-in.-diameter grout nipple holes were drilled on the centerline of the joints, puncturing the embedded portion of the copper waterstop as shown in Figure 21. It should be noted that the waterstop was punctured in such a manner as not to disrupt its seal across the joint. After the grout nipples had been grouted in place and the quick shut-off valves installed, the 1-1/2-in.-diameter grout holes were extended through the conduit a few inches into the surrounding material. Back pressures were encountered at seven grout holes located at four different joints. Whenever the shut-off valve for six of these holes was opened, a mixture of sand, water, and a few lumps of clay would flow out. The remaining hole flowed water only. Prior to and during grouting, leakfng areas along the joints or around the grout pipes were caulked with lead wool as necessary.

49. The grouting machine was set up on the embankment surface adjacent to the right stilling basin wall. Grout supply and return lines were so 


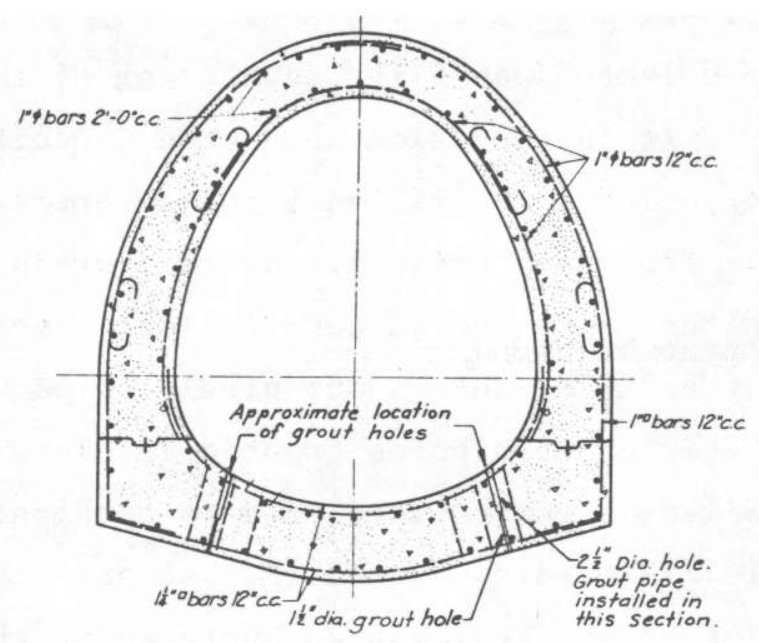

a. Typical conduit section

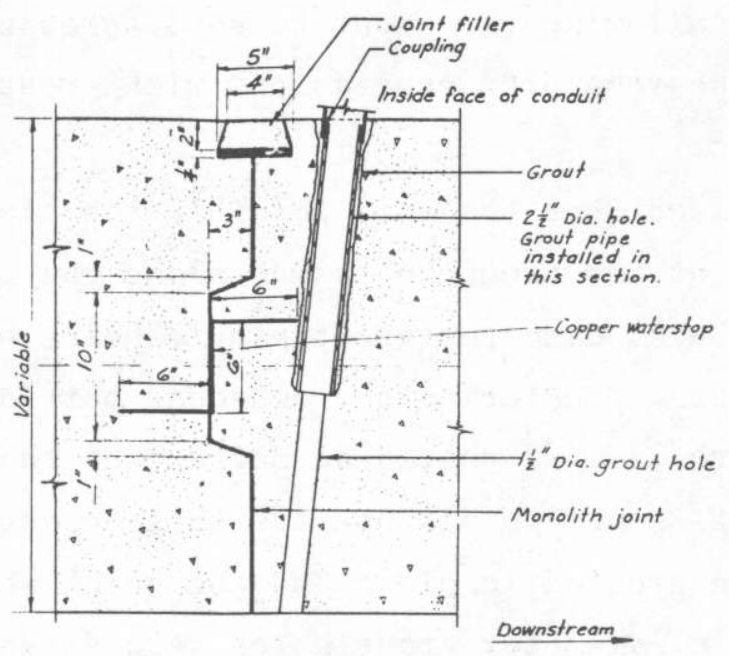

b. Section through grout hole

Figure 20. Original location of grout holes, Sardis Dam 
Figure 21. Final location of grout holes, Sardis Dam

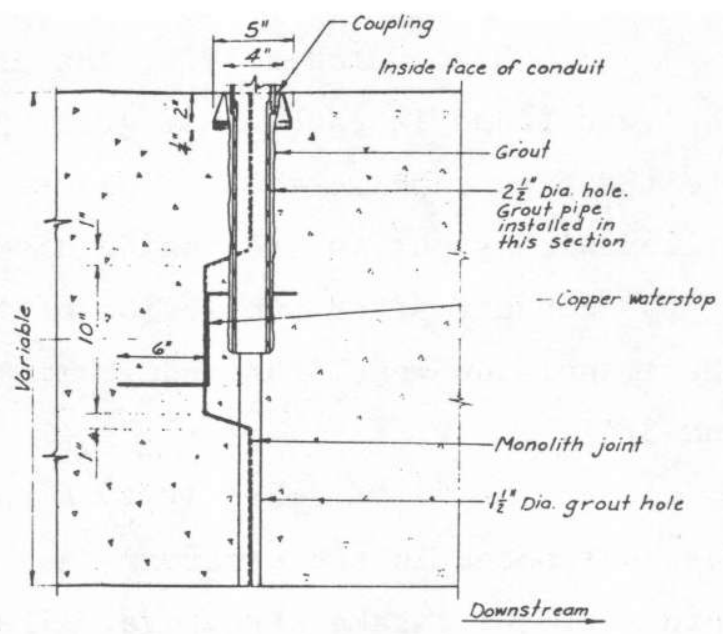

arranged that a control valve and a pressure gage were at the hole to be grouted. The maximum allowable grout pressure for each hole was calculated based on the depth of overburden and estimated water level at that location. Grout pressures used were approximately 80 percent of the calculated maximums. 50. Grouting began on 3 october 1972. The grout mixture was a $3: 1 \mathrm{mix}-$ ture of water and Type I portland cement, with $3 \mathrm{lb}$ of bentonite per sack of cement added to reduce grout shrinkage. Prior to grouting, the valves on holes having back pressures were opened for 3 to 5 seconds to allow the sandy material to flow out. This was an attempt to loosen the material so the grout could force it out of the pipe. The grout line was then connected and pressure attained prior to opening the quick shut-off valve.

51. After all the holes had been initially grouted, the holes at the joint between the transition monolith and conduit monolith 1 were regrouted. Grout leakage had been noted at this joint from spring line to spring line across the crown during the initial grouting. During regrouting of these holes, the grout leakage was about the same, so grouting at this joint was stopped. The hole on the left side of joint $1 / 2$ was then regrouted because of the presence of back pressure and negligible grout-take initially.

52. On 4 October 1972, each grout hole was probed to determine whether a positive grout seal was present. Two holes were not sealed and started flowing sand and water after the quick shut-off valve was opened. The grout machine was used to introduce water into each of these holes to force the sandy material out. After a sufficient volume of water had been introduced, the quick shut-off valve was closed to prevent a reverse flow, and then each hole was regrouted. 
53. On 5 October 1972, the grout holes were again probed and a posttive seal was found in each. All grout pipes were then filled with a thick grout and the pipe caps screwed in place. The depression around each pipe was filled with grout to the inside diameter of the tunnel. During an inspection of the conduit after completion of the grouting, minute seepage was noted at the transition monolith/conduit monolith 1 joint at two conduit joints (1/2 and $3 / 4)$.

54. On 11 December 1974, a hole approximately $12 \mathrm{ft}$ in diameter and $8 \mathrm{ft}$ deep was noted in the upstream face of Sardis Dam adjacent to the southwest corner of the intake structure. The top of the hole was at approximately elevation $252 \mathrm{ft}$. Lake elevation on 11 December was $243.0 \mathrm{ft}$, the lowest lake level since before the $1973 \mathrm{flood}$. It was suspected that the sinkhole was caused by leakage and loss of foundation sands through monolith joints similar to that previously occurring in the conduit. This was verified when dye poured into the hole was noted coming through openings in the joint between the intake monolith and the first conduit transition monolith (Figure 22). A small quantity of foundation sand was also observed escaplng at the floor of the conduit through two small openings in this joint. Approximately an inch of differential settlement had occurred between the intake monolith, which is founded on piles and the transition monolith which rests on foundation sands. This settlement apparently ruptured the copper waterstop, permitting loss of the foundation sands. On 20 December, the hole was dug out to about $1 \mathrm{ft}$ above the conduit and was repaired by backfilling with compacted impervious material, bedding material, and riprap to the original grade.

55. The areas around the joint between the intake structure and first transition monolith were grouted with a neat cement grout from inside the conduit (US Army Engineer District, Vicksburg 1975). A series of 12 holes were drilled through the center of the joint as shown in Figure 23. Grout-take at the joint was about $40 \mathrm{cu}$ ft with most of the take along the bottom and the south wall in the vicinity of the sinkhole. Grouting operations were completed on 3 January 1975.

56. During the inspection of the interior of the conduit, some minor leakage was noted at several joints. Leakage was most prevalent at joint 4/5, but there was no evidence of loss of material through the joint. This joint was previously grouted during 1970 and again in 1972. 


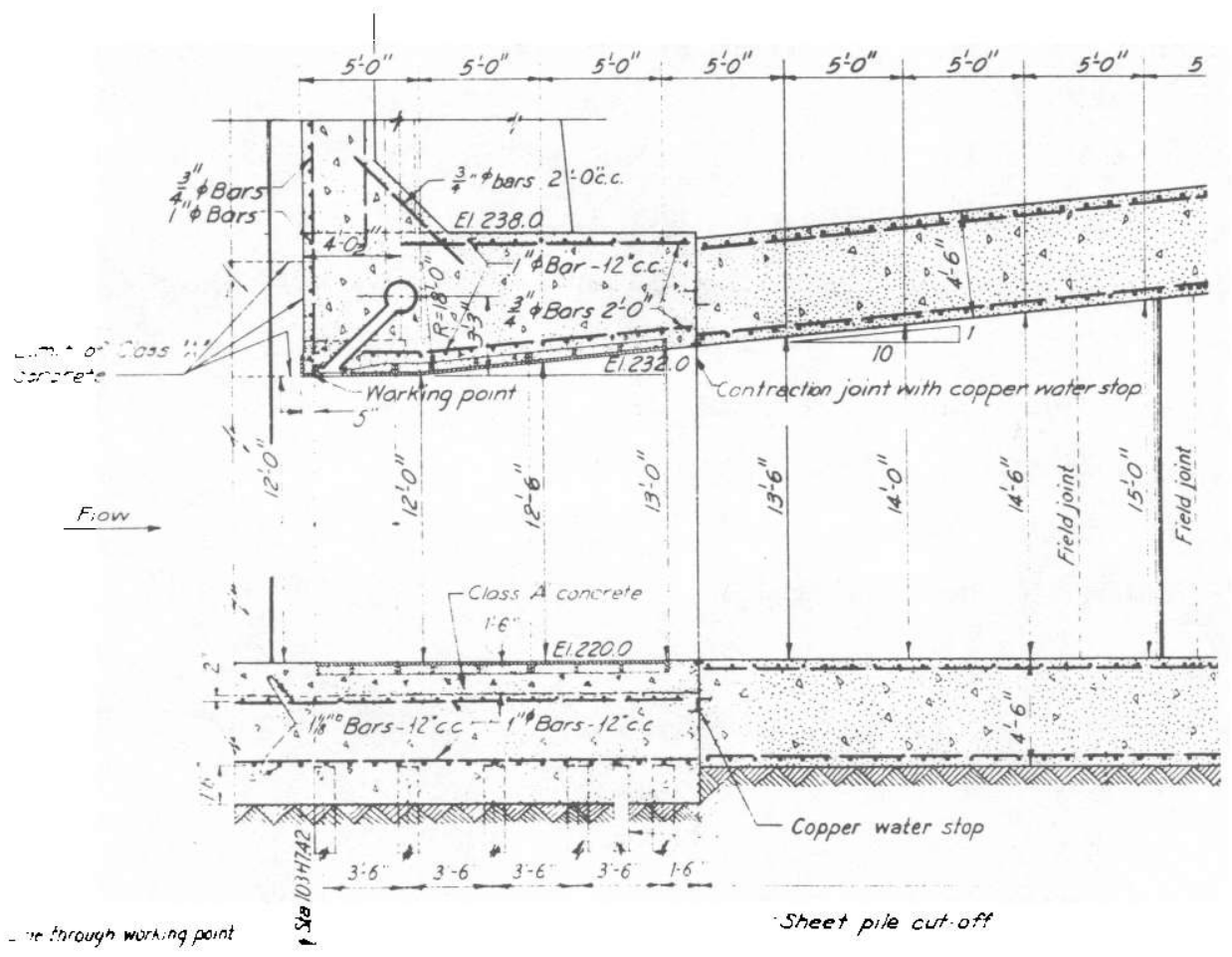

Figure 22. Partial section through intake monolith and transition monolith, Sardis Dam

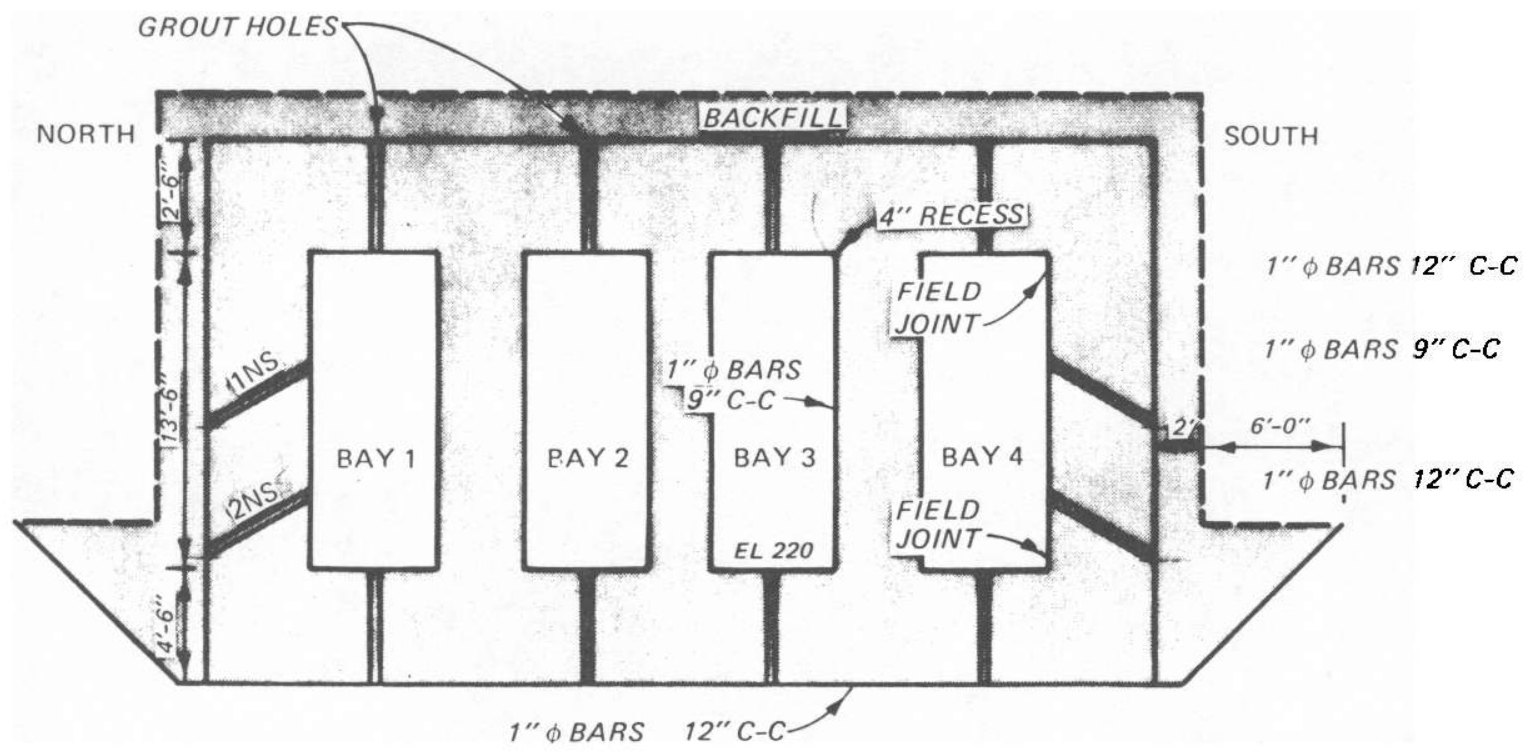

Figure 23. Section through joint between intake monolith and transition monolith, Sardis Dam 
57. During the grouting operations, all previously grouted joints that were leaking were redrilled and regrouted. Six previously grouted joints were regrouted through the old grout nipples. The maximum grout-take (about $7.5 \mathrm{cu} f \mathrm{f}$ ) was at joint 6/7. All other joints had 1ittle or no take, and a11 leaks were stopped as a result of the grouting.

58. In a November 1976 inspection, very small leaks were noted at several monolith joints, but there was no evidence of piping of material and the leaks were not considered detrimental. There was no evidence of leakage or piping of materials at the joint between the intake structure and the transition conduit. In August 1981, a few very small leaks were noted at some monolith joints in the conduit, none of which was considered significant.

\section{Lock and Dam No. 3, Arkansas River}

59. Lock and Dam No. 3 is located on the Arkansas River, approximately 29 miles downstream from Pine Bluff, Ark. The 110- by 600-ft lock, located on the left bank of the river, was designed for a normal lift of $20 \mathrm{ft}$. The lock walls, guard walls, and a 60-ft-long segment of each guide wall upstream and downstream of the lock are semigravity type, reinforced concrete walls supported on steel bearing piles. The remaining portions of the guide walls are supported on steel bearing piles which are located in sand-filled, steel, sheet pile cells. A 3,590-ft-long overflow embankment section adjoins the lock on the left bank. The dam consists of a 1,260-ft-long, semigravity, gated concrete spillway section with 18 tainter gates. The spillway section is supported on steel bearing piles. A 997-ft-long overflow embankment section adjoins the dam on the right bank (Figure 24). The training walls upstream and downstream of the dam are supported on steel bearing piles.

60. After impoundment of the Lock and Dam No. 3 pool in December 1968, it was discovered that water from the upstream pool was leaking through the vertical monolith joints in the dam training wall. An earth-fill overflow embankment abuts this training wall and extends to higher natural ground approximately $1,000 \mathrm{ft}$ landward. The centerline of the embankment is approximately $60 \mathrm{ft}$ upstream from the concrete dam axis. The waterstops across the monolith joints of the training wall had been omitted during construction, thus allowing water from the upstream pool to flow through the monolith joints onto and into the downstream pervious zone of the embankment. This leakage or 

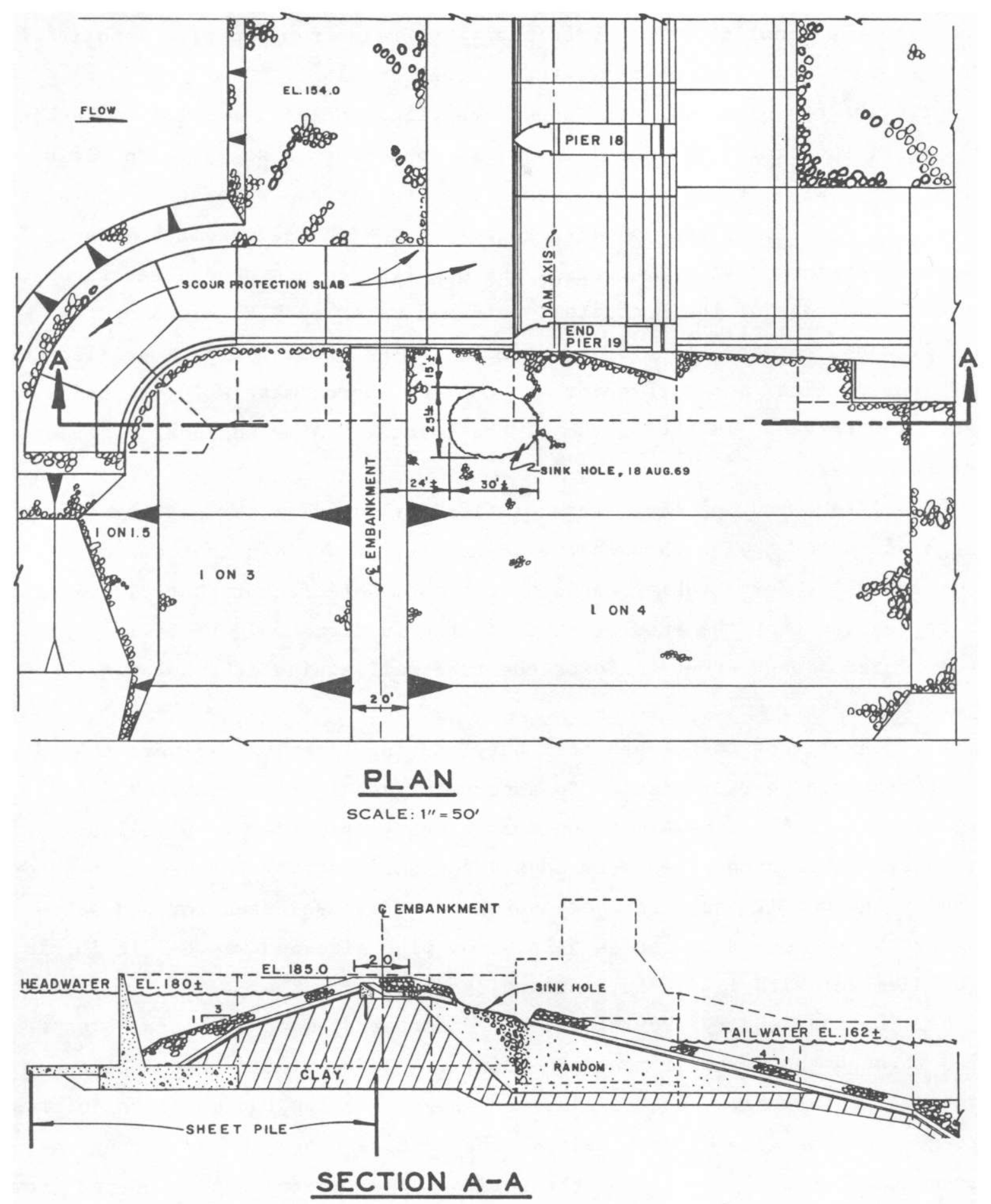

SCALE : $1^{\prime \prime}=50^{\prime}$

Figure 24. Sinkhole in overflow embankment, Lock and Dam No. 3, Arkansas River 
flow created an erosion condition which could have endangered the stability of the embankment in time. A sinkhole of undetermined dimension, which developed adjacent to the monolith joint immediately upstream from end pier monolith 19, was filled with gravel which prevented further erosion.

61. The training wall was founded on piles and each monolith is subject to movement; therefore, the monolith joints could not be sealed with rigid materials. It was determined that some type of flexible waterstop should be installed in a vertical hole drilled to coincide with the monolith joint. It was also determined that only four of the monolith joints needed waterstops, since the remainder of the monolith joints had water on both sides of the wall. It was determined that 6-in.-diameter holes should be core drilled down through the vertical monolith joints to a point approximately 18 in. below the horizontal waterstops in the bottom of the joint (US Army Engineer District, Little Rock 1972).

62. After studying many types of flexible material for sealing off the hole against water coming through the joint, it was decided that a closed cell, thick wall, Butyl tubing would be the most satisfactory material. It was also decided that the annular space in the tubing should be filled with nonshrink neat cement grout to force the tube wall against the hole wall and shut off the water.

63. Samples of the closed cell Butyl tubing (Armflex 22) were tested for stress-strain characteristics to ascertain installation problems. Armflex 22 is manufactured by Armstrong Cork Company primarily as pipe insulation; however, its properties were considered satisfactory for use as a waterstop under the conditions described above. The tube selected for use was designated by the manufacturer as 5-in. iron pipe size and was 8-1/16 in. in outside diameter with 1-1/16-in. wall thickness.

64. During January 1969, the 6-in.-diameter diamond bit core holes were drilled through the vertical monolith joints. The 6-in. core bit made a 7-3/4-in.-diameter hole. The driller was able to follow the monolith joint by observing the thickness of each half of the core recovery and adjusting the drill as necessary. A section of the horizontal waterstop was recovered from each of the four core holes drilled. The holes were approximately $36 \mathrm{ft}$ deep. 65. Six-foot lengths of the Butyl tubes were glued together to form the four required 36-ft waterstops. One end of each $36-\mathrm{ft}$ tube was plugged with a wooden plug and clamped. Prior to installing the tubes in February 1969, the 
core holes were flushed to remove silt sediments and about 75 gal of thick bentonite slurry was pumped into the four holes to provide a lubricant on the walls. The 36-ft tubes were placed over a 38-ft length of $\mathrm{N}-\mathrm{size}$ drill rod which hung from the boom of a crane. A thick bentonite paste was applied to the outside of the tube as it was gradually forced into the core hole by the weight of the drill rod and by men pulling downward on ropes fastened to the top of the drill rod.

66. During installation the tubes elongated from 10 to 20 percent due to the friction along the walls of the core holes. This amount of elongation was considered acceptable since a minimum of 29 percent strain was required for rupture as indicated by previous testing.

67. A relatively thick nonshrink neat cement grout slurry ( 0.35 water content) was pumped through the drill rod into the tube resulting in a filling action from the bottom to the top ensuring the formation of no alr pockets within the column of grout. After removing the drill rod, the tube was filled to several feet above the top of the wall to provide some additional pressure. The pressure head of grout was sufficient to force the tube tightly against the walls of the core hole but not sufficient to completely flatten out the wall of the tubing. Therefore, it was believed that a positive but flexible waterstop seal was obtained at the monolith joints.

68. The installation of the waterstop tubes was considered relatively easy even though the tubes were slightly larger than the core holes. Full penetration of each core hole by the tube was assured by measuring the depth of the hole before and after installing the tubes. The only difficulty that occurred was during the installation of the tube in the joint immediately upstream of the end pier, and this was attributed to a crook in the core hole. It is believed that this tube developed a small rupture as indicated by the return of grout between the tube and the wall of the core hole. However, this rupture was small and self-sealing inasmuch as a head of approximately $10 \mathrm{ft}$ of grout was quickly attained and held constant within the tube until the grout had set.

69. It was believed that the leakage through the monolith joints was effectively cut off. The waterflow through one of the joints was observed to diminish simultaneously with the rise of the grout within the tube. All flow through this joint had ceased by the time the tube had been filled with grout. 70. In August 1969, a sinkhole approximately $25 \mathrm{ft}$ wide, $30 \mathrm{ft}$ long, 
and $7 \mathrm{ft}$ deep was discovered on the downstream slope of the right overflow embankment (Figure 24). During grouting operations to correct seepage through the embankment, the waterstop installed between the training wall and monolith 19 began leak1ng. The waterstop installed between training wall monoliths USTW-1 and USTW-2 also began leaking. It was speculated that during the summer following installation, the concrete had expanded and compressed both the closed cell foam Butyl tube and the grout it contained. When the concrete cooled, the concrete contracted and the rubber tubing and the grout it contalned did not rebound from its compressed state sufficiently to retain the seal around the circumference of the hole. Also, the rupture in the rubber tube which occurred during installation of the waterstop between the training wall and monolith 19 may have contributed to the leakage.

71. As a temporary repair, rubber tubes in the leaking joints were replaced with similar tubes of smaller diameter. An attempt was made to backfill one of the tubes with hot asphalt in the hope that the more fluid asphalt would keep the rubber tube expanded against the sides of the hole better than the cement grout. The backfill attempt was unsuccessful and the hole was again temporarily backfilled with a foam rubber tube filled with cement grout. Because of the limitations of the foam rubber tube and cement grout backfill, it was planned that a permanent solution would be provided when the proper materials were located.

72. Several methods of installation were studied in an attempt to improve the existing waterstops; however, it was concluded that a thin resilient tube installed in the existing core holes and filled with a high specific gravity liquid would provide the most satisfactory waterstop. Some of the installation methods studied and reasons for rejection are listed below.

a. Drill additional holes on each side of the existing core holes and install a nonmetallic type waterstop across the joint. A material was not found that could be used to secure the waterstop in place with water flowing through the joint.

b. Fill the existing core holes with a fibrous material impregnated with asphalt or some other mastic. There was no assurance that the material used would rebound any better than the Buty1 tube or that the hole would be filled watertight as the material was packed into the hole.

73. After it was decided that a thin resilient tube was needed to provide a satisfactory waterstop at each joint, a search was initiated to secure the proper material. The Firestone Tire and Rubber Company was contacted 
about the manufacturing of a resilient tube the same diameter as the existing core hole in the training wall joints. Firestone indicated that a tube could be manufactured that would meet these requirements; however, the cost would be prohibitive since regular production would have to be stopped and spectal tooling would be necessary. A discussion with Goodyear Tire and Rubber Company revealed almost identical conditions.

74. A visit was made to several rubber specialty companies in the Houston, Texas, area in search of one that could manufacture tubes $40 \mathrm{ft}$ in length and of sufficient diameter to fill the existing core holes. It was found that rubber tubing of the specific size and length required was not avallable as a standard item, but such tubing could be manufactured by at least two companies in Houston. Murray Rubber Company could manufacture the tubes by foining two 20-ft sections of ethylene-propylene-diene-monomer (EPDM) synthetic rubber formed and cured on a steel mandre1. The tubes would be 7-3/4-in. outside diameter with 1/8-1n. wall thickness. The wall thickness at the joint would be greater than $1 / 8 \mathrm{in}$. and less than $3 / 16 \mathrm{in.}$ The joint would be as strong as the other section of the tubing. The rubber for manufacture of the tubes would have a Young's modulus of approximately 500 psi and a durometer hardness of 40-45. The EPDM polymer was recommended because of its resistance to deterioration due to weather, water, and temperature. Details of the tube are shown in Figure 25.

75. A search was also conducted for a fluid to be placed in the tube that was heavy enough to press the rubber tube against the circumference of the hole with sufficient pressure to prevent seepage. This fluid also had to remain in a liquid state permanently. A fluid which met these requirements and would not affect the rubber tubing was obtained from Baroid Division, National Lead Company. The fluid is commonly used as ship ballast, remains permanently liquid, and could be obtained with the desired specific gravity.

76. During the fall and winter of 1970 the cooler weather caused the concrete training walls to contract. The foam rubber tubes previously installed as waterstops in the training wall joints had lost their resiliency by crushing and did not expand to fill the holes. Leakage was observed at the joint between the dam and the first upstream training wall monolith. Piezometers with tips near the joints began to indicate higher water levels. This trend continued throughout the winter. 


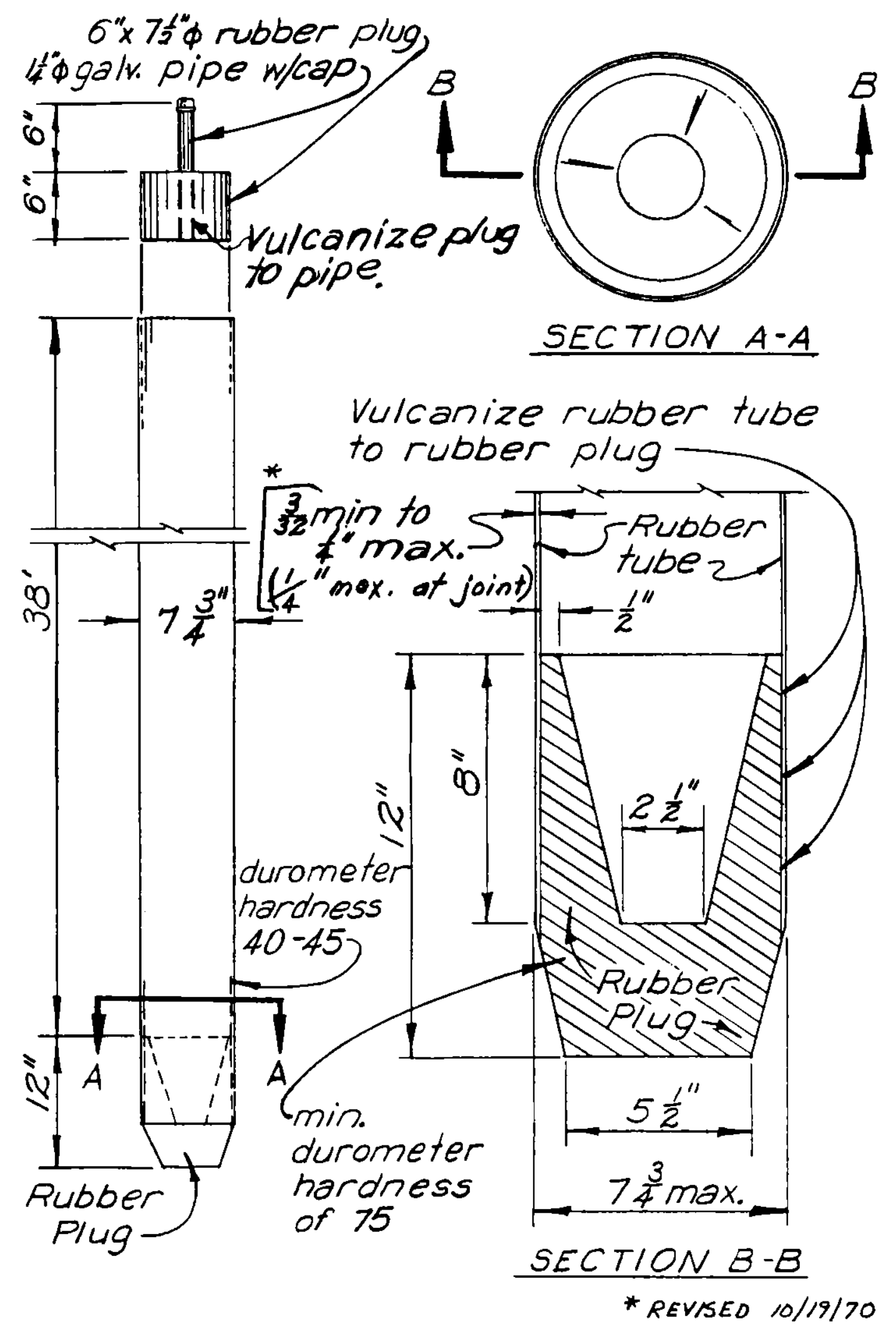

Figure 25. Waterstop detail, Lock and Dam No. 3, Arkansas River 
77. Waterstops were installed in April 1971 as a permanent repair measure. Each temporary waterstop was removed by drilling with a 7-5/8-in. roller rock bit. The new waterstop consisted of a 40-ft length of 7-3/4 in. outside diameter synthetic rubber tubing with approximately $1 / 8-1$ n. wall thickness. The tubes were fabricated with hard rubber plugs in the lower end. The tubes and 40-ft lengths of drill rod were placed in the drilled holes with a crane. The tubes were backfilled by pumping a heavy fluid through the drill rods. This fluid was designed to weigh approximately $150 \mathrm{lb} / \mathrm{cu} \mathrm{ft}$ and to remain permanently fluid. The fluid was mixed in the proportions shown below.

\begin{tabular}{lc}
\multicolumn{1}{c}{ Item } & Quantity \\
\cline { 3 - 3 } Fresh water & $19.3 \mathrm{gal}$ \\
Aquagel & $11.5 \mathrm{lb}$ \\
Baroid & $630 \mathrm{lb}$ \\
Flaked aldacide & $1 \mathrm{bb}$ \\
Surflo-H35 or stabilite & $0.033 \mathrm{gal}$ \\
Ethylene glycol & $4.6 \mathrm{gal}$
\end{tabular}

After they were filled, the tubes were capped with a hard rubber plug with an inspection pipe. The plug was set about 6 in. below the top of the concrete, with the inspection pipe flush, and the hole was patched with cement mortar. The cost of replacing the existing waterstops was approximately $\$ 15,000$.

78. The water level at the piezometer near the joint between the first and second upstream training wall monoliths dropped significantly when the new waterstop was installed. While the joint between the dam and the first upstream training wall monolith was open, the water level in a piezometer near the joint rose about $5 \mathrm{ft}$. After the installation of the new waterstop in this joint, the water level dropped over $5 \mathrm{ft}$ and continued to drop to a satisfactory level near the tailwater. The piezometers were read weekly for 2 weeks after installation of the new waterstops and monthly thereafter. The significant drop in the piezometers demonstrates the inftial effectiveness of the new waterstops. The permanence of the installations will only be known with time. The piezometers will be monitored to determine the continued effectiveness of the system and the fluid level will be checked periodically to determine whether the ingredients remain in suspension as desired.

John Day Lock and Dam

79. John Day Lock and Dam is located on the Columbia River between 
Oregon and Washington, about 110 miles upstream from Portland, Oregon. Construction of the navigation lock began in December 1959 and was completed in November 1963. The lock (Figures 26 and 27) is $675 \mathrm{ft}$ long, $86 \mathrm{ft}$ wide, and provides a maximum lift of $113 \mathrm{ft}$, making it one of the highest singlelift locks in the world.

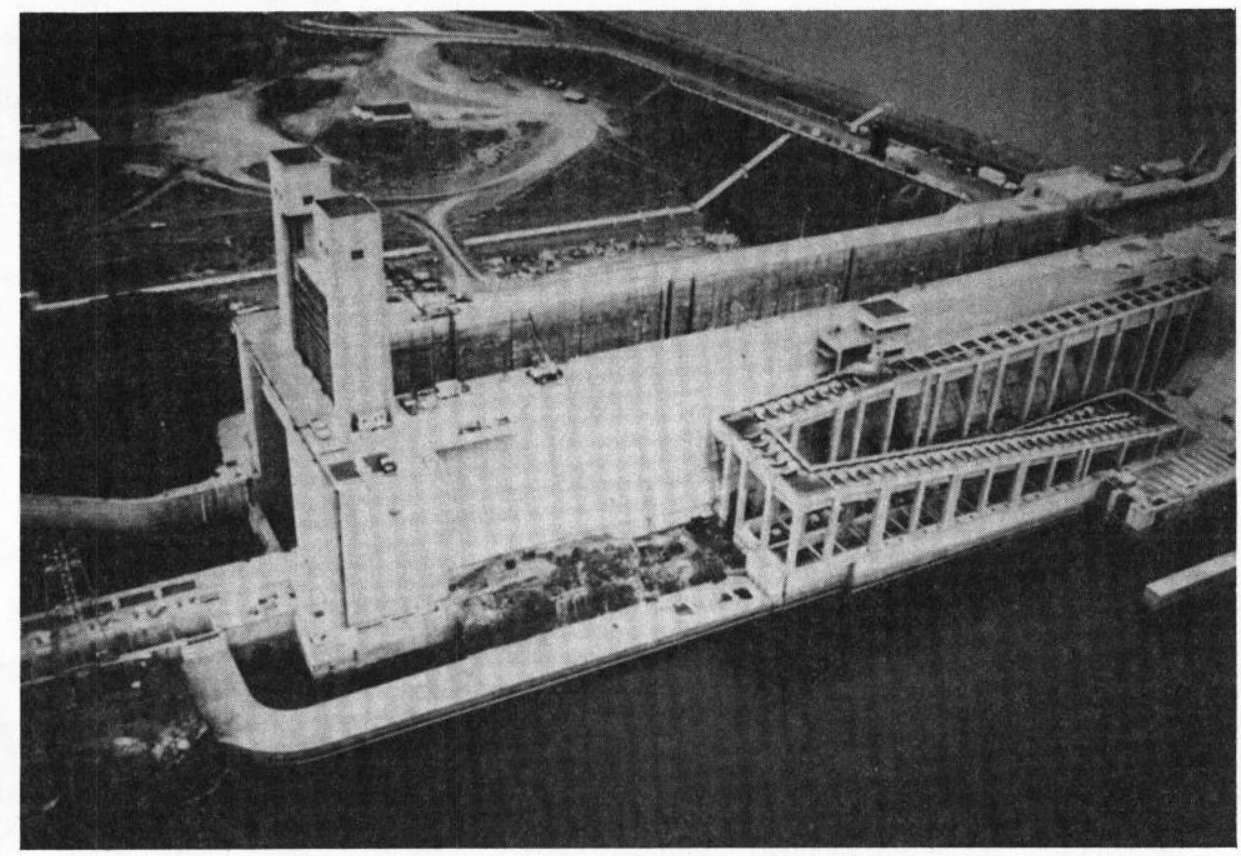

Figure 26. Aerial view of John Day Lock

80. The first periodic inspection of the project in October 1968 reported that the joints between monoliths $27 / 29,28 / 30$, and $16 / 18$ leaked badly when the lock was full. Leakage was attributed to ruptured waterstops caused by either poor installation of the waterstop or unequal deflection between monoliths. It was recommended that the leakage be stopped and two methods of repair were suggested:

a. Drill a hole on the joint and fill it with a sand-bentonite mixture.

b. When the lock is dewatered for maintenance, thoroughly clean and dry the joint on the chamber side and pressure pack it with an elastic compound, polyurethane, or Igas.

Since it was considered difficult to drill a hole on the monolith joints the full distance required, the second method was recommended. It was also recommended that the stability of the monoliths be checked with a full lock chamber and the leaking joints be instrumented to determine movement. 

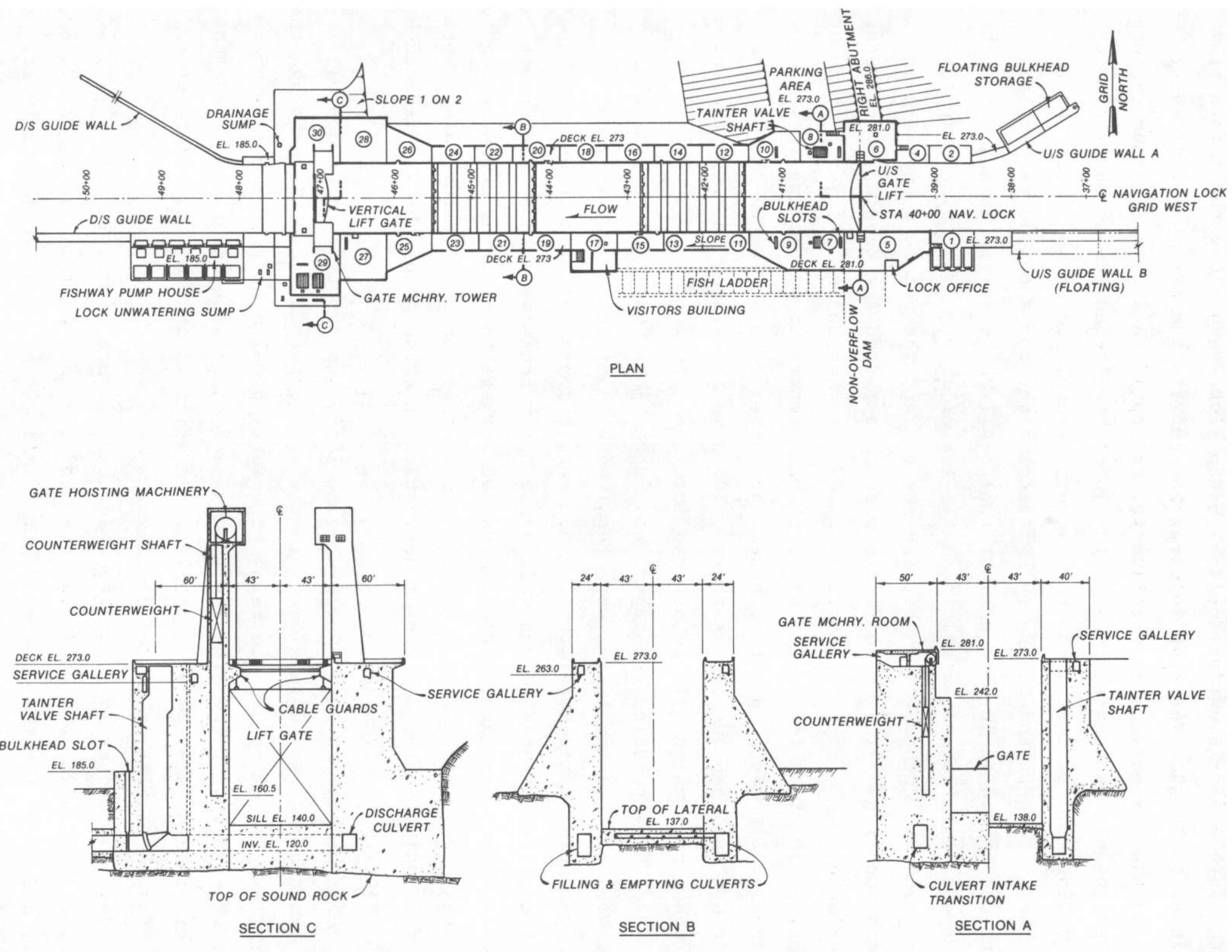

Figure 27. Plan and typical sections, John Day Lock 
81. Repair of the leaking joints consisted of forcing a 1-1/8-in. rubber rod into a 3/4-in.-wide, 3-1/2-in.-deep slot sawed along the joints from* the level of the tailwater up to elevation $268 \mathrm{ft}$, the maximum upper water level in the chamber. This was expected to provide a 1/8-in. minimum residual compression of the rubber rod when the joint had opened to its maximum under load during cold weather. The contractor, however, could not force the rod into the slot as intended. He then stretched the rod about 30 percent in length and forced it in with a blunt tool. All three joints leaked after the rubber was installed so experimental fillets of Thiokol were placed in the outer reentrant corner formed between the rod and the concrete in the joint between monoliths 27/29. The joints were measured on the deck and each opened approximately $1 / 16 \mathrm{in}$. on lock filling. Water came out of the joint at about elevation $210 \mathrm{ft}$, which was 25 or $30 \mathrm{ft}$ below where it was coming from originally. It was proposed to reset the rubber rods during the winter when the joints are open in cold weather, using a mastic sealer on both sides of the rubber rods which will be pressed into the joint.

82. Repairs using the rubber rod in the joint were not successful; therefore, all leaking joints were repaired by contract in May 1971 using surface-mounted plate waterstops. This repair consisted of a rubber membrane over the joint, secured to the wall using epoxy adhesives and bolted keeper plates. This repair substantially reduced leakage through the downstream gate monoliths $(28 / 30$ and $27 / 29)$. Electro levels positioned after the joints were repaired indicated the downstream deflection of these monoliths was reduced by approximately 50 percent.

83. Leakage through monolith joint $10 / 12$ was reported in October 1971 . This leakage had caused subsidence in the adjacent fill and drains through the rock fill. There appeared to be no structural problem at that time; however, close observation of the area was recommended since washing of the embankment fill might eventually cause a problem. Backfill in area of the joint between monoliths $22 / 24$ also exhibited dampness.

84. In October 1972, leakage was noted at monolith joints $10 / 12,12 / 14$, $16 / 18,22 / 24,24 / 26$, and $28 / 30$ for the landside lock wall and at 21/23, 23/25, $25 / 27$, and $27 / 29$ for the riverside wall. All except monolith joints 10/12, $12 / 14$, and $22 / 24$ had been repaired in May 1971. Leakage from the landside lock wall with the lock full of water is shown in Figure 28. Leakage apparently entered the landward backfill and some subsidence was reported. 


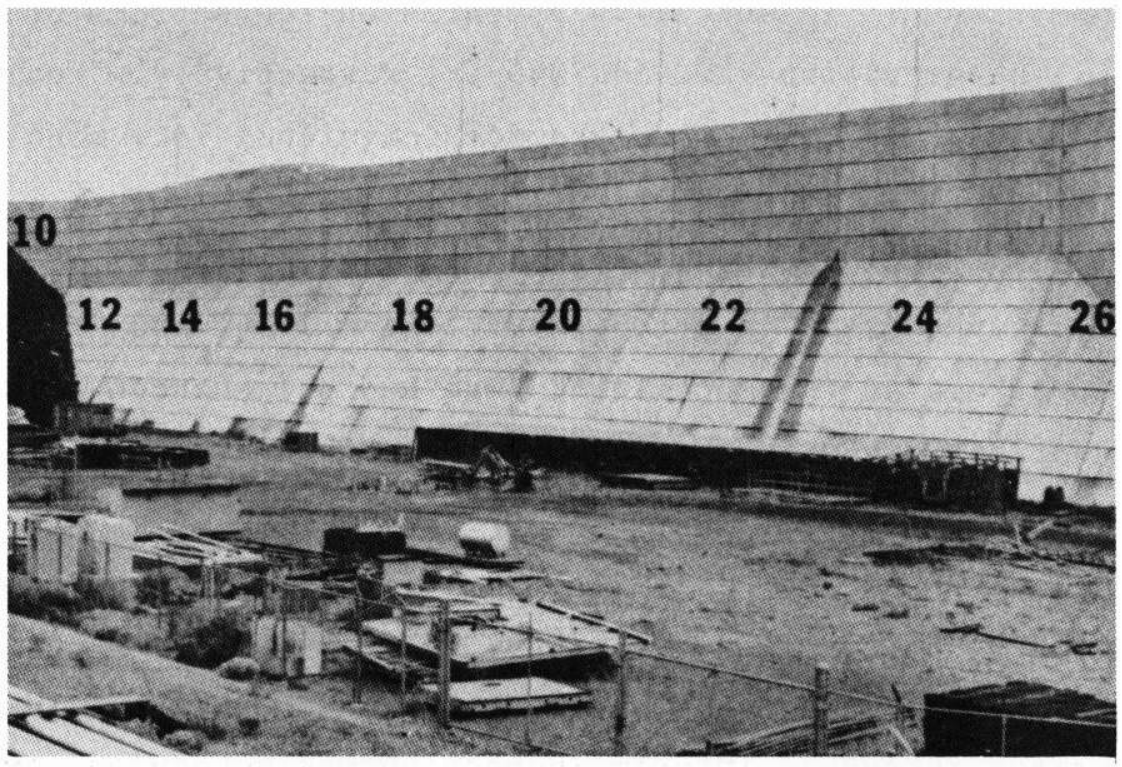

a. Overall view

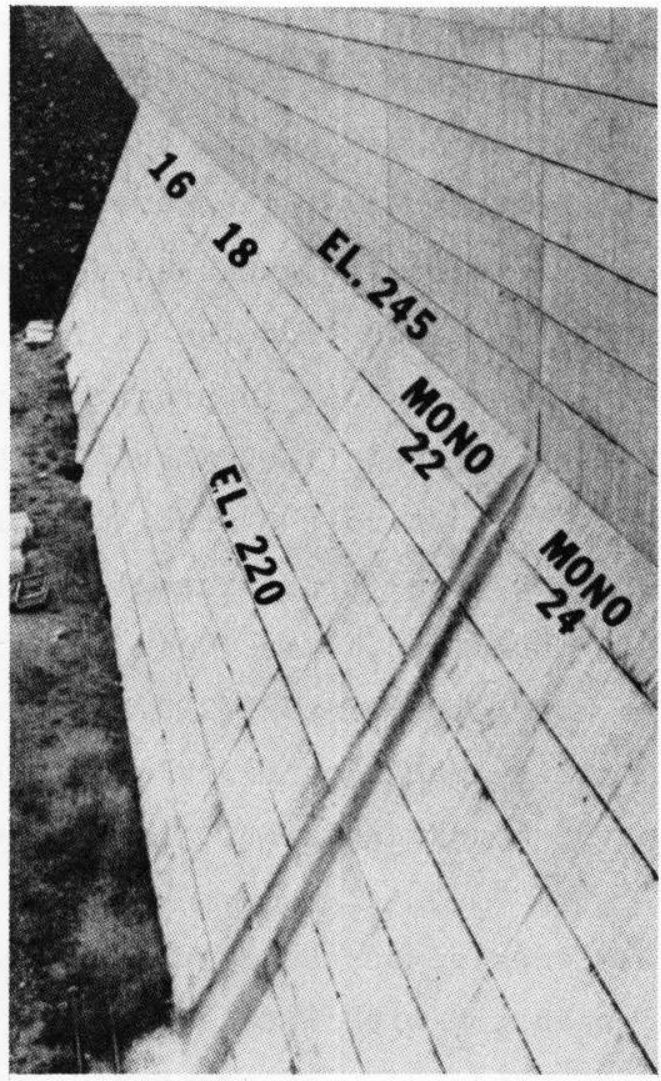

b. Closeup of monolith joint $22 / 24$

Figure 28. Landside lockwall leakage, John Day Lock, October 1972 
Leakage from monoliths $16 / 18$ and $22 / 24$ appeared on the surface of the back side of the wall at elevations 220 and $245 \mathrm{ft}$, respectively. Measured deflections in excess of $1 / 2 \mathrm{in}$. were reported for individual lock monoliths (Figure 29).

85. Periodic inspection No. 6 was conducted in October 1974. A comparison of photographs taken in October 1972, June 1974, and October 1974 indicated that leakage at the monolith joints had not changed significantly. Lock monolith deflections with the chamber full of water were reported for summer and winter conditions as shown in Figures 30 and 31 . During the winter, monoliths tend to deflect as individual units; whereas, during the summer, monoliths tend to move together as one unit. As a result of the significant movements in the monolith joints during the winter season and continued high leakage rates, an interim inspection was scheduled for April 1975. Also, seven additional monolith joints were scheduled for repair in 1977. Since surface plate waterstops previously installed had substantially decreased leakage, it was proposed to use a similar repair for the additional joints. Estimated cost of the repair was $\$ 250,000$.

86. On 3 February 1975, a barge damaged the upstream lock gate necessitating keeping the chamber full for several days. During this time, leakage through lock monolith joints completely inundated the low lying area north of the navigation lock. Washing of fines from the fill caused by the leakages resulted in at least one visible sinkhole (approximately $15 \mathrm{ft}$ in diameter by $2 \mathrm{ft}$ deep). Removal of fines by excessive leakage in the area of the visible sinkhole was not considered a threat to the stability of the navigation lock since the $\mathrm{fill}$ is a shallow covering (approximately $15 \mathrm{ft}$ ) over bedrock. However, visible leakages at monolith joint $10 / 12$ starting at elevation $246 \mathrm{ft}$ (same leakage elevation as monolith joint 22/24 where exceptionally heavy discharge occurs) and possible leakage at monolith joint $8 / 10$ could result in unknown erosion of the north embankment section adjacent to the navigation lock.

87. Leakages on the landside of the lock were generally greater than during the October 1974 inspection with leakages at the monolith 16 crack and monolith joints $10 / 12,12 / 14$, and $22 / 24$ of greater volume and surfacing at higher elevations. Leakages were less at monolith joints $16 / 18$ and $28 / 30$.

88. Overall, leakages on the riverside wall were approximately the same in April 1975 as in October 1974 with leakages at several joints being less 


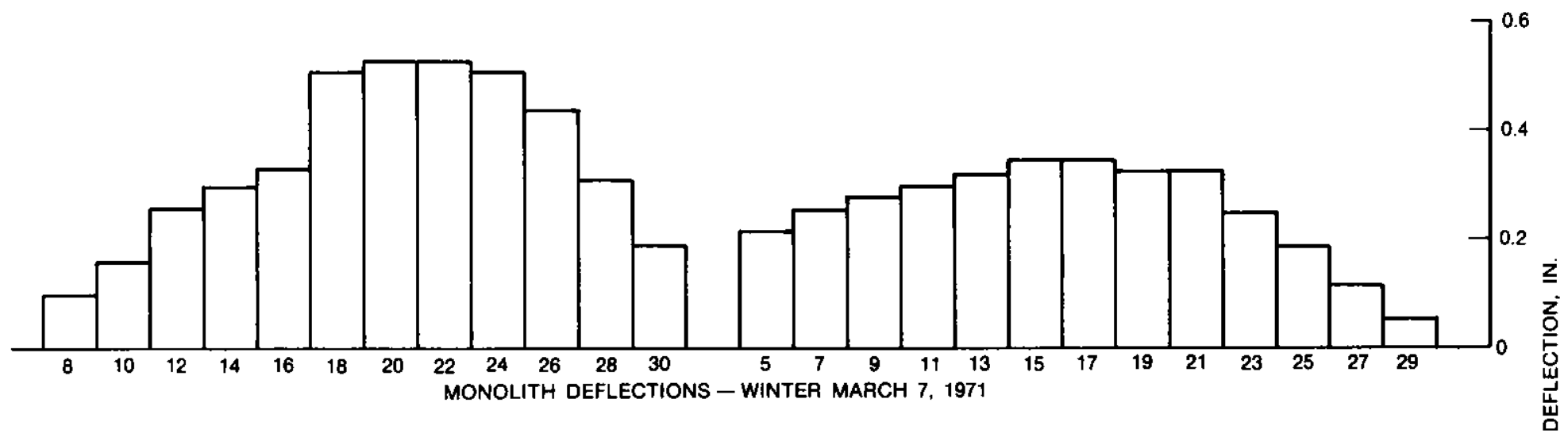

NOTE: DEFLECTIONS ARE NOAMAL TO LOCK $\&$ AND OUT FROM $\&$

AT ELEVATION 273.

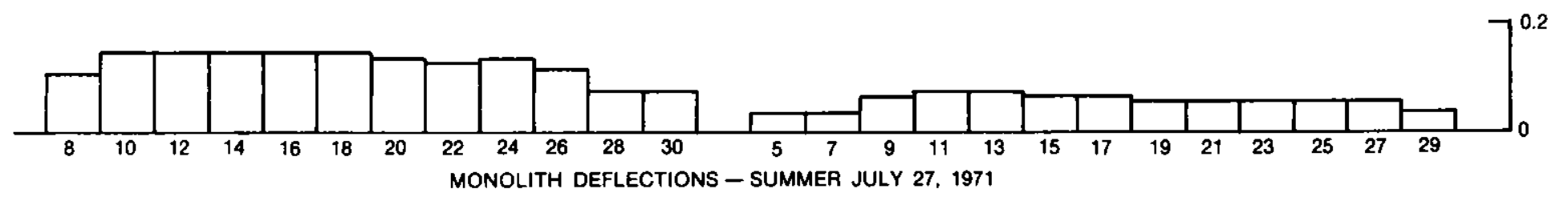

Figure 29. Monolith deflections due to lockage water loading, John Day Lock 


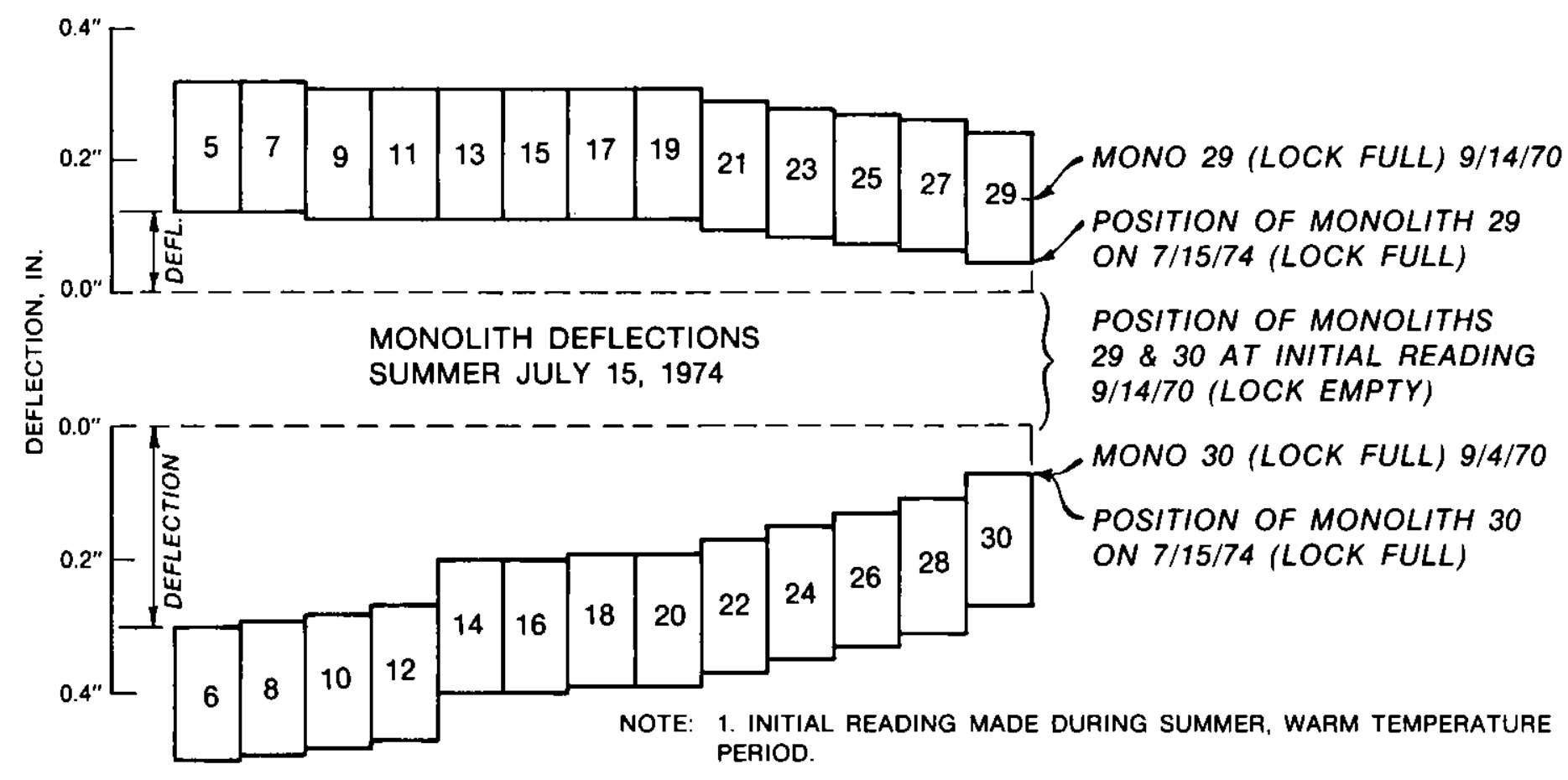

2. A 0.06 INCH INCREASE/DECREASE IN MEASURED DISTANCES BETWEEN MONOLITHS 29 AND 30 (DUE TO EXPANSION AND CONTRACTION OF BRIDGE BETWEEN MONOLITHS 29 AND 30) CAN BE EXPECTED FOR EACH $10^{\circ} \mathrm{F}$ CHANGE IN TEMPERATURE.

3. LOCK MONOLITH MOVEMENTS ARE REFERENCED TO MONOLITHS 29 AND 30. TOTAL RELATIVE MOVEMENTS BETWEEN MONOLITHS 29 AND 30 ARE DETERMINED BY MEASUREMENT OF DISTANCES BETWEEN BRIDGE AND ADJOINING MONOLITHS.

4. DEFLECTIONS ARE NORMAL TO LOCK CENTERLINE, AND OUT FROM CENTERLINE AT EL. 273.

Figure 30. Lock monolith deflections, summer conditions, John Day Lock 


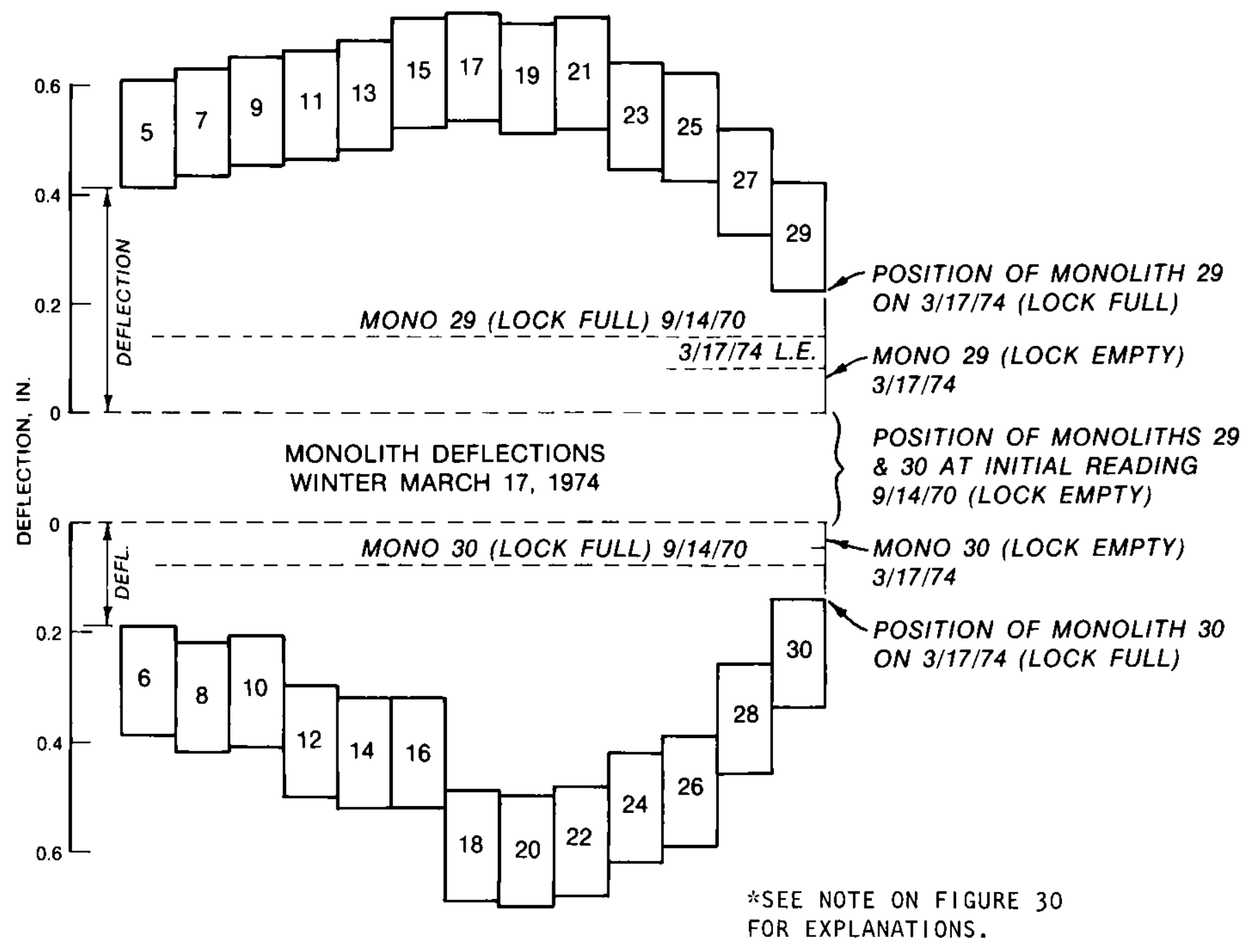

Figure 31. Lock monolith deflections, winter conditions, John Day Lock 
while several joints showed slight increases in leakage. Observation of the discharge pipe that drains the fill north of the lock appeared to show some color after lock filling, Indicating the possibility of slight washing of fines from the fill area. As a result of this interim inspection, it was recommended that a contract be awarded for the installation of additional waterstops during the next lock outage.

89. During the October 1975 lock shutdown, surface-mounted plate waterstops were installed to elevation $273 \mathrm{ft}$ on monolith joints $8 / 10,10 / 12$, $20 / 22$, and $22 / 24$. Also, partial installation of waterstops to elevation $168 \mathrm{ft}$ on monolith joints $12 / 14,14 / 16,18 / 20,5 / 7,7 / 9,9 / 11,11 / 13$, $13 / 15,15 / 17,17 / 19$, and $19 / 21$ was accomplished. Surface-mounted plate waterstop installation on these foints was completed to elevation $273 \mathrm{ft}$ in July 1976. These repairs significantly reduced leakage through the monolith joints. The only joint leakage observed in the October 1976 inspection was at monolith joints 16/18, 24/26, and 28/30 which were repaired in 1969 .

90. Relatively heavy leakage from the landside filling and emptying condu1t through cracks and monolith joints into the rock-fill embankment adjacent to the lock was reported in September 1978. This leakage resulted in sinkholes and general disruption of the embankment. It was suggested that a drill hole with a elastic filler-type waterstop installed landward from the filling conduit be considered for repair of the conduit leakage. This would involve drilling a 6-in.-diameter hole along the joint and then filling the hole with an elastic grout.

91. During the October 1981 inspection, leakage at monolith joints $16 / 18$ and $28 / 30$ was visible when the lock chamber was full. Also, leakage from the north filling and emptying culvert was reported similar to that previously reported in 1978 .

92. Monolith joints $28 / 30,18 / 20,16 / 18,14 / 16,12 / 14$, and $10 / 12$ in the north (landside) emptying and filling culvert (Figure 32) were repaired in 1982 using chemical grout. Also, a crack in the ceiling of monolith 10 between joint $10 / 12$ and the bulkhead slot was chemically grouted.

93. EX-size drill holes were evenly spaced around the culvert approximately $1 \mathrm{ft}$ from the joint. Holes were drilled from inside the culvert at an angle of 65 degrees to intersect the joint behind the existing waterstop. All drilling was done by the Government. 


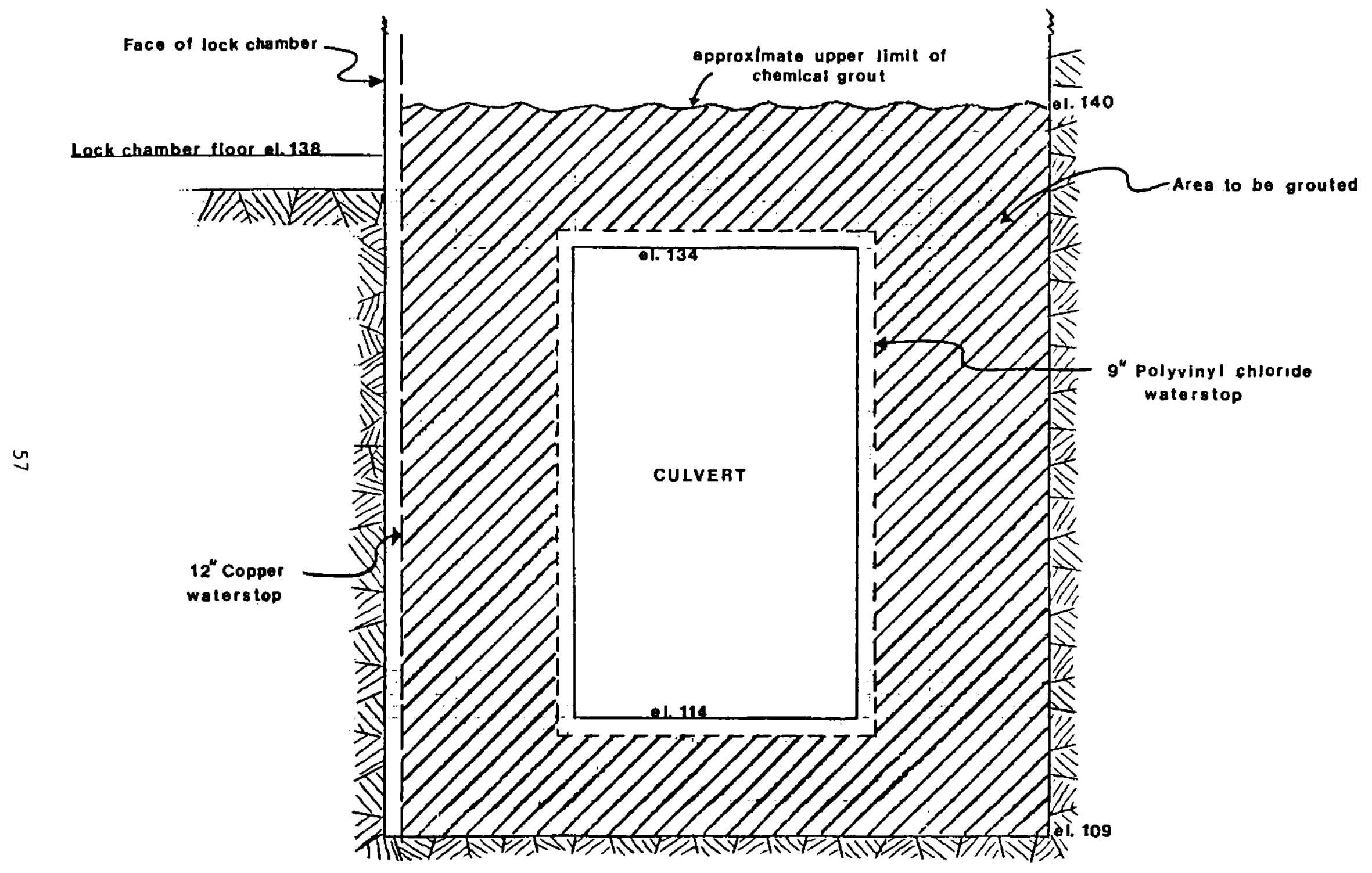

Figure 32. Detall of culvert area to be grouted, John Day Lock 
94. 3M Company's hydrophilic polyurethane gel (CR-250) was specified for the repair. The polymer grout was mixed at a ratio of 1 gal polymer to 7.75 gal of water. An accelerator (CR-251) and a shrinkage control agent (CR-252) were added to the fluid grout. Also, diatomaceous earth (Celite 209) was added in the amount of 6 percent by weight of the fluid grout. Unoiled oakum saturated in hydrophilic polyurethane foam (CR-202) was used on joints $10 / 12$ and $28 / 30$ to control the flow prior to injections of the CR-250 grout. 95. A total of $282 \mathrm{gal}$ of grout was pumped into the 6 joints as follows:

\begin{tabular}{lcl} 
Joint & No. of Injections & Grout Volume, gal \\
\hline $10 / 12$ & 11 & 39.5 \\
$12 / 14$ & 5 & 57 \\
$14 / 16$ & 4 & 40 \\
$16 / 18$ & 5 & 50 \\
$18 / 20$ & 7 & 37 \\
$28 / 30$ & 8 & 58.5
\end{tabular}

The joints required an average of 47 gal of grout each compared to a theoretical volume of 34 gal which was calculated assuming a joint area of 544 sq $\mathrm{ft}$ and a joint opening of $0.1 \mathrm{in}$. In addition, $46 \mathrm{gal}$ of grout was pumped into the monolith 10 crack using eight injections (Figure 33). Grouting equipment, materials, and labor were furnished by GELCO Grouting Services, Salem, Oregon. The grouting was successfully accomplished by GELCO during the period 16-19 March 1982 at a contract price of $\$ 21,700$.

\section{Ice Harbor Lock and Dam}

96. Ice Harbor Lock and Dam (Figures 34 and 35) is located on the Snake River near Pasco, Washington. The concrete gravity dam is comprised of a spillway, powerhouse, and two nonoverflow sections. The single-lift navigation lock (Figure 36) has a chamber width and length of 86 and $675 \mathrm{ft}$, respectively, with a maximum lift of $105 \mathrm{ft}$.

97. Waterstops in the two construction joints where the upper sill block abuts the lock walls were reported as "not wholly effective" during the initial periodic inspection in September 1966. Moderate leakage was viewed from the gallery at elevation $407.79 \mathrm{ft}$ and from the drainage gallery at 


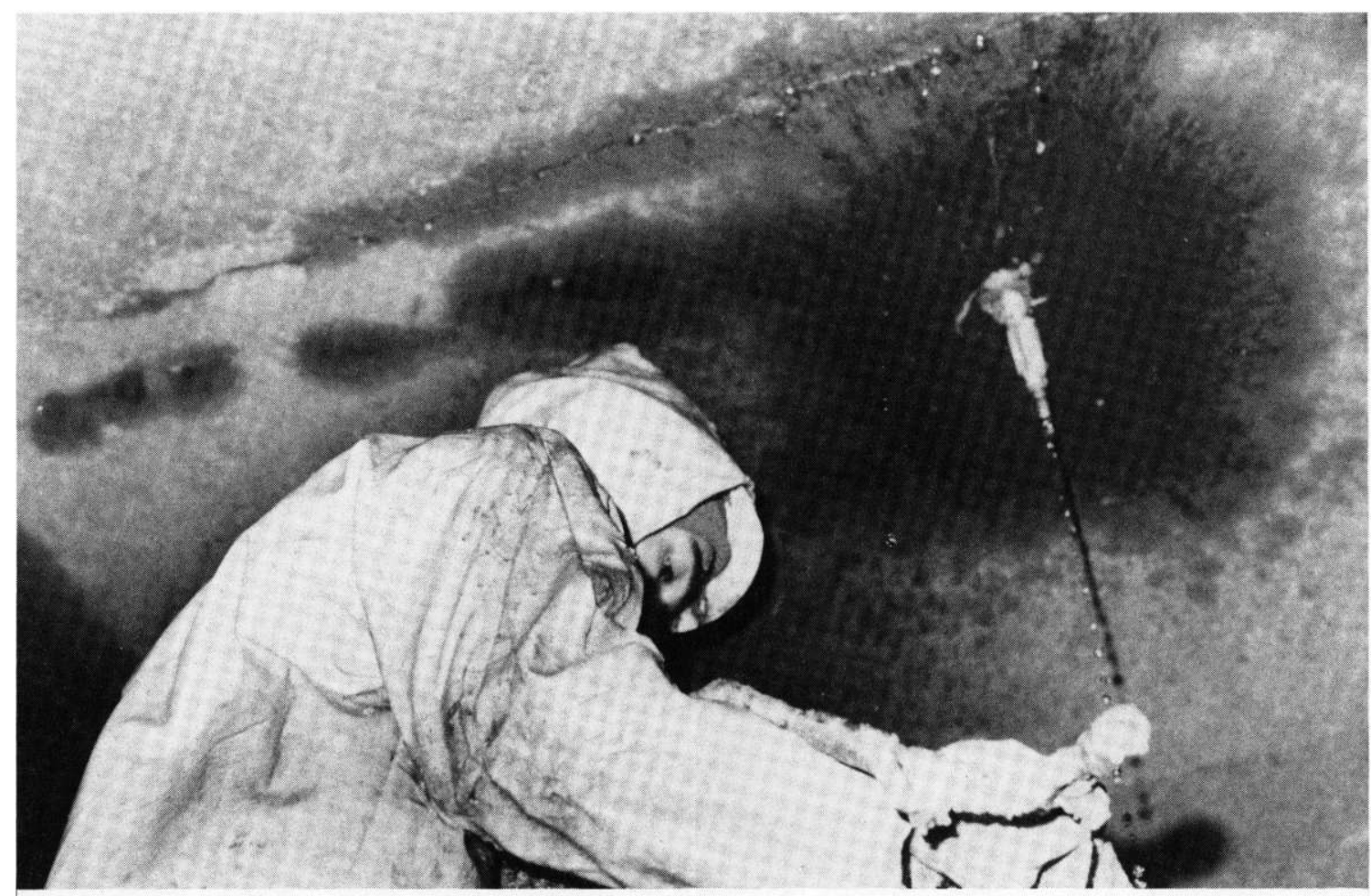

a. Prior to grouting

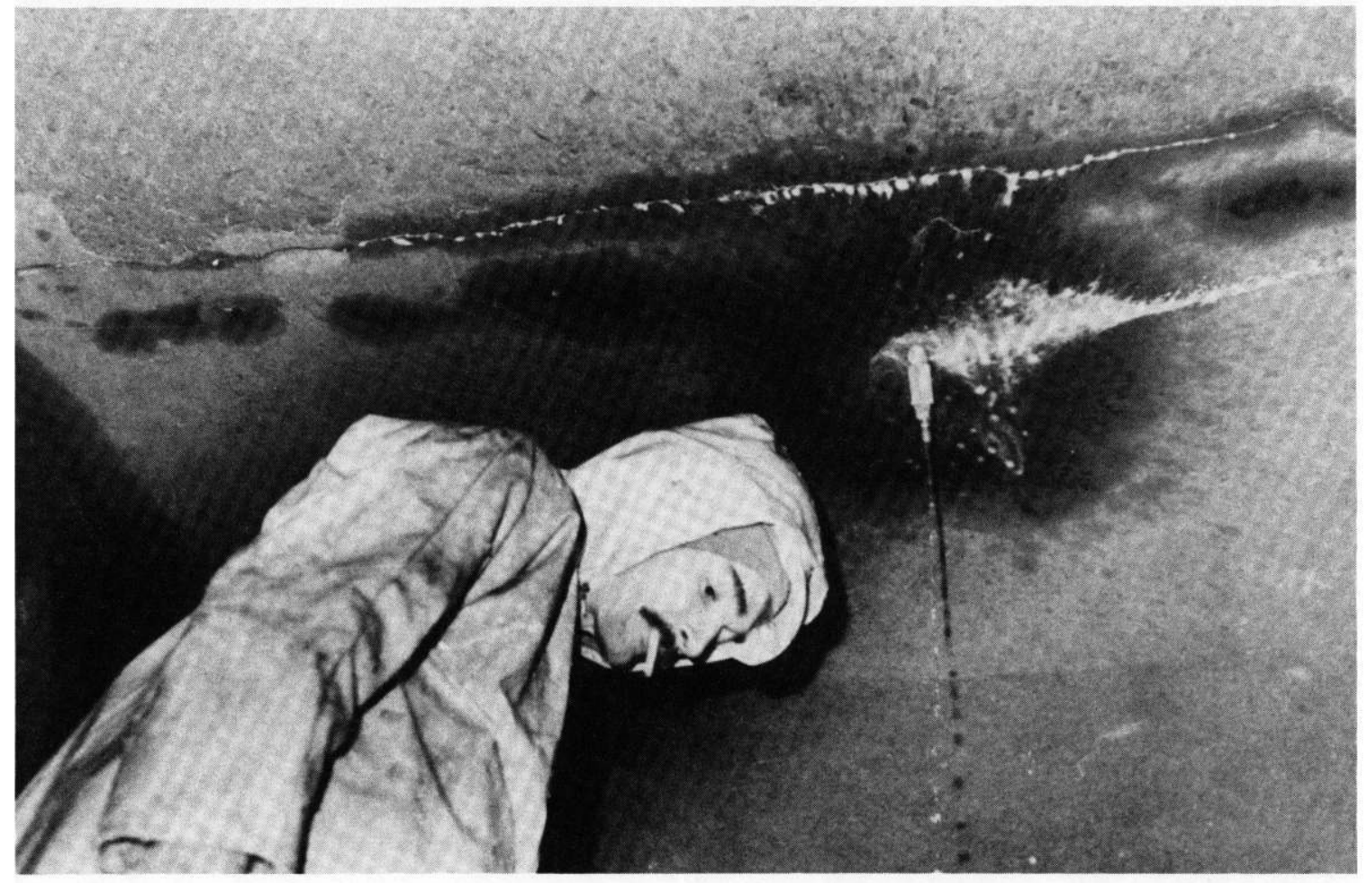

b. Following grouting

Figure 33. Monolith 10 crack grouting, John Day Lock 


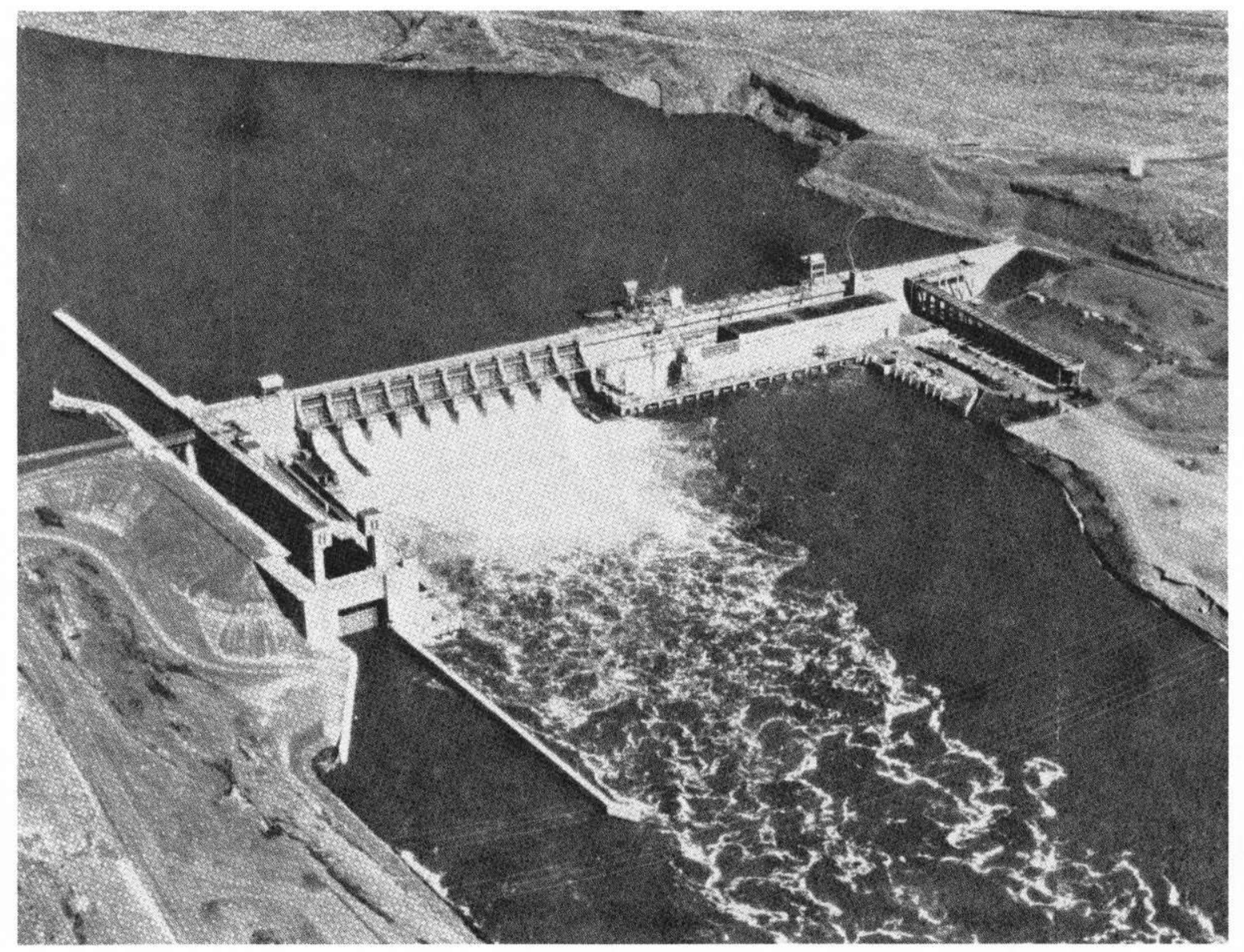

Figure 34. Aerial view, Ice Harbor Lock and Dam

elevation $326.0 \mathrm{ft}$. Leaking from the joints did not occur when the water level in the lock was at tailwater elevation, indicating that the waterstop between the sill and the pool retained its integrity. Remedial action was not considered necessary at the time. Also, waterstops in the construction joints of powerplant intake units 1 through 3 were reported as "partially ineffective." Holes were drilled diagonally into the concrete at approximately elevation $360 \mathrm{ft}$ and pipes inserted so that water which infiltrates the construction joints could be intercepted and led off to drains at floor level, elevation $355.5 \mathrm{ft}$. The malfunction of the waterstops was not considered a serious problem at the time since the flow of water from the pool was along a transverse path between units, and structural integrity was not involved.

98. There were no visible signs of structural disorder on the exterior of the north nonoverflow dam. However, in the drainage gallery at elevation $326 \mathrm{ft}$ at Station $23+45$, there was a crack which leaked essentially 


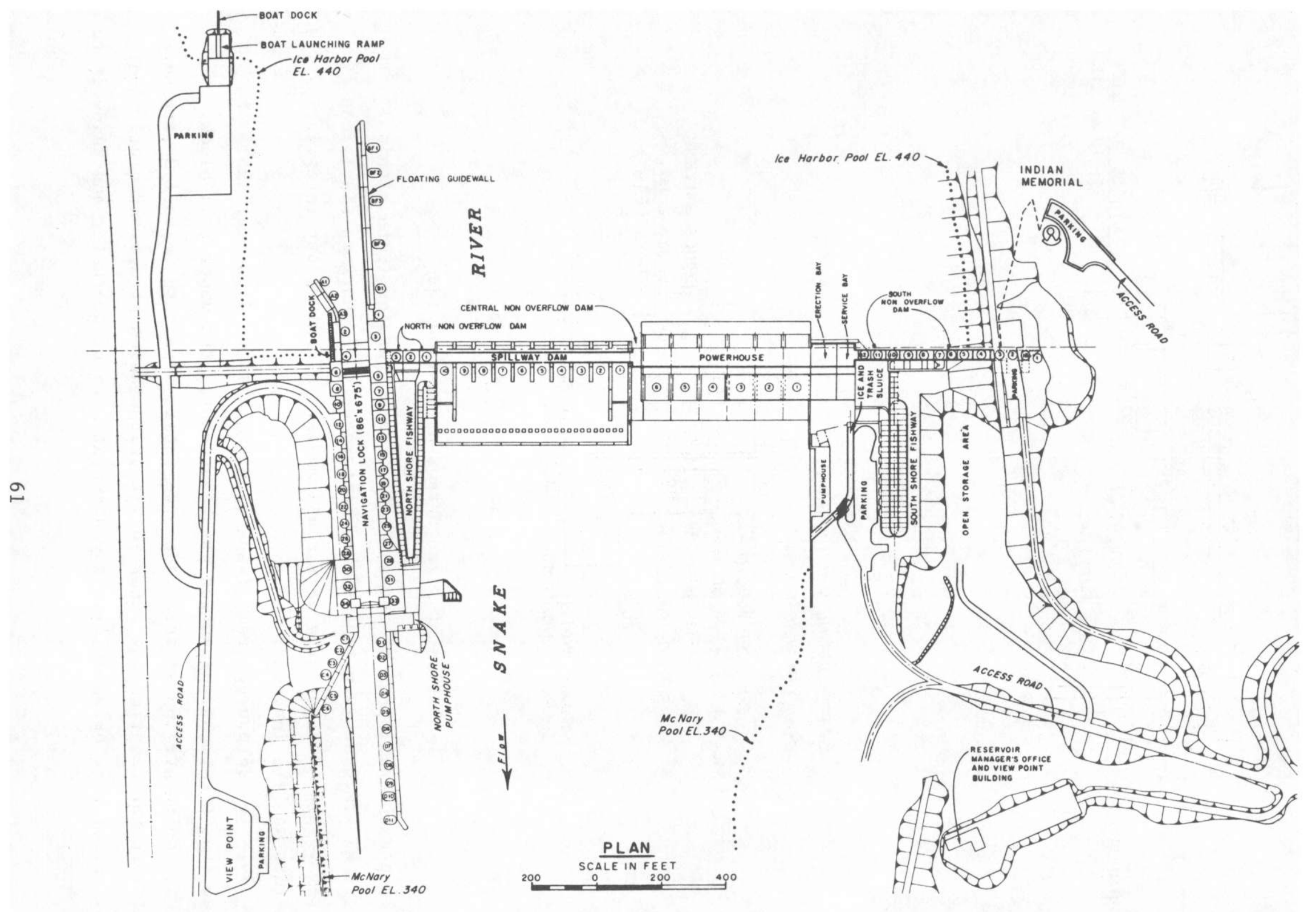

Figure 35. Plan, Ice Harbor Lock and Dam 

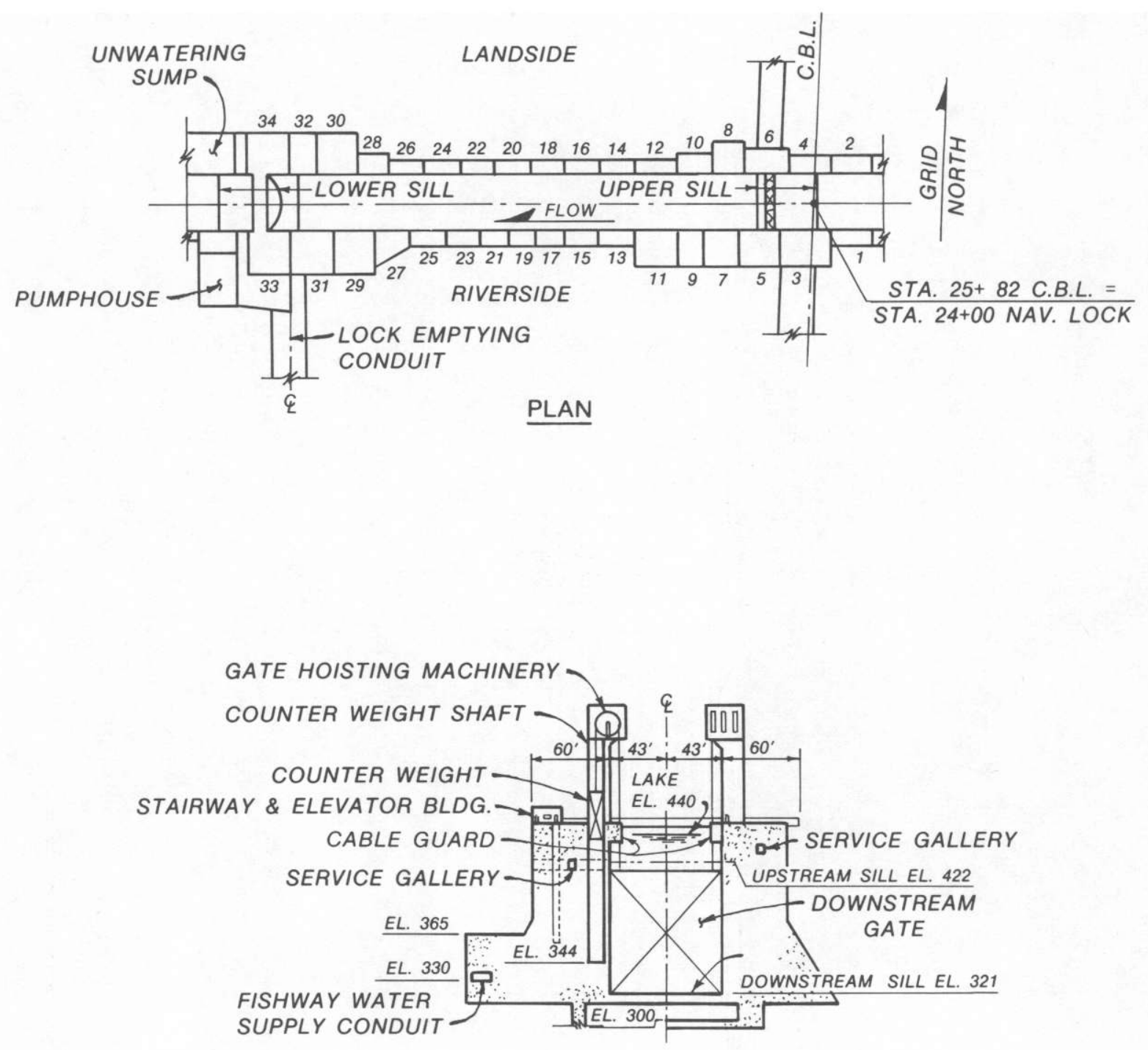

SECTION

Figure 36. Ice Harbor navigation lock

all around the periphery of the gallery. The two drains (both within $12 \mathrm{ft}$ of the crack) immediately north of the fracture were discharging significantly greater volume than any others in the immediate vicinity, but integrity of the structure was not involved.

99. The second periodic inspection was held in September 1967. No change from the first inspection was reported for the upper sill block. Diagonal holes previously drilled in the intake structure units 1-3 were successful in intercepting the water infiltrating the construction joint. Additional holes were being drilled to intercept more of the water and guide it to 
the drains. Leakage in the north nonoverflow dam noted in the initial inspection was not as great during the 1967 inspection.

100. The south nonoverflow dam appeared to be structurally sound. However, a vertical crack was evident at Station $8+19$ through three lifts of concrete (elevation 350 to $365 \mathrm{ft}$ ) and was seeping water. A crack was also evident at the same station around the gallery near the upstream monolith face. Further inspection was being made, but it did not appear that there was any structural significance at the time that would require remedial action.

101. Leakage through monolith joint $32 / 34$ was reported during a September 1969 inspection (Figure 37). This joint had been repaired in the spring of 1969 by drilling a 6-in.-diameter vertical hole along the joint and filling it with sand-bentonite mixture. The failure of this repair was attributed in part to the inability to properly place the mixture. Another repair attempt in the spring of 1970 tried placing the sand-bentonite mixture into elongated bags inserted into the drill hole.

102. The ends of the monolith joints $31 / 33$ and $32 / 34$ were measured before and after filling the lock. All ends maintained the same measurement after filling except the riverward end of joint $31 / 33$ which opened about 1/16 in. on filling. Installation of extensometer points across these joints at the top deck was recommended.

103. In the 1974 inspection, it was noted that the upper sill block was drier than in previous inspections. Additional drilling and piping had been completed that satisfactorily relieved water leakage previously reported at monolith joints in the powerhouse intakes. This was being observed to see if additional drilling would be beneficial. Very little or no leakage was reported at monolith joints in the lock. Extensometer readings made on the construction joints between lock monoliths indicated very little differential shifting. Leakage in the south nonoverflow dam was negligible and continually decreasing. A leak in monolith 7 was not considered to be structurally significant; however, it was planned to grout the leak for aesthetic reasons when the O\&M schedule permitted.

104. In 1976, it was reported that additional work was necessary in the powerhouse to reduce leakage at monolith joints previously described. This work was required for safety, due to icing, and also for appearance. 


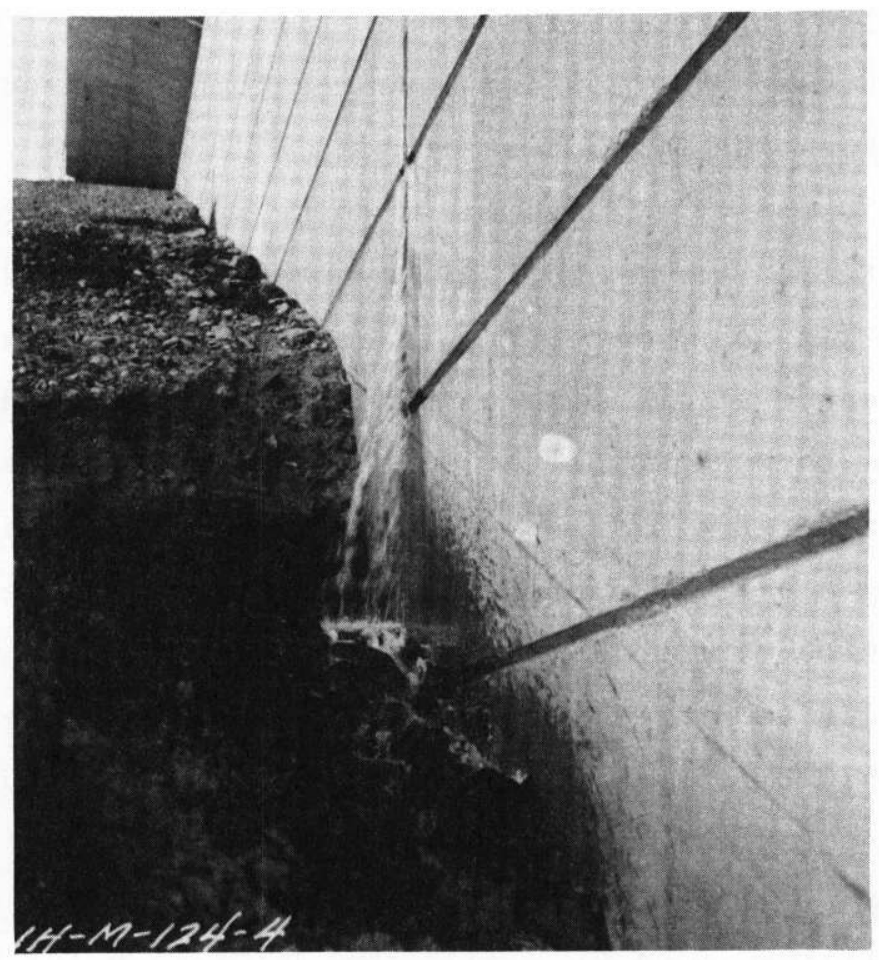

Figure 37. Monolith joint 32/34 leakage, Ice Harbor Lock, 1969

105. Trial waterstop repairs were conducted at Ice Harbor Lock during August 1977 to evaluate the potential of four materials as elastic fillers for remedial waterstops. Materials were placed in individual drill holes as described in the following paragraphs.

106. The Takenaka Aqua-Reactive Chemical Soil Stabilization (TACSS) System T-035NF was used at monolith joint $8 / 10$ to grout a 6-in.-diameter vertical hole, $160 \mathrm{ft}$ deep, drilled $4 \mathrm{ft}$ from the lock face. The materials were furnished by TJK, Inc. and Associates of North Hollywood, California, and the grouting equipment was furnished by Continental Drilling of Seattle, Washington. The original proposal was to use 40 gal of TACSS T-020NF and 4 gal of $\mathrm{C}-852$ Accelerator. This material was chosen after reading the literature provided by the manufacturer, Dainippon Ink and Chemicals, Inc., Japan. However, based on the recommendation of the supplier, TACSS T-035NF was substituted. The equipment used included a diesel engine-powered air compressor, air-powered injection pump, a 48-gal mixing tank with air-powered agitator, about $200 \mathrm{ft}$ of 1/2-in. inside diameter plastic tubing, and a 6-in.-diameter packer. Photographs of the equipment are shown in Figure 38 . 


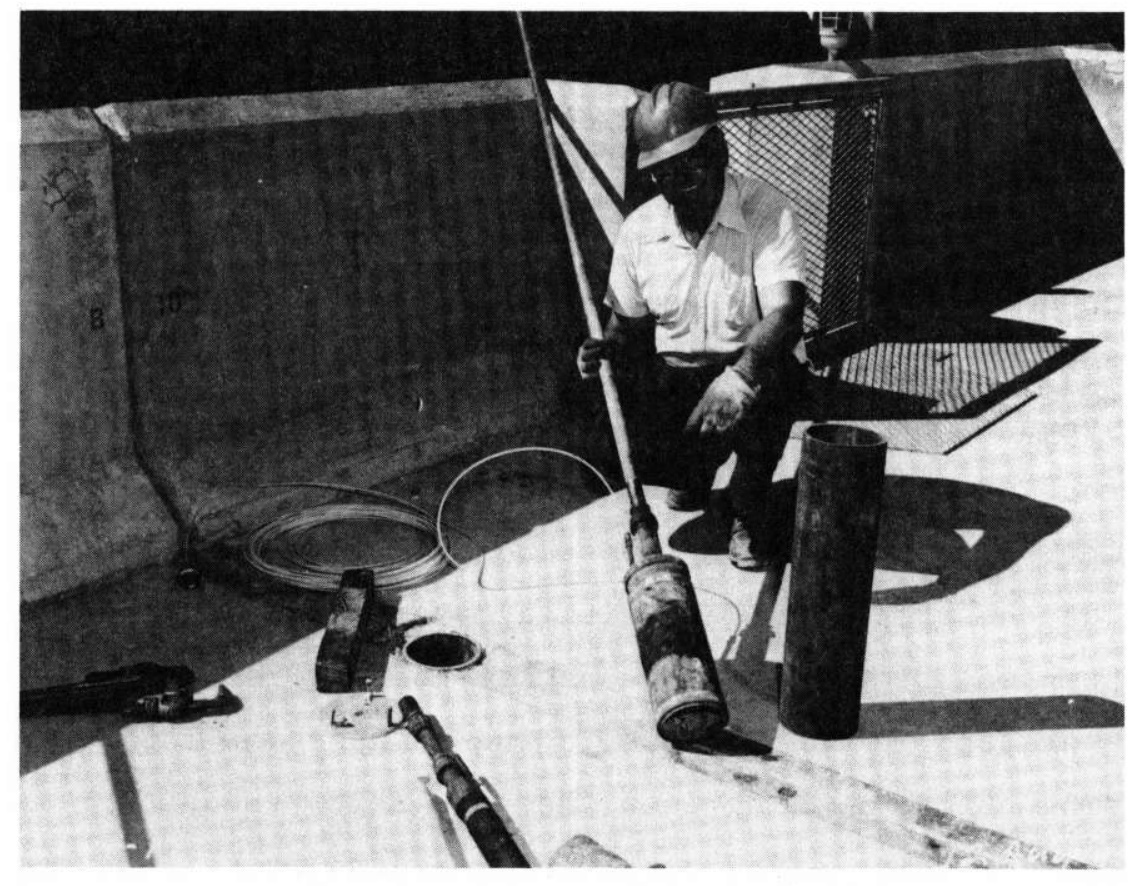

a. 6-in. packer

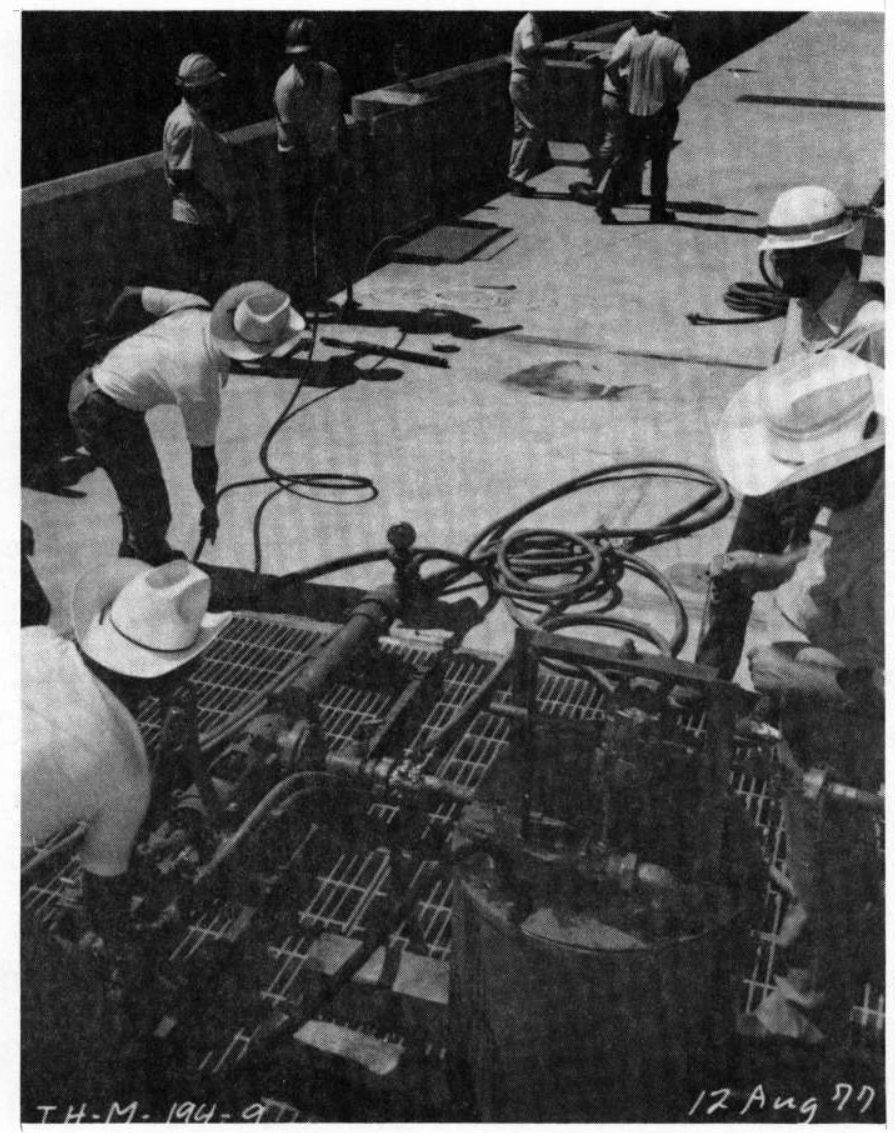

b. Mixing tank and injection pump

Figure 38. TACSS grouting equipment, Ice Harbor Lock 
107. The TACSS material was brought to the site in steel drums. TACSS $\mathrm{T}-035 \mathrm{NF}$ is a pale yellow, transparent liquid resembling lightweight lubricating oil. The accelerator is added in the mixing tanks and since the grout reacts with water, only one injection line is required. The TACSS material with 10 percent accelerator has a gel time of less than 1 min. The reaction includes generation of gas, foaming, and solldifying into a spongy material. The grout is supposed to displace the water in the hole before it reacts.

108. Grouting was accomplished on 12 August 1977. During the first grouting attempt, with the packer $150 \mathrm{ft}$ below the surface of the deck, pressure built up at the pump, but very little material moved into the injection tubing. The pump was stopped and the packer pulled from the hole. Some water must have been present in the plastic tubing because the TACSS had reacted and set in the tubing before getting into the hole below the packer. After the tubing had been removed, cleaned, and replaced, the packer was again placed in the hole at $150 \mathrm{ft}$ below the surface. The remaining material was stage grouted into the hole by raising the packer in 10-ft increments. The amount of material required to form a cylinder $6 \mathrm{in}$. in diameter by $10 \mathrm{ft}$ long was determined by the supplier. When this amount had been pumped into the hole, the packer was raised and pumping resumed. When the material supply was exhausted and the packer removed from the hole, the grout level was about $15 \mathrm{ft}$ from the surface.

109. On 24 August 1977, the depth of the hole to the grout was measured as $57 \mathrm{ft}$, and on 2 September 1977, the measurement was $52 \mathrm{ft}$. It appeared that some of the grout was floating when the lock was filled. Also, when the tape used to measure the hole was removed, the smell of the solvent used to clean the tubing and other equipment was quite strong and the tape felt slippery. Some small, broken bits of spongy material clung to the weight attached to the measuring tape and also to the tape. During October 1977, a 6-in.-diameter hole $118 \mathrm{ft}$ deep was drilled $8 \mathrm{ft}$ from the lock face as an observation we11. On 29 November 1977, the water level in the observation well $4 \mathrm{ft}$ landward of the test hole was measured at $30 \mathrm{ft}$ below the deck when the lock was filled.

110. Hydrophobic sand was used at monolith joint $28 / 30$ to fill a 6-in.diameter vertical hole, $120 \mathrm{ft}$ deep, drilled $4 \mathrm{ft}$ from the lock face. The materials were furnished by Pro-Con Systems of Spokane, Washington, and the equipment was from Pre-Mix Concrete of Kennewick, Washington. The sand was 
made hydrophobic by mixing with chemicals in a transit truck mixer. The material was supposed to hold the water back with surface tension and remain "dry" even when under water.

111. The drill hole was filled on 12 August 1977 by discharging the hydrophobic sand directly from the transit mixer into the hole (Figure 39). Approximately $35 \mathrm{cu} \mathrm{ft}$ of hydrophobic sand was used. Excess sand was stored at the lock. By 17 August, the sand had settled about $5 \mathrm{ft}$ and the hole was refilled. The sand appeared to settle about $1 / 4$ in. with each lockage (Figure 40). On 24 August, the sand was about 5 in. below the surface and the hole refilled. On 2 September, the sand was down about 9 in. and the hole was again refilled. During 0ctober 1977, a 6-in.-diameter hole $118 \mathrm{ft}$ deep was drilled $7 \mathrm{ft}$ from the lock face to be used as an observation well to check the effectiveness of the material as a waterstop. On 29 November, the sand was down about $15 \mathrm{ft}$ in the test hole. When the lock was filled, the water in the observation well rose almost as fast as the water in the lock. When the lock was full, the water was within $15 \mathrm{ft}$ of the deck. The water was also running over the top of the sand in the test hole. The water was running fast enough to be clearly heard and seen flowing through the joint looking down both holes from the deck. Since that time, sand has continued to be washed out of the test hole through the joint into the observation hole.

112. AM-9 chemical grout was used at monolith joint $6 / 8$ to fill a 6-in.-diameter vertical hole, $160 \mathrm{ft}$ deep, drilled $4 \mathrm{ft}$ from the lock face. The first $50 \mathrm{ft}$ of the hole had been enlarged to an 8-in. diameter to allow the drill to be replumbed. About $200 \mathrm{gal}$ of AM-9 with 10 percent Celite were used. The equipment used included a gasoline engine-powered hydraulic pump, two hydraulic-powered injector pumps, four mixing tanks with hydraulic-powered agitators, rubber hose, and 6-in. packer. Air pressure for the packer was obtained from a navigation lock outlet. The materials and equipment were furnished by GELCO Grouting Service, Salem, Oregon.

113. AM-9 acrylamide grout is manufactured by American Cyanamid Company. It was brought to the site in plastic-lined paper bags weighing $50 \mathrm{lb}$ each. The AM-9 powder was mixed with water and the catalyst was also mixed with water in a separate tank. The gel time was controlled by adjusting the catalyst materials. Celite, a diatomaceous earth, manufactured by Johns Manville Corporation, was used as an inert mineral filler. Five percent Celite by weight was added to the water in both tanks. When AM- 9 is dissolved 


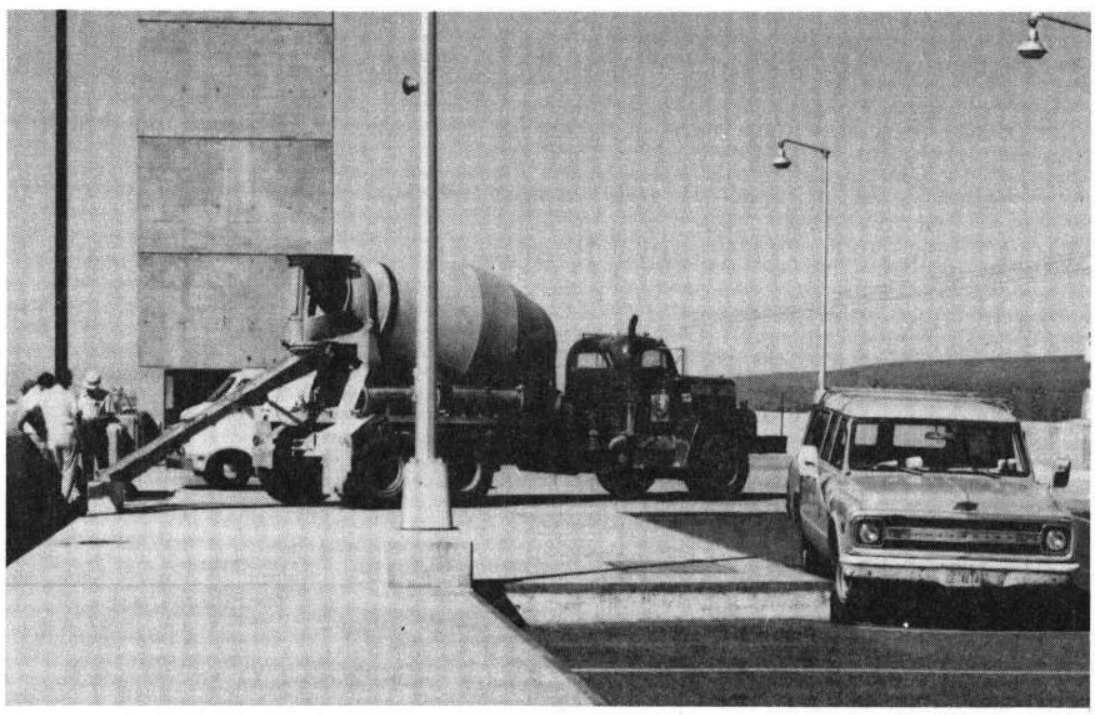

a. Overall view

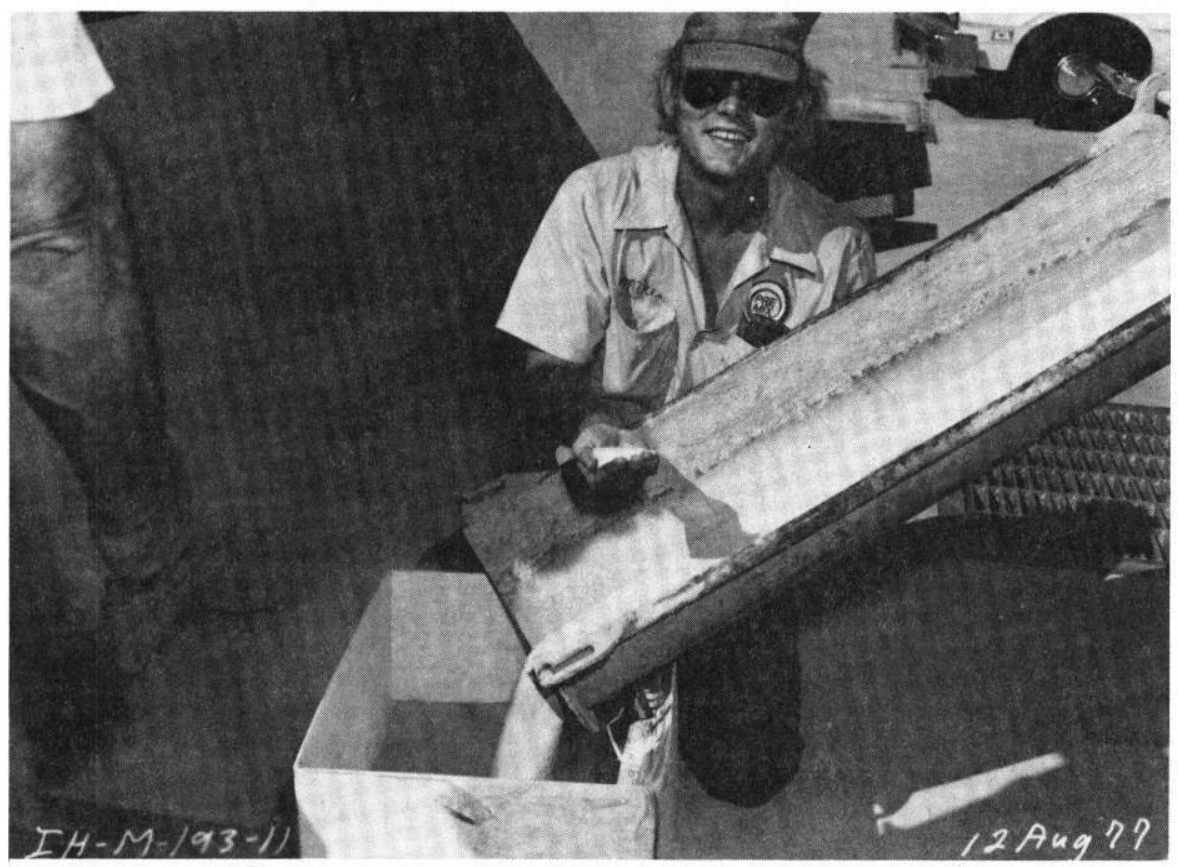

b. Close-up

Figure 39. Discharging hydrophobic sand into drill hole, Ice Harbor Lock 


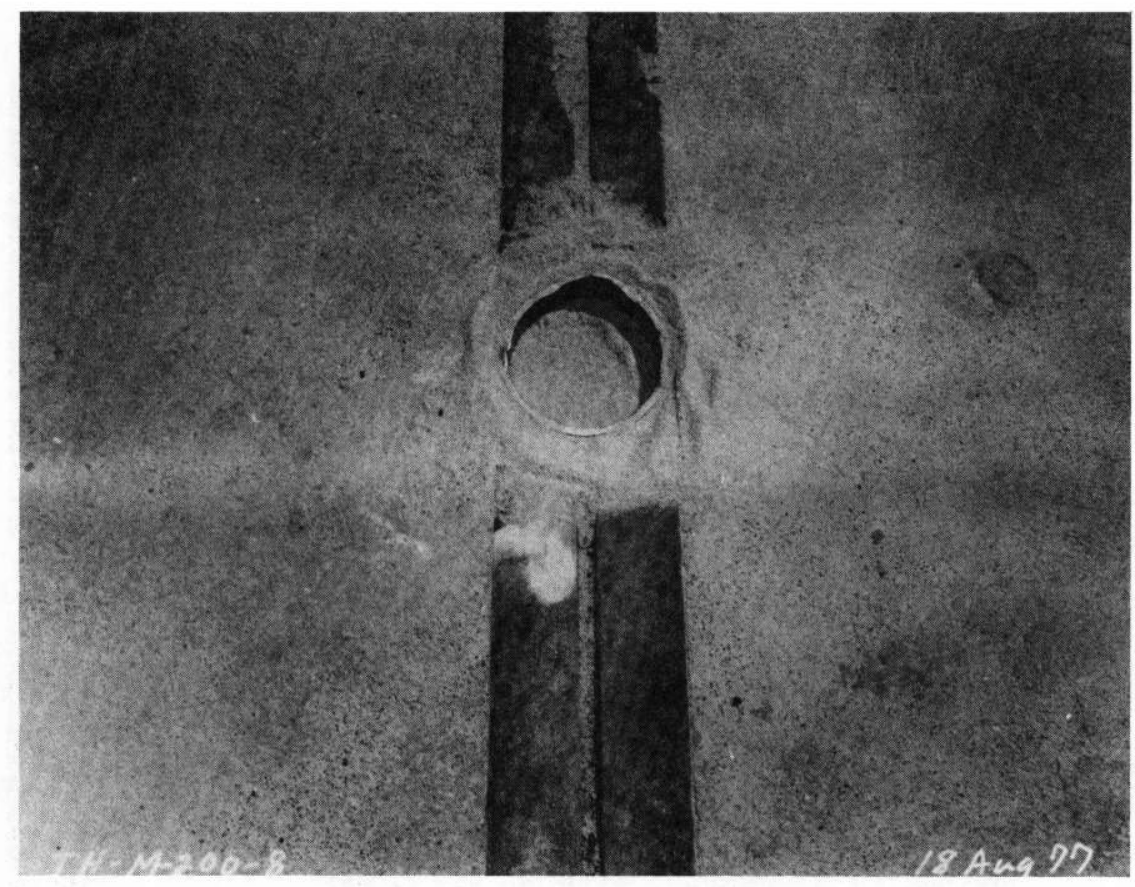

Figure 40. Settlement of hydrophobic sand in drill hole after three lockages, Ice Harbor Lock

in water, an endothermic reaction takes place; that is, the solution gets colder. The material reacts when mixed with the catalyst solution in equal parts at the mixing nozzle below the packer. The reaction includes generation of heat and the material sets in a gel that is weak and deteriorates if allowed to dry. Care must be used when handling the AM-9 powder and the catalysts because they are considered to be toxic if swallowed or inhaled. The gel is considered to be inert and nontoxic.

114. The drill hole was grouted on 17 August 1977. The packer was inserted into the hole to about $150 \mathrm{ft}$ below the surface. Two separate solutions of grout materials were mixed (Figure 41) and then pumped separately through two hoses (Figure 42) which were connected to a mixing nozzle suspended below the packer. The grout was pumped in 10-ft stages. This necessitated stopping grout injection while the packer was being moved and then resuming pumping. The top $30 \mathrm{ft}$ of the grout was diluted by water in the hole. This material was removed from the hole using a high-velocity water cleaner and the section of the hole was regrouted. Grouting was accomplished while the lock water was at tailwater level. A view of the completed repair is shown in Figure 43. 


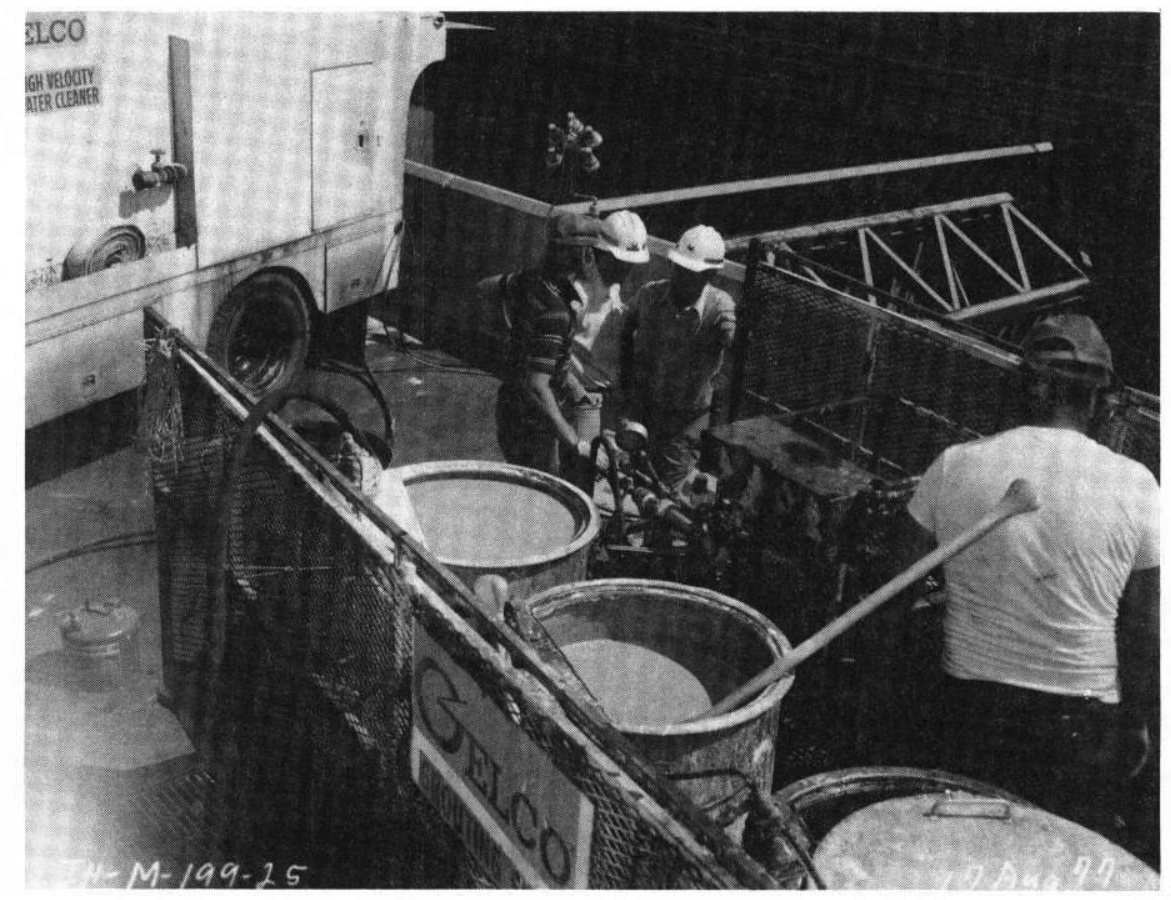

Figure 41. Mixing and pumping equipment for acrylamide grouting, Ice Harbor Lock

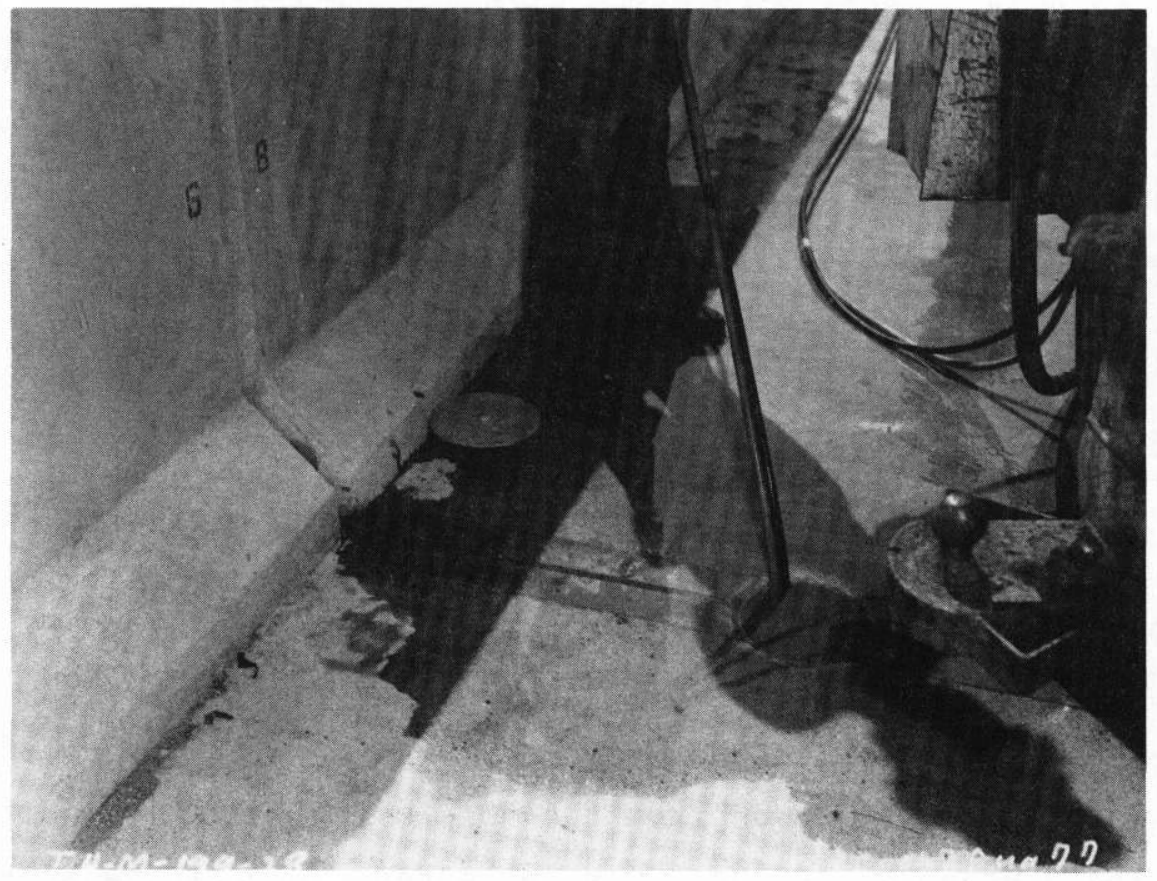

Figure 42. Double injection lines used to pump both acrylamide grout solutions to the bottom of drill hole, Ice Harbor Lock 


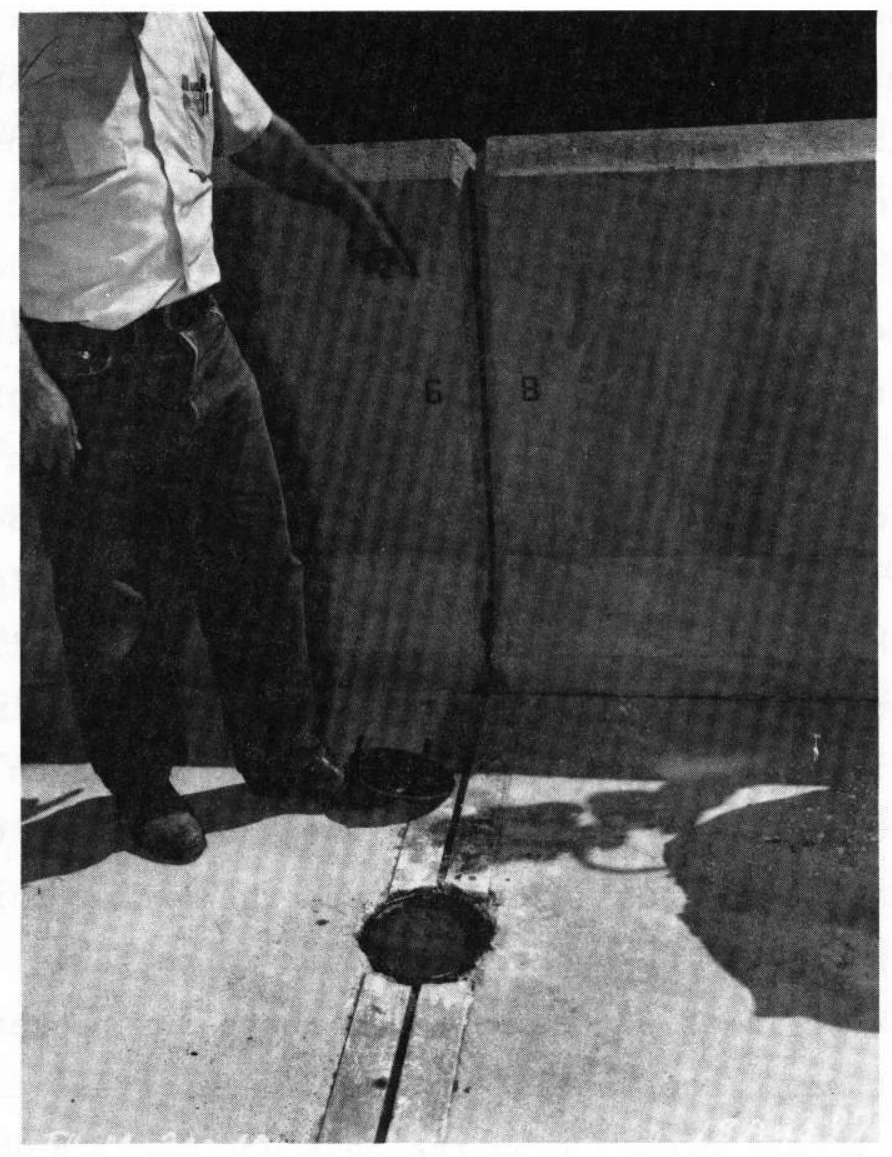

Figure 43. Drill hole filled with acrylamide grout, Ice Harbor Lock

115. The grout still looked good when inspected on 2 September. An observation hole was drilled $4 \mathrm{ft}$ landward of test hole in October 1977 . On 29 November 1977, the water level was measured at $95 \mathrm{ft}$ below deck with the lock filled. The water level was below the end of a 100-ft tape before the lock was filled; depth to tailwater was about $108 \mathrm{ft}$. The AM-9 was still in the test hole to within an inch of the top.

116. Hydrophilic polyurethane foam was used at monolith joint $32 / 34$ to fill a 6-in.-diameter vertical hole, $120 \mathrm{ft}$ deep, drilled $18 \mathrm{ft}$ from the lock face. About $100 \mathrm{gal}$ of the polyurethane foam (CR-202), manufactured by 3M Company, were to be used. Grouting equipment and materials were furnished by GELCO Grouting Service, Salem, Oregon.

117. The polyurethane foam used is a liquid resin of relatively low viscosity ( 300 to 600 centipoises) at ambient conditions. After it is injected into a joint containing water, the resin reacts with the water, begins 
to foam, and expands in place. Cure times of 5 to $6 \mathrm{~min}$ are typical at $40^{\circ} \mathrm{F}$. The grout works in three ways to seal a leaking joint. First, because it is hydrophilic, the liquid resin mixes readily with water and penetrates into the pores or fissures of the concrete surface. After subsequent curing, the foam forms a mechanical anchor within the concrete. Second, it bonds chemically to the wet and unprimed concrete surface of the joint. In addition, it aggressively bonds to various metals or polyvinyl chloride used for most waterstops. Third, through the expansion of the foam grout, a tough, yet flexible, compression seal is formed in the joint (Kostyk and Parnell 1984).

118. The drill hole was grouted on 18 August 1977 (Figure 44). A 6-in. packer built for this test would not fit into the 6-in. drill hole, so a shorter aluminum sewer grouting nozzle was used. The grouting was started at the bottom of the $120-\mathrm{ft}$ hole and was being raised in stages when a boat lockage through the navigation lock raised the water surface in the hole very quickly. This caused the grout to flow around the packer through the joint and set above the packer. The packer was stuck in the hole about $60 \mathrm{ft}$ from the surface with about $15 \mathrm{ft}$ of the material above the packer. The retrieval equipment would not raise the packer, so the $3 / 8$-in. steel cable and the rubber hoses attached to the packer from the hole and the 3/8-in. cable broke.

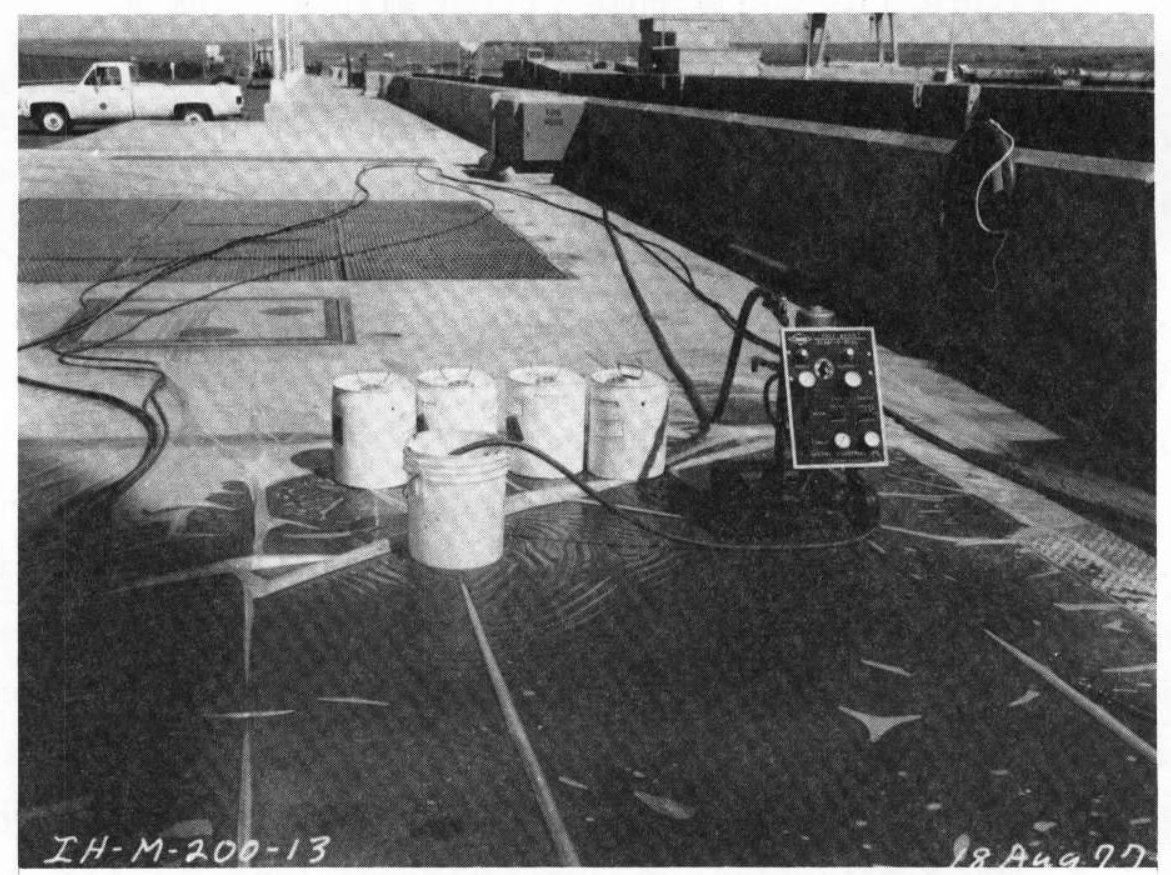

Figure 44. Polyurethane grout installation with proportioning pump, Ice Harbor Lock 
The depth of the hole was measured at $44 \mathrm{ft}$ on 2 September.

119. An observation well was drilled $7 \mathrm{ft}$ from the lock face during October 1977. On 29 November, the water surface in the observation hole was measured at $20 \mathrm{ft}$ below the surface when the lock was filled. Water was flowing but not as fast as in the observation well at monolith joint $28 / 30$. The tubing left in the test hole prevented observation of the water surface in the test hole. The landside of monolith joint $32 / 34$ is above ground so that water flowing from the joint could be observed. The flow appeared to be less than it was before the grouting attempt.

120. It was concluded that these trial repairs demonstrated that a 6-in.-diameter hole can be drilled along the vertical monolith joints for their full height and that these drill holes can be filled from the roadway deck with chemical grout to form an effective cast-in-place remedial waterstop. It was recommended that the acrylamide grout with inert mineral filler be used in future waterstop repairs at Ice Harbor Lock. The other materials tested were not recommended because they were considered to be either ineffective, too costly, or more difficult to place.

121. In contrast to the last inspection (1974), severe leakage at the joint between the cross-over gallery of the upstream sill and monolith 3 was reported in September 1977. Coupled with problems with the drainage gallery sump pump, this leakage had caused flooding of the drainage gallery to a depth of about $5 \mathrm{ft}$. Cover plates bolted over the joint (Figure 45) help control the leakage but certainly have not solved the problem. The leakage appeared to be coming from the lock chamber and not from the upstream face of the end sill. If the sump pump were to fail, flooding of the drainage galleries all the way across the powerhouse and ultimately the powerhouse would occur. Therefore, repairs to stop the leakage were recommended.

122. Although there was no evidence of significant distress such as spalling at the lock wall monolith joints, some of the joints in the landside wall were believed to be leaking. Leakage into the north embankment filter system greatly increases in the winter months when the concrete monoliths cool and the joints separate indicating failure of the waterstops. Future repairs based on the results of recently completed trial repairs were planned.

123. Extensometer measurements taken since 1970 to determine relative displacements between adjacent monoliths indicated displacements of less than $0.05 \mathrm{in}$. at elevation $448 \mathrm{ft}$. The largest movements during a lockage had not 


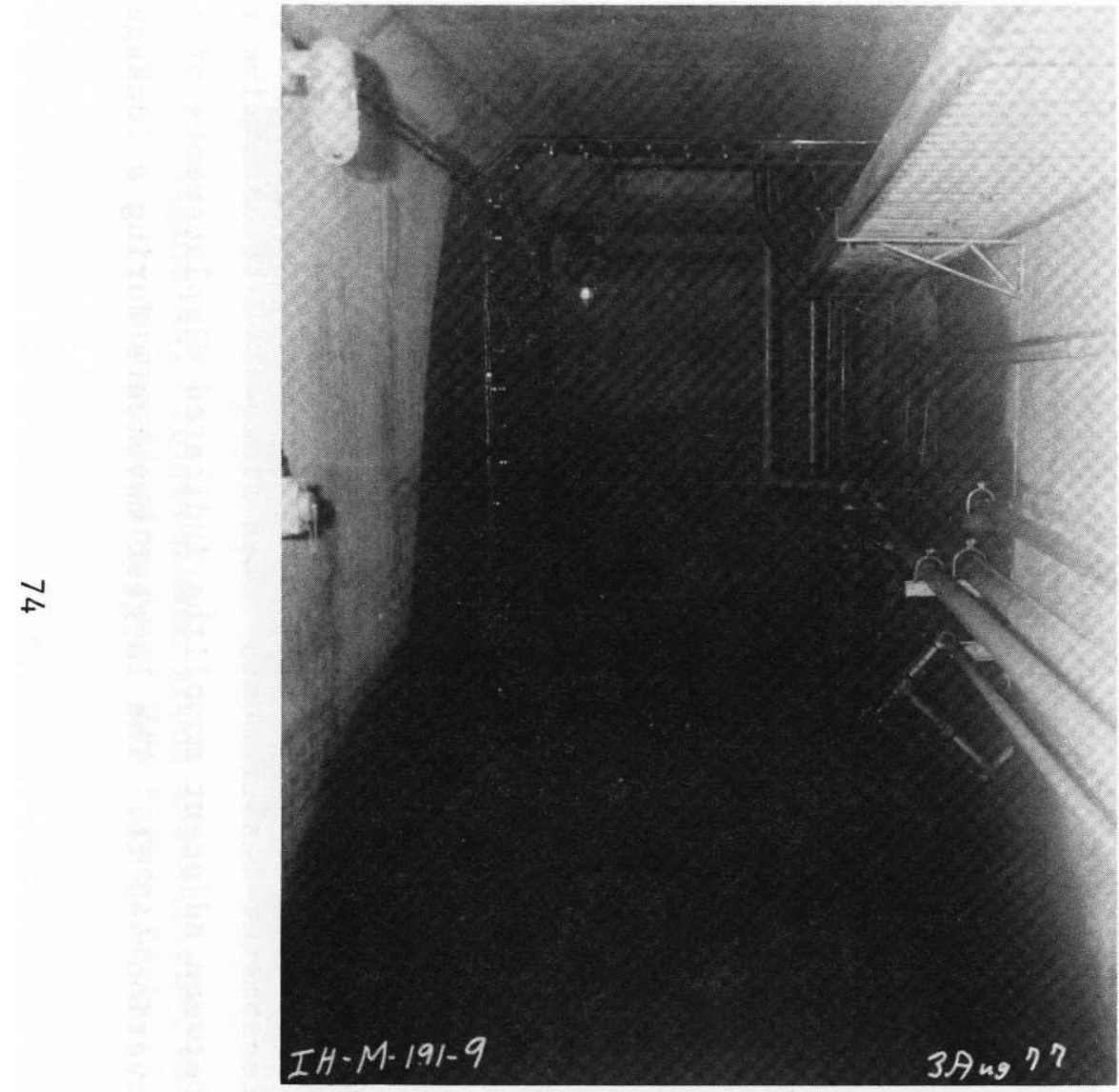

a. Overall view of joint area

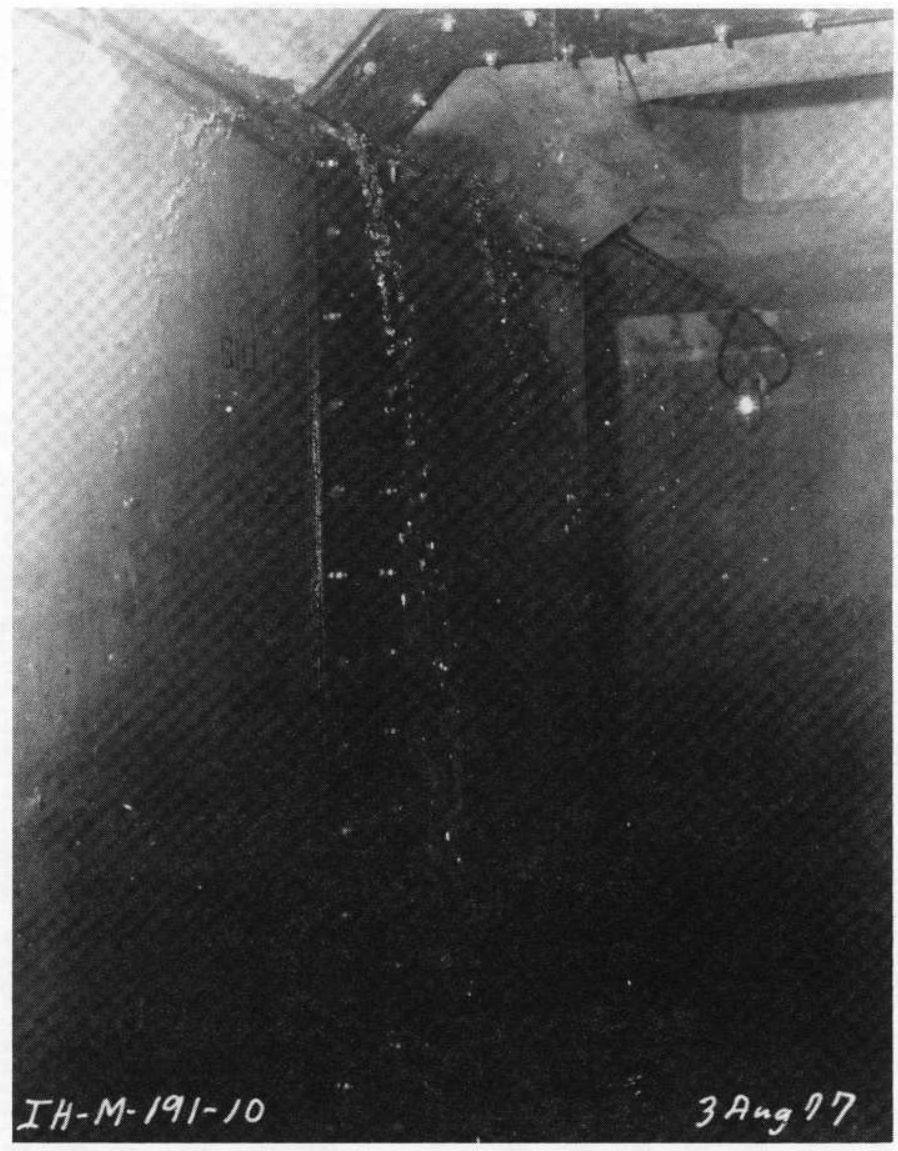

b. Leakage past the cover plate over the joint

Figure 45. Joint between the cross-over gallery of the upstream sill and monolith 3 , Ice Harbor Lock 
exceeded 0.1 in. Movement of the individual monoliths at Ice Harbor are substantially less than movements observed at Little Goose and Lower Monumental, locks of similar size also located on the Snake River.

124. Considerable leakage was reported through north nonoverflow monolith joints $1 / 2$ and $2 / 3$, especially during the winter. This leakage had been controlled by wooden channels built on the downstream face of the dam (Figure 46). The leakage was unsightly and inconvenient, but was not considered to be a serious structural or safety problem.

125. Leakage of varying intensities was reported between monolith joints of the different bays in the powerhouse. As would be expected, the amount of leakage varies with the seasons. Garden-type hoses are used at the joints in the powerhouse interior to help divert leakage and control it from flowing onto the generator floor. Joint $1 / 2$ leaks every winter, joint $2 / 3$ has leakage that runs through the hose fairly regularly, and joint $4 / 5$ started leaking when the additional powerhouse units were watered up. Leakage at the outside transformer deck is substantial and is contained in metal troughs and pipes (Figure 47). It was noted that if the pipes were to freeze or if the leakage increased considerably during the winter, a problem of ice buildup and possible flooding of the transformer deck could occur.

126. Contraction joints between the upstream sill block and the lock monoliths were repaired by contract in FY 79. Leakage into the service and drainage gallery was reduced by drilling a series of EX-size drill holes and chemically grouting the perimeter of the contraction joints at either end of the sill block. Additional drilling and grouting were done around the perimeter of the drainage and service galleries at the same contraction joints to further decrease the inflow of water. The drilling and grouting procedure was initially successful but within a year some of the chemical grout used to form the waterstops had extruded through one contraction joint onto the gallery floor. As a result, this joint exhibited significant leakage (Figure 48). As part of a miscellaneous repair contract, new or modified backup plates will be installed over the joints extruding grout and a new grout formulation will be installed.

127. Under contract in 1978, flexible vertical waterstops were installed along all the navigation lock monolith joints except those joints with full pool on either side of the monolith. Six-inch-diameter holes were drilled along each joint at the lock side of the monolith from the roadway deck down 


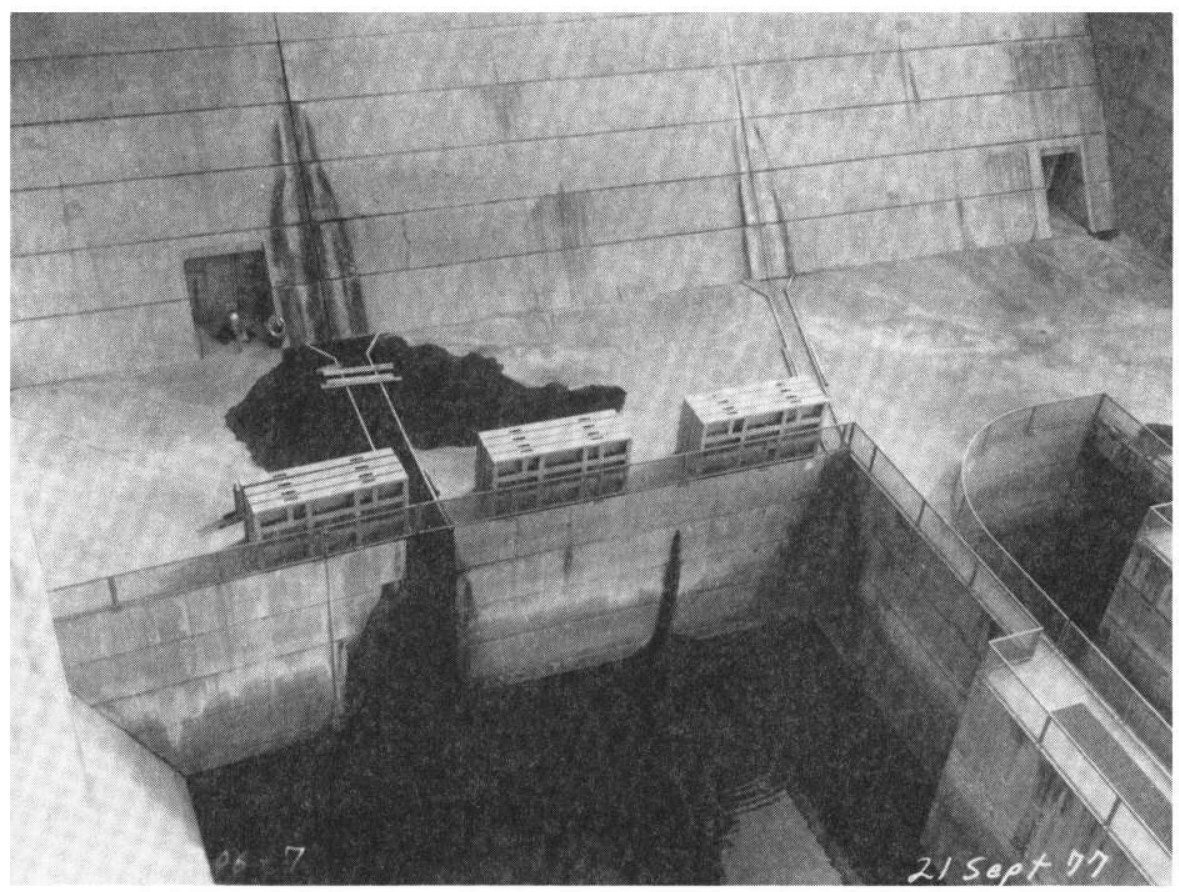

Figure 46. Leakage through north nonoverflow monolith joints, Ice Harbor Dam

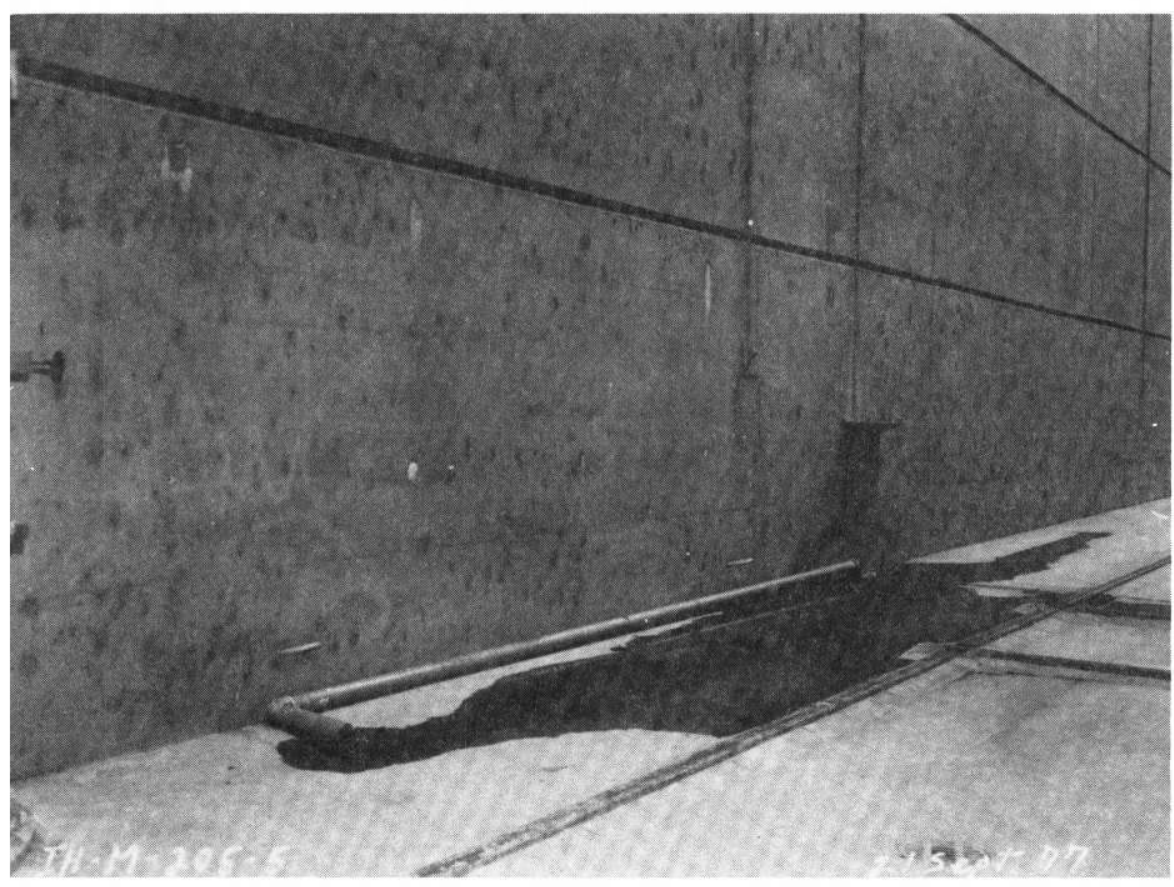

Figure 47. Trough and piping to help contain monolith joint leakage in powerhouse, Ice Harbor Dam 


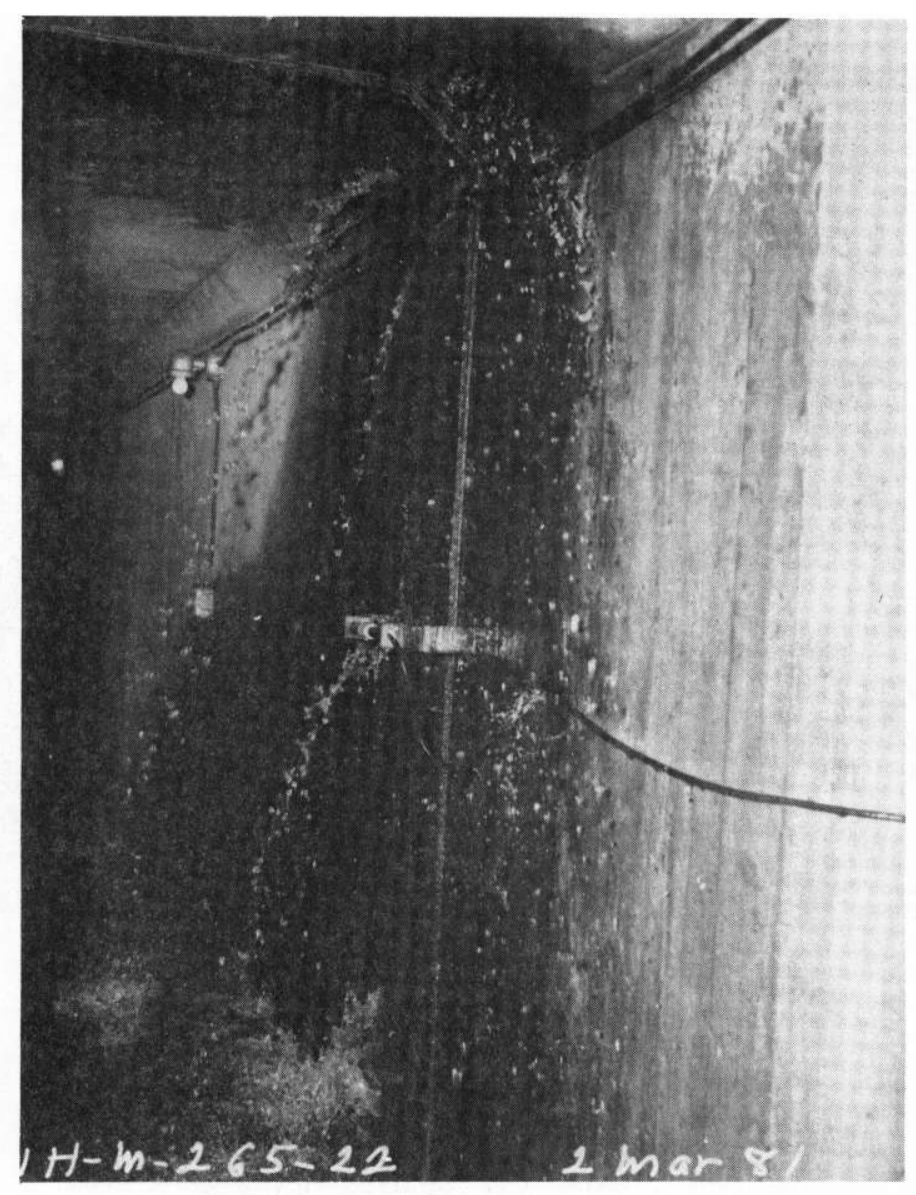

Figure 48. Leakage through joint between sill block and lock monolith 3, Ice Harbor Lock

into bedrock (Figure 49). The drill holes were filled with an impermeable flexible chemical grout. Greatly decreased flow of water into the landside fill from the navigation lock joints was attributed to the waterstop repair. Visible contraction joints showed no sign of leakage when inspected in November 1980. Lock monolith displacements, as measured by extensometers, remained unchanged from the previous inspection in 1977.

128. Major leakage into the north nonoverflow dam was eliminated by the 1978 installation of chemical grout vertical waterstops similar to those installed in the navigation lock. Backup plates that were installed during the grouting operation are to be replaced in the next repair contract. The plates, which are bolted along one side in one monolith (Figure 50), were bolted so tightly against the neoprene pad behind the plate that the plate was sprung, eliminating any possibility of sealing the joint from water leakage and grout extrusion. It was suggested that the steady water seepage into the 


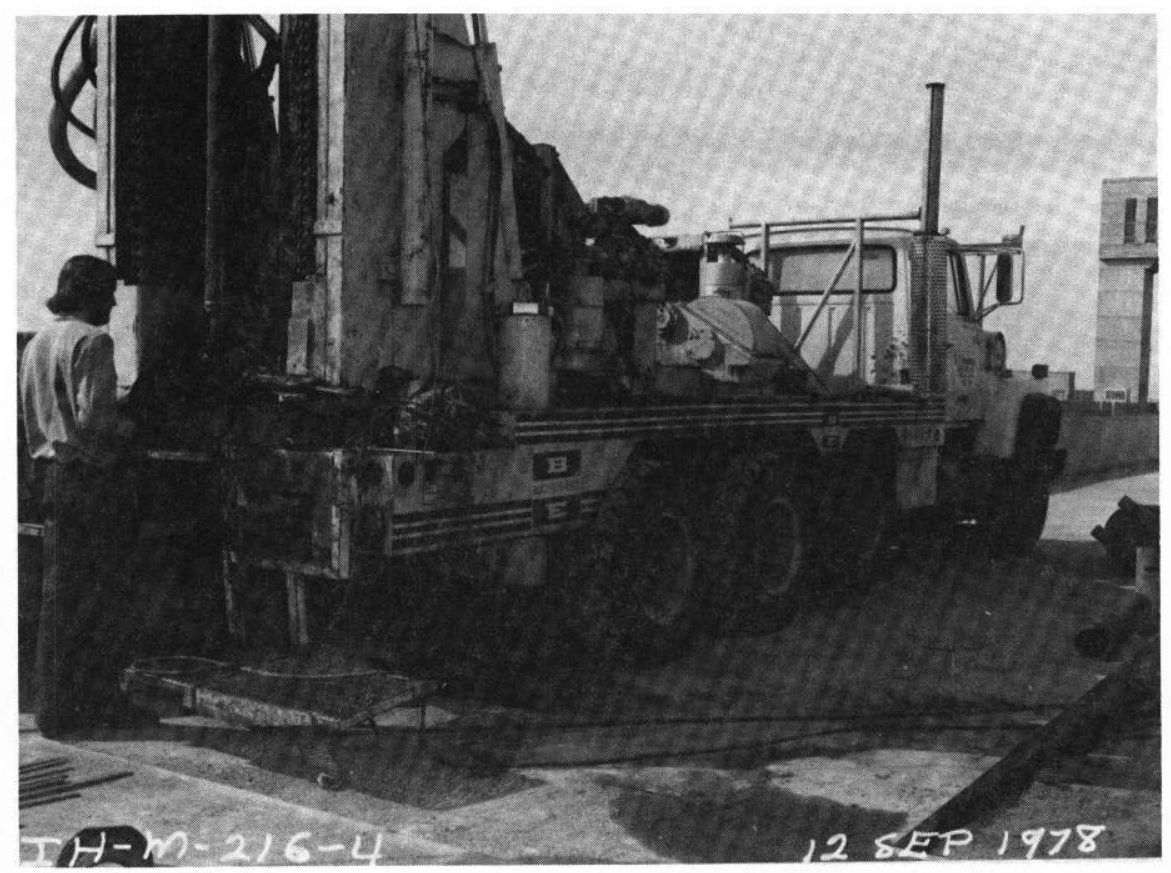

a. Truck-mounted drill rig

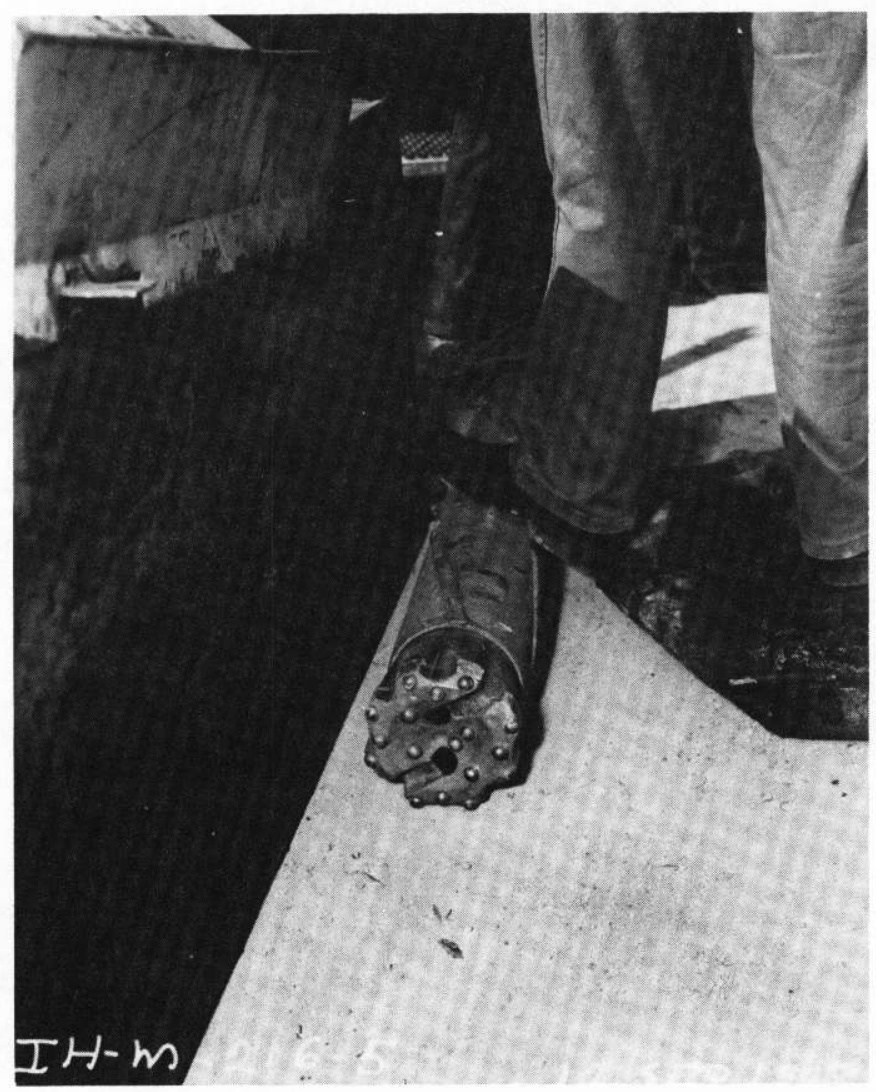

b. Down-the-hole hammer

Figure 49. Equipment used to drill holes along monolith joints for remedial waterstops, Ice Harbor Lock 


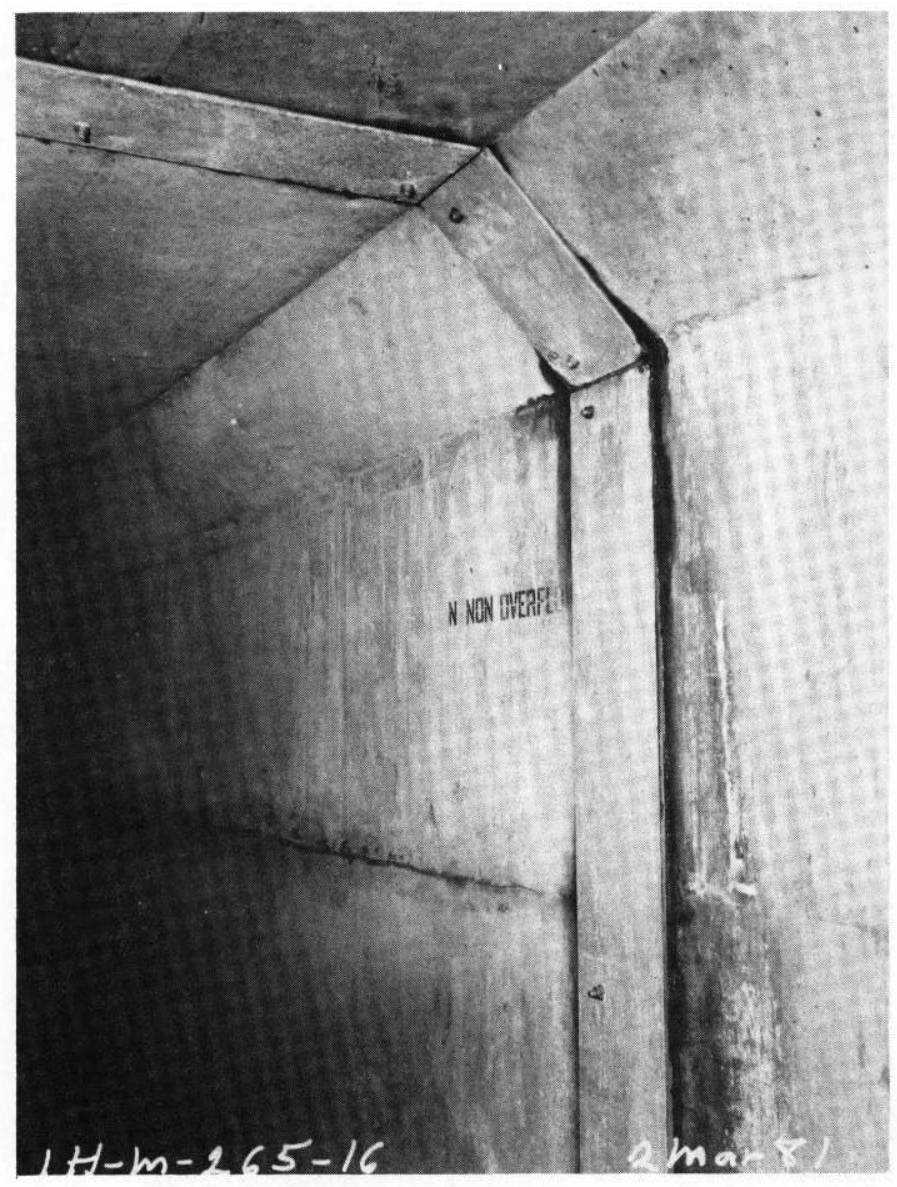

Figure 50. Steel backup plate installed at nonoverflow monolith joint $1 / 2$, Ice

Harbor Dam

gallery occurring in November 1980 could be eliminated by the installation of an effective backup plate system. Extensometer measurements have been taken since November 1972 to monitor adjacent monolith movement at elevation $453 \mathrm{ft}$ in the nonoverflow dam and powerhouse dam. They indicated relative movements were less than 0.1 in. in November 1980 .

129. The crack in monolith 8 of the south nonoverflow was previously investigated with drill holes. The crack extends through the dam from the upstream face to the downstream face. An array of EX-holes was drilled from the elevation $355 \mathrm{ft}$ drainage gallery to intersect the crack at a point $5 \mathrm{ft}$ from the upstream face on $10-\mathrm{ft}$ vertical centers. These holes were to intercept the water leaking into the crack and channel it away. The flows proved to be so great that the holes and crack were chemically grouted using AM-9 as part of the 1978 grouting contract. The leakage was stopped but a year later 
the crack began leaking again. Leakage in March 1981 was as shown in Figure 51.

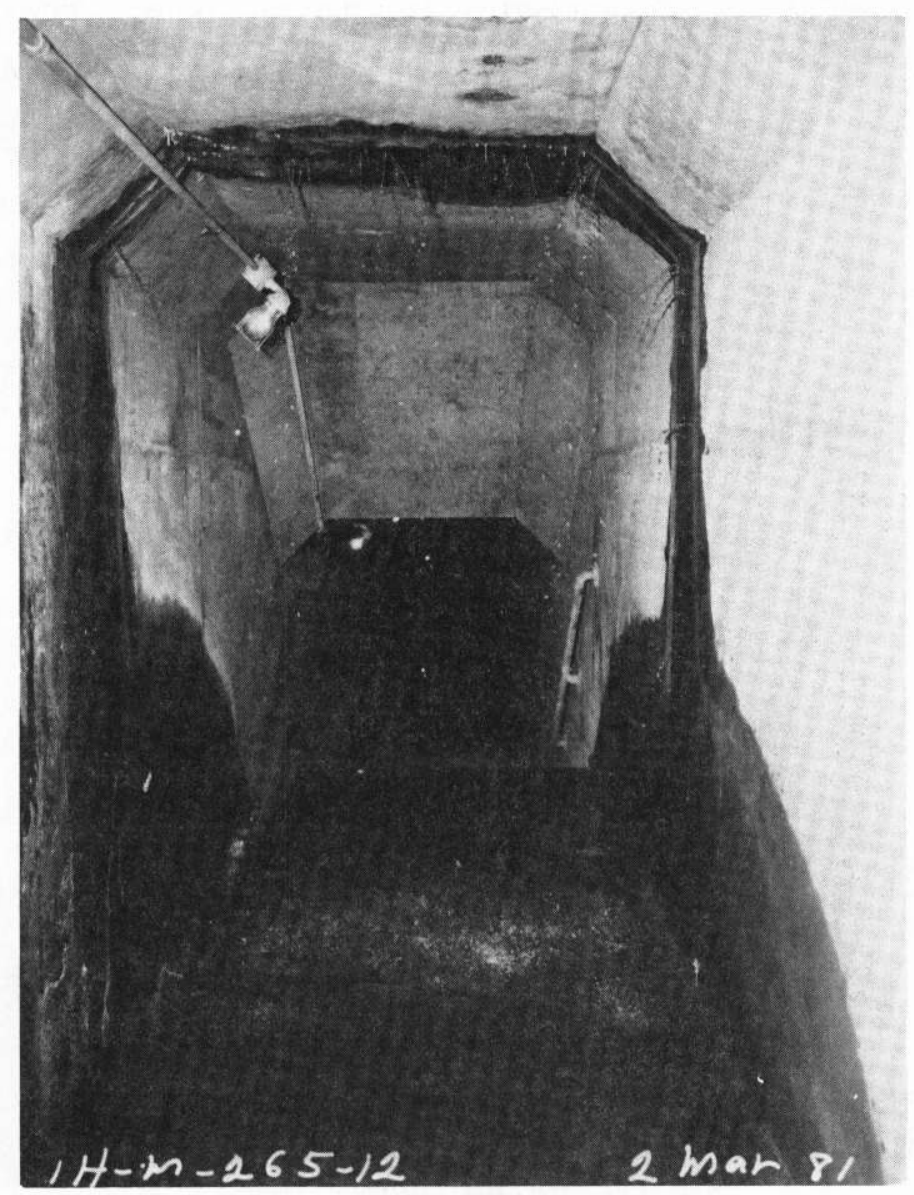

Figure 51. Monolith 8 crack as viewed from the drainage gallery, Ice Harbor Dam

130. Installation of new vertical, upstream waterstops in the powerhouse was included in the 1978 crack and joint repair contract. The repair was successfully completed and was performing satisfactorily in November 1980. However, the erection bay/service joint was omitted from the repair work and was in need of waterstop installation. This joint was leaking steadily, creating a maintenance problem in the gate storage pit area and causing ceiling and wall damage in the control room lavatory.

131. In September 1981, a contract was awarded to International Chemical Systems, Honolulu, Hawaii, for additional drilling and grouting to control leakage through monolith joints and cracks. Continental Drilling Company subcontracted the drilling work and provided labor for all nongrouting 
operations. The total contract for the Ice Harbor project was approximately $\$ 116,000$.

132. Additional holes were drilled to intersect the crack in monolith 8 on 5-ft centers and the previously grouted holes on 10-ft centers were flushed. Holes above elevation $363 \mathrm{ft}$ produced water when cleaned or drilled to the crack; whereas, holes below this elevation produced little or no water. Holes at the lower elevations were extended or relocated and still no water was seen. This indicated that the crack was wider or more open at the top than at the bottom, which is not uncommon in the cracking of large monoliths. Chemical grouting was done using Q-Seal, an acrylamide grout marketed by Ques Corporation that is essentialiy 1dentical to AM-9. It was hoped that a higher consistency grout mixture could be used to prevent further extrusion of grout from the crack. However, the "heavier" grout could not be pumped into the small crack openings so a highly concentrated grout mixture was used without mineral filler.

133. After an extensive series of dye and pressure tests, the grout was pumped through only two of the packered holes. Other packers were opened to provide flow paths for the grout and to assure complete coverage of the grout. Eight hundred gallons of grout were continuously pumped. The grout began to set after 15 to $20 \mathrm{~min}$ and with continued pumping the grout was pumped through the gelled grout. This process is termed extrusion grouting and it worked we11. Grout material extruded out of the downstream face crack indicating coverage of a large area of crack. Four of the new holes were drilled from the service gallery at elevation $422.5 \mathrm{ft}$. These also were packered and then opened during grouting operations. Grout flowed through these drill holes also. Drill holes below elevation $363.0 \mathrm{ft}$ did not take any grout. The holes were flushed out again and now remain open to monitor the crack condition at this elevation. If the holes begin making water, an opening of the crack will be indicated. EX-drill hole packers have been provided to plug the holes if the flows become extensive. The remaining holes were plugged using a dry-pack grout. The crack, as seen on the downstream face of monolith 8 , has remained dry since the grouting. Minor leakage through the crack into the drainage gallery has not significantly changed since the grouting. This minor leakage is from a lack of grout between the gallery and the upstream face and is not considered a problem. 
134. During construction of the dam, the half-round vertical joint drains were plugged or partially plugged with debris, sand, mortar, or concrete. This resulted in poor drainage of water leaking through the upstream waterstop and later the drains ceased functioning completely. Plugged joint drains do not allow water to exit the drains, creating hydrostatic loads on the monolith which were not a part of the original structural design. Holes were drilled to intercept the drains at a point above the blockage. Contract drawings showed the new drain holes intercepting the joint drain at a 37-degree angle from the gallery centerline. Drain holes at joints $2 / 3$ and $3 / 4$ were drilled in this fashion and showed no results. The location of the holes was changed by drilling along the joint intersecting the joint drain at a higher elevation. This proved more successful. Three of the overhead holes flowed so much water that packers and plastic hose were installed to carry the flow to the gutter. An additional hole is now making water at the monolith 12 /service bay joint. It was felt that several of the holes not flowing water were not drilled deep enough. The project will attempt to open these holes using a large punch rod and sledgehammer. Cross-gallery trenches and grating were eliminated from the contract because the joint drain intercepts were repositioned. Packers and plastic drain lines handle the water flow more effectively.

135. New backup plates were installed on both monolith joints in the service gallery of the upper sill block. No other backup plates were installed on the project. All the drill holes extending to the gallery perimeter of the lock monolith 5 and upper sill block joint were flushed of the existing AM-9 chemical grout. Most of the flushed holes flowed water freely during a lockage, indicating penetration of the monolith joint. Several of the holes in the floor area would not make water even when the lock was filled. Additional holes were drilled in the lower areas in an attempt to get complete perimeter sealing during grouting operations. Grouting was attempted using a Cherney grout pump and a hydrophilic polyurethane gel (CR-250). The grout pump was inadequate for the grout formulation and site conditions. After wasting a day and $100 \mathrm{gal}$ of grout material, grouting operations were stopped. The crew moved to Little Goose Dam and returned to Ice Harbor in January 1982. Grouting was then accomplished in a similar manner to that done in the Little Goose sill block. 
136. A near vertical 6-in.-diameter hole was drilled along the powerhouse erection bay/service bay monolith joint to a depth of $137 \mathrm{ft}$. The hole was set at a 10-to-1 vertical angle to avoid embedded steel surrounding the gate repair pit and the drainage gallery at elevation $335 \mathrm{ft}$. The hole was drilled using a Copco track drill and a down-the-hole hamer. Grouting began a few days later by a subcontractor who had done the 1978 grouting work at Ice Harbor. It was soon evident why many of the monolith joints the subcontractor had grouted earlier leaked. The equipment was old and very worn and his grouting technique was less than adequate. After pumping only 5 to $10 \mathrm{gal}$ of grout, the operation was shut down and a new crew using much better equipment was hired. Grouting was completed using a grout mix of $50 \mathrm{lb}$ of acrylamide grout, $50 \mathrm{lb}$ of bentonite, and enough water to make 50 gal of grout. The hole topped out at the calculated volume of grout, which meant the joint was tight and little grout penetrated into the joint or the foundation rock.

\section{Lower Monumental Lock and Dam}

137. Lower Monumental Lock and Dam is located on the Snake River about 40 miles from Pasco, Washington. Initial construction began in 1961 and the project was put into operation in 1970. The dan consists of a concrete gravity structure, a six-bay powerhouse, and earth-fill embankments (Figures 52 and 53), and has a total length of 3,800 ft. Included between the powerhouse and south embankment is a navigation lock with chamber dimensions of 86 by $675 \mathrm{ft}$ and a lift height of $103 \mathrm{ft}$.

138. Lock monolith joint $26 / 28$ began to leak when the lock was filled during a September 1969 inspection. Leakage was attributed to a fractured waterstop; however, concrete placed in the lock had a history of stiffening and workability problems during construction which may have contributed to incomplete consolidation of the concrete around the waterstop. Leakage through the south nonoverflow joint $1 / 2$ also began after the first filling of the lock chamber and stopped when the lock was emptied.

139. Leakage through gate monolith joints $25 / 27$ and $26 / 28$ was repaired by contract while the lock was dewatered in November 1970. A neoprene membrane epoxied to the concrete surface and retained by stainless steel cover plates was used in the repair (Figure 54). The areas which appear gray in Figure 54 have been treated with two coats of an epoxy, Colma-Kote M, 


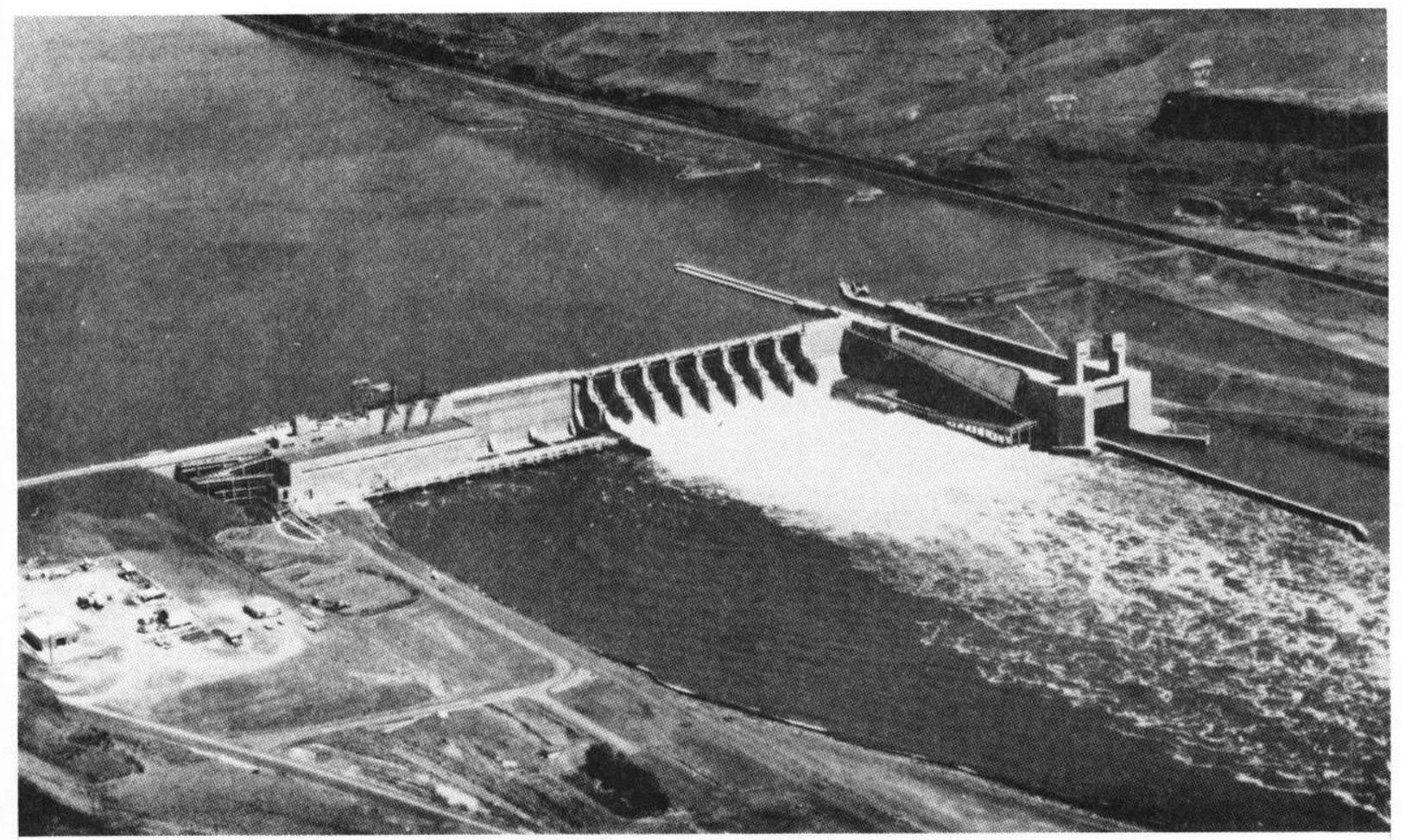

Figure 52. Lower Monumental Lock and Dam

manufactured by Sika Corporation, to form a temporary membrane over areas of deteriorated concrete adjacent to the joint. In September 1971, it was reported that the epoxy showed signs of deterioration and also that the concrete deterioration appeared progressive, as evidenced by increased flows through joints 26/28, 25/27, and 18/20 (Figure 55).

140. A condition survey of the navigation lock in December 1976 indicated that the original monolith joint waterstop, a 20-oz copper sheet positioned 9 in. from the lock face, had failed at a number of monolith joints with subsequent joint leakage of varying degrees. Also, a number of monoliths exhibited leakage at horizontal lift joints and at vertical cracks within the monolith. Lock monolith joint conditions, as described in the condition survey, were as follows:

a. Joint 5/7. There was no evidence of spalling at this monolith joint; however, the joint exhibited substantial leakage at the five lifts above the ground surface on the river side. Also, it appeared that the joint previously leaked at much higher elevations.

b. Joint 18/20. Concrete along the joint was spalling apparently due to relative movement between the monoliths which caused shear forces at the lock wall surface. The joint had leaked 

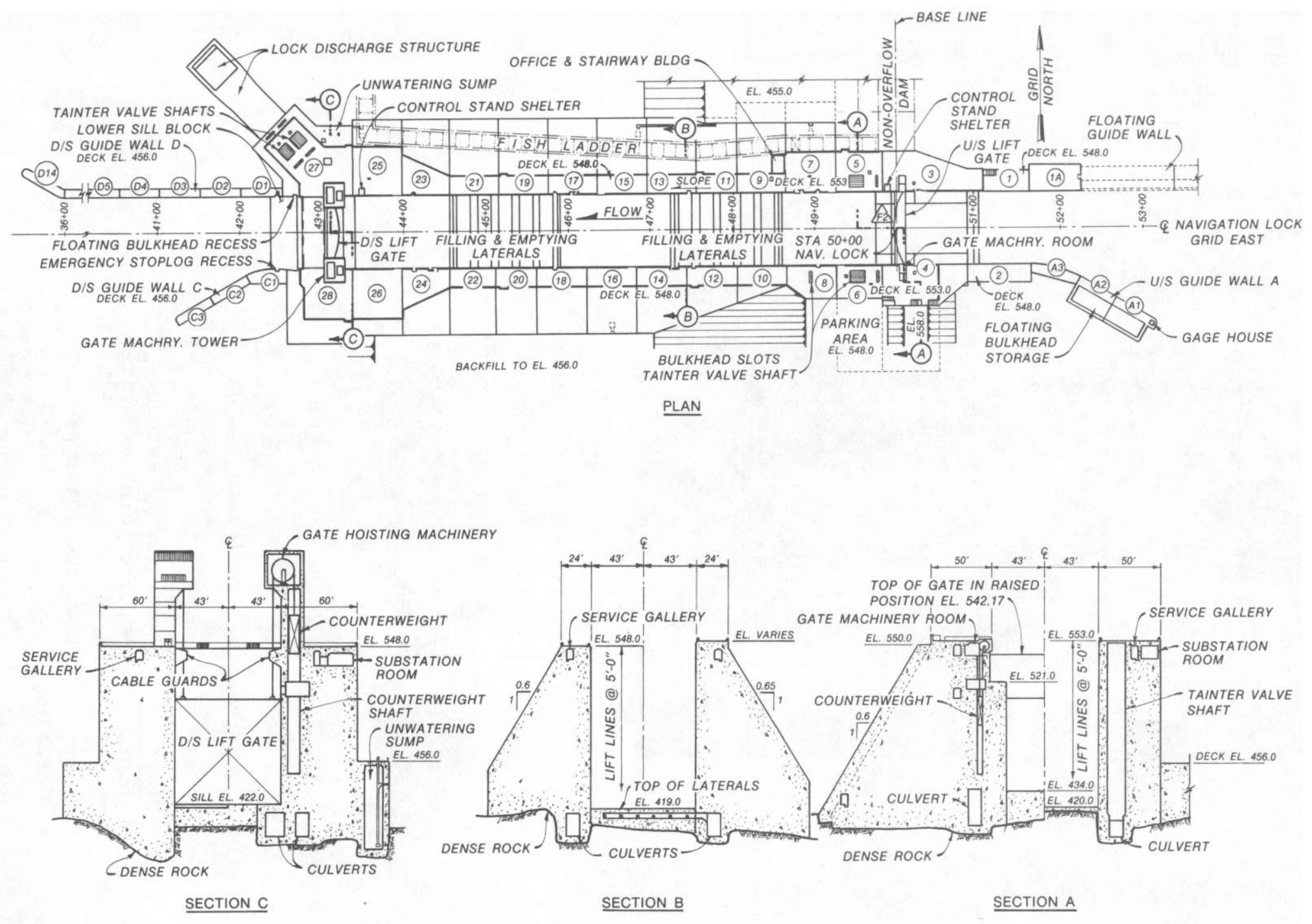

Figure 53. Plan and typical sections, Lower Monumental Lock 


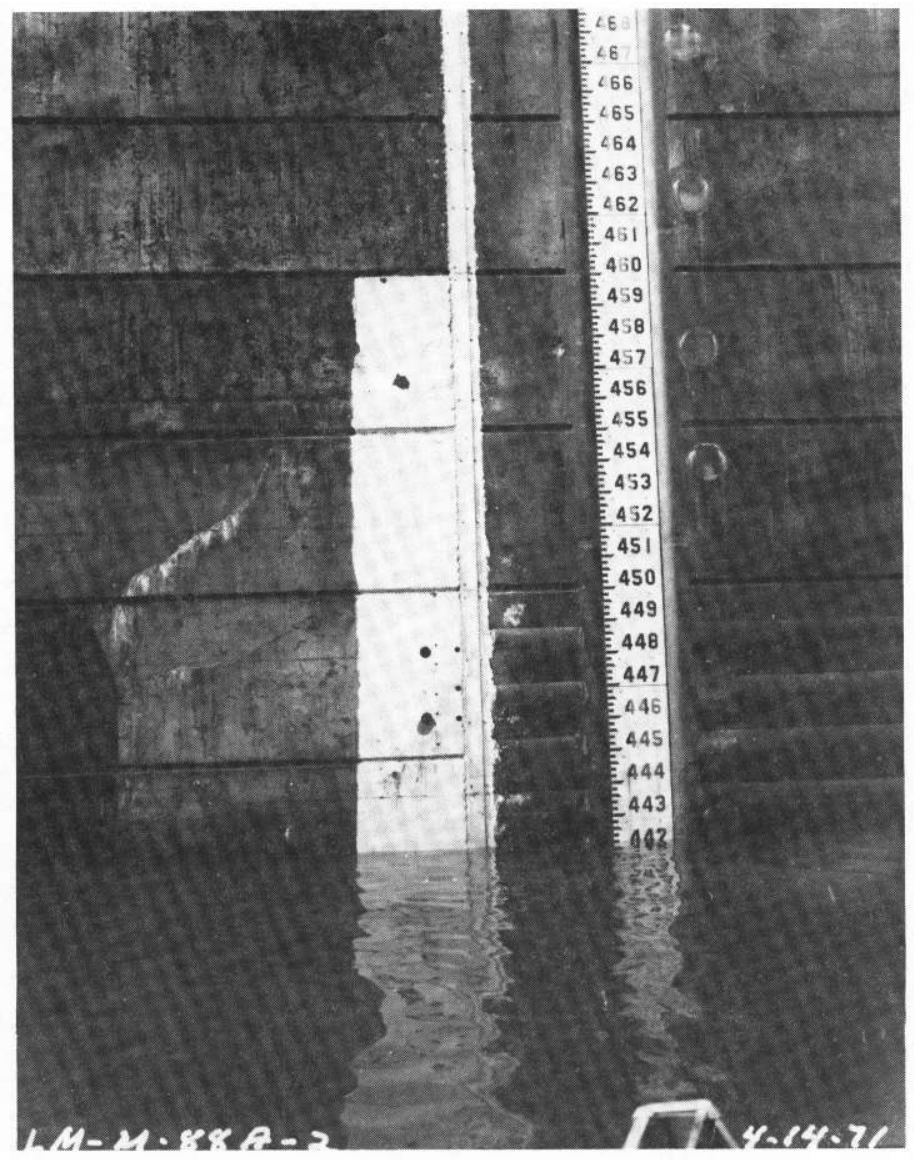

Figure 54. Joint $26 / 28$ repairs, Lower Monumental Lock

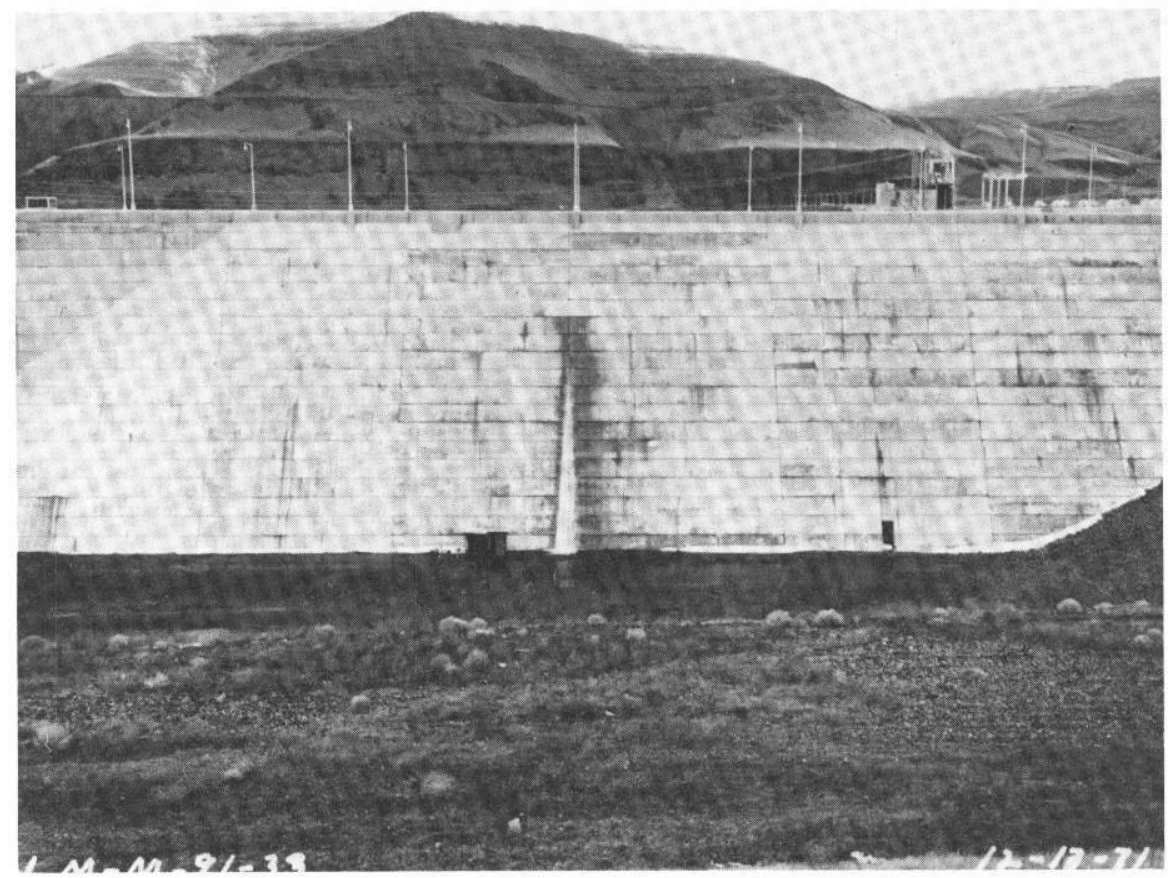

Figure 55. Leakage through joint $18 / 20$ with full lock chamber, Lower Monumental Lock, December 1971 
significantly in the past and was repaired by District personnel in March 1975. A groove $3 / 8$ in. wide and $1-1 / 2$ in. deep was sawed along the joint and filled with Dow Corning 790 building sealant (Figure 56). The sealant was applied during a period when the lock was out of operation for approximately $24 \mathrm{hr}$. Cost of the repair was approximately $\$ 2,000$. The sealant was tightly bonded and totally filled the sawed groove which was inspected during the December 1976 condition survey. However, there was some leakage through the joint from elevation $470 \mathrm{ft}$ to the ground. Since the sealant was only applied down to the existing tailwater elevation, the leakage may have been coming through the joint below this level. Regardless of the reason, the leakage was much less than occurred prior to installing the sealant.

c. Joint 20/22. One 1ift of monolith 22 exhibited concrete spalling along the joint inside the lock chamber. The spall, about 9 in. wide by 6 in. deep, was apparently caused by relative movement of the monoliths. After repair of monolith joint 18/20, joint $20 / 22$ began to leak badly. The joint was repaired by contract in December 1975. Repair procedures were similar to that described for joint $18 / 20$ except that a backing material was used in the lower part of the joint to prevent the sealant from being forced through the joint under water pressure from lockages. The sealant was not bonded to the concrete at the time of the condition survey and appeared to have been improperly installed. In some areas the sealant extended only to a depth of about $1 / 2 \mathrm{in.} \mathrm{instead} \mathrm{of} \mathrm{the}$

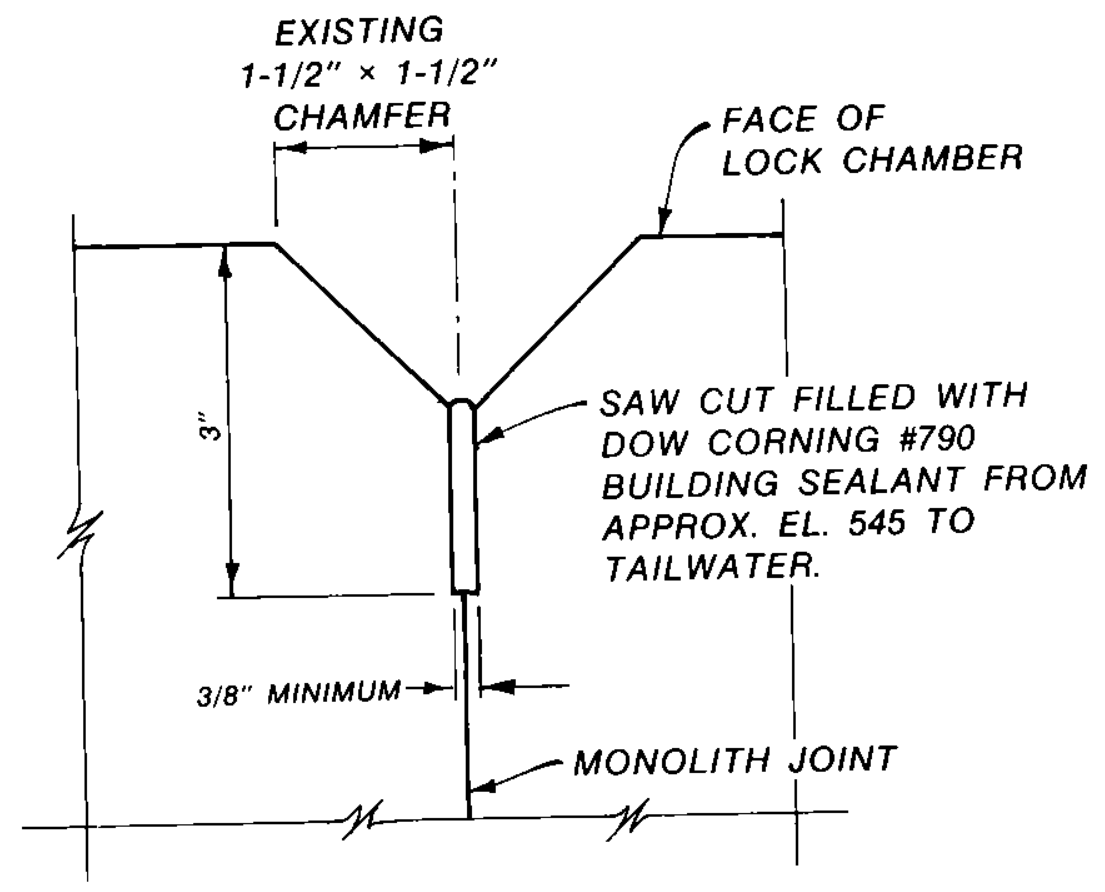

Figure 56. Caulked joint repairs, Lower Monumental Lock 
specified 1-1/2 in. Unlike the sealant applied by District personnel, sealant applied by contract did not have an opportunity to cure for approximately a day prior to lockages. When surveyed in December 1976, the joint exhibited leakage on the land side from elevation $465 \mathrm{ft}$ to the ground. Again, some of the leakage could have originated below the tailwater. The rate of flow was substantially decreased in comparison to that occurring prior to repair. Apparently the sealant, even though it was not bonded to the concrete, was providing restriction to leakage through the joint.

d. Joint 22/24. Concrete inside the lock chamber in monolith 22 had failed along the joint. The failed area, roughly 2 to $3 \mathrm{ft}$ wide and estimated at 6 to $9 \mathrm{in}$. deep, extended from the top 5-ft lift down to about elevation $455 \mathrm{ft}$. The joint leaked from elevation $470 \mathrm{ft}$ to the ground at the time of inspection.

e. Joint 23/25. There was no evidence of distress, but the bottom three lifts above tailwater (elevation $455 \mathrm{ft}$ ) were seeping water.

f. Joint 25/27. This joint had previously been badly spalled due to relative movements of the two monoliths which apparently also ruptured the original copper waterstop. A surfacemounted plate waterstop with neoprene backing subsequently installed over the joint had also failed. The plate waterstop was removed when spalling along the full height of the joint was repaired in March 1975 using a fibrous concrete pour-back. Simultaneously, a copper waterstop was reinstalled according to the original design. It failed after a short period, so the joint was later filled with elastic sealant as previously described for joint 20/22. The sealant appeared to have been installed poorly and was not bonded to the joint. Even though the amount of leakage has been reduced, the joint still leaked badly from elevation $460 \mathrm{ft}$ to the tailwater and floods the lower access deck of monolith 27.

g. Joint 26/28. Concrete along this joint was repaired in March 1975 in a manner similar to that described for joint $25 / 27$. This joint also had a surface-mounted plate waterstop which failed and was removed. A copper waterstop was reinstalled as part of the repair, but it failed soon afterward. Project personnel then packed the joint with oakum and a black mastic. The joint leaked very badly from elevation $445 \mathrm{ft}$ to the ground at the time of the condition survey. To prevent erosion of the earth fill, this leakage was controlled through a concrete channel (Figure 57).

141. A report describing lock deficiencies, recommended repairs, and estimated cost was prepared based on 1976 inspections of the lock (US Army Engineer District, Walla Wa1la 1977). It was recommended that monolith joints previously sealed from maximum pool elevation $548 \mathrm{ft}$ to the tailwater be sealed below the tailwater to floor elevation $420 \mathrm{ft}$. Also, areas where the 


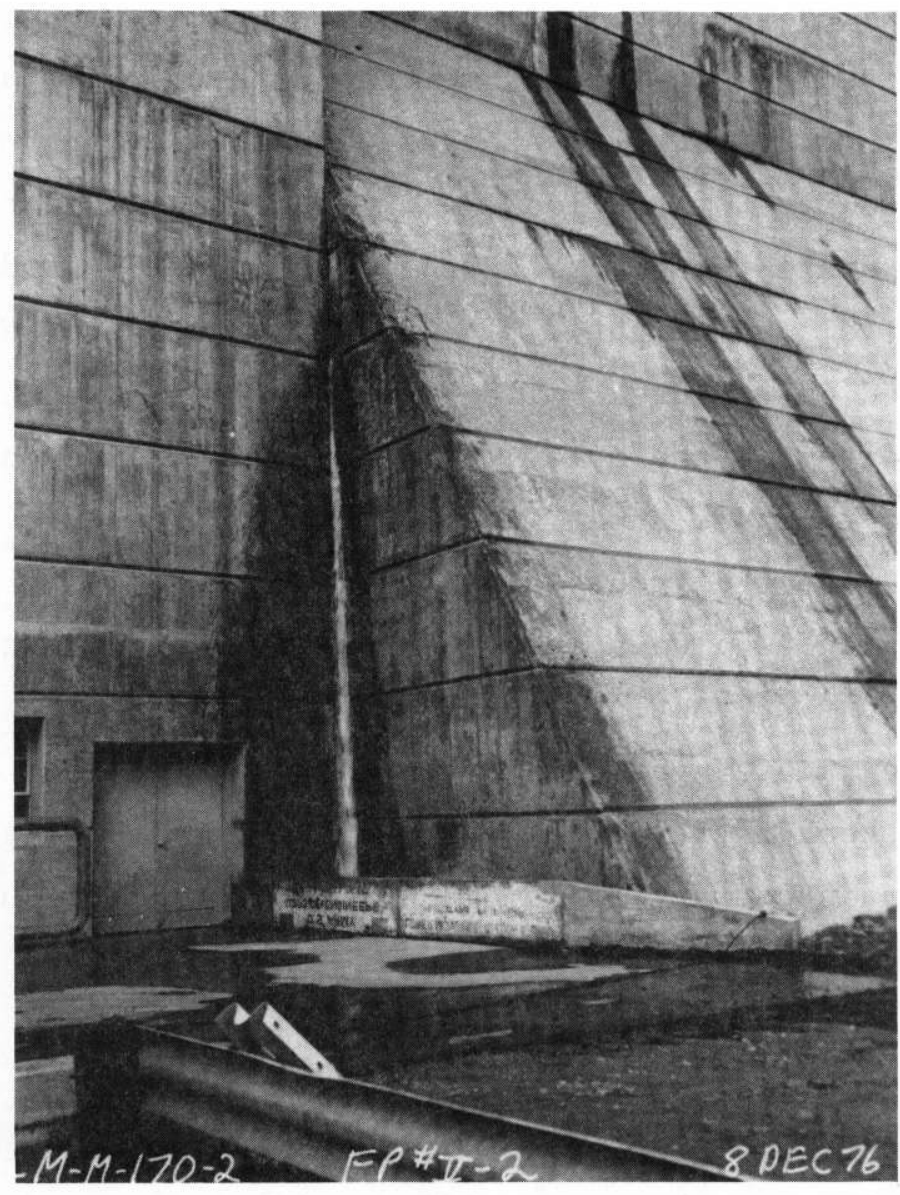

Figure 57. Joint 26/28 leakage, December 1976, Lower Monumental Lock

existing sealant was poorly applied should be cleaned and refilled. All remaining joints should also be sawed and sealed. Estimated cost of this work was $\$ 105,470$. Because of the excessive relative movements between the downstream gate monoliths and adjacent upstream monoliths $(0.3 \mathrm{in}$. as measured in December 1976), it was possible that the elastic sealant might tear and be less than 100 percent effective in these areas. Therefore, a second waterstop capable of withstanding significant relative movements along the joint was recommended for monolith joints $25 / 27$ and 26/28. An NX hole drilled vertically along each of the two joints about 2-1/2 ft from the lock face and filled with highly elastic chemical grout was suggested at an estimated cost of $\$ 9,260$.

142. In September 1977, a contract was awarded to W. H. Gregory Company for Lower Monumental Lock repairs. The drilled hole with elastic filler waterstop work was subcontracted to GELCO Grouting Service. A 6-in.-diameter 
hole was rotary drilled vertically along each of the 23 monolith joints to be repaired. The holes averaged $162 \mathrm{ft}$ from the deck to their bottoms, which were drilled $5 \mathrm{ft}$ into bedrock. The holes were located approximately $3 \mathrm{ft}$ back from the Inside face of the lock wall. The grout used to fill these holes was the AM-9 system mixed at 10 to 15 percent AM-9 powder and 20 percent diatomaceous earth (all by weight). It was mixed into two separate solutions at the plant located on the deck. Two pumps pushed separate solutions through two hoses to the bottom of the hole, where they were mixed into one solution and discharged into the hole under water. The mixture had a specific gravity in excess of unity. As the grout level rose in the hole and gelled, the hoses were retracted, trying to always keep them below the grout-water interface but above the gelled grout. Grouting was usually done while the lock water level was below or at the same elevation as the discharge from the hose; therefore,

no large hydraulic head differential was present across the grouting zone. In several cases it was necessary to remove gelled grout from the hole and regrout.

\section{Little Goose Dam}

143. Little Goose Lock and Dam (Figure 58) is located on the Snake River approximately halfway between Lower Monumental and Lower Granite Dams. The navigation lock (Figure 59) has a width of $86 \mathrm{ft}$, a length of $675 \mathrm{ft}$, and a maximum lift of $101 \mathrm{ft}$. The project began operation in 1970 .

144. The first periodic inspection of the project (July 1970) reported some lock monolith joints were spalled and a few monolith and lift joints had very minor leaks. Also, monolith joint leaks were reported at monoliths $2 / 3$ and $5 / 6$ in the powerhouse. It was recommended that in the future, monolith joints be designed with a compressible material in the joint for a distance of 3 or $4 \mathrm{ft}$ back from the face to prevent spalling and that waterstops be placed both in front and behind a full-round drain in the monolith joint. Drains should be accessible from both ends for cleaning purposes. Extensometer points located on each monolith joint indicated that shear movements between monoliths were generally small ( 0.01 to 0.05 in.). However, shear movement was still occurring at joint $2 / 3$ in the north nonoverflow with monolith 3 moving downstream 0.21 in. No significant cracking was observed, but some spalling in the galleries through the joint area was reported. 


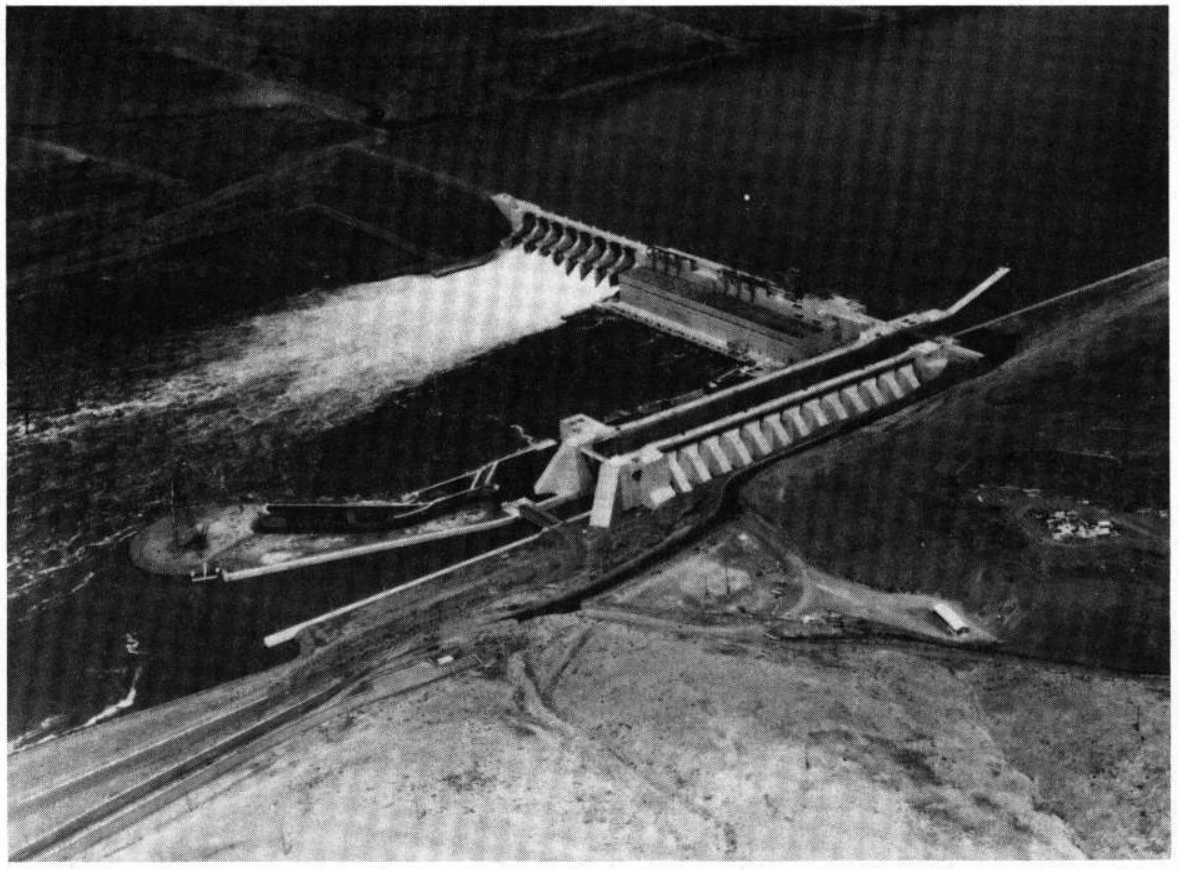

Figure 58. Little Goose Lock and Dam

145. The second periodic inspection was conducted in July 1971. Almost all of the lock wall monoliths exhibited concrete spalling along the monolith joints. Spalling was particularly bad at monolith joints $4 / 6$ and $28 / 30$ where differential movement occurred as a result of change in monolith shape. Apparent permanent offset had occurred between monoliths as measured by extensometer points (Figure 60). When the lock chamber was full, minor leakage was occurring at several monolith joints with the worst leakage at joints $4 / 6$ and $28 / 30$.

146. Small flows were reported at monolith joints $4 / 6,10 / 12,28 / 30$, $3 / 5,11 / 13,13 / 15,17 / 19$, and $25 / 27$ when inspected in July 1972. Seepage was reported at monolith joints $8 / 10,12 / 14,14 / 16,18 / 20,22 / 24,26 / 28,5 / 7$, and $9 / 11$. The remaining joints were dry.

147. Subsequent deflection measurements indicated continued outward tilting of the riverside lock monoliths. Maximum permanent deflections, measured by extensometers, of more than $0.7 \mathrm{in.}$ (Figure 61) were reported in 1974. Displacements were attributed to compression of the relatively weak flow breccia stratum underlying the wall buttresses. The largest relative displacements occurred at monolith joints $4 / 6,10 / 12,16 / 18$, and $28 / 30$ 


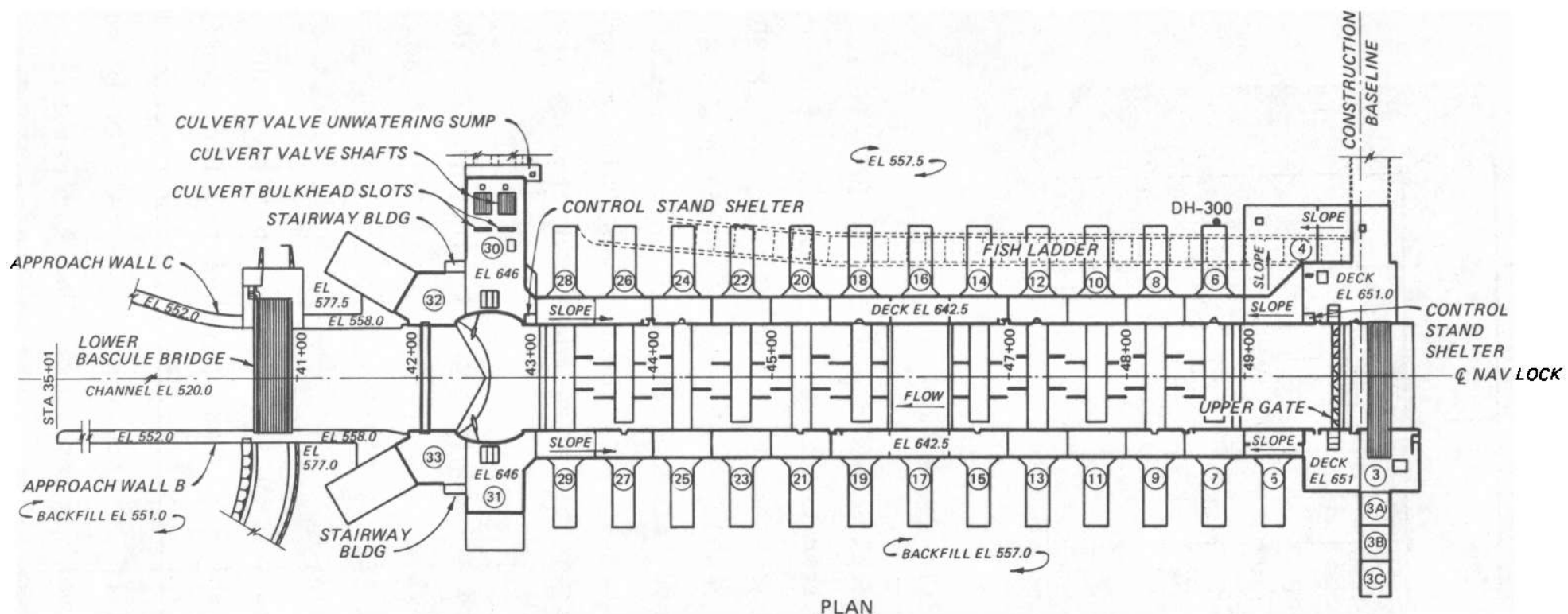

PLAN

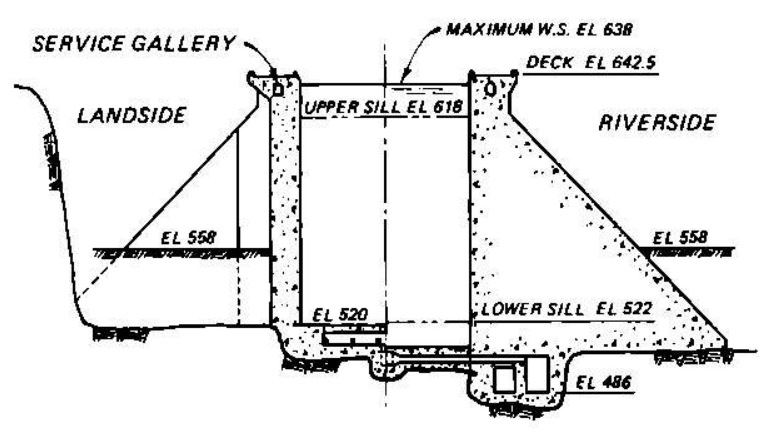

SECTION THRU LOCK

Figure 59. Little Goose navigation lock 

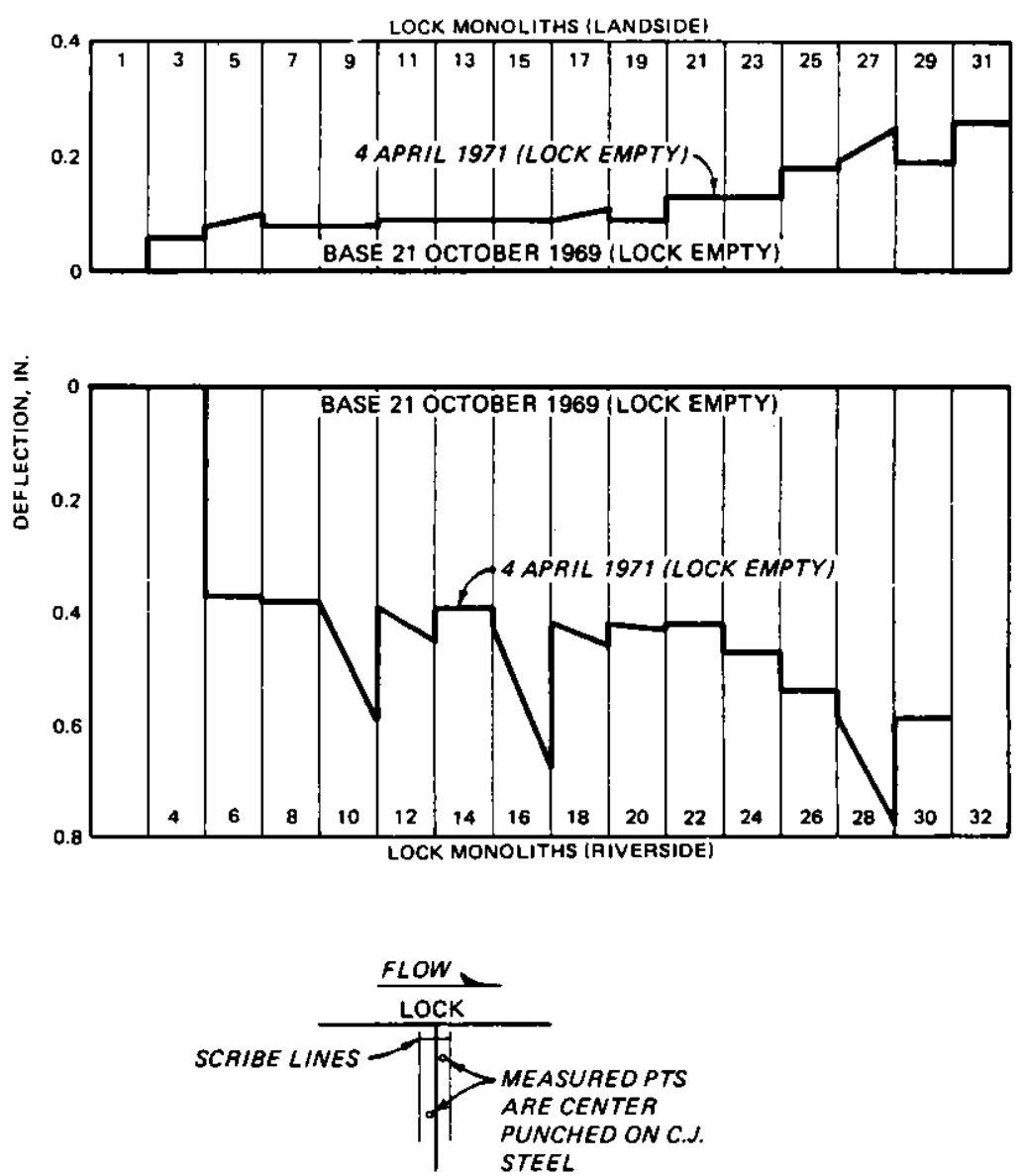

Figure 60. Lock monolith deflections, Little Goose Lock

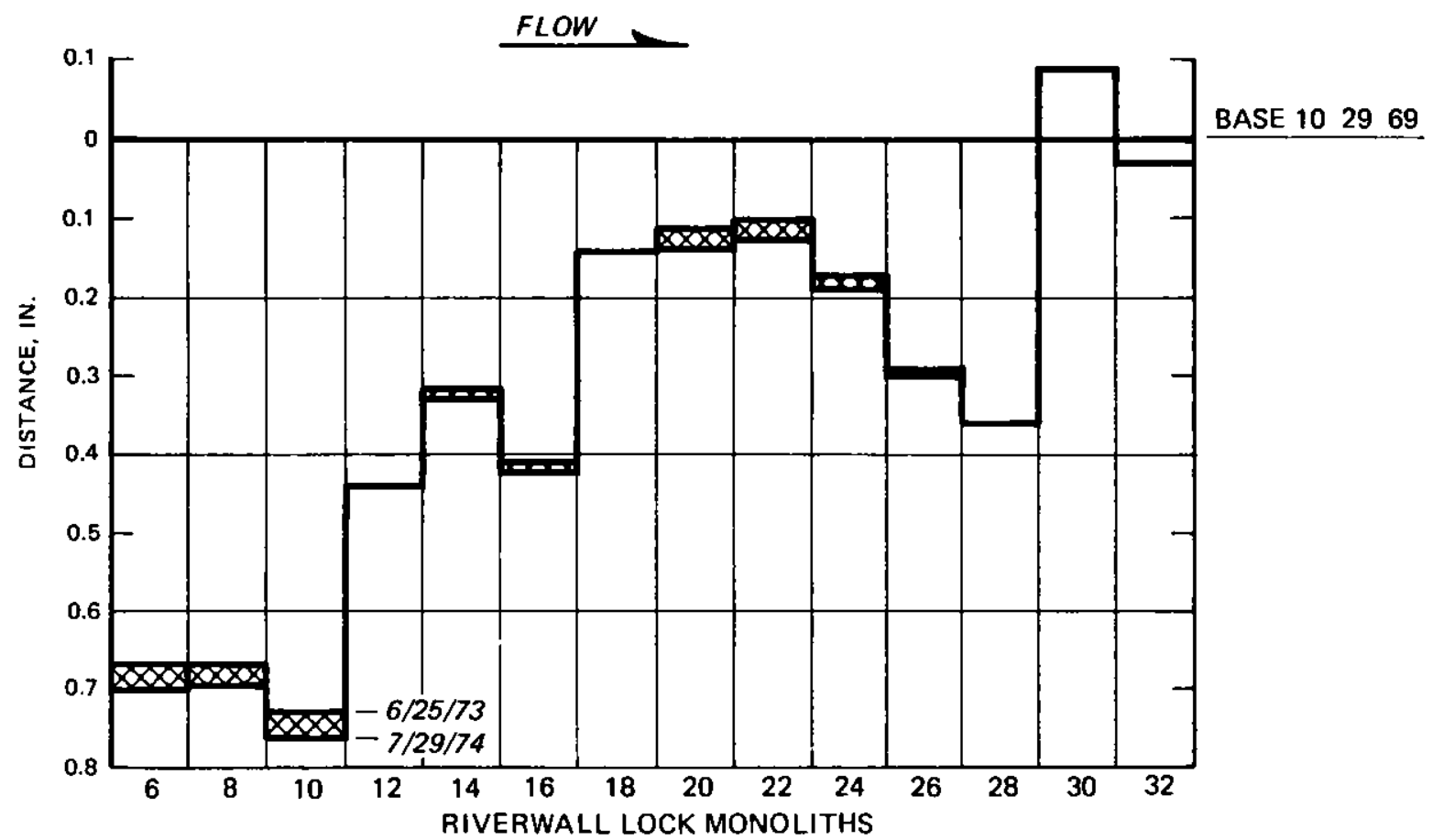

Figure 61. Permanent deflections measured with lock chamber empty, Little Goose Lock 
(Figure 62). Total fallure of the waterstop at monolith joint $4 / 6$ was reported as a result of the relative displacement between the adjacent monoliths. When the lock was filled, water leaked through the joint and spilled knee deep into the parking area near monolith 6 (Figure 63). Most of the other monolith joints exhibited varying rates of leakage.

148. A trial foundation grouting program was initlated in 1975 in an effort to stabilize the lock monoliths. Monolith No. 6 was selected for the trial grouting. In 1976, a trial waterstop repair was made along monolith joint 4/6. A report describing both trials was prepared (US Army Engineer District, Walla Walla 1978). Since the original waterstops were located $9 \mathrm{ft}$ from the lock face, exposing and repairing these waterstops was not considered practical. Surface-type waterstops were considered unacceptable because (a) they had not been permanent or 100 percent effective when used previously on similar locks in the Walla Walla District and (b) structural design considerations required the waterstop to be located about $9 \mathrm{ft}$ back from the lock face. Therefore, a hole drilled along the joint and filled with an elastic material was selected as the repair method for the trial repair. The purpose of the trial repair was to demonstrate that a hole could be successfully drilled along the joint and to evaluate different impermeable fillers for the hole. The trial was accomplished with Corps equipment and personne1. The drill hole was located $12 \mathrm{ft}$ from the lock face, $3 \mathrm{ft}$ behind the original and failed copper waterstop (Figure 64). This position required drilling the holes through the underlying service gallery. The drill hole through the deck and to below the service gallery was $10 \mathrm{in}$. in diameter and was accomplished by diamond drilling. This allowed cutting all embedded metals until the hole was into the mass concrete. Upon completion of the diamond drilling work an 8-in. pipe was placed in the hole. A Winter-Weiss rotary drill was set up on the deck. The drill was equipped with a down-the-hole pneumatic hammer which drills a 6-in. nominal diameter hole. Special precautions were taken for maintaining hole alignment. Generally, there was constant surveying of the drill mast for vertical position from two directions and the hole was drilled using a reduced drilling speed. The hole was completed in three shifts and then thoroughly washed to remove all drill cuttings and fines. The total cost of the drilling phase was $\$ 6,050$.

149. A video survey of the hole condition was made and recorded on tape. This service was provided by Video Scan under a purchase order for a 

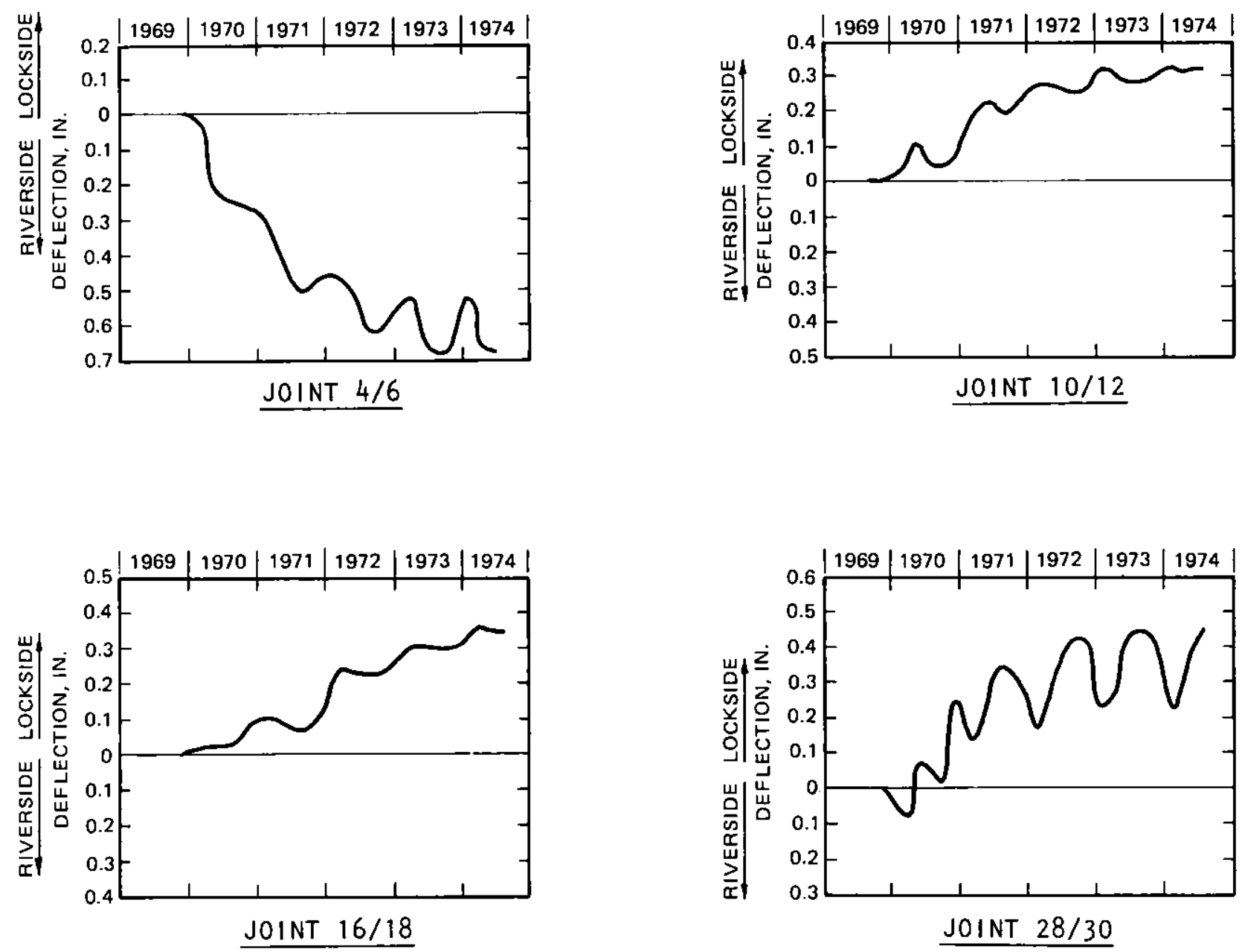

Figure 62. Maximum relative displacements of lock monoliths, Little Goose Lock

cost of $\$ 450$. The video survey indicated that the wall of the hole was not generally smooth. In many instances, the drilling operation broke out aggregate pieces which made the wall rough. In addition, there was visible shearing in the concrete parallel to the construction joint. Again, in some instances, the disrupted concrete would break out, making the wall rough. The construction joint was visible in the videotape from top to bottom.

150. A search was conducted to secure a suitable material to line the boring. A reinforced plastic firehose was selected at a cost of $\$ 500$. It was manufactured by the Hercules Equipment and Rubber Company, Inc., of San Francisco, California. The hose was a polyvinyl tube covered with nylon reinforcement. It was resistant to abrasion and weathering and had a temperature range of $-10^{\circ}$ to $+150^{\circ} \mathrm{F}$. It was identified as the "blue line hose" with a 


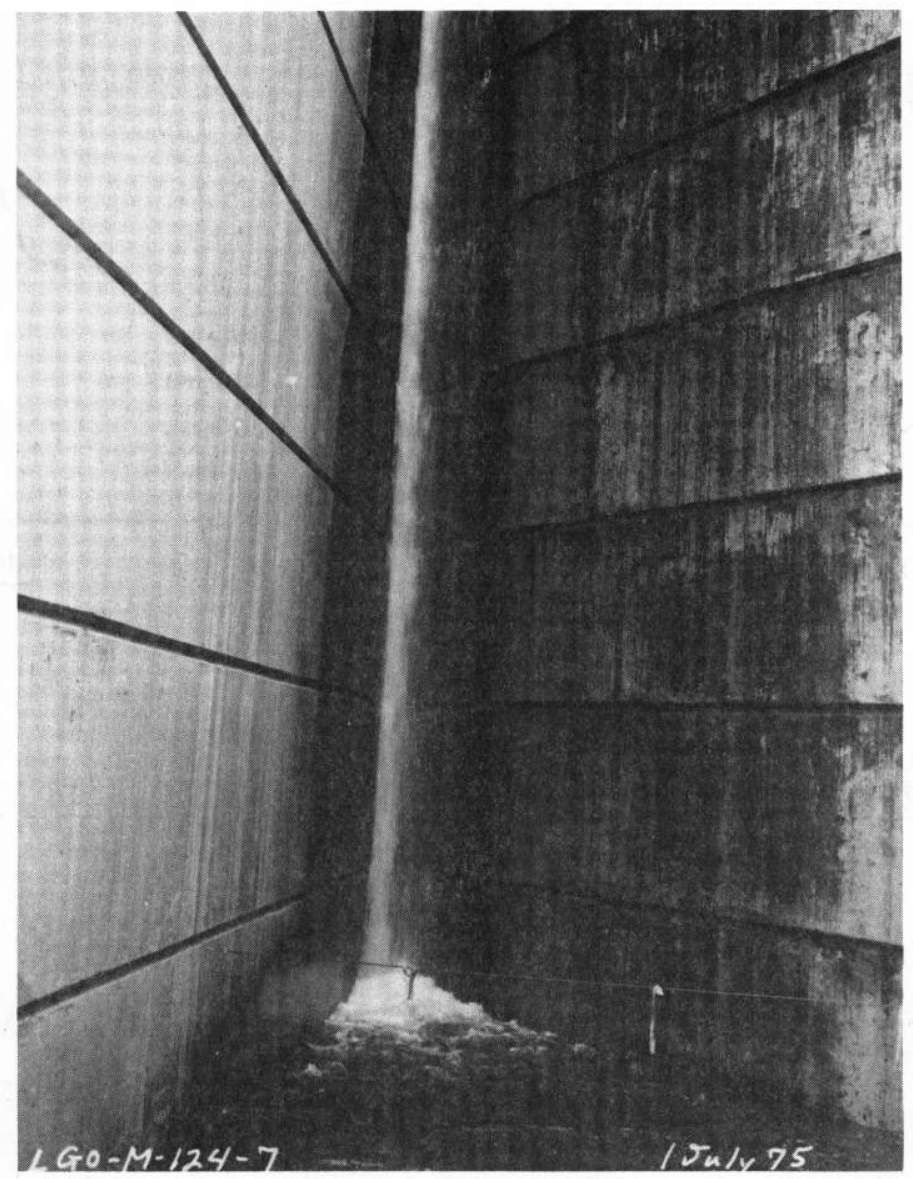

Figure 63. Monolith joint 4/6 leakage, July 1975, Little Goose Lock

Product number 36-0060, and had a normal inside diameter of 6 in. It weighed approximately $0.8 \mathrm{lb} / \mathrm{ft}$, and had a working pressure of $35 \mathrm{psi}$ and a bursting pressure of 107 psi. Wall thickness was 3/32 in., and the hose would deform or expand $1 / 2$ to $3 / 4 \mathrm{in}$. to approximately $7 \mathrm{in}$. in diameter.

151. The hose was filled with water and had a leakproof cover which was fitted with an air valve. Filling the hose required approximately 185 gal of water. An air gap was left at the top, and the system was then charged with an additional air pressure of 10 psi. It took several days for the air pressure to bleed off. This system decreased leakage through the construction joint by an estimated 90 percent. After a couple months a leak developed in the hose which required considerable maintenance to keep the water level up. Since water and air periodically had to be added to this system, the hose was filled with a bentonite slurry, approximately 10 percent by weight, which was pumped into the hose through a down pipe. The water was displaced by the slurry until the system was full and capped. The pressure at the base of the 


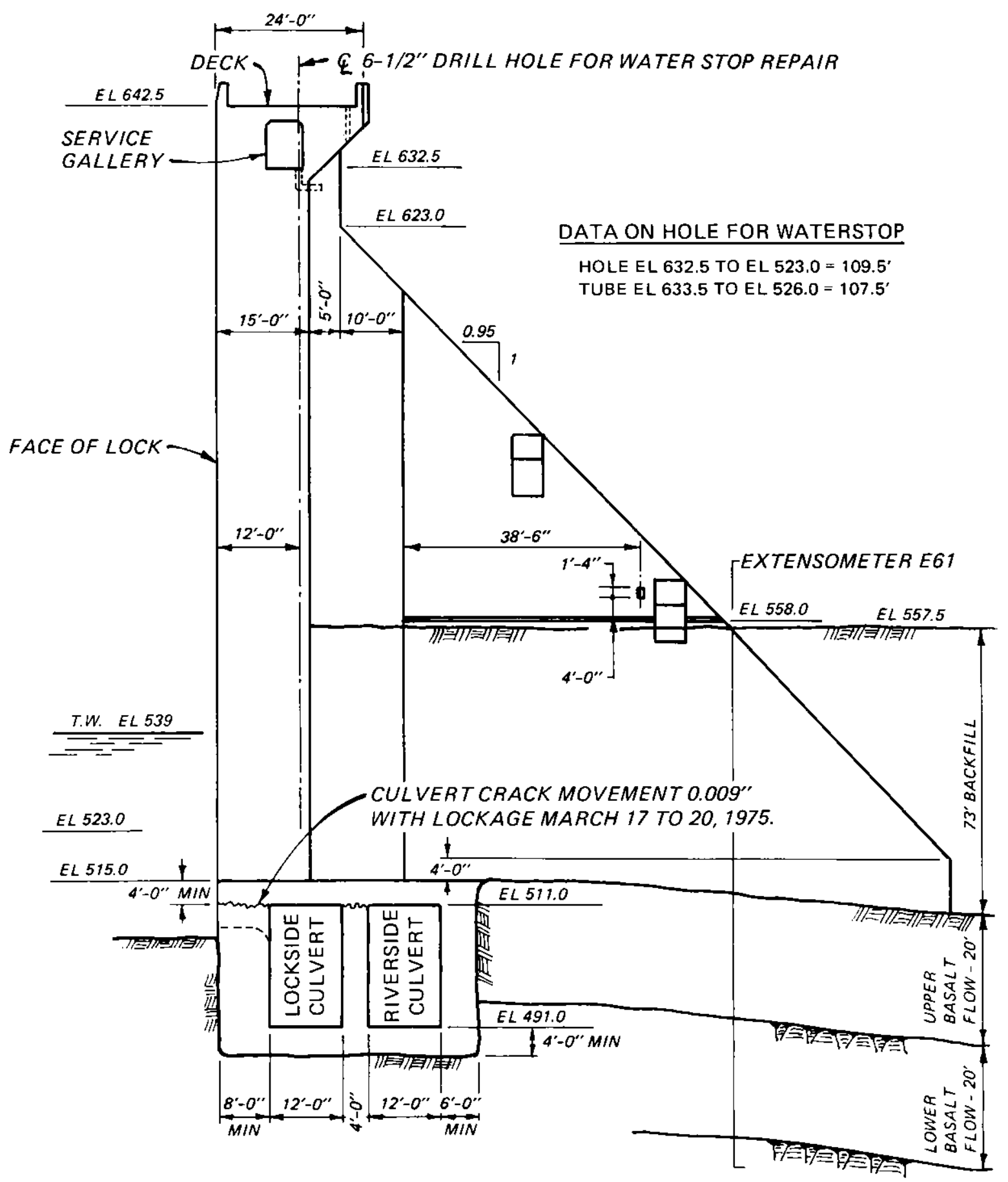

UPSTREAM ELEVATION

Figure 64. Location of trial waterstop repair, Little Goose Lock 
hose was 51 psi; however, the hose had lateral support so the pressure was not critical. The slurry was partially effective but did not result in a maintenance free and positive waterstop. An alternate procedure for providing an effective waterstop would be to remove the plastic tube and fill the drill hole with an elastic material. In effect, this would be a 6.5-in.-diameter cast-in-place waterstop. It was decided to try this technique at Ice Harbor Lock using four different fillers in holes along four joints as previously described.

152. Based on the Ice Harbor and Little Goose trial repairs, the drill hole with elastic filler method was selected to reestablish monolith joint waterstops at Little Goose Lock. Repairs were accomplished under contract in 1978 by drilling a 6-in.-diameter vertical hole along the joints from the deck to about $5 \mathrm{ft}$ into bedrock and then filling the holes with AM-9 chemical grout to create a cast-in-place waterstop. This repair stopped an estimated 95 percent of the leakage. Leakage at selected joints before and after repair is shown in Figures 65 and 66.

153. Based on an inspection in August 1979, it was reported that several monolith joints exhibited small amounts of leakage (Figure 67) and would probably require regrouting in the future. It was suggested that one of the advantages of this repair system is that regrouting could be done easily and economically by an experienced chemical grouting crew. Other observations reported during this inspection included:

a. The upstream sill was displaced about $1 / 8$ to $1 / 4$ in. downstream of monolith 4. As a result, the joint leaked very badly at elevation $603 \mathrm{ft}$. When the lock was filled, about 4 in. of water flooded the floor. At elevation $525 \mathrm{ft}$ the joint between the sill and monolith 4 spurted water about $4 \mathrm{ft}$ high when the lock was filled and about 6 in. high when emptied. A contract to chemically grout the joints where needed was planned for FY 81 .

b. Both the upstream and downstream grouting galleries of the south nonoverflow (elevation $495 \mathrm{ft}$ ) were leaking at the joint to the erection bay. Both were leaking badly, but, in genera1, it appeared that the worst leakage was at the upstream gallery. The leakage presented no direct structural problems, but had associated hydrostatic pressures that were not a part of the intended design. It also represented a considerable volume to be pumped out of the gallery sump. A contract to chemically grout the joint and stop leakage either through drill holes from the galleries or from a cast-in-place waterstop drilled from the deck was planned for FY 81. 


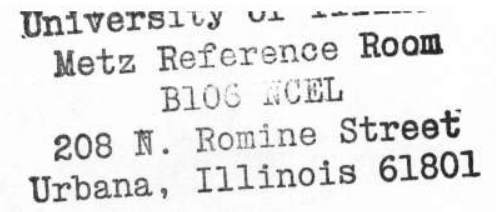

a. January 1977
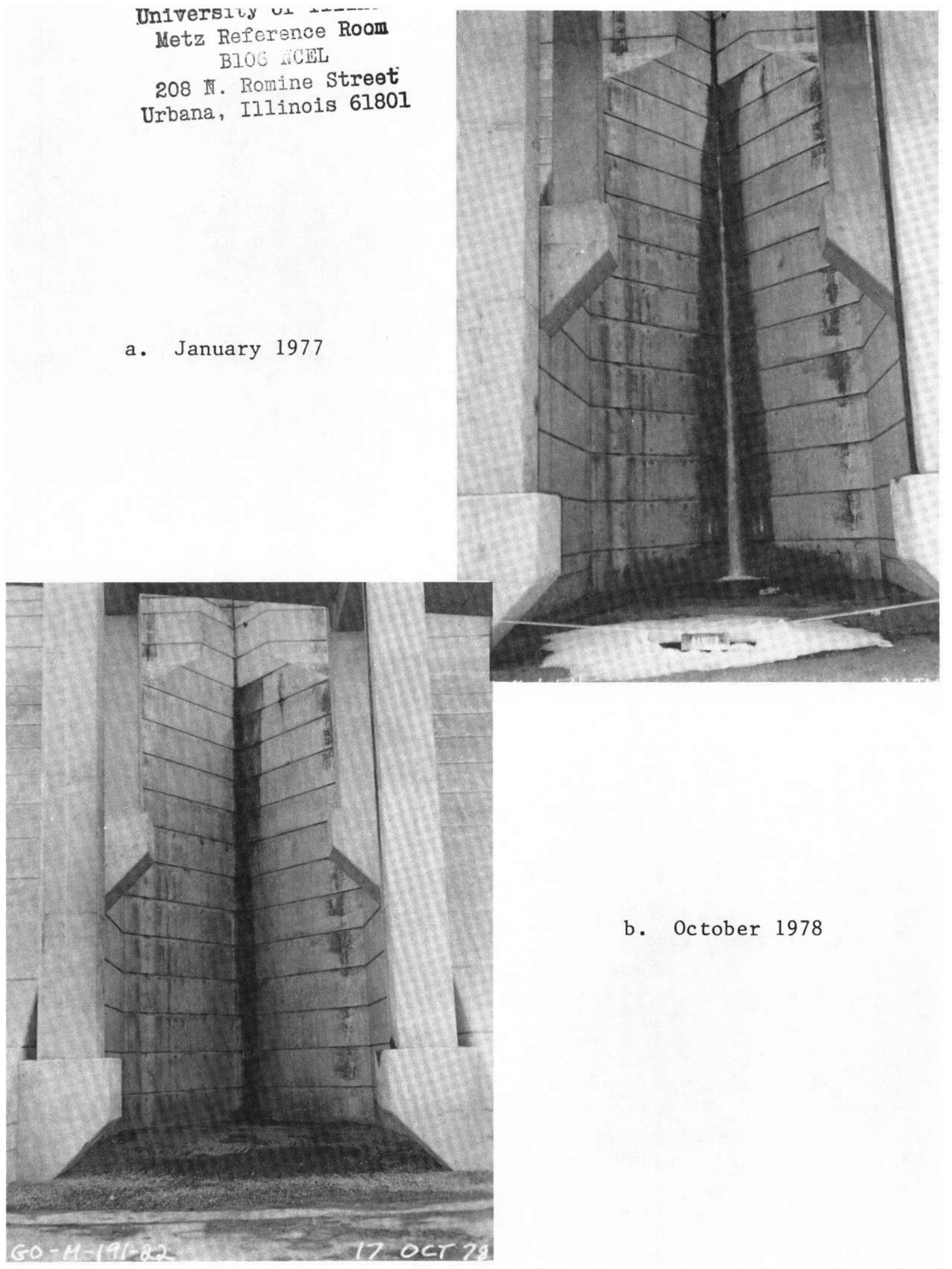

b. October 1978

Figure 65. Monolith joint 10/12 leakage before and after repair, Little Goose Lock 


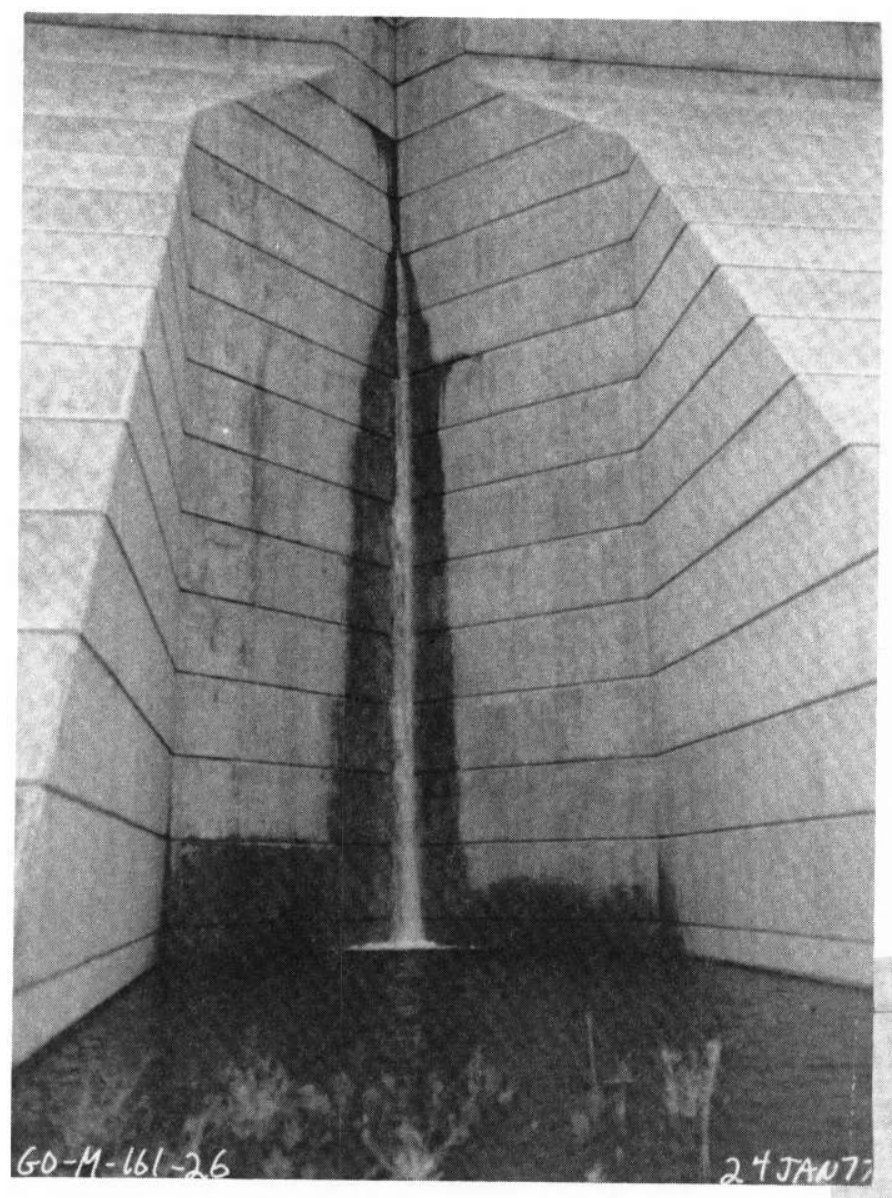

a. January 1977

b. October 1978

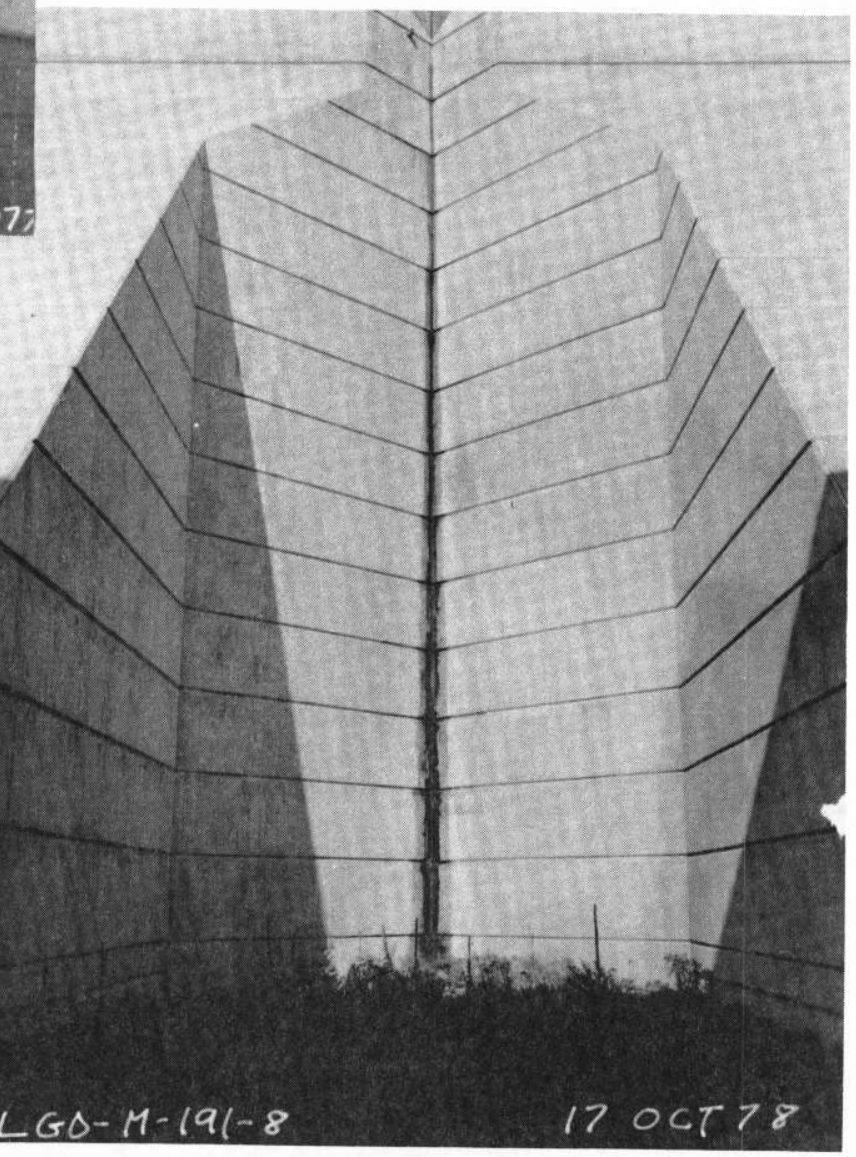

Figure 66. Monolith joint 11/13 leakage before and after repair, Little Goose Lock 
a. Monolith joint $13 / 15$
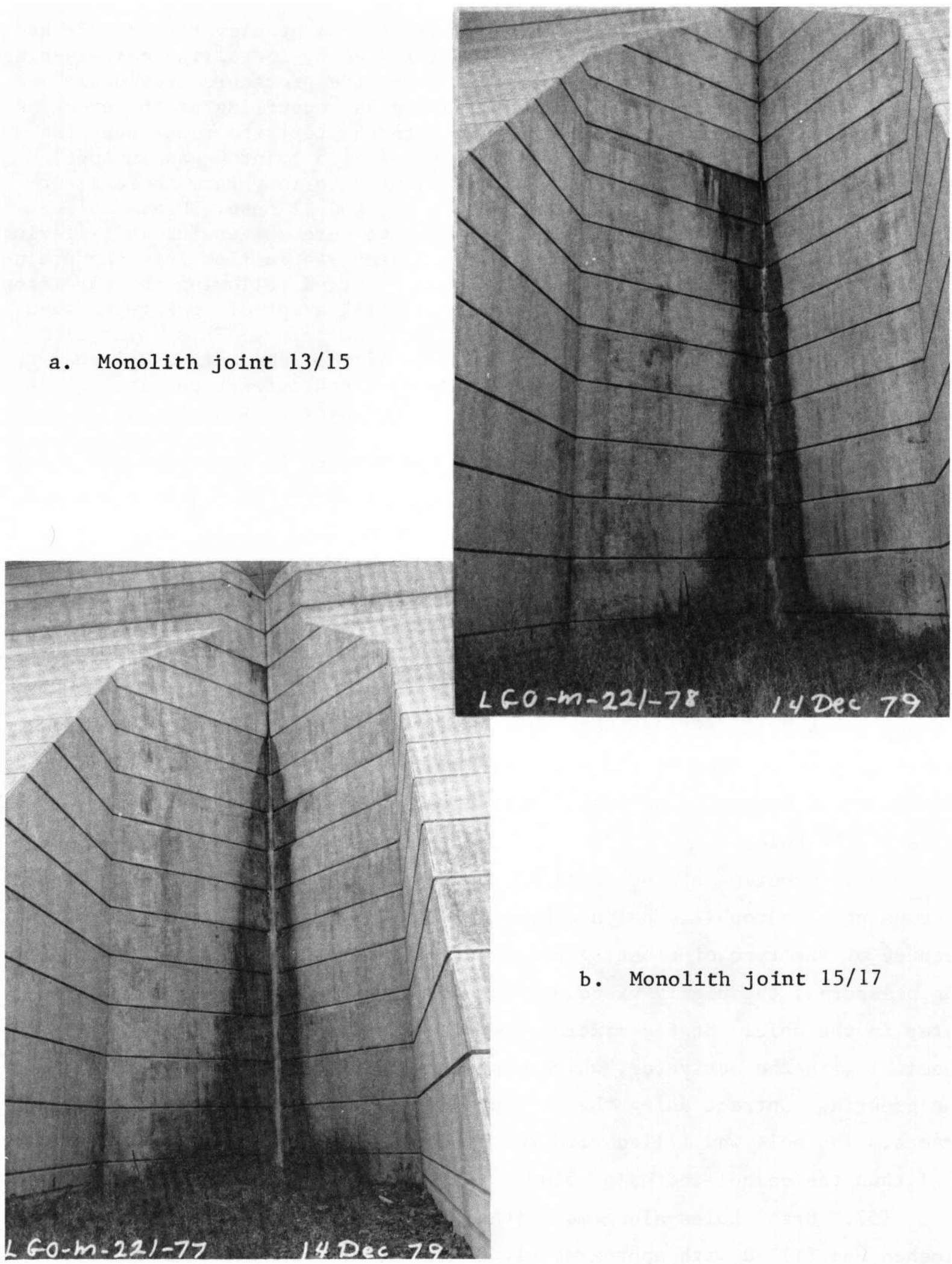

b. Monolith joint $15 / 17$

Figure 67. Monolith joint leakage, Little Goose Lock, December 1979 
c. Leakage of the powerhouse bay joints at elevation $542 \mathrm{ft}$ had been greatly reduced or eliminated by installing cast-in-place chemical grout waterstops using the procedure previously described. Some minor leakage was occurring at the erection bay/bay 1 joint. Leakage onto the terrazzo floor near the erection pedestal at the bay 4/bay 5 joint began in April 1979. The leakage was attributed to long-term thermal contraction of new concrete in the spiral case. Drain holes drilled to intercept the leakage were successful in relieving the hydrostatic pressure. A decrease in flow into the drainage and grouting gallery was reported following the waterstop repairs. However, there was still a lot of leakage between the erection bay/south nonoverflow joint. This joint also leaked on the downstream face of the dam. It was planned to regrout the joint with a heavier consistency chemical grout when other waterstop repairs are made at the project.

154. In September 1981, a contract was awarded to International Chemical Systems of Honolulu, Hawaii, to regrout some of the cast-in-place waterstops installed in 1978. Continental Drilling Company subcontracted the drilling work and provided labor for all nongrouting operations. The total contract was approximately $\$ 137,000$.

155. Holes to be regrouted were flushed and cleaned using a combination of drilling and high pressure air/water blasting. This was accomplished using a Copco track drill. (Figure 68) and a 6-in. roller bit. Two 6-in.-diameter stabilizers were added to the drill string as is done when drilling with a down-the-hole hammer. The stabilizers acted as reamers in cleaning the sidewalls of the holes.

156. Grouting of the drill hole along monolith joint $21 / 23$ was to be done using a hydrophilic polyurethane gel (CR-250) marketed by 3M Company. Because of the type of grouting equipment, the water temperature, and operating pressures, the highly viscous grout could not be adequately mixed with water in the hole. Static mixers were not effective in mixing the viscous chemical with the activator, which was water. The decision was made to finish the grouting contract using the acrylamide grout as used on previous contracts. The hole was filled with this grout using about 20 percent more material than the calculated hole volume.

157. Drill holes along monolith joints $15 / 17,22 / 24$, and $24 / 26$ were flushed and filled with approximately 300,350 , and 250 gal of acrylamide grout, respectively. Photographs of the grouting operation are shown in Figure 69. At one point, the grout line stuck in the monolith joint $24 / 26$ hole 


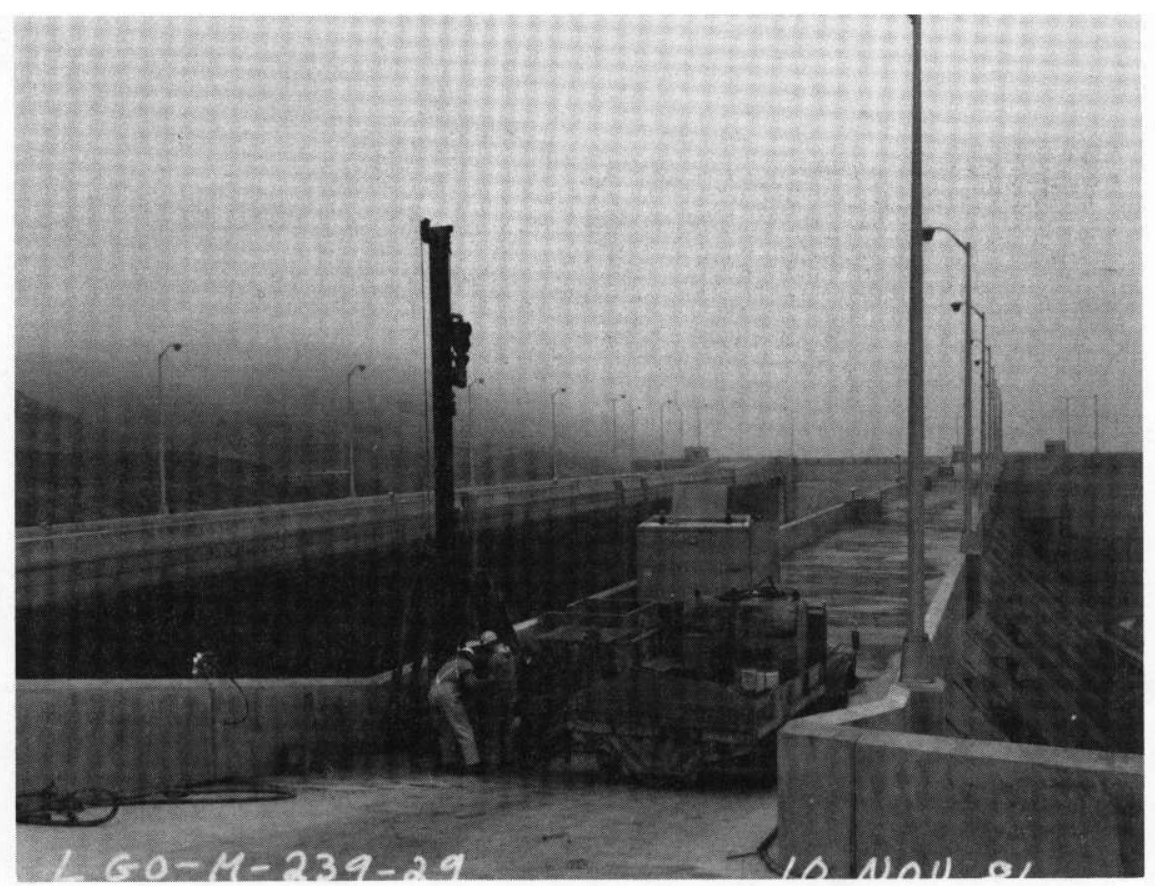

Figure 68. Track drill used to clean holes of grout from previous repair, Little Goose Lock

and the double hose line (70 ft of hose) had to be cut off and left in the hole. The 2-ft length of 2-in.-diameter pipe used to hold the grout line in place was lost also.

158. Grouting of drill holes along monolith joints $10 / 12$ and $4 / 6$ resulted in large volumes of grout being pumped because of high water flows out the bottom of the drill holes into the fractured foundation rock. Two hundred gallons of grout were pumped in the 10/12 hole and 850 gal in the 4/6 hole with little or no effect. A small volume of cinders (10 lb) was then dumped in the holes and the water flow ceased. Each hole was then filled with 250 gal of chemical grout. The last 50 gal of grout placed in the 10/12 hole contained no mineral filler as a result of poor instructions to the laborer from the contractor. This was not considered critical since most of this grout is above normal pool elevations.

159. Leakage through monolith joint $2 / 4$ was a continuing problem which appeared to become more complicated with each attempt to easily or economically correct the leakage. Leakage through monolith joint $2 / 4$ apparently entered the 4-in.-diameter drain line which was broken at the monolith joint. Since the discharge end of the drain line was previously plugged at the gallery to reduce excessive pumping caused by water coming through the failed waterstop, leakage backed up in the drain until it exited into the deck and upper gallery floor drain system. As a result, the otherwise separate drain 


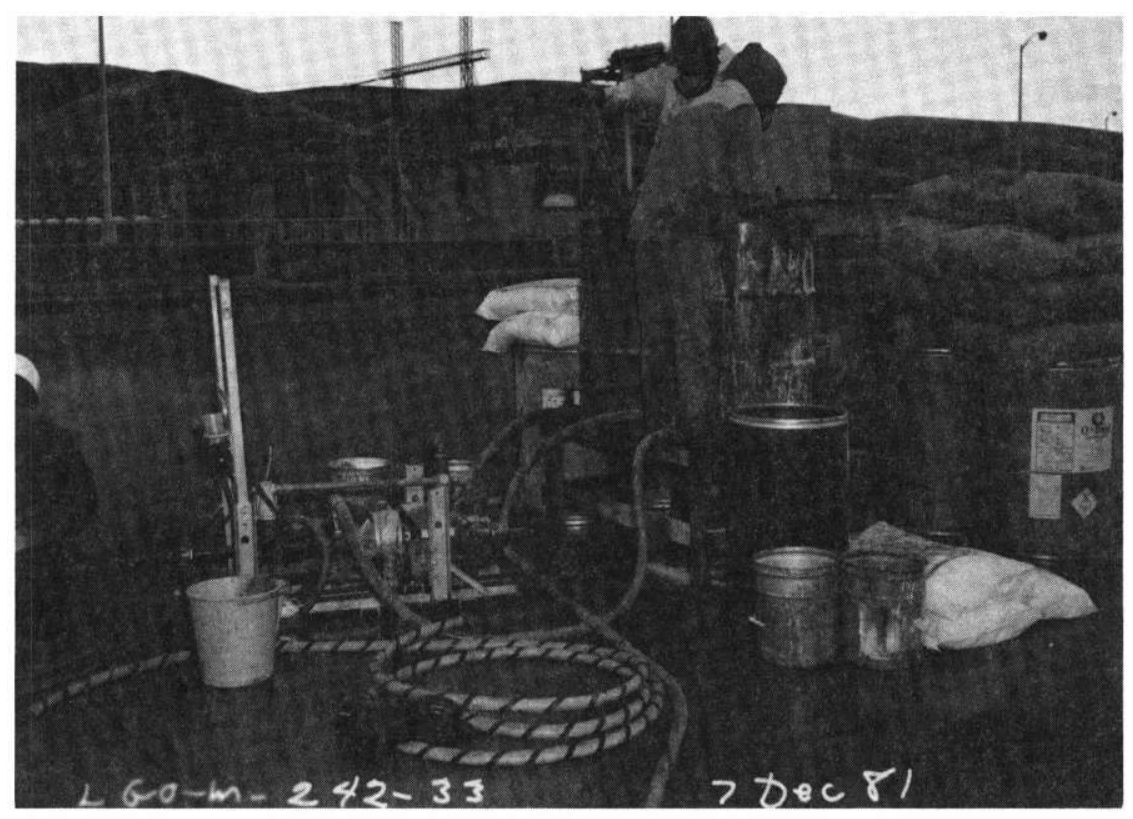

a. Mixing tanks and dual pump

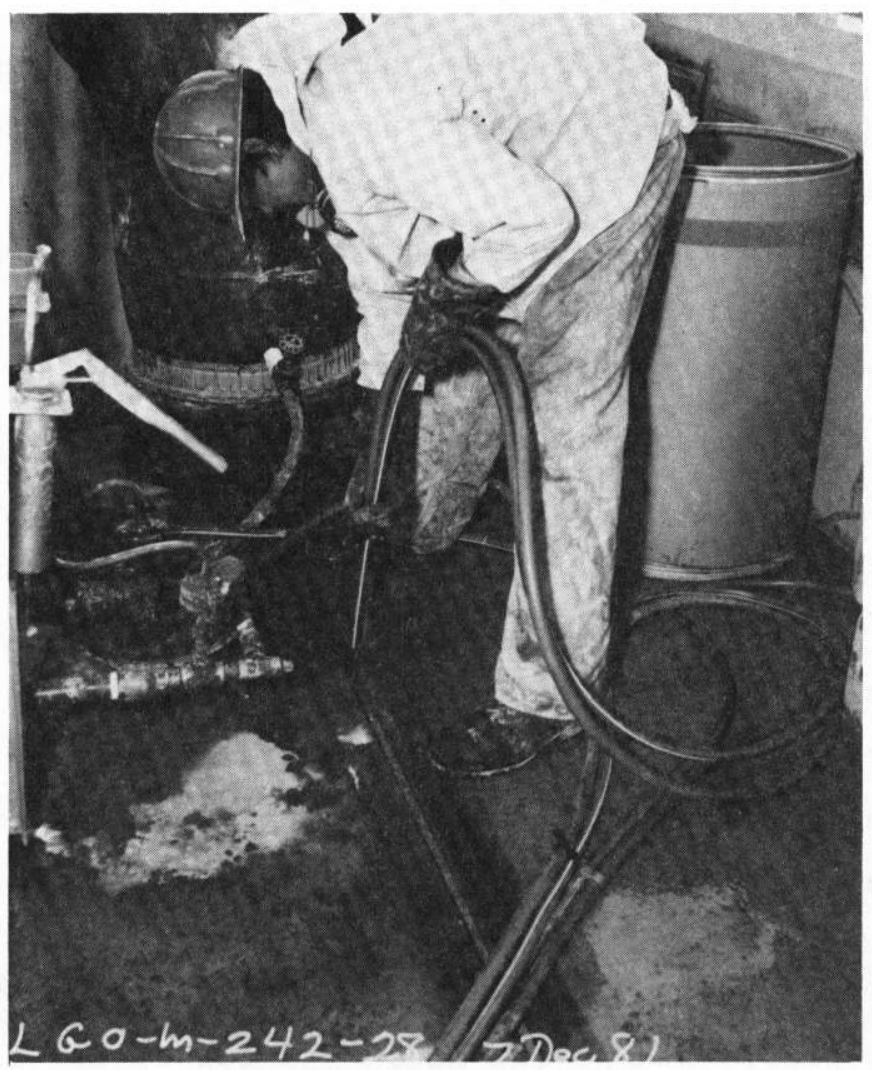

b. Individual grout hoses for each major grout component

Figure 69. Acrylamide grouting operations, Little Goose Lock 
system for the galleries, roadway deck, and various rooms of monoliths 2 and 4 were all interconnected to leakage coming through the falled copper waterstops at monolith joint 2/4. In an attempt to correct this problem, two 6-in.diameter holes were drilled along the joint a few feet from each face of the lock wall. The holes were drilled to a depth of about $185 \mathrm{ft}$ of which 5 to $7 \mathrm{ft}$ was foundation rock. The holes were located to avold the equipment rooms, the embedded items, and the main culverts. The riverside hole was grouted using 500 gal of chemical grout. The joint was belleved to be quite wide and with the flow of water through the fractured rock and through the fractured drain line, grout could travel a great distance along the joint. High water flows were discovered in the landside waterstop hole of the $2 / 4$ joint. By the time grouting was completed on the landside hole, 1,500 gal of grout had been used. In both holes, one 2-ft section of pipe was lost in the grout hole because of stuck grout 1ines. Although grouting of these two holes was successful, the water flow to the fractured pipe was not decreased. Most likely, water is now entering the joint through the foundation rock rather than through the vertical monolith joints.

160. Monolith joint $3 / 5$ was drilled as an added work item by the contract work force. The hole was positioned so drilling could be done on the ramp section leading down to the landside navigation lock monoliths. The hole passed between the horizontal refnforcement and the cable and utility trays in the service gallery below. The cable trays and pipe had to be moved to provide room for the drill string. The first $10-1 / 2 \mathrm{ft}$ of hole between the deck and the service gallery was drilled using core drilling equipment to minimize damage to the service gallery ceiling concrete. The down-the-hole hammer was used after penetrating the service gallery. The hole was filled with 260 gal of chemical grout.

161. Leakage through the upper sill block (USB) monolith joints into the service gallery and drainage gallery had been steadily increasing for years. During lockages, flows into the service gallery were more than the floor drains could handle. To solve this leakage problem, EX-holes were drilled around the perimeter of the gallery intercepting the monolith joint $5 \mathrm{ft}$ from the gallery walls. Galvanized steel backup plates with Butyl rubber seals were installed over the upper sill block and lock monolith 3 and 4 joints in the service gallery and the USB/monolith 4 joint in the drainage gallery. The USB/monolith 3 joint in the drainage gallery was not plated and 
grouted because no leakage through the joint had been observed. The contractor was to pump grout through the EX-holes in a specified sequence with the lock filled. The contractor could not or would not pump the grout as specified. He was allowed the option of grouting the joints by injection-type methods. This involved removing portions of the backup plates and inserting grout tubes and sealing the joint using quick-set mortar. Grout was then pumped through the tubes, thereby sealing the immediate perimeter of the gallery. Once the preliminary sealing was done, the EX-holes were successfully grouted to establish a larger perimeter of sealant. Grouting was completed at al1 three joints in this manner. After grouting, packers were removed, the EX-holes were dry-packed, and backup plates were reinstalled.

162. For many years, excessive leakage through the powerhouse erection bay/south nonoverflow (SNOF) joint had been evident in both the drainage ga1leries and on the downstream face. A chemical grout vertical waterstop was installed in 1978 with much effort. Several grout formulations were used and with the addition of cement into the mix, the hole was successfully filled. The hole was flushed and regrouted under the 1981 contract. Grouting was relatively simple using volcanic cinders to slow the flow of water into the joint. The cinders were sucked into the joint, blocking the flow of water. The water in the drill hole was observed dropping from elevation 638 to $537 \mathrm{ft}$, which was the tailrace elevation. It was then an easy matter to fill the hole with chemical grout. Leakage of the erection bay/SNOF which was visible on the downstream face stopped completely after grouting. Leakage into the drainage gallery along this joint was not affected by the grouting. The flows were observed to be about the same as before grouting. This indicated that the water source was downstream. The drainage gallery at elevation $493 \mathrm{ft}$ is $44 \mathrm{ft}$ below tailwater and behind the grout curtain, making the tailwater a very possible source of water.

163. Lift joint leakage into the powerhouse level 5 had been a maintenance problem for years. An estimated $20 \mathrm{gal} / \mathrm{min}$ flowed out of a sizable rock pocket located on a lift joint about $15 \mathrm{ft}$ off the floor at elevation $598 \mathrm{ft}$. Repair of the leak was done by installing a 1-1/4-in.-diameter pipe in the void and packing around the pipe with quick-set cement grout, forcing all the water through the pipe. Chemical grout was later hand pumped through the pipe, sealing the void and open lift joint. Minor leaks such as this can easily be repaired by project personnel using simflar equipment. 
164. An inspection a few months following completion of the 1981 repairs indicated that regrouting of selected navigation lock monolith joints had been very effective and stopped much of the leakage. However, some of the other joints exhibited a small amount of leakage which was not considered a problem at the time. Continued water leakage through monolith joint $2 / 4$ was reported. Rather than attempting to repair the fractured drain pipe which allows the inflow of water, it was decided to contain the effluent and pipe it to a dry well. This solution was much more economical than proposed leakage repairs and provided a functional floor drain system. The rate of movement between lock monolith joints having the largest deflections indicated that the 1978 foundation grouting had been effective. Continued leakage into drainage gallery from the erection bay/SNOF joint was reported. The cyclic motion of lock monolith 4 bearing on the SNOF and erection bay monoliths probably caused a bond failure between the chemical grout and the walls of the drill hole allowing leakage past the remedial waterstop. More direct mechanical methods of sealing the drainage gallery joints are necessary to curtail the inflow of water. Leakage of the powerhouse bay joints was greatly reduced or eliminated by installing cast-in-place chemical grout waterstops. Some minor leakage through the erection bay/bay 1 joint was reported at elevation $542 \mathrm{ft}$. Project personnel have sawed trenches in various powerhouse galleries to channel minor joint leakage to the drains. This is an ongoing, low-priority maintenance work item for the project.

\section{New Cumberland Locks}

165. The New Cumberland Locks are located on the Ohio River at Stratton, Ohio. The navigation lock chambers are both $110 \mathrm{ft}$ wide with lengths of 600 and 1,200 ft (Figure 70). The lift height is $21 \mathrm{ft}$. Construction was completed in 1959.

166. Leakage through some of the monolith joints in the middle lock wall was reported in 1969. The leakage was attributed to normal opening of the joint due to initial concrete shrinkage and contraction of the concrete during cold weather. This project did not utilize waterstops at the joints to prevent such leakage.

167. Joints in the middle wall were repaired in FY 77 by drilling a vertical 6-in.-diameter hole along each monolith joint to the required depth 

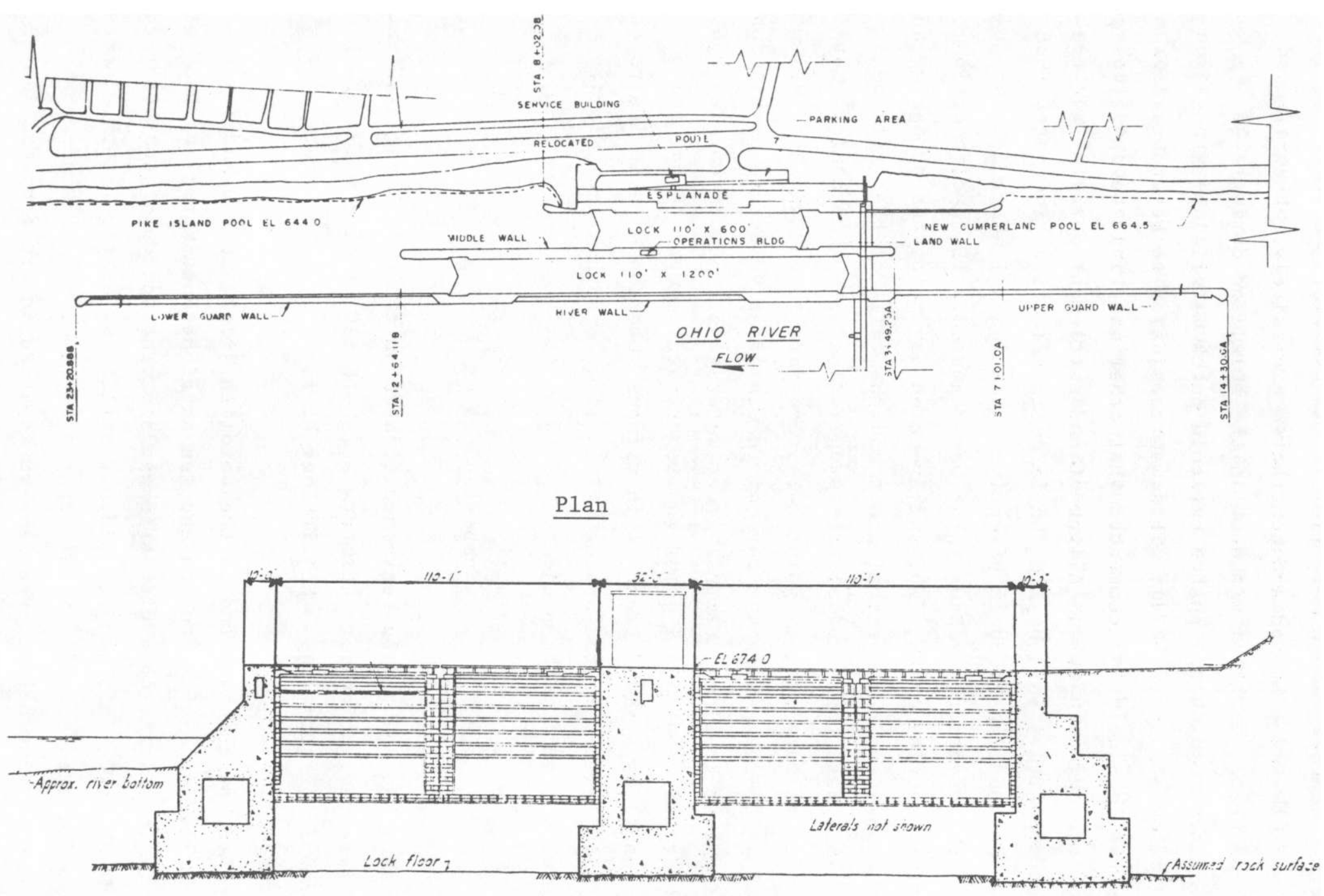

Figure 70. New Cumberland Locks 
and then filling the drill hole with a hot-pour bituminous material (Pennsylvania Department of Transportation asphalt sealer J-1). It was reported in 1981 that the repair appeared to be performing satisfactorily. However, the sealer was very soft and expanded and contracted excessively. When the temperature was cool, the filler was down in the hole, and during a hot period, the filler expanded and pushed out cold patch material previously placed to fill the hole (Figure 71). This was considered to be undesirable by District personnel and it was recommended that other materials be investigated for sealing joints in the future. Alignment and settlement data for the middle wall is shown in Figure 72.

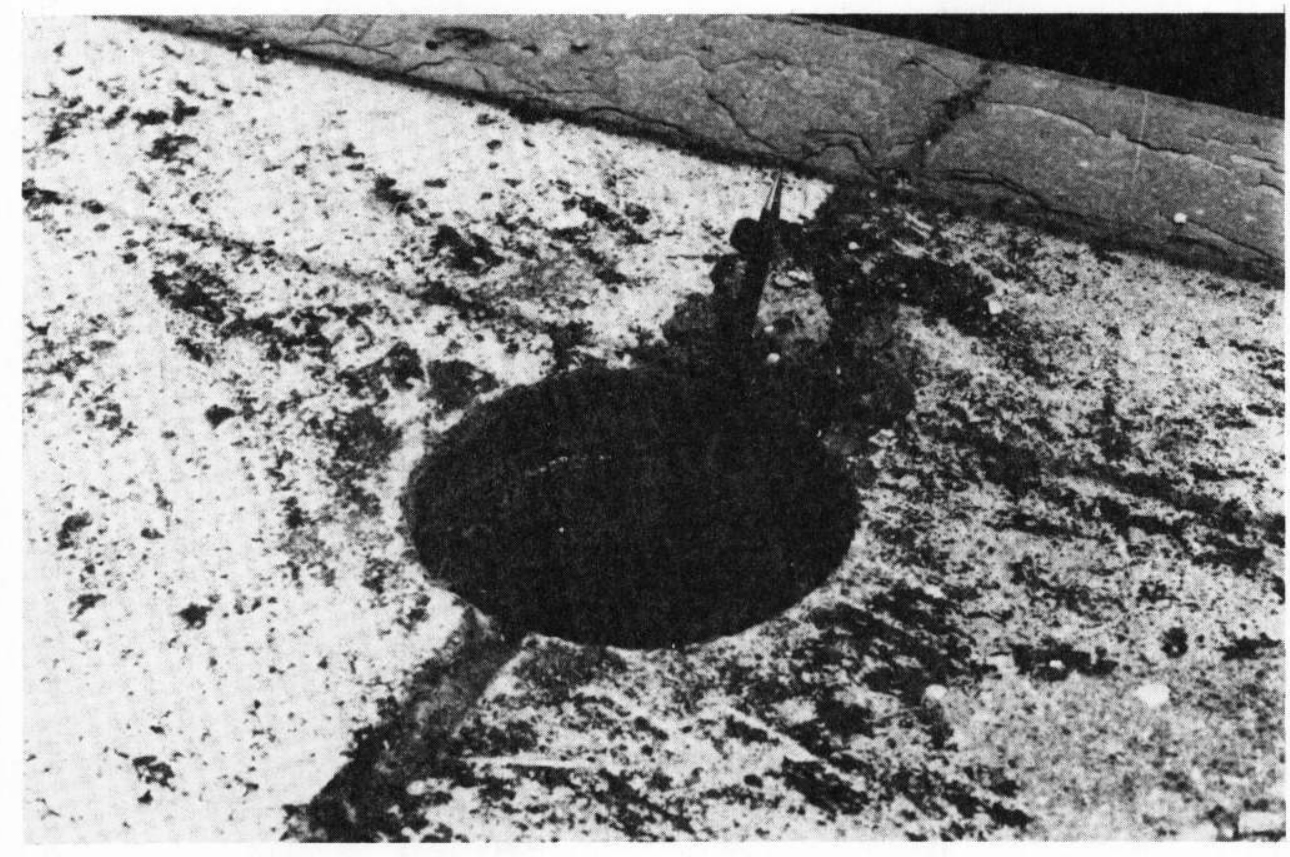

Figure 71. Monolith joint repair, New Cumberland Locks, August 1981

\section{McNary Lock}

168. McNary Lock is located on the Columbia River, near McNary, Oregon. The navigation lock has a clear width and length of 86 and $675 \mathrm{ft}$, respectively, with a maximum lift of $92 \mathrm{ft}$ (Figure 73). The lock was put into operation in 1952.

169. During the initial periodic inspection in 1967, it was reported that the project had experienced problems with waterstops in construction 


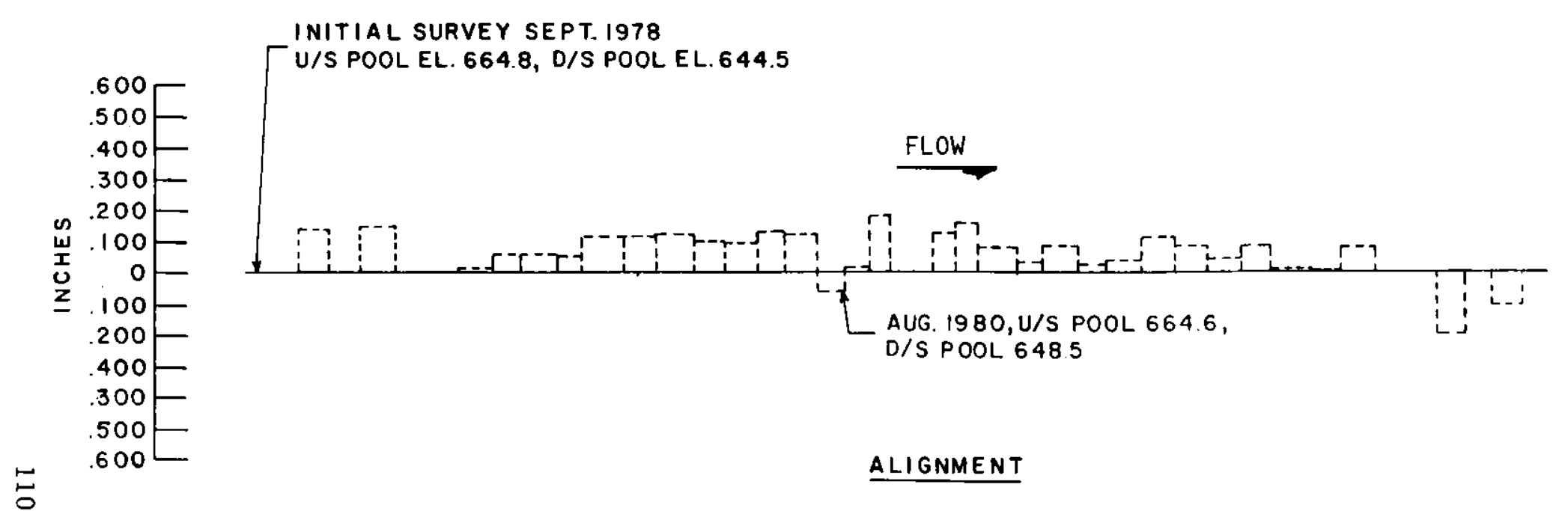

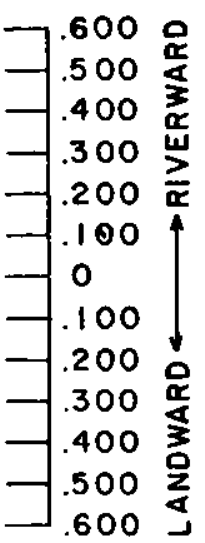
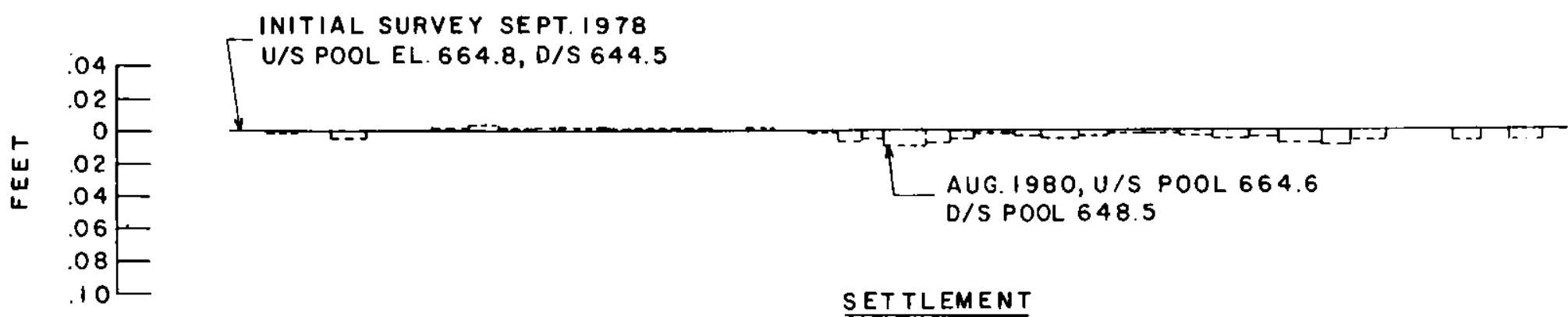

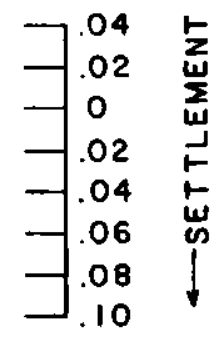

Figure 72. Alignment and settlement of middle wal1, New Cumberland Locks 


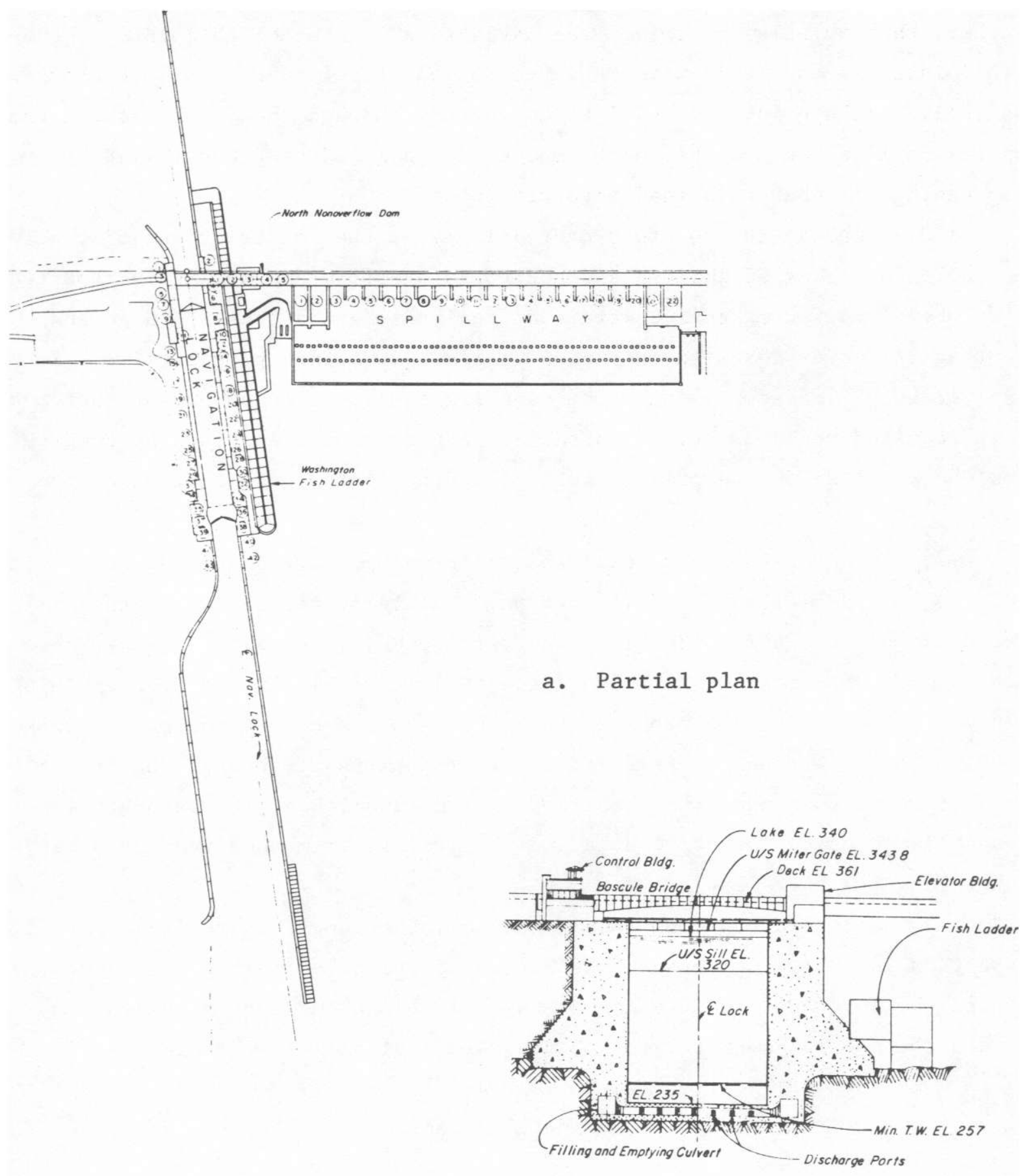

b. Typical lock section

Figure 73. McNary Lock and Dam 
joints since the beginning of operation. Whether the contractors inadvertently omitted the waterstops or punctured them during installation could not be determined. In any case, water leakage was significant during cold weather, particularly in some of the navigation lock monolith joints. Monolith joints $4 / 6$ and $36 / 38$ were reported to leak freely when the lock chamber was full. Leakage into the sill block gallery through the joint between the upstream sill block and the north nonoverflow dam had been controlled by compressing a rubber bulb seal into the joint.

170. Leakage in the cross-over gallery at the construction joint between the lock's upstream sill block and the north overflow dam was again reported in October 1974. Progressive waterstop fallures in the lock drainage and grouting galleries resulted in excessive leakage at the upstream sill. In 1978, leakage flooded the pump room damaging equipment to an extent that much of it required replacement. A surface-type gasket held in place by compressed steel bars bolted to the gallery walls (Figure 74) was used to control the leakage.

171. Some of the lock monolith joints were reported leaking in 1979 due to failed or partially failed waterstops. The large settlement in the fill placed against the north monoliths was attributed, in part, to leakage through the landside monolith joints. Since the fill is rock fill and free draining, this was not considered a problem other than appearance. Although the leaking monolith joints were not considered to be of serious structural concern at the time, it was recommended that, as funds become available, the waterstops be reestablished using the drill hole and chemical grout method used at other locks along the Snake River.

172. Joint leakage remained essentially unchanged at the next periodic inspection in 1983. A surface-type waterstop installed in the cross-over gallery at the joint between the downstream sill block and lock monolith 38 (Figure 75) continues to provide an adequate seal against leakage.

\section{Pine Flat Dam}

173. Pine Flat Dam is located on the Kings River in the central Sierra Nevada mountains approximately 30 miles east of Fresno, Calif. The concrete gravity dam (Figure 76), $429 \mathrm{ft}$ high and containing 37 monoliths with a total concrete volume of $2,150,000 \mathrm{cu}$ yd, was completed in 1954. Each monolith 


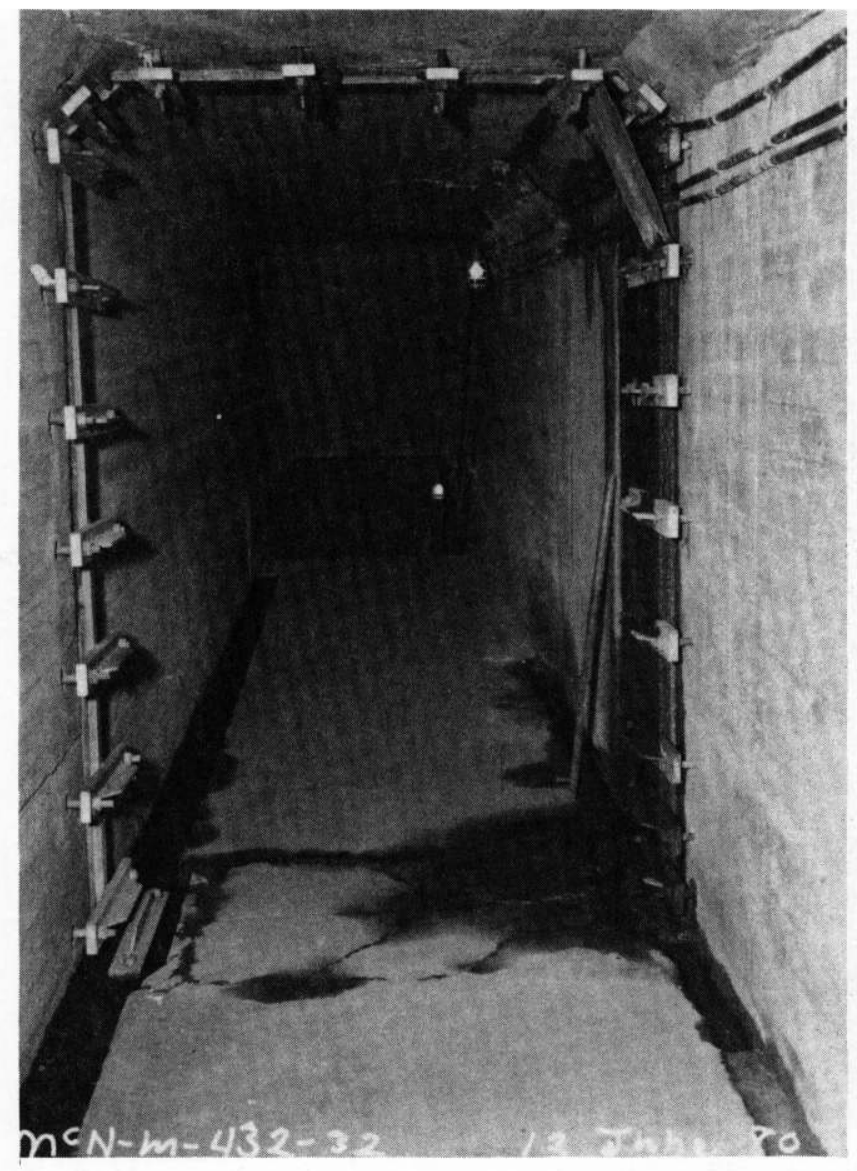

a. Joint $4 / 6$ in the drainage gallery

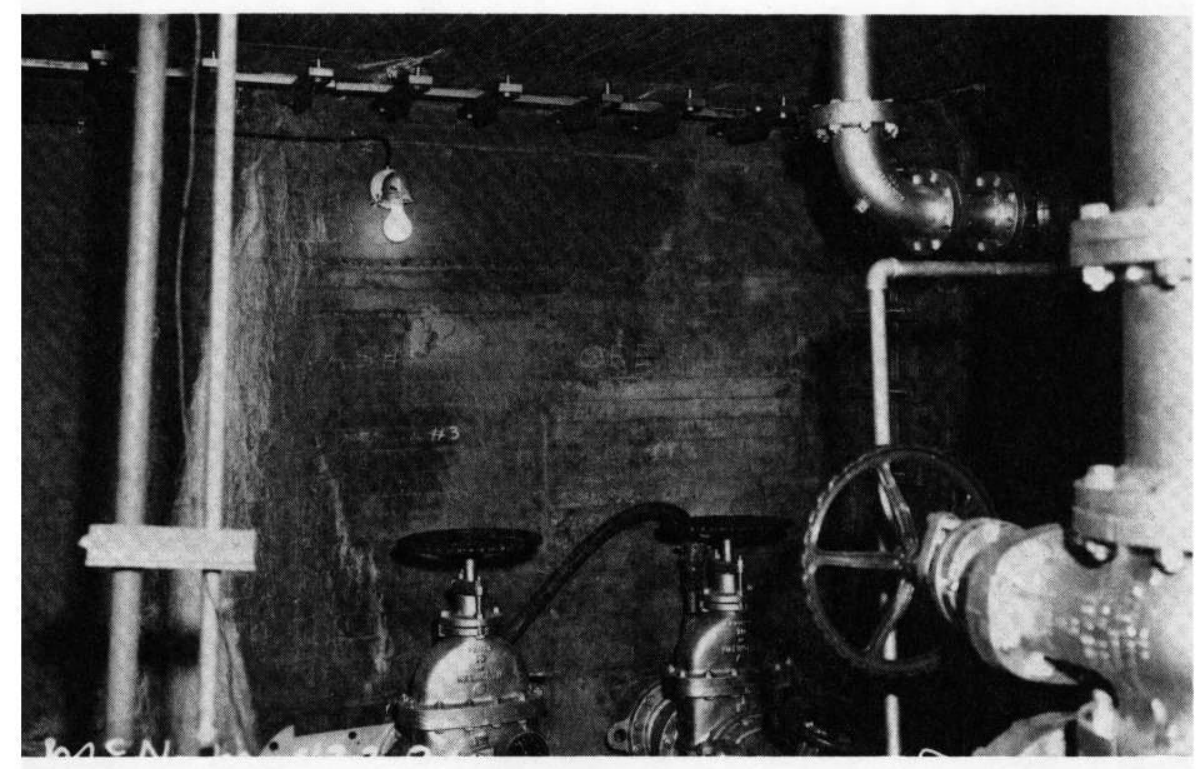

b. Joint $6 / 8$ in the lower pump room

Figure 74. Surface-type waterstops, McNary Lock, 1980 


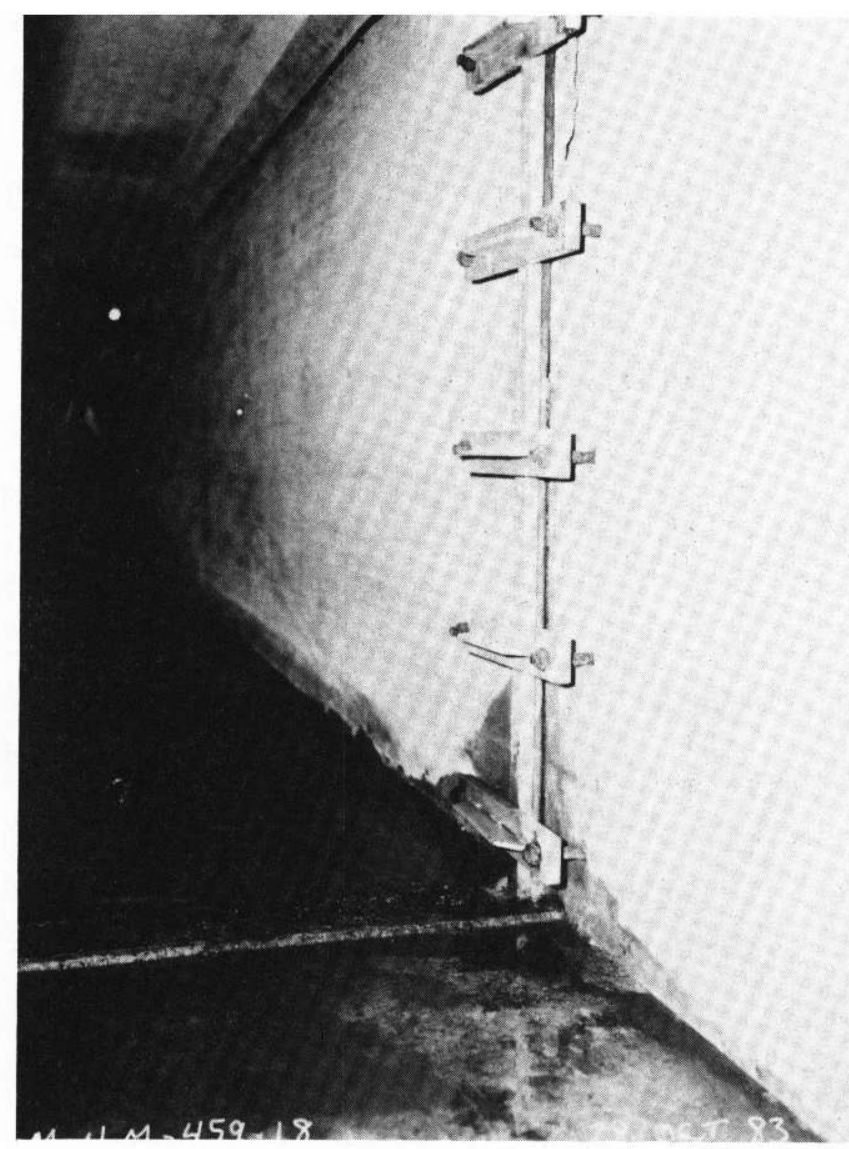

Figure 75. Surface-type waterstop, McNary Lock, 1983

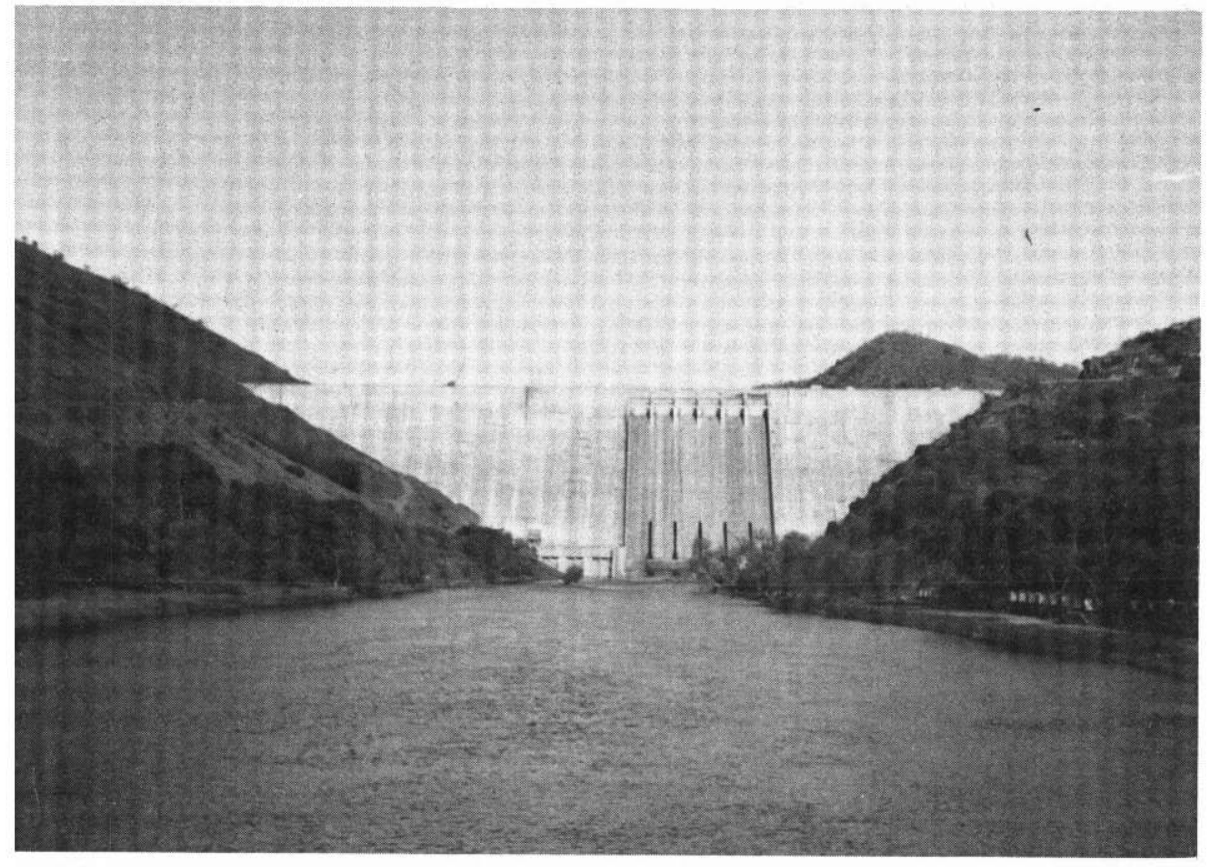

Figure 76. Pine Flat Dam 
joint has two continuous $20-0 z$ copper waterstops, 15 in. wide, which extend the full height of the dam.

174. The dam has experienced progressive leakage between joints since the early 1970's, apparently as a result of waterstop failures. Leakage through monolith joint $29 / 30$ on the left abutment and joint $8 / 9$ on the right abutment was of particular concern. Although there are many theories, the actual reason(s) for the failure of these waterstops is/are not certain.

175. In 1979 , a contract totaling approximately $\$ 100,000$ was awarded to establish remedial waterstops at three monoliths joints $(28 / 29,29 / 30$, and 30/31) by drilling nearly vertical holes along the joint (Figures 77 and 78) and filling the holes with an elastic chemical grout. Initially, diamond plug bits were used for drilling; however, these tools wandered off the joint, necessitating the backfilling and abandonment of two partial depth attempts. Down-the-hole hammer tools were then used to successfully drill 6-1/2-in.diameter holes to depths of at least $5 \mathrm{ft}$ into bedrock. Each hole was located between the two existing copper waterstops at a distance between 10 and $12 \mathrm{ft}$ from the upstream face of the dam. Hole depths ranged from 189 to $257 \mathrm{ft}$.

176. The three drill holes were grouted 18-30 December 1979, using an elastic chemical grout. At the time of grouting, water levels in the drill holes ranged from 157 to $200 \mathrm{ft}$ below the roadway surface on top of the dam. In comparison, the reservoir pool level was at elevation $860 \mathrm{ft}$, approximately $110 \mathrm{ft}$ below the top of the dam. Ambient and water temperatures during grouting operations ranged from $55^{\circ}$ to $75^{\circ} \mathrm{F}$ and $38^{\circ}$ to $54^{\circ} \mathrm{F}$, respectively.

177. The chemical grout consisted of acrylamide powder (AV-100), catalyst or activator (DMAPN), initiator (AP), diatomaceous earth (Celite), and water. Typical mixture proportions were as follows:

$\begin{array}{lc}\text { Acrylamide powder, } 1 \mathrm{~b} & 170 \\ \text { Celite, lb } & 150 \\ \text { AP, lb } & 8 \\ \text { DMAPN, gal } & 1.5 \\ \text { Water, gal } & 60\end{array}$

The grout was field mixed on top of the dam in two separate solutions. One solution contained the acrylamide powder and mineral filler dissolved in water. The catalyst and initiator were similarly diluted in a separate water solution. Each solution was pumped through individual hoses to a mixing chamber suspended at the bottom of the hole where they were force mixed into one solution and 


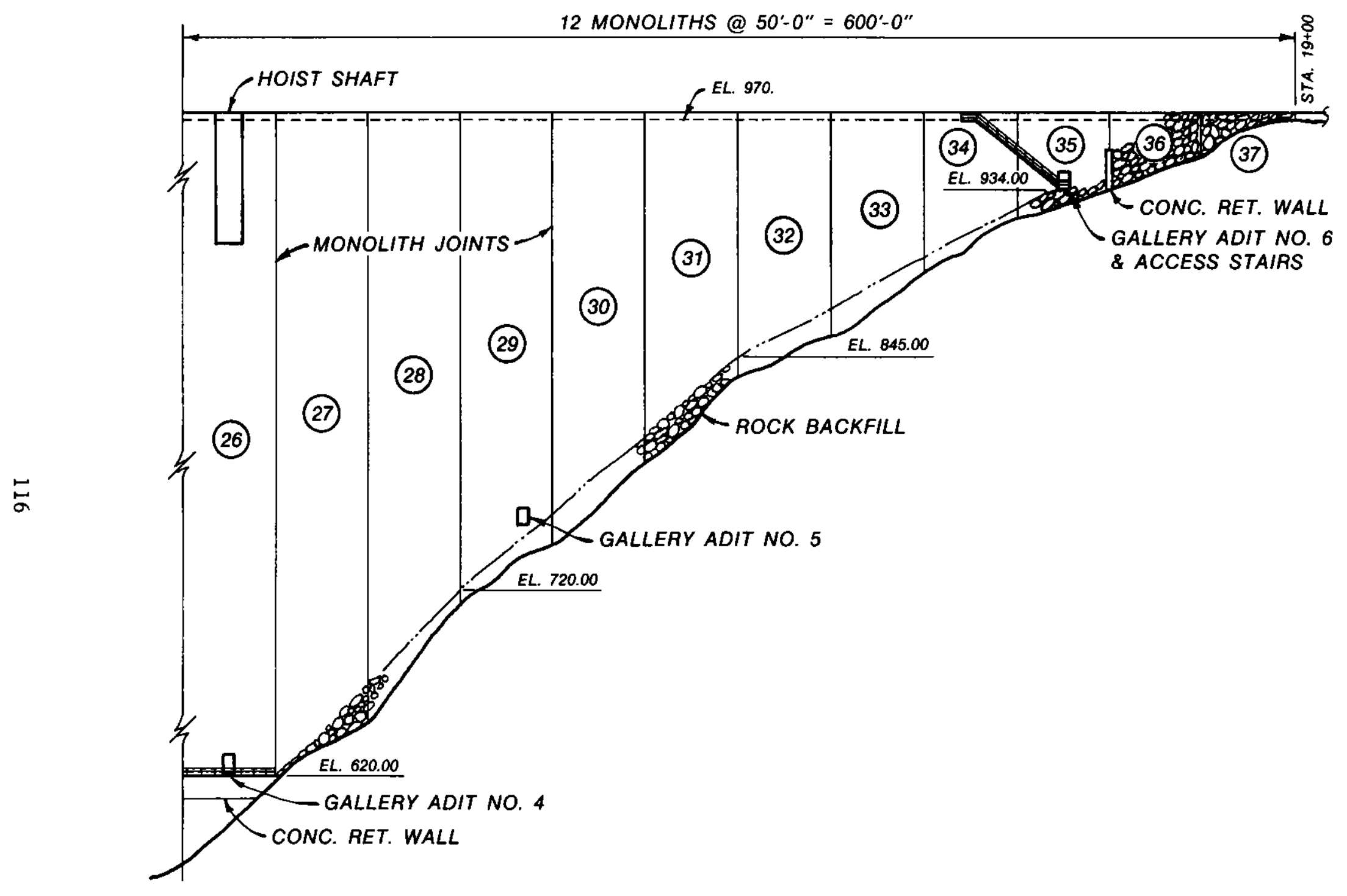

Figure 77. Downstream elevation (partial), Pine Flat Dam 


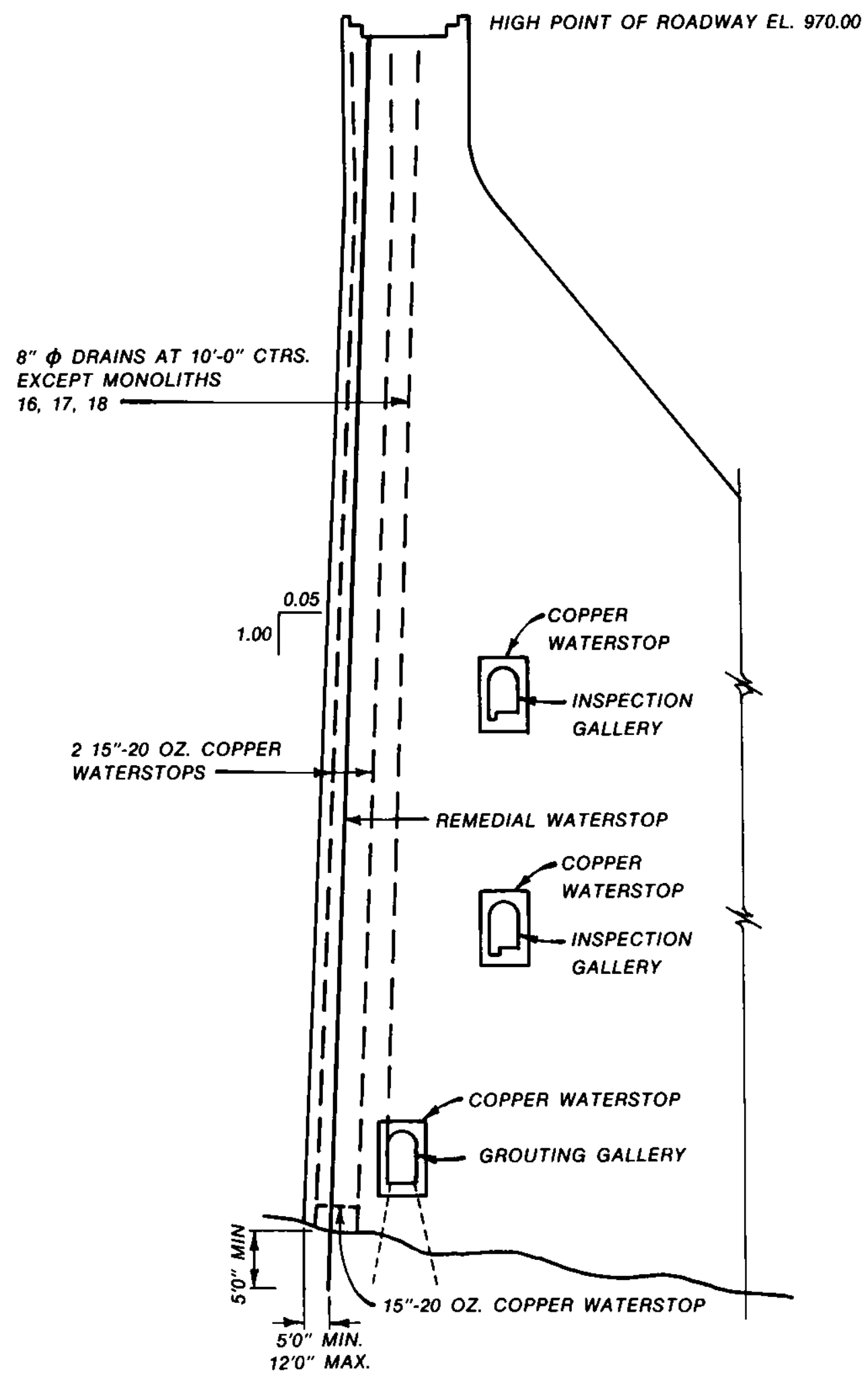

Figure 78. Section through nonoverflow portion of Pine Flat Dam 
discharged into the drill hole. Gel times ranged from $22 \mathrm{sec}$ to approximately $2 \mathrm{~min}$. As the grout level rose in the hole and began to ge1, the hoses were retracted, trying to always keep the mixing chamber below the grout-water interface but above the gelled grout. In some cases the mixing chamber was retracted at an excessive rate and was positioned above the grout-water interface. As a result, sections of the holes were incompletely grouted. When this was discovered, grouting was stopped and the grout was cleaned out of the hole to a depth thought to be below the trouble zone. Generally, the hole was then regrouted using a grout mixture with a faster gel time. This was repeated until the hole was completely filled.

178. Initially, the repair appeared to be successful since leakage through the three joints was significantly reduced. However, when the reservoir pool reached elevation $890 \mathrm{ft}$ on 14 January 1980, leakage through the joints returned to its previous high levels. Project personnel have been monitoring flows through the three joints since 1979. Leakage through the joints is intercepted by joint drains approximately $8 \mathrm{ft}$ downstream of each remedial waterstop. Piping has been installed where these drains intersect the gallery to route discharges to the downstream face of the dam. Flow rates are determined at the discharge by measuring the time required to fill a container of known volume. Historically, flows from these three joints are directly related to reservoir pool levels. Full pool levels normally occur in June or July with flows of approximately $800 \mathrm{gal} / \mathrm{min}$ associated with a pool elevation of $950 \mathrm{ft}$.

179. In August 1983, a Request for Technical Proposal (Step One) was advertised by the Sacramento District to solicit concepts for design of a repair to reduce seepage through existing monolith joints $(28 / 29,29 / 30,30 / 31)$ at Pine Flat Dam. The repair method had to meet the following requirements:

a. Reduce water seepage through monolith joints a minimum of 75 percent of total historical (July 1979-July 1983) flows from vertical drains in monoliths 29 and 30 for a period of 1 year.

b. Permit joints to accommodate movement between monoliths. The top of the dam deflects up to 1 in. with a differential deflection between monoliths up to $1 / 4 \mathrm{in}$.

c. Protect water sources (lake and downstream) from contamination.

d. Withstand water heads up to $200 \mathrm{ft}$.

e. Repair will not seriously affect the appearance of the dam.

$\underline{f}$. Shall not be corrosive or detrimental to adjacent concrete. 
Based on reviews by a technical evaluation team, two proposals were ultimately deemed acceptable. The contractors who made these proposals were then given the opportunity to participate in Step Two of the proposal process, Invitation for Bids, which was advertised in November 1984. A contract in the amount of $\$ 90,000$ was awarded to GELCO Grouting Service, Salem, Oregon, in December 1984.

180. During the proposal review process, an investigation was initiated to locate zones of leakage in the monolith joints to be repaired. Fluorescent dye tests of each joint were conducted during March 1984 by the US Army Engineer Waterways Experiment Station. Fluorescent dyes selectively absorb light in the visible range of the spectrum and then instantly emit light of a longer wavelength than the light absorbed. Most common fluorescent tracers are compounds which absorb green light and emit red fluorescent light, such as the Rhodamine $B$ used in this investigation. These dyes are sufficiently stable to permit tests up to several weeks and are detectable instrumentally in concentrations as low as one part per billion.

181. The dye injection system was set up on top of the dam near its upstream face. A separate investigation of each of the suspected monolith joints was possible because of the 50 -ft horizontal distance between the joints, the design of the diffuser, and the small amounts of dye injected at depths with little water movement. Three Rhodamine B tablets were dissolved in about $5 \mathrm{gal}$ of water. The dye solution was then injected at depth intervals of about $10 \mathrm{ft}$, with the maximum depth being at or near the sediment deposits along the upstream face of the dam. For 1 min, the dye solution was pumped into the reservoir. The next minute was used to flush the system with water stored in a separate bucket. The flushing removed some of the excess dye along the walls of the injection tubing and aided in the diffusing of the solution. A schematic representation of the dye injection system is shown in Figure 79.

182. The seepage discharge monitoring system (Figure 80 ) was set up in the gallery of the dam to continually analyze the downstream discharge. The seepage discharge for monolith $28 / 29$ was located on the third level in the dam's gallery at an elevation of about $754 \mathrm{ft}$. Seepage from monolith joints 29/30 and 30/31 was discharged simultaneously from a common drain. Shutoff valves on the individual input drains provided isolation of seepage water from each monolith joint for analysis (Figure 81 ). The discharge drain for these 


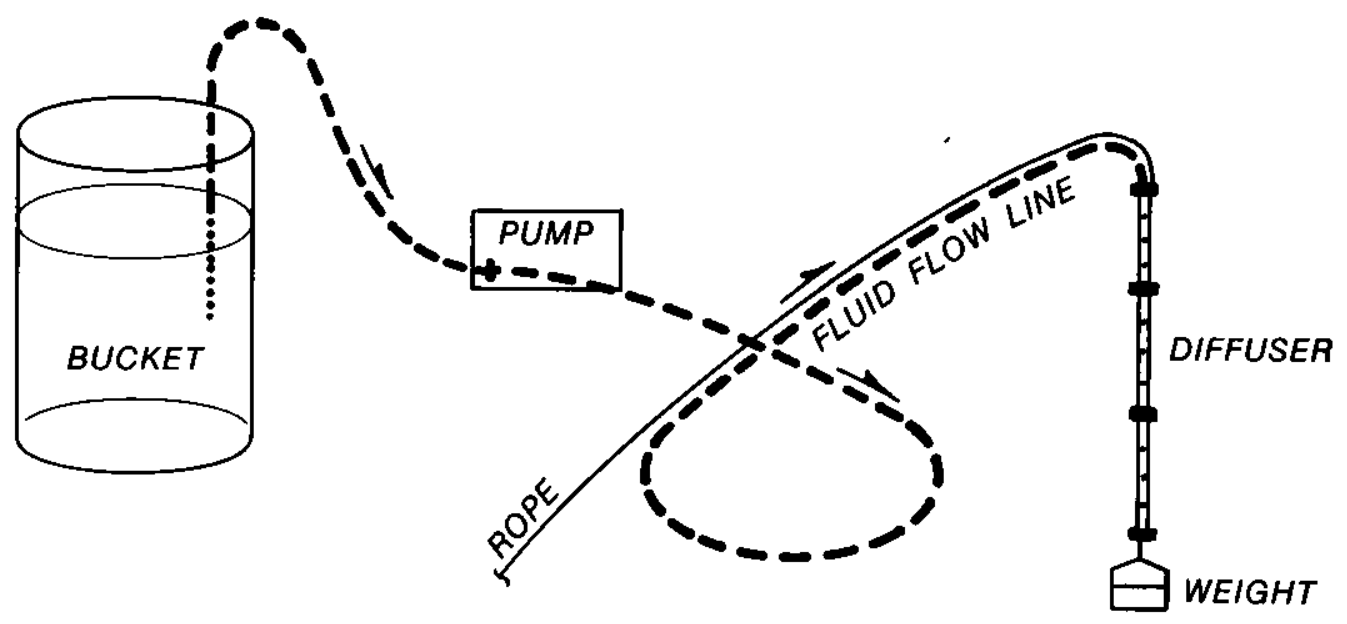

Figure 79. Dye injection system, Pine Flat Dam
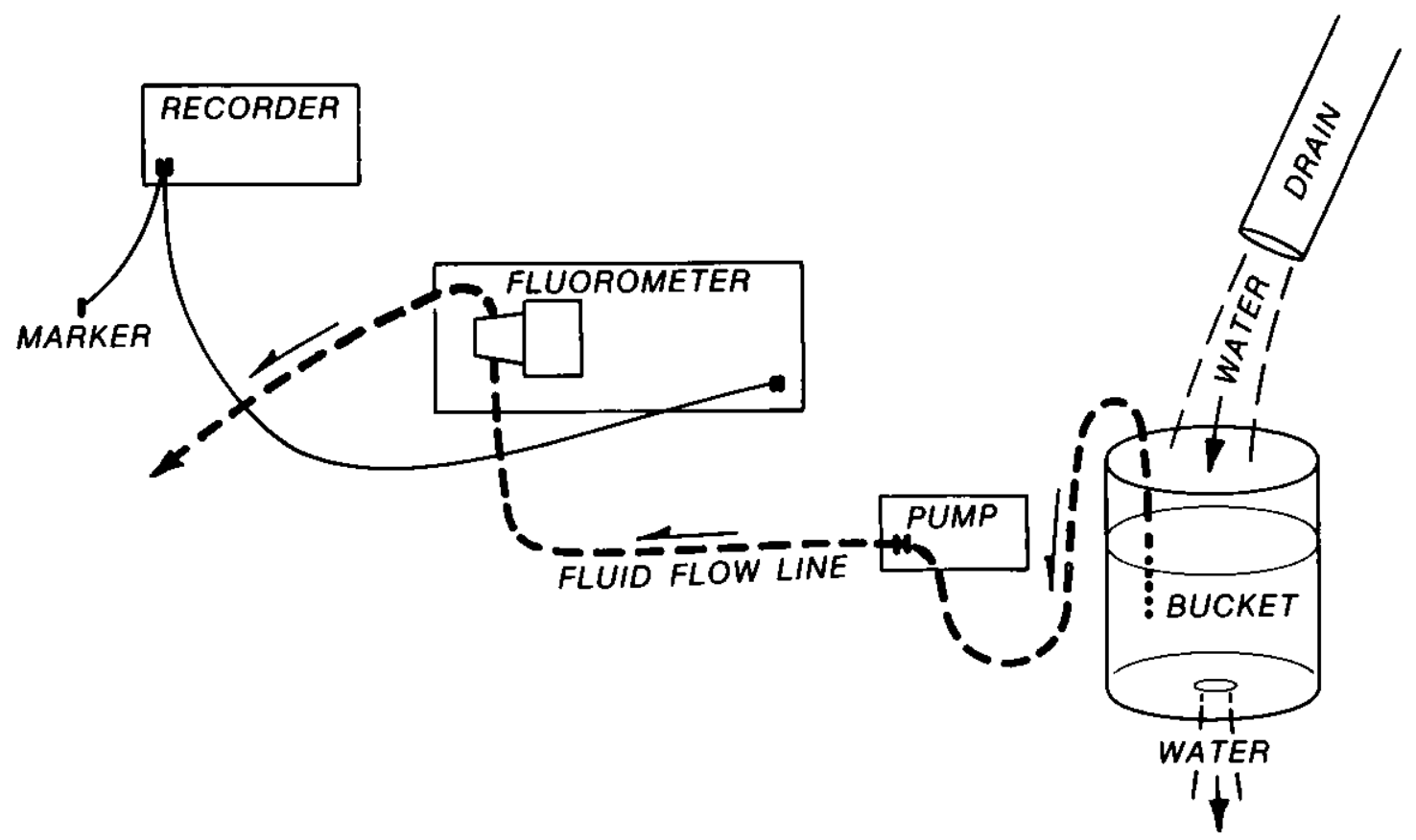

Figure 80. Seepage discharge monitoring system, Pine Flat Dam 


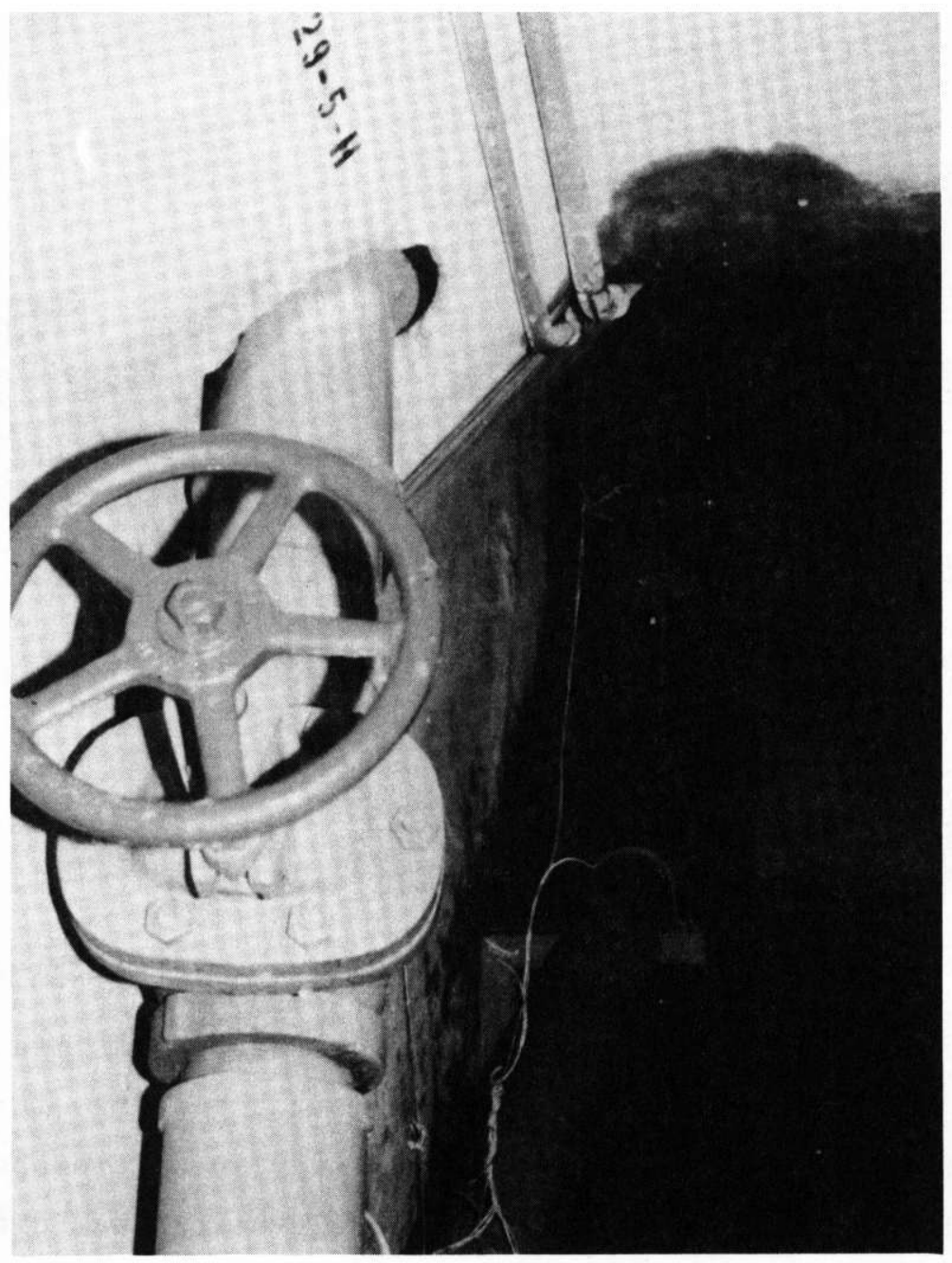

Figure 81. Piping system to control leakage through drains, Pine Flat Dam

monoliths was located on the downstream face of the dam at about the same elevation as the drain for monolith $28 / 29$ (Figure 82 ).

183. Simplicity is a major asset in fluorescent dye testing. However, modification of test equipment for testing at extreme water depths was a major drawback. The hydrostatic pressures involved when the diffuser was lowered into the reservoir necessitated several modifications. The investigation was incomplete in that equipment malfunction and a rigid schedule would not allow results obtained to be verified with additional testing. However, there were elevations along the vertical face of the dam where fluorometric measurements of seepage water indicated that stronger traces of dye were passing through the monolith joints. 


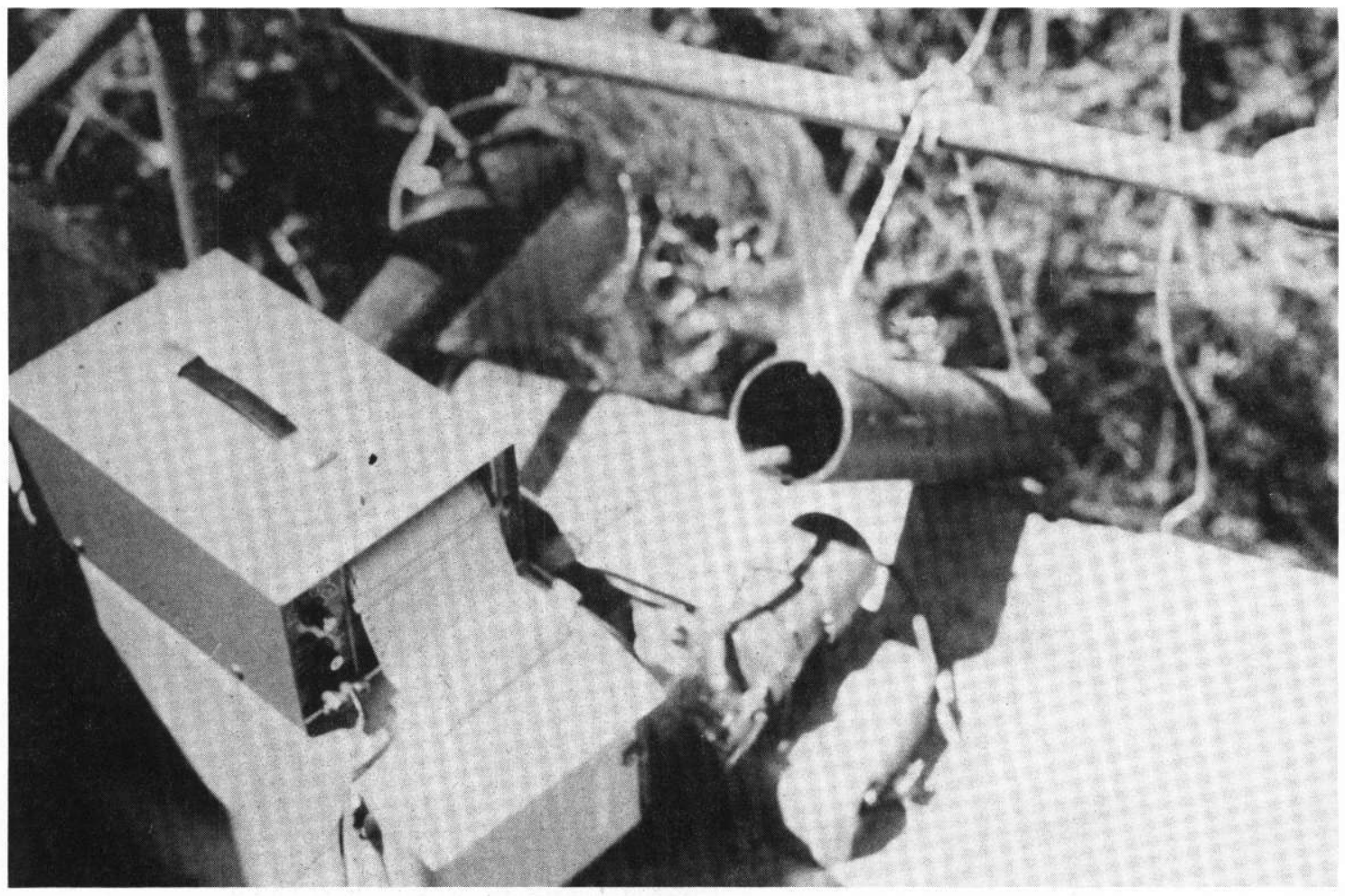

Figure 82. Fluorometric monitoring system, Pine Flat Dam

184. Pertinent data on the fluorometric measurements made at the three monolith joints are shown in Table 1. Fluorometric readings for monolith joint $28 / 29$ indicated the critical area of leakage in waterstops is at elevation $820 \mathrm{ft}$. Accurate delineation of leakage elevations was difficult since the area of dispersion of dye was unknown. An interpolation of fluorometer readings may have affected better definition, but more accurate measurements of volumes of dye injected would have been necessary. The first dye test at this vertical joint indicated increased leakage at higher elevations, but this was found to have been caused by the random addition of dye solution. Measurements at monolith joint 29/30 indicated an increased leakage rate at elevation $860 \mathrm{ft}$. Dye injection began at elevation $810 \mathrm{ft}$, but no fluorometric indications occurred until dye was injected at elevation $850 \mathrm{ft}$. Monolith $30 / 31$ had the lowest leakage rate of the three vertical joints. At elevation $880 \mathrm{ft}$ the fluorometer was reading a 90 parts per billion dye concentration in the leakage water. Dye injection at elevation $890 \mathrm{ft}$ caused a continual change of scale of the fluorometer, possibly indicating no traces of dye present at that elevation. 
Table 1

Fluorometric Data, Pine Flat Dam

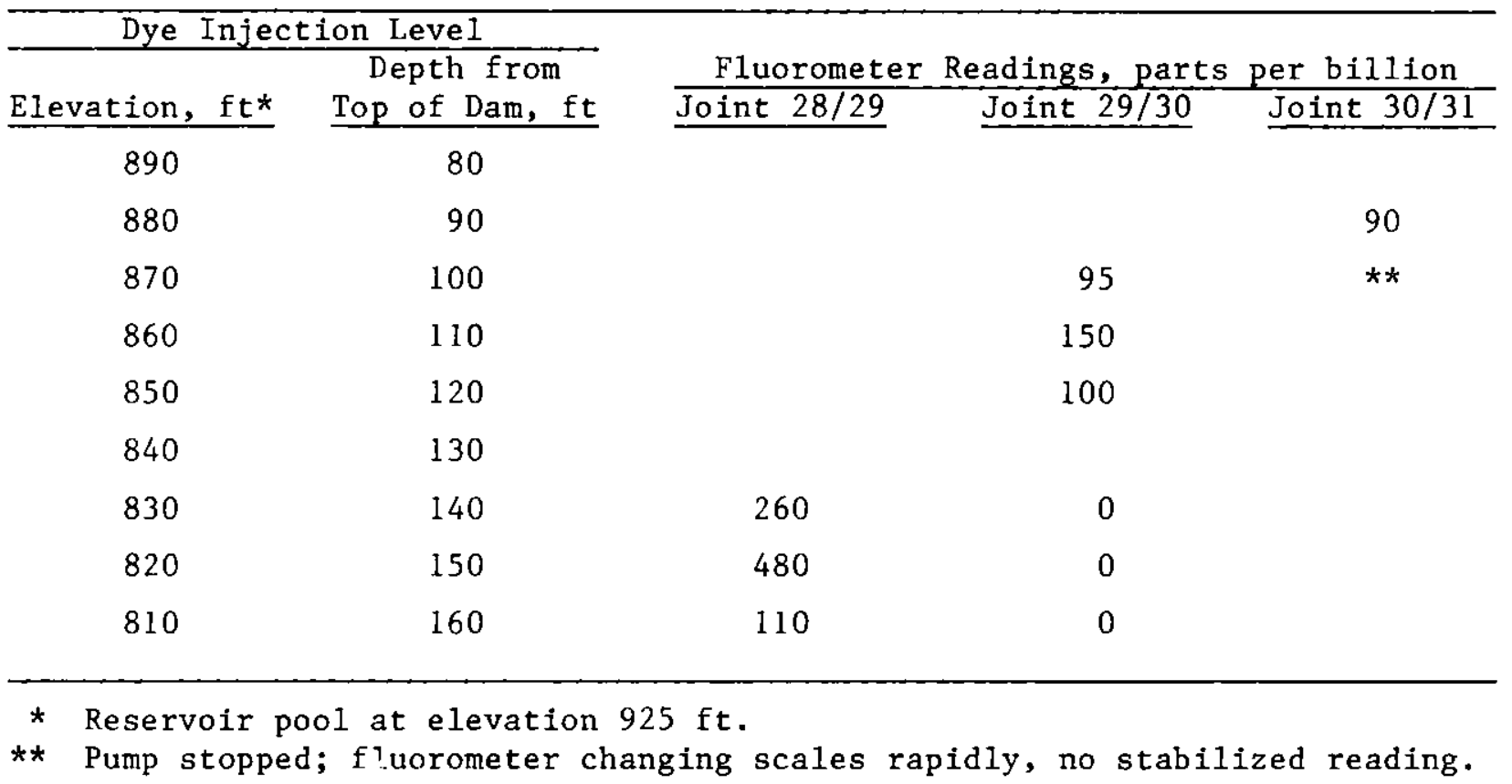

185. Major elements of work required under the GELCO Grouting Service contract were as follows:

a. Complete final design of the repair concept including preparation of construction specifications and drawings.

b. Remove grout from existing remedial waterstop holes and prepare holes for installation of new waterstops.

c. Test and document condition of the existing waterstop holes.

d. Install remedial waterstops.

e. Clean up site to original condition.

f. Submit project report.

186. Work on site at Pine Flat Dam began on 20 February 1985. Initially, a rodding truck was used to remove existing grout from the drill hole at joint 30/31. However, the 1/2-in. rod would not enter the hole beyond $20 \mathrm{ft}$ because of the long radius set in the rod. A water jet truck in conjunction with a 165-cu ft/min, l25-psi air compressor also encountered difficulties in penetrating and breaking up the grout. Also, as progress was made, flushing the broken-up grout from the hole became more and more difficult. Removal of grout from hole $30 / 31$ was completed on 27 February 1985. A rotary drill rig was brought on site 28 February to expedite grout removal (Figure 83). Using 


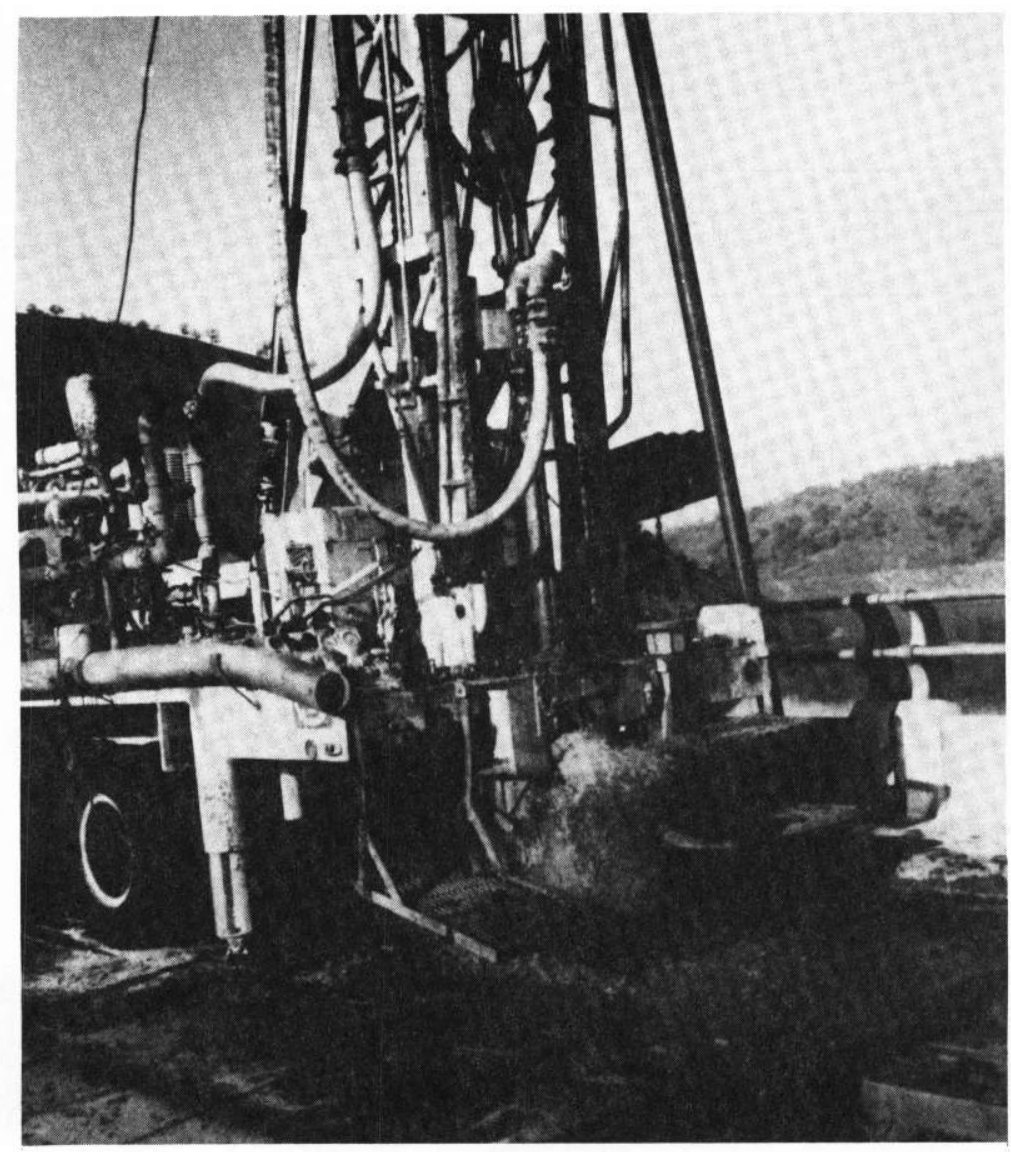

Figure 83. Removal of chemical grout waterstop, Pine Flat Dam

the drill rig with a 6-in.-diameter tri-cone bit, hole $30 / 31$ was proof reamed and the grout removed from the two remaining holes in 2 days. Since the drilling left some grout residue clinging to the walls of the holes, each hole was washed with water pressurized to 1,200 psi. Washing was accomplished using a 65-gal/min spray nozzle with 12 orifices oriented to impact the surface at an angle of 45 degrees above horizontal. Compressed air was also used through the same nozzle. In addition, each hole was flushed with both air and water with the addition of a drilling foam to aid particle suspension and reduce lost circulation.

187. The bottom $10 \mathrm{ft}$ of each hole was subjected to flow and pressure tests (Figure 84) to determine whether the joint was capable of evacuating water at depth. All three holes exhibited high leakage rates with packer settings approximately $10 \mathrm{ft}$ above the bottom of the hole. Therefore, it was decided that tests need not be performed at higher elevations since the bottom 


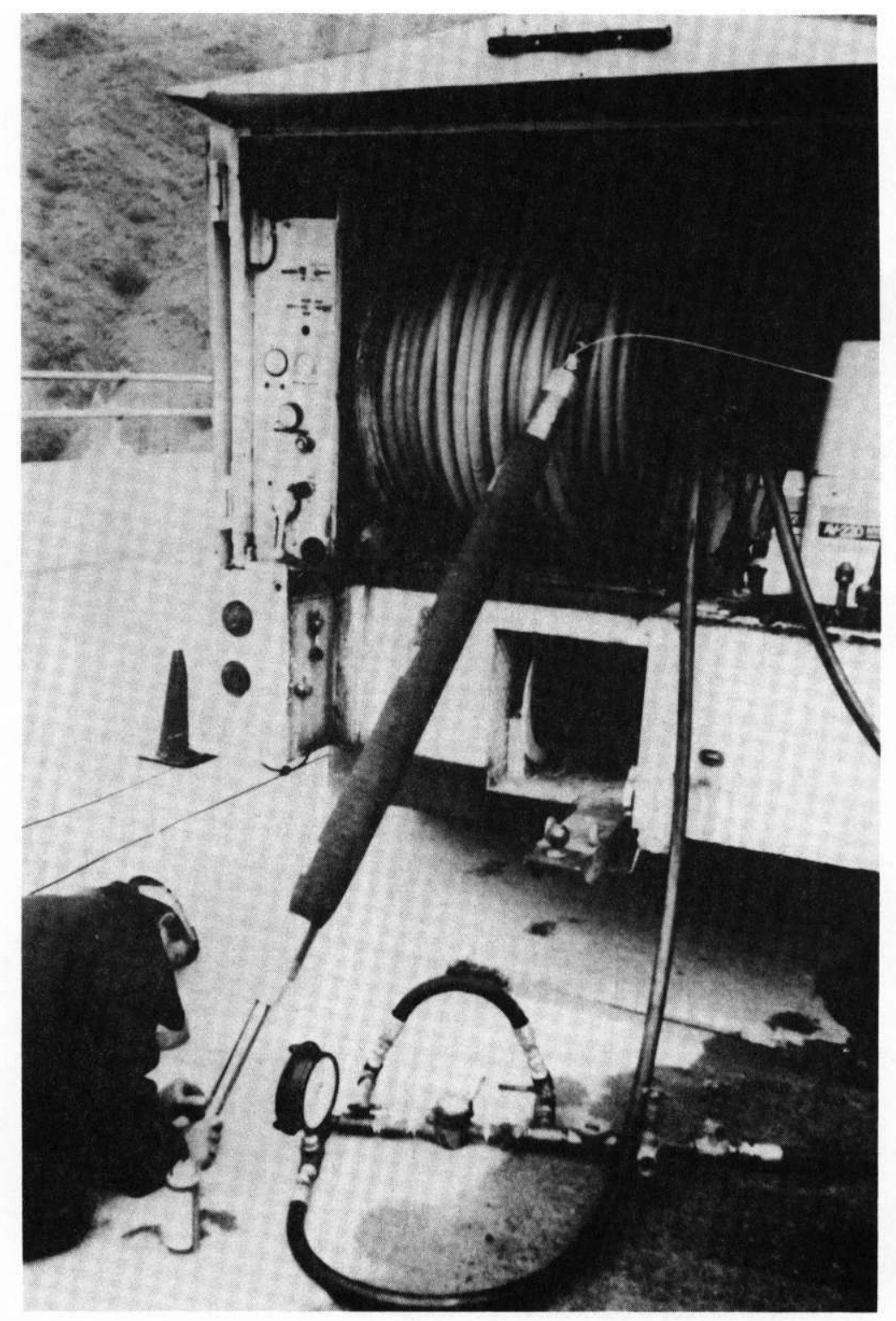

\section{Figure 84. Flow and pressure test apparatus, Pine Flat Dam}

was permeable. Later video inspection indicated the holes had very rough walls in the areas where the packer was set. It is likely that much of the pressure and flow test losses were past the packer. This together with the fact that the packer can easily be circumvented through an open monolith joint make these test results suspect.

188. The interior of each hole was inspected at least once, using a closed circuit television camera system (Figure 85), prior to installation of the remedial waterstops. The purpose of these inspections was to examine the concrete quality, determine orientation and width of the joints, and observe 


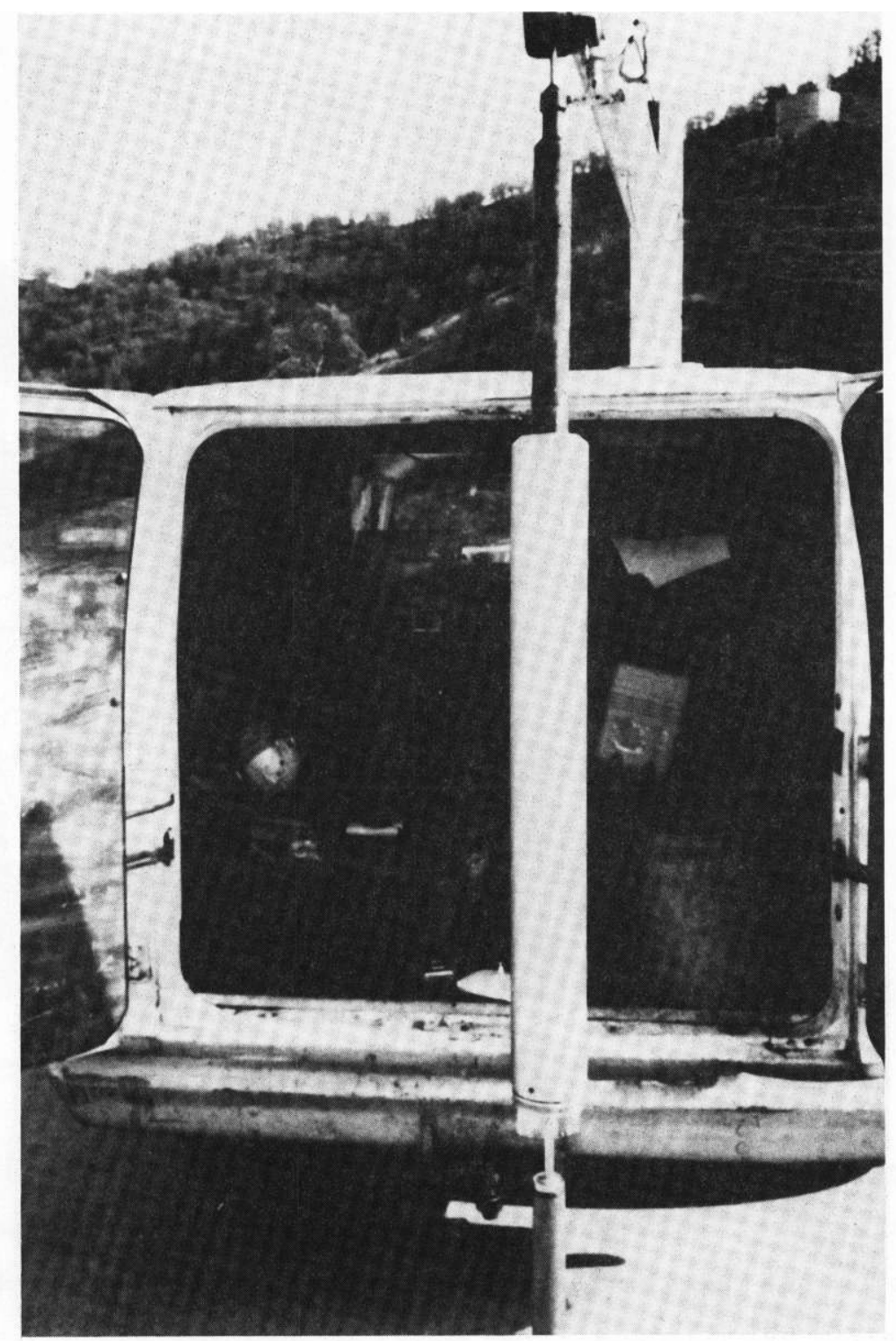

Figure 85. Closed circuit television camera for drill hole inspection, Pine Flat Dam

surface roughness of the holes. All inspections were recorded on videotape and written logs were maintained. These inspections indicated that the walls were quite rough with each hole containing large percentages of its length where there had been losses of cement paste and aggregate. The rounded surfaces of aggregate were very visible in many locations, and in several locations the stones were exposing subrounded points. The loss of material had resulted in several rather large cavities within the concrete. In addition, each hole contained rock pockets which appeared to be areas of honeycombed concrete. Hole 29/30 in particular exhibited this condition on each side of 
the downstream joint intercept. The interface between concrete and foundation rock was not clearly visible in hole 29/30, while in the other two holes this feature was more easily discernible. The condition of the visible portion of the joint varied in each hole. In general, the top portion of each hole had a tight and unbroken joint. However, with increased depth the condition of the joint changed to being more open with rock pockets and spalled corners. Much of the lower portions of the holes exhibited a V-shaped groove at the joint. There were a few locations where there appeared to be more than just two joints. This was probably a condition where a spall had fractured but remained in place. The alignment of the holes on the joints was not perfect; in some cases the two joints were only separated by perhaps $4 \mathrm{in}$. on one side of the hole.

189. Photographs taken from the videotape of the inspection made in hole 28/29 are shown in Figures 86-90. The camera system used to inspect this hole utilized a light head which extended in front of the lens. The dark spot in the center of the photograph is the light head while the two lines leading to it are power cables.

190. In Figure 86, one joint is at the upper right and the other is to the left. The well lighted lower wall is smooth and round, but the upper wall between the two joints is very rough, with a substantial cavity just to the right of center. A cavity surrounded by exposed aggregate is shown in Figure 87. The cavity was estimated to be approximately 4 in. deep, not including the joint which passes through it at the lower right. The joint is not wel1 defined in Figure 88; however, the rough surface of the hole is obvious. Also, it is apparent that some mortar has been lost, leaving portions of the aggregate exposed. Spalling along both joints created a very ragged hole at elevation $752 \mathrm{ft}$ (Figure 89). Also, a piece of the grout used in the previous repair can be seen in the joint at the lower right. At a depth of $240 \mathrm{ft}$ (elevation $730 \mathrm{ft}$ ) the hole was very ragged with the right joint appearing to be $1 / 2$ to 1 in. wide (Figure 90).

191. The repair concept employed by GELCO Grouting Service was based on techniques used for in situ relining of pipelines. A tube-type liner is inserted into the drill hole and bonded to the concrete surfaces of the hole. The liner consists of a thin polyurethane membrane with an underlayer of felt approximately $1 / 4 \mathrm{in.} \mathrm{thick.} \mathrm{Prior} \mathrm{to} \mathrm{installation,} \mathrm{water-activated} \mathrm{resin} \mathrm{is}$ poured into the tube to saturate the felt lining. The tube is then inserted 


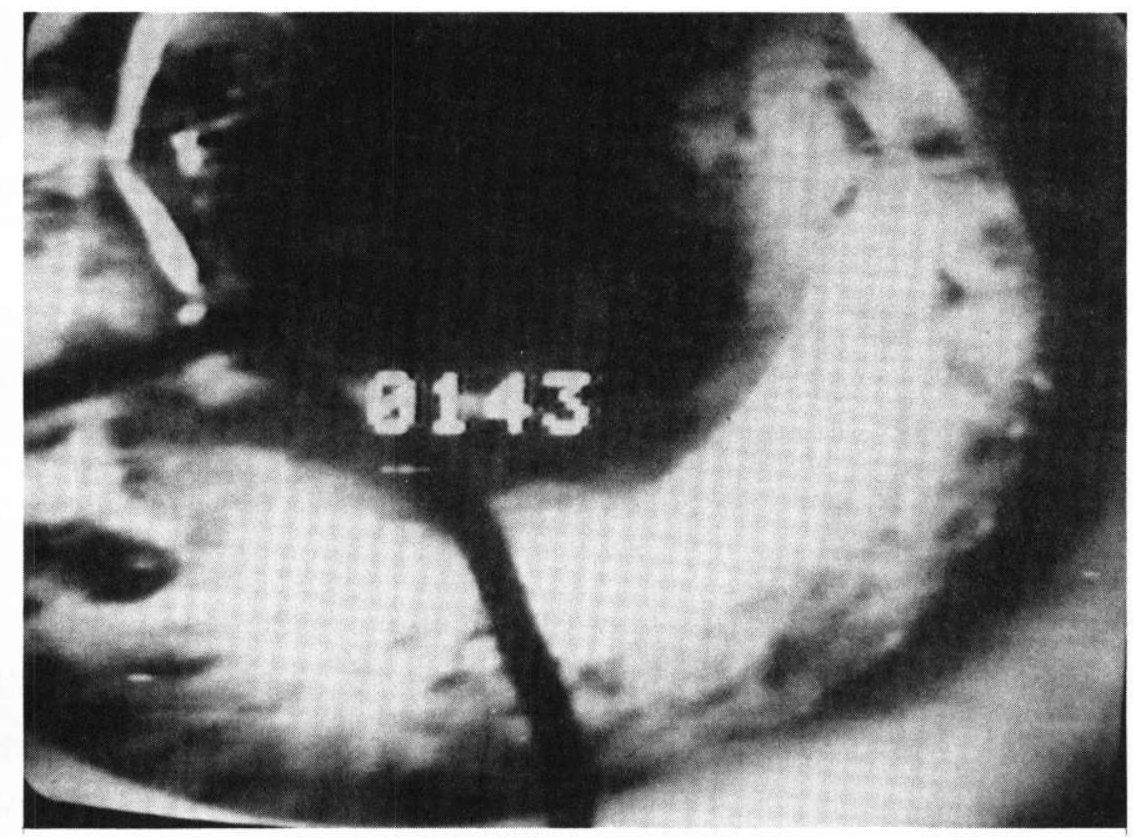

Figure 86. Condition of hole $28 / 29$ at elevation $827 \mathrm{ft}$, Pine Flat Dam

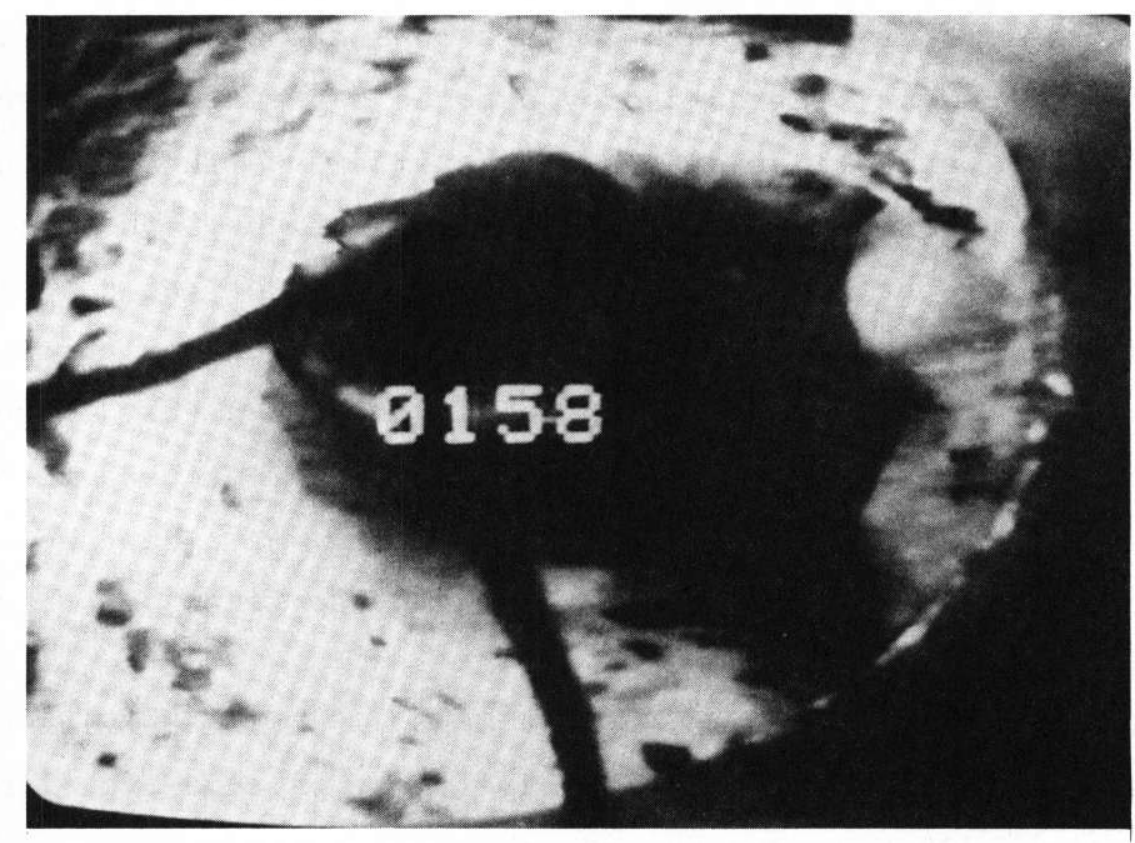

Figure 87. Condition of hole $28 / 29$ at elevation $812 \mathrm{ft}$, Pine Flat Dam 


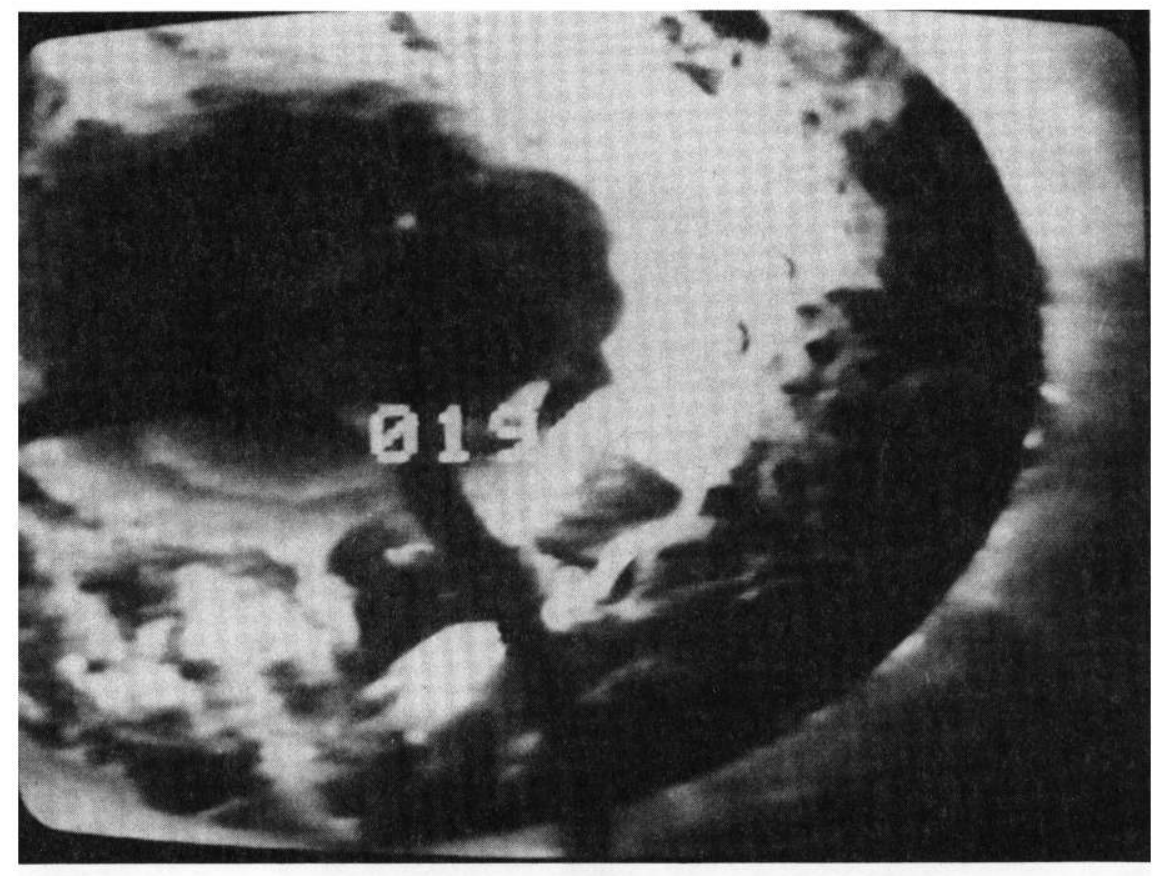

a. Rough surface of the hole

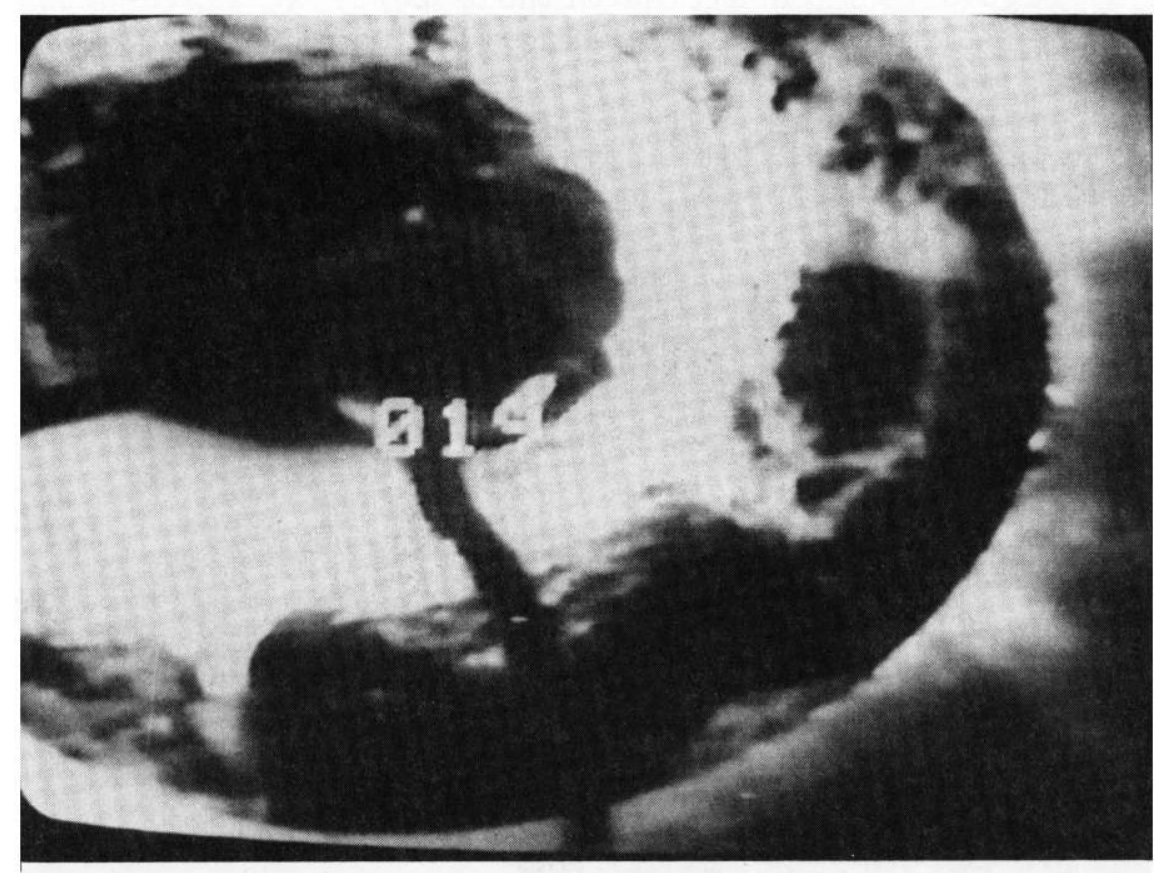

b. Close-up view of stone shown above directly beneath the "01"

Figure 88. Condition of the hole 28/29 at elevation $776 \mathrm{ft}$, Pine Flat Dam 


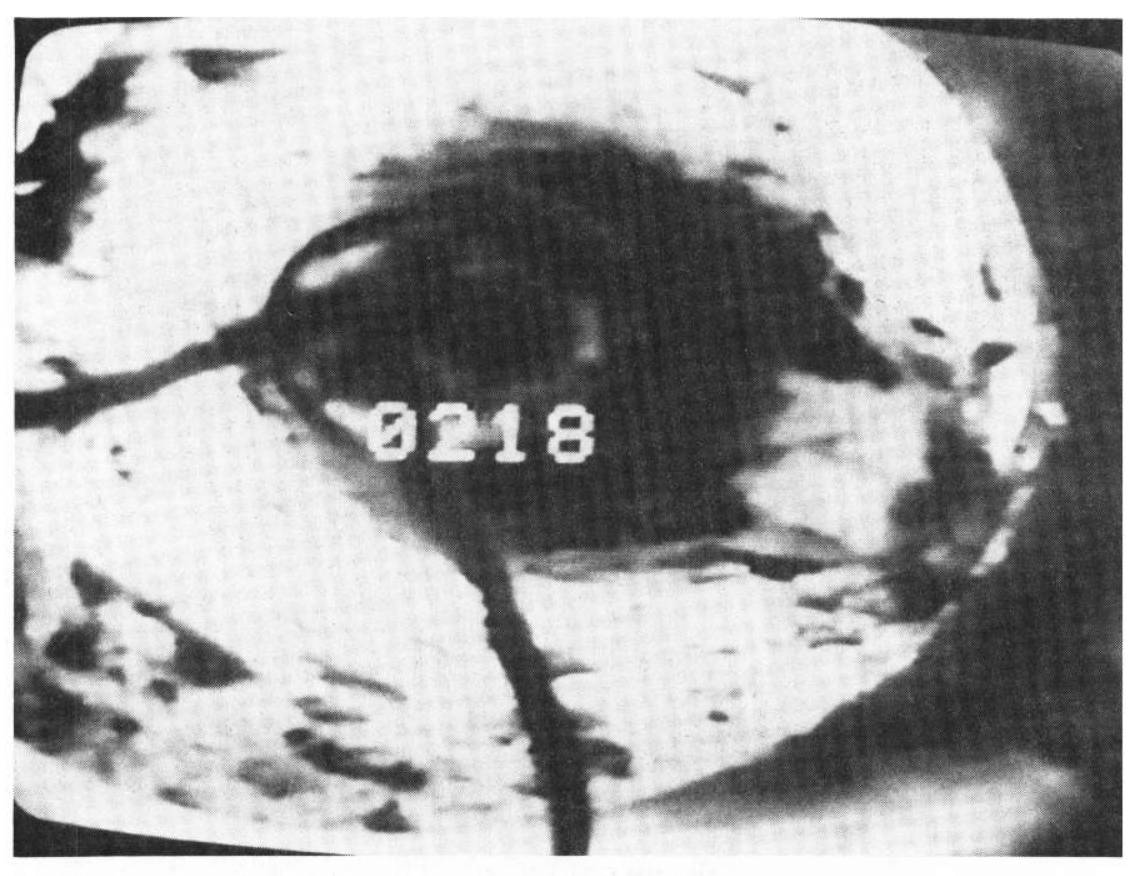

Figure 89. Condition of hole $28 / 29$ at elevation $752 \mathrm{ft}$, Pine Flat Dam

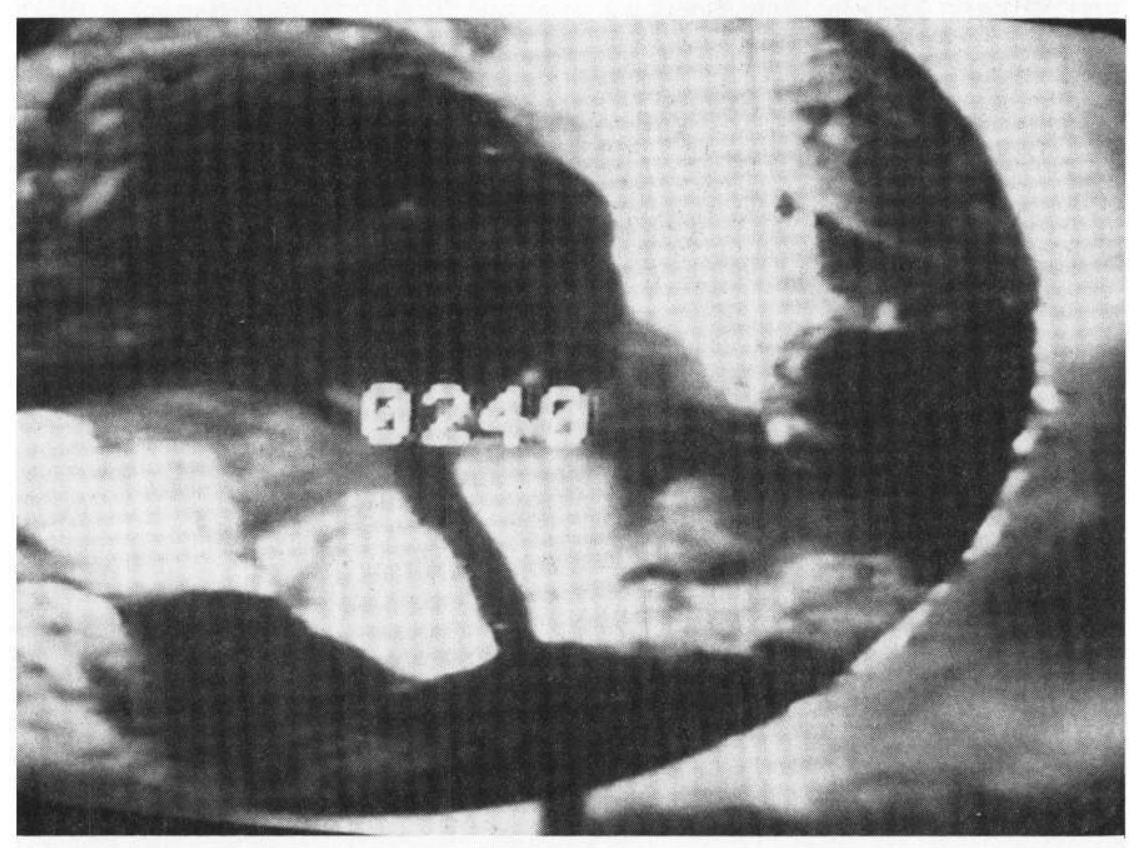

Figure 90. Condition of hole 28/29 at elevation $730 \mathrm{ft}$, Pine Flat Dam 
into the drill hole using air and water pressure to turn the tube inside-out as it is being forced into the hole (Figure 91). Water within the drill hole is forced out of the hole through the joint by the advancing tube. The resinimpregnated felt is isolated from water until the internal pressure turns the tube inside-out and presses the felt against the wet walls of the drill hole. Once wetted, the resin cures into a tough elastic adhesive, creating a bond between the liner and the drill hole. After the resin cures, the interior of the tube is filled with chemical grout to form a strong yet flexible core. The repair process was described in detail by Waring (1985) and is summarized in the following paragraphs.

192. Liner tubes were prefabricated in lengths $5 \mathrm{ft}$ Ionger than the depth of the drill hole into which they were inserted. Since the resin used is water activated, hot air was blown through the tube to ensure that the felt was dry prior to filling the tube with resin (Figure 92). Resin, AV-220, Hydracure was poured into the tube through a funnel attached to one end of the tube (Figure 93). The amount of resin was calculated on the basis of $1 \mathrm{gal} /$ $5 \mathrm{ft}$ of hole rouncied up to the next multiple of $5 \mathrm{gal}$. To ensure that the resin was evenly distributed throughout the length of the tube, the tube was drawn through pinch rollers set to the proper opening (Figures 94 and 95). 193. The apparatus used to insert the liners into the drill holes is shown in Figure 96. Prior to liner installation, a water hose is used to wet the concrete which is above the level of the water in the drill hole. Also, a 6-in.-diameter pipe was placed on top of the hole in order to obtain a representative sample of the remedial waterstop. Photographs of a typical installation are shown in Figures 97-102. Liner installation was accomplished as follows :

a. The liner tube was placed over the roller on top of the installation apparatus and threaded through a slit in the top of the pressure canister (Figure 97).

b. Once the liner tube exited the nozzle of the bottom of the canister, the end of the tube was turned inside-out and attached to the nozzle (Figures 98 and 99).

c. Air pressure within the canister was increased to turn the liner tube inside-out in the drill hole such that the resinimpregnated felt was pressed against the sides of the hole (Figure 100).

d. As insertion progressed, water pressure was substituted for air to force the liner tube into the drill hole. The amount 

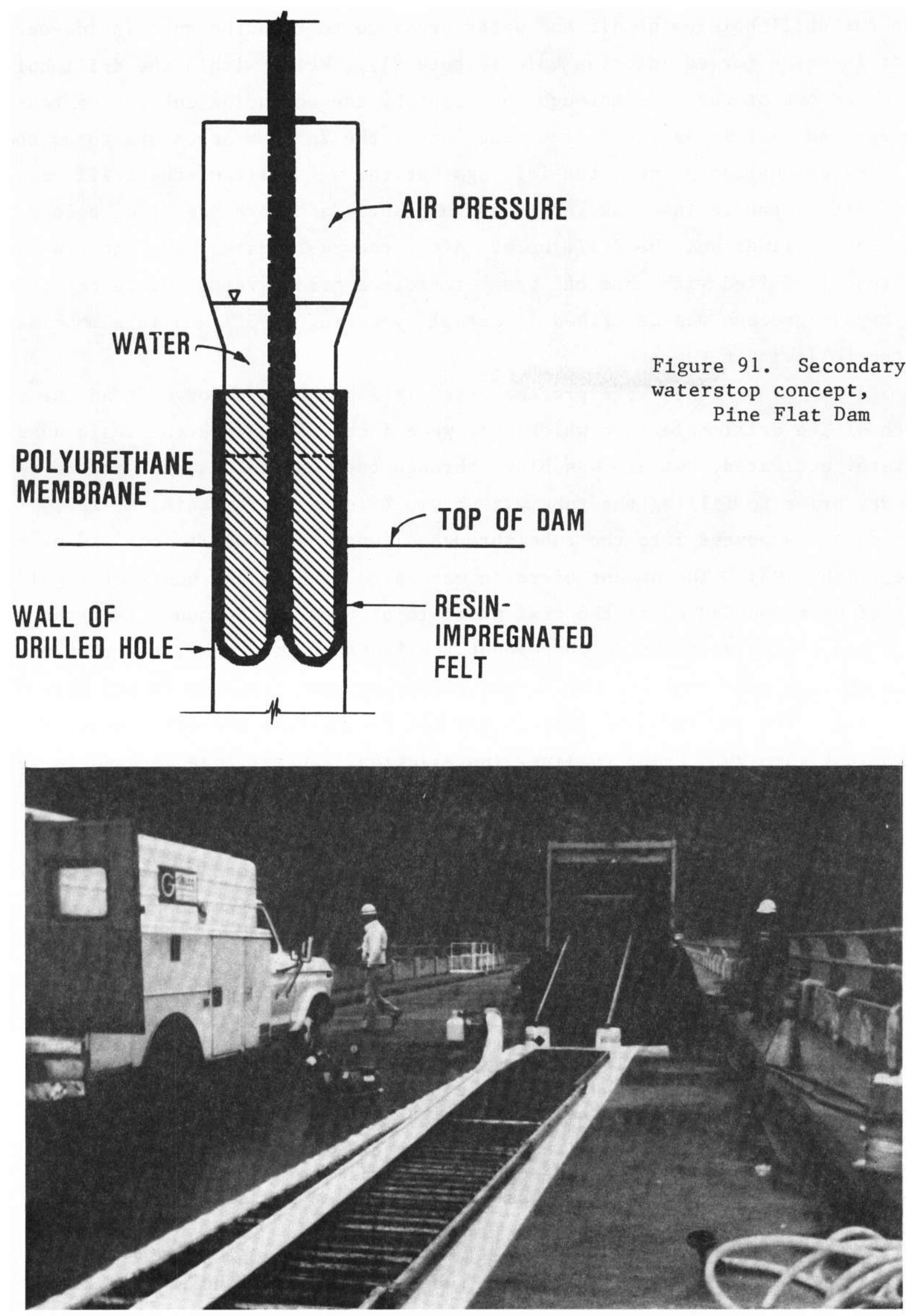

Figure 92. Drying the liner tube with forced hot air, Pine Flat Dam 


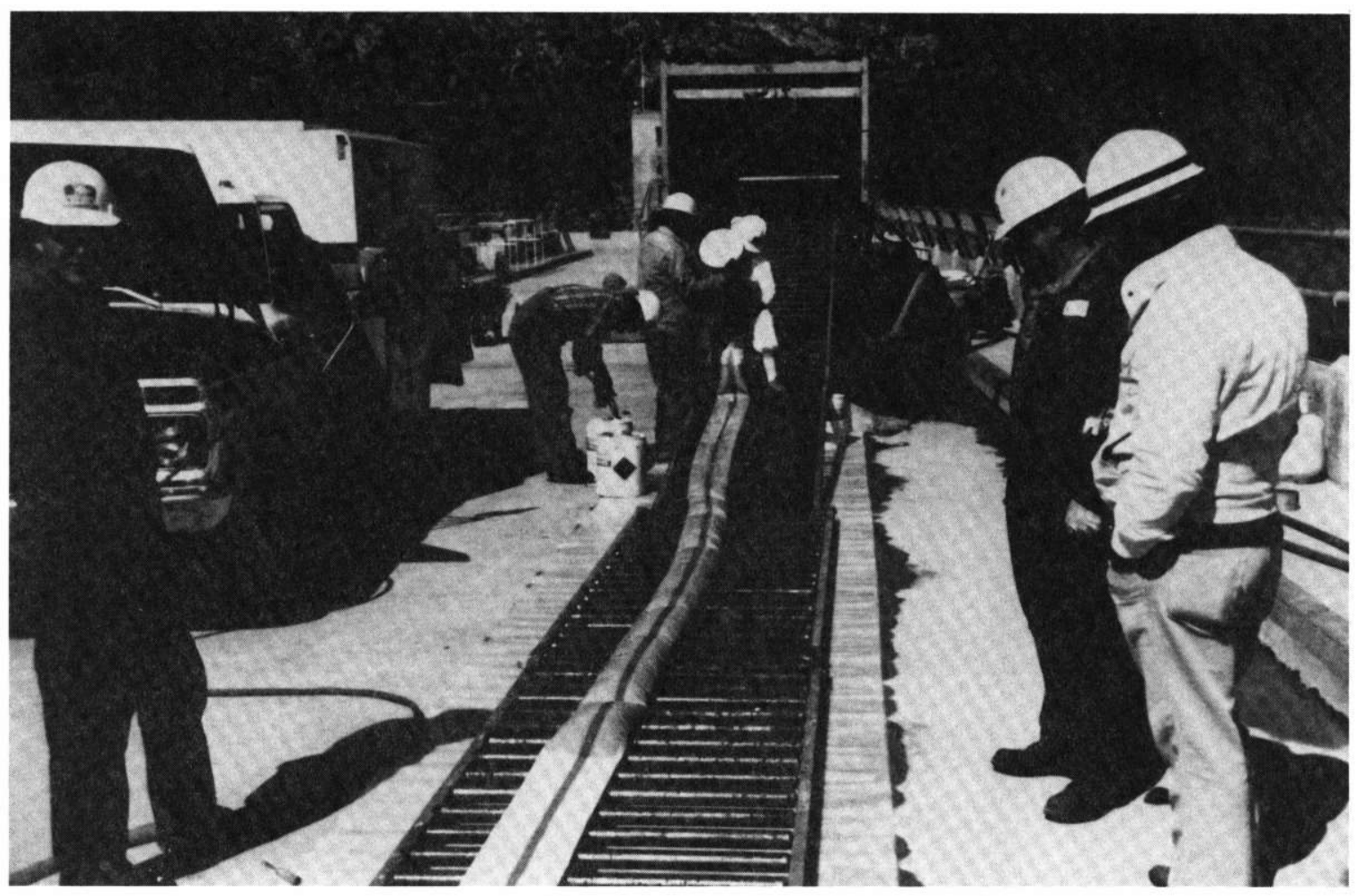

Figure 93. Filling the liner tube with resin, Pine Flat Dam

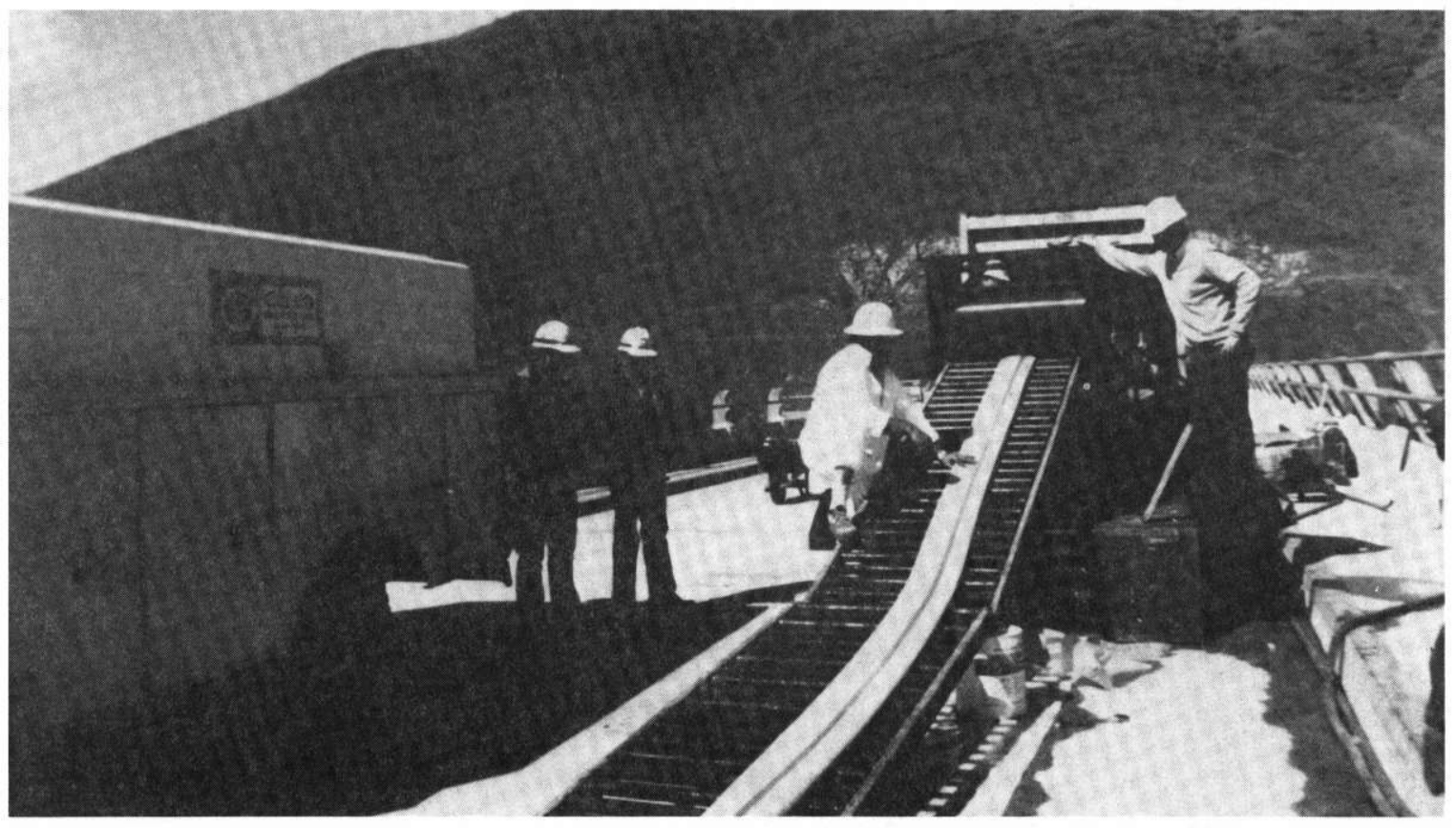

Figure 94. Drawing the liner tube through pinch rollers to evenly distribute the resin, Pine Flat Dam 


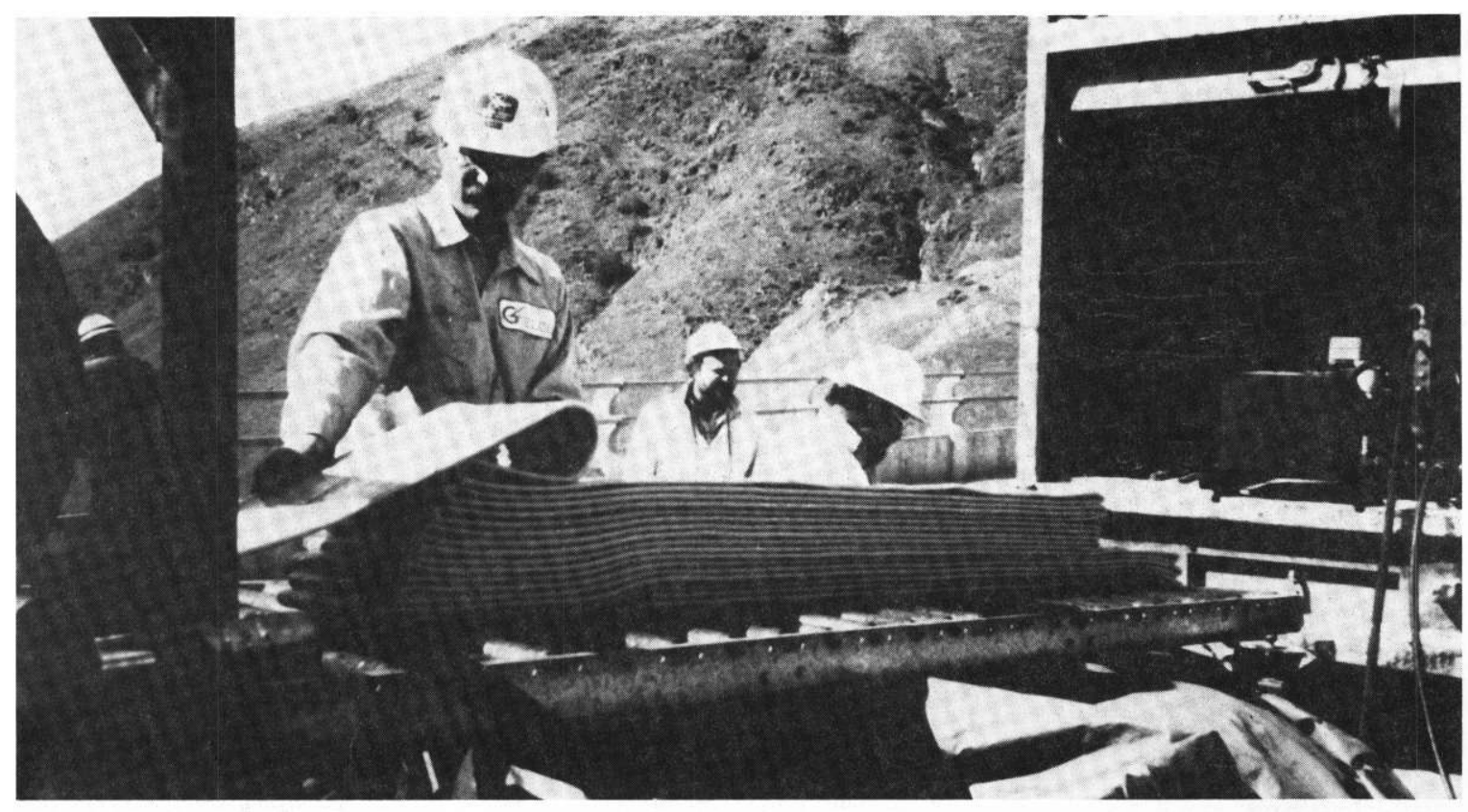

Figure 95. Prepared liner stacked and ready for installation, Pine Flat Dam

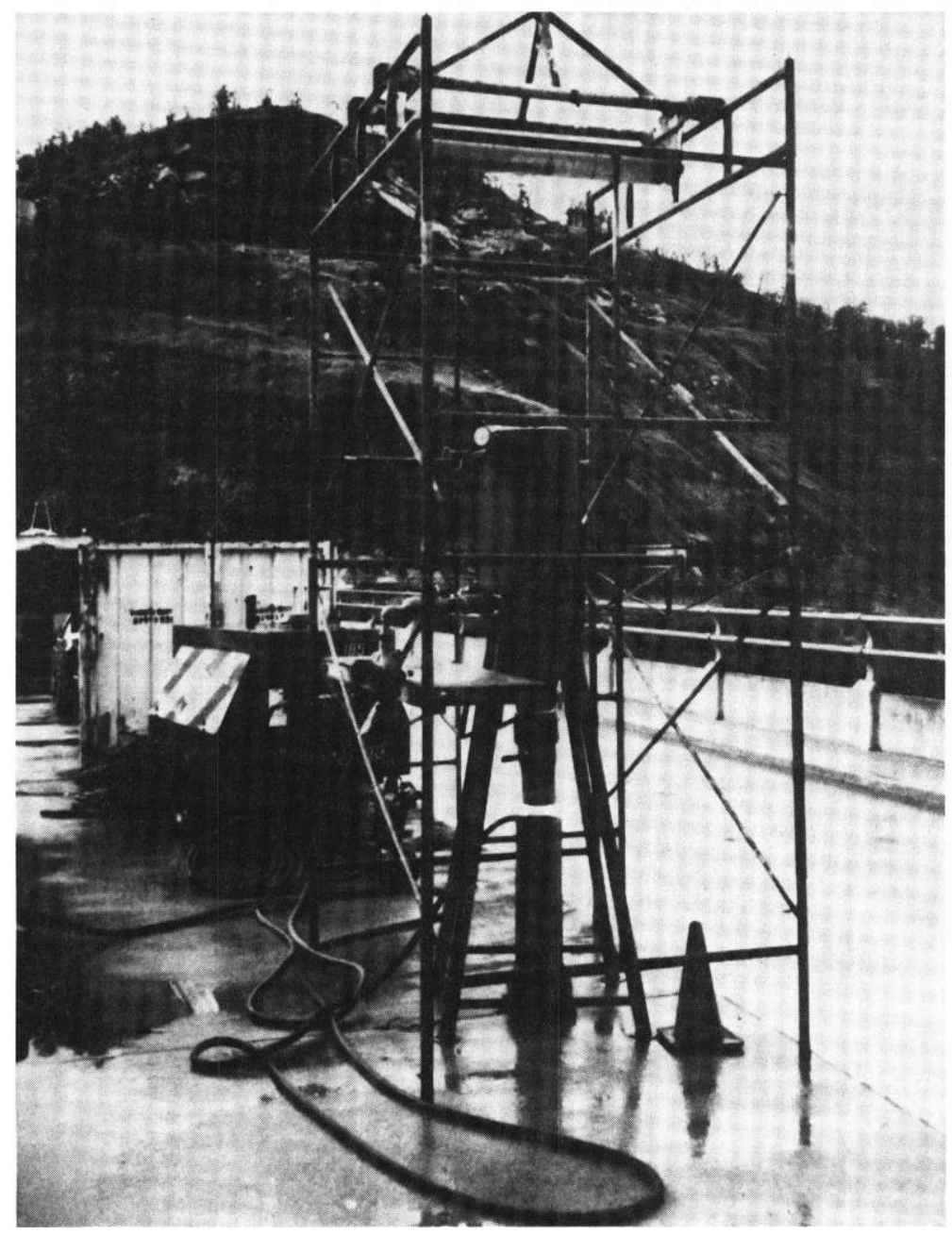

Figure 96. Liner installation apparatus, Pine Flat Dam 


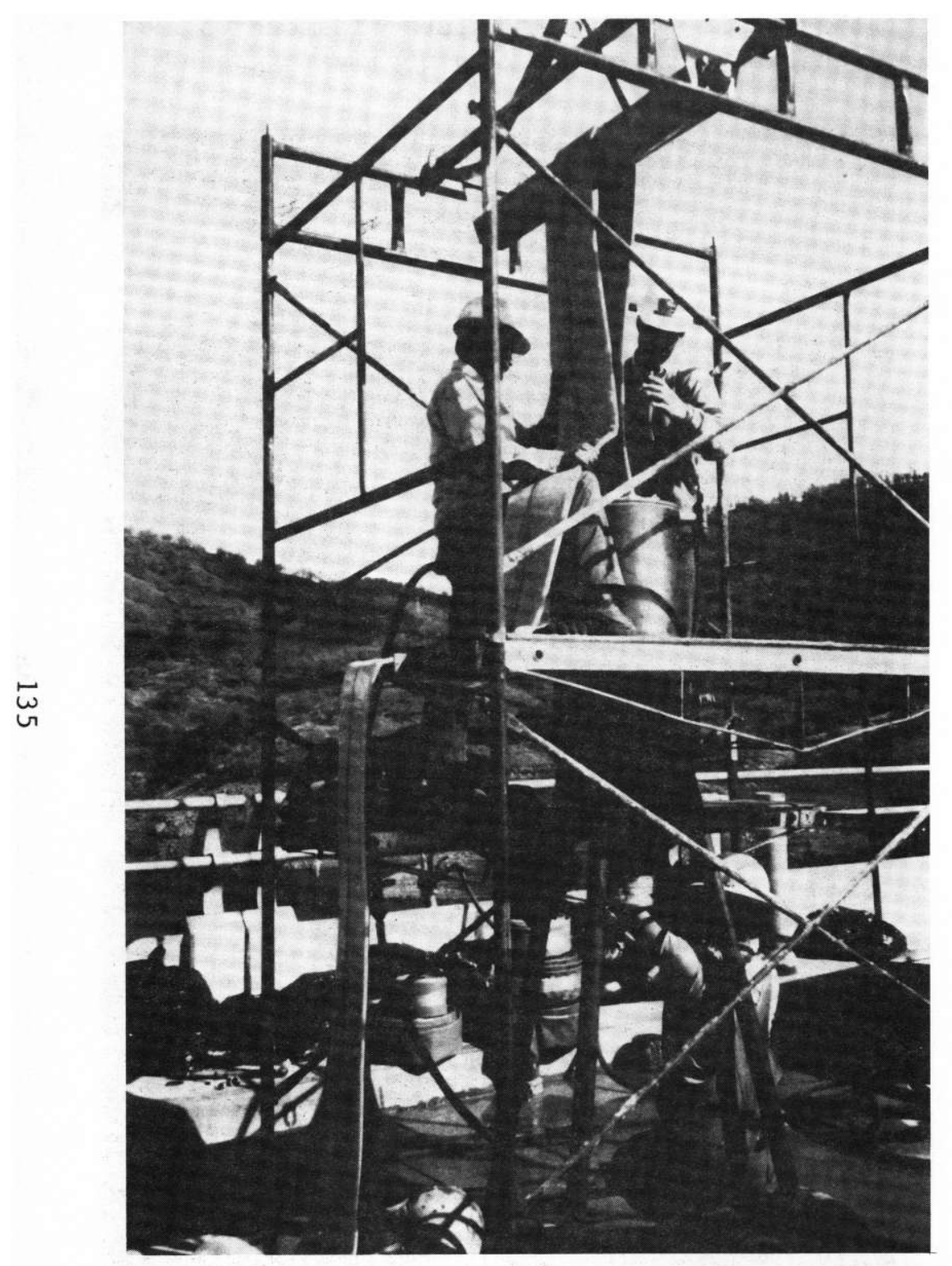

Figure 97. Inserting the liner into the pressure canister, Pine Flat Dam

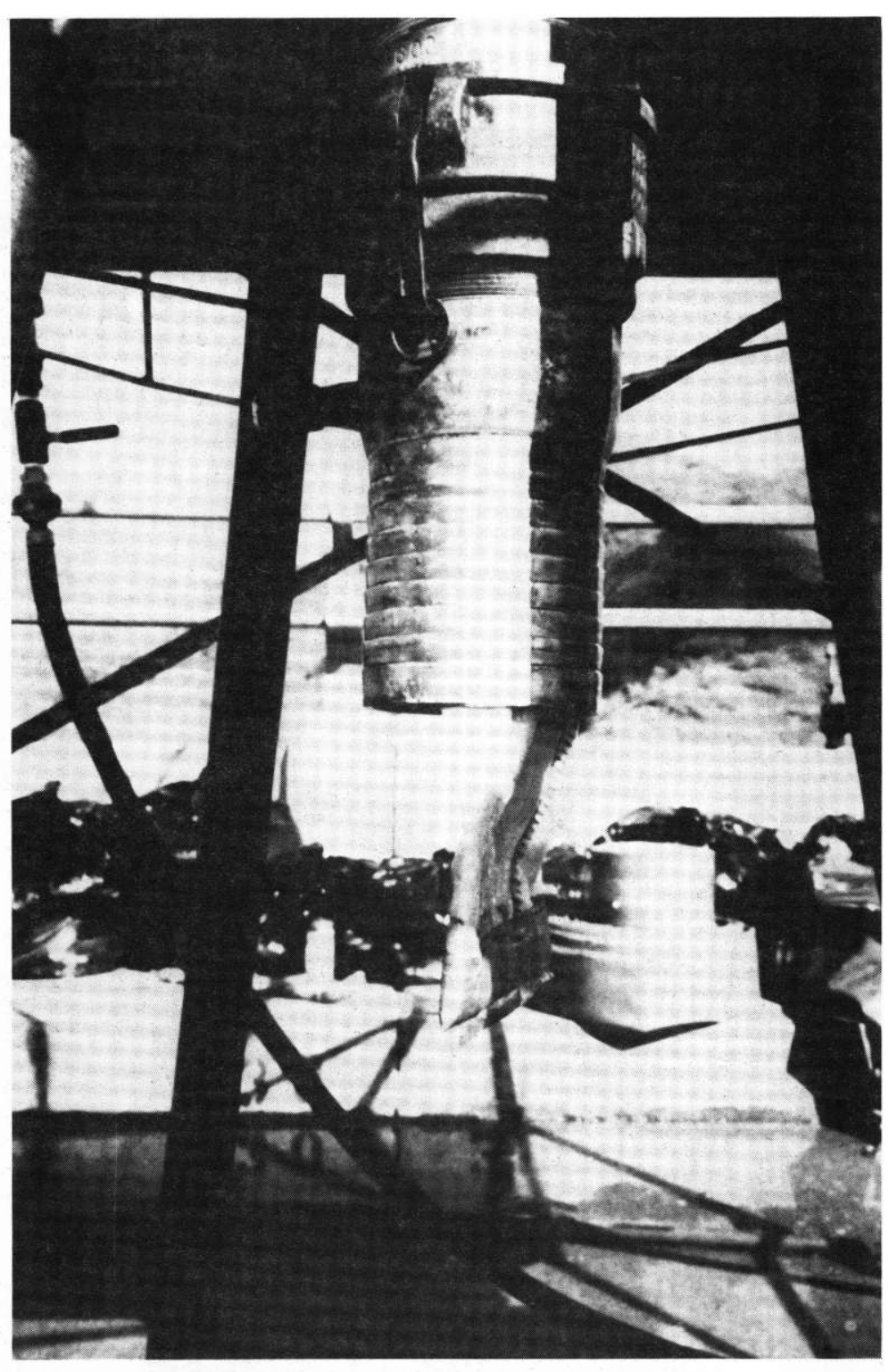

Figure 98. Liner tube inserted through the pressure canister, Pine Flat Dam 


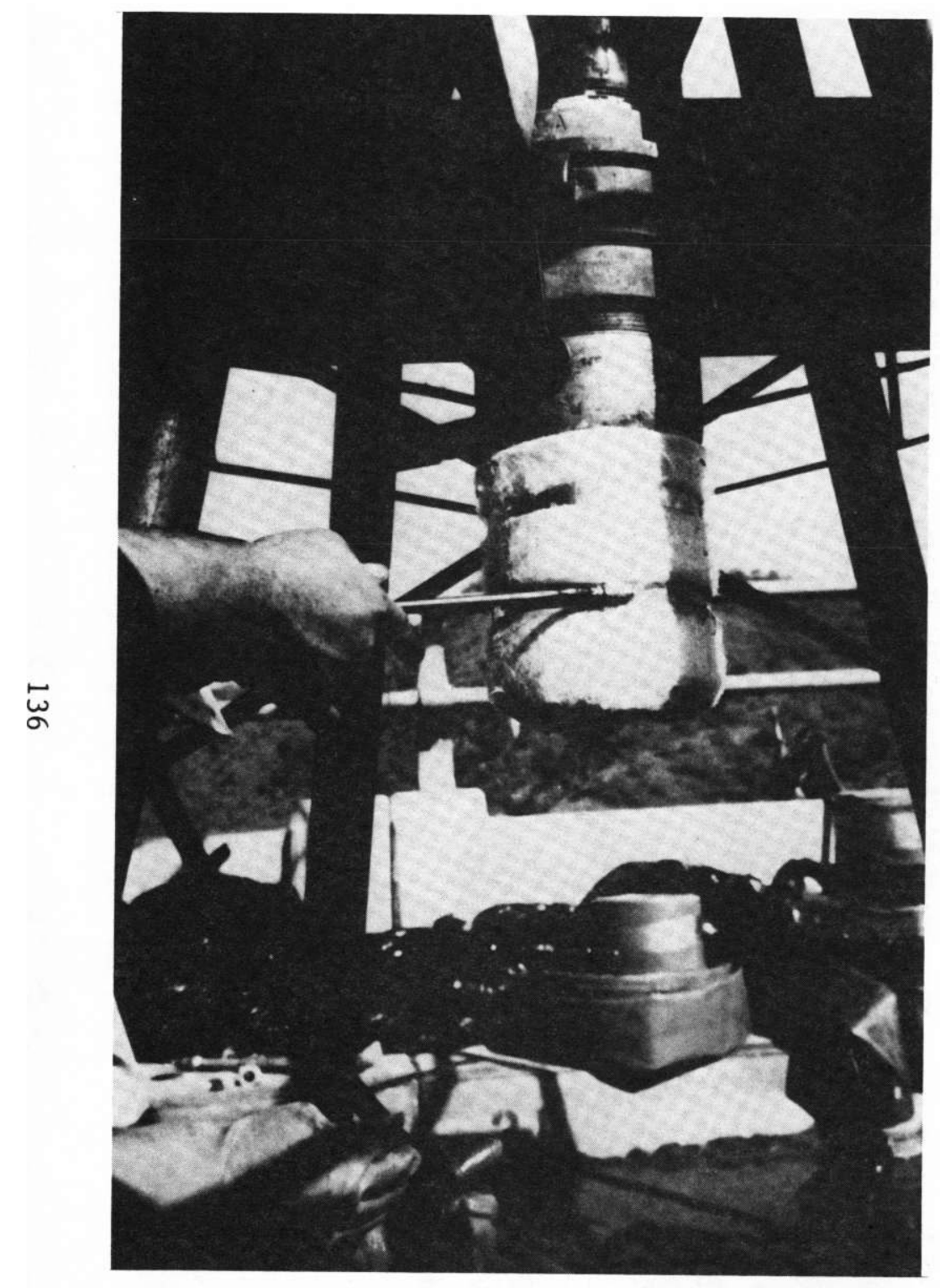

Figure 99. Attaching the end of liner tube to pressure canister, Pine Flat Dam

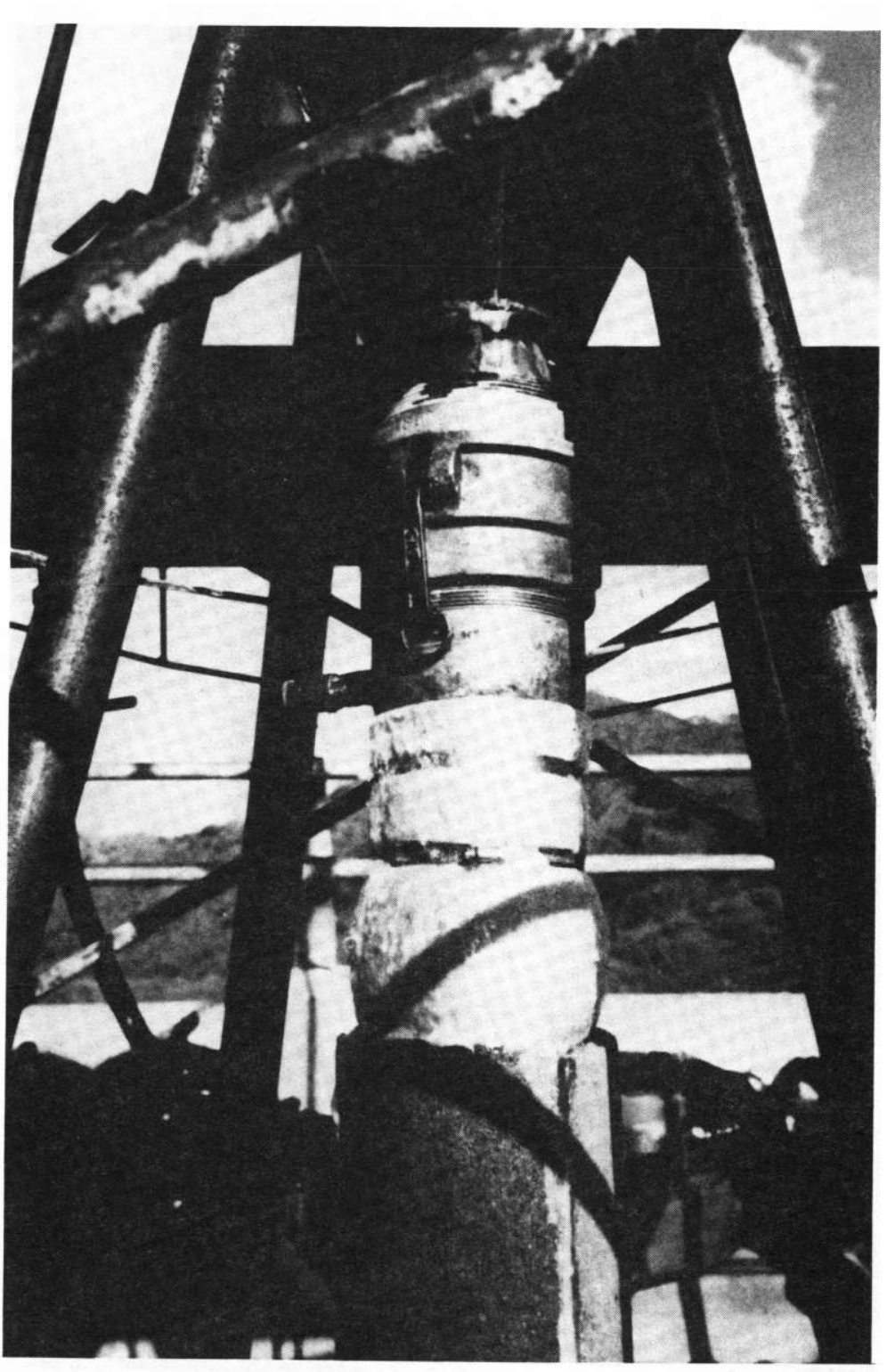

Figure 100. Beginning liner tube insertion, Pine Flat Dam 


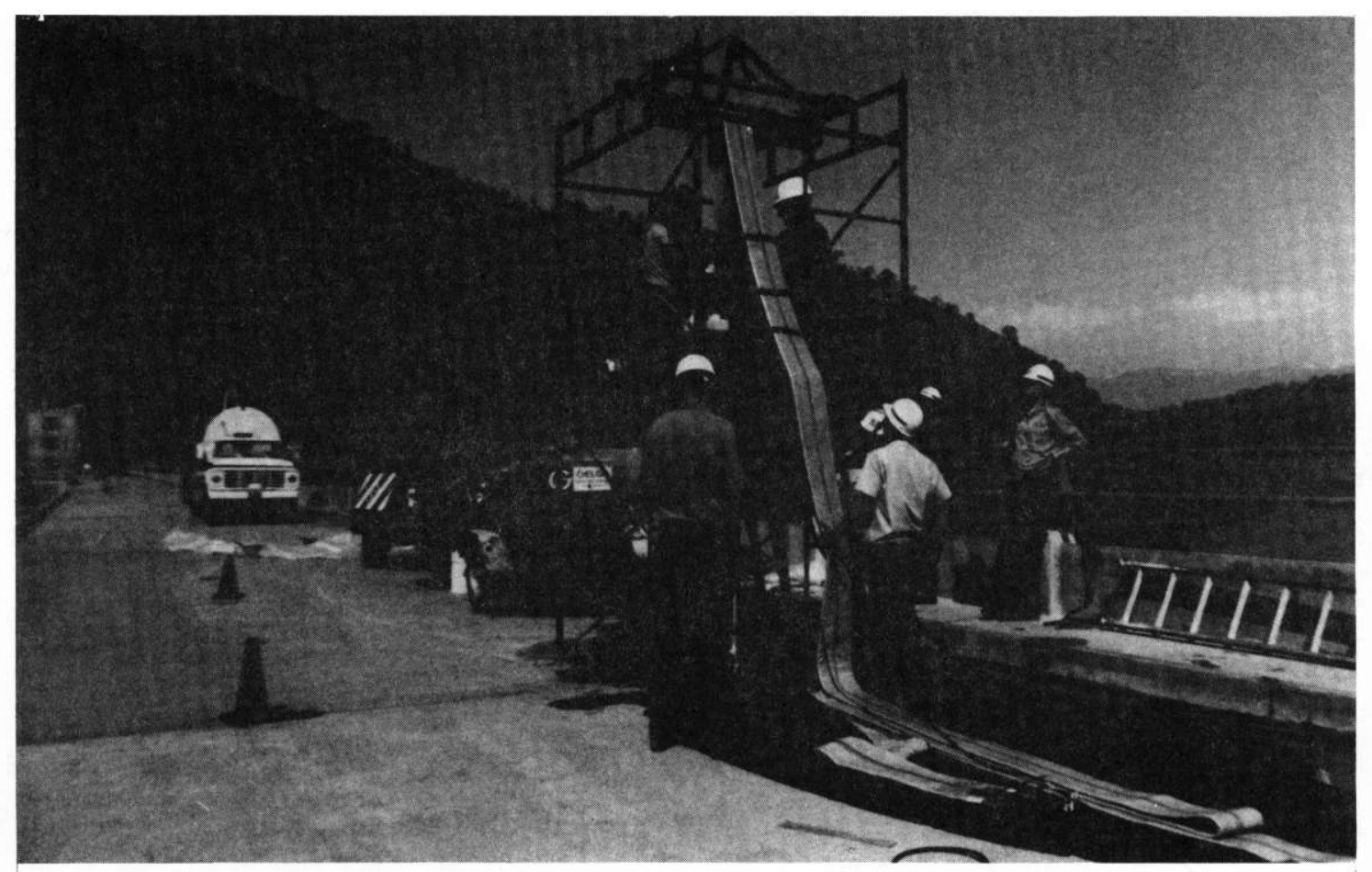

Figure 101. Approximately one-half of the liner tube installed, Pine Flat Dam

Figure 102. Liner tube installation complete, Pine Flat Dam

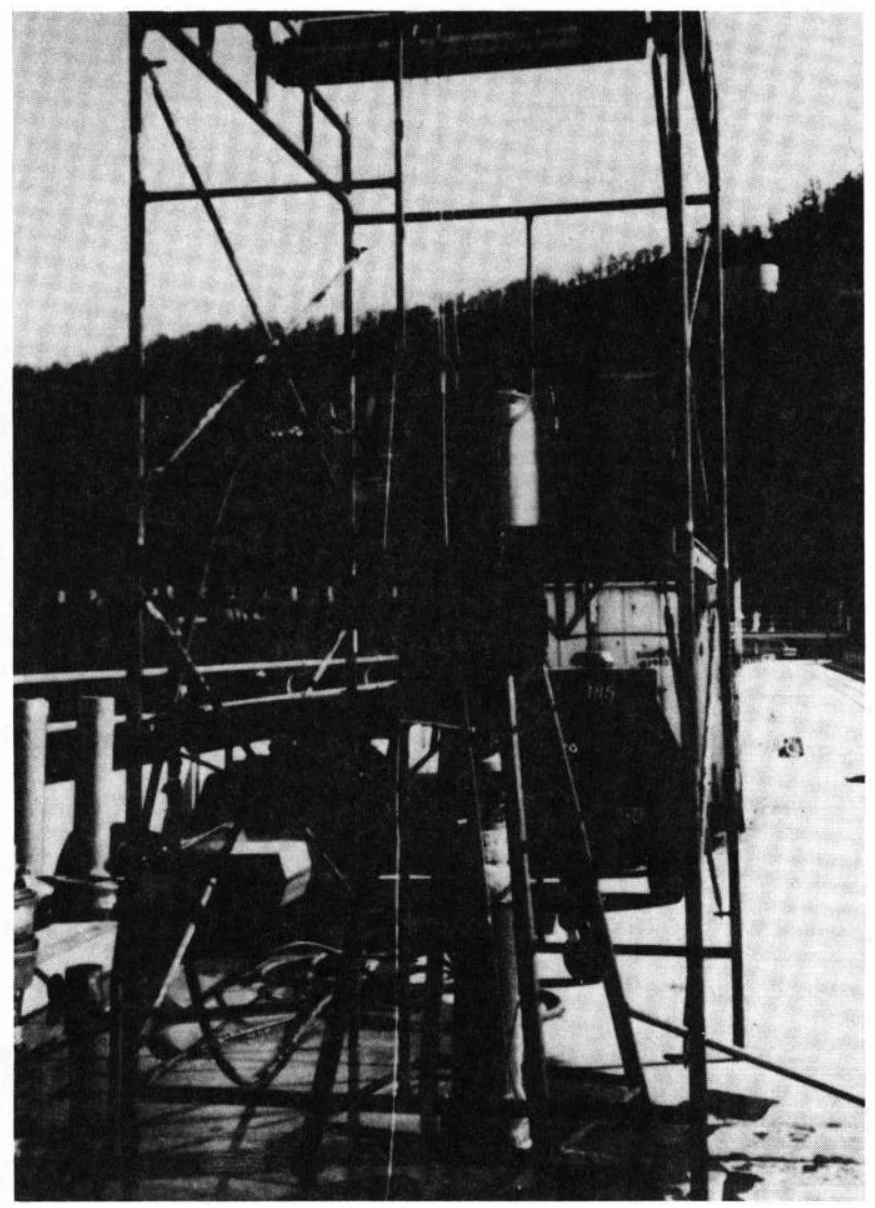


of water added to the tube is related to length of tube installed to ensure adequate internal pressure (Figure 101).

e. Once the end of the liner tube entered the pressure canister, a small cable attached to the end of the tube was used to lower the end of the tube to the bottom of the hole while addi. tional water was added to compensate for the increased volume inside the liner (Figure 102).

194. Once installed, the liner tube was cut loose from the installation apparatus. Figure 103 shows a tube being cut the day after installation. Water flowing from a slit cut in the tube indicated that the water level inside the liner tube had remained constant overnight. After the installation apparatus was removed, the television camera was lowered into the interior of the liner tube to inspect the liner.

195. After the postinstallation inspection was completed, the liner tube was filled with an acrylamide grout (Figures 104 and 105) proportioned for a specific gravity of 1.11. Typical grout mixture proportions for a 28.5-gal batch were as follows:

\begin{tabular}{ll}
\multicolumn{1}{c}{ Material } & $\frac{\text { Weight }}{25 \mathrm{lb}}$ \\
\hline Acrylamide powder (AV-100) & $25 \mathrm{lb}$ \\
Celite & $25 \mathrm{lb}$ \\
Bentonite & $1.25 \mathrm{lb}$ \\
Ammonium persulfate (AP) & $1.0 \mathrm{lb}$ \\
Triethanolamine (TEA) & $0.4 \mathrm{oz}$
\end{tabular}

The grout delivery hose was extended to the bottom of the liner tube within the drill hole. Water inside the Iiner was displaced as the grout was batched and pumped to the bottom of the liner. The gel time of the grout was approximately I hr which allowed a slow retrieval of the hose during the grouting operation.

196. A remedial waterstop was installed in hole $30 / 31$ (191 ft deep) on 7 March 1985. As the end of the liner tube approached the bottom of the drill hole, resistance to further progress was encountered. This was mistakenly interpreted to indicate that the bottom had been reached and the control cable was tied off. Later television inspection showed that the tube was within approximately $10 \mathrm{ft}$ of the bottom of the hole. Apparently, the joint near the bottom of the drill hole is relatively tight. Since water within the drill 


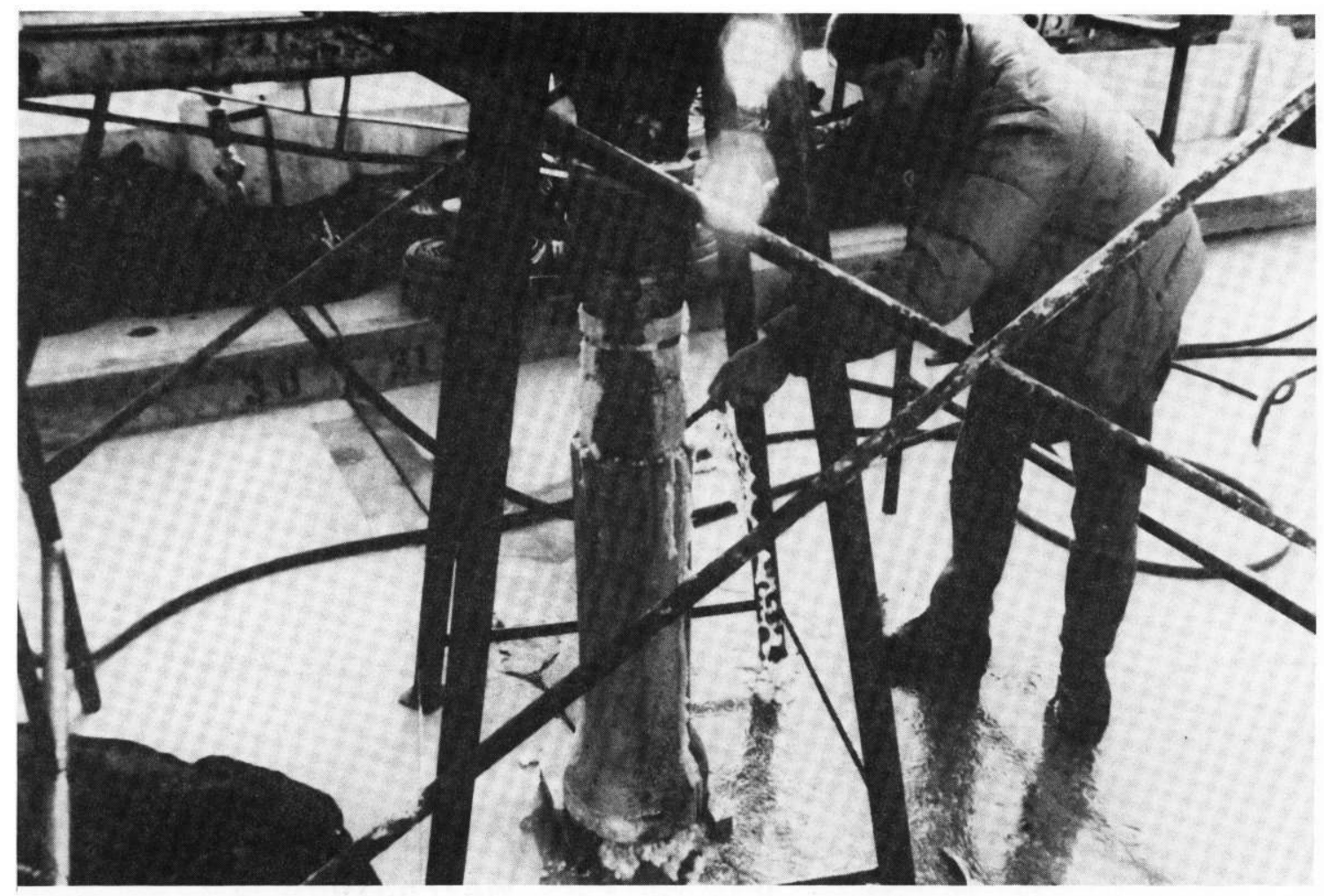

Figure 103. Cutting the liner tube loose from the installation apparatus, Pine Flat Dam

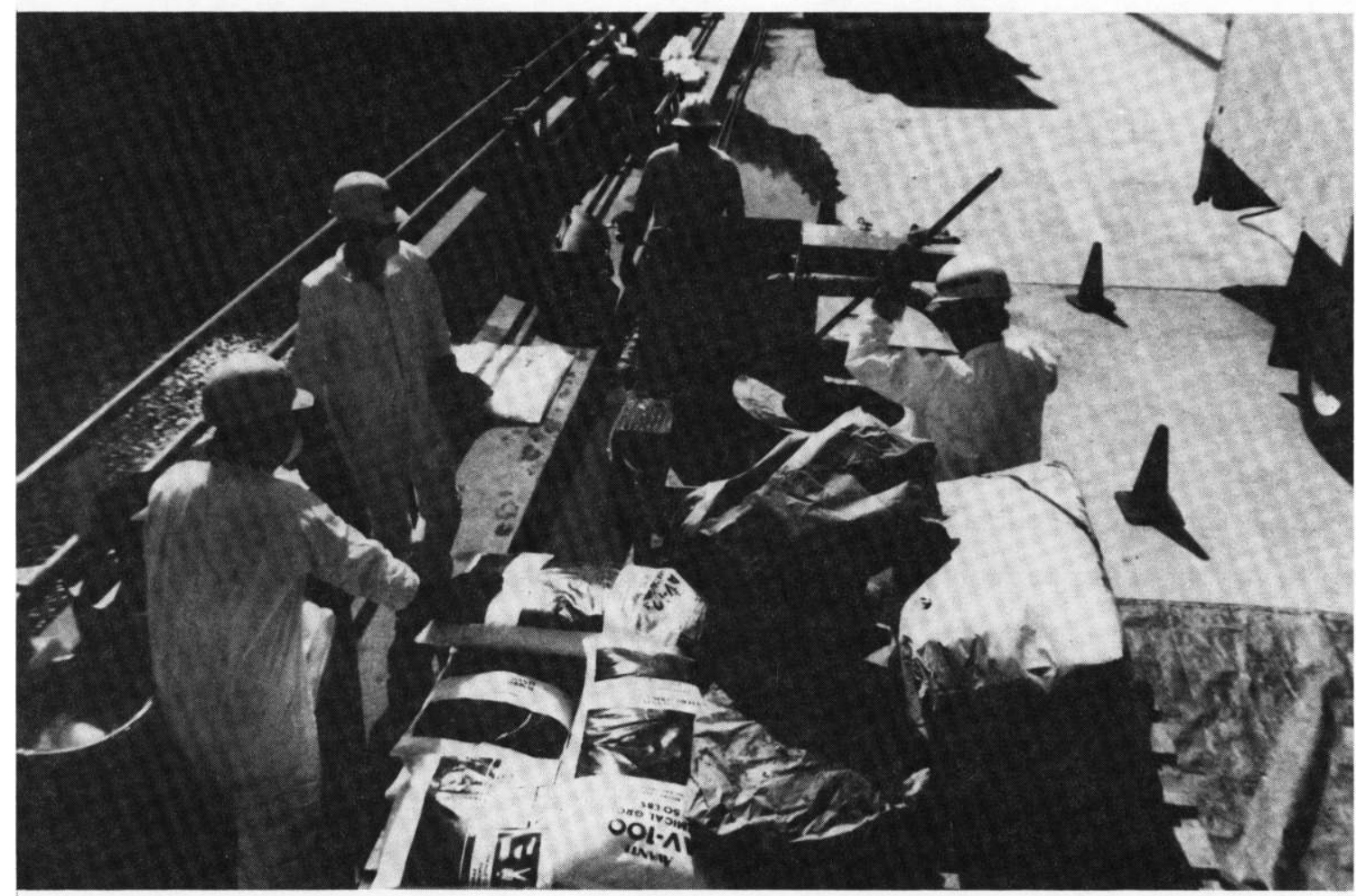

Figure 104. Filling the interior of the liner tube with chemical grout, Pine Flat Dam 


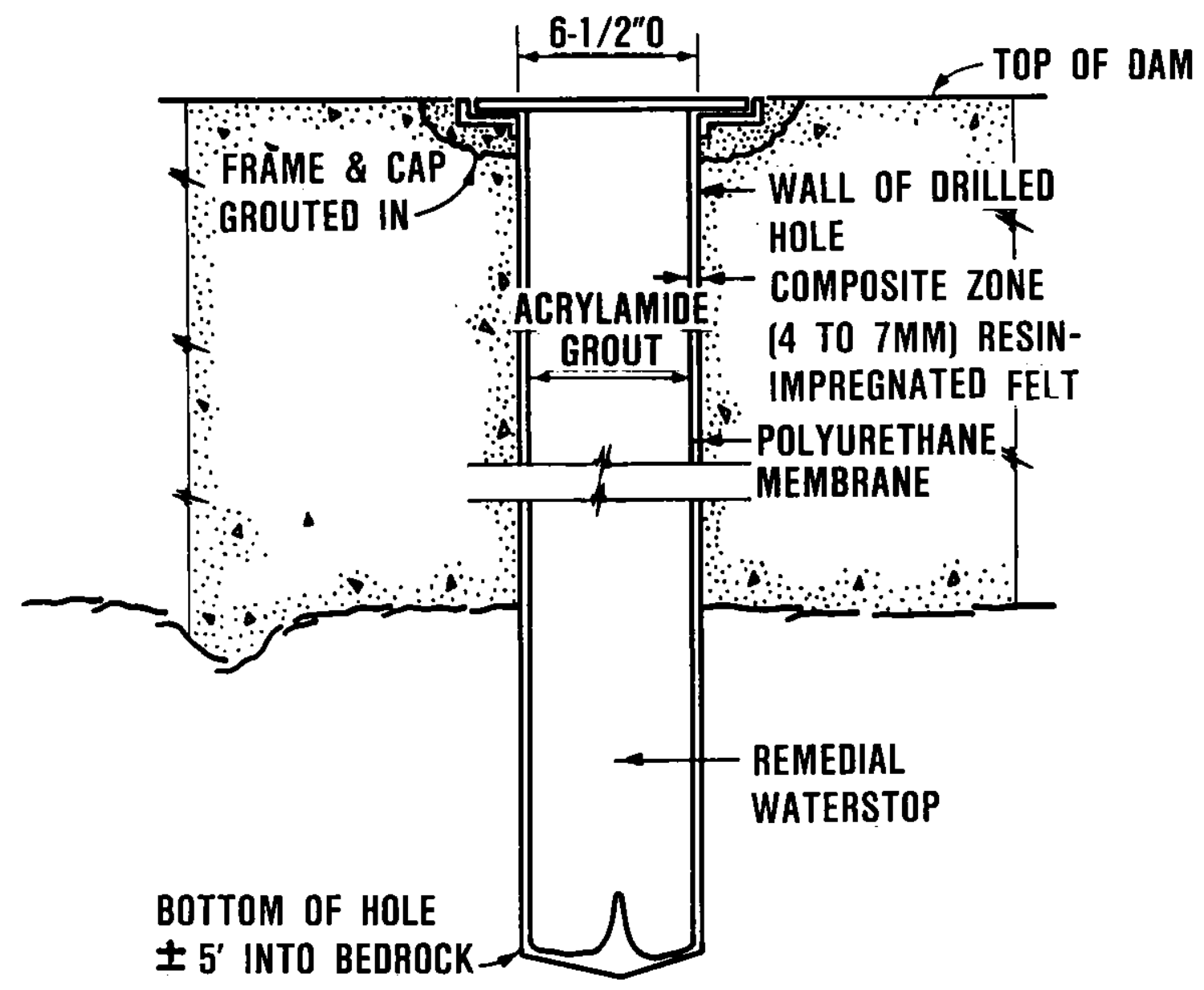

Figure 105. Completed remedial waterstop, Pine Flat Dam

hole must be forced out through the joint to allow the liner tube to proceed, joint conditions near the bottom of the hole did not allow complete installation of the liner. Obviously, if the joint will not allow water within the drill hole to escape, then the joint is certainly not leaking in that area.

197. Installation of the remedial waterstop in hole 29/30 (237 ft deep) was begun on 8 March 1985. However, when the waterstop reached a depth of approximately $145 \mathrm{ft}$, water inside the liner was lost and the installation was aborted. The liner tube was removed from the hole with great effort (Figure 106). The extraction process was the reverse of the procedure for installation; i.e., the tall end of the liner tube was pulled up thereby peeling the as yet not fully cured resin away from the walls of the drill hole. While the tube experienced significant elongation during extraction, it did not tear.

198. An examination of the 11ner indicated that a stitched seam had failed at a hole depth of approximately $145 \mathrm{ft}$. This allowed the water to 


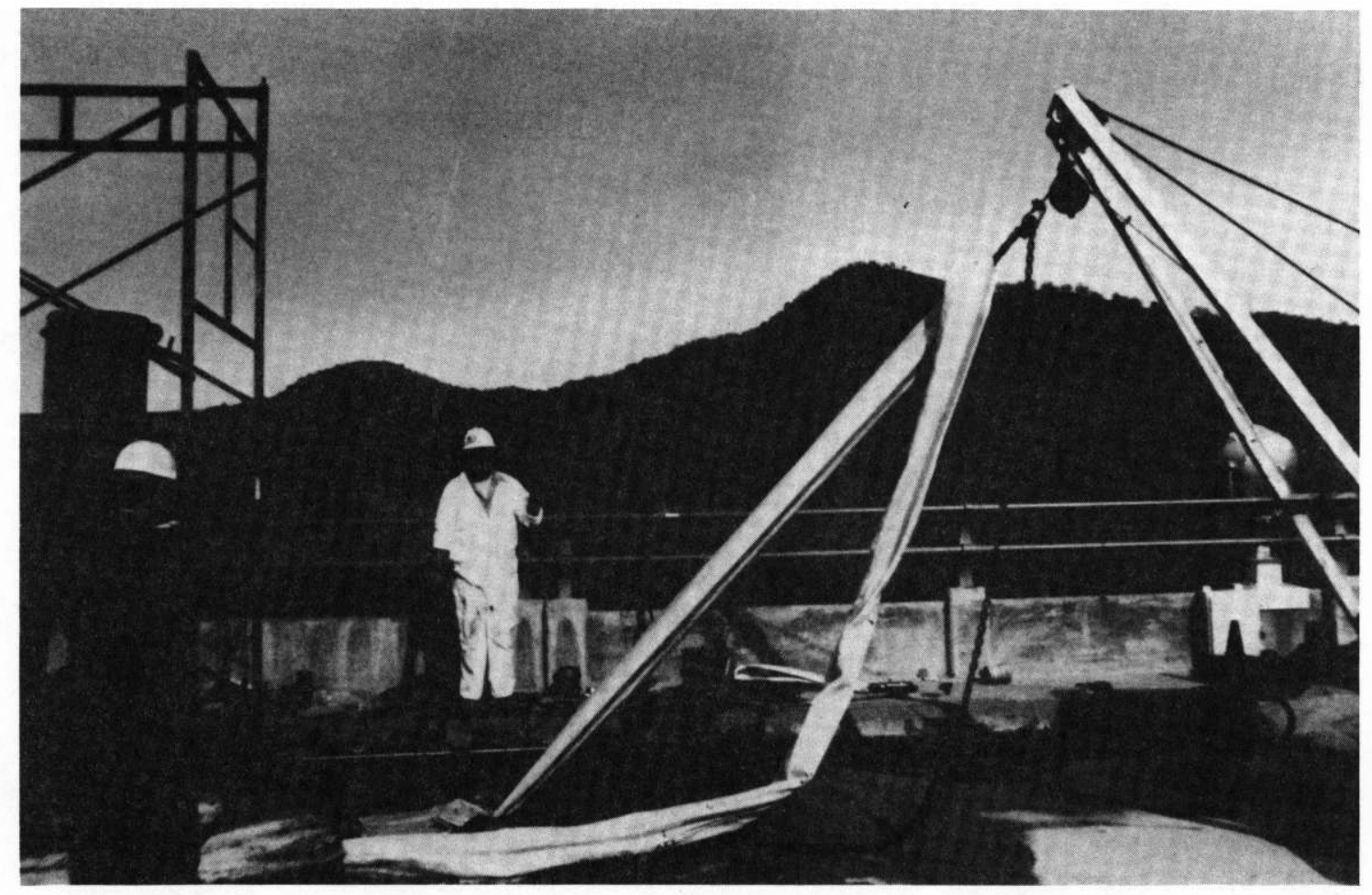

Figure 106. Removing the aborted tube from hole 29/30, Pine Flat Dam

evacuate and the internal head which forces installation was lost. Failure of the seam was attributed to excessive internal head. At the time of failure, the internal head had been raised to the top of the pressure canister, a height of $8 \mathrm{ft}$ above the top of the hole. The resulting pressure on the seam at the point where the tube is turning inside-out, this being the weakest point because the tube is unsupported by the walls of the drill hole, exceeded the strength of the seam. To avoid such failures in future installations, a mathematical model of the installation procedure was developed which related allowable internal head to depth of the tube considering external head and material strengths.

199. The liner tube which was removed from hole 29/30 was dissected (Figure 107) to examine the interface between the resin-impregnated felt and the drill hole. The bond at the interface was obviously well developed since several small pieces of concrete bonded to the felt were pulled out the drill hole wall when the tube was extracted. The outline of aggregate particles could be clearly distinguished from the darker areas of cement paste. Also, two raised strips of resin along the tube indicated that excess resin was being forced into the joint on each side of the drill hole. 


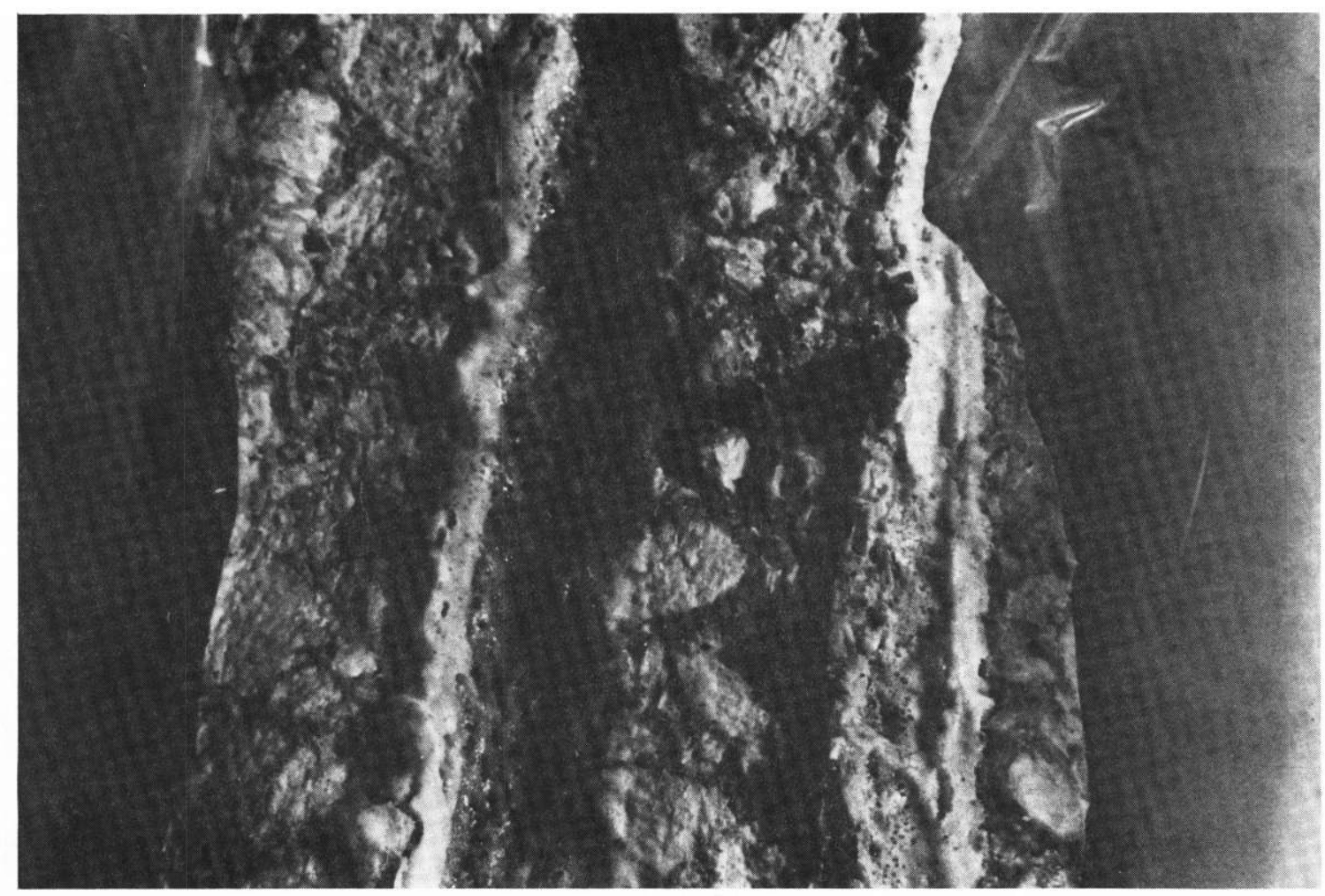

Figure 107. Dissected portion of the failed liner tube, Pine Flat Dam

200. The remedial waterstop was installed in hole 28/29 (257 ft deep) on 12 March 1985. Some resin was washed into the tailwater pool but was quickly dissipated with the use of additional flow into the pool through a sluice gate which was opened briefly. A postinstallation inspection indicated that the liner tube had penetrated to within approximately $2 \mathrm{ft}$ of the hole bottom.

201. A television inspection of hole 29/30 revealed that reacted resin had formed a plug in the hole at the static water level. This plug was removed and the hole flushed to remove remaining turbidity and particles which had settled to the bottom of the hole. The remedial waterstop was installed on 14 March 1985. The installation was performed quickly and without incident using the previously developed model to control internal water pressure.

202. On 15 March 1985, each liner tube was cut approximately 8 in. down inside each hole to allow replacement of existing cast iron cap frames (Figure 105). The resin-impregnated felt which was removed had small pieces of concrete adhering to its surface indicating good bond. The cap frames were 
regrouted with a sanded mortar, and the interior of each liner tube was filled with acrylamide grout.

203. Typical photographs taken from the videotape of the postinstallation inspection of hole 28/29 are shown in Figures 108-110. When compared to similar photographs taken at the same elevations prior to installation (Figures 86,87 , and 90 ), it is obvious that the liner tube is sufficiently flexible to conform to the irregular shape of the hole.

204. Historically, maximum flow through the three joints totals approximately $800 \mathrm{gal} / \mathrm{min}$ with a reservoir pool at elevation $950 \mathrm{ft}$. The reservoir pool level during the repair project ranged between elevation 880 and $870 \mathrm{ft}$ (Figure 111) with a total flow of approximately $150 \mathrm{gal} / \mathrm{min}$ prior to repair. of this total less than 1 gal/min was contributed by hole $30 / 31$. Following installation of the remedial waterstops, total flow was stabilized at approximately $25 \mathrm{gal} / \mathrm{min}$. As in most structures of this type, it is difficult to isolate leakage through monolith joints from that which is passing through horizontal lift joints. It is not known how much, if any, of the leakage into the drain was a result of openings in the lift joints. Results of this project indicate that the majority of flow has been through the vertical joints, yet it cannot be concluded that all of the flows are from the vertical joints.

205. It should be noted that flows prior to remedial waterstop installation are affected by work being performed in the holes. The previous grout plug presumably restricted leakage below what might occur without obstruction. However, removal of the grout created particles which were washed into the joint and again restricted flows. The flushing operations removed much of those particles and the flows increased, as can be seen in Figure 111, between 28 February and 7 March. A reversal of the trend on 7 March is due to limited flushing on 7 March which apparently only agitated the grout particles causing them to flow into the joints. A more thorough flushing on 9 March using drilling foam removed particles from the joints and flushed them out of the holes. This caused the flow through joint $28 / 29$ to reach a level of approximately. $75 \mathrm{gal} / \mathrm{min}$.

206. Flow through joint $29 / 30$ peaked at $75 \mathrm{gal} / \mathrm{min}$ on $7 \mathrm{March}$ (Figure 111). On 8 March, the aborted installation reached a depth of $145 \mathrm{ft}$ (elevation $825 \mathrm{ft}$ ) before the tube was removed. The fluorescent dye test performed in May 1984 indicated a zone of leakage between elevations 870 and 


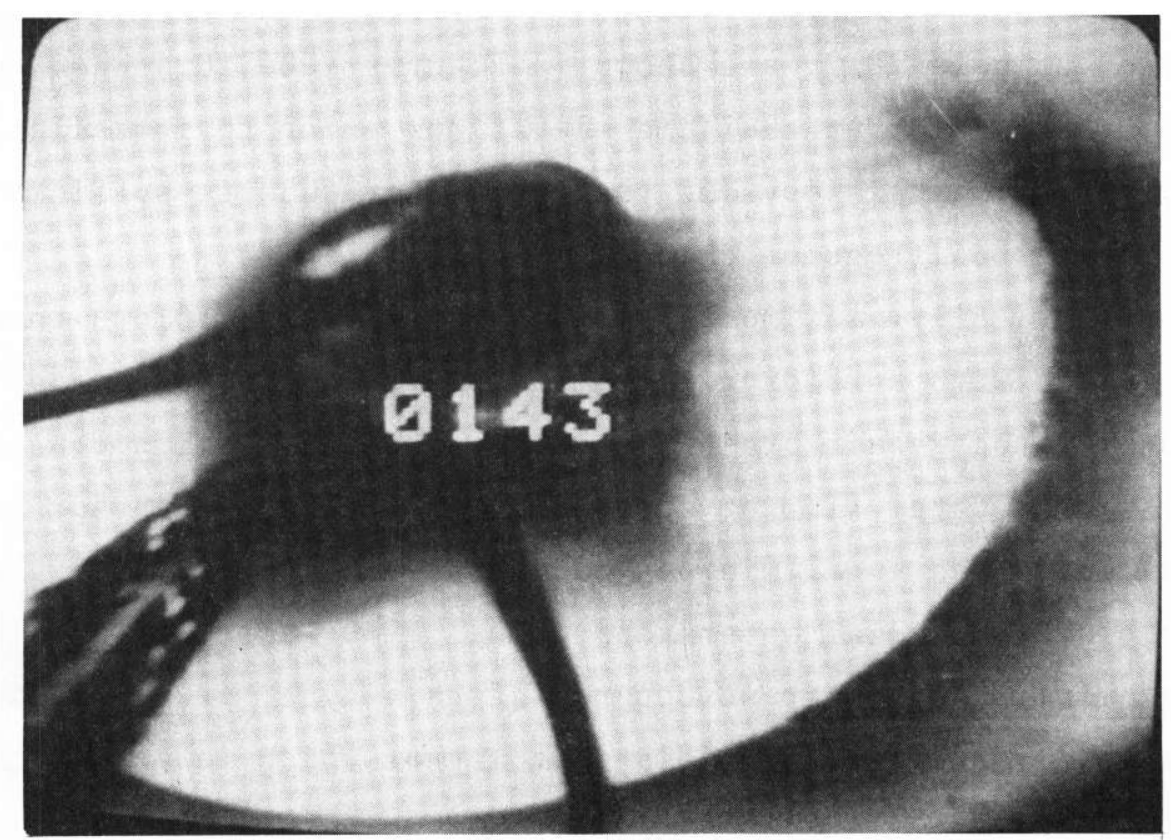

Figure 108. Postinstallation condition of hole 28/29 at elevation $827 \mathrm{ft}$, Pine Flat Dam

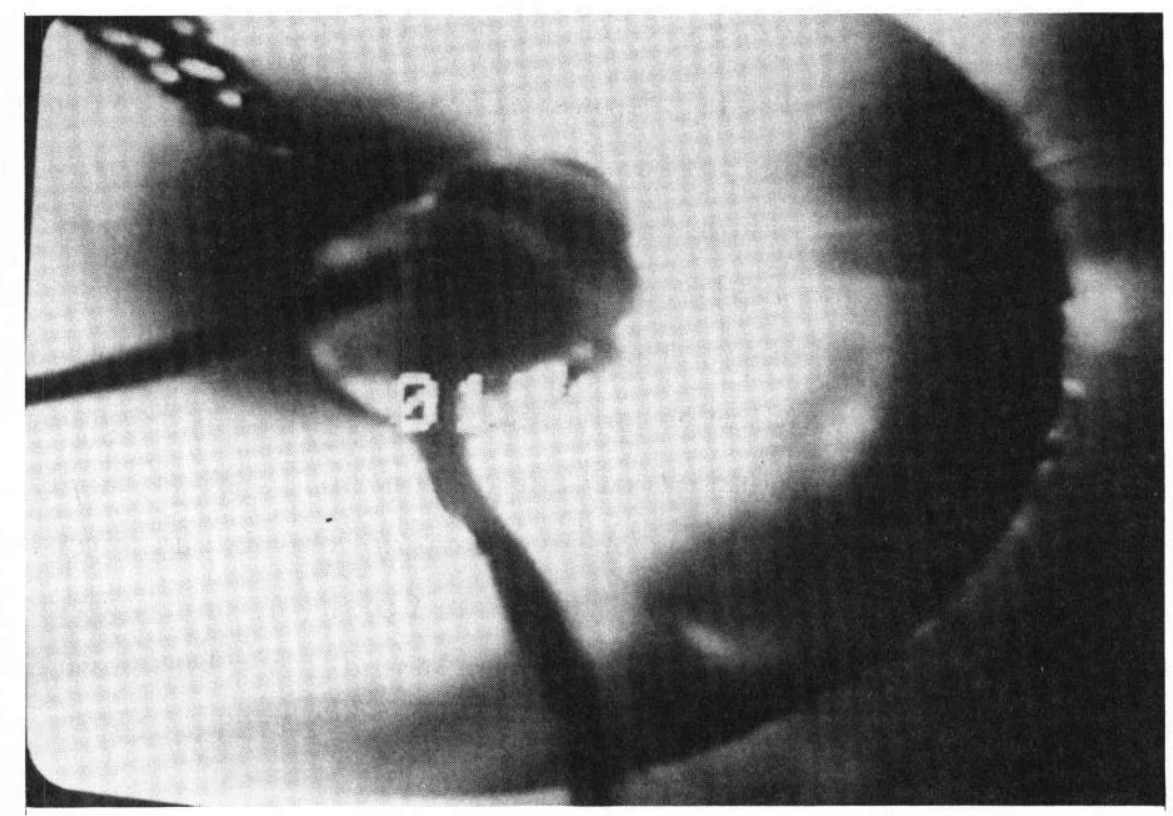

Figure 109. Postinstallation condition of hole 28/29 at elevation $812 \mathrm{ft}$, Pine Flat Dam 


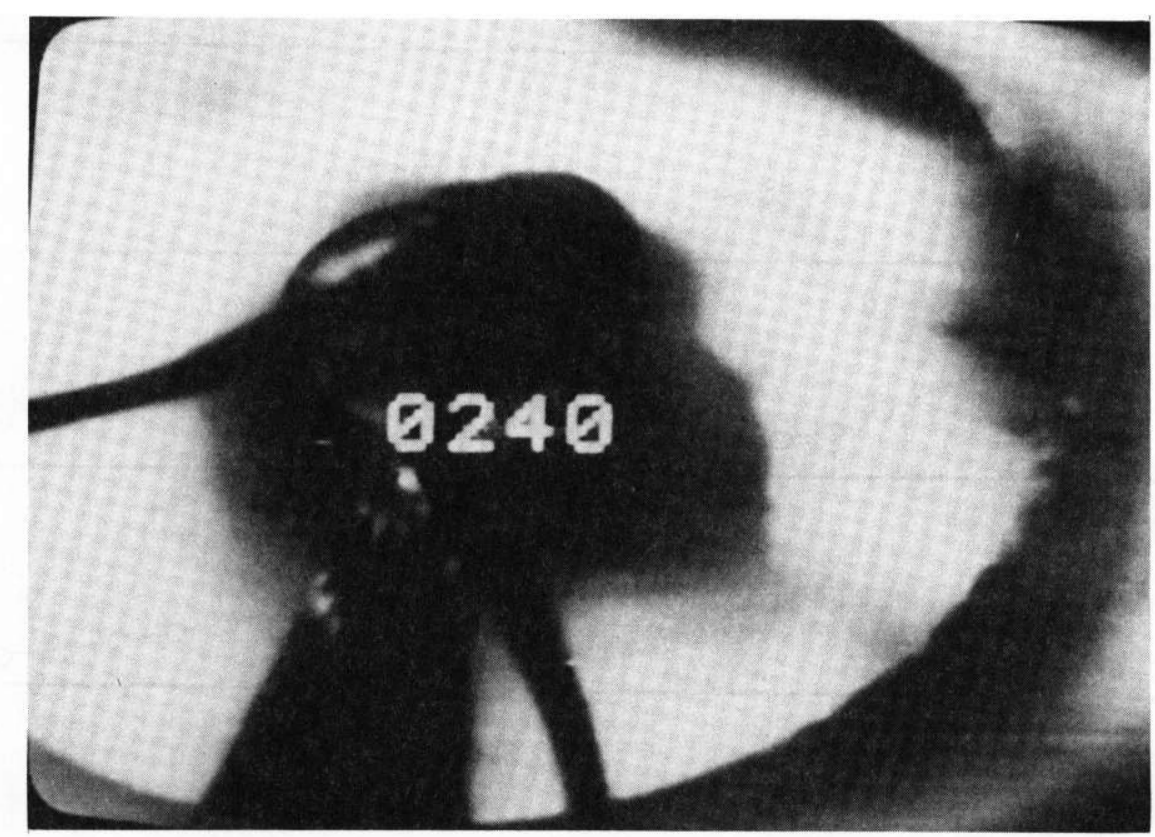

Figure 110. Postinstallation condition of hole $28 / 29$ at elevation $730 \mathrm{ft}$, Pine Flat Dam

$850 \mathrm{ft}$. Independently, the video inspection indicated cross-hole flows at elevations 840 and $815 \mathrm{ft}$. This indicates that the tube had been installed into the major leakage area before it was removed. Between 8 March (aborted attempt) and 14 March (successful installation), flows through this hole decreased daily with the exception of the upward blip caused by the flushing on 9 March discussed above. This would indicate that beneficial penetrations of the joint by the resin occurred even though the tube was removed. Resin thus forced into the joint would not be removed by the flushing. Such an effect can be expected to improve the quality of the seal obtained and thus its long-term performance. However, only a rise in reservoir pool level will provide conclusive evidence as to the efficiency of these repairs.

207. Approximately one year after completion of repairs, the drain at joint $30 / 31$ was described as wet but the flow was too small to be measured. Flow through the drains at joints $28 / 29$ and $29 / 30$ were 17.6 and $30.0 \mathrm{gal} / \mathrm{min}$, respectively, with the pool at elevation $928 \mathrm{ft}$. In comparison, the total flow through the same two drains was $267 \mathrm{gal} / \mathrm{min}$ in July 1984 with the pool at elevation $926 \mathrm{ft}$. Approximately $1 \mathrm{ft}$ of grout has been pushed out of hole 28/29 lifting the cover plate over the hole (Figure 104). The cover plate was removed and the hole left open. No additional grout has been forced out of the hole since that time. 


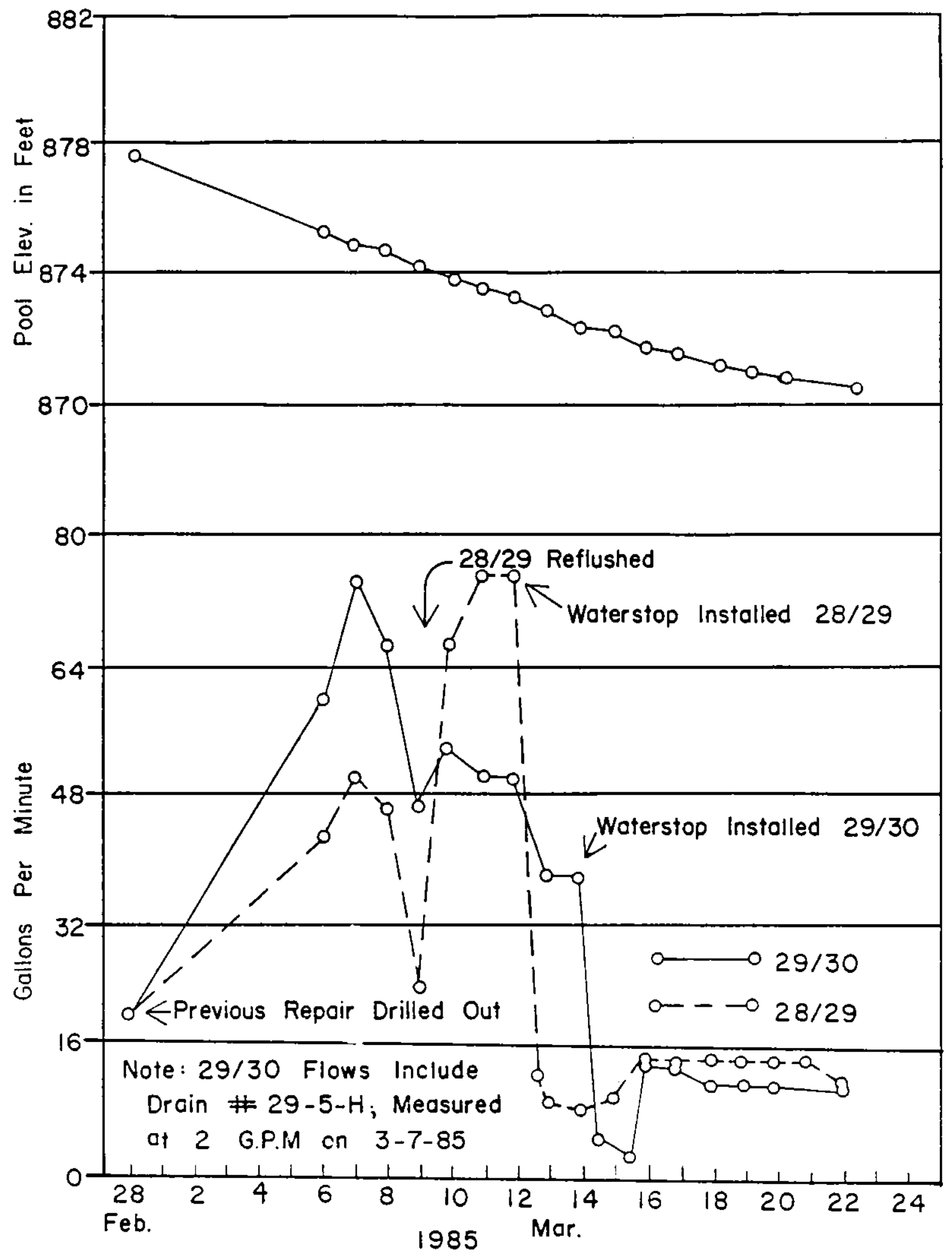

Figure 111. Joint laakage rates, Pine Flat Dam 
208. The Dardanelle Lock and Dam is located on the Arkansas River, 5 miles southwest of Russellville, Ark. The project consists of a short embankment section and a single-lift lock on the left side of the river, a gated spillway about 1,200 ft long in the river channel, a power plant, and short concrete gravity dam on the right side of the river. The general arrangement of the lock is shown in Figure 112. The lock is Ohio River type with clear inside dimensions of 110 by $600 \mathrm{ft}$. The lift between normal (minimum) lower pool (elevation $284 \mathrm{ft}$ ) and top of power pool (elevation $338 \mathrm{ft}$ ) is $54 \mathrm{ft}$. Tops of the lock walls are at elevation $348 \mathrm{ft}$, providing $10 \mathrm{ft}$ of freeboard for operational purposes. All of the lock is founded on rock except the upstream riverward approach wall which is a concrete-capped cellular steel sheet pile wall. Overall, construction was initiated in June 1957 and completed November 1969.

209. The Dardanelle Lock had six vertical monolith joints that had been leaking since 1975. The leakage only occurred during cold wintertime conditions. They were first investigated in January 1977 when the leakage had increased significantly (Figures 113 and 114). Observation and dye tests proved that water from the lock chamber, both at low and full chamber, was passing through the monolith joints. Defective copper waterstops were the probable cause of the leakage. Visual leakage existed at river wall monolith joints $R 7 / 8, R 8 / 9, R 10 / 11, R 13 / 14, R 18 / 19$, and land wa11 joint L21/22. Monolith joints $R 18 / 19$ and $L 21 / 22$ are located at the lower miter sill and leakage through these joints entered the lock wall grouting galleries and then to the lower miter sill cross-over gallery where sump pumps are located. Total inflow during full lock chamber (wintertime) increased from $75 \mathrm{gal} / \mathrm{min}$ in January 1977 to $382.2 \mathrm{gal} / \mathrm{min}$ in January 1981. The sump pumps were taxed to the maximum and were modified several times to handle the high inflow.

210. Several methods for sealing the monolith joints were studied before it was decided that the preferred method to stop the leakage was to construct a permanent waterstop similar to the methods used at Lock and Dam No. 3 on the Arkansas River. There, four waterstops were installed in the joints of the right training wall by drilling 6-in. core holes at monolith joints and installing a waterstop device consisting of a neoprene tube filled with an aquagel-baroid-ethylene glycol mixture. The holes at Dardanelle Lock 


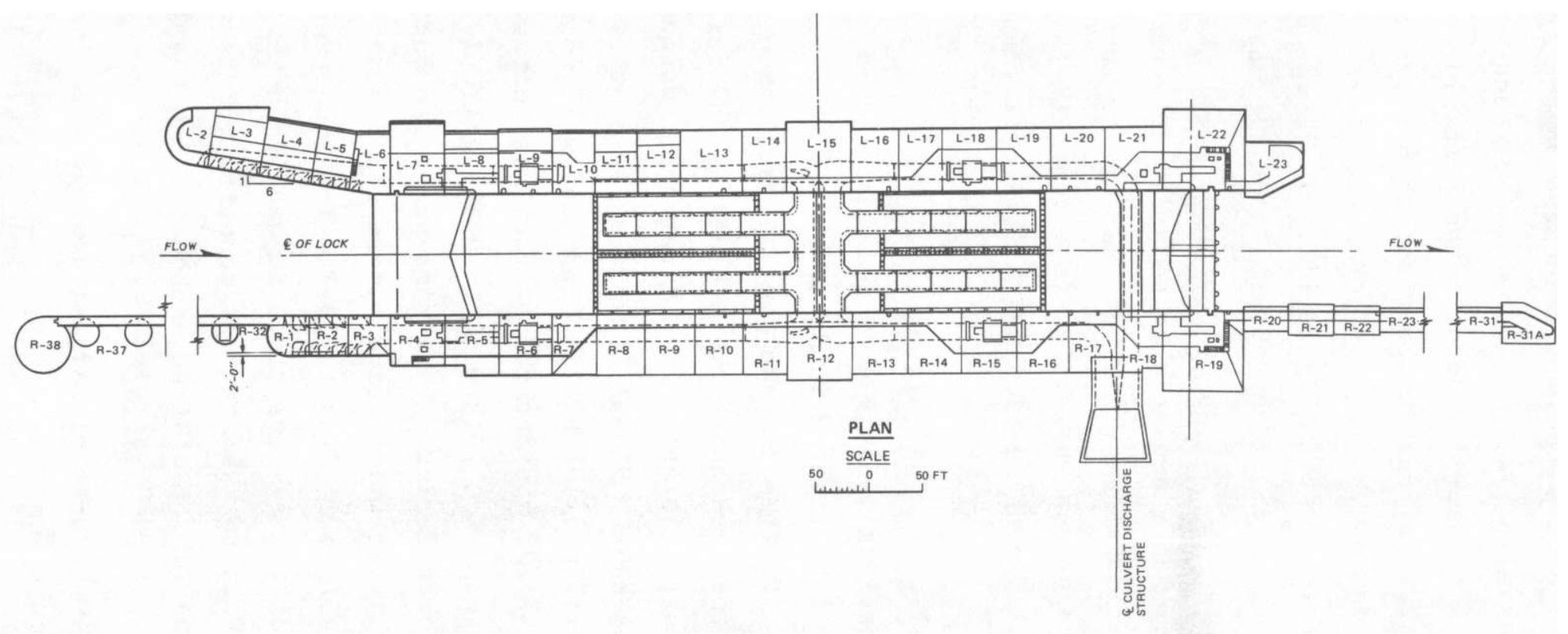

Figure 112. Plan view of lock, Dardanelle Lock 


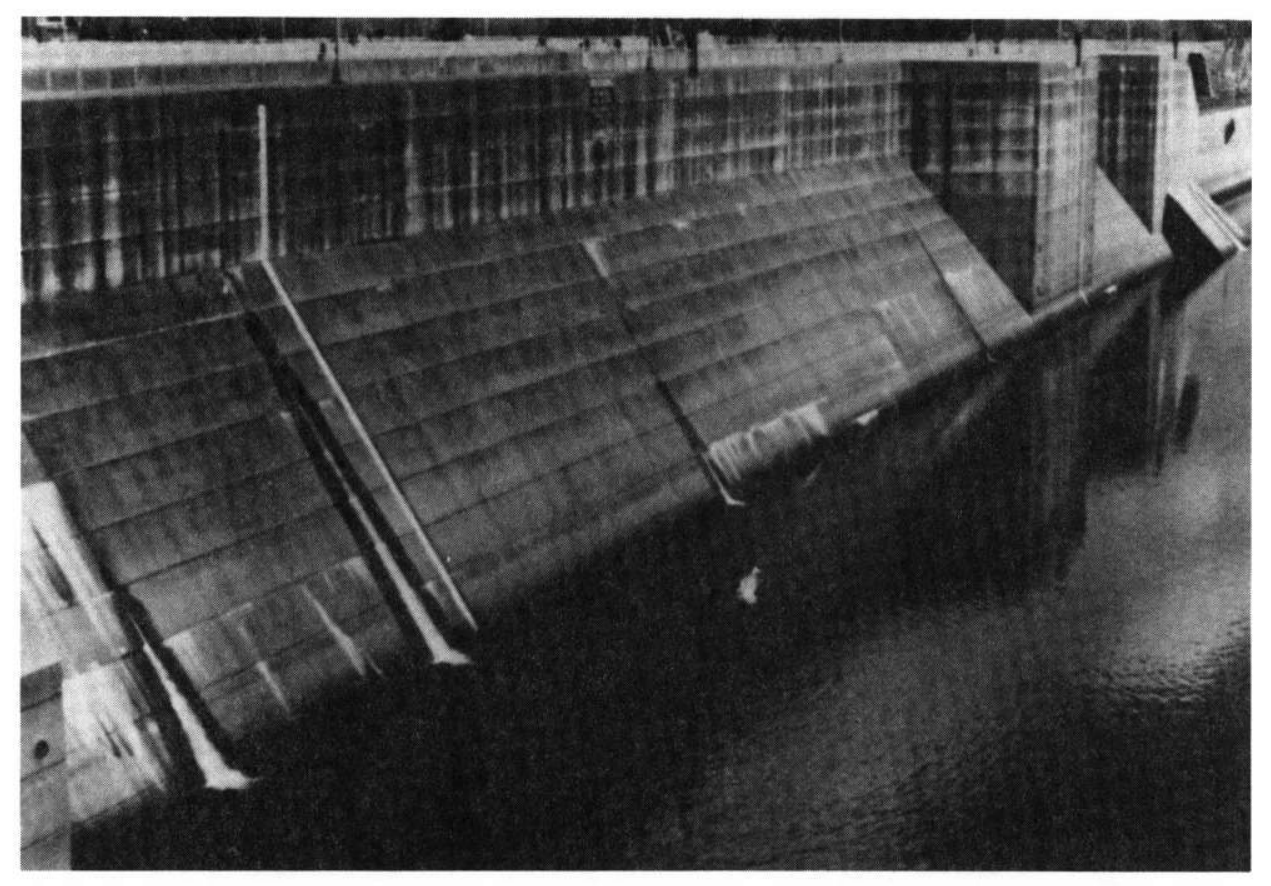

a. View of riverward lockwall taken from dam looking downstream

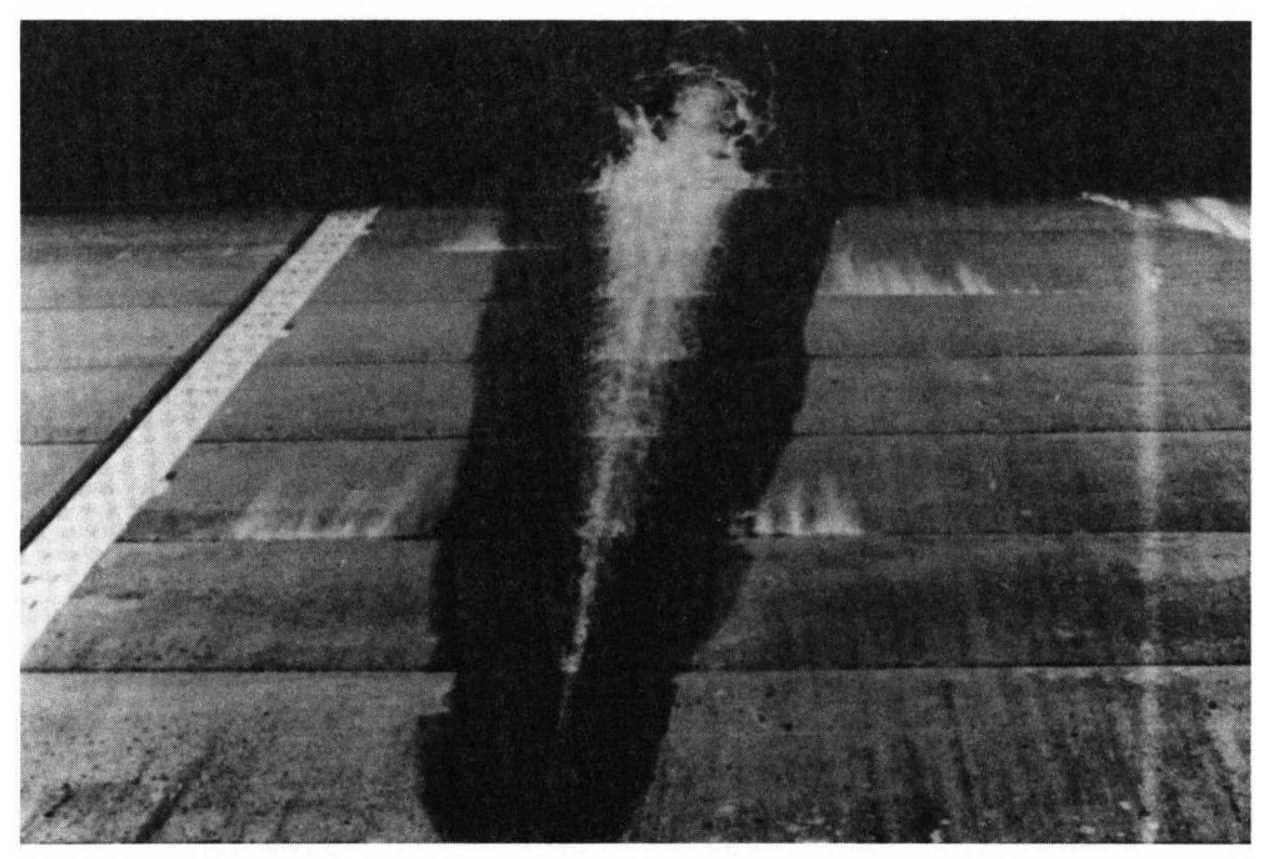

b. Close-up of largest leakage

Figure 113. Leakage through monolith joints with lock chamber at upper pool level 


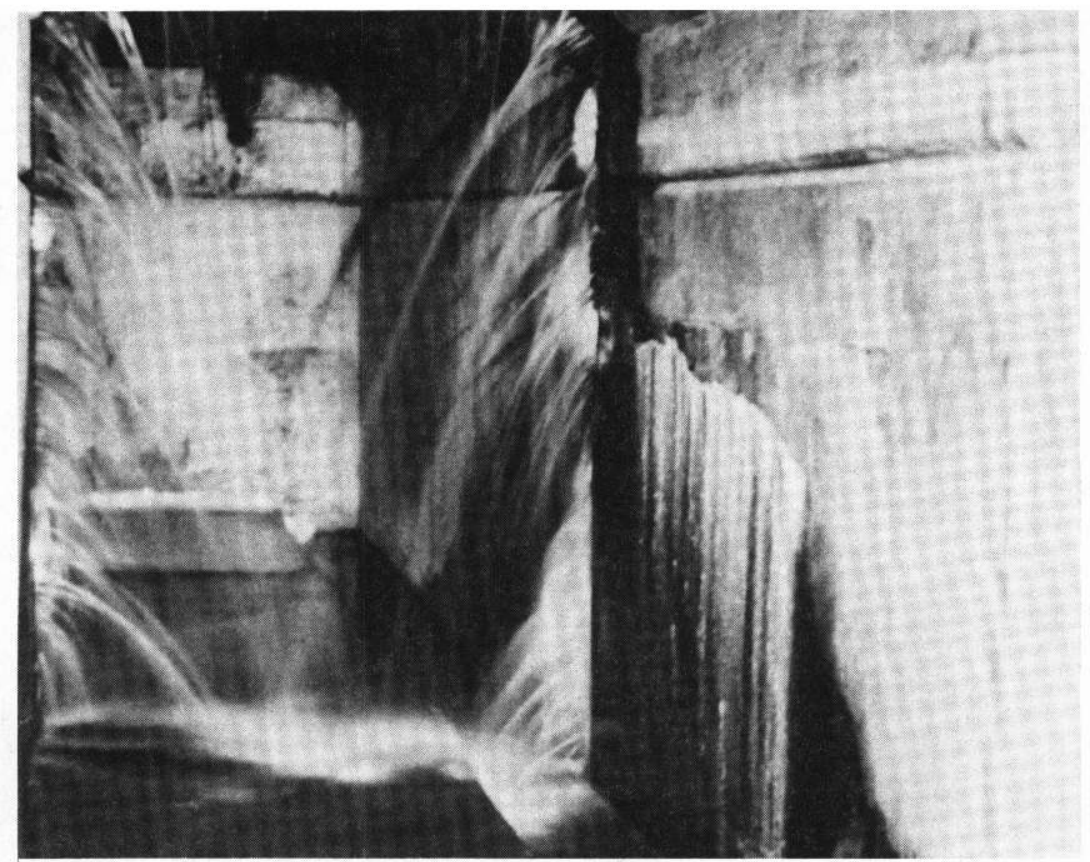

Figure 114. Leakage from monolith joint R18/19 into grouting gallery with full lock chamber

were to be twice as deep ( $82 \mathrm{ft}$ ) as those at Lock and Dam No. 3 and because of the difficulties anticipated in placing long neoprene tubes, it was decided to use a waterstop material consisting of burlap bags soaked in expandable chemicals.

211. New waterstops were installed only in lock wall monolith joints L21/22 and R18/19 located in the lower miter sill area. The joints are located at the same downstream station directly opposite each other in the miter gate recesses. A sectional view of the waterstop and boring location is shown in Figure 115. The waterstops were installed in the leaking joints by means of drilling vertical core holes from the top surface of the lock wall to bedrock at each joint location. The cored holes were filled with burlap bags (18 by 24 in.) that had been saturated with a chemical which had the capability to swell, producing a permanent pliable seal along the cored construction joint. Installation of the waterstops, which was done intermittently, was initiated August 1981 and completed April 1982. The work was performed without dewatering the lock and priority was given to lock operations during installation.

212. Drilling was accomplished using a skid-mounted drill rig. Drilling was done from the top of the lock walls; and to facilitate placement of 


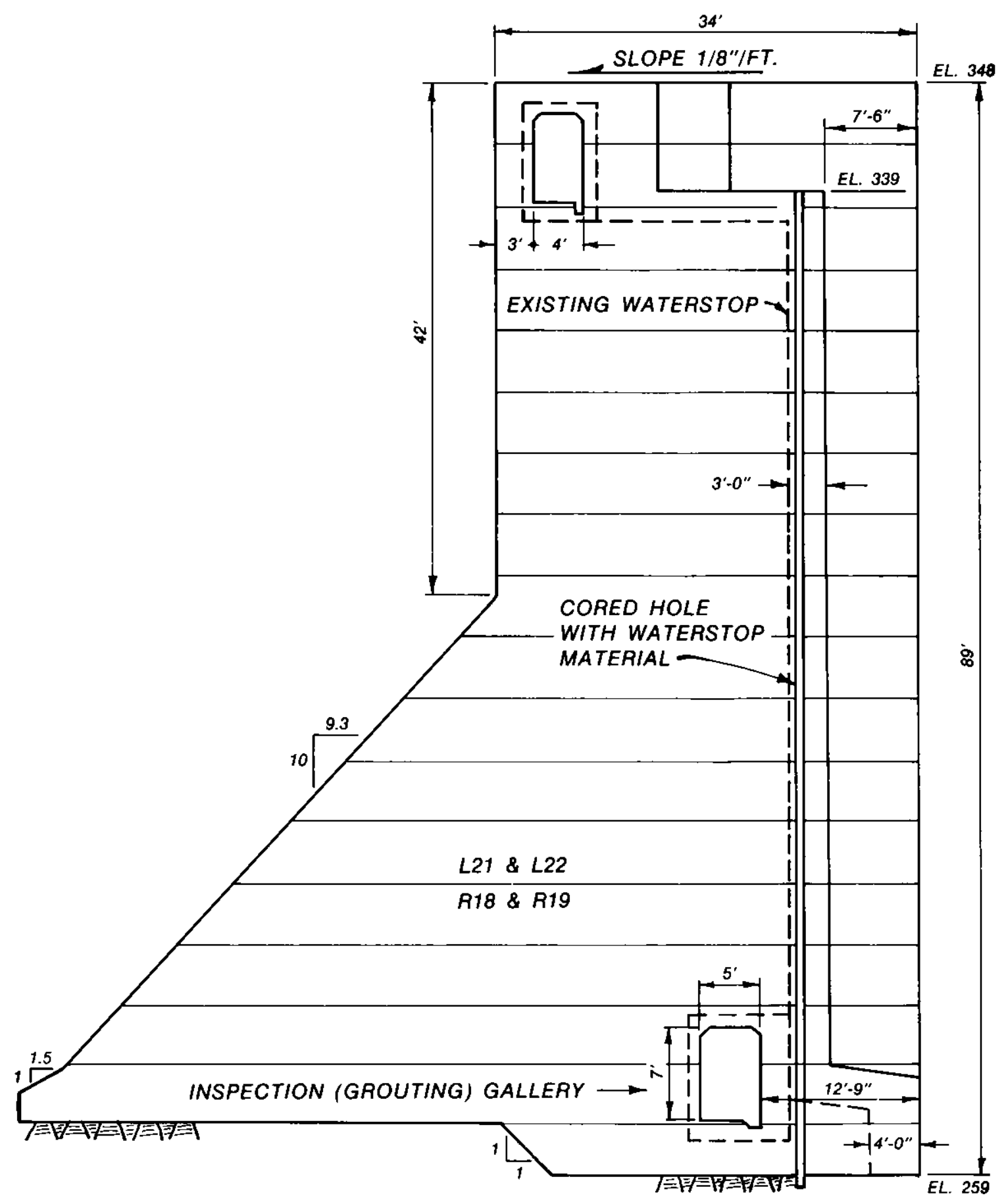

Figure 115. Monolith joint repair, Dardanelle Lock 
the drill rig on location, a work platform was designed and built to enable a barge-mounted crane to do the task from the lock chamber (Figure 116). The drill was put in top working condition in order that accurate drilling alignment could be maintained.

213. Both holes went to a depth of $82 \mathrm{ft}$ which bottomed $1-2 \mathrm{ft}$ into foundation rock (sandstone). The core holes were started on location, centered across the monolith joint by means of an anchored metal template. Difficulty was encountered on the first hole (L21/22, landward lock wal1) when the core lost the monolith joint at $41.2 \mathrm{ft}$. At $51.2 \mathrm{ft}$ the drill hole was stopped when it was judged that the drill hole completely left the joint. Attempts were made to straighten the drill hole with no success and the hole was abandoned. A wireline core barrel (4.827-in. hole, 3.345-in. core) was obtained to complete the profect which produced better results in drilling a plumb hole.

214. Vertical drill rig alignment was monitored during drilling by two transits located at right angles to each other. Sightings were made on the drill head quill and on the drill rod to ensure vertical drilling. Slight leveling of the rig was necessary during drilling operations because of settlements due to vibrations. As the coring progressed, the extracted core was studied for joint alignment (Figure 117). Plumbness of the cored hole above the waterline was easily checked by a plumb bob and flashlight. After a depth of about $20 \mathrm{ft}$, plumbness of the hole was checked every $5 \mathrm{ft}$ by a device designed out of necessity. The device was a pencil-shaped plumb bob and a can with the bottom lined with modeling clay. The can (slightly smaller than the hole, perforated, weighted with washers in the clay bottom, and suspended by two nylon strings) was very slowly lowered to the bottom of the hole, ensuring correct orientation. The plumb bob was lowered to the bottom and suspended through a hole in a template placed on top of the hole. The plumb bob was stopped $\mathrm{l}$ ft above the bottom, allowed to plumb for $5 \mathrm{~min}$, and then allowed a free fall into the clay making an indentation. The total procedure was repeated a second time as a check. This method will indicate deflection of the bottom of the hole in relation to the top of the hole, and direction of the deflection. A hole that has deflected can be straightened generally. However, this procedure should be attempted only by experienced personnel. Briefly, in a vertical hole that has deflected to the right, the drill rig and drill stems should be moved vertically to the right (same as the deflection). 


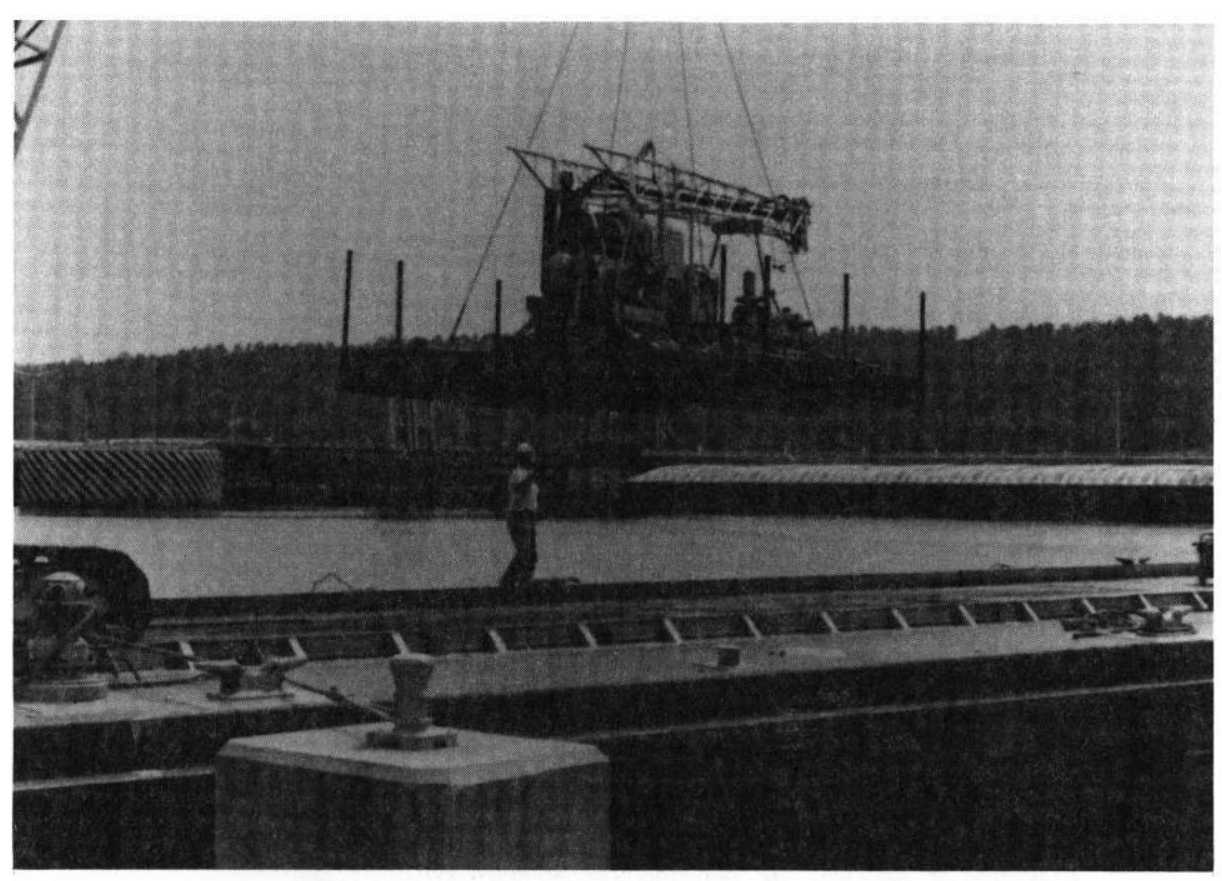

a. Drill rig being hoisted onto river barge

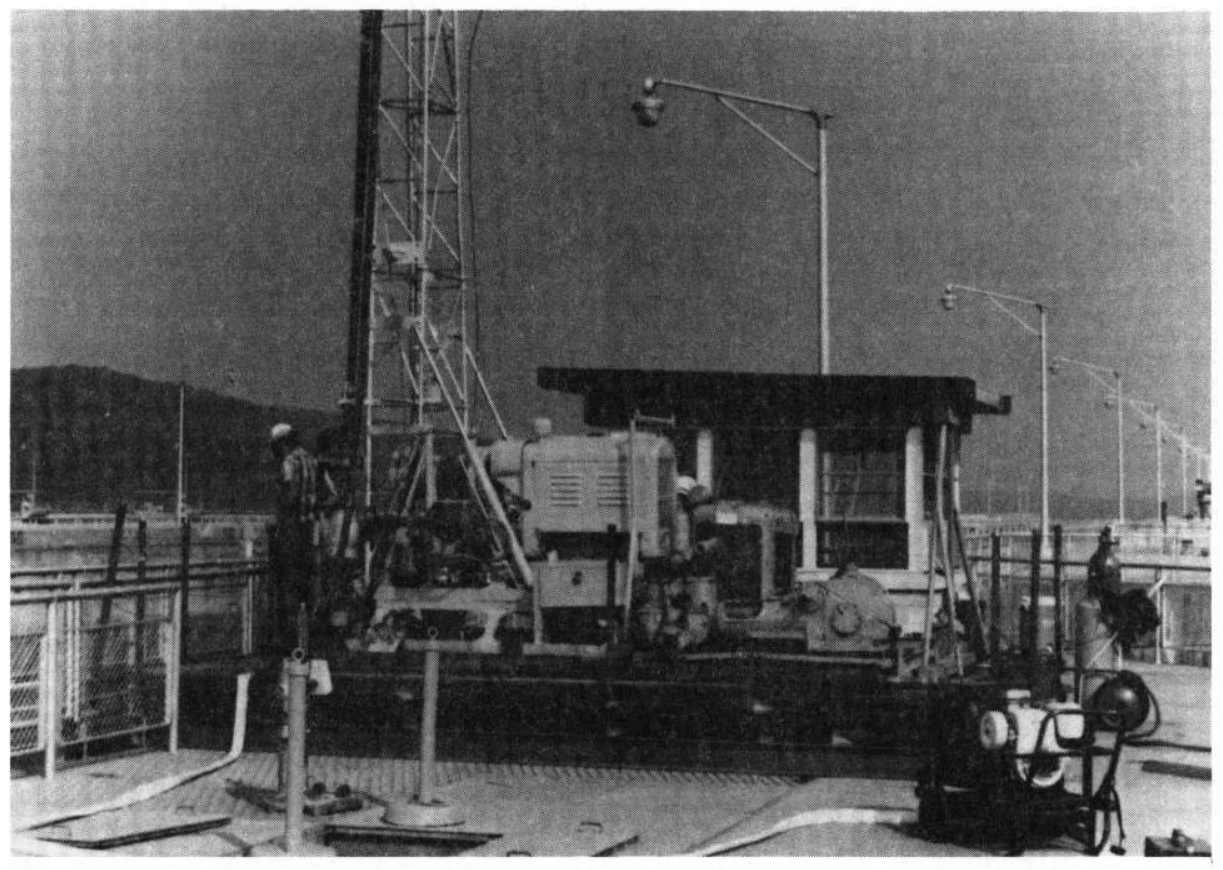

b. Drill rig secured on location

Figure 116. Drilling operations, monolith joint L21/22 


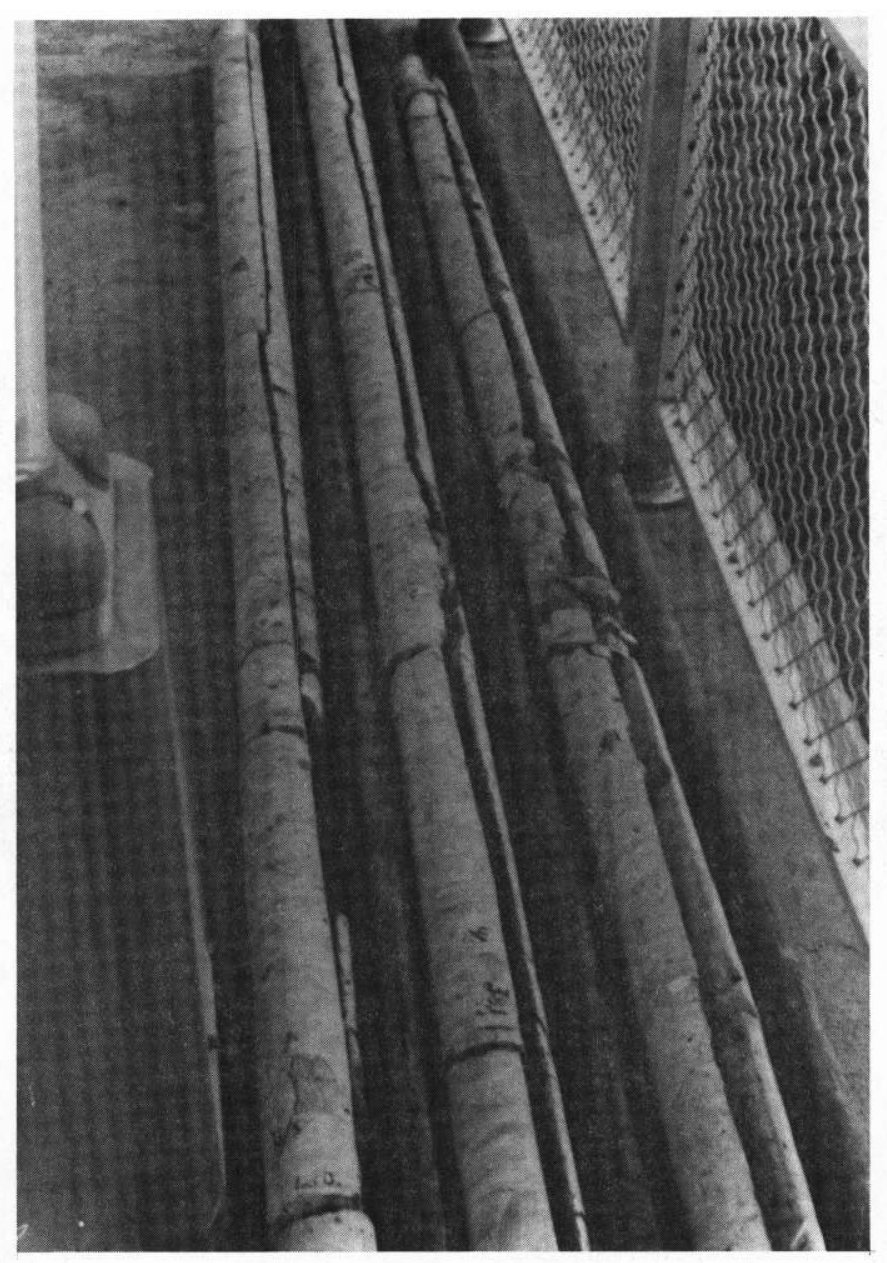

\section{Figure 117. Concrete core from drill hole along monolith joint}

After a few short core runs, when it can be determined that the hole has started to return to plumbness, the decision must be made to move the drill rig, vertically back to its original location. After a few short core runs, the bottom of the hole should be drilling plumb back at its original location. Should the last adjustments be made too late, the hole would cross the plumb point and continue out of plumb on yet the other side (left).

215. The cored hole was filled with burlap bags (18 by 24 in.) that had been saturated with a chemical that produced a product with a swelling capability of about four times its volume when mixed with water. The chemical used was Grouting Compound CR-202, produced by Chemical Resources Division of 3M Company. Distributor in the Arkansas area was Avanti International, Houston, Tex. The chemical is a hydrophilic polymer which contains toluene diisocyanate (TDI) acetone. In its uncured form, CR-202 is a low-viscosity 
liquid similar in appearance to medium-weight motor oil. In its liquid form, it is highly toxic to the eyes, respiratory system, and skin, and after curing it is essentially nontoxic. It can be used in potable water. The liquid chemical will swell 10 times its volume in an unconfined state when mixed with water and resembles a yellow-amber tough, flexible, cellular rubber. The foam and cure time of the product is relative to the ambient temperature. Cure time on this project was about 7 min.

216. Special safety precautions were taken to protect the health of the work personnel while mixing and placing the chemical product. The men were equipped with: hooded disposable paper coveralls, rubber gloves, plastic face shields, and breathing masks. The specifications for the masks assured protection from toxic fumes. Fans were used in the confined areas of the gate recess to remove the fumes. Cans of water, to be used for washing, were stored nearby if needed.

217. The burlap bags and the CR-202 chemical were mixed together in large plastic garbage pails. Fifty bags were added to 5 gal of CR-202, one bag at a time, while being thoroughly agitated with a broom stick until fully saturated. The bags were then wrung by hand, leaving enough chemical in the bag to do the job expected (Figure 118). The saturated bags were stored in plastic garbage pails with lids.

218. The objective was to install the waterstop materials into the hole in a continuous operation. The hole was previously cleaned and contained water only. A driller and four helpers were needed during installation. Two men were on standby to relieve as needed. Bags were placed over the hole (Figure 118), one at a time, and a 20-ft $\mathrm{N}$ rod attached to drill line was allowed to free fall, taking each bag to the bottom of the hole. Tamping of the hole with the rod was done every seventh bag to remove voids. The driller had a marker on the drill line to indicate the bottom of the hole during "free falls" and the $\mathrm{N}$ rod was brightly painted to assist in visual safety. During short breaks the $\mathrm{N}$ rod was allowed to rest on bottom keeping the bags from floating upward, but not for over 2 min since the bags would have bonded to the rod. The bags were placed to within $2 \mathrm{ft}$ of the top of the hole. Two dry burlap bags were placed on top of the saturated bags and weighted down until all curing had taken place. Later, the top of the hole was cleared of all CR-202 waste and capped with cement. 


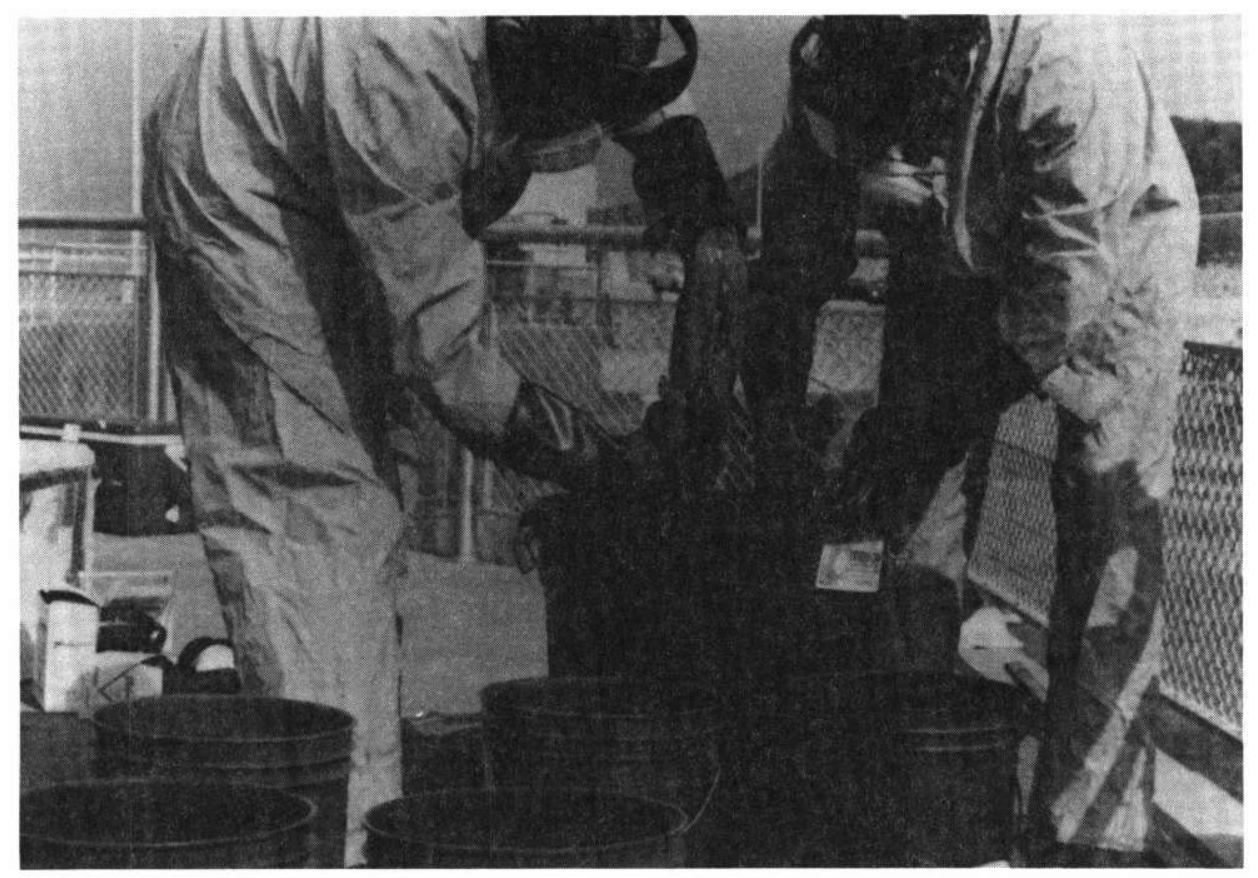

a. Saturating burlap bags with chemical grout

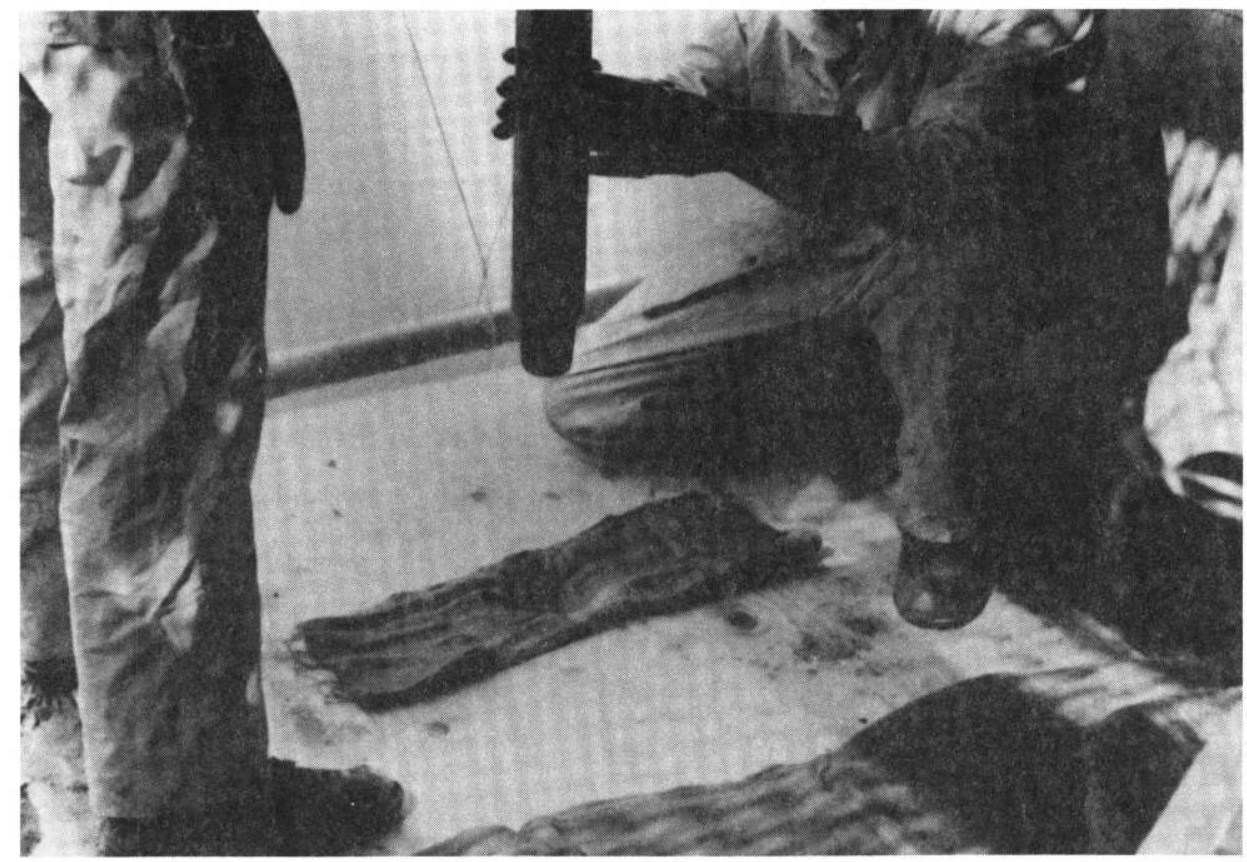

b. Saturated bag on top of drill hole awaiting insertion

Figure 118. Mixing and placing operations 
219. The amount of materials used will vary with the bag soaking process, the amount of joint leakage, and the degree of compaction in the hole. During installation, large amounts of uncured CR-202 were pressed out of the joint and flowed into the river. Monolith joint L21/22 required 478 burlap bags and 85 gal of CR-202. Monolith joint R18/19 required 425 burlap bags and 80 gal of CR-202. The price of a 5-gal can of CR-202 in March 1982 was $\$ 365.75$.

220. The new waterstops reduced the leakage into the galleries by at least 95 percent. Photographs of the leakage before and after waterstop installation are shown in Figures 114 and 119.

\section{R. D. Bailey Dam}

221. The dam is located on the Guyandot River in Mingo and Wyoming Counties, approximately 1 mile northeast of Justice, W. Va. The 310-ft-high (maximum) rolled, random rock-fill dam has a reinforced concrete facing (Figure 120). R. D. Bailey Dam is a unique water-retaining structure in that it was designed to accommodate large volumes of seepage without affecting proper and safe functioning of the structure.

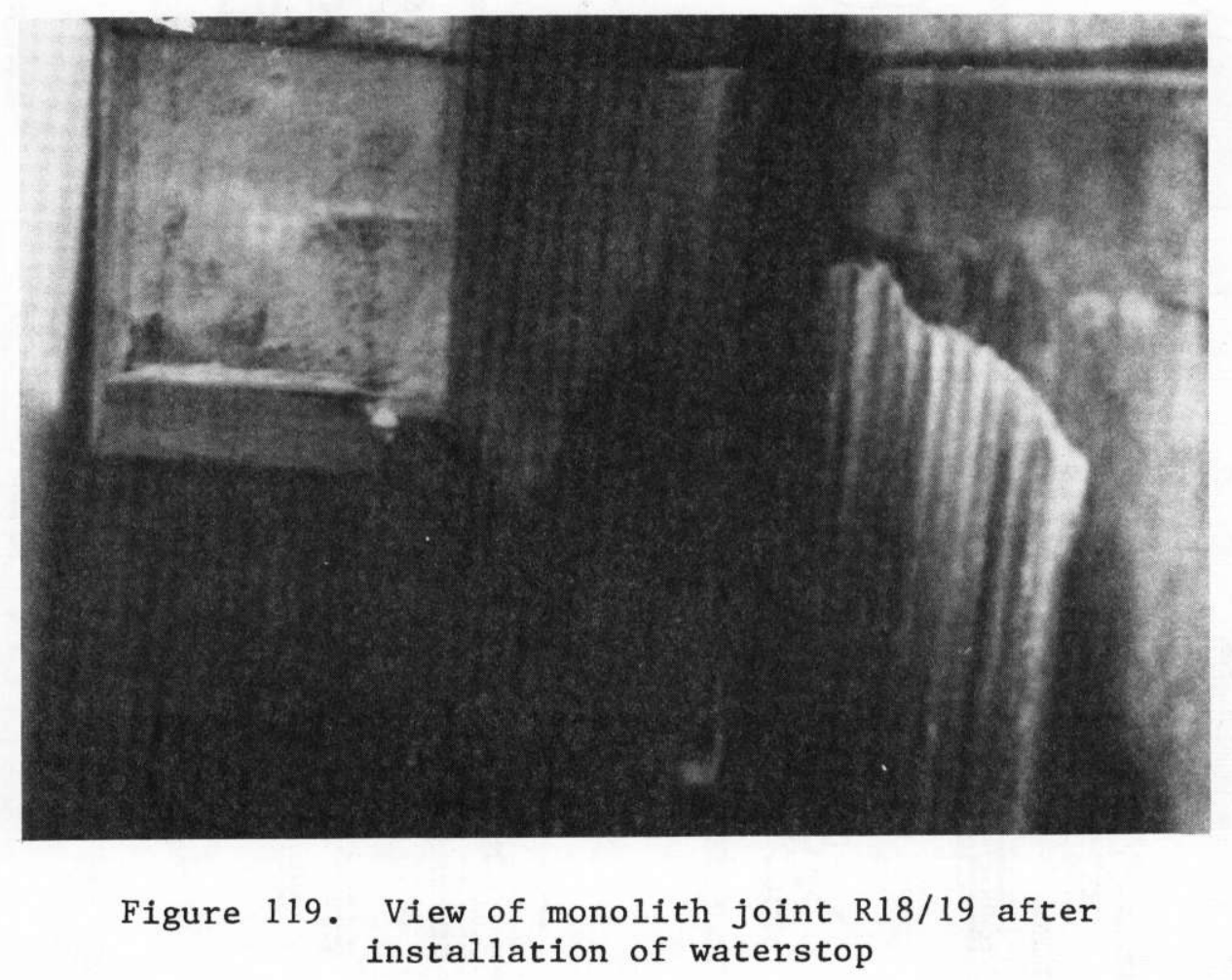




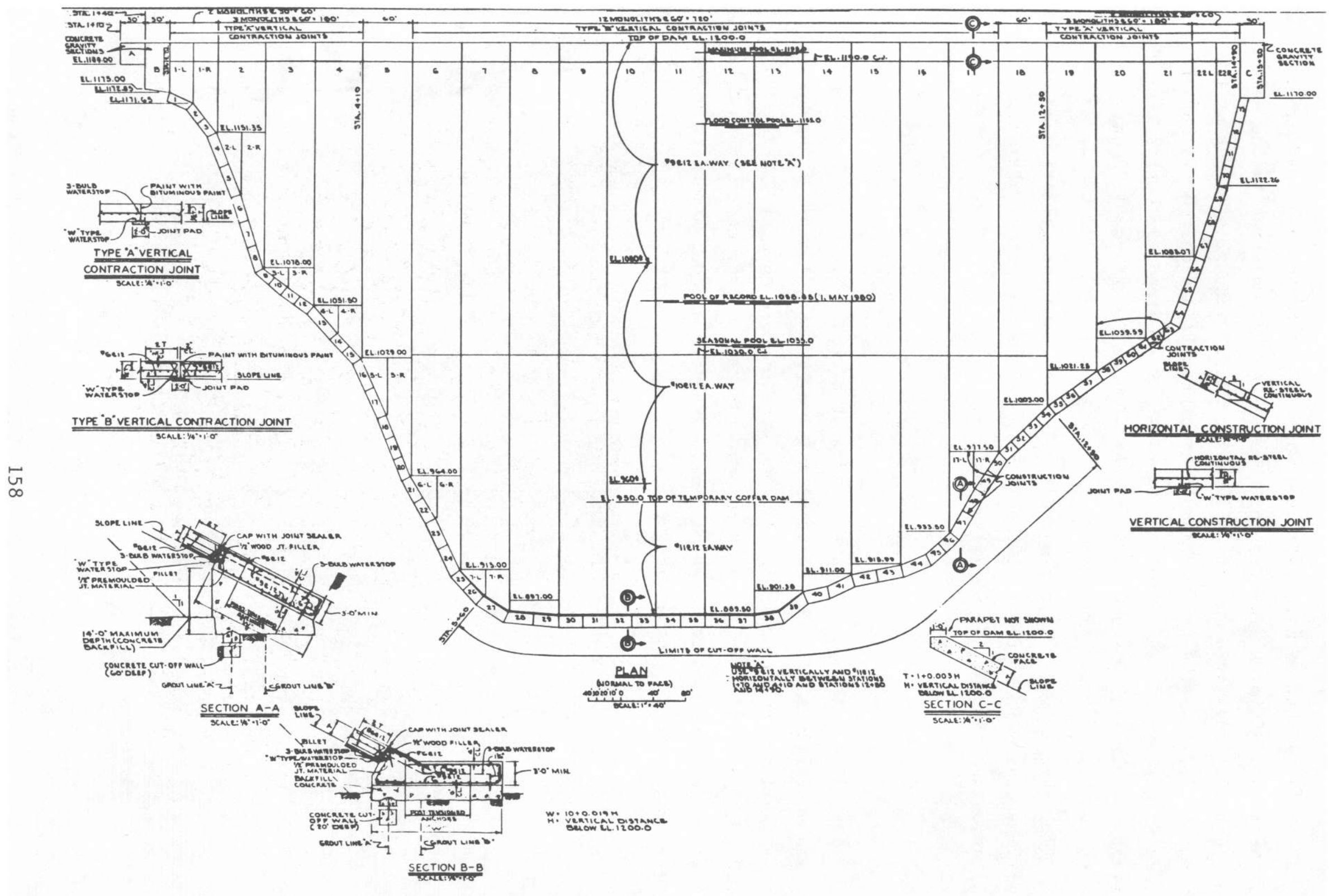

Figure 120. Concrete facing details, R. D. Bailey Dam 
222. Filling of R. D. Bailey Lake began in February 1980. On 1 May 1980 seepage outflow reached a recorded maximum of $13 \mathrm{cu} f \mathrm{f} / \mathrm{sec}$ with the reservoir pool at elevation $1,058.5 \mathrm{ft}, 23.5 \mathrm{ft}$ above seasonal pool. The outflow was clear, indicating no significant movement of solids. The outflow with pool elevation at $1,035 \mathrm{ft}$ decreased from $10 \mathrm{cu} \mathrm{ft} / \mathrm{sec}$ in late July to about $5.5 \mathrm{cu} \mathrm{ft} / \mathrm{sec}$ in early 0ctober 1980. Subsequent to normal winter drawdown, outflow remained constant at approximately $5 \mathrm{cu} f t / s e c$ with a pool elevation of $1,012 \mathrm{ft}$. Seepage estimates prior to impoundment indicated a base flow of approximately $1 \mathrm{cu} \mathrm{ft} / \mathrm{sec}$.

223. Because the volume of seepage outflow during the initial filling of the lake was greater than that anticipated after reaching full pool, it was decided to inspect the face slab joints and the joint between the face slab and the toe blocks (perimeter joint) for possible points of seepage or differential settlement. Several methods of performing the inspection were considered including: (a) using divers with an underwater video camera, (b) using a video camera mounted on a cart guided by ropes from the concrete face, and (c) unwatering the lake.

224. In an effort to avoid unwatering the lake, the underwater methods were attempted. The least costly method initially selected was a video camera mounted on a cart, using a remote monitor. A camera, monitor, and technician were furnished by the Nashville District to assist in this effort. Two trials of lowering the cart along the vertical joints were made; however, viewing of the slab joints was unsuccessful due to the silt deposits on the face slab. The next underwater method consisted of divers using the camera to minimize stirring of the silt deposits. Arrangements were made for a military diving team from Ft. Belvoir, Va, to perform the inspection in March 1981.

225. The initial procedure was for the divers to use a video camera to inspect all joints and for their supervisor to view the remote monitor for indications of seepage. Because of the deposits of silt on the face slab, the slightest movement of the diver would cloud the water with silt, which prevented viewing on the monitor. Therefore, this procedure was changed to have the divers clean the joints and use their hands to check for flow through the joints. If flow was felt, as indicated by suction, the underwater video camera was then used to verify and record their findings. This revised procedure produced acceptable results and was used throughout the remainder of the inspection. 
226. Efforts were limited by: (a) the length of time a diver could spend from the moment of entering the water until returning to the surface (approximately $30 \mathrm{~min}$ when diving to depths of $120 \mathrm{ft}$ ), (b) turbidity of the lake which prevented diver observation, (c) silt deposits (4 in. in some areas), and (d) low water temperature (about $38^{\circ} \mathrm{F}$ ) which numbed the divers' hands despite the heavy gloves they wore. It should be noted that because of the numbing cold, the divers may not have detected seepage areas which were small and exhibited less "suction" (flow due to differential head) than those which they reported.

227. All of the vertical joints in the face slab and the perimeter joint below elevation 1,012 ft were inspected by the divers with the following results:

a. A seepage area was identified which was about 6 in. long in the vertical joint between lanes 11 and 12 at about elevation $904 \mathrm{ft}$. Suction was slight.

b. A seepage area was identified in the perimeter joint extending from the middle of lane 16 to lane 18. The elevation of this seepage area varied from approximately elevation $920 \mathrm{ft}$ to elevation $975 \mathrm{ft}$. Suction was quite strong at several isolated points. Also in this area the face slabs had settled about $6 \mathrm{in}$. at the intersection of lanes 16 and 17 , and the toe block (Figure 121).

c. A small section of the face slab, about $3 \mathrm{ft} 1$ long and $1 \mathrm{ft}$ wide, at the offset in the joint between lanes 16 and 17 , was broken and depressed about $4 \mathrm{in.}$ Suction was moderate.

d. A small spalled area of concrete, about $1 \mathrm{ft}$ long and 6 in. wide, was identified along the perimeter joint at toe block 49 . Suction was slight.

228. The divers attempted to seal the seepage areas by inserting manila rope in the joint and covering the joint with 5-ft-wide plastic sheets. To determine the extent of seepage reduction, readings below the dam in the seepage collection structure were taken before and after the sealing effort. These observations were inconclusive due to increasing pool. levels and precipitation immediately following the sealing effort.

229. A Task Force was formed in April 1981 to investigate the seepage through the dam face slab. Specifically, the Task Force's objectives were to investigate the causative factors leading to the seepage, determine their effects, recommend remedial measures, and evaluate the impact of such measures. The Task Force concluded (US Army Engineer District, Huntington 1981) that the 


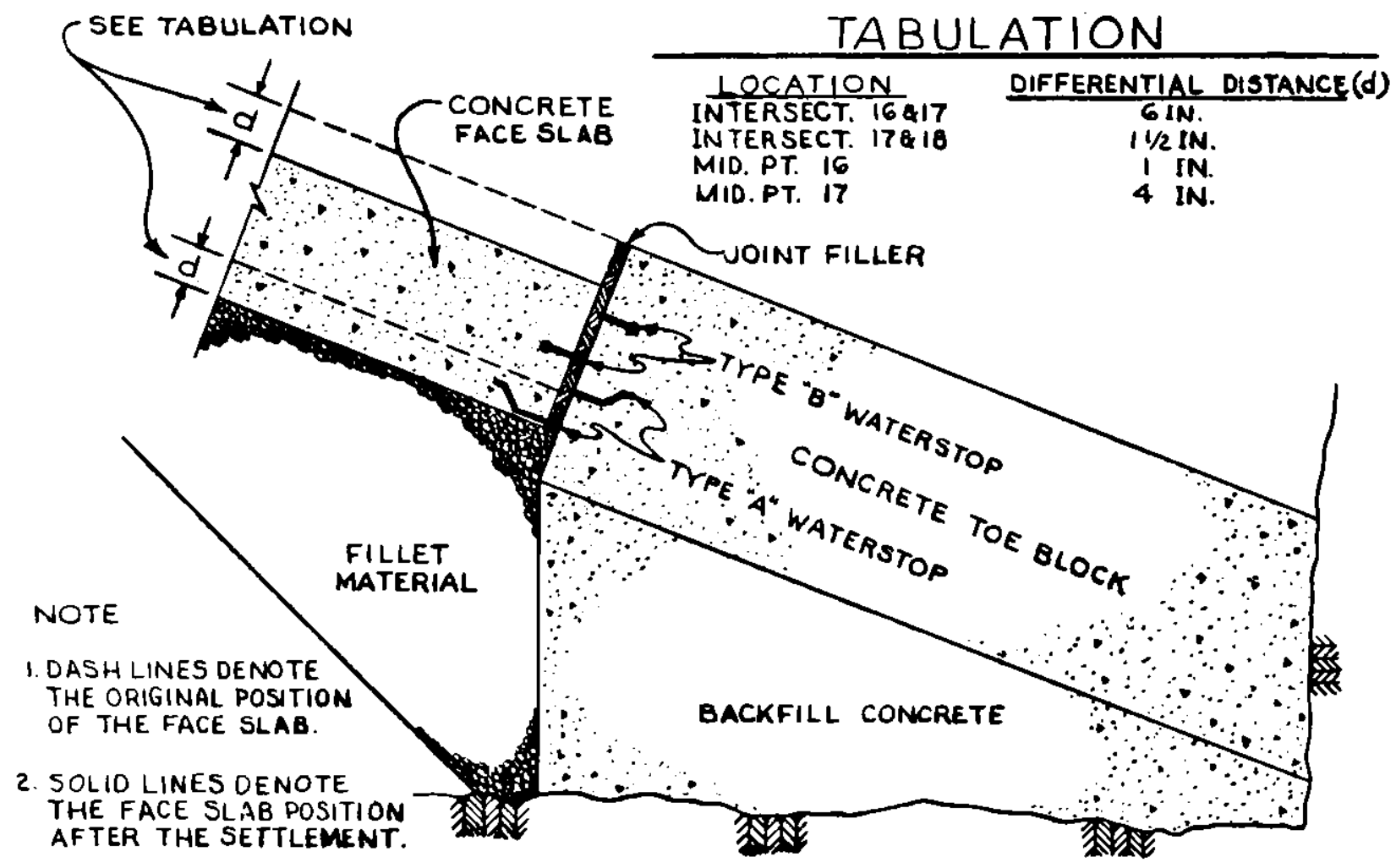

Figure 121. Displacement between face slabs and toe block, R. D. Bailey Dam most probable cause of the distress was consolidation of the fillet material, aggravated by the introduction of water, under head, into the fillet zone. Potential entry paths for the water included (a) a known discontinuity in the waterstops, (b) defective or damaged waterstops, (c) a defective cutoff wall, and (d) waterstop failure due to excessive consolidation of fillet material upon application of load. Considering the condition of the distressed area of the dam together with the performance requirements, it was also concluded that the dam was functioning as designed and that there was no cause for concern for either rapld or progressive fallure.

230. It was recommended that a mixture of concrete sand and clay be fed into seepage areas to fill any voids behind the face slab and cover the distressed areas. This was accomplished in December 1981 by lowering bags filled with the sand and clay mixture down the face of the dam by a cart and having divers empty the bags in the distressed areas. After the mixture was placed, no flow through this area could be detected.

231. A diver inspection in February 1982 detected a depression in sand and clay material covering the distressed area; therefore additional material 
was added. Diving inspections of the entire dam face in November 1982 and 1983 revealed no problems. In May 1984, the pool of record, $53 \mathrm{ft}$ higher than the previous record, was experienced. Flow at the collection structure peaked at $7.5 \mathrm{cu} \mathrm{ft} / \mathrm{sec}$ and decreased to $3.5 \mathrm{cu} \mathrm{ft} / \mathrm{sec}$ as the pool dropped down to summer levels.

\section{Applegate Dam}

232. Applegate Dam is located in southwest Oregon on the Applegate River about 23 miles southwest of Medford. The dam is a 244-ft-high, 1,200-ft-long zoned gravel embankment with a central impervious core. Principal appurtenant structures include a gated, concrete gravity spillway on the left abutment and a regulating outlet tower, conduit, st1lling basin, and fish facilities at the toe of the left abutment. The oblong outlet conduit is 9 by 14-1/2 ft and $930 \mathrm{ft}$ long (Figure 122). A 20-in., 20-oz copper waterstop is located in the center of the 4-ft-thick reinforced concrete walls at each contraction joint. Construction was completed in 1980.

233. During the 20 May 1981 periodic inspection, significant leakage was observed through three joints in the regulating outlet conduit. Leakage at joint $15 / 16$ was reportedly flowing at 3-5 gal/min from near the upper left side of the joint. Water was assumed to be flowing from the foundation rock along the joint to either a break in the waterstop or through a zone of porous concrete around the waterstop. Impervious core material is in direct contact with the conduit in this area (Figure 122). The potential for erosion of the core material was felt to be serious enough to warrant immediate repair. Leaks at the other two joints were located under the cobble and boulder zone and were not considered a threat to the integrity of the embankment. The District Hydrology Section recommended that repairs be made between 1 and 12 June. This time frame allowed for the best flow and temperature conditions when diverting water through the fish/water supply pipe.

234. Repalr procedures called for core drilling two $1-1 / 2$ in. holes near the bottom of the conduit with one hole on each side of the conduit. The characteristics of the water source were to be determined from these holes prior to grouting. Grout was to be pumped through the two drili holes into the contraction joint behind the waterstop and allowed to vent at the leak. 


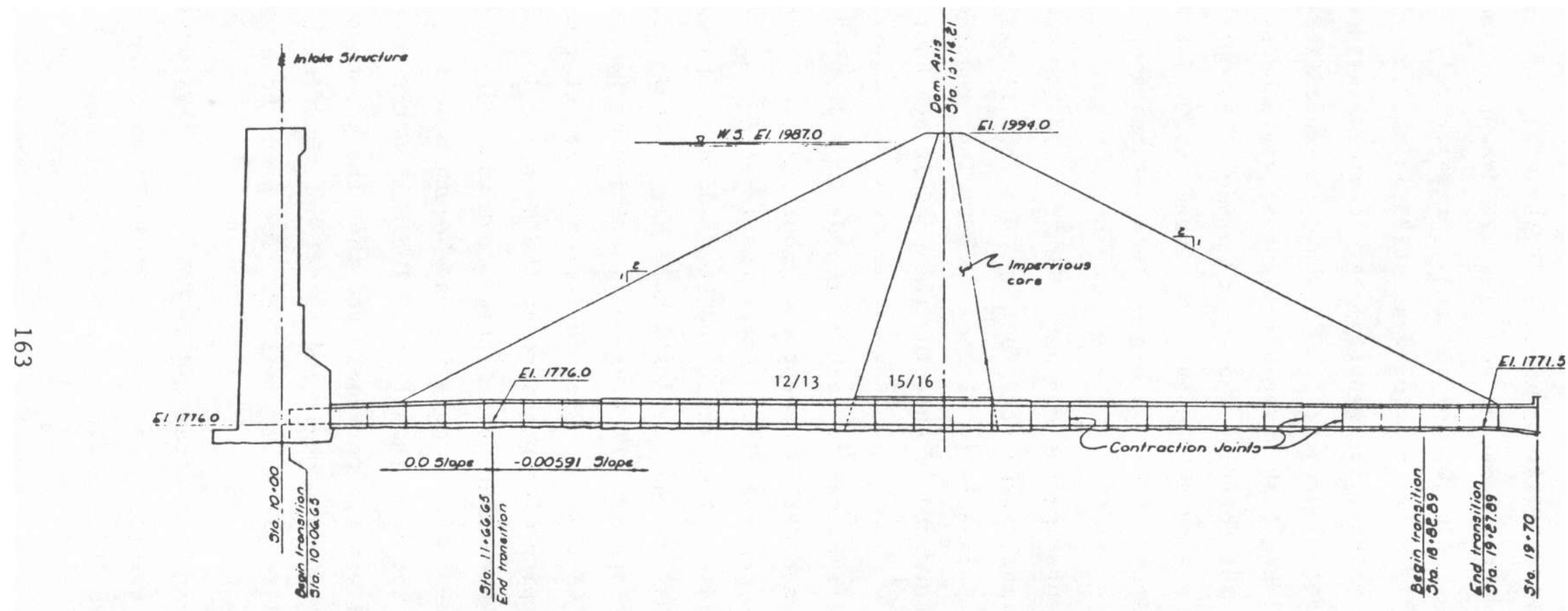

Figure 122. Regulating outlet conduit elevation, Applegate Dam 
235. US Army Corps of Engineers crews began mobilizing on Monday, l June, and were ready to enter the conduit at the beginning of shift on 3 June. Two holes were drilled, as shown in Figure 123 and 124, and the conduit was made ready for the grouting contractor. Measured flow from the drill holes was 12.5 and $8 \mathrm{gal} / \mathrm{min}$ for holes 1 and 2, respectively. Flow through the leak with both drill holes flowing was estimated at $2.5 \mathrm{gal} / \mathrm{min}$.

236. A supply contract for grouting services was awarded to GELCO Grouting Services of Salem, Oregon, for $\$ 5,000$. The specifications required the contractor to seal the leak using a grout that would be permanent, flexible, and watertight. The contractor elected to use a hydrophilic polyurethane gel (CR-250) manufactured by 3M Company. Set time for CR-250 alone was reported by the contractor to be $1.5 \mathrm{~min}$ or less depending upon the temperature of the material.

237. Prior to entering the conduit, $250 \mathrm{ft}$ of $1 / 2-\mathrm{in}$. hose was added to the $500 \mathrm{ft}$ of hose normally used for grouting. The additional hose was described as slightly permeable to air and water. The grout house was prefilled prior to the contractor's entering the condutt at about 9:00 a.m. on 4 June.

238. Packers were placed in each of the drill holes. Hole No. 1 was fitted with a quick connector to accept the grout injector, and hole No. 2 was fitted with a valve to control flow. After the injector was connected and pumping commenced, Celite filler which had been added to the water side was transmitted to both the leak and to drill hole No. 2 within seconds, but the grout material did not appear. Pressure at the injector remained low after 3 or 4 min of pumping. CR-851 was added to increase the set time. After several minutes of pumping with pressure at the pump and low pressure at the injector it was discovered that very little grout was being injected and that, because of the high pressures, a coupling had begun to leak. Total loss of grout at the coupling was less than 1 gal. The contractor discovered that the 250-ft section of hose was too permeable and that the grout was taking on water through the hose and was beginning to set up. Sufficient grout had been pumped 1nto hole No. I to partially seal it. The grout hose was removed from the conduit and repaired.

239. Grouting was next attempted at hole No. 2. Very little grout was injected before the pressure began to rise. Injection ceased after pressure at the injector rose to $100 \mathrm{psi}$ with no flow, indicating the hole was plugged 


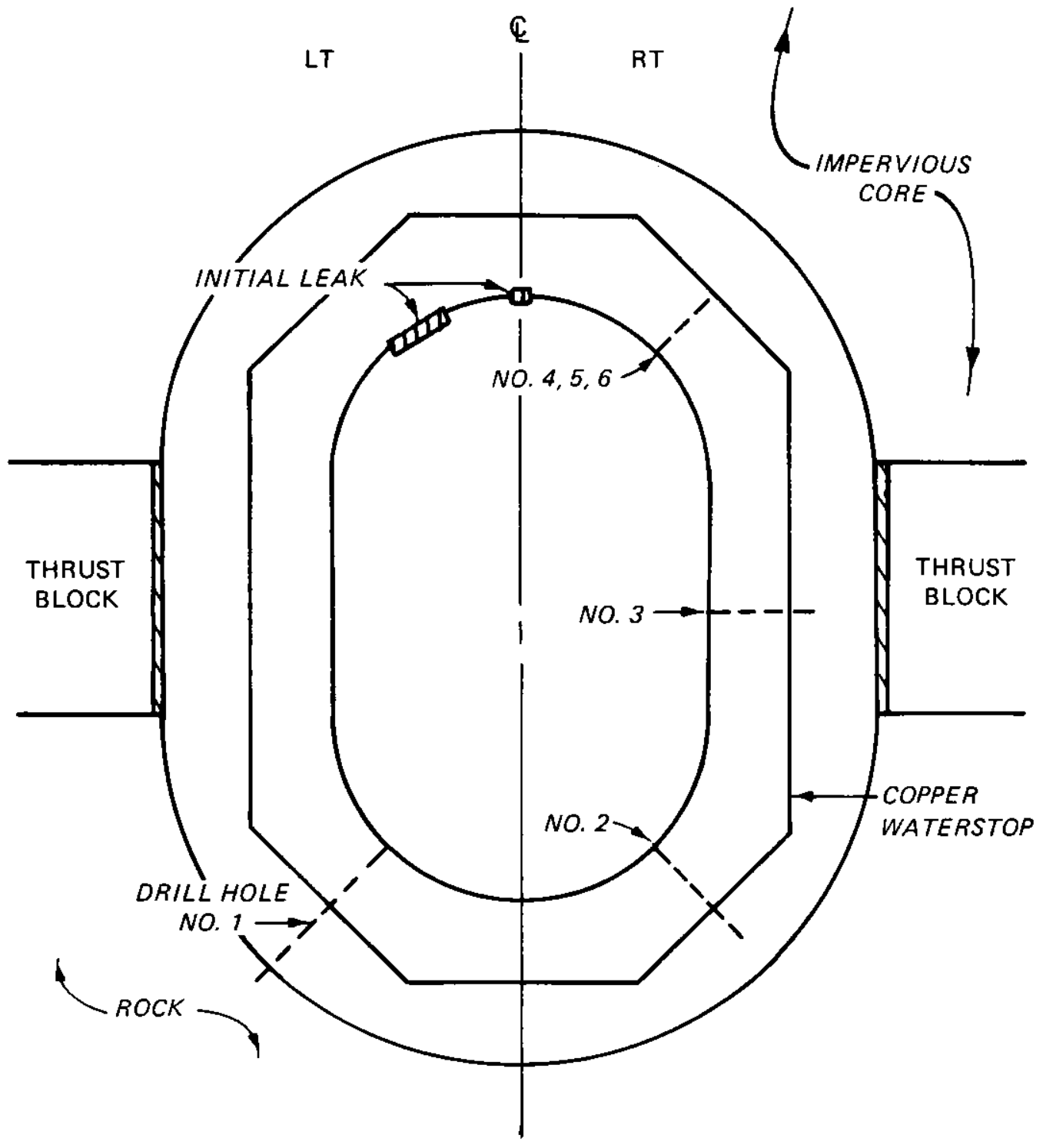

Figure 123. Grout hole locations, Applegate Dam 


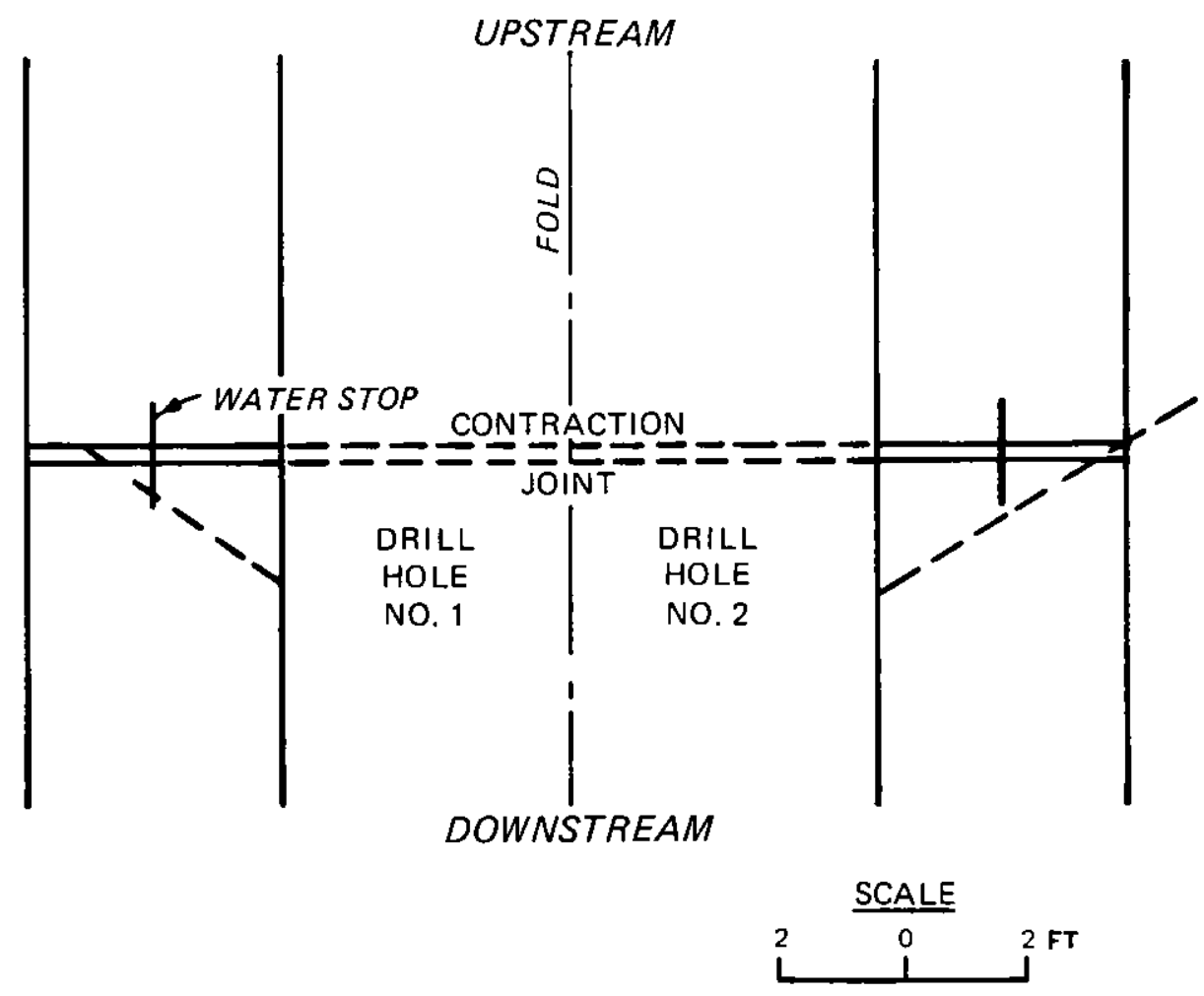

Figure 124. Section through grout holes 1 and 2, Applegate Dan

off. It appeared that the initial injection had sealed the lower portion of the expansion joint; therefore additional holes would have to be drilled in an effort to get grout to the leak. The contractor was asked to attempt to drill into the expansion joint with his hand-held impact drill using a 5/8- by 32-in. bit. The first hole (No. 3) was drilled halfway up the right wall (Figure 123). This hole produced some jelled grout and a minor flow of water. Drilling was then attempted at the midpoint of the right side of the crown. The first hole (No. 4) entered the contraction joint inside the waterstop. A second hole (No. 5) was attempted which hit rebar and was abandoned. A third hole was started (No. 6) and after drilling 18 to 20 in., grout fragments and water were seen coming from hole No. 4 and the right side of the roof area; therefore, the hole was terminated. Within a few seconds about $8-10 \mathrm{gal} / \mathrm{min}$ of water was flowing from the new leak in the roof.

240. The next grouting attempt was through hole No. 3. Water with Celite was injected into the hole at about 45-50 psi for 5 to $10 \mathrm{sec}$ and then 
allowed to drain. After surging the hole several times, good communication was made with the leak on the right side of the roof. Grouting began and the pressure at the injector was maintained at less than $50 \mathrm{psi}$. Grout was noted flowing from the expansion joint near the invert after grouting for about a minute. It could not be determined where the grout was flowing through the waterstop. The grout began setting up in the expansion joint at the invert and progressed up the right wall to about 6 in. above the elevation of injector. At that point the pressure began increasing at the injector. The pressure was allowed to increase to 80 psi before the pumping rate was decreased. Pumping continued at a reduced rate for a short time before the pressure began to increase. The pumping rate was left constant and the pressure was allowed to increase to about 120 psi at which point the pressure dropped to 40 psi and grout was noted flowing from the leak on the right side of the roof. A constant pumping rate was maintained and after about $1 \mathrm{~min}$ of pumping, the leak on the right side stopped. Shortly thereafter the water drip in the center stopped and then the leak on the left stopped. At that time the leak on the right started again and after about a minute stopped. Grouting continued for another few minutes with completion at 2:50 p.m.

241. A total of 52 gal of grout were pumped, of which 8 gal remained in the hose. If it is assumed that the contraction joint outside of the waterstop is full of grout, then approximately 30 gal of grout were injected into the joint. Between 10 and $15 \mathrm{gal}$ of grout were wasted. The contractor patched the drill holes and two shea bolt holes with "octocrete" described as a high-strength concrete patch. Patching and demobilization of the conduit was completed at $3: 00 \mathrm{p} \cdot \mathrm{m}$. The grouted joint was inspected at that time and the joint was free of any leakage.

242. Based upon observations made during the repair, it was concluded that:

a. The leak was the result of water running around the waterstop and not through it, possibly due to minor honeycombing or poor contact between the waterstop and the concrete.

b. The source of the water was from the lower left side of the conduit and was probably related to concrete in contact with a shear zone. There was no indication that any of the flow was originating from the portion of the conduit which is in contact with the core.

c. The leakage source had a total capacity of about $30 \mathrm{gal} / \mathrm{min}$ with a head of about 50 psi at maximum pool. 
d. Little if any grout entered the fractured rock.

e. The use of chemical grout to seal the leakage into the conduit was effective.

243. During the June 1984 periodic Inspection, leaks were observed at several contraction joints, including joints $15 / 16$ and 12/13. Although joint $15 / 16$ had been repaired previously, concerns about possible erosion of the core were still valid. Leakage through the joint during the inspection was estimated at 1-2 gal/min at a spot about $8 \mathrm{ft}$ up the right wall and 4-5 gal/min through a l/2-in. drill hole (used in prevfous grouting efforts) located $18 \mathrm{in.}$ upstream of the joint and halfway between the crown and spring line on the right side. US Army Engineer Division, North Pacific representatives at the inspection recommended that a repair be conducted within 60 days. 244. A contract was awarded to GELCO Grouting Service, Salem, Oregon, and repairs were begun on $25 \mathrm{July}$ 1984. Fourteen holes were drilled around the perimeter of the conduit to intersect the contraction joint outside of the waterstop (Figure 125). The holes were 5/8-in. diameter and drilled with a Rotohammer drill. Flow through the holes varied from 0 to $5 \mathrm{gal} / \mathrm{min}$, with a total flow of 15-20 gal/min. The system was open, because the contractor was unable to take pressure readings at any of the holes. Also, plugging one hole would cause an increase of flow at other holes.

245. Grouting was started on 26 July using a hydrophilic polyurethane ge1 (CR-250). Grout was pumped into three of the drill holes, starting at hole No. 5 (Figure 126). Grouting at hole No. 5 and 2 apparently plugged those holes but did not fill the joints behind the holes because of flowing water. Hole No. 3 was successfully used to plug all the leaks, because a very fast-setting accelerator was used to shorten the set time of the grout to approximately $5 \mathrm{sec}$.

246. All holes were redrilled on $27 \mathrm{July}$. Hole No. 2, 12, 10, and 11 were leaking very small quantities (approximately $0.5 \mathrm{gal} / \mathrm{min}$ maximum) of water after redrilling. The grout formula was changed to a setting time of 3 min. Hole No. 2 water pressure was measured at 50 psi when it was the only hole flowing. Hole No. 2 was used for grouting with the slow-setting grout which was pumped at up to $1-1 / 2 \mathrm{gal} / \mathrm{min}$. Total grout take was $20 \mathrm{gal}$. Pressure at the pump ranged from 95 to 145 psi at the start of grouting (2:50 p.m.) compared to 110 to 150 psi at completion of grouting (3:15 p.m.). Total grout pressure at the hole was 60 psi. Hole No. 13 and 14 were drilled to confirm 


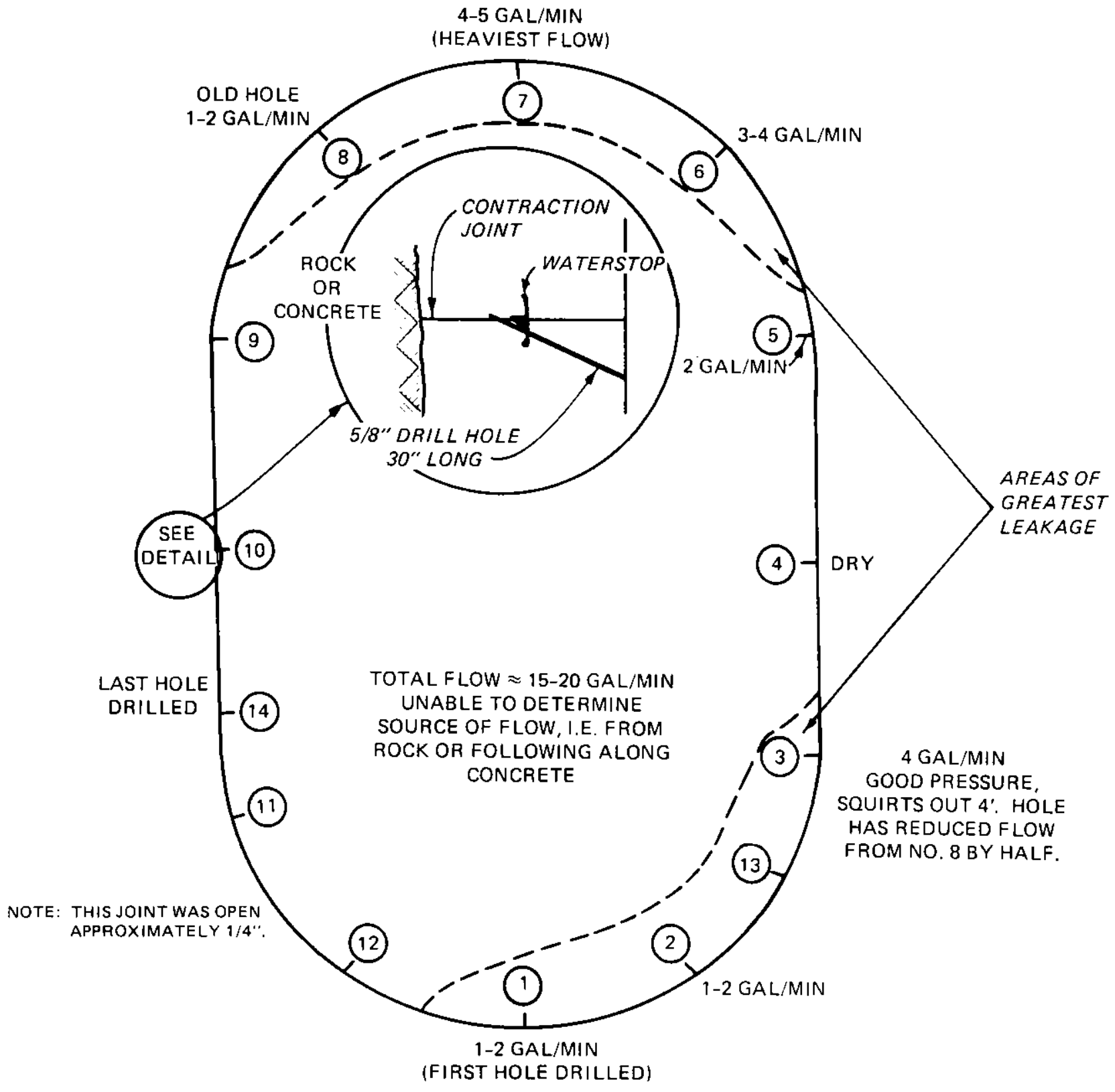

Figure 125. Section at joint 15/16 looking upstream, Applegate Dam 


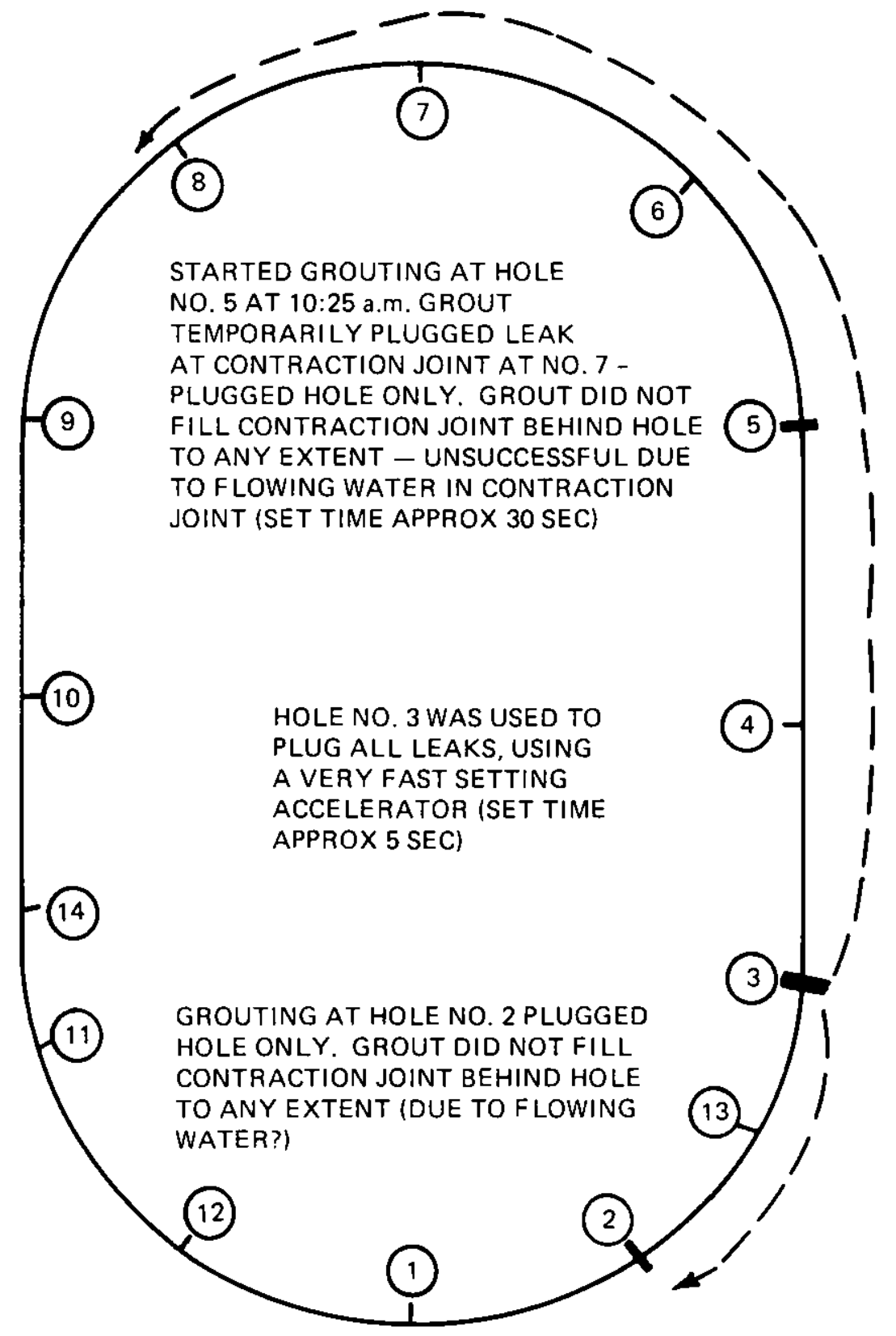

Figure 126. Section at joint $15 / 16$ looking upstream, Applegate Dam 
the repair. No grout was taken at efther hole at the full pressure of 60 psi. Grout was encountered when the hole was drilled through the contraction joint. All grout holes were plugged with portland cement grout. Most holes were redrilled to $1-1 / 4-i n$. diameter to allow drypacking.

247. On $28 \mathrm{July}$, seven holes were drilled at joint 12/13 with the 5/8-in.-diameter Rotohammer (Figure 127). Hole No. 4, in the crown, had the largest flow and greatest pressure prior to grouting of any of the drill holes in either joint. Hole No. 4 was grouted first. Pump pressure built up very rapidly and was at 240 psi after 5 minutes when grouting was stopped. The grouting successfully stopped the slight leakage along this joint. Prior to grouting hole No. 5 water pressure was measured at 90 psi. Hole No. 5 took 10 gal of CR 250 grout with no grout pressure buildup. The hole was plugged after $5 \mathrm{~min}$ and it was assumed the grout was venting to the gravel fill. An attempt was made to grout the other holes but there was no take in any of them. All holes were backfilled with Preco Plug and the repair was completed at $8: 30 \mathrm{p} . \mathrm{m}$. on $28 \mathrm{July}$.

248. A successful repair of the joints was achieved, but some difficulties were encountered with the drilling method used. Drill bits used to intersect contraction joints should be longer than $30 \mathrm{in.}$ to ensure that the joints are intersected on the back side of the waterstop. In several instances during the job, holes were drilled at angles that either missed the contraction joints or intersected the joint and the waterstop. Intersecting the waterstop at hole No. 7 made it impossible to inject grout without grout leakage on the front side of the waterstop. Approximately 50 percent of the actual time spent within the conduit on this job was for repairing damage that occurred at hole No. 7. At other holes where no leakage occurred, it is possible that the contraction joint was missed by the drill hole. Rotohammer drill bits longer than 36 in. (30 in. available for drilling) are not available. To ensure intersecting the contraction joint at the proper location it would be necessary to use a larger type drill system such as an air rotary CP-65. Although considerably slower and requiring a longer outage of conduit, a high-quality repair job would be assured by using larger equipment.

249. Water samples taken at joints $15 / 16$ and $12 / 13$ and at joint $4 / 5$ upstream of the core area were clear and no suspended solids could be detected. Water temperatures measured during the repair operations were $44^{\circ}$ and $45^{\circ} \mathrm{F}$ at joints $6 / 7$ and $15 / 16$, respectively. 


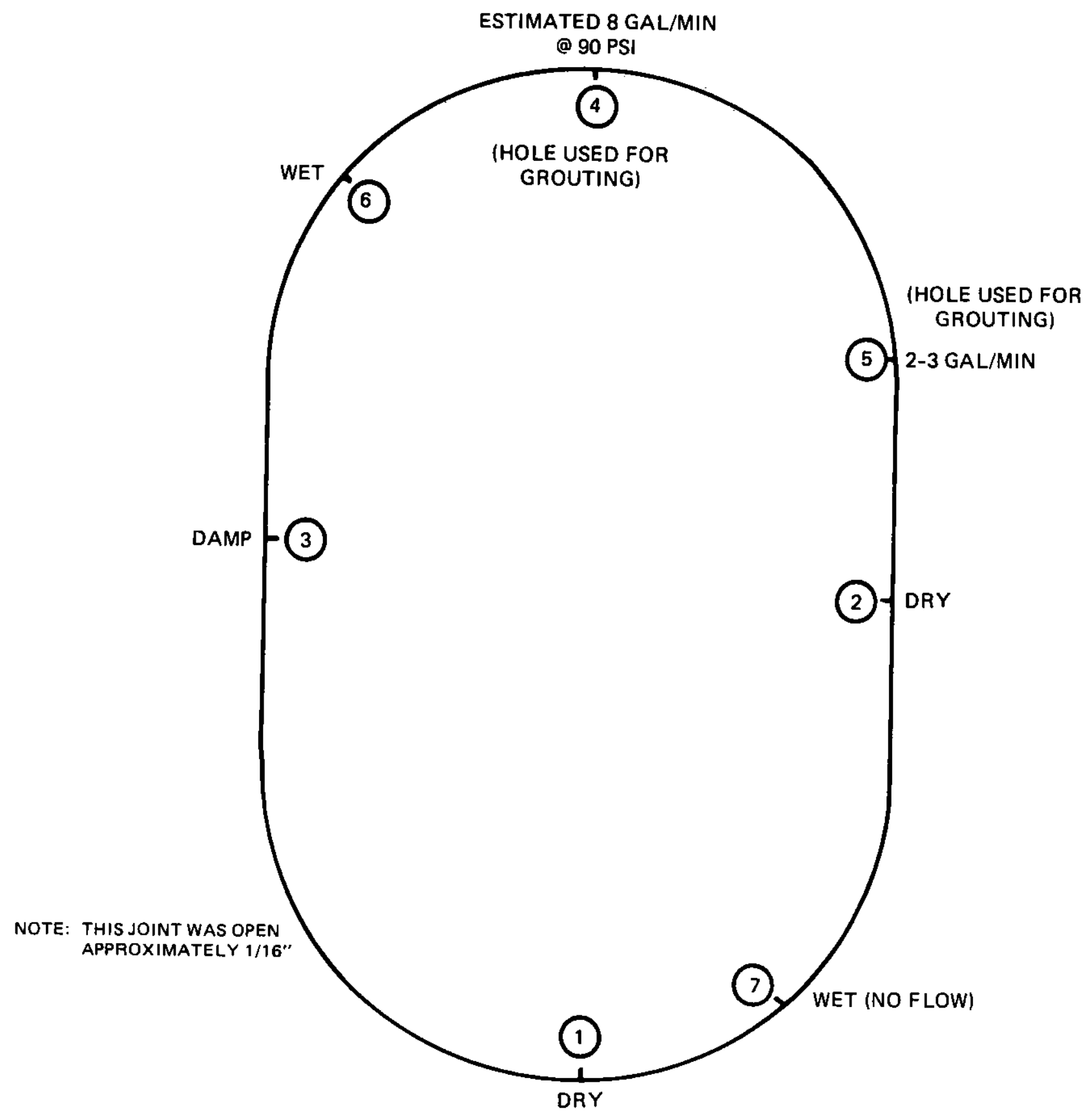

Figure 127. Section at joint 12/13 looking upstream, Applegate Dam 
250. Leakage of 1-3 gal/min was noted at several joints when the conduit was inspected in June 1985. However, there was no leakage reported at joints 12/13 and 15/16, which were chemically grouted in July 1984.

\section{R1chard B. Russe11 Dam}

251. The Richard B. Russell Dam is a concrete gravity structure with earth embankments located on the Savannah River between Georgia and South Carolina (Figure 128). Its 32 monolfths include a 599.5-ft power intake section for the elght power units, a 590-ft gated spillway section, and nonoverflow and transition sections totaling $694 \mathrm{ft}$. An upstream elevation of the dam, with typical sections through the power intake, spillway, and nonoverflow sections is shown in Figure 129. Internal face and joint drains have been emphasized on this drawing. Selected typical horizontal cross sections at key locations and elevations are shown in Figures 130 and 131 . These figures show the locations of the face and joint drains in relation to the dam face, contraction joints, waterstops, and other pertinent features.

252. Throughout calendar year 1982, some water leakage was detected in the face and joint drains flowing into the inspection gallery of the dam. This leakage occurred with the reservoir at very low levels, generally between elevation 330 and $350 \mathrm{ft}$. Flood-control operations at the upstream Hartwell Dam during the period 27 December 1982 through 14 January 1983 raised the Russell pool to elevation $381 \mathrm{ft}$ on 31 December 1982. This was approximately $20 \mathrm{ft}$ above normal and was the highest elevation reached since second-stage diversion in January 1982. Between 29 December 1982 and 14 January 1983, the lake fluctuated between elevations 365 and $381 \mathrm{ft}$. During this period, significant leakage through the concrete dam was detected.

253. In view of potentially unacceptable levels of leakage, a two-phase plan was formulated to quantify and to deal with the leakage problem. Phase I would include all preventive repatrs possible prior to filling the reservoir. Phase II would address any leakage repairs required on an individual basis after reservolr filling. The final plan included the following events:

a. Ra1se the pool to elevation $400 \mathrm{ft}$ and quantify the rate of leakage.

b. Develop and execute tests to determine the location(s), cause(s), and correction(s) for the leakage. 


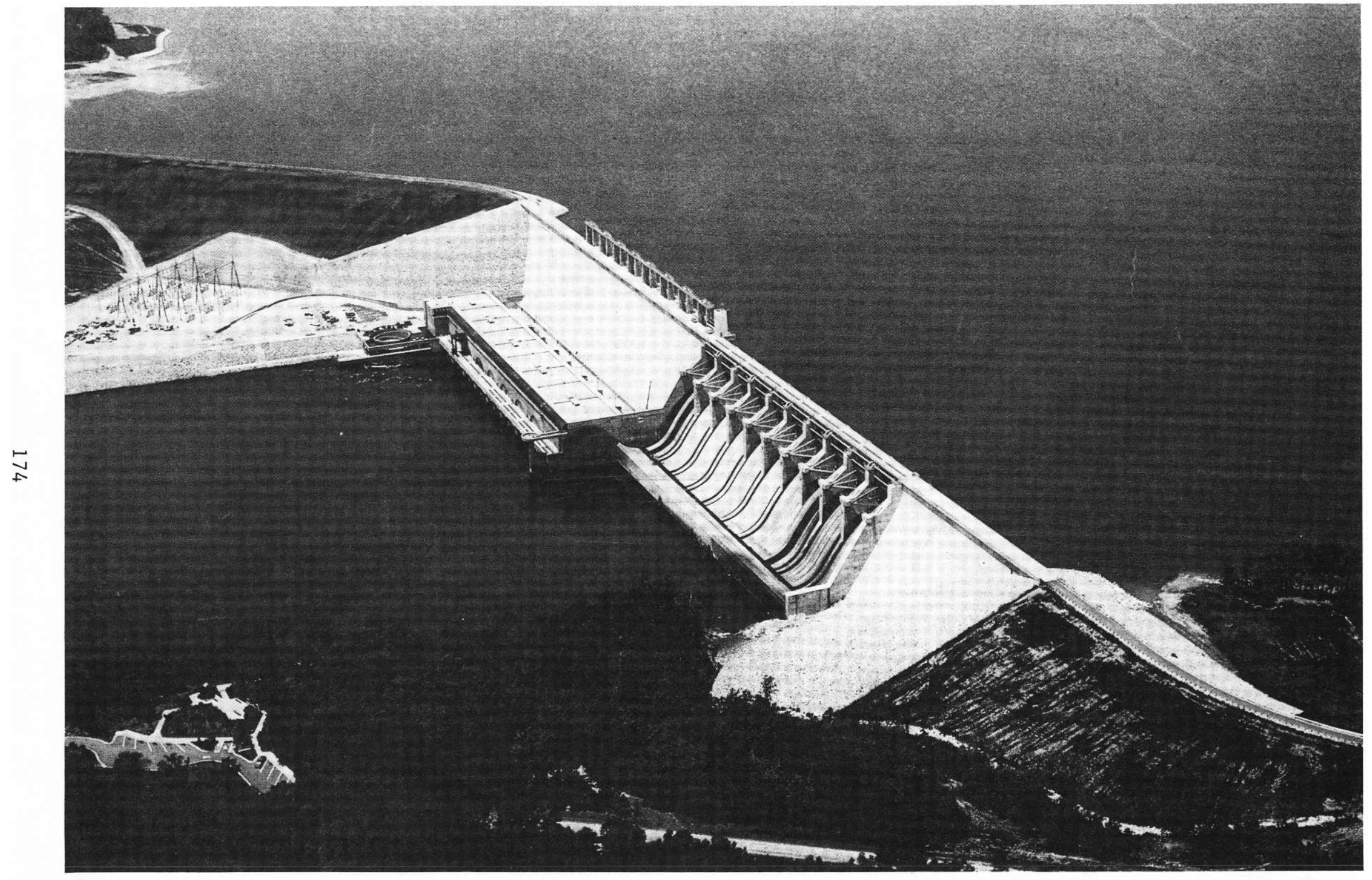

Figure 128. Richard B. Russell Dam 

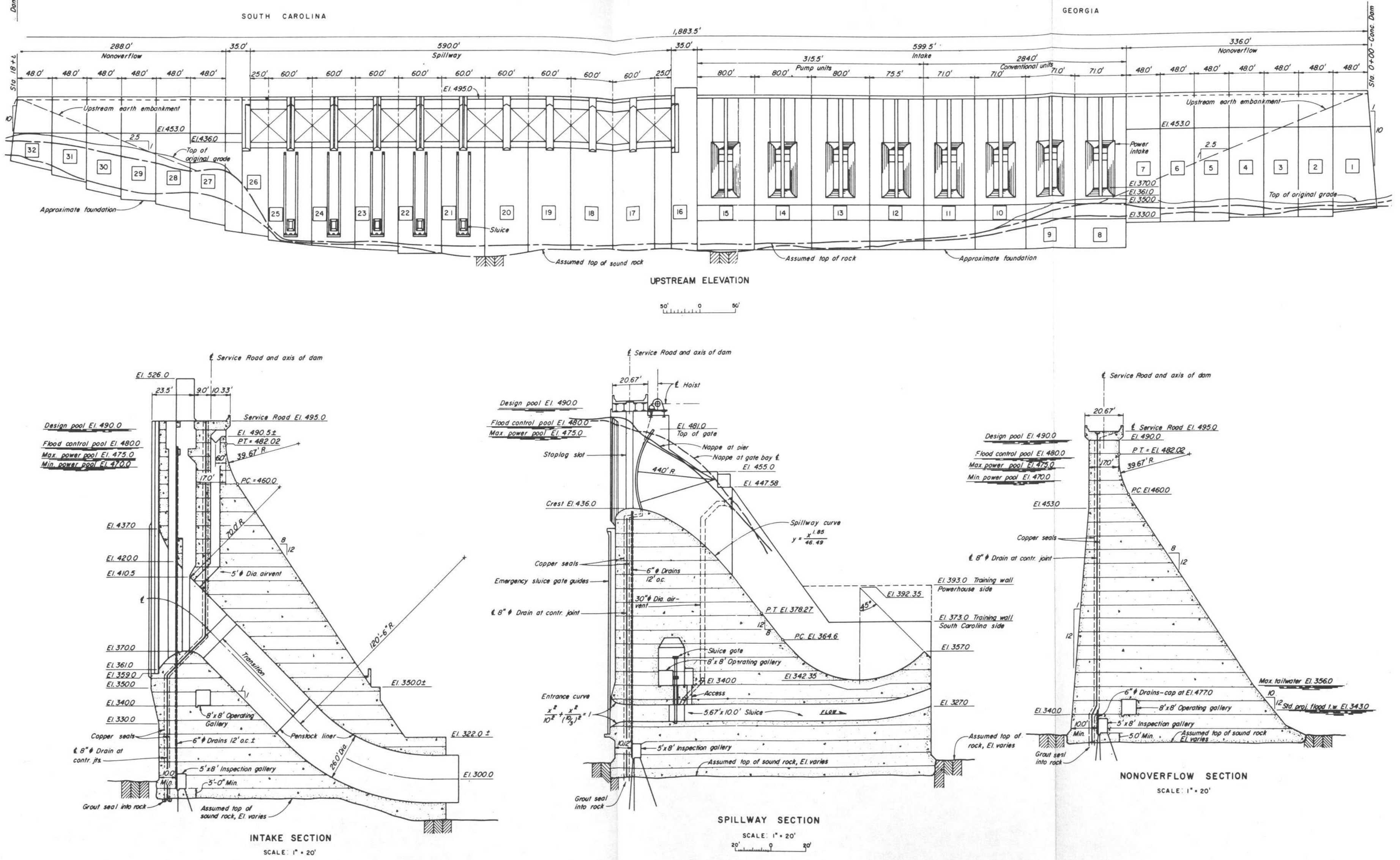

Figure 129. Upstream elevation and typical sections, Richard B. Russell Dam 



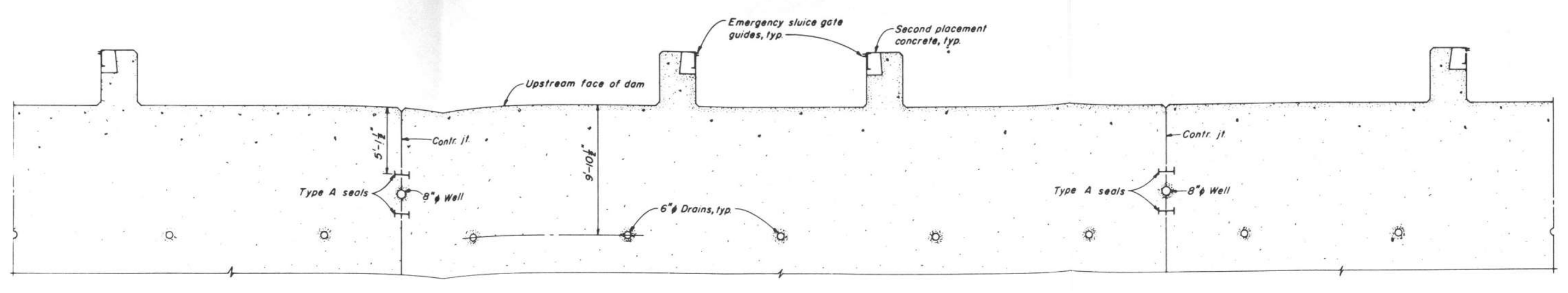

EL. 370
SPILLWAY SECTION

i...i.

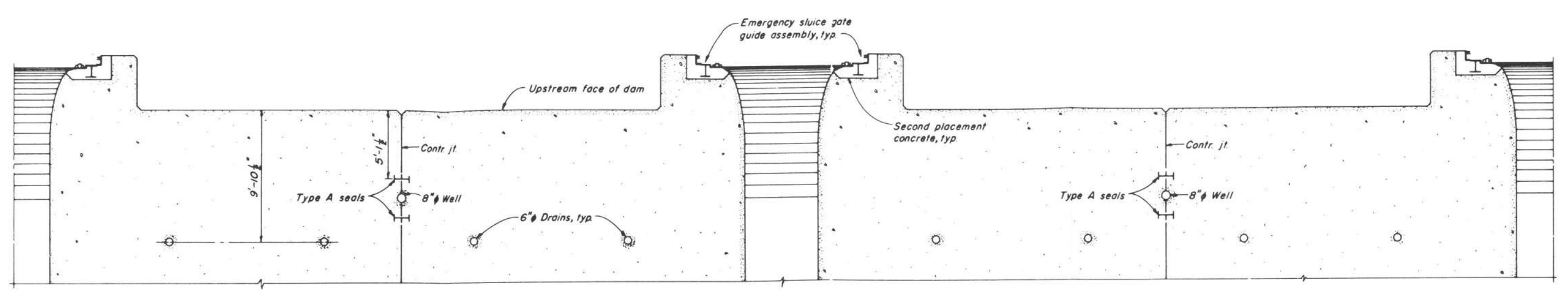

EL. 322
SPILLWAY SECTION

i... i.

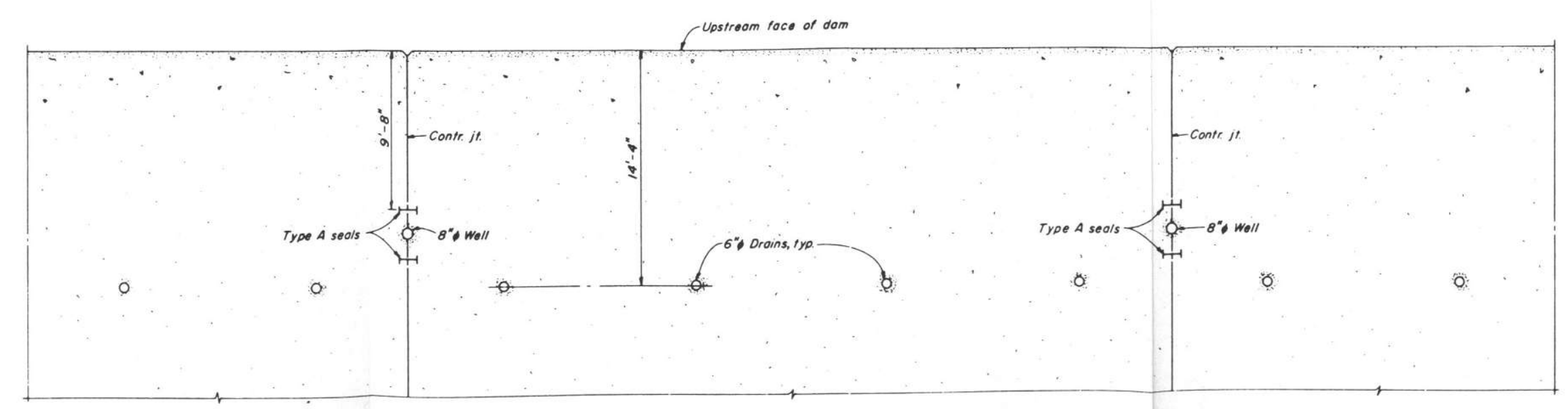

EL. 350

NONOVERFLOW SECTION

"in

Figure 130. Typical spillway and nonoverflow sections, Richard B. Russell Dam 


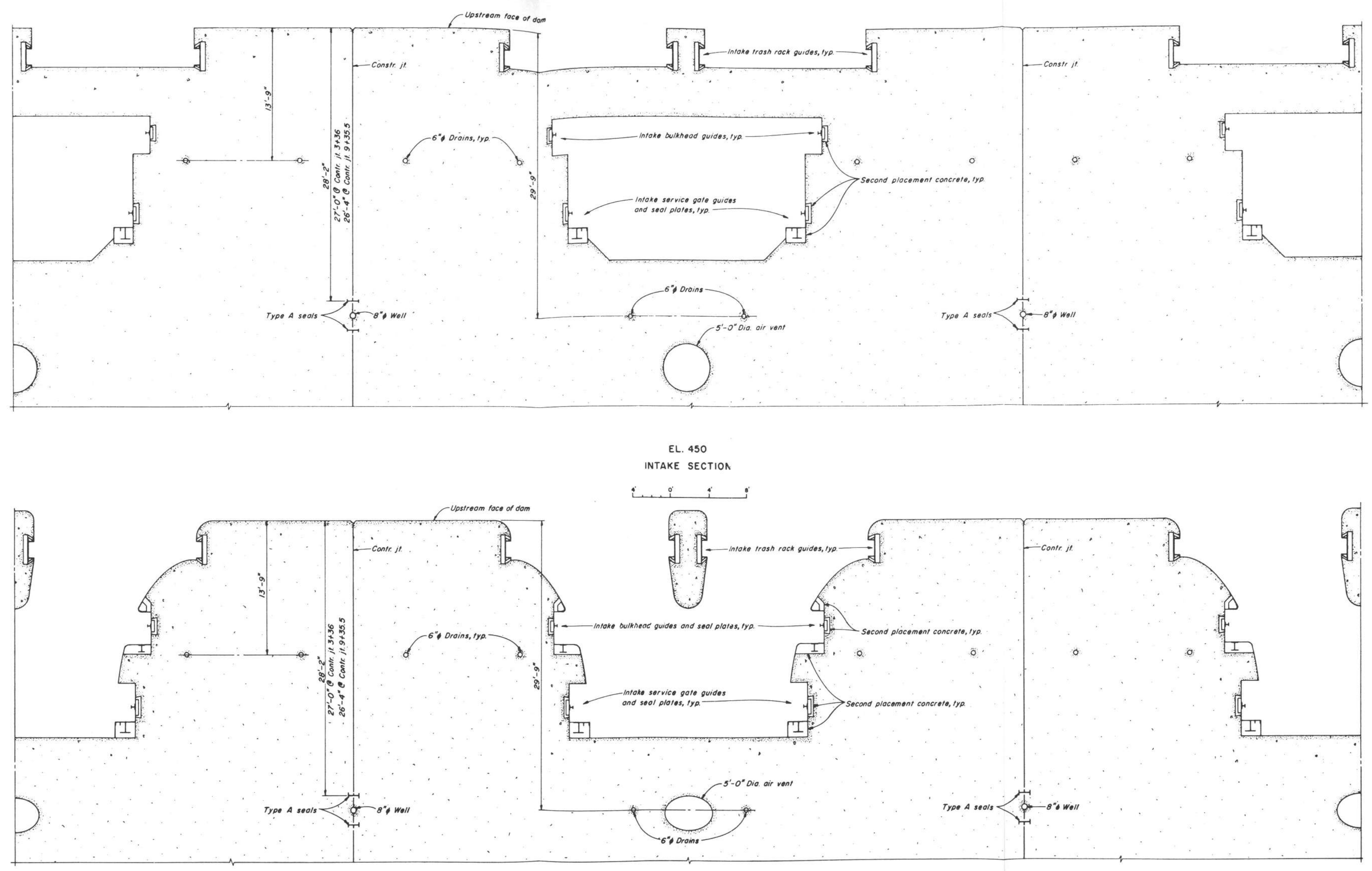

EL. 410

INTAKE SECTION

Figure 131. Typical intake sections, Richard B. Russell Dam 

c. Make initial test repairs based on leakage tests.

d. Raise pool to elevation $400 \mathrm{ft}$ again in order to determine the effectiveness of initial test repair.

e. Effect additional testing if required.

f. Make Phase I preventive leakage repairs to the dam based on the testing and the effectlveness of initial test repairs.

g. Make final Phase II repairs as required to isolate leakage areas after raising reservoir pool level. Also conduct any additional testing as required.

Investigation

254. The sluice gates were closed on 10 February 1983 and the lake allowed to rise from elevation $368 \mathrm{ft}$ until it reached elevation $400 \mathrm{ft}$ on 20 February. Detailed measurements of leakage flow were made by District personnel throughout this period (US Army Engineer District, Savannah 1985). Results of the monitoring indicated that at elevation $400 \mathrm{ft}$, total leakage through the concrete dam into the galleries flowed at a rate of approximately $600 \mathrm{gal} / \mathrm{min}$. Projections at full pool (elevation $475 \mathrm{ft}$ ) indicated a probable leakage rate in excess of $3,000 \mathrm{gal} / \mathrm{min}$. When compared to flows of similarly constructed projects, the projected Russell leakage rate was considered unacceptable. At elevation $400 \mathrm{ft}$, a total of 15 face and joint drains exhibited flow rates equal to or greater than $10 \mathrm{gal} / \mathrm{min}$ with a maximum rate of $90 \mathrm{gal} / \mathrm{min}$. These drains were located throughout the structure; however, the majority (nine) were located in the power intake section.

255. Since measurements indicated that less than 10 percent of inflow was coming from the foundation drains, it was concluded that foundation grouting was adequate and that foundation drainage was within acceptable limits for the reservoir hydrostatic head. Therefore, remedial measures should be directed at the concrete dam for control of the leakage.

256. It was evident from the outset that detailed testing would be necessary to help determine the location(s), cause(s), and cure(s) of the leakage. The specialized types of testing that were developed and conducted are described in detail in US Army Engineer District, Savannah (1985) and summarized below.

257. Preliminary smoke test. Tests were conducted in the dam galleries during March 1983 to evaluate the feasibility of using smoke to detect leakage paths between the gallery drains and the face of the dam. Smoke was generated using military smoke canisters and was injected into preselected face drains 
with compressed air. Various colors of smoke were used with limited results, due to the fact that the interior openings in the concrete were damp and the smoke did not travel as well as expected. However, it was established that there were interconnections between face drains and joint drains, between different face drains, and between face drains and the upstream face of the dam. Smoke was observed coming out of several contraction joints on the upstream face of the dam. Also, the smoke odor was noted in the open joint drains at the top of the dam and in the recesses for the intakes. These preliminary smoke tests, although somewhat limited in scope, established that there were openings in the concrete. These results set the stage for the design of additional physical test methods.

258. Compressed air test. The purpose of the air test was to eliminate from further testing the drains that were not suspected of leakage and to identify the drains that had probable major leakage for more Intensified testing. This test was chosen to precede the following tests because of its short set-up time and fast operation. The test involved sealing the bottom of the face and joint drains, sealing the top of the joint drains, piping compressed air into a face or joint drain, and measuring the amount of air flow necessary to maintain a constant pressure within the drain. The compressed air test equipment was configured as shown in Figure 132. The afr test performed on Richard B. Russell Dam was successful in eliminating 38 percent of the 182 drains from further testing. Most of the drains ellminated were in the nonoverflow sections of the dam. The test also showed, because of the interconnection of drains, that the horizontal lift lines had voids that could possibly reach to a vertical contraction joint and the face of the dam.

259. Detailed smoke test. The smoke test was developed to help determine leakage locations after the air test established the drains with significant air loss (in excess of $200 \mathrm{cu} \mathrm{ft} / \mathrm{min}$ ). The intent was to construct an apparatus which would safely contain or be connected to the smoke-generating device, while allowing the output to be discharged under pressure. Numerous pyrotechnic devices were custom manufactured for this test with various colors, burn rates, and discharge temperatures. The device finally selected was manufactured by R. T. F. Enterprises of Marshall, Texas, and was manufactured in a cylindrical form with an outside diameter of 6 in. and a length of $14 \mathrm{in.} \mathrm{It} \mathrm{was} \mathrm{designed} \mathrm{to} \mathrm{be} \mathrm{electrically} \mathrm{detonated,} \mathrm{to} \mathrm{burn} \mathrm{for} 5 \mathrm{~min}$, and to produce a violet-colored smoke while operating at a temperature of $350^{\circ} \mathrm{F}$ 


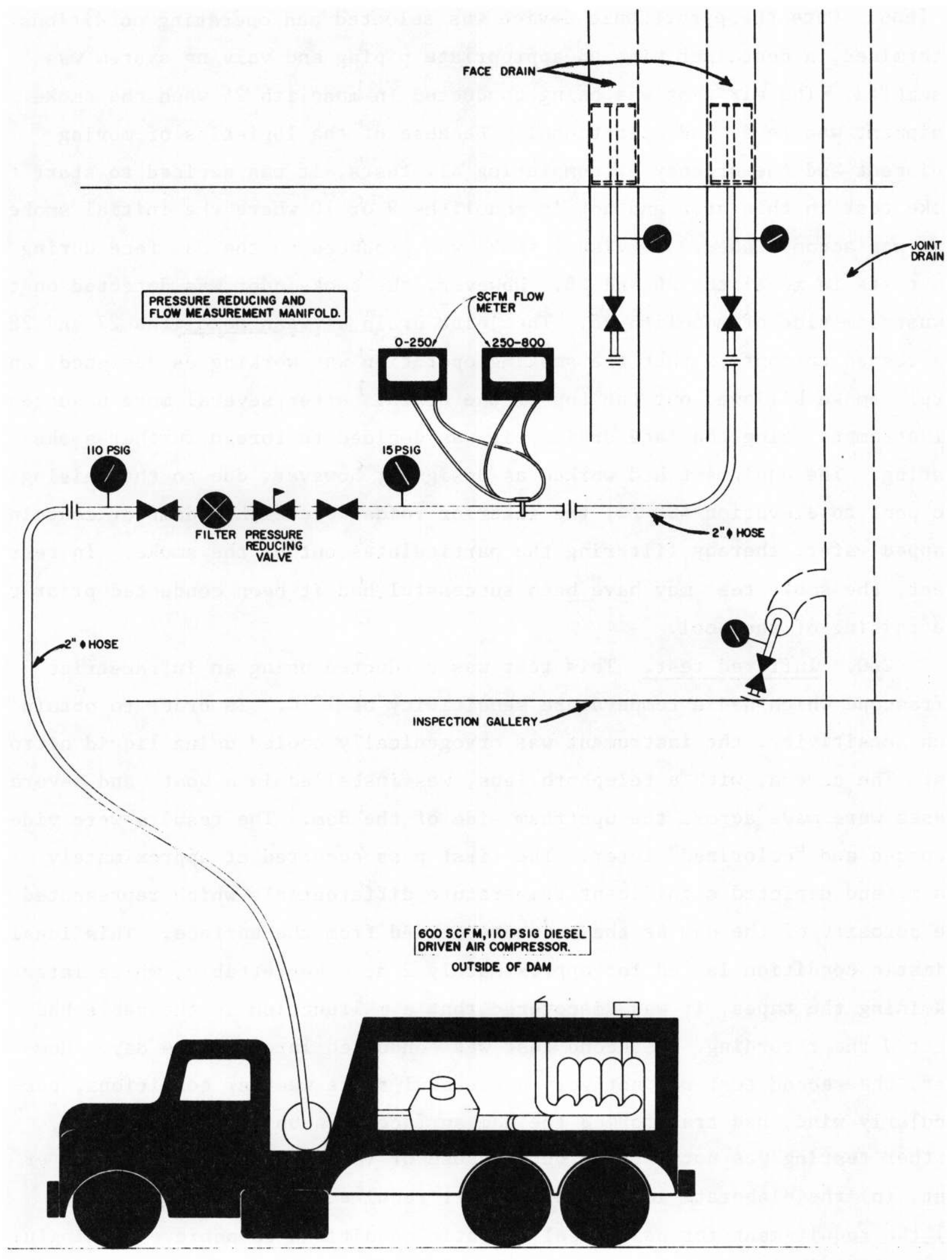

Figure 132. Schematic of air test equipment, Richard B. Russell Dam 
or less. Once the pyrotechnic device was selected and operating conditions determined, a container with an appropriate piping and valving system was assembled. The air test was being conducted in monolith 26 when the smoke equipment was ready and operational. Because of the logistics of moving equipment and the urgency of completing all tests, it was decided to start the smoke test in this area and not in monoliths 9 or 10 where the initial smoke test was accomplished. No visual smoke was produced on the dam face during the tests in monoliths 26 and 28. However, the smoke odor was detected on the downstream side of monolith 26. The joint drain between monoliths 27 and 28 was tested to confirm that the smoking operation was working as designed, and purple smoke billowed out the top of the drain. After several more unsuccessful attempts using the face drains, it was decided to forego further smoke testing. The equipment had worked as designed; however, due to the raising of the pool to elevation $400 \mathrm{ft}$, the interior voids were either damp or contained trapped water, thereby filtering the particulates out of the smoke. In retrospect, the smoke test may have been successful had it been conducted prior to the raising of the pool.

260. Infrared test. This test was conducted using an Inframetrics infrascope which had a temperature sensitivity of $1^{\circ} \mathrm{C}$. In order to obtain such sensitivity, the instrument was cryogenically cooled using liquid nitrogen. The camera, with a telephoto lens, was installed in a boat, and several passes were made across the upstream side of the dam. The results were video recorded and "colorized" later. The first pass occurred at approximately 9 a.m. and depicted significant temperature differentials which represented the porosity of the dam as the moisture exuded from the surface. This ideal climatic condition lasted for approximately $2 \mathrm{hr}$. Regrettably, while later examining the tapes, it was discovered that a malfunction in the cable had negated the recording. A second test was conducted later in the day. However, the second test was not very successful since weather conditions, particularly wind, had transformed the dam surface to a uniform temperature. Further testing was not carried out because of (a) the success of the water test, (b) the elaborate logistical support required for the system, and (c) the requirement for near-ideal climatic conditions to achieve meaningful results. 
261. Water test. The water test was performed on drains which, according to the results of the air test, had the greatest potential for leakage. The purpose of the water test was to attempt to determine the location of the seepage. The water test consisted of sealing the bottom of the drains with packers and then filling the drains with green water in incremental steps. At each step, the flow required to hold water at that given level was measured. Concurrently, a video camera team was suspended over the side of the dam to observe and to record evidence of leakage, noting locations and elevations. The water test equipment was configured as shown in Figure 133. Almost a11 of the leakage, as observed from outside the dam by the camera crew, occurred at the contraction joints. This leakage ranged from a mere trickle to a steady stream squirting several feet from the face of the dam. In some cases, leakage was observed from these joints on the downstream face as well as the upstream face. On occasion, leakage was also observed at: lift lines, the area around the intake gates and penstocks, as well as at cracks and joints in operating and inspection galleries. Video recording of the water test, using a 12-power zoom lens, provided the most revealing and successful data regarding the exact locations of leakage on the face of the dam. However, this method obviously could not document the internal voids and leakage paths indicated by the testing.

262. Pulse echo test. The entire concrete dam was tested using the pulse echo technique in an attempt to reveal internal anomalies. This test is based on the principal that as mechanical energy (sound waves) passes through a medium, a portion of the energy will be reflected if changes in density are encountered. These changes in density can be the opposite side of the structural member or internal discontinuities such as cracks, voids, and honeycomb. These tests indicated that there were honeycomb, or void, areas of concrete located approximately 15 to $20 \mathrm{ft}$ inward from the face of the power intake. This defective concrete was on the lower side and bottom of the intake openings of all eight power intake monoliths, with monoliths 8 through 13 being the most severe. This defective concrete was at the approximate elevation where test data indicated the leakage entered into the drains. No suspect concrete areas were located in the concrete above the power intake openings or elsewhere on the upstream face. It is felt that if this test had employed more current technology (such as an electronic hammer rather than a mechanical hammer along with other methods of modulation and tone generation), the 


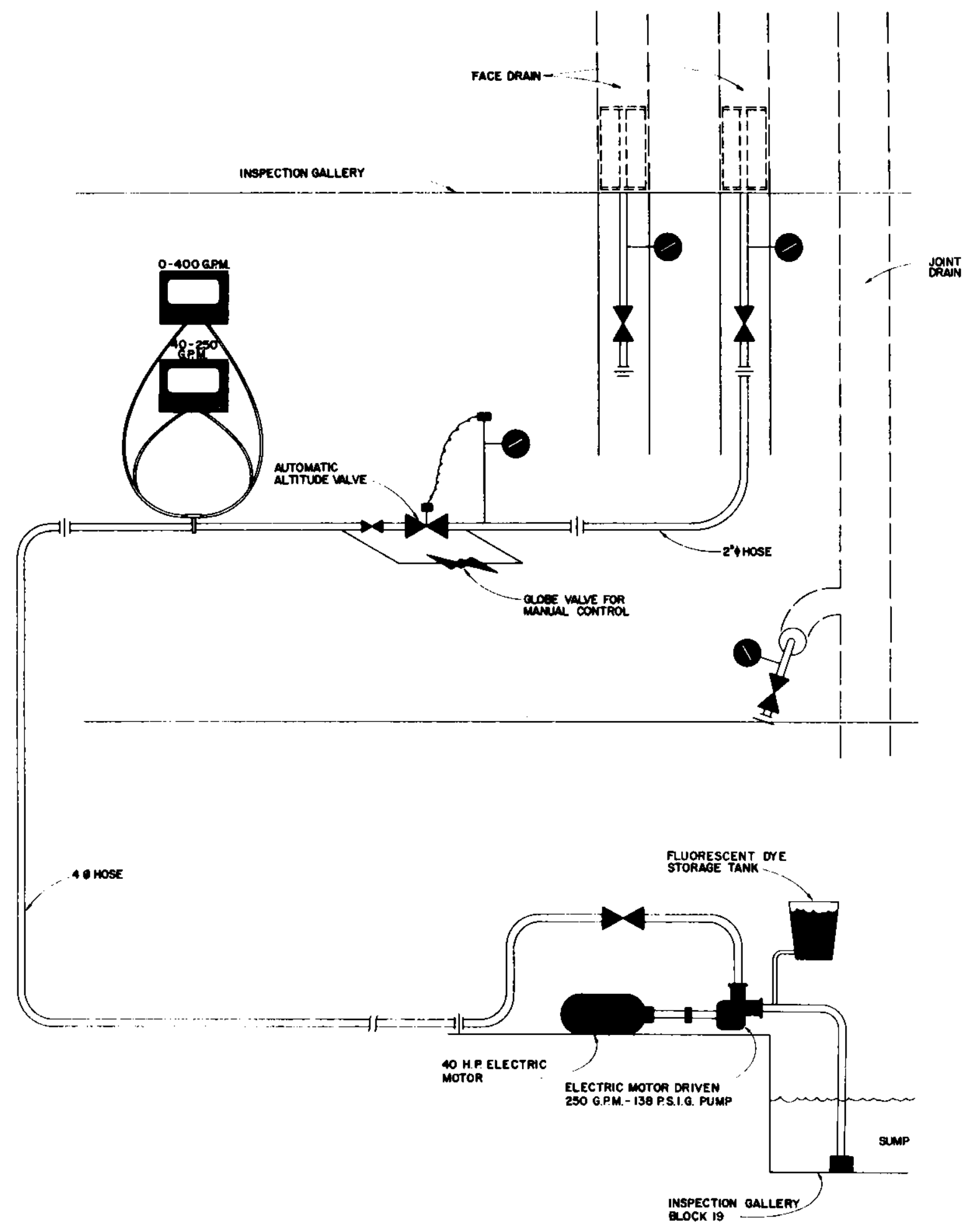

Figure 133. Schematic of water test equipment, Richard B. Russell Dam 
results could have been computerized for enhancement and a three-dimensional plot of the dam developed. However, since this test was less refined, it did not lend itself to video display and was valuable in detecting only very large anomalies (US Army Engineer District, Savannah 1985).

263. U1trasonic pulse velocity tests. This investigation was accomplished by placing a transmitter of ultrasonic energy inside the operating gallery. A matching receiver was placed at varying elevations on the upstream face of the dam and readings taken from within the gallery. Any interruption, scatter, or discontinuity of the signal would indicate poor-quality concrete (cracks, honeycomb voids, etc.) between the two instruments. The known positions of the instruments were then used to help determine the location of the anomaly. Some defective areas of concrete were located in seven of the eight power intake monoliths. Six of these defective concrete areas were at elevations where the leakage data indicated flow entering the drains. This investigation had some limitation due to the lower elevation of the transmitter with respect to the higher elevations of the receiver on the upstream face. Also, the configuration of the power intake and penstock opening restricted placement of the exterior receiver. However, the tests were considered successful because they confirmed poor concrete in the areas of high leakage. Approximately 14 percent of the signal paths indicated some problem area concrete. It was concluded that, overall, the concrete was of good quality and that the structural integrity of the concrete dam was not affected by the minor areas of poor concrete detected.

264. Based upon a careful study and analysis of the construction history, visual observations, and the extensive testing previously described, the following conclusions were reached:

a. Most of the face drains experiencing significant leakage were adjacent to vertical monolith contraction joints. These face drains were also generally in the latter monolith of any given two monoliths. This would tend to indicate some difficulty in placement and/or consolidation of concrete material in the second monolith (Figure 134). From this and other correlative data, it was concluded that water was entering the vertical contraction joints and traveling horizontally along lift lines and/or honeycomb voids to the face drains. The flow was also traveling around the contraction joint copper waterstops and into the contraction joint drains.

b. Most of the leaking drains were located in the power intake section of the concrete dam. A further analysis of the data 


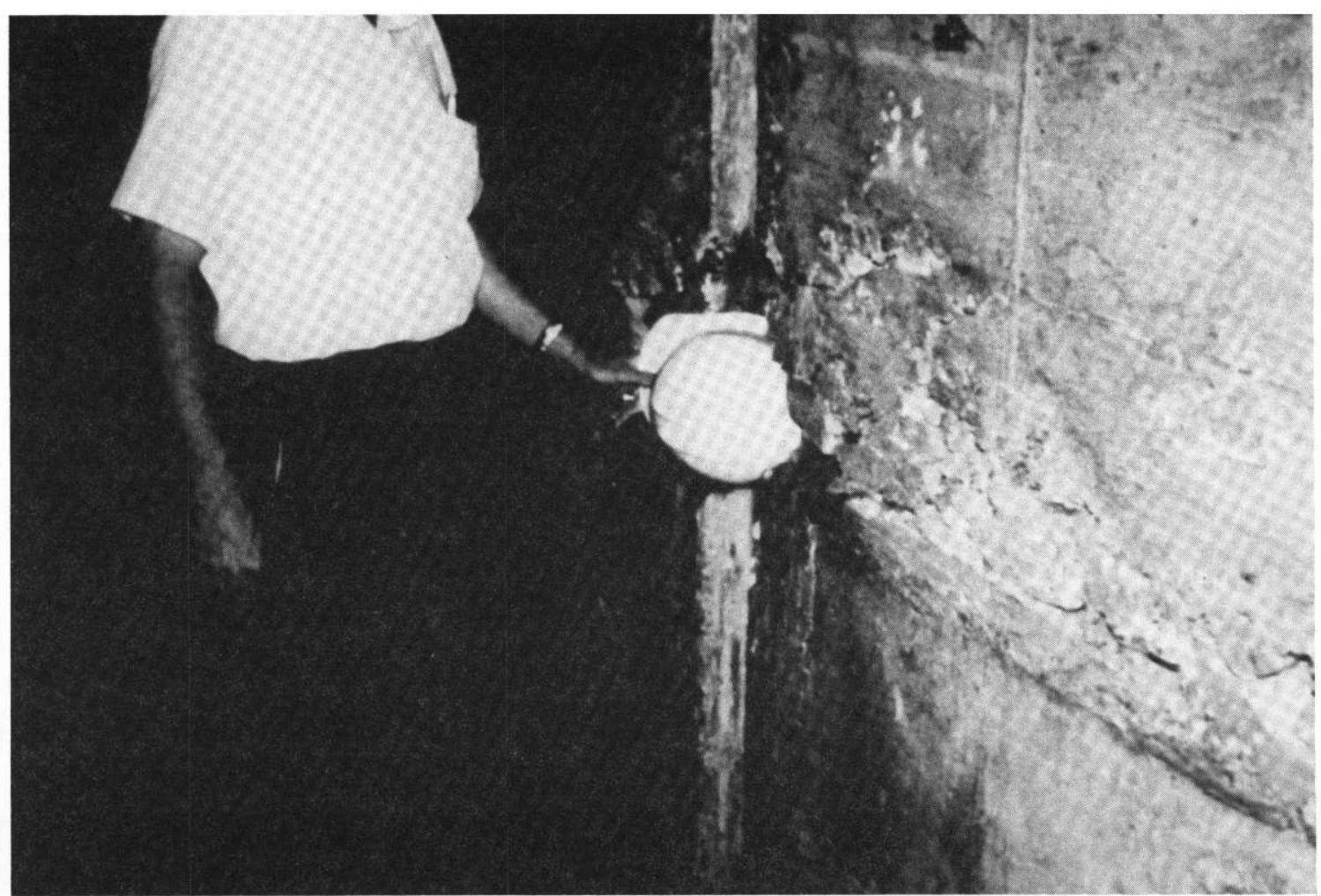

Figure 134. Poorly consolidated concrete adjacent to face drain, Richard B. Russe11 Dam, July 1980

indicated that most of the leakage was entering the penstock intake opening areas at approximately elevation $380 \mathrm{ft}$.

c. An analysis of concrete placement and construction by a dam construction investigation team noted problems in placing the concrete in these suspect areas. It was thought that support steel frames for the power intake which contained embedded metal may have made concrete placement more difficult, and therefore concrete consolidation was inadequate in these areas.

d. A minor amount of leakage was originating from areas of poorly consolidated concrete on the upstream face of the dam.

In summary, leakage through the dam apparently stemmed from one or more of the following: (a) underconsolidated concrete, (b) lack of bonding between lifts, (c) cracks, and (d) failure of waterstops.

\section{Corrective measures considered}

265. Two general approaches to stopping the leakage were recognized. One would be to seal the dam at its face to prevent inflow entry (i.e., elastomeric or epoxy coatings, joint seals, etc.). The other general approach would be to pressure grout the leakage areas with hard grout. Specific 
methods considered as potentially feasible plans for stopping the leakage were as follows:

a. Coal furnace cinders - for leakage areas below reservoir pool leve1.

b. Elastomeric or epoxy coating - for sealing or covering over lift lines or other small leakage areas above and below water.

c. Underwater drilling and grouting - for leakage areas below water.

d. Concrete or epoxy cement grouting - for local drilling or grouting into honeycomb or other leakage areas.

e. Angle drilling and grouting - for local drilling or grouting into honeycomb or other leakage areas.

f. Conventional drilling and grouting - for drilling and grouting into leakage areas from the top of the dam.

g. Metal seals - for cover over contraction joint leakage areas.

h. Plug drains - last resort.

i. Combinations of the above.

Initial repair

266. Based on an analysis of testing, observations, and conclusions previously outlined, the following plan for inftial repair was established:

a. Install elastomeric grout seals at very low elevations on all vertical contraction joints between monoliths 3 and 30 to seal out leakage inflow from lower elevations.

b. Install similar seals on the upper ends of vertical joints in the spillway section.

c. Place full-length elastomeric seals in five of the vertical contraction joints suspected of causing the greatest leakage inflows.

Locations and details of this repair are shown in Figure 135.

267. A contractor specialist in the field of grouting was retained in May 1983 to begin application of the expansive elastomeric grout. An elastomeric, or soft, grout was desired due to expansion and contraction of the concrete monoliths. A maximum opening or closing of approximately $1 / 4 \mathrm{in}$. could be expected for the power intake monolith joints.

268. The low-level elastomeric grout was placed as low as possible (elevation $347.5 \mathrm{ft}$ ) on the contraction joint in order to prevent leakage inflow behind the face of the dam from a lower elevation. This expansive elastomeric grout was grouted into the joint from the dam face to the interior copper waterstop. Generally, the elastomeric seal was placed into the joint 
vertically from elevation $347.5 \mathrm{ft}$ to a lift height of $7.5 \mathrm{ft}$. Expansive elastomeric grout was specially selected for this job not only for its superior sealing qualities, but also because its elastic properties would allow it to expand and contract with the concrete movement at the joint. 269. A permeable grout tube (INJECTO) manufactured by De Neef America, Inc., was placed into the "V" joint and covered with a sealant. After the sealant hardened, grout was injected into the tube to seal the joint to elevation $490 \mathrm{ft}$, or to the spll1way crest in the spillway section. Thus the joint was sealed of at the bottom and up the vertical face for the full length of the joint. The joints at monoliths $7 / 8,8 / 9,10 / 11,17 / 18$, and $18 / 19$ were thus sealed because test data indicated they were the cause of major leakage inflow.

270. After test repalrs on the five joints were completed, the pool was again raised to elevation $400 \mathrm{ft}$ to evaluate the effectiveness of the repair. The sluice gates were closed on 6 June 1983 when the lake was at elevation $342.1 \mathrm{ft}$. As the lake level began to rise, leakage was measured at approximately 5-ft intervals until the lake reached elevation $400 \mathrm{ft}$ on 10 June. The sluices were opened 11 June, and the lake was allowed to fall. The monttoring process continued through 15 June, as the lake stabilized at elevation $360 \mathrm{ft}$, with results as shown in Figure 136.

271. The maximum leakage measured (292 gal/min) was less than one-half the leakage measured during February 1983 with the lake at the same elevation. Also, leakage into the drains near four of the five grouted joints was efther eliminated or drastically reduced. Face drain 19a was not affected by sealing joint 18/19; this leakage was believed to be entering from below the bottom of the sea1 (elevation $347.5 \mathrm{ft}$ ).

Phase I repair

272. Based on the demonstrated success of inftial test repairs, a contract was awarded in July 1983 for additional repairs to be accomplished prior to reservoir filling. All vertical contraction joints, except the two end joints on each abutment, were fully sealed as a precautionary measure. Seals were installed upward to elevation $490 \mathrm{ft}$, or to the spillway crest in the spillway section. This was accomplished because the pool had been raised only to elevation $400 \mathrm{ft}$, leaving the area from elevation 400 to $490 \mathrm{ft}$ suspect. Also, the water and initial smoke tests had indicated some leakage potential from the dam face and through vertical joints above elevation $400 \mathrm{ft}$. 


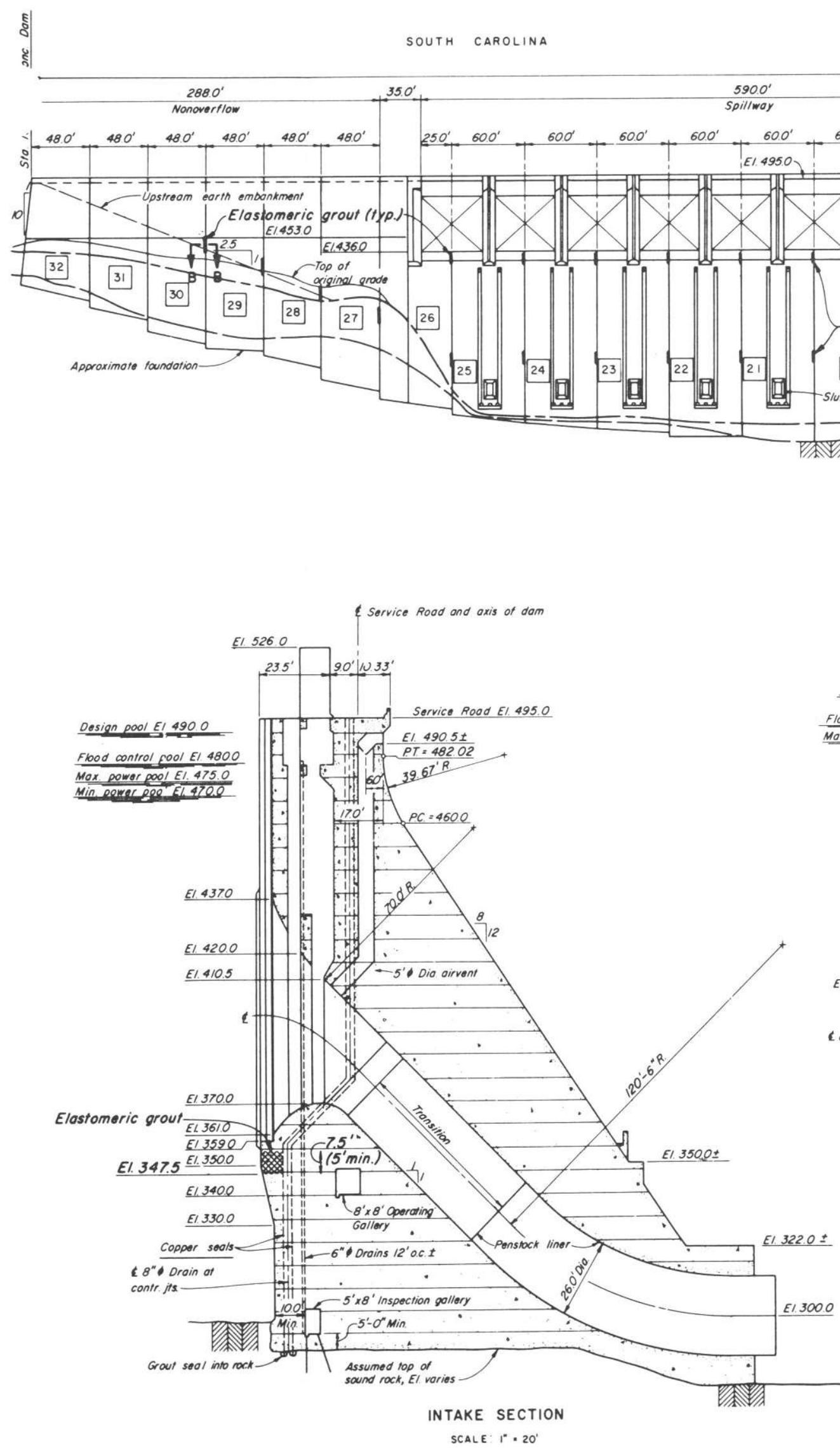

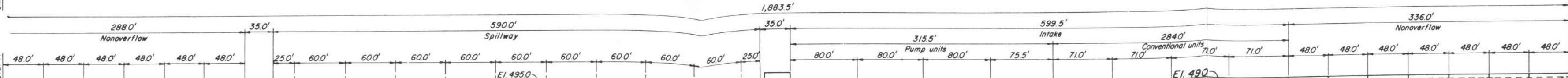
(32)
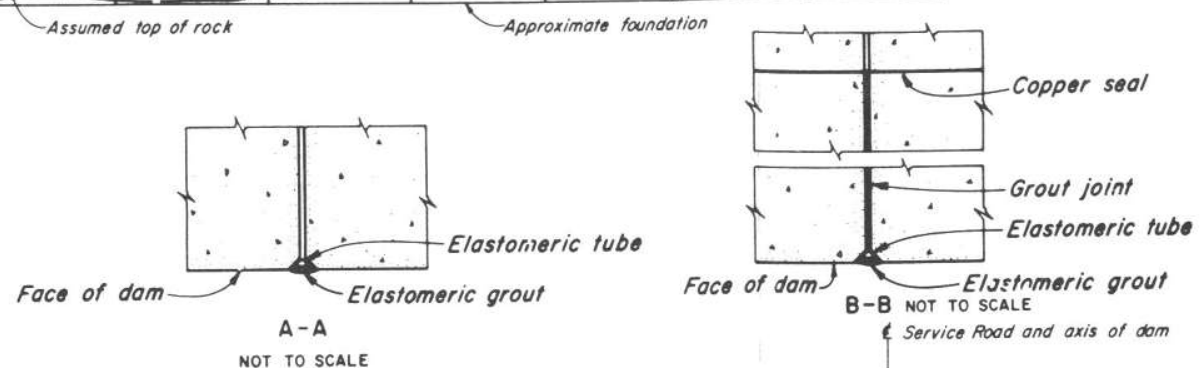

$0001 E 149000$ NOT TO SCALE

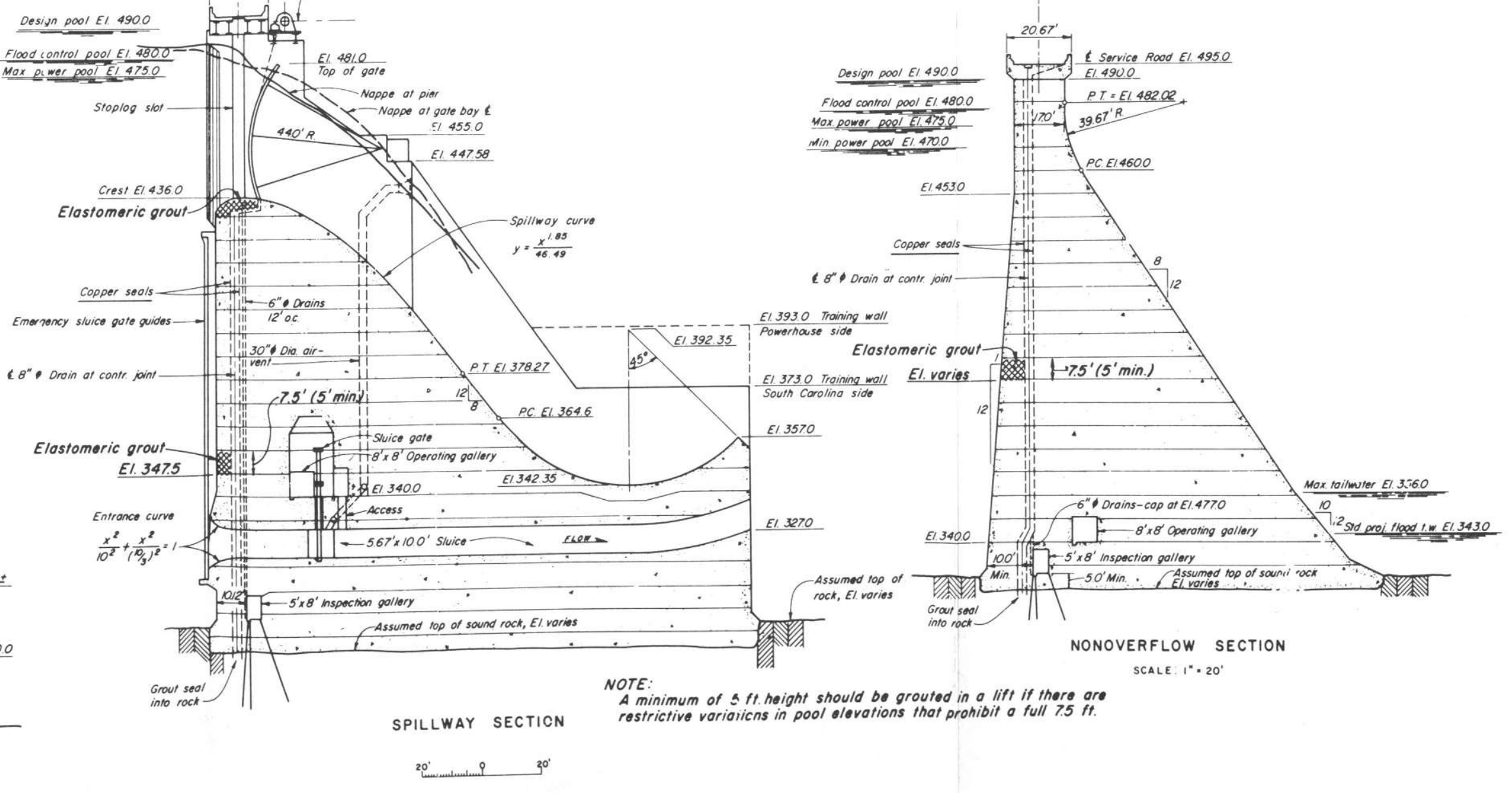

Figure 135. Initial repairs, Richard B. Russell Dam 



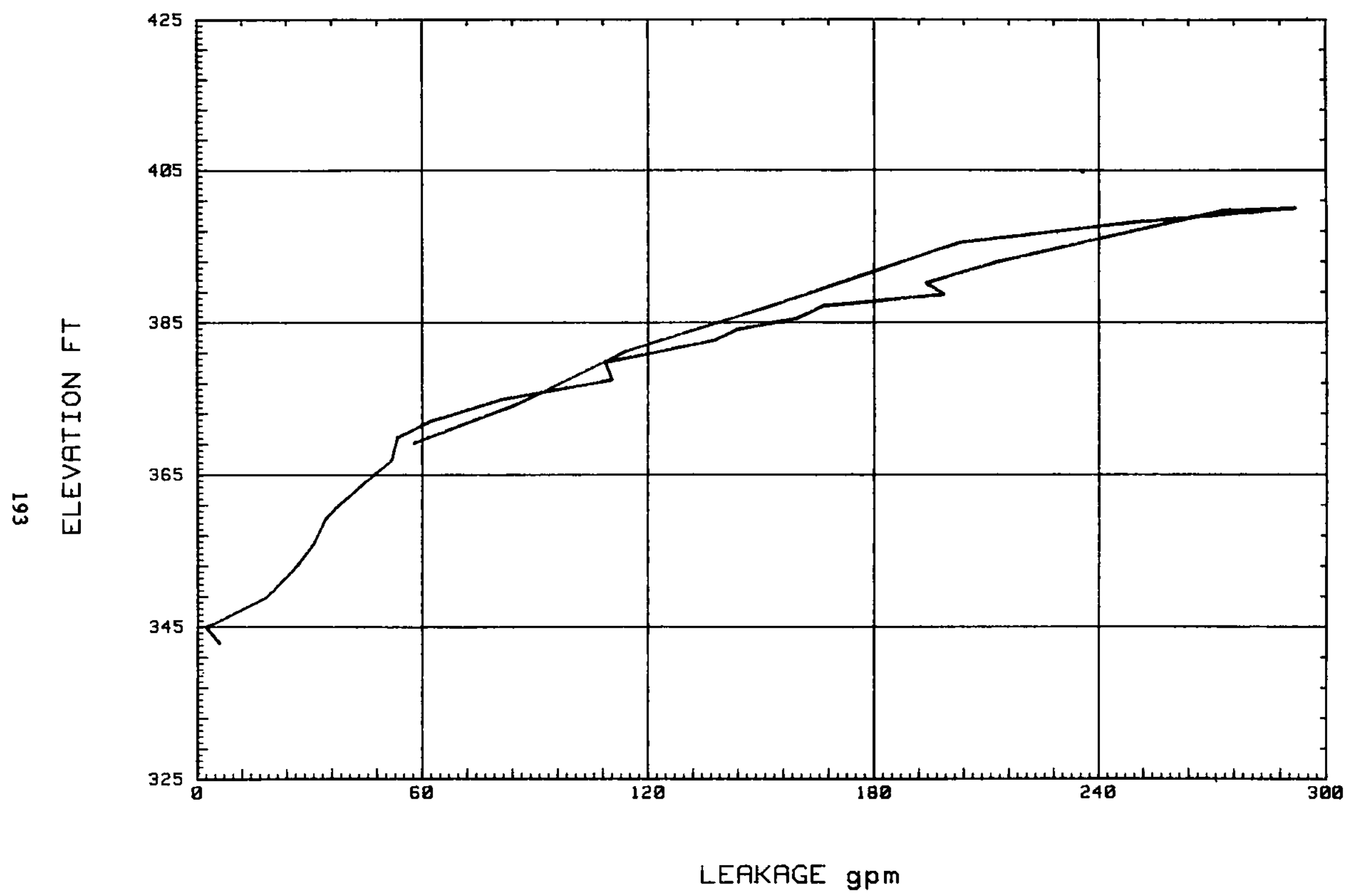

Figure 136. Leakage measurements, Richard B. Russell Dam, 6-15 June 1983 
273. Plans and details of the Phase I repairs are shown in Figures 137 and 138. Phase I repair procedures, refinements of the methods used in the initial repair, were as follows:

a. To ensure the effectiveness of the low-level grout seals placed during the initial repair, a 4-in.-diameter hole was cored into each seal near the bottom of the lift joint. This horizontal hole extended from the dam face inward to a point 4 in. beyond the first waterstop. Also, an overlapping hole was drilled on each side of the vertical contraction joint hole to a depth of 12 in. All holes were filled with a polysulfide elastomeric. An examination of the concrete core removed during the drilling operation revealed that the original elastomeric grout did not expand and contract as hoped. The grout had been crushed and only a thin film of material was visible at the joint.

b. A permeable grout tube was placed in the vertical contraction "V" joint and covered with a sealant (Figure 139). After the sealant hardened, the grout tube was injected with a low viscosity, flexible epoxy to seal the joints. The injection grout used was a two-component system, Type IG-100, supplied by Prime Resins, Inc.

c. The remainder of the "V" joint was then filled with a polysulfide sealant that was also spread 8 in. of either side of the joint. Before the sealant set, a stainless steel waterstop, 20-gage thickness and 16 in. wide, was installed over the contraction joints (Figures 140 and 141). The external waterstop was tied into the lower polysulfide grout core and extended upward to elevation $490 \mathrm{ft}$. Special attention was given to sealing contraction joints in the spillway section. These joints were sealed into the internal copper waterstops on the spillway crest as well as at the lower joint seals.

d. Water pressure testing of the face drains indicated some minor leakage from small honeycomb areas on the dam face. It was decided that this leakage could be effectively controlled by sealing the surface in lieu of pressure grouting the areas. The affected areas were chiseled out approximately $1 \mathrm{ft}$ square and 1 in. deep, coated with epoxy and, while still wet, filled with nonshrink grout.

Phase II testing and repair

274. Phase I repairs were systematic for the entire concrete dam, but the plan for Phase II testing and repair was to address any leakage areas on an individual basis. It was believed that any leakage after Phase I repaix and reservoir pool filling would vary in type and location. Therefore, the repair methods would vary with the types of leaks.

275. Some additional testing was required to locate the external leakage areas into the concrete dam. The water dye test was made at any suspected 

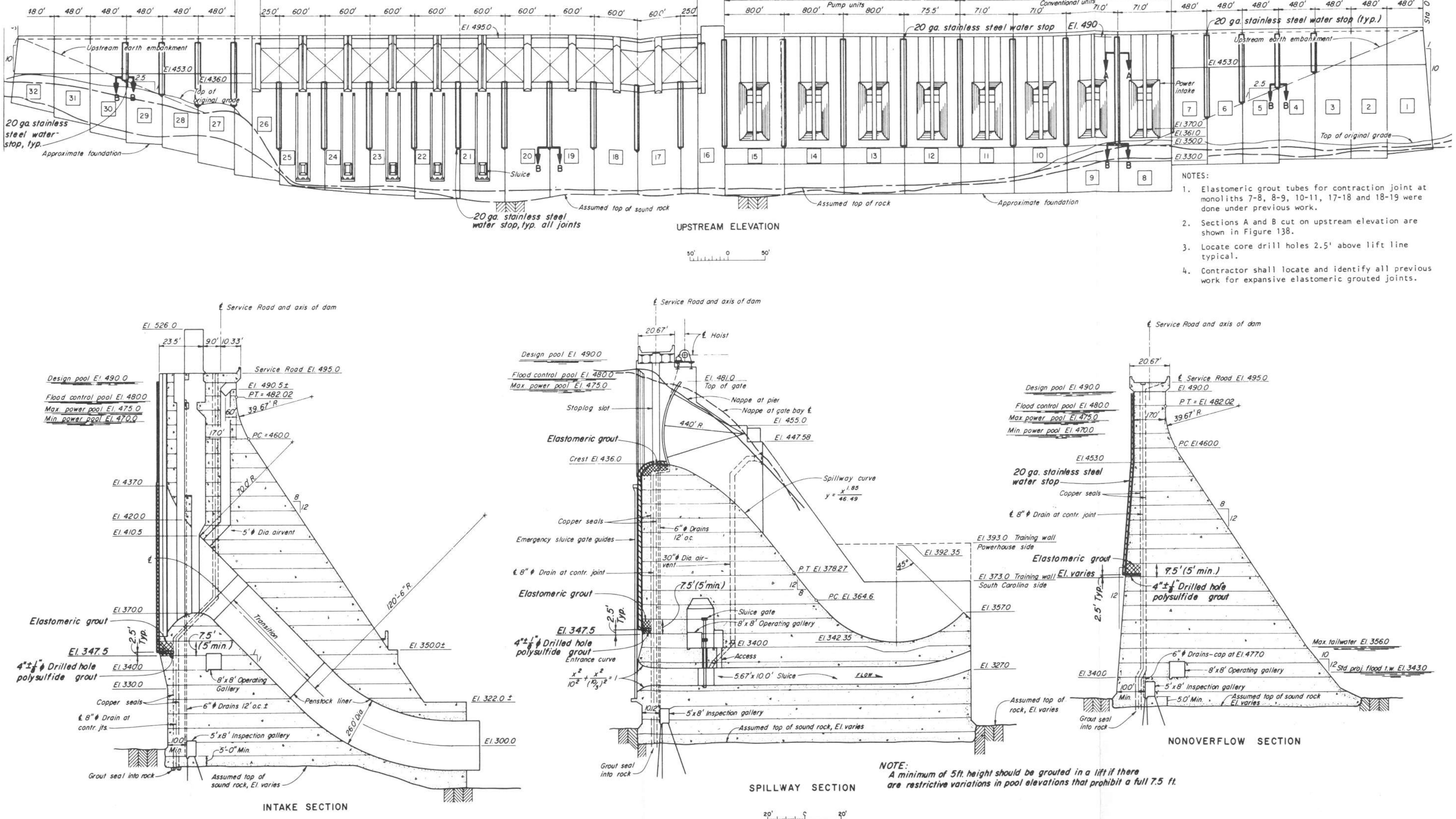

4. Contractor shall locate and identify all previous
work for expans ive elastomeric grouted joints.

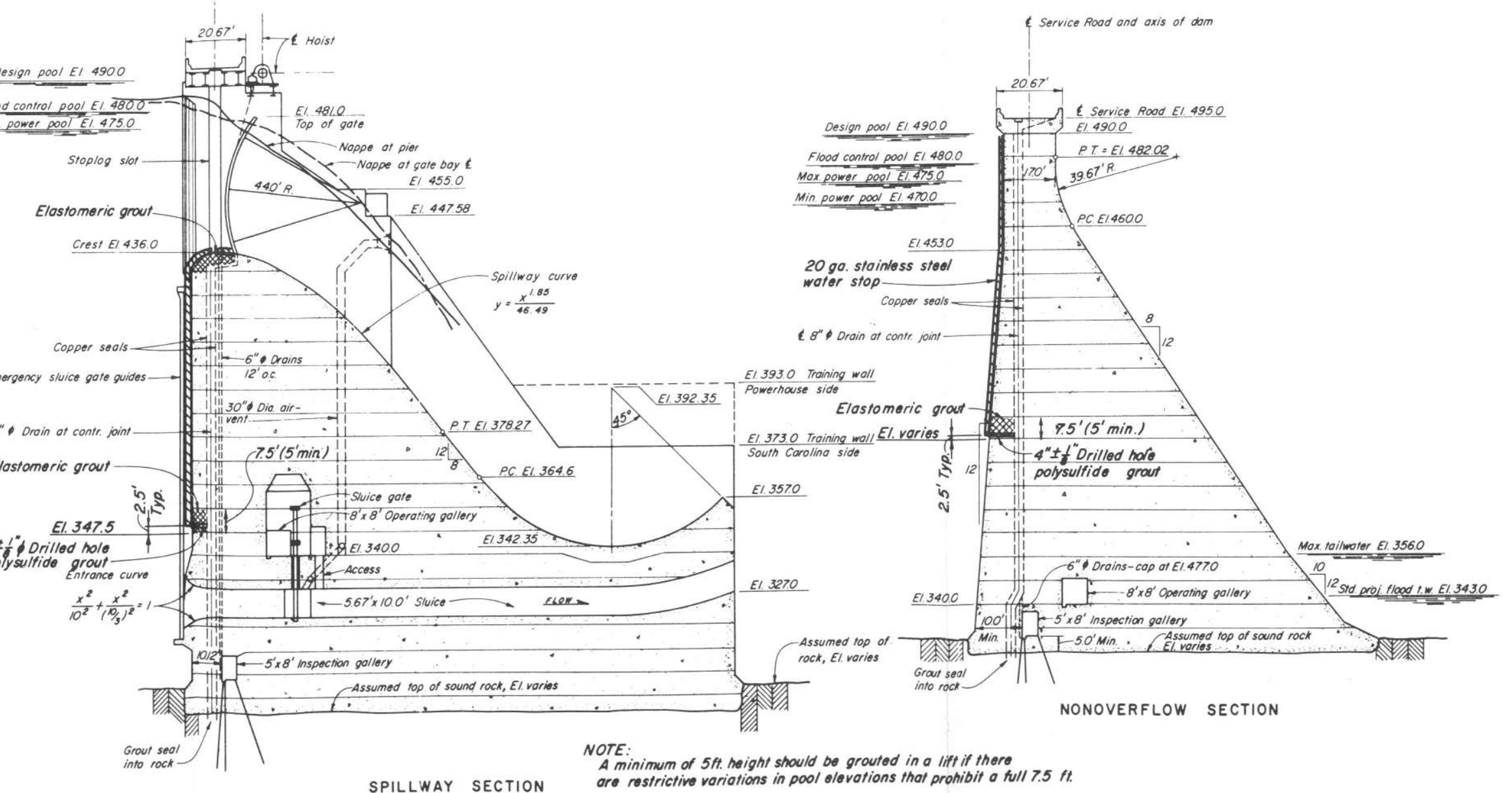

Figure 137. Phase I elastometric grouting of contractiong joints, Richard B. Russell Dam 



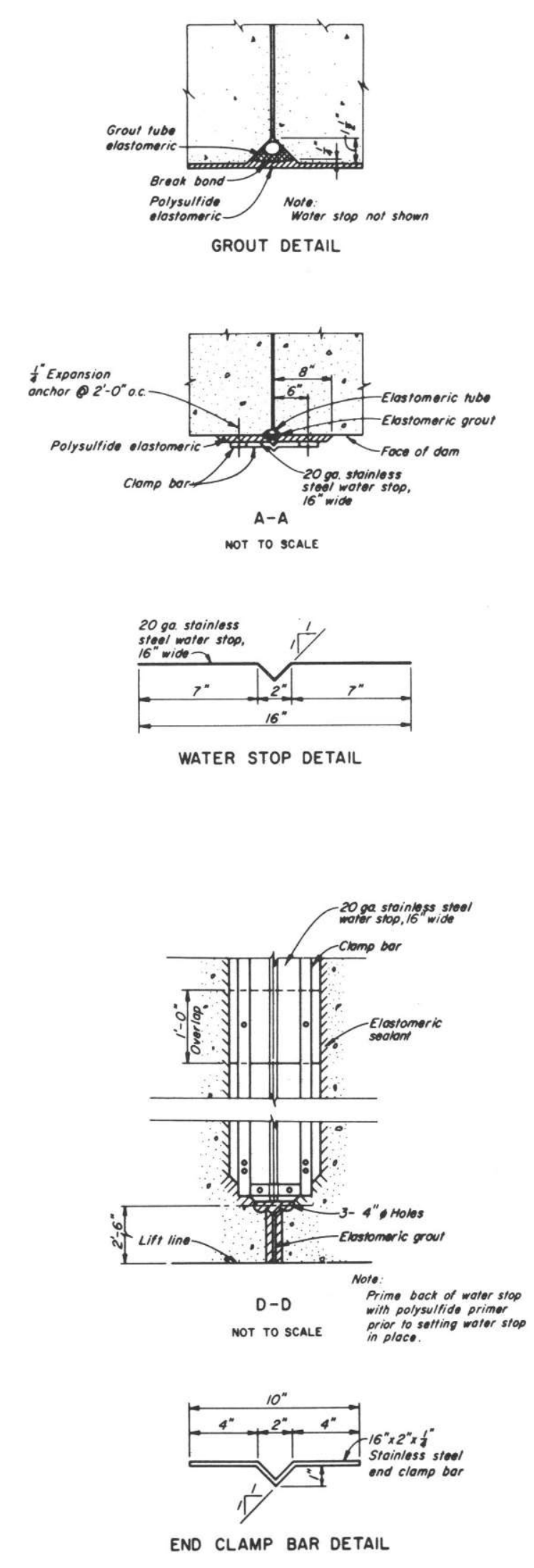

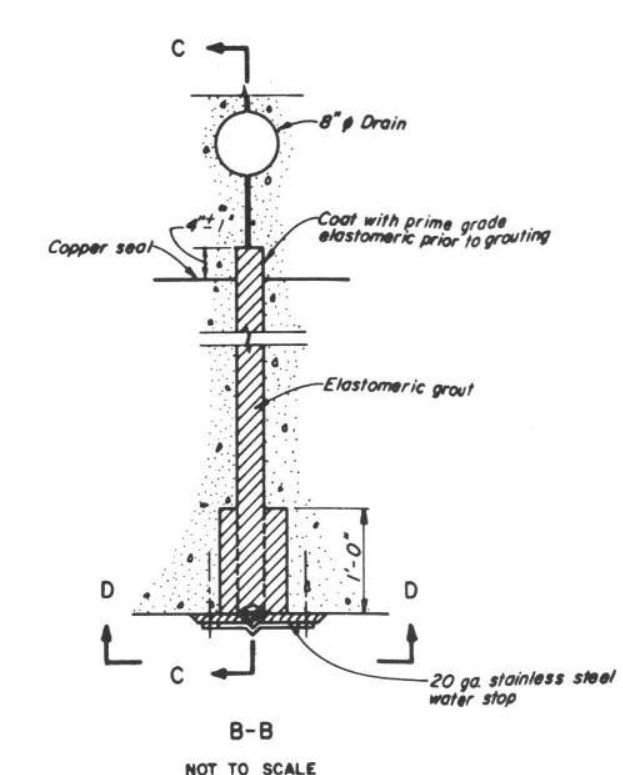
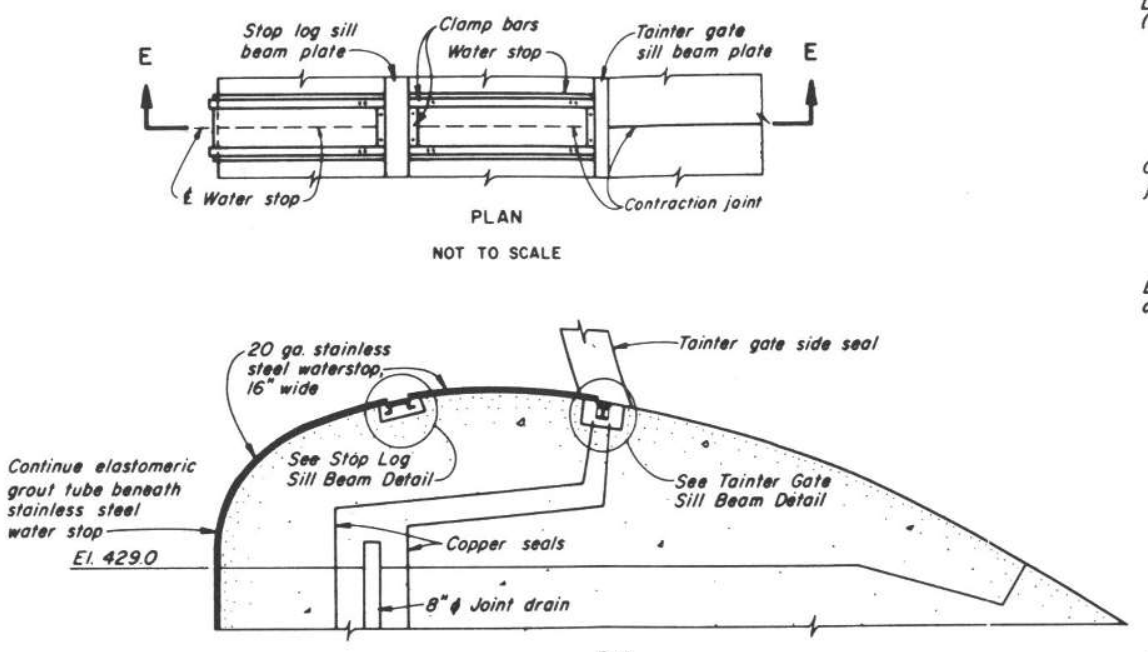

SPILLWAY CONTRACTION JOINT SEAL
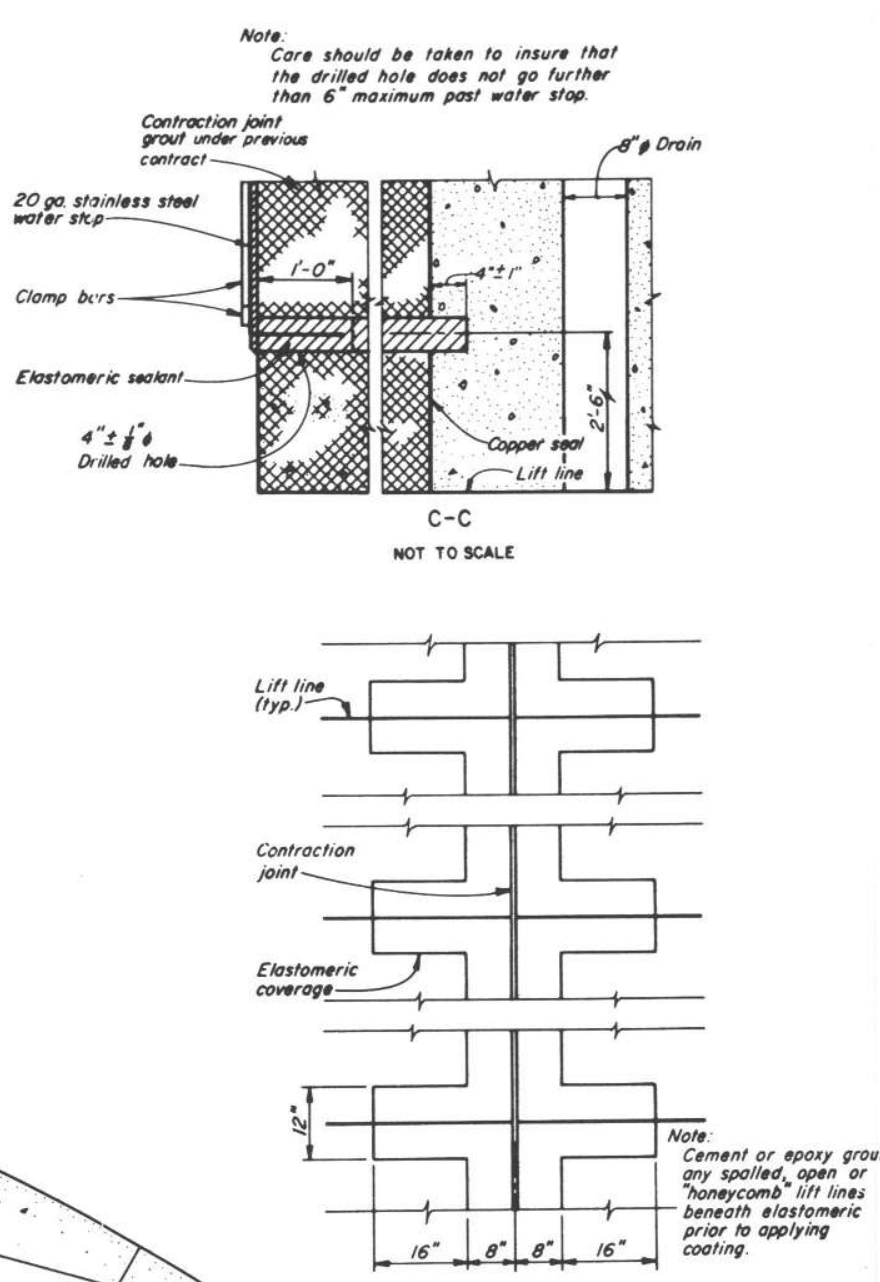

ELASTOMERIC COVERAGE AT
TYPICAL LIFT LINE AND CONTRACTION JOINT

$$
\text { 唯, i.... }
$$

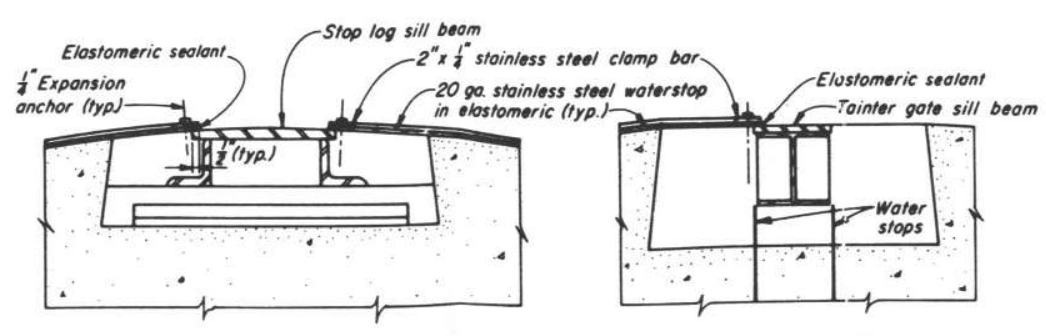

STOP LOG SILL BEAM DETAIL

TAINTER GATE SILL BEAM

Rim

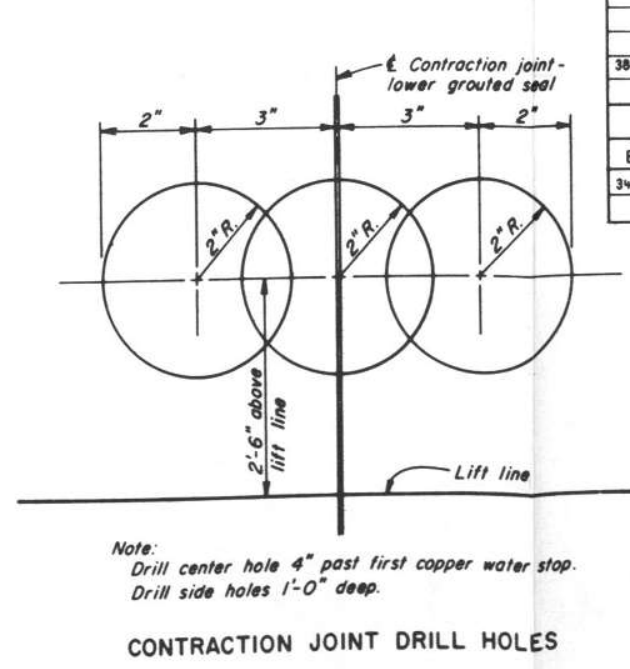

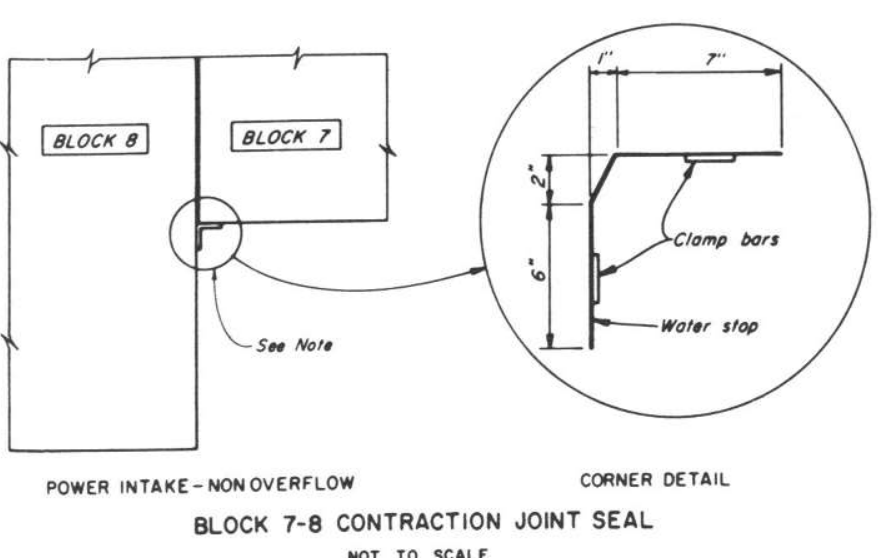$$
\text { NOT TO SCALE }
$$

DISTANCE FROM FACE OF DAM TO FIRST COPPER SEAL

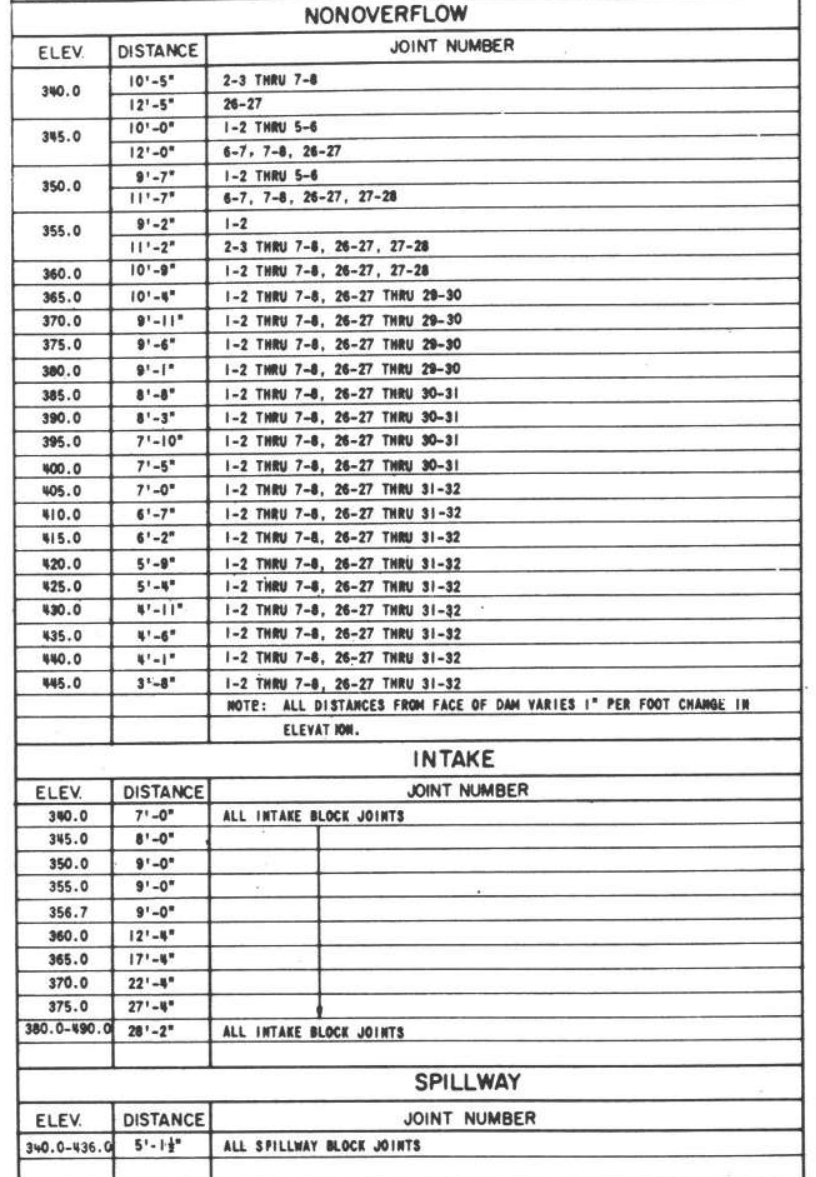

Figure 138. Phase I repair details, Richard B. Russell Dam 



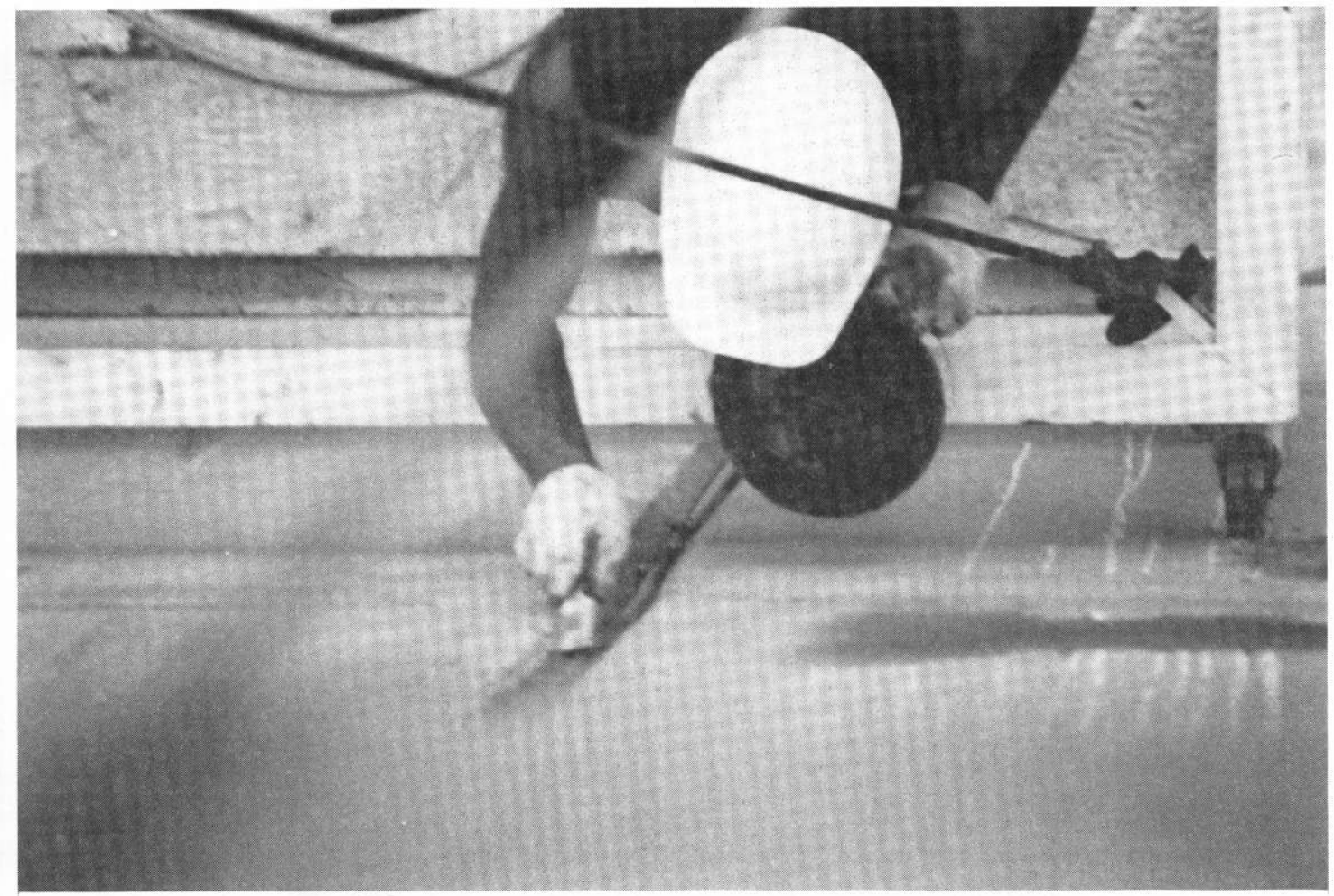

Figure 139. Permeable grout tube in the contraction joint being covered with sealant, Richard B. Russel1 Dam

external leakage area to pinpoint the leakage. It was also determined that injecting compressed air into the drains from the inspection gallery would help locate the exterior leakage areas. This procedure required deepwater divers to follow the air bubbles down and mark the leakage area. These two methods were used with varying degrees of success to locate leaks on the upstream face of the concrete dam. It was generally believed that the leaks were located in the contraction joints beneath the bottom elevation of the stainless steel joint seals. There was also the possibility that leakage was coming around the stainless steel seals at the lift lines.

276. Several leakage repair methods were developed that had been used with success on other dams to control leaking. They included the use of Silva-Cel wood fibers, cinders, and granular bentonite. The use of hard cement and soft chemical grouts to help repair and control the leaks was considered. It was also planned to use new types of underwater adhesives and epoxies on the leaks if these materials prove to be beneficial.

277. A waterstop of sheet rubber approximately $2 \mathrm{ft}$ wide was placed by divers over construction joint $10 / 11$ in the area below the stainless steel 


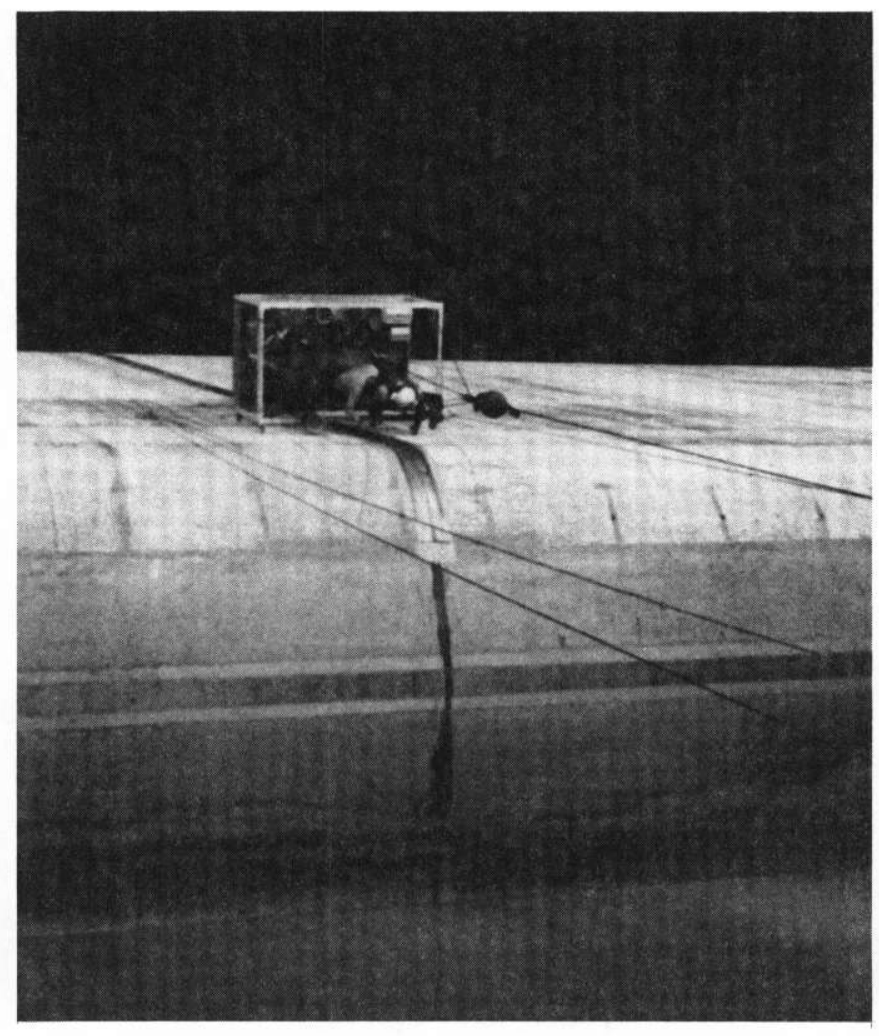

a. During installation

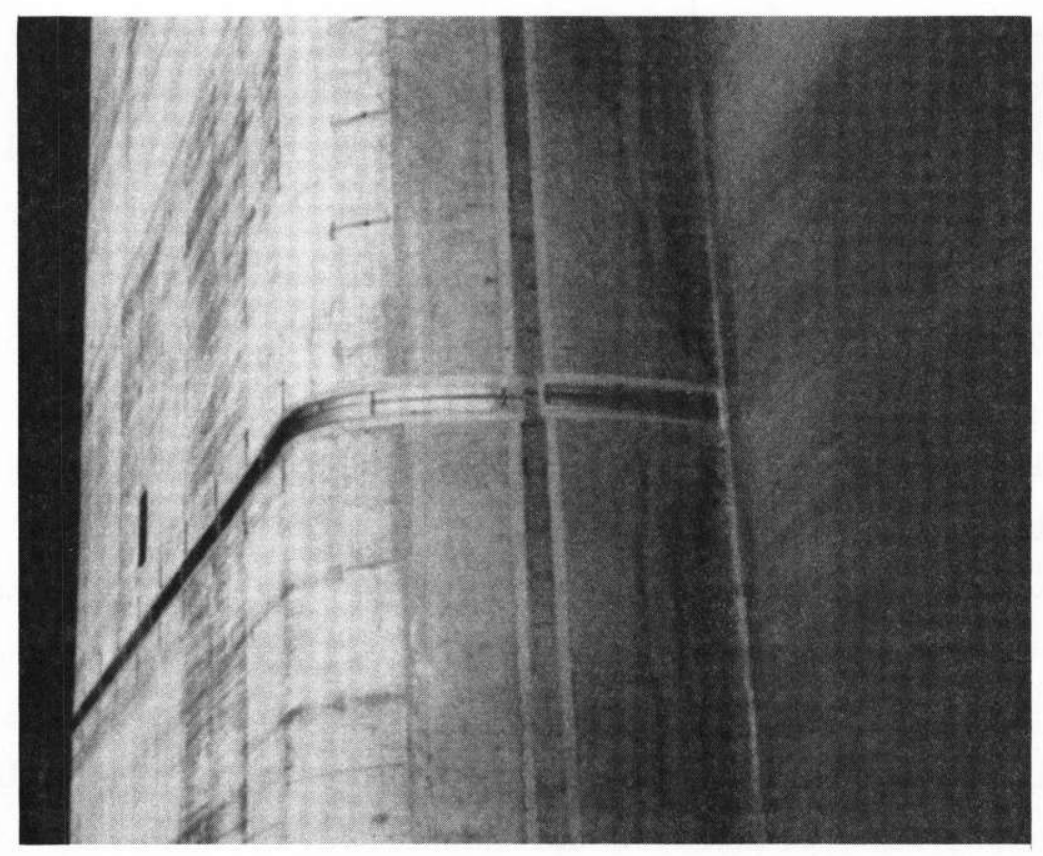

b. Completed waterstop

Figure 140. External waterstop, Richard B. Russell Dam 


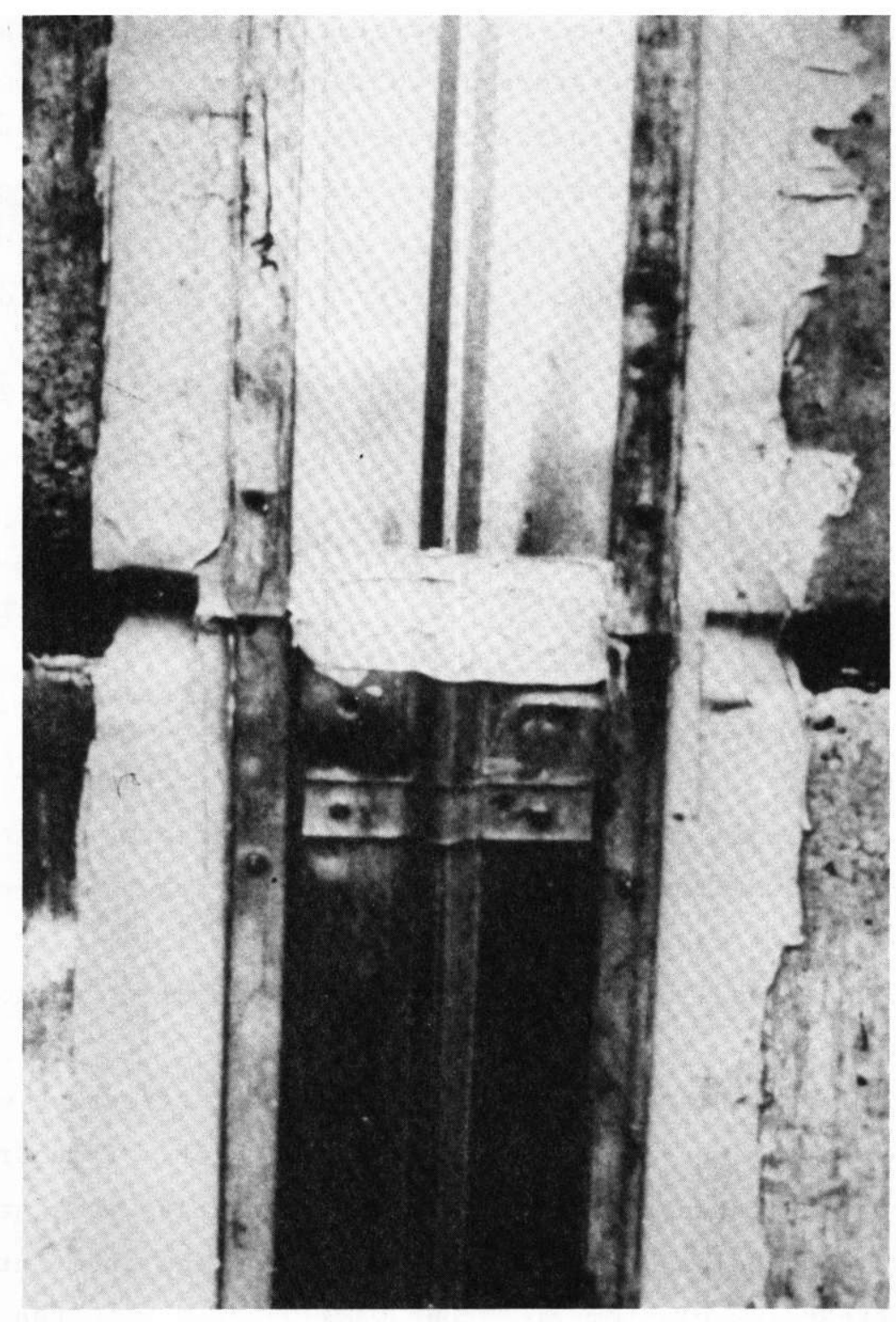

Figure 141. Upstream face of monolith joint with completed external waterstop, Richard B. Russe11 Dam

waterstop placed during Phase I repairs. However, the underwater adhesive used to bond the rubber to the concrete failed and this type of seal was only temporarily effective.

278. External grouting from the reservoir with an expansive elastomeric grout was attempted on contraction joint 15/16 which was leaking at a rate of approximately $100 \mathrm{gal} / \mathrm{min}$. This required drilling access holes from the reservoir side into the concrete below the level of the previously placed stainless steel waterstop. Underwater injection of a hydrophilic polyurethane foam (3M 
Company's Chemical Grout 5600) was only partially successful because the rate of water flow and a water temperature of $40^{\circ} \mathrm{F}$ prevented the grout from completely gelling and bonding to the concrete before it exited the joint. One-half of the block 15 face drains were sealed off with packers but this was not sufficient to slow the inflow to a rate adequate to permit the grout to set. This entire operation proved to be very difficult and was only partially effective.

279. One of the techniques employed as a surface seal in connection with the elastomeric grouting of joint 15/16 was to use fiberglass strands or ropes covered with epoxy resin. The epoxy used on the fiberglass strands was a two-component ge1, "SPLASH ZONE" A778, manufactured by Koppers Company. These fiberglass-epoxy strands called "snakes" were easily used to sea1 the contraction and lift line joints by divers. Also fiberglass-epoxy patches were used to seal any honeycomb leakage areas. The epoxy resin, SPLASH ZONE, apparently has superior qualities for adhering to concrete under water. As shown in Figure 142, six lower unsealed contraction joints in the power intake section and two spillway joints were sealed with the fiberglass-epoxy strands. Leakage in these joints was reduced approximately $142 \mathrm{gal} / \mathrm{min}$ by using this sealing method. This sealing method was the most efficient ad hoc fix made on the dam.

280. Interior grouting was considered the most effective way to control the leakage at contraction joint $4 / 5$ and face drain $15 \mathrm{~F}$. Face drain $15 \mathrm{~F}$ was plugged with grout injected through a packer. Corrective work at joint 4/5 consisted of drilling holes beside the drain and angling them into the suspect leakage path. Expansive elastomeric grout was injected into the suspect honeycomb areas adjacent to joint $4 / 5$. This grouting was effective in stopping the contraction joint leakage and also reducing leakage into an adjacent face drain. This procedure was successful at joint $4 / 5$ primarily because the elevation at which high leakage occurred was midway up the inspection gallery wal1. Face drain 24C, which leaked at over a $100 \mathrm{gal} / \mathrm{min}$ in 0ctober 1983, was successfully sealed as follows: Power plant personnel placed the emergency bulkhead at the adjoining sluiceway to perform a dye test. With bulkhead placement in the sluiceway, leakage to $24 \mathrm{C}$ stopped. Subsequent investigation of the sluiceway uncovered four or five honeycomb areas in the ceiling around the door. These problem spots were also grouted. The expansive grout was a hydrophilic polyurethane foam, CG 5600, manufactured by the $3 \mathrm{M}$ Company. 


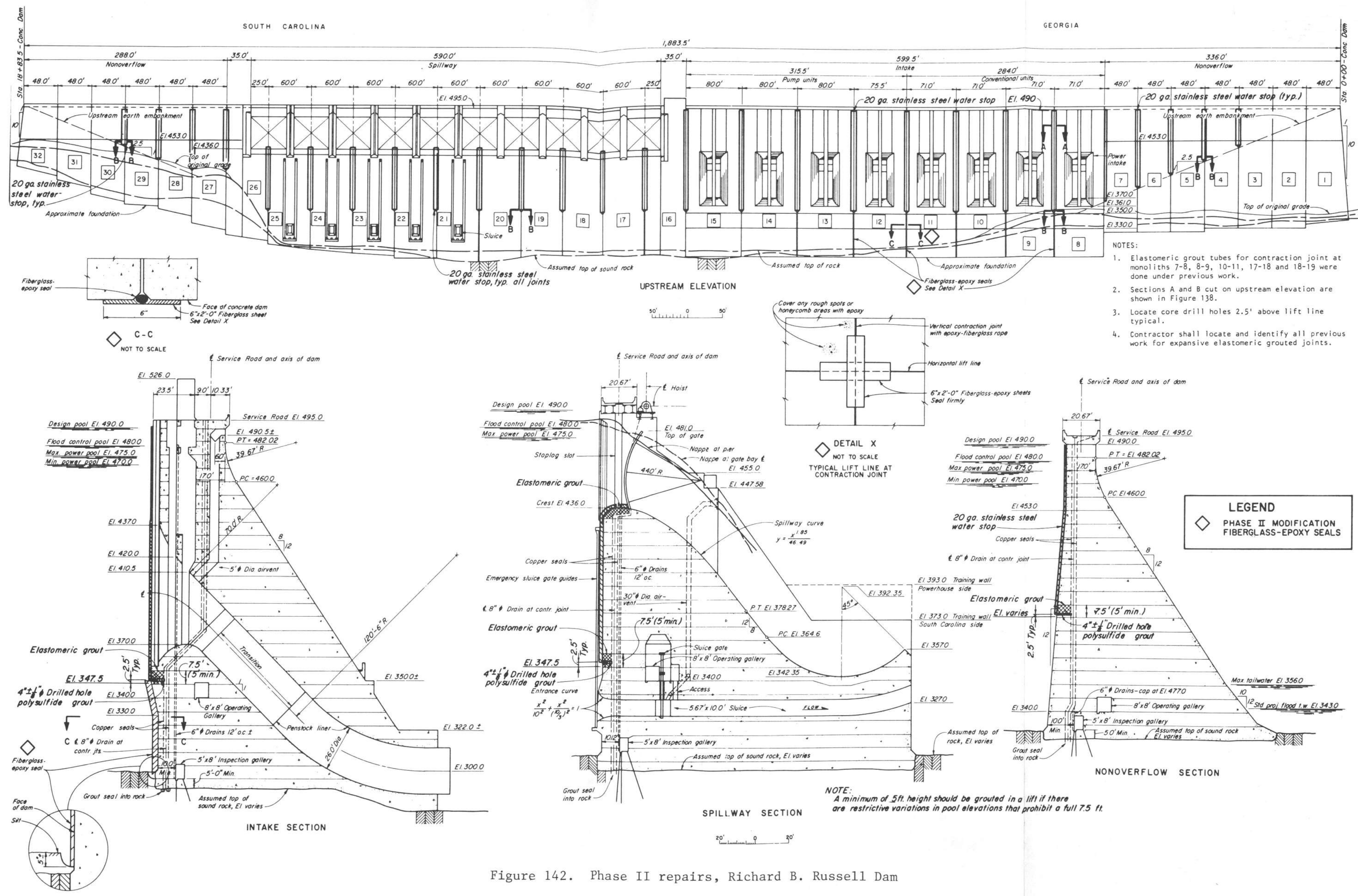



281. There was some leakage around the penstock perimeter downstream in monolith 14 when the pool was raised to elevation $400 \mathrm{ft}$. It was decided that this could be controlled by grouting the space between the penstock liner and the penstock interior near the area where the liner exits the dam. A series of holes was drilled in the penstock liner $6 \mathrm{ft}$ from the downstream face of the dam, and a "ring" of grout was injected. A second grout ring was installed $5 \mathrm{ft}$ upstream from the first. There were a total of 24 holes drilled in this work.

282. Inasmuch as the pool had not been raised above elevation $400 \mathrm{ft}$ and the effects of completely filled penstocks were thus uncertain, it was decided to grout all penstock perimeters similar to that accomplished on monolith 14. This grouting should be effective in diverting leakage to respective face drains and preventing leakage at the penstock exit. Both the regular cement grout and the expansive elastomeric grout, CG 5600, were used to stop the penstock liner leakage. The expansive elastomeric grout was used where the cement grout was not effective in leakage control.

283. Phase II repairs, undertaken while the lake rose approximately $75 \mathrm{ft}$, reduced the leakage from approximately 950 to $350 \mathrm{gal} / \mathrm{min}$. In addition, it is believed that the repair also kept the leakage from increasing substantially as the pool was raised. Therefore, the repairs were considered to be an overall success. Regarding individual repair methods, the use of Silva-Cel wood fibers, cinders, and bentonite had no noticeable effect on stopping the leakage. Application of an external sheet rubber waterstop was only temporarily effective due to fallure of the bonding agent. Underwater grouting from the reservoir side was very difficult and only partially effective. The application of fiberglass-epoxy resin strands and patches on the exterior of the concrete dam under water produced very good results. Grouting from the gallery interior was effective, but it was difficult to keep the grout out of the drains. Two drains were clogged, one intentionally. Leakage monitoring

284. Leakage has been monitored throughout the filling of the Richard $B$. Russell Lake. Total leakage has been monitored weekly by measuring the sump filling rates. The individual drain leakage has been measured by actually timing the filling of containers held below each drain. The individual drain leakage measurements are approximate because of the difficulty in receiving all of the water in a measuring container. During the first winter following 
repairs, a maximum leakage of 1,001 gal/min was recorded on February 20, 1985 followed by a steady decline to 131 gal/min on October 31, 1985 (Figure 143). In 1986, the maximum leakage of $750 \mathrm{gal} / \mathrm{min}$ was recorded on February 19. Continued measurements and observations are planned through another winter cycle. Based on experience at other dams, it is believed that the formation of ca1cium carbonate will further reduce the leakage.

\section{Easton Reservo1r Dam}

285. Easton Reservoir Dam is located on the Mill River near Easton, Conn. The concrete gravity structure is approximately $1,040 \mathrm{ft}$ long with a maximum height of about $105 \mathrm{ft}$. New waterstops, designed to stop leakage through vertical monolith joints, were installed in the existing dam during November and December 1983 by Structural Preservation Systems, Inc, of Baltimore, Md. These remedial waterstops consisted of a drilled hole along each joint filled with polyurethane foam grout.

286. Sixteen 6-in.-diameter holes were drilled from the roadway on top of the dam to a minimum depth of $35 \mathrm{ft}$, or $5 \mathrm{ft}$ into bedrock. The drill holes were located between 2 and $3 \mathrm{ft}$ from the upstream face of the dam. Drilling was accomplished using truck-mounted and skid-mounted drills with a down-thehole hammer. The hole was kept centered on the joint by withdrawing the drill every $5 \mathrm{ft}$ and checking the alignment by visual inspection. This was possible because little or no water was present in the holes. The contractor had a downhole video camera on site to monitor the hole center if required. The drilling went smoothly and no extra holes had to be drilled.

287. The grout used was TACSS Flex 44, a polyurethane foam with Environmental Protection Agency (EPA) approval for use around potable water. Because of concerns about the grout being washed through the joint before it set, the grout was not pumped directly into the hole. Burlap was cut into 24-in. squares and attached to a 1-1/2-1n.-diameter plastic pipe on approximately 1-in. centers with the pipe through the center of the burlap squares. The pipe sections with the burlap attached were soaked in a long trough filled with the Flex 44 grout (Figure 144). The pipe was removed from the trough and after the excess grout drained off, the pipe was inserted into the hole (Figure 145). The pipe sections were designed to fit together rapidly and lock so the entire $35-f t$ length of hole could be filled with the burlap and grout 


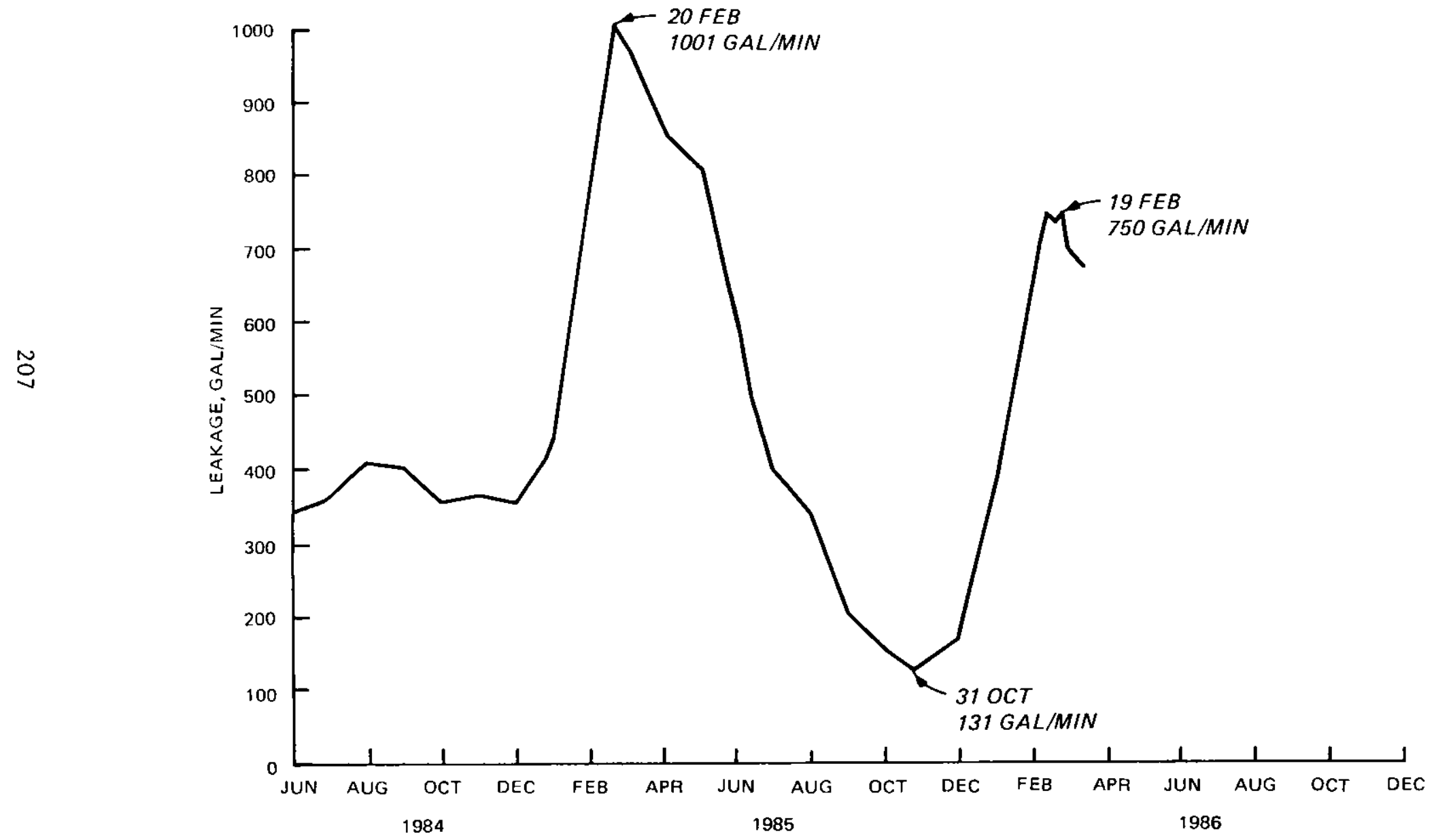

Figure 143. Results of leakage measurements, Richard B. Russe11 Dam 


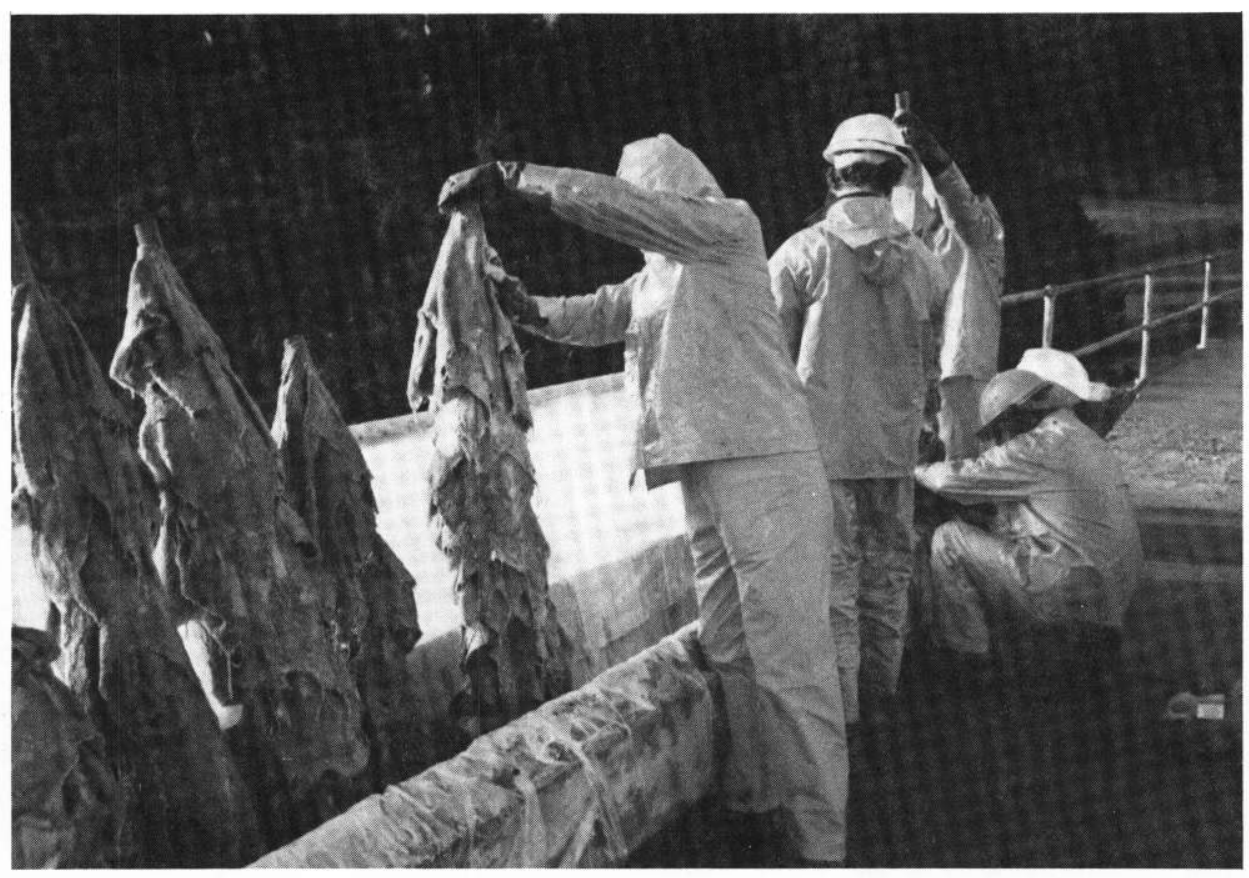

Figure 144. Soaking burlap "Christmas trees" in polyurethane foam grout, Easton Reservoir Dam

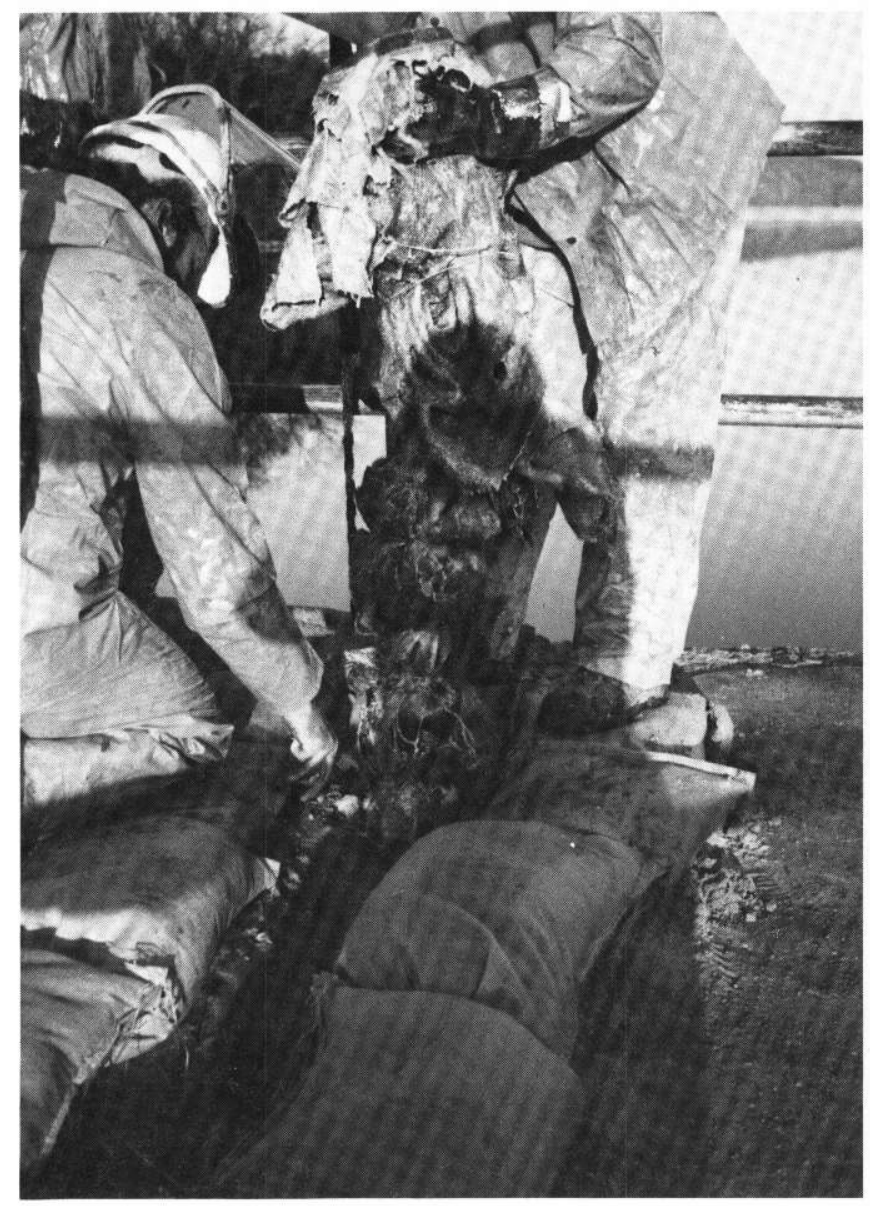

Figure 145. Installing

"Christmas tree" in the

drill hole, Easton Reservoir Dam 
before the grout started to form. This arrangement allowed for positive placement of the grout and removal of the "Christmas tree," if required during installation, before the grout formed. Because most of the holes were dry, water was pumped into the hole after the "Christmas tree" was placed to activate the form. The holes were capped flush with the roadway surface using a concrete plug.

\section{$\underline{\text { Bagnell Dam }}$}

288. Bagne11 Dam, owned and operated by Union Electric Company, is located on the Osage River near Osage Beach, Mo. The concrete gravity structure is $2,543 \mathrm{ft}$ long and consists of a 511-ft-long power station, 520-ft-long spillway section, and two nonoverflow retaining sections. US Highway 54 runs along the top of the structure. The dam, containing 533,000 cu yd of concrete, was completed in 1931.

289. In 1984, Union Electric contracted with Structural Preservation Systems, Inc. (SPS) to stop leakage between concrete monoliths of six vertical joints in the west nonoverflow section of the dam. Water from the reservoir leaking through the vertical drainage system could be seen (Figure 146) and measured in a dam gallery which runs approximately $83 \mathrm{ft}$ below the roadway surface. These vertical drains empty into a large horizontal drain at the bottom of the dam. In addition, there are horizontal drains at each lift joint that feed into the vertical drains. On 2 April 1984, joint leakage ranged from 50 to $660 \mathrm{gal} / \mathrm{min}$ with an average flow for the six joints of $211 \mathrm{gal} / \mathrm{min}$. 290. A primary concern about the leakage through the monolith joints was increased uplift pressures that had been measured with piezometers. It was believed that this increased uplift pressure was caused by the flow in the bottom horizontal drain being at or near capacity. Therefore, decreasing the flow from some of the vertical joints would reduce the flow in the horizontal drain at the bottom of the dam, which in turn would reduce the uplift pressure. In order to stop the flow through the vertical joints, a waterstop system was designed using a drill hole lined with a rubber hose which was filled with chemical grout. Later in the design phase this was changed and eventually evolved into the two-component rubber sleeve filled with water that was actually used. 


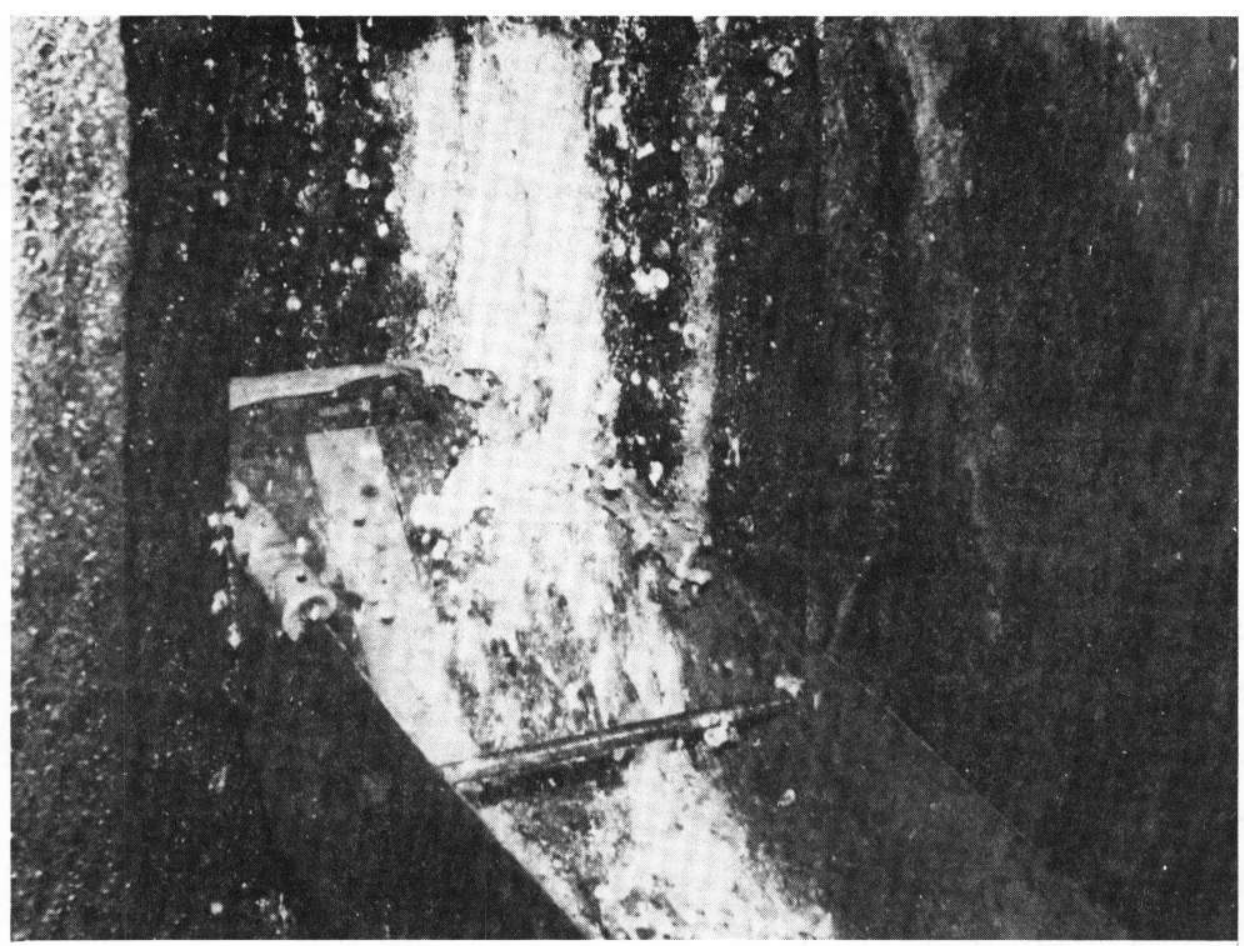

a. Joint 15 with hole drilled to a depth of $10 \mathrm{ft}$

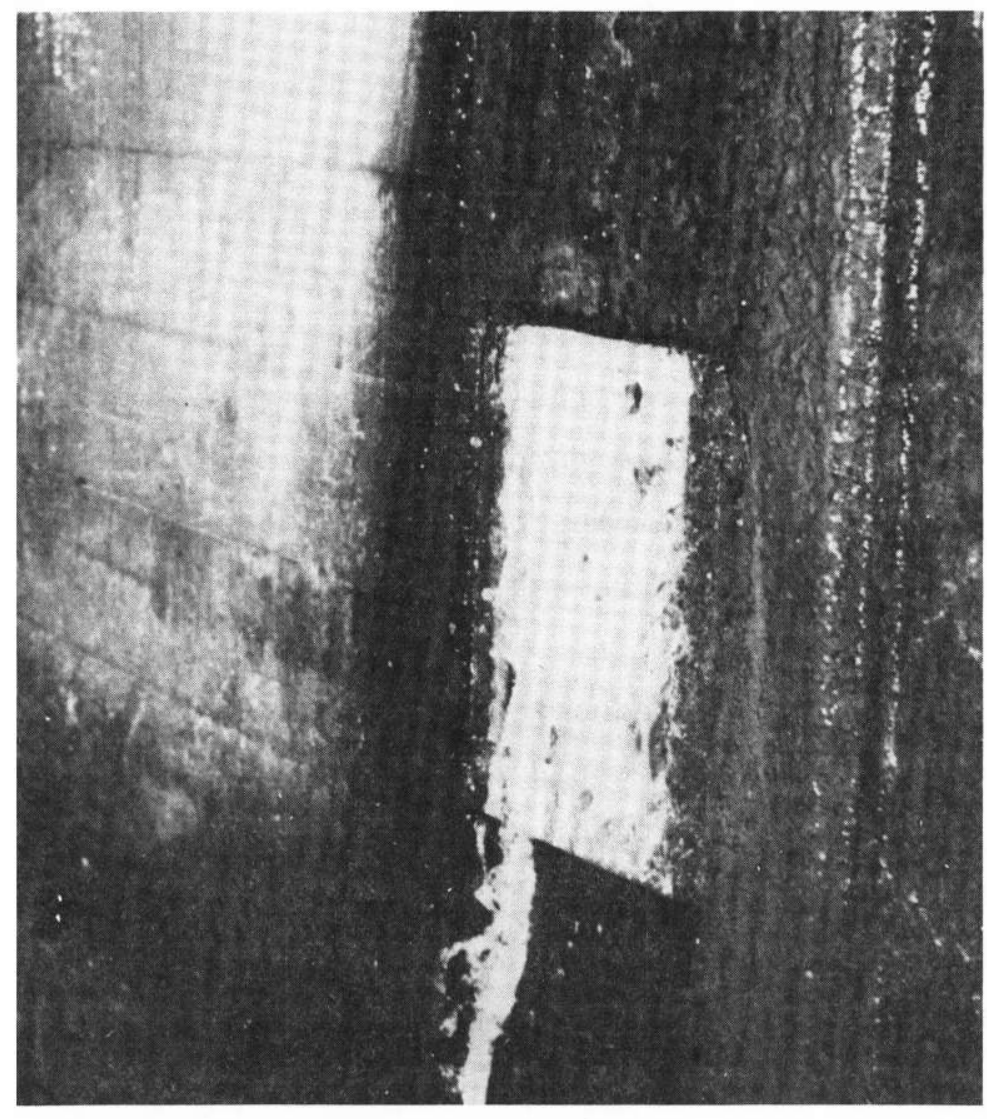

b. Joint 17 prior to drilling

Figure 146. Leakage of joints 15 and 17 as seen in the gallery, Bagnell Dam 
Drilling

291. Construction Drilling, Inc. (CDI), the drilling subcontractor, began mobilizing on 3 April 1984. The mobilization took about a day and a half because numerous patches in the roadway had to be planked and bridged over, a requirement of the Missouri State Highway Department. CDI used an Acker track-mounted drill rig with many modifications specifically for drilling with a down-the-hole hammer. Drilling was accomplished with a 6-in. downthe-hole hammer, a type of rotary/percussion drilling equipment. The head of the hammer pounds as it rotates. At $150 \mathrm{psi}$, the hammer is operating at approximately 1,000 blows/min. This rate varied as the air pressure at the hammer changed due to depth and frictional losses. In addition to the downthe-hole hammer, a 6-in. core barrel was used to obtain concrete core to verify joint location in the borehole. Drill hole locations are shown in Figure 147.

292. The first hole drilled was located at joint 15. The hole was drilled to a depth of $10 \mathrm{ft} 6 \mathrm{in}$. below the roadway. At that point, a video inspection was made to determine whether the borehole straddled the joint, and whether the joint detail existed, as it was anticipated. The upstream joint was readily verified at exactly 12 o'clock, with water intruding. However, the downstream joint could not be verified with the video camera so a 6-in. core was drilled and extracted. The joint could be clearly seen in the core, and as expected, the borehole was on target. The remainder of the drilling of the hole at joint 15 continued on target to a depth of approximately $60 \mathrm{ft}$ below the roadway. At that point, the hammer drifted into the corner of the copper waterstop due to the poorly consolidated concrete adjacent to the waterstop. The borehole followed the copper waterstop down to approximately $135 \mathrm{ft}$ below the roadway. At $139 \mathrm{ft}$ below the roadway, the borehole drifted off the joint altogether.

293. The apparent wandering of this first hole was attributed to two factors. First, the video showed that the concrete around the waterstop was fragmented and poorly consolidated. Since the theory behind the down-the-hole hammer is that it will follow the weakest plane, it followed the weakened plane along the waterstop. Second, there were several attempts to correct the alignment (away from the waterstop) which may have actually worsened the alignment. The driliing of the first hole was accomplished in $34 \mathrm{hr}$ of drilling; its final depth was $154.8 \mathrm{ft}$, and it was completed on 14 April 1984 . 

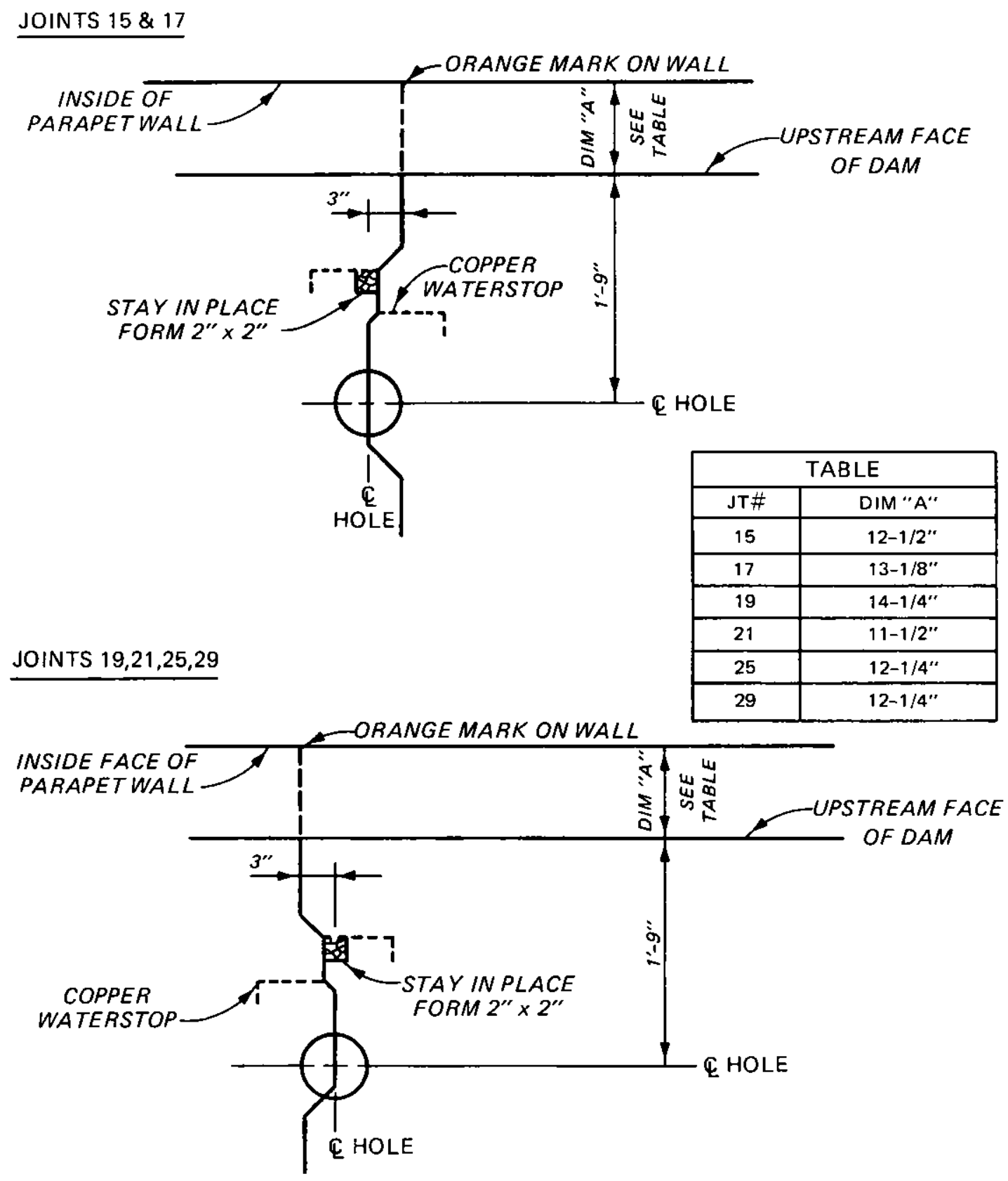

Figure 147. Drill hole locations, Bagnell Dam

294. The second hole drilled was at joint 29. The hole maintained alignment without any major problems. Water was not encountered until $58 \mathrm{ft}$ below the roadway. The final depth of the hole was $144.5 \mathrm{ft}$, and the drilling took $29.5 \mathrm{hr}$. The drilling of the second hole was completed on 18 April 1984. 295. The third hole was drilled at joint 25. As with all other joints, the hole was drilled to $10 \mathrm{ft} 6 \mathrm{in}$. and the joint detail inspected by way of a 6-in. core. At approximately $11 \mathrm{ft} 6 \mathrm{in.}$ from the roadway surface, a large 
void was encountered on the downstream side. The driller lost all circulation to the top of the hole; that is, all cuttings were going down the vertical drains. The drilling was stopped at this point and the hole was filled with $3 \mathrm{ft}$ of a dry pack cement grout. After a 3-day cure, the grout was cored through with a 6-in. barrel and drilling with the down-the-hole hammer continued. The remainder of the hole was drilled without any major problem. It required $27.5 \mathrm{hr}$ of drilling to complete the $149.5-\mathrm{ft}$ depth of hole No. 3 at joint 25 .

296. Hole No. 4 was drilled at joint 21 beginning on 25 April 1984. The joint was found to be as expected and the borehole on target at $10 \mathrm{ft}$ 6 in. below the roadway. Water intrusion began at approximately $52 \mathrm{ft}$ below the roadway. The copper waterstop was encountered at approximately $110 \mathrm{ft}$ below the roadway; however, not as much copper was expelled in the cuttings as at joint 15. The final depth of hole No. 4 was $151.5 \mathrm{ft}$, and the time of actual drilling was $25 \mathrm{hr}$.

297. The fifth hole attempted was at joint 19. The drill was initially positioned 2 in. too far upstream, and a 6-in. hole was drilled at that location. At the 10-ft 6-in. depth when the core was taken, it was discovered that the hole was off the desired location. The drill rig was then set up over the design location and another 6-in. hole was drilled $13 \mathrm{ft}$ deep. At that time it was realized that the joint detail did not exist as anticipated. An attempt was made to ream out the second hole to 9-in. diameter; however, this was unsuccessful and the hole was abandoned. The hole was backfilled with 3,000-psi concrete with a joint installed to coincide with the monolith joint. Fourteen hours were expended on joint 19.

298. The sixth and final hole was drilled at joint 17, beginning on 28 April 1984. The core taken at $10 \mathrm{ft} 6 \mathrm{in}$. showed that the joint detail was only offset $1 \mathrm{in.}$ as opposed to the 3-in. offset anticipated. The hole was reamed to $9 \mathrm{in}$. and the 6-in. down-the-hole hammer centered over the joint. Heavy water intrusion was encountered at $65 \mathrm{ft}$, and a slight amount of copper was expelled with the cuttings at $115.5 \mathrm{ft}$. The final depth of the hole was $154.5 \mathrm{ft}$, and drilling was completed in $17 \mathrm{hr}$.

299. After the holes were drilled, they were thoroughly flushed and a complete video inspection made. The video equipment used on this project was manufactured by PLS International of Strongsville, Ohio, Mini Camera System FS 3760 . The camera system consisted of a 1-1/2-in.-diameter underwater camera 
on $160 \mathrm{ft}$ of control cable, a portable control unit with a built-in. 9-in. TV monitor, and a JVC portable video cassette recorder. The camera was equipped with flve halogen lights that could be adjusted to maintain the proper light level in the borehole for excellent picture quality. The video inspection included viewing the upstream and downstream joints along the full length of the borehole where they were visible. Also included on the final tapes are the rock concrete interface and a video of the inside of the sleeves after installation.

Sleeve installation

300. The two-component sleeve used on this project consisted of a resilient inner sleeve and a reinforced outer sleeve. The inner sleeve used was 5-1/2-in. inside diameter by 5-7/8-in. outside diameter and of sufficient length for each borehole. It was composed of pure gum natural rubber compound and manufactured by Rubber Engineering Company of Salt Lake City, Utah. This compound is designed for high tensile strength, resilience, and abrasion resistance, especially where impingement is encountered. Typical physical properties of the inner sleeve at $73^{\circ} \mathrm{F}$ are as follows:

$\begin{array}{lc}\text { Hardness, Shore A } & 40 \\ \text { Tensile strength, psi } & 3,500 \\ \text { Elongation, percent } & 650 \\ \text { Specific gravity } & 0.98 \\ \text { Bashore resilience, percent } & 80 \\ \text { Tear (Die C), PPLI } & 200 \\ \text { Maximum service temperature, degrees F } & 160\end{array}$

301. The outer sleeve used was an elastomer-coated fabric (neoprene over nylon), 0.025 in. thick. The material used was Fairprene NN-5798, a general-purpose, high-strength fabric manufactured by Fairprene Industrial Products. The Fairprene material was furnished in rolls 22 in. wide, sufficient to wrap around the inner sleeve with a 3-in. overlap. 302. The intended method of sleeve installation initlally was by the inversion process. The inner sleeve was to be delivered inside out to the jobsite. The outer sleeve was to be weighted and lowered into the hole first (Figure 148). Next the inner sleeve was to be attached to a temporary flange at the roadway surface. The inner sleeve would then be inverted down the hole by turning it inside out and filling the annular space with water (Figure 149) 


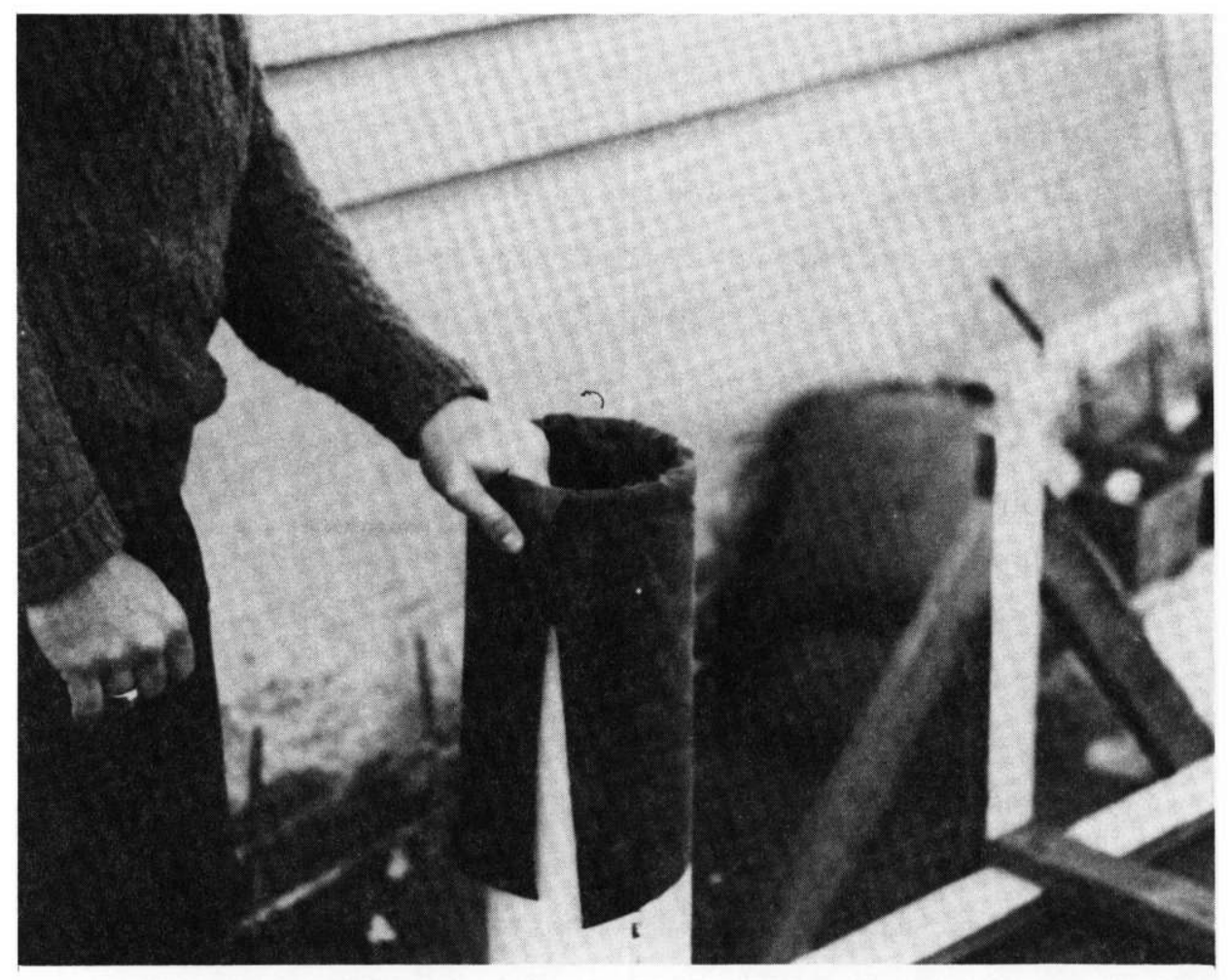

Figure 148. Outer sleeve in place in the drill hole, Bagnell Dam

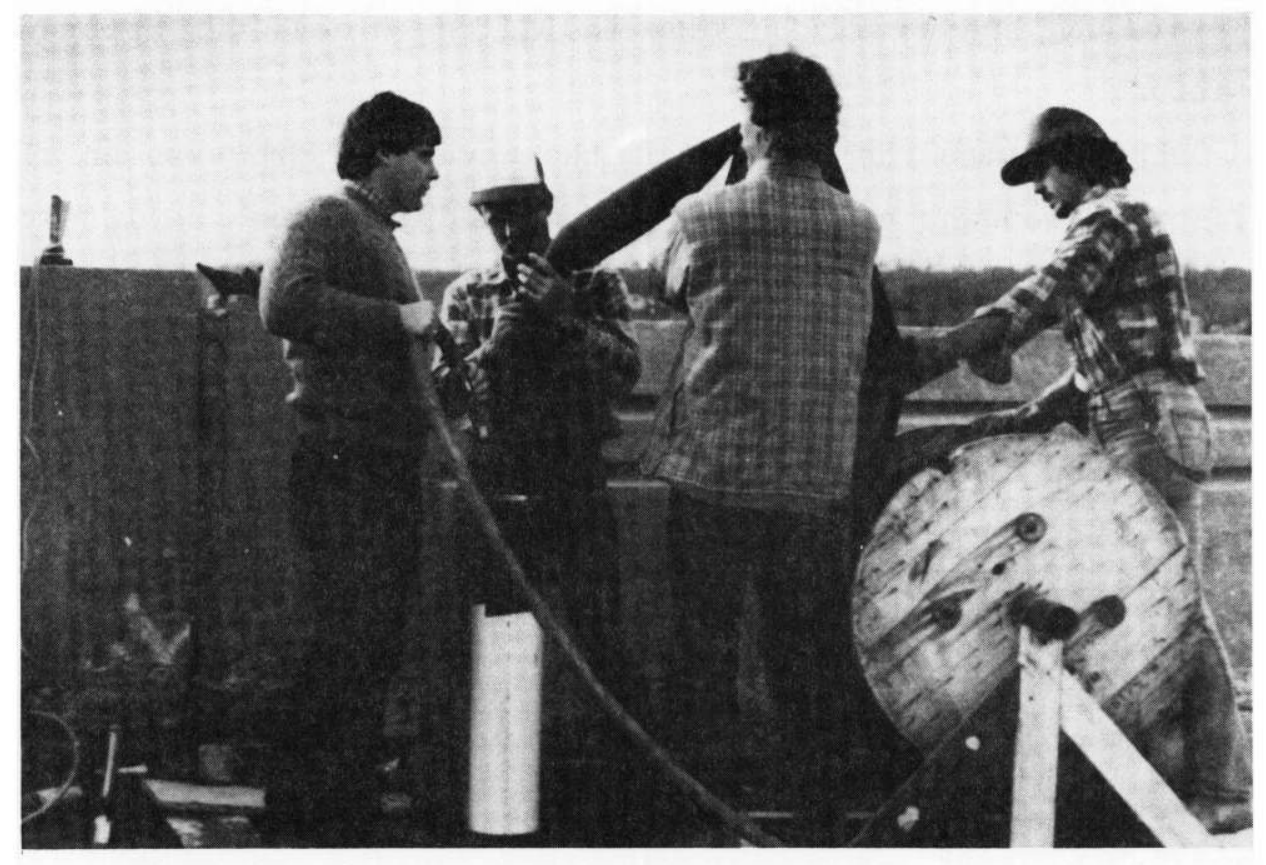

Figure 149. The inversion process underway, Bagnell Dam 
The theory was that the weight of the water would unroll the sleeve in the hole. A cable was to be attached to the sealed end of the inner sleeve for ease of removal of the sleeve.

303. This method was attempted on the first sleeve, which was to be installed in joint 29. The process worked well until it was halted during the inversion stage at a 35-ft depth. The hose was extracted, and insertion repeated, but once again, progress was stopped $35 \mathrm{ft}$ below the roadway. A video inspection of the inside of the outer sleeve was made and no obstructions were seen. Based on this video inspection, it was hypothesized that the inversion process was halted due to the fact that the borehole was filled with water. Since the drilling operation clogged most of the downstream joint with cuttings, the only relief would have been for the water to escape through the upstream joint. The second contributing factor was the tremendous frictional force buildup between the surfaces of the inner sleeve as it unrolled. Liquid soap was used as a lubricant to help ease the friction, but because of the length of the sleeve, it is still likely that the buildup of friction was responsible. There was some discussion at the jobsite about the possibility of an air lock causing the problem. However, it is not felt that this was a significant problem due to the fact that an air vent was provided at the end of the inner sleeve, and no air buildup inside the sleeve was apparent during the installation.

304. Subsequent to the failure of the inversion process, an alternate method of installation was employed. This method involved the insertion of both sleeves simultaneously (Figure 150). This was accomplished by weighting one end and lowering the composite sleeve into the hole. This method proved to be fast and effective, and was used in installing all five sleeves. A detailed description of the preparation and installation procedure follows:

a. The outer sleeve was rolled out on the roadway deck and cut to the appropriate length. Next, the inner sleeve was placed on the outer sleeve and a packer placed in its open end. Approximately 10 psi of air was then induced into the inner sleeve and it was soap tested for leaks (Figure 15l). In the event that any leaks were found, they were repaired by patching with a commercially available tire patch and vulcanizing fluid, a method approved by Rubber Engineer Company.

b. Once the leak test and any necessary patching was complete, a 10-1b weight was attached to the end of the composite sleeve. The weight consisted of either a piece of 1-1/2-in.-diameter 


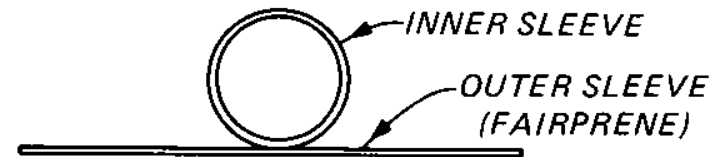

STEP 1: LAY OUT OUTER

SLEEVE, PLACE INNER

SLEEVE IN MIDDLE OF

OUTER SLEEVE.

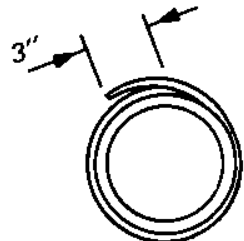

STEP 2: WRAP OUTER

SLEEVE AROUND INNER

SLEEVE ALLOWING A

$3^{\prime \prime}$ OVERLAP.

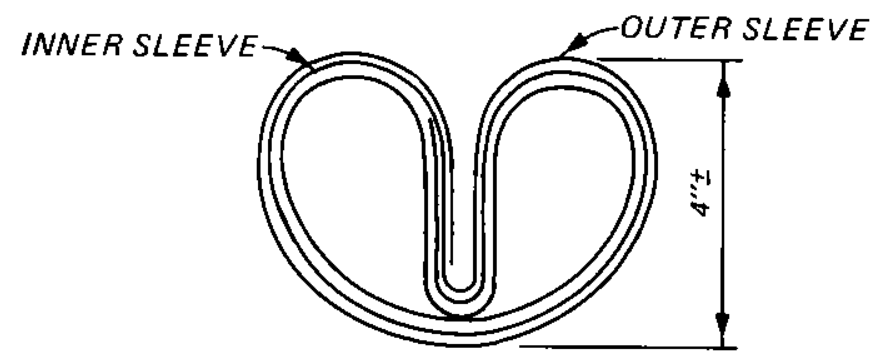

STEP 3: FOLD COMPOSITE SLEEVE ON ITSELF.
INNER SLEEVE

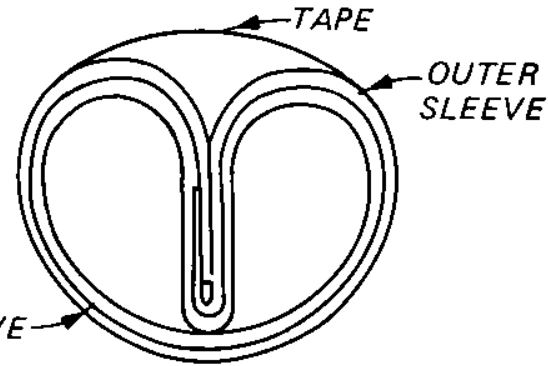

STEP 4: INSTALL BANDING STRAPS ON TAPE WITH WATER-SOLUBLE ADHESIVE.

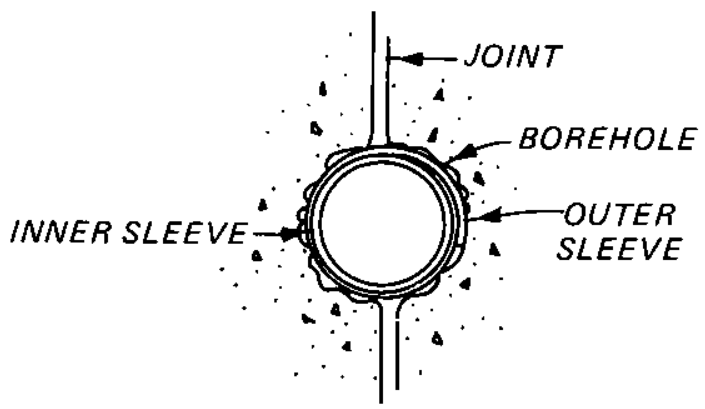

INSTALLED SLEEVE AFTER BANDING STRAPS BREAK.

Figure 150. Sleeve installation procedure, Bagne11 Dam

steel pipe filled with lead shot, a piece of 2-in.-diameter polyvinyl chloride pipe filled with lead shot, or a lead doughnut $4 \mathrm{in.}$ in diameter (Figure 152).

c. The attachment of the weight was accomplished by wrapping the outer sleeve around the inner sleeve, leaving a 3-in. overlap of the outer sleeve material. Then the composite sleeve was wrapped around the weight and fastened with stainless steel hose clamps.

d. The remainder of the sleeve was then prepared in a similar manner. First, the outer sleeve was wrapped around the inner sleeve leaving the same 3 -in. overlap. Next, the composite sleeve was rolled over itself to approximately a 4-in. 


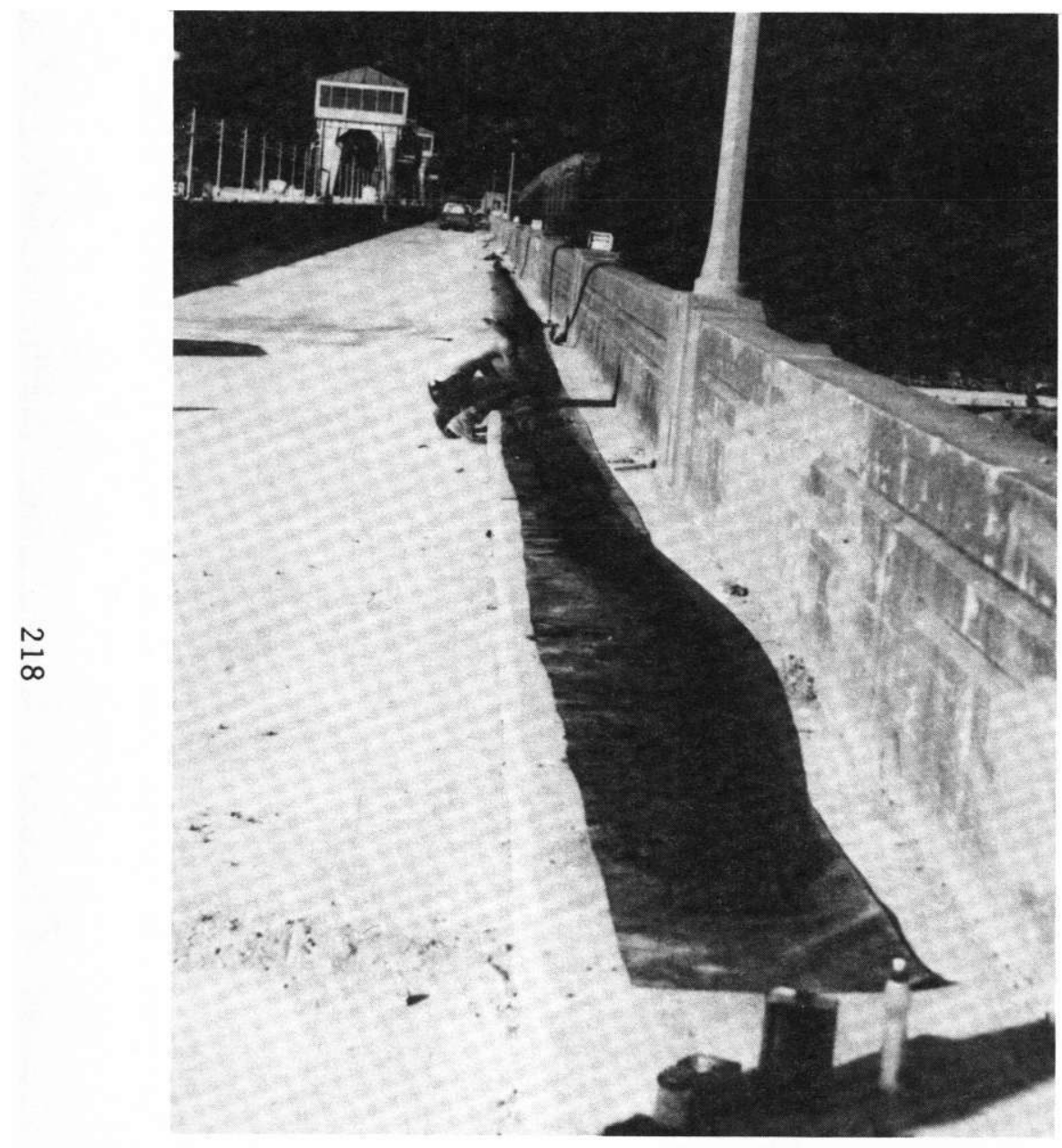

Figure 151. Soap testing the inner sleeve, Bagne11 Dam

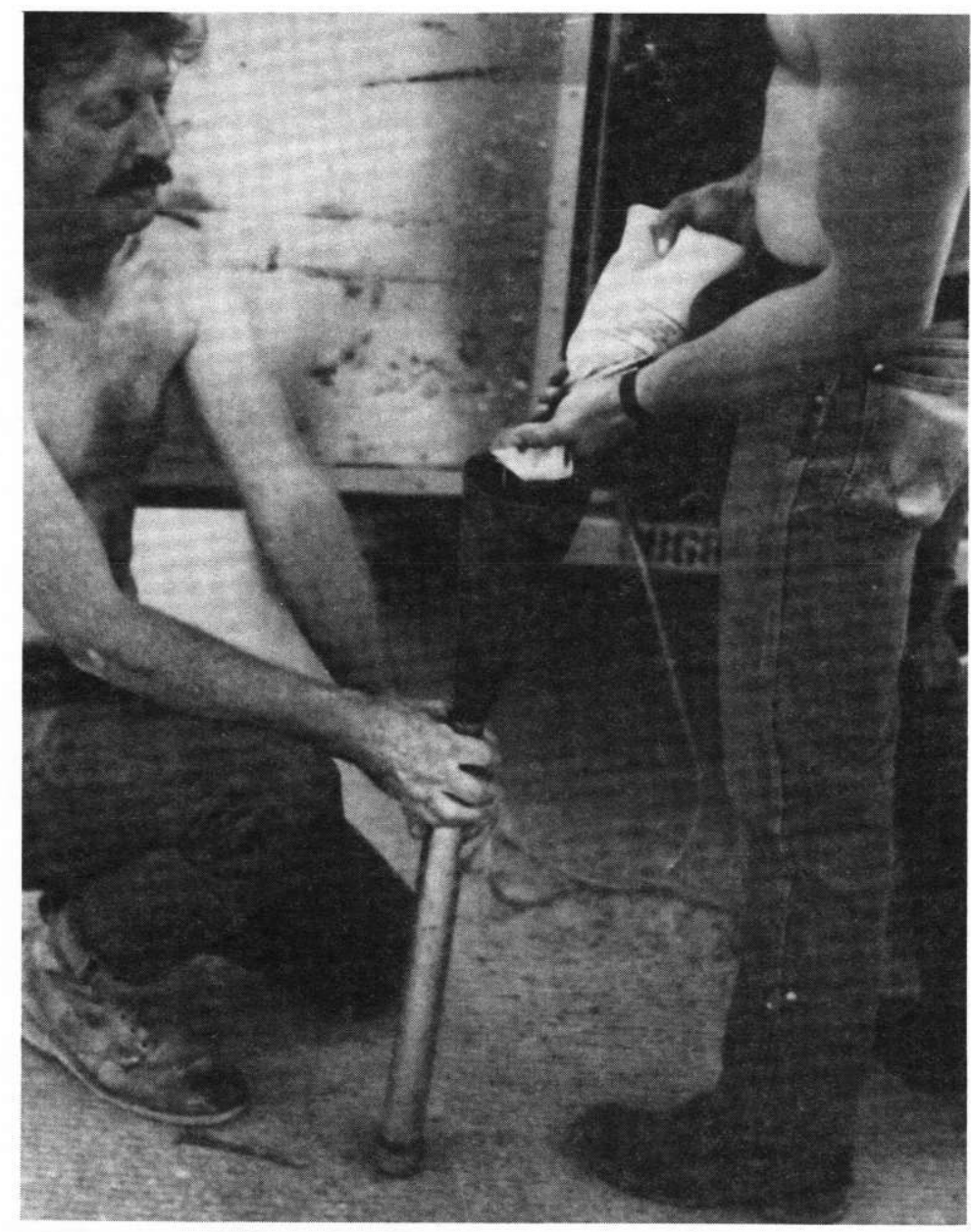

Figure 152. Steel pipe filled with lead shot to weight the composite sleeve, Bagne11 Dam 
diameter and secured with masking tape bands spaced at approximately $12 \mathrm{in.}$ on center (Figure 153).

e. After the sleeve was prepared and the final video of the borehole completed, the composite system was lowered in the hole, weighted end first. When the composite sleeve was at the bottom, it was rolled over and attached to a temporary flange at the roadway surface (Figure 154). The outer sleeve was marked at $10-\mathrm{ft}$ increments so that it was known that the sleeve was actually lowered to the bottom of the hole.

f. Once the sleeve was in the bottom of the hole, it was filled with water. Because of the welght of the water and the fact that the adhesive on the masking tape was water soluble, the banding straps would break and the sleeve would seat against the borehole walls.

305. The process of inserting the sleeve took only about 5 min and it was only an additional $35 \mathrm{~min}$ before the sleeve was full of water. As soon as the water level in the sleeve stabilized, a video inspection of the inside of the sleeve was made to ensure that there were no wrinkles.

306. A cast Iron cleanout with a brass plug was installed at each joint where a sleeve was installed (Figures 155-157). This cleanout was a trafficbearing model mounted flush with the roadway surface. The top is easily removable for periodic inspection of the water level in the sleeve. The water level was left at $1 \mathrm{ft}$ below the roadway to allow for thermal expansion and contraction.

307. The sleeve Installation was essentially the same on all five holes. The order of installation from first to last was as follows: joint $29,21,17,15$, and 25 . On joint 29 a 4-in.-diameter lead doughnut was used as a weight. On joints 21 and 17 a 1-1/2-in.-diameter steel pipe filled with lead shot weighted the end of the sleeve. The steel pipe was changed to 2-in.-diameter polyvinyl chloride pipe at joints 15 and 25.

308. Joint leakage was monitored throughout the repair project by Union Electric personnel with results as follows:

\begin{tabular}{lrrrrrrrr} 
Joint & \multicolumn{1}{c}{ Flow Rates on Dates Shown, gal/min } \\
\cline { 2 - 5 } & $\frac{4 / 2}{15}$ & $\frac{4 / 11}{0}$ & $\frac{4 / 23}{0 *}$ & $\frac{4 / 25}{0}$ & $\frac{4 / 27}{0}$ & $\frac{4 / 30}{0}$ & $\frac{5 / 23}{0}$ & $\frac{5 / 29}{0}$ \\
17 & 115 & 97 & 79 & 92 & 85 & $51 *$ & 2 & 1 \\
19 & 111 & 120 & 98 & 100 & 93 & 97 & 33 & 21 \\
21 & 660 & 506 & 384 & 388 & $206 *$ & 167 & 78 & 58 \\
25 & 246 & 258 & 170 & $30 *$ & 34 & 29 & 13 & 10 \\
29 & 86 & 77 & $1 *$ & 0 & 0 & 0 & 0 & 0
\end{tabular}

* Initial readings were taken after completion of drilling. 


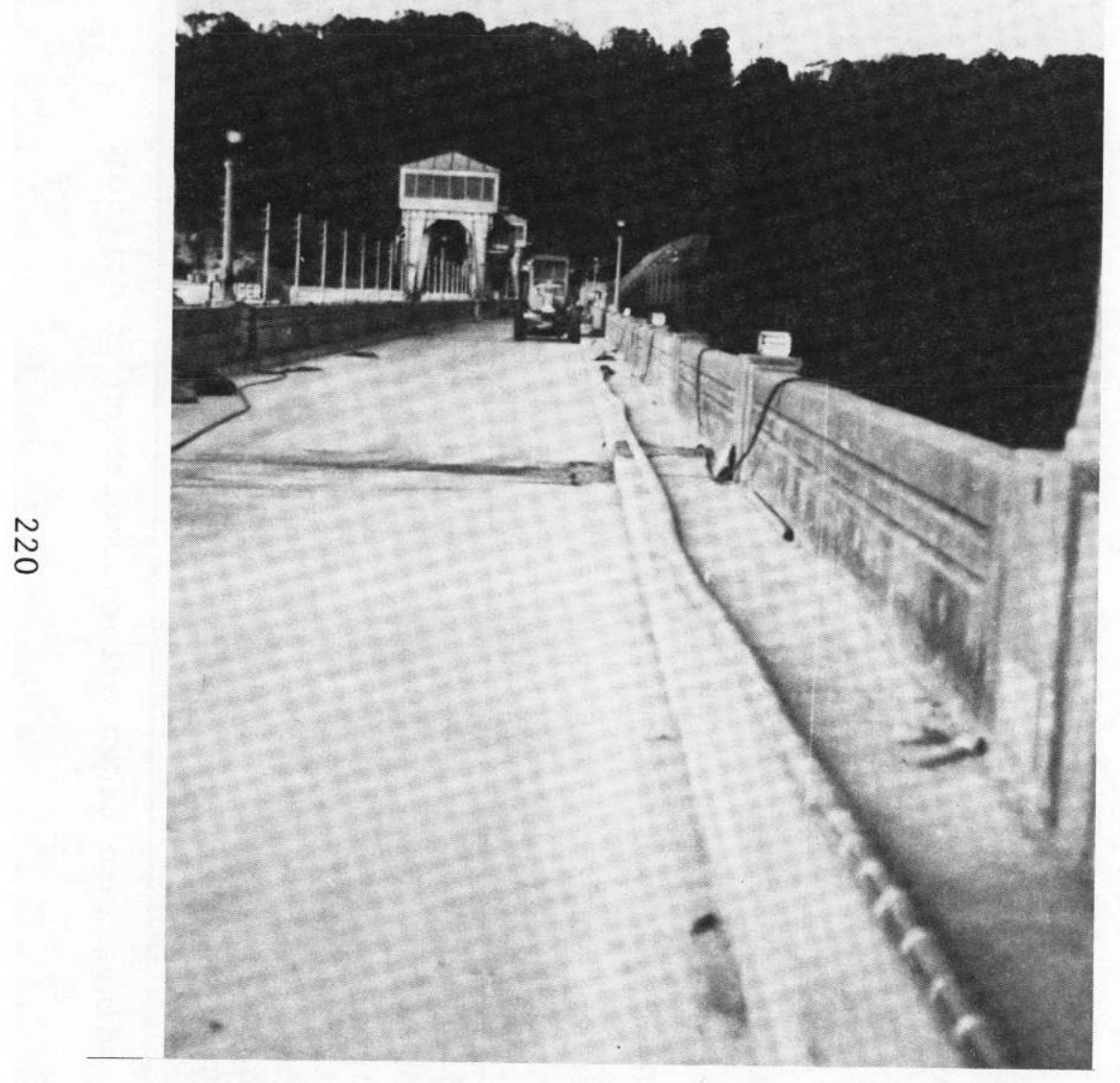

a. Overall view

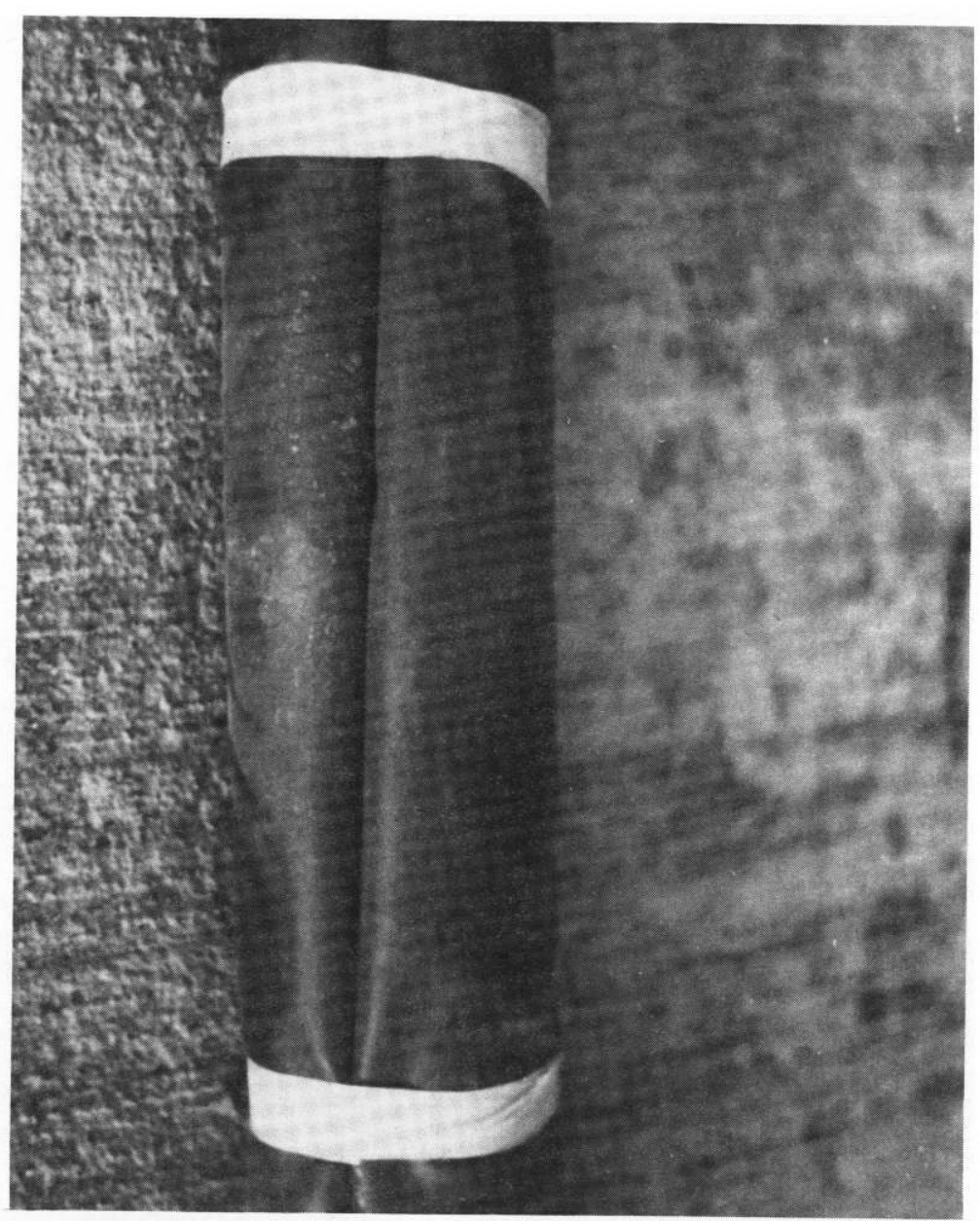

b. Close-up

Figure 153. Composite sleeve ready for installation, Bagnell Dam 


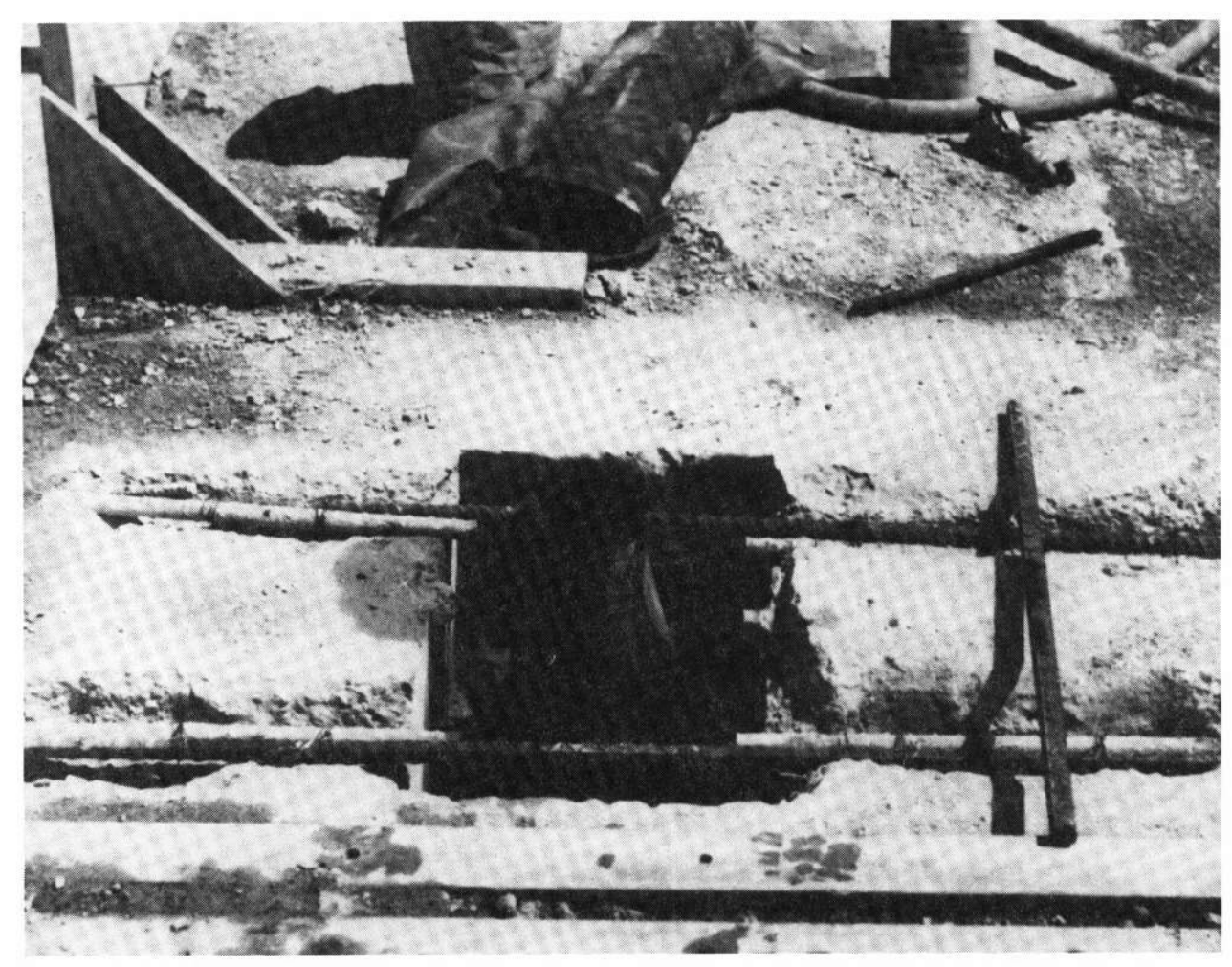

Figure 154. Composite sleeve installed, Bagnel1 Dam

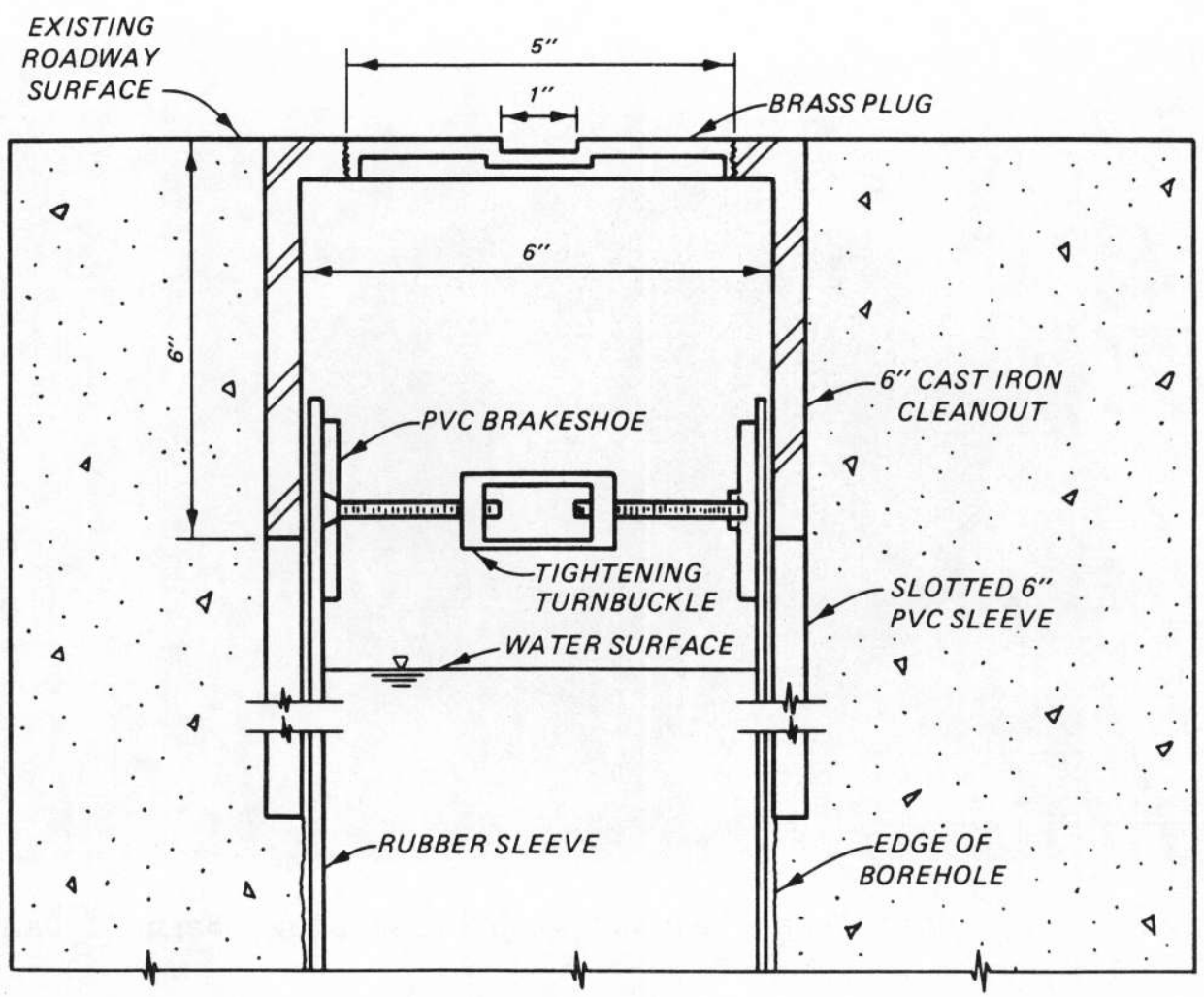

Figure 155. Section through top connection, Bagnell Dam 


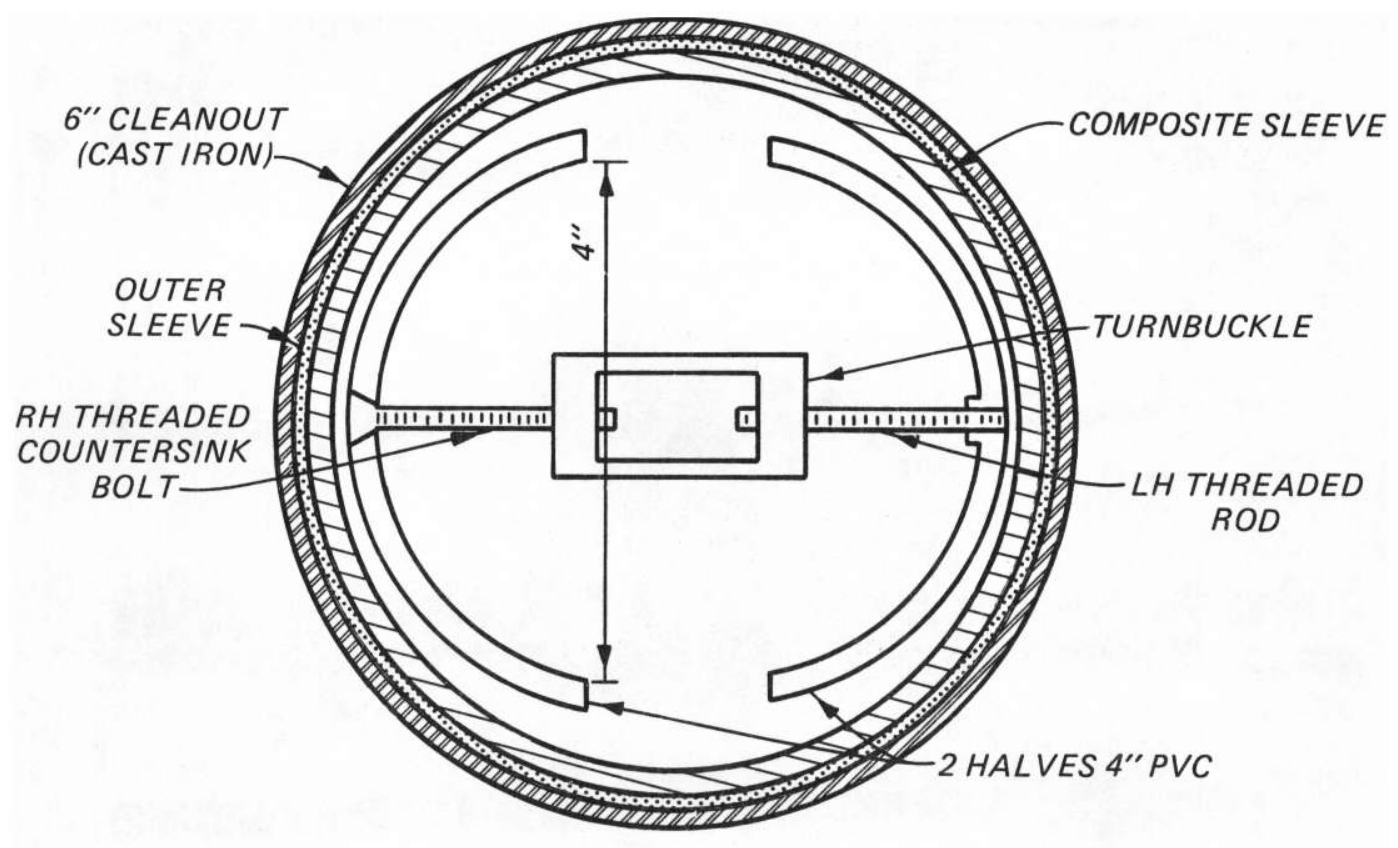

Figure 156. Plan view of top connection, Bagnell Dam

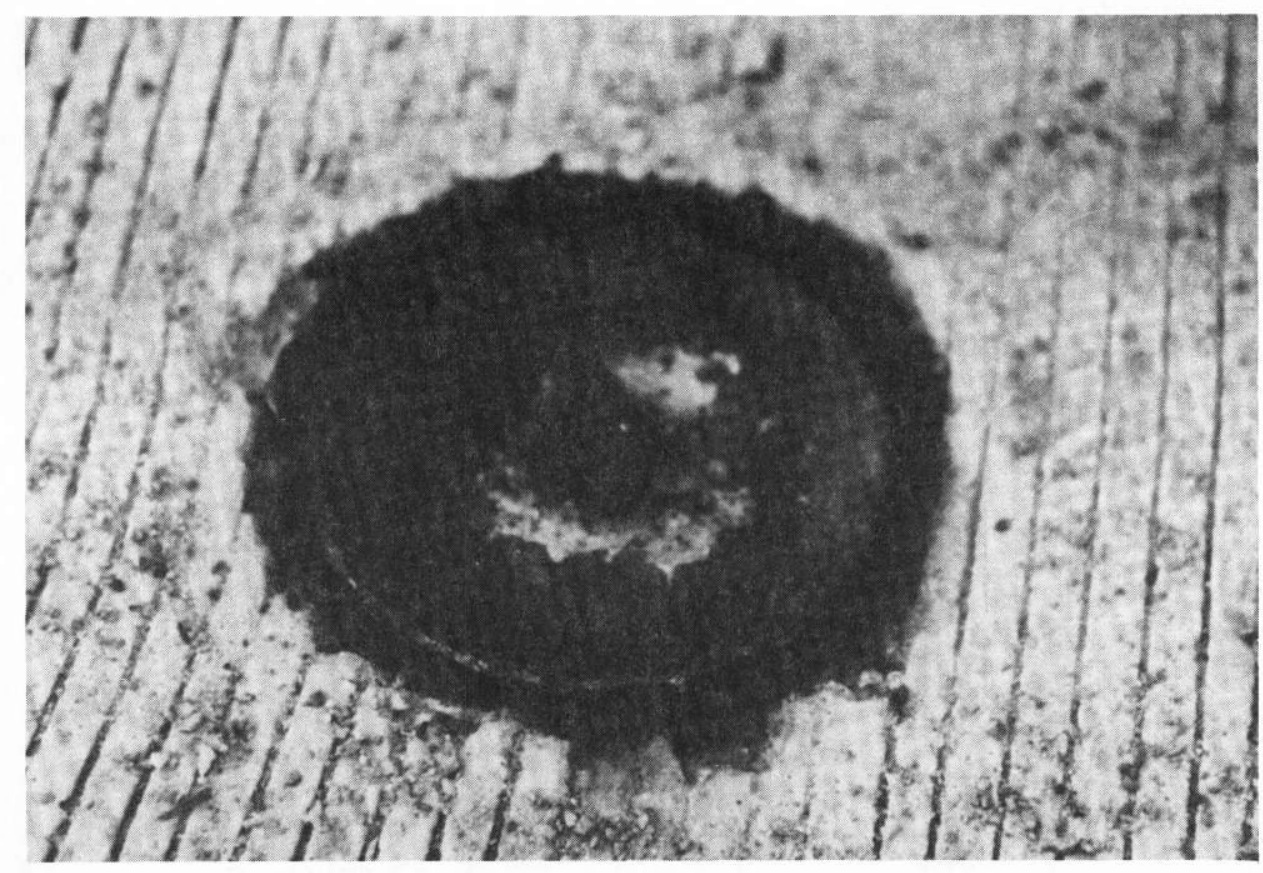

Figure 157. Cast iron cleanout with brass plug, Bagnell Dam 
The drill hole at joint 19 was abandoned after drilling to a depth of only $13 \mathrm{ft}$, and no sleeve was installed. The general decrease in flow through this joint would be expected due to thermal expansion of the dam at the time of the year repairs were accomplished. Average flow through the remaining joints decreased from $154 \mathrm{gal} / \mathrm{min}$ prior to drilling to $58 \mathrm{gal} / \mathrm{min}$ following completion of drilling. This approximately 60 percent reduction in flow rate is primarily attributed to drill cuttings restricting flow paths. No significant change in flow was noted between completion of drilling and sleeve installation.

\section{Caruthersville Floodwall}

309. The floodwall is located at Caruthersville, Mo., along the right bank of the Mississippi River. The 2,990 ft of concrete gravity wall was constructed in 1932. Approximately 2,000 ft of the floodwall incorporates an old wall whlch was constructed sometime prior to 1932 (Figure 158). A 3/8-in.-thick steel plate, $1 \mathrm{ft}$ wide and $12 \mathrm{ft}$ long, was used as a waterstop in each vertical joint between monoliths (Figure 159). An asphaltic compound was applied to that half of the plate in one monolith to prevent bond to the concrete, and a vertical slot was provided at that edge of the waterstop to accommodate movement of the plate. The joint on each side of the steel plate was filled with an asphalt-impregnated fiber joint filler.

310. Concrete cracking and spalling around the monolith joints (Figure 160) was repaired in 1984. Also a new waterstop was installed in 22 of the joints. The center portion of the existing waterstop was removed by drilling a 4-in.-diameter core vertically at the intersection of the steel plate and the joint. A one-piece diamond drill bit $13 \mathrm{ft}$ long was used to core the holes to a depth of $12 \mathrm{ft}$. The one-plece drill bit was used because the core was divided into four sections by the steel plate and the joint filler and would not stay together in one piece. Also, even if all four pieces of concrete were removed, the drill operators could not free the steel plate until the hole was drilled all the way through the wall. If they had tried to drill deeper after a section of the core was removed, the steel plate probably would have locked up inside the drill bit, causing it to jam. Torque created by such a bit jam could have stripped the threads between the tube sections used to lengthen the drill bit. 


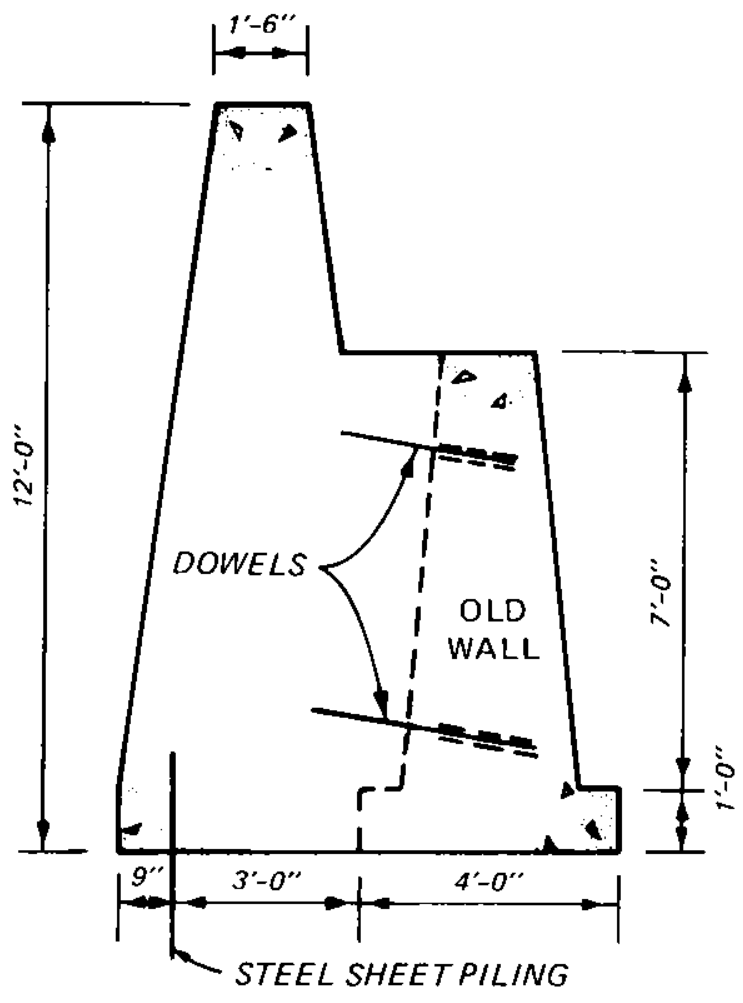

Figure 158. Typical wall section, Caruthersville Floodwall

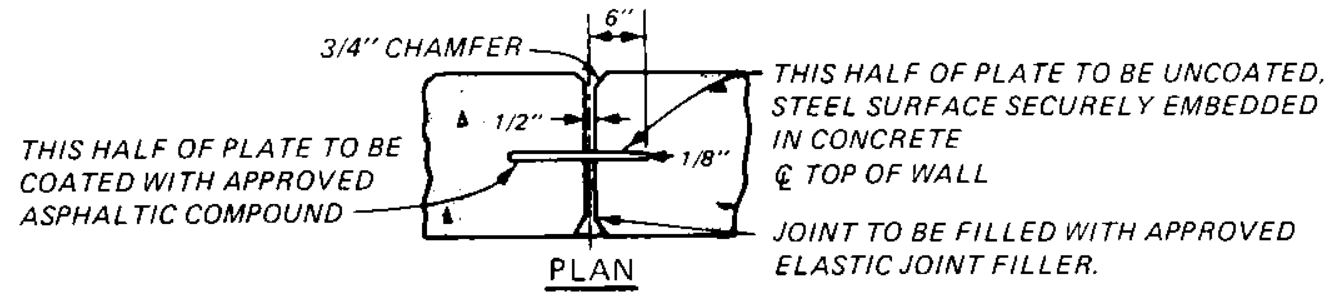

SLOT IN CONCRETE

TO EXTEND FULL DEPTH OF WALL,

AND TO BE OFFSET 2"AT TOP

AS SHOWN. SLOT TO BE MADE

BY CARDBOARD TUBE PLACED

ATEND OF PLATE BEFORE CONCRETING AND TO BE LEFT IN PLACE.

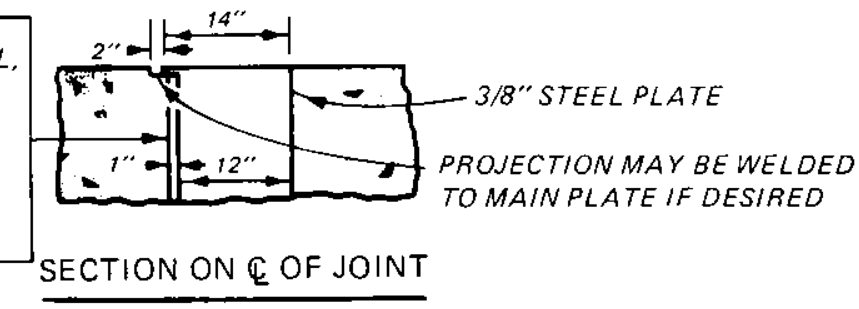

Figure 159. Waterstop detail, Caruthersville Floodwall 

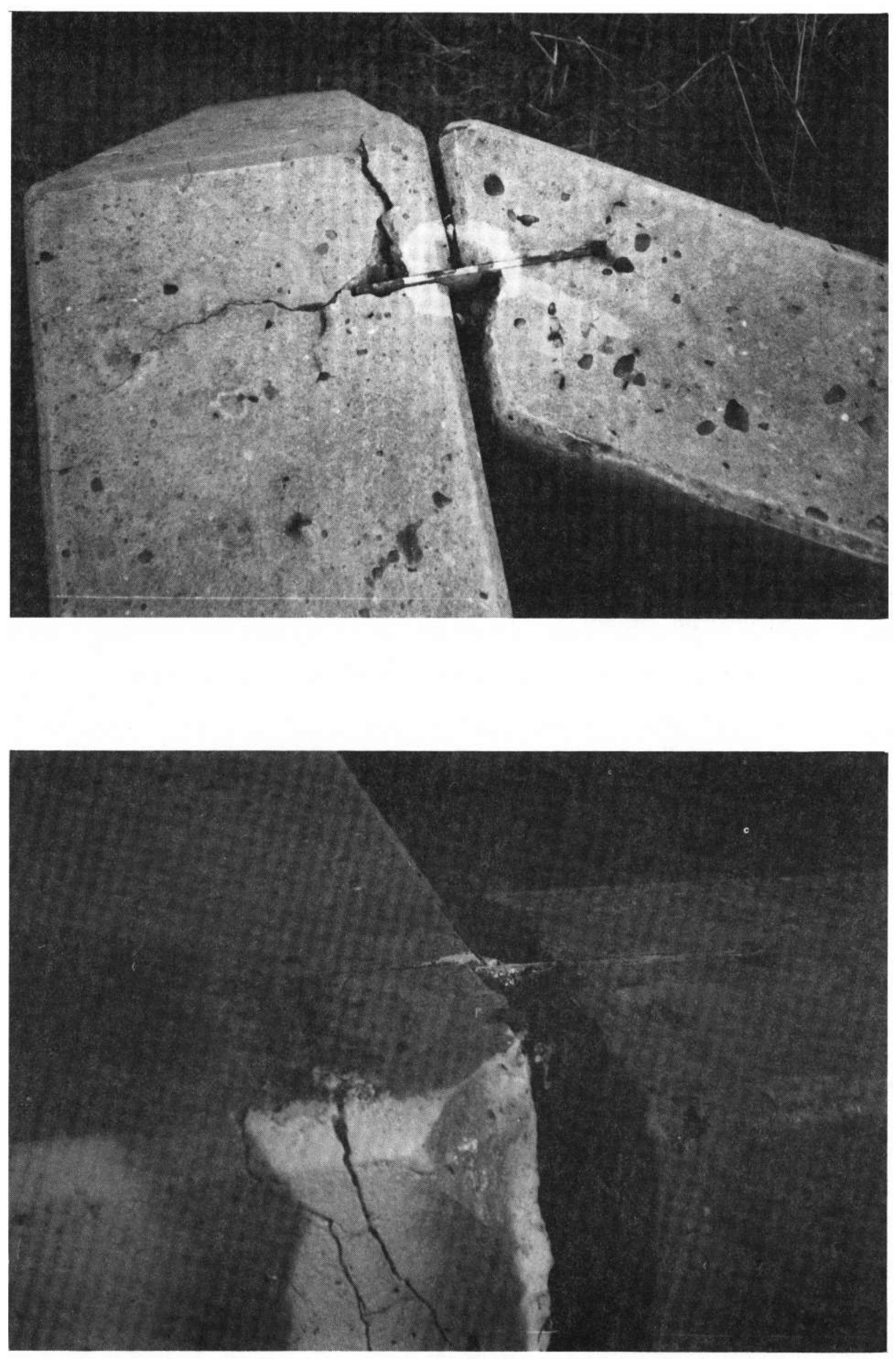

Figure 160. Typical concrete cracking and spalling around the steel plate waterstop, Caruthersville Floodwa11 
311. The 8-hp air drill was mounted on a 15-ft-high mast that was anchored to the top of the floodwall. Operators had to work from a manlift (Figure 161). Asphalt in the joint filler tended to gum up the drill bit and cause it to jam also. To minimize this, the drillers used a mild soap solution to lubricate the bit. The drill bit still jammed up, however. When this happened, operators had to remove the bit; but when they did this, the concrete and joint filler also often came out. The steel plate remained embedded in the concrete at the bottom of the hole. To keep the plate from flopping around and locking up inside the tube when drilling was resumed, they filled the cored portion of the hole with low-strength grout and then redrilled the entire hole. Because of bit jams, some holes took 7 to 10 days to drill and others took only 1-1/2 days. Dixie Construction Products, Atlanta, Georgia, was the drilling contractor.

312. After the holes were drilled (Figure 162), they were filled with a flexible grout. FLEX 44, a polyurethane grout distributed by De Neef America, Inc., was used to fill the holes. When FLEX 44 comes in contact with water, it expands and solidifies into a closed-cell flextble sealant. After the grout was mixed by hand with 10 percent water in a bucket, each hole was filled approximately one-third full (Figure 163). The top of the hole was then blocked and through expansion of the grout the remainder of the hole and adjacent joint was filled with the flexible grout.

\section{Miscellaneous Repairs}

313. Leaking cracks in the counterweight walls of the gate recess at Norfork Dam were repaired by divers in 1982 at an estimated cost of between $\$ 15,000$ and $\$ 20,000$. The reservoir side of the structure was cleaned using scrapers, manila rope caulking was placed in the cracks, and the caulked cracks were coated with flexible epoxy (Aquata) which is compatible with underwater placement techniques and environments. The repair is still performing as designed and could be easily adapted for repair of leaking monolith joints.

314. A leaking joint in a culvert in the Ozark navigation lock was repaired by first drilling 6-in.-diameter holes on 10-ft centers around the culvert near the joint. Next, a 4-in.-diameter plastic nipple was inserted in each drill hole through which portland cement slurry was pumped under pressure 


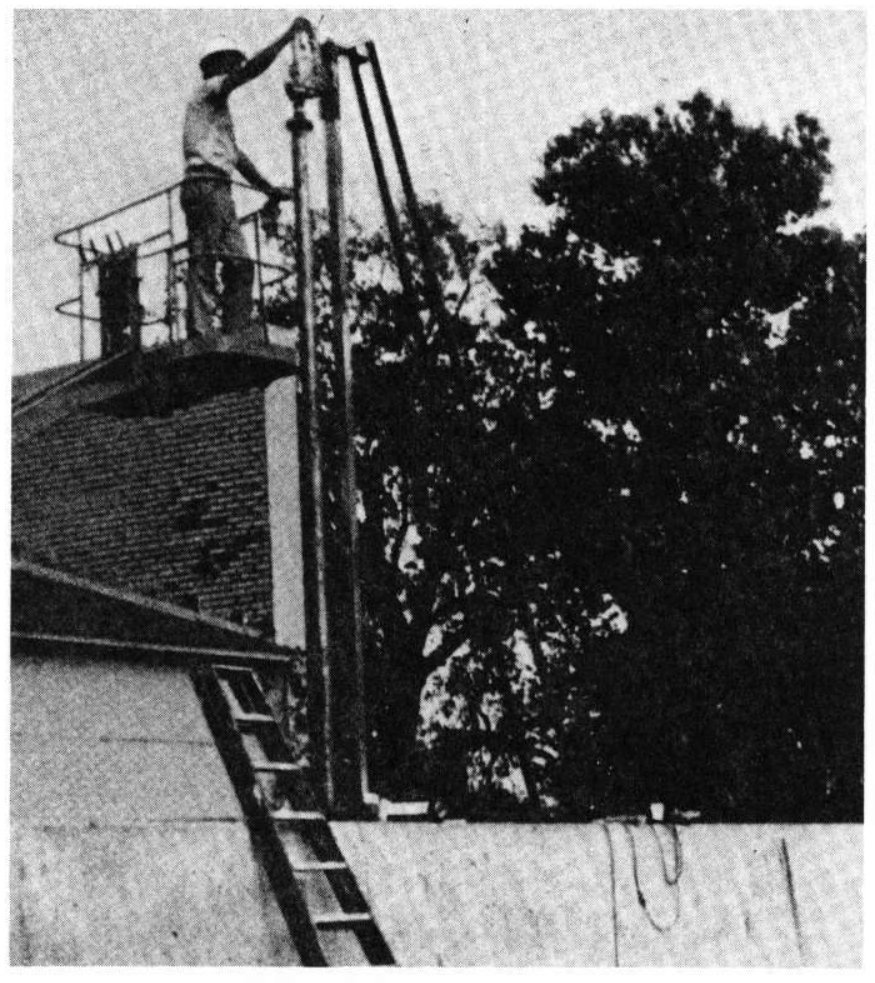

Figure 161. Drilling through existing waterstop, Caruthersville Floodwall

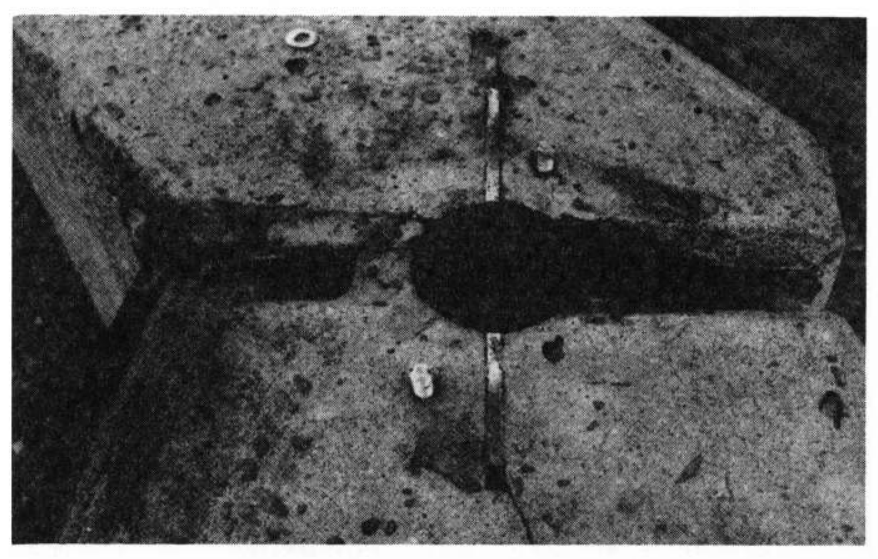

Figure 162. Drill hole prior to grouting, Caruthersville Floodwall 

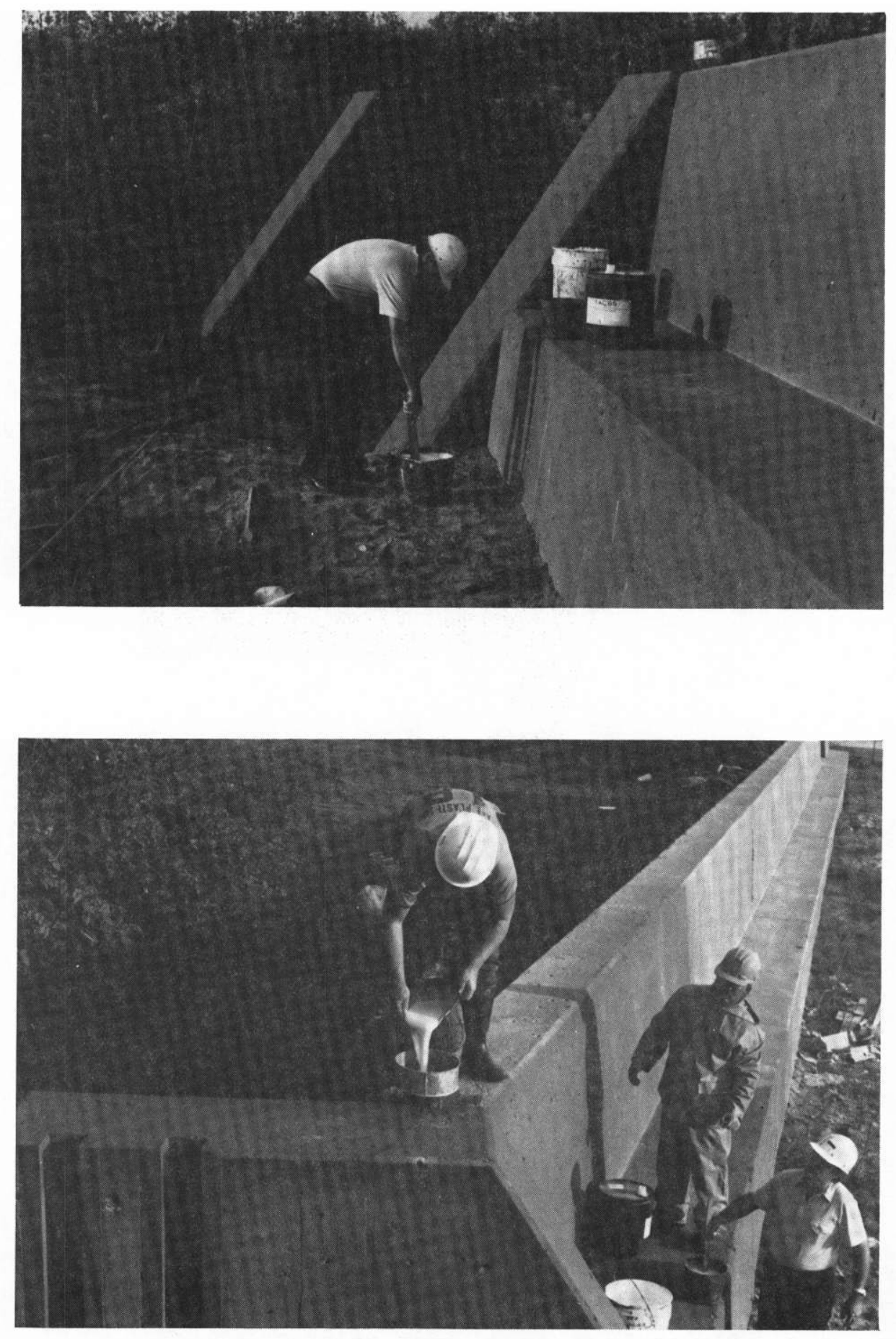

Figure 163. Mixing and placing polyurethane grout, Caruthersville Floodwall 
until an effective seal was accomplished. This repair was estimated to cost a little less than $\$ 10,000$ and was estimated to have been effective for approximately 2 years.

315. Repair of a Table Rock Dam monolith joint at a point $160 \mathrm{ft}$ below the water surface was necessitated as the result of a section of wood form being inadvertently left in the joint during construction. The wood completely deteriorated with time and allowed large volumes of water to enter the inspection gallery. The first repair effort consisted of divers placing lead plug caulking in the opening. The effort was only partially successful. After a time a second effort consisting of placing sheet neoprene over the area from the lakeside was attempted. The water pressure forced the neoprene into leaking spaces around the lead plug caulking. This formed an effective seal for approximately 6 years. The third effort to stop the leaking consisted of placing nylon rope from the lakeside in the leaking portions around the previous repairs so that the water pressure could "self-place" the rope for an effective seal. District personnel stated that "the repair needs to be redone currently." It was estimated that these repairs cost between $\$ 10,000$ to $\$ 15,000$. 
316. Typical waterstop defects include (a) excessive movement of the joint which ruptures the waterstop, (b) honeycomb areas adjacent to the waterstop resulting from poorly consolidated concrete, (c) contamination of the waterstop surface which prevents bond to the concrete, (d) puncture of the waterstop or complete omission during construction, and (e) breaks in the waterstop due to poor or no splices. Since it is usually difficult to remove sufficient concrete along a joint to allow replacement of an embedded waterstop, grouting of the joint or installation of a secondary waterstop are the remedial measures most often used. Several types of secondary waterstops have been tried (Table 2) with various degrees of success and expense. Generally, they can be grouped into four basic types: surface plates, caulked joints, grouted joints, and drill holes with some type of filler. The particular method used depends on a number of factors including joint width and degree of movement, hydraulic pressure and rate of water flow through the joint, environment, type of structure, economics, avallable construction time, and access to the upstream joint face.

\section{Surface Plates}

317. The surface plate type waterstop was used on 11 of the 23 projects (Table 2) described in this report. Surface plates have been used as both primary remedial waterstops and as backup plates for caulked and grouted joint repairs. Generally, the surface plate waterstop consists of a natural or synthetic rubber membrane which spans the monolith joint. The membrane is usually retained by either a single steel plate which spans the joint or two smaller plates located along the edges of the membrane. In some cases, an epoxy adhesive was used to bond the membrane to the concrete surface in addition to the anchored steel plates. This type of remedial waterstop has had varying degrees of success. At Algiers Lock, the exposed upper portion of the membrane deteriorated with time. Ruptured membranes at Kirwan Dam were attributed to localized material weakness or passage of rough and sharp-edged debris through the conduit. Surface plate type waterstops have been relatively successful at John Day and McNary Locks, but they failed at Lower Monumental Lock. Failure was attributed to (a) loosening of the anchor bolts, 
Table 2

Sumary of Materials and Technlques Used In Repair of

Waterstop Faflures

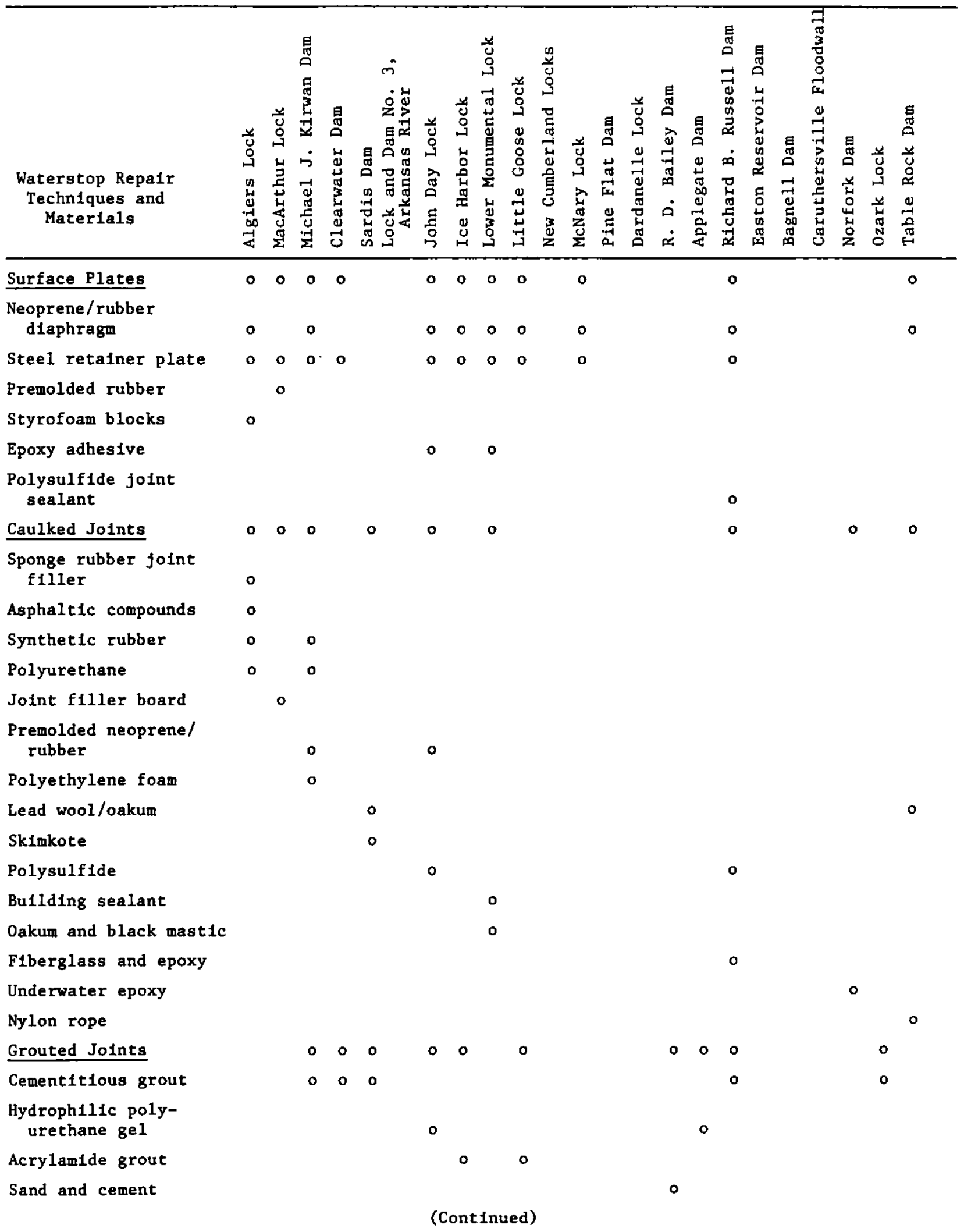




\begin{tabular}{|c|c|c|c|c|c|c|c|c|c|c|c|c|c|c|c|c|c|}
\hline $\begin{array}{c}\text { Waterstop Repalr } \\
\text { Techniques and } \\
\text { Materials }\end{array}$ & 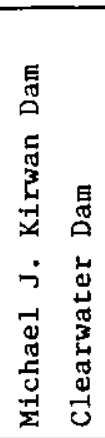 & 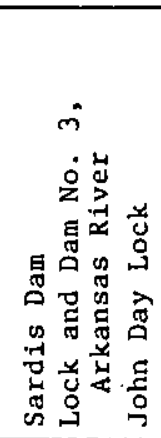 & 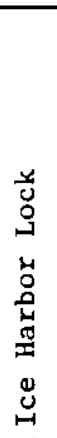 & 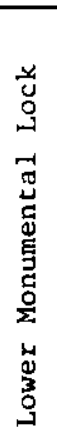 & 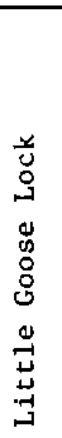 & 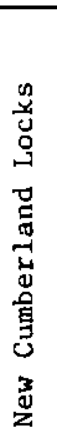 & 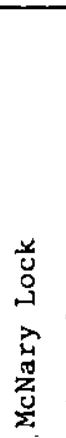 & 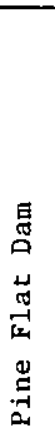 & 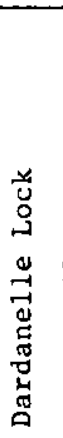 & 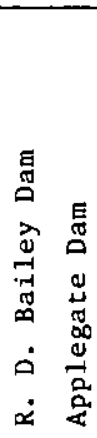 & 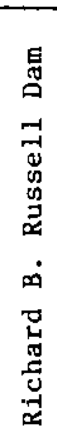 & 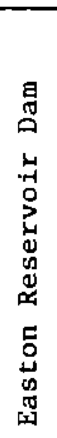 & 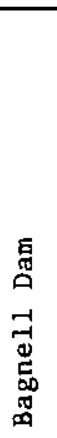 & 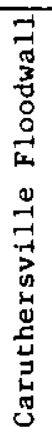 & 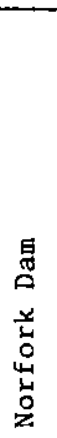 & 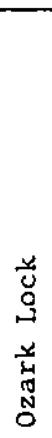 & 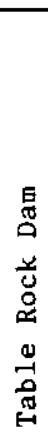 \\
\hline \multicolumn{18}{|l|}{ Grouted Joints (Cont'd) } \\
\hline \multicolumn{17}{|l|}{$\begin{array}{l}\text { Polysulfide foint } \\
\text { sealant }\end{array}$} & \\
\hline \multicolumn{18}{|l|}{$\begin{array}{l}\text { Hydrophtlic poly- } \\
\text { urethane foam }\end{array}$} \\
\hline Drill Hole with Filler & & o & $\circ$ & o & o & o & & $\circ$ & 0 & & & 0 & 0 & 0 & & & \\
\hline Synthetic rubber liner & & $\circ$ & & & & & & & & & & & & & & & \\
\hline $\begin{array}{l}\text { Nylon reinforced poly- } \\
\text { vinyl liner }\end{array}$ & & & & & o & & & & & & & & & & & & \\
\hline $\begin{array}{l}\text { Felt Ifned polyurethane } \\
\text { membrane }\end{array}$ & & & & & & & & 0 & & & & & & & & & \\
\hline Burlap & & & & & & & & & 0 & & & o & & & & & \\
\hline $\begin{array}{l}\text { Natural rubber and } \\
\text { elastomer-coated fabric }\end{array}$ & & & & & & & & & & & & & o & & & & \\
\hline Cementitious grout & & $\circ$ & & & & & & & & & & & & & & & \\
\hline $\begin{array}{l}\text { Aquagel, baroid, and } \\
\text { ethylene glycol }\end{array}$ & & $\circ$ & & & & & & & & & & & & & & & \\
\hline Sand and bentonite & & & o & & & & & & & & & & & & & & \\
\hline $\begin{array}{l}\text { Hydrophoblc polyurethane } \\
\text { grout }\end{array}$ & & & 0 & & & & & & & & & & & o & & & \\
\hline Hydrophobtc sand & & & 0 & & & & & & & & & & & & & & \\
\hline Acrylamide grout & & & o & o & o & & & o & & & & & & & & & \\
\hline $\begin{array}{l}\text { Hydrophilic polyurethane } \\
\text { foam }\end{array}$ & & & $\circ$ & & & & & o & $\circ$ & & & $\circ$ & & & & & \\
\hline Water under pressure & & & & & o & & & & & & & & & & & & \\
\hline Bentonite slurry & & & & & o & & & & & & & & & & & & \\
\hline Hydroph1lic polyurethane gel & & & & & $\circ$ & & & & & & & & & & & & \\
\hline Asphaltic sealer & & & & & & o & & & & & & & & & & & \\
\hline Water & & & & & & & & & & & & & $\circ$ & & & & \\
\hline Reinstall Existing Waterstops & & 。 & & ○ & & & & & & & & & & & & & \\
\hline Rubber & & $\circ$ & & & & & & & & & & & & & & & \\
\hline Copper & & & & 0 & & & & & & & & & & & & & \\
\hline
\end{tabular}


(b) reverse hydrostatic pressure from water trapped behind the waterstop when the water level dropped, (c) mechanical abuse such as a barge tearing of $f$ the plate, (d) ice pressure from moisture trapped behind the plate, and (e) hardening of the flexible pad due to aging (Schrader 1980). Where a sheet rubber membrane was used alone at Russell Dam, the underwater adhesive used to bond the rubber to the concrete failed.

318. A different type of surface plate waterstop was used successfully at MacArthur Lock. In this case, a premolded rubber rod was positioned over the joint and retained by a steel angle and clamp bars with set screws. This procedure has worked quite effectively and no maintenance other than adjusting the set screws and painting exposed steel surfaces had been required during the approximately 30 years in service.

\section{Caulked Joints}

319. The caulked joint type of remedial waterstop was used on 9 of the 23 projects described in this report (Table 2). In those cases where the joint was sawed prior to caulking, a typical saw cut $1 / 2$ in. wide by $1-1 / 2$ in. deep was caulked. In other cases, the " $V$ " formed by chamfering of adjacent monoliths during construction was filled with the caulking material. In most cases (7 of 9), a surface plate type waterstop was used in combination with the caulked joint to resist extrusion of the caulking material as the monoliths contract.

320. Caulked joint repairs at Algiers Lock were generally successful initially. However, continued progressive opening of the monolith joints significantly reduced their efficiency. Joints without surface membranes experienced problems with extrusion of the sealant at Kirwan Dam and several required resealing after approximately 10 years. Once problems with partial extrusion due to inadequate curing were solved, caulked joints performed with reasonable success for several years at Lower Monumental Lock. Caulked joint repairs at John Day Lock were not successful. Caulking of joints at MacArthur Lock and Sardis Dam in combination with surface plate and grouted joint repairs, respectively, were successful. Used in combination with surface plates and joint grouting, caulked joint repairs drastically reduced leakage at Russell Dam initially; however, long-term performance data are not available. Successful underwater caulk repaix of cracks at Norfork Dam could be 
easily adapted to repair of waterstop fallures. Underwater joint caulking at Table Rock Dam was only partially successful.

321. A varfety of materials have been used as caulking sealants (Table 2) with varying degrees of success. To perform satisfactorily, the sealant must not sag in vertical applications, must set rapidly, bond to cool and damp concrete, remain flexible under anticipated service conditions, and not extrude through the foint under hydrostatic pressure. The sealant should follow the joint to its base or be keyed into a grouted joint as was done at Russel1 Dam. Otherwise, water will migrate underneath the sealant and along the joint to the deficlent waterstop.

\section{Grouted Joints}

322. The grouted joint type of remedial waterstop was used in 10 of the 23 repair projects reviewed (Table 2). This type of remedial waterstop is most often used in repair of conduits, culverts, galleries, etc. Typically, an array of small-diameter holes is drilled from various locations within a gallery to intercept the joint behind the waterstop. An elastic chemical grout is then injected through the drill holes to fill the joint. Another approach is to drill holes through a conduit and inject cementitious grout behind the conduit in areas of leakage. Injection grouts should have low viscosity; fast gel or set times; good bond to unprepared, wet concrete surfaces; and good elastic strength. Hydrophilic polyurethane gels and foams generally meet the desired criteria and have been successful in most applications.

323. Grouted joint waterstops in combination with caulked joint and surface plate waterstop techniques was used to seal vertical contraction joints on the upstream face of Richard B. Russell Dam. A permeable grout tube was placed in the vertical " $V$ " along the face of each joint and covered with an elastomeric sealant. After the sealant hardened, the grout tube was injected with a polysulfide sealant to fill the joints from the dam face into the embedded waterstop. The polysulfide sealant was also placed on the face of the dam for a distance of $8 \mathrm{in.}$ on either side of the joints. Prior to hardening of the sealant, a surface plate waterstop of 20 gauge stainless steel was anchored into position over the joint. 


\section{Drill Hole with Filler}

324. This approach consists of drilling a hole from the top of the monolith along the joint and into the foundation, and filling the hole with an elastic material. Typically, the hole is 3 to 6 in. in diameter and drilled by a down-the-hole hammer or core drill. The more costly core drilling allows easy visual inspection of hole alignment along the joint, but the down-the-hole hammer has proven to be the preferred method of drilling. Small underwater video cameras can also be used to inspect hole alignment and condition of the joint.

325. The drill holes are filled with an elastic filler material to establish a seal against water penetration through the joint. Criteria for the filler require that it displace water, attain some degree of bond to the concrete surface, remain elastic throughout the life of the structure, be practical for field application, be economical, and have sufficient consistency so that it will not extrude under the hydraulic head to which it will be subjected (Schrader 1980). Various liquids, slurries, cementitious grouts, and chemical gels and foams have been used as fillers.

326. Acrylamide grout systems have been used as the elastic filler in several applications. Developed primarily for filling voids in permeable sand and grave1 foundations, these systems consist of an acrylamide powder, a catalyst, and an initiator. When dissolved in separate water solutions and mixed together, a gelatinous mass results. The mass can be given more stability, weight, and rigidity through the addition of inert mineral fillers such as diatomaceous earth, bentonite, and pozzolans. In some early applications, portland cement was used to thicken the grout and allow its use in open flowing holes with substantial hydraulic head. However, as the cement hydrates, the grout mass hardens resulting in a nonflexible filler. Repairs of waterstops using acrylamide grout systems have performed with varying degrees of success. Repairs which have been subjected to small relative joint movements have generally performed well, while simflar repairs subject to large relative joint movements have failed and required regrouting. It has been suggested that one of the advantages of this repair technique is that regrouting can be done easily and economically by experienced chemical grouters.

327. Hydrophilic polyurethane gels and foams have also been used as elastic fillers. These materials are activated when they come into contact 
with water and upon curing form a tough, flexible gel approximately 10 times its original volume. Gel times will vary with ambient and water temperatures but can generally be controlled through additives to be in the range of 5-10 min. Under static water conditions these materials can be simply poured into the drill hole. Where significant water flow is present, burlap saturated with the polyurethane can be used successfully. This procedure was used at Dardanelle Lock to reduce leakage by approximately 95 percent.

328. In some cases, a continuous tube-type liner has been inserted into the drill hole to contain the filler material. Liner materials include reinforced plastic firehose, natural rubber, elastomer-coated fabric, neoprene, synthetic rubber, and felt-lined polyurethane tubes. In most cases, the liners are not bonded to the walls at the drill holes and rely on differential pressure between the interior of the liner and the external water level to force the liner against the sides of the hole. Obviously, any type of liner material should be of sufficient flexibility to allow the tube to conform to any volds and irregularities in the surface of the drill hole and to accommodate differential movement between adjacent monoliths. A bonded liner system, which allows bonding of the liner to the surface of the drill hole, was successfully installed at Pine Flat Dam. This approach appears promising but long-term performance data under high hydrostatic heads are unavallable at present.

329. A variety of materials have been used as fillers inside the drill hole liners. These include water, bentonite slurry, and various formulations of chemical grout. Criteria for the filler are generally the same as those for drill holes without liners. Filler grouts should have a density greater than that of water and should be placed by tremie tubes starting at the bottom of the liner to displace all water in the liner. Once the filler material is in place, the hole should be capped flush with the top surface. The cap should contain a removable plug for periodic inspection of the filler material.

330. Video inspections of the drill holes before and after insertion of the liner have proven to be beneficial in determining the exact location of the concrete-foundation interface, irregularities in the concrete surface, seepage locations, and adequacy of the insertion process. Also, if the inversion technique is proposed for liner insertion, the bottom 25 percent of the 
drill hole should be pressure tested to determine whether leakage rates in this zone are sufficient to allow water in the hole to escape during inversion. 


\section{PART IV: CONCLUSIONS AND RECOMMENDATIONS}

\section{Conclusions}

331. Leakage through monolith joints reported herein ranged from minor flows to more than $600 \mathrm{gal} / \mathrm{min}$. In general, leakage was the result of waterstop defects including (a) excessive movement of the joint which ruptures the waterstop, (b) honeycomb areas adjacent to the waterstop resulting from poorly consolidated concrete, (c) contamination of the waterstop surface which prevents bond to the concrete, (d) puncture of the waterstop or complete omission during construction, and (e) breaks in the waterstop due to poor or no splices. Since most of these deficiencies are the result of poor construction practices, it appears that the installation of waterstops warrants increased attention during design and construction of future projects.

332. More than 80 different materlals and techniques have been used, individually and in varfous combinations, to repair waterstop failures reported herein. Some appear to have been successful, while many have failed. Because of a lack of appropriate test methods and equipment, most materials have been used in prototype repairs with Iimfted or no laboratory evaluation of their effectiveness in the particular application. Obviously, there is a definite need for development of testing procedures and equipment to allow systematic laboratory evaluation of waterstop repair techniques prior to application in prototype structures.

\section{Recommendations}

333. A functional laboratory test apparatus should be designed and fabricated to evaluate the effectiveness of the various materials and techniques being used to install remedial waterstops in concrete navigation locks and dams where existing waterstops have failed. The test apparatus should satisfy the following requirements:

a. Should be capable of accommodating test specimens which incorporate the various materials and techniques being used to install remedial waterstops.

b. Should permit differential movement between simulated monolith joints; up to 0.3 in. longitudinal along plane of the waterstop and up to $0.5 \mathrm{in}$. along plane transverse to waterstop. 
c. Should be capable of applying water heads up to $300 \mathrm{ft}$.

d. Should permit water flow up to $100 \mathrm{gal} / \mathrm{min}$ along the joint.

e. Should be capable of testing environment temperatures of $40^{\circ}$ to $85^{\circ} \mathrm{F}$.

f. Should have independent and variable controls on differential movement, water head, flow, and temperature to accommodate the full range of each testing parameter.

g. Should be fully instrumented using appropriate gages, recorders, and other pertinent instruments to completely monitor and record the test operation.

334. Monitoring of field installation and performance of remedial waterstops should be continued. Based on an evaluation of field performance, product data sheets and case histories describing prototype repairs should be prepared as appropriate for inclusion in the REMR Notebooks. 
Kostyk, B. W., and Parnell, J. E. 1984. "An Effective Repair for Leaking Waterstops," Concrete Construction, Vo1 29, No. 6, pp 594-596.

McDonald, J. E., and Campbel1, R. L., Sr. 1985. "The Condition of Corps of Engineers Civil Works Concrete Structures," Technical Report REMR-CS-2, US Army Engineer Waterways Experiment Station, Vicksburg, Miss.

Schrader, E. K. 1980. "Repair of Waterstop Failures," Journal, Energy Division, American Society of Civil Engineers, Vol 106, No. EY2, pp 155-163.

US Army Engineer District, Huntington. 1981. "Report on Seepage Through Concrete Face Slab, R. D. Bailey Lake, West Virginia," Huntington, W. Va.

US Army Engineer District, Little Rock. 1972. "Seepage Through Right Embankment, Lock and Dam No. 3, Arkansas River," Little Rock, Ark.

US Army Engineer District, Savannah. 1985. "Investigation and Remedial Measures for Excessive Leakage in the Concrete Dam, Richard B. Russell Dam," Savannah, Ga.

US Army Engineer District, Vicksburg. 1972. "Sardis Dam, Periodic Inspection Report No. 2, Supplement B," Vicksburg, Miss. ment D,"Vicksburg, Miss. 1975. "Sardis Dam, Periodic Inspection Report No. 2, SuppleUS Army Engineer District, Walla Walla. 1977. "Lower Monumental Lock, Design Memorandum No. 9, Monolith and Joint Repairs, Supplement No. 2," Walla Walla, Wash.

- 1978. "Special Report: Foundation Grouting, Waterstop Repairs, and Chemical Grouting, Little Goose Lock and Dam," Walla Walla, Wash.

US Army Engineer Waterways Experiment Station. 1959. "Review of Soils Design, Construction, and Performance Observations, Algiers Lock, Louisiana," Technical Report No. 3-503, Vicksburg, Miss.

Waring, S. T. 1985. "Demonstration Project of the GELCO Remedial Waterstop to Rehabilitate Monolith Joint Waterstops at Pine Flat Dam in Fresno County, California," GELCO Grouting Service, Kent, Wash. 
Universitty of Illinois 详ettz Reference Room B106 NCEL

$208 \mathrm{\pi}$. Romine street

Urbana, Illinois 61801 
Inlversity of Illinols

Metz Reference Room

BI06 NCEI

208 I. Romine Street

Urbana, Illinois 61801 